\title{
DESENVOLVIMENTO DE METODOLOGIA DE PROJETO DE SISTEMA DE POSICIONAMENTO DINÂMICO APLICADO A OPERAÇÕES EM ALTO-
}

MAR

Tese apresentada à Escola Politécnica da Universidade de São Paulo para obtenção do título de Doutor em Engenharia.

Área de Concentração:

Engenharia Mecânica

Orientador:

Prof. Dr. Celso Pupo Pesce

Co-orientador

Prof. Dr. Décio Crisol Donha

São Paulo 
Ficha Catalográfica

Tannuri, Eduardo Aoun

Desenvolvimento metodologia de projeto de sistema de posicionamento dinâmico aplicado a operações em alto-mar. São Paulo, 2001.

$273 p$.

Tese (Doutorado) - Escola Politécnica da Universidade de São Paulo. Departamento de Engenharia Mecânica.

1. Posicionamento Dinâmico. 2. Controle não-linear. I. Universidade de São Paulo. Escola Politécnica. Departamento de Engenharia Mecânica II.t 
Aos meus pais,

Helwe e Uenis. 


\section{AGRADECIMENTOS}

Ao Prof. Dr. Celso Pupo Pesce, que desde o meu segundo ano de faculdade, vem me orientando de uma maneira brilhante, ensinando a pensar e fornecendo sólidos conhecimentos que me permitiram transitar num tema multidisciplinar tão complexo.

Ao Prof. Dr. José Augusto Penteado Aranha, pelas oportunidades, pelos ensinamentos e pelo exemplo admirável.

Ao Prof. Dr. Décio Crisol Donha, pelas inúmeras e valiosas sugestões.

Aos professores do Departamento de Engenharia Naval e Oceânica da EPUSP, em especial ao Prof. Dr. Hélio Mitio Morishita e ao Prof. Dr. Kazuo Nishimoto, pelas inúmeras sugestões ao longo do desenvolvimento e oportunidade de trabalhar num grupo de pesquisas tão seleto.

Ao Prof. Dr. José Jaime da Cruz, pela ajuda constante ao longo de todo o trabalho.

Ao Prof. Dr. José Sotelo Júnior, a quem devo grande parte dos meus modestos conhecimentos na área de controle.

Aos engenheiros da Petrobras que contribuíram com discussões, análise de casos práticos e dados experimentais, em especial ao Dr. Isaías Quaresma Masetti, ao Msc. Sylvio Correa e ao Eng. Guilherme Serra Alves.

Aos engenheiros do IPT Kazuo Hirata e Carlos H. Umeda, por disponibilizarem dados experimentais.

Aos amigos Dr. Alexandre N. Simos, Dr. André C. Fujarra e Msc. Carlos H. Fucatu, pelas discussões frutíferas, que contribuíram significativamente no trabalho e na minha formação.

Aos meus pais e à minha irmã Claudia, pela revisão de parte do texto.

À minha irmã Ana Cristina, que muito me ensinou ao longo das nossas vidas.

Em especial, à Daniela, pelo apoio, interesse, incentivo e compreensão.

À FAPESP, pela bolsa de estudos concedida. 


\section{Resumo}

O presente trabalho aborda três tópicos de pesquisa e desenvolvimento em Sistemas de Posicionamento Dinâmico (SPD).

Desenvolveu-se uma nova metodologia para o projeto de controlador de posição e aproamento baseada na teoria de controle robusto não-linear por modos deslizantes. $\mathrm{O}$ controlador integra uma malha de compensação direta dos esforços ambientais (ondas, vento e correnteza) a uma malha de realimentação que realiza correções de erros residuais. A estrutura não-linear do controlador assegura o desempenho e estabilidade para qualquer aproamento da embarcação. A malha de compensação direta, por sua vez, garante maior faixa de aplicabilidade em termos de condições ambientais, não apresentando degradação de desempenho em condições extremas. A malha de realimentação possui apenas nove parâmetros, existindo equações e regras que tornam suas calibrações simples. Já a malha de compensação direta possui, internamente, modelos para a estimativa das forças ambientais que agem sobre o navio. Graças às características de robustez, o controlador não requer um ajuste refinado dos diversos parâmetros destes modelos e das condições ambientais, podendo-se utilizar estimativas pouco acuradas dos mesmos.

O controlador desenvolvido foi testado em simuladores computacionais do VLCC Vidal de Negreiros amarrado pelo sistema turret e de uma barcaça de lançamento de dutos, ambos contendo modelos validados dos esforços ambientais. As simulações emularam erros de modelagem e de estimação das condições ambientais, e confirmaram as boas características de robustez e desempenho do controlador em diversas condições e a facilidade no ajuste de parâmetros.

Desenvolveu-se também um modo de controle apropriado para operações com liberdade de aproamento realizadas na Bacia de Campos, onde é comum a incidência de agentes ambientais em direções não alinhadas. Neste modo calcula-se, baseado nas estimativas das condições ambientais, o aproamento que minimiza um funcional relacionando parâmetros operacionais relevantes, como movimento de roll, tração dinâmica em risers, solicitação do sistema de amarração e consumo de combustível. Uma análise numérica de sensibilidade, aplicada ao VLCC Vidal de Negreiros, indicou que o cálculo do aproamento ótimo não apresenta elevada sensibilidade a erros nas estimativas das condições ambientais em condições extremas. Testes numéricos comprovaram também a superioridade do presente modo de controle comparado ao tradicional modo Weather vane nas condições da Bacia de Campos.

Como a estimação do espectro de ondas incidentes ainda apresenta problemas técnicos e operacionais, desenvolveu-se também um método de estimação do espectro baseado na medição dos movimentos da embarcação. Utilizou-se uma abordagem paramétrica, cuja sensibilidade a erros no conhecimento da resposta dinâmica da embarcação mostrou-se aceitável. O método foi testado numericamente e validado com resultados de ensaios em tanque de provas. Os erros de estimação foram plenamente compatíveis aos erros admissíveis pelo controlador desenvolvido, alcançando, no caso da altura significativa, o valor máximo de $25 \%$. O método foi comparado à abordagem não paramétrica Bayesiana, muito utilizada em trabalhos correlatos, e apresentou resultados mais acurados. 


\begin{abstract}
The present work deals with three research and development topics related to Dynamic Positioning Systems.

A new design methodology of ship position and heading controller was developed, based on the robust and nonlinear Sliding Mode Control theory. The controller contains a feedforward action, which compensates environmental forces (wind, waves and current) and a feedback loop, responsible for the elimination of residual errors. The nonlinear formulation of the controller assures performance and stability requirements for all heading angles. The feedforward action guarantees its applicability in a large range of environmental conditions, without performance degradation in severe conditions. The feedback loop contains only nine parameters, which can be calibrated easily by simple equations. The feedforward loop internally contains models for the estimation of the environmental forces acting on the ship. However, due to robustness properties, the controller does not require a fine adjustment of its several parameters and the environmental conditions, allowing the use of nonaccurate estimates.

The controller was tested in computational simulators of the turret moored VLCC Vidal de Negreiros and of a pipe-laying barge, both comprising validated models of environmental forces. The simulations emulated modeling and environmental conditions estimation errors, confirming the good robustness and performance properties of the controller in several environmental conditions and the simple parameter adjusting process.

A control mode adapted for heading-free operations in Campos Basin was also developed, where non-aligned environmental agents frequently happen. In this mode, it is calculated the optimal heading that minimizes a functional relating important operational parameters, such as roll motion, risers dynamic tension, mooring system forces and energy consumption. Estimations of environmental conditions are used in the calculation. However, a numerical sensibility analysis of this control mode applied to the VLCC Vidal de Negreiros indicated that the optimal heading calculation presents low sensibility to errors in these estimations under severe environmental conditions. Numerical trials showed that this control mode is more adequate to Campos Basin conditions compared to the traditional Weather vane mode.

Since wave spectrum estimation still presents technical and operational problems, a spectrum estimation method was also developed, based on measurements of ship motions. A parametric method was used, which presented low sensitivity to errors in ship dynamic response functions. The method was numerically tested and validated through towing tank tests. Estimation errors were compatible to the controller admissible errors. For example, the maximum error in significant wave height estimation was $25 \%$, smaller than the errors usually obtained using the non-parametric Bayesian method, widely applied for this class of problems.
\end{abstract}




\section{Sumário}

\section{Lista de Figuras}

\section{Lista de Tabelas}

\section{Lista de Abreviaturas}

\section{Lista de Símbolos}

\section{Glossário}

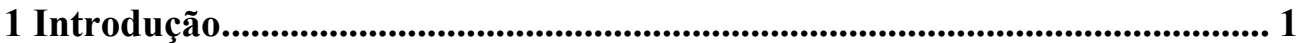

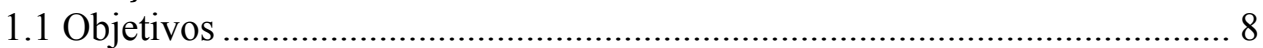

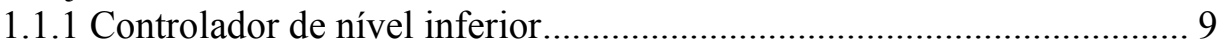

1.1.2 Controlador de nível superior ...................................................... 10

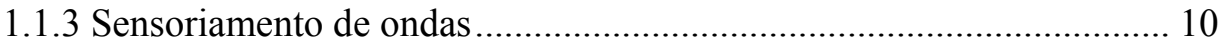

1.2 Organização do texto............................................................................... 10

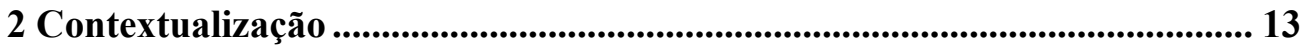

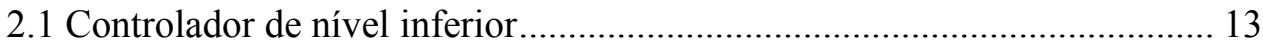

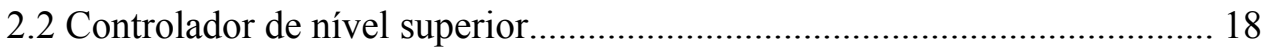

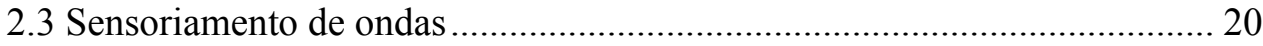

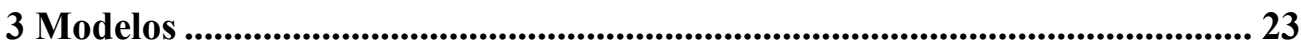

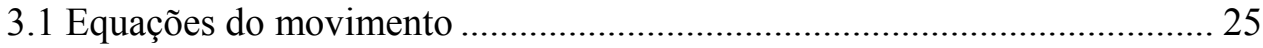

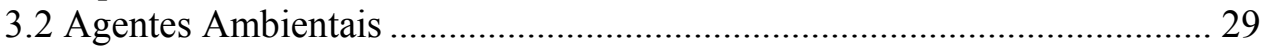

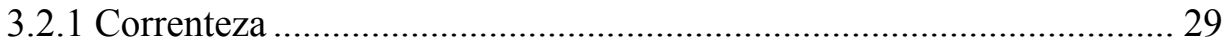

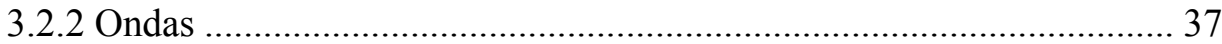

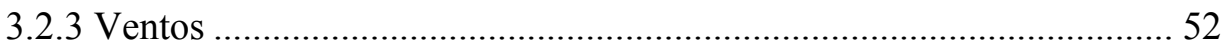

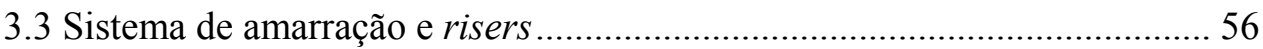

3.3.1 Forças de restauração .......................................................................... 56

3.3.2 Amortecimento e arrasto em linhas e risers........................................ 58

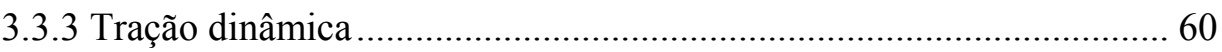

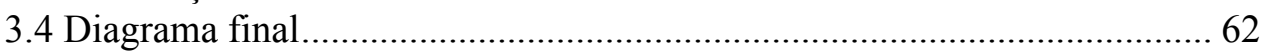

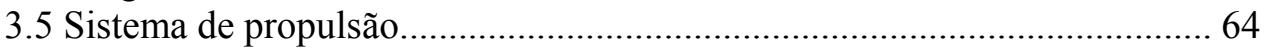

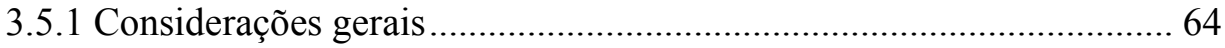

3.5.2 Modelo hidrodinâmico do propulsor................................................ 67

3.5.3 Modelo do sistema de controle do propulsor ..................................... 70

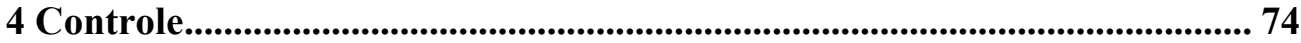

4.1 Projeto do controlador de nível inferior .................................................... 75

4.1.1 Controle não linear por modos deslizantes ...................................... 77

4.1.2 Adaptações do modelo do sistema ..................................................... 90

4.1.3 Controle de aproamento .................................................................... 93

4.1.4 Controle combinado dos movimentos de translação e rotação .......... 104

4.1.5 Cálculo do valor estimado e do máximo erro para esforços atuantes 106

4.2 Projeto de controlador de nível superior ................................................ 115

4.2.1 Critérios operacionais utilizados no cálculo do aproamento ótimo ... 116

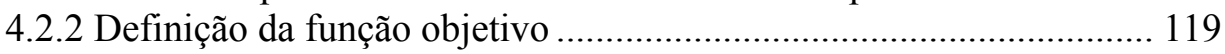


4.2.3 Aplicação a uma condição ambiental típica....................................... 120

4.2.4 Sensibilidade a erros nas condições ambientais................................. 124

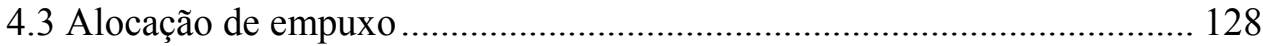

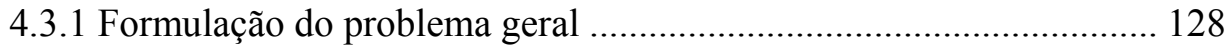

4.3.2 Considerações adicionais ao problema de alocação de empuxo........ 130

4.3.3 Solução do problema de alocação de empuxo ................................... 134

4.3.4 Comparação entre os métodos .......................................................... 137

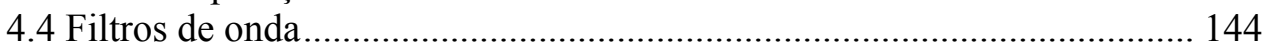

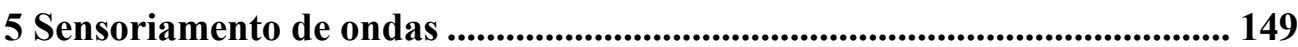

5.1 Método Paramétrico de Estimação de Espectro de Ondas........................ 150

5.2 Movimentos utilizados na estimação .................................................... 152

5.3 Análise numérica de mares unimodais................................................... 154

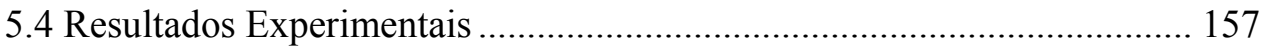

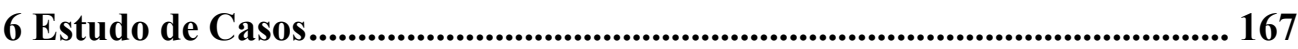

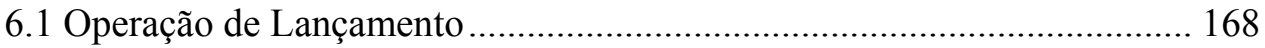

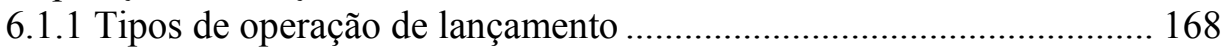

6.1.2 Características da barcaça e comentários sobre o modelo utilizado .. 171

6.1.3 Configuração do sistema de propulsão ............................................ 174

6.1.4 Projeto do controlador e ajuste de parâmetros .................................. 175

6.1.5 Simulações utilizando controlador por modos deslizantes ................ 178

6.2 FPSO amarrado em sistema turret.................................................. 183

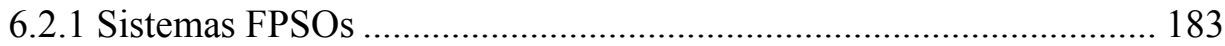

6.2.2 Características do VLCC e comentários sobre o modelo utilizado ... 187

6.2.3 Sistema de amarração e risers......................................................... 191

6.2.4 Projeto do controlador e ajuste de parâmetros ................................... 193

6.2.5 Aplicação do controlador de nível superior e inferior ........................ 195

7 Conclusões e Comentários Finais ............................................................. 204

8 Referências Bibliográficas ....................................................................... 208

Apêndice 1 - Modelo analítico para tração dinâmica em risers .................... 217

Apêndice 2 - Principais sensores utilizados em SPDs ..................................... 220

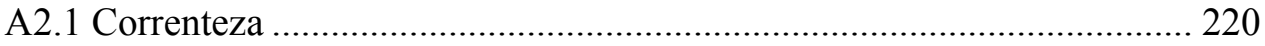

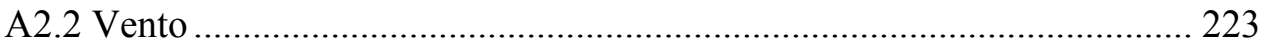

A2.3 Posição e Velocidade ............................................................................ 226

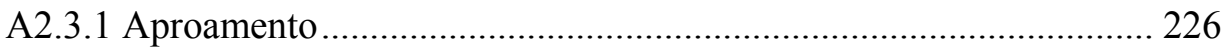

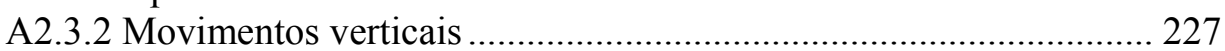

A2.3.3 Posição no plano horizontal ......................................................... 228

Apêndice 3 - Simulador dinâmico da barcaça BGL1 dotada de SPD ......... 238 


\section{LISTA DE FIGURAS}

Figura 1.1 Exploração de petróleo no mar em Summerland, Califórnia, 1902 (extraído de The Hubbert Peak of Oil Production, 2002) ...................................................... 1

Figura 1.2 Plataforma do tipo jaqueta (extraído de Offshore Technology, 2002)........... 1

Figura 1.3 FPSO P-35 (José Bonifácio) (extraído de Petrobras, 2002).......................... 2

Figura 1.4 Plataforma de lançamento de foguetes em alto mar (extraído de Sea-Launch, 2002) 3

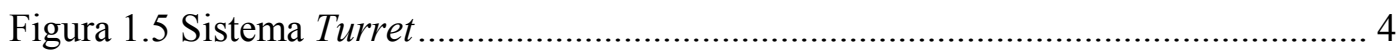

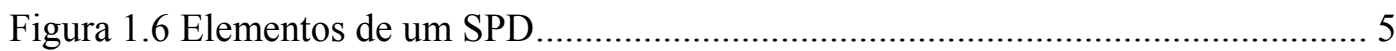

Figura 1.7 (a) Propulsor azimutal (b) Propulsor em túnel......................................... 6

Figura 2.1 Diagrama de blocos do controle PID aplicado em SPDs............................ 14

Figura 2.2 Diagrama de blocos de um tipo de controle baseado em modelo aplicado em

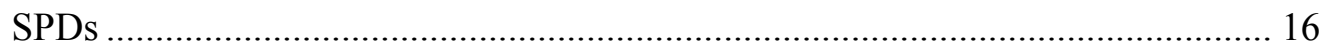

Figura 2.3 Gráfico de capacidade para manutenção de aproamento (extraído de

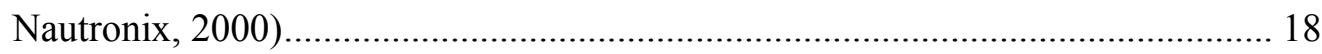

Figura 3.1 Sistemas de coordenadas utilizados ................................................... 26

Figura 3.2 Definições para Modelo Estático de correnteza........................................ 31

Figura 3.3 Coeficientes estáticos de forças e momento: comparação entre resultados teóricos e experimentais (resultados extraídos de Leite et al. (1998)..................... 34

Figura $3.4 \mathrm{C}_{\mathrm{D}, \mathrm{FALT}}(\mathrm{x})$ e funções de ponderação $\mathrm{g}_{1}(\mathrm{x}), \mathrm{g}_{2}(\mathrm{x})$ e $\mathrm{C}_{\mathrm{D}}(\mathrm{x})$ calculados para $\mathrm{o}$ navio Vidal de Negreiros em situação carregada. .................................................. 36

Figura 3.5 Navio Vidal de Negreiros, condição 100\%. Ensaios de yaw-rotating com rotação $\mathrm{r}=0.58^{\circ} / \mathrm{s}$ Velocidade de avanço $(\mathrm{a}) \mathrm{U}=2,37 \mathrm{~m} / \mathrm{s} ;(\mathrm{b}) \mathrm{U}=1,90 \mathrm{~m} / \mathrm{s}$ (extraídas

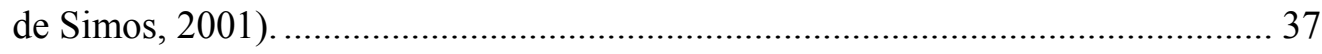

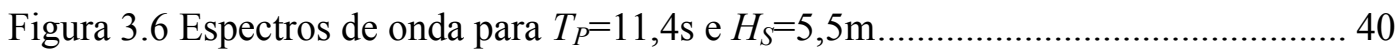

Figura 3.7 Definição dos ângulos de incidência de onda ............................................ 41

Figura 3.8 Coeficiente de deriva em sway incidência de través.................................... 42 
Figura 3.9 Forças de deriva média para VLCC $100 \%$ carregado $\left(T_{p}=11,4 \mathrm{~s}\right.$ e $\left.H_{s}=5,5 \mathrm{~m}\right) 43$

Figura 3.10 Realizações temporais das forças de deriva lenta para VLCC $100 \%$

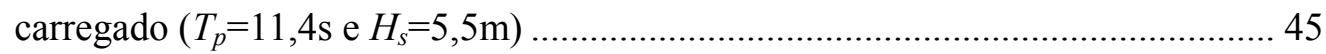

Figura 3.11 Efeito do wave damping sobre as forças de deriva média ........................ 47

Figura 3.12 RAO's do movimento de sway (incidência de través) e do movimento de pitch (incidência de proa) - VLCC e BGL1 ........................................................ 50

Figura 3.13 Movimentos de primeira e segunda ordem do VLCC 100\% carregado

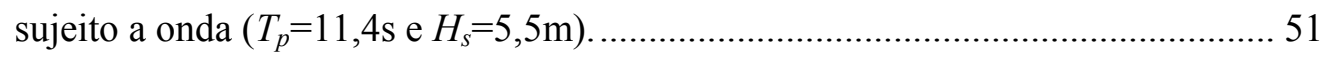

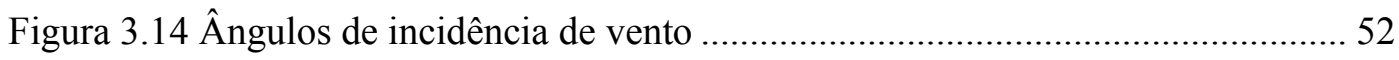

Figura 3.15 Coeficientes adimensionais de vento para um VLCC (OCIMF, 1977) ...... 53

Figura 3.16 Espectros de rajada para velocidade média de vento de $20 \mathrm{~m} / \mathrm{s}$................. 55

Figura 3.17 Velocidade do vento : (a) Espectro de Harris; (b) Espectro de Occhi-Shin 56

Figura 3.18 Linha de amarração típica composta por segmentos de poliéster e correntes de aço (a) Curva de restauração ; (b) Curva de rigidez .................................... 57

Figura 3.19 Cálculo das forças restauradoras no sistema turret ................................. 58

Figura 3.20 Movimentos dentro e fora do plano da linha ........................................ 58

Figura 3.21 Comparação da formulação analítica (Aranha et al., 1993 e Pinto et al., 1999) para cálculo da tração dinâmica em risers com solução utilizando-se programa ORCALFEX - extraída de Pinto et al., 1999 _....................................... 62

Figura 3.22 Diagrama de blocos do modelo completo do movimento horizontal da embarcação 63

Figura 3.23 Propulsor de passo variável (adaptada de Bray, 1998) ............................... 64

Figura 3.24 Propulsor em túnel (extraída de Schottel, 2002) ......................................... 66

Figura 3.25 Propulsor azimutal montado em bocal (extraída de Marine Propulsion International, 1998) 66

Figura 3.26 Curvas dos coeficientes de propulsor série Ka e bocal 19A. Passo 1,6m e diâmetro $2 \mathrm{~m}$. 
Figura 3.27 Eficiência do propulsor série Ka e bocal 19A (Passo 1,6m e diâmetro 2m) para duas velocidades $\mathrm{V}$

Figura 3.28 Diagrama de blocos do sistema de controle do propulsor - controle de rotação 71

Figura 3.29 Diferença entre empuxo de comando $\left(T_{r e f}\right)$ e empuxo fornecido devido a variação da velocidade do fluxo na entrada do propulsor (série Ka e bocal 19A. Passo $1,6 \mathrm{~m}$ e diâmetro $2 \mathrm{~m}$ ) 72

Figura 3.30 Empuxo aplicado pelo propulsor - referência igual ao empuxo máximo $(280 \mathrm{kN})$ 73

Figura 4.1 Trajetórias próximas a superfície de escorregamento 78

Figura 4.2 Efeito de chattering. 79

Figura 4.3 Superfície de escorregamento para o caso $n=2$ (adaptado de Slotine e Li, 1991) 81

Figura 4.4 Trajetória típica de sistema controlado para caso $n=2$ (adaptado de Slotine e Li, 1991) 83

Figura 4.5 Suavização da lei de controle para evitar chattering (adaptado de Slotine e $\mathrm{Li}, 1991)$ 86

Figura 4.6 Ponto de referência genérico ao longo do eixo longitudinal. 90

Figura 4.7 Esforços nos propulsores de um FPSO gerando o mesmo momento $F_{6 R T} \ldots . .97$

Figura 4.8 Manobra de alteração de aproamento - VLCC Vidal de Negreiros 100\% carregado 100

Figura 4.9 Suposta configuração dos propulsores para VLCC Vidal de Negreiros ..... 100

Figura 4.10 Simulação com controlador sem as alterações da seção 4.1.3.1. Esquerda: Posição do ponto de referência e aproamento; direita: esforços de controle e variável $s(t)$ 102

Figura 4.11 Simulação com controlador sem as alterações da seção 4.1.3.1. Forças nos propulsores 102

Figura 4.12 Simulação com controlador com as alterações da seção 4.1.3.1 103 
Figura 4.13 Simulação com controlador com as alterações da seção 4.1.3.1. Forças nos propulsores 103

Figura 4.14 Incertezas na intensidade e direção de correnteza.................................... 107

Figura 4.15 Incertezas na altura, período e direção de onda 110

Figura 4.16 Relação entre forças e momento de deriva média para diferentes espectros de incidência (VLCC100\%, $\mathrm{H}_{\mathrm{s}}=5,5 \mathrm{~m}, \mathrm{~T}_{\mathrm{p}}=11,4 \mathrm{~s}$ ) 112

Figura 4.17 Amplitudes do movimento de roll para VLCC em três condições de carregamento (40\%,60\% e 100\%) - adaptado de Albuquerque et al. (2000) ..... 117

Figura 4.18 Configurações de equilíbrio para VLCC $80 \%$ carregado sujeito a onda e correnteza anuais.

Figura 4.19 Momento médio de controle em relação ao turret 121

Figura 4.20 Deslocamento médio do sistema de amarração 122

Figura 4.21 Máxima amplitude de roll e tração dinâmica em um riser do sistema ..... 122

Figura 4.22 Configurações de mínimo movimento de primeira ordem induzido ........ 123

Figura 4.23 Função $\mathrm{J}(\psi)$; os pontos marcados com (x) correspondem a aproamentos nos quais os limites superiores e inferiores dos critérios não são violados 124

Figura 4.24 Aproamento ótimo 124

Figura 4.25 Função $\mathrm{J}(\psi)$ próxima ao ponto de aproamento ótimo 126

Figura 4.26 (a) Segunda derivada de $J(\psi)$ no ponto de mínimo; (b) Valor $J(\psi)$ no ponto de mínimo

Figura 4.27 Definições para (a) propulsores azimutais - $i=1 . . n_{\text {azim }}$ e (b) propulsores fixos $-i=1+n_{\text {azim }} \ldots n_{\text {prop }}$ 129

Figura 4.28 Interação casco-propulsor em uma plataforma 131

Figura 4.29 Interação entre propulsor e casco em um casco tipo catamarã de uma plataforma semi-submersível (extraído de Moberg; Hellstrõm, 1993) ................ 131

Figura 4.30 Interação entre propulsores (extraída de Moberg e Hellstrõm , 1983) ..... 133

Figura 4.31 Posição dos 6 propulsores azimutais da BGL1 137 
Figura 4.32 Força de sway e momento de yaw comandados

Figura 4.33 Azimutes e Forças de propulsão em cada propulsor - minimização sem considerar saturação 140

Figura 4.34 Forças comandadas e forças efetivamente aplicadas - minimização sem considerar saturação 140

Figura 4.35 Azimutes e Forças de propulsão em cada propulsor - minimização considerando saturação

Figura 4.36 Forças comandadas e forças efetivamente aplicadas - minimização considerando saturação

Figura 4.37 Azimutes e Forças de propulsão em cada propulsor - algoritmo SQP ..... 142

Figura 4.38 Forças comandadas e forças efetivamente aplicadas - algoritmo SQP .... 142

Figura 4.39 Sistema de posicionamento dinâmico aplicado a BGL1 - algoritmo de alocação sem considerar saturação 144

Figura 4.40 Sistema de posicionamento dinâmico aplicado a BGL1 - algoritmo de alocação considerando saturação 144

Figura 4.41 Gráfico de bode do filtro Butterworth de ordem 3 e freqüência de corte $0,2 \mathrm{rad} / \mathrm{s}$ 145

Figura 4.42 Gráfico de bode do filtro notch (4.95) com $\omega_{\mathrm{n}}=0.5 \mathrm{rad} / \mathrm{s}$ e $\zeta=0.1$ 146

Figura 4.43 Gráfico de bode do filtro notch em cascata implementado no simulador. 148

Figura 4.44 (a) Condições ambientais; (b) Movimento total medido e movimento filtrado utilizando-se o filtro notch em cascata 148

Figura 5.1 Espectro bimodal 151

Figura 5.2 RAO's do movimento de roll para onda incidente a $135^{\circ}$ (extraído de Tannuri et al., 2001) 153

Figura 5.3 RAO's dos movimentos de sway, heave, pitch para onda incidente a $135^{\circ}$ (extraído de Tannuri et al., 2001) 154

Figura 5.4 Direções de incidência consideradas na análise numérica do método paramétrico 155 
Figura 5.5 Máximos erros de estimação para mares unimodais - análise numérica Condição carregada 156

Figura 5.6 Máximos erros de estimação para mares unimodais - análise numérica Condição de lastro 157

Figura 5.7 Direções de incidência consideradas nos ensaios 158

Figura 5.8 (a)Aparato experimental durante ensaio de incidência B (b)Ensaio de incidência A (fotografia gentilmente cedida pela Petrobrás) 158

Figura 5.9 (a) Altura de onda medida ; (b) Espectro de potência calculado (ambos em escala real) 159

Figura 5.10 Exemplos de espectros estimados para três incidências 163

Figura 5.11 Resultados do método paramétrico (a) altura significativa; (b) período de pico; (c) direção 164

Figura 5.12 Espectro de potência real e estimado. Caso Cheio, incidência A, repetição 3. 165

Figura 5.13 Resultados do método não paramétrico Bayesiano (a) altura significativa;

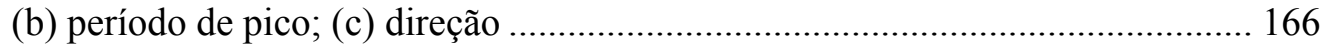

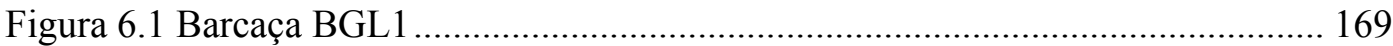

Figura 6.2 Operação de lançamento S-lay (adaptado de Bray, 1998) ........................... 169

Figura 6.3 Operação de lançamento J-lay (adaptado de Bray, 1998)........................... 170

Figura 6.4 Forças do duto durante lançamento e pontos de aplicação; casos J-lay e S-lay 171

Figura 6.5 Coeficientes de corrente para BGL1, com stinger e sem banda 172

Figura 6.6 (a)Ensaio cativo de vento com o modelo emborcado; (b)Coeficientes de vento 172

Figura 6.7 Coeficientes de deriva da BGL1 para diversas direções de incidência de onda (a) surge; (b)sway; (c)yaw 173

Figura 6.8 Módulo dos RAO's dos movimentos horizontais da BGL1 para diversas direções de incidência de onda (a) surge; (b)sway; (c)yaw 174 
Figura 6.9 Condições ambientais consideradas nas simulações $(\mathrm{C} 1)$ incidência de través ; (C2) incidência de proa 176

Figura 6.10 Lançamento S-lay, condição ambiental C1, embarcação estacionária (a) Posição e aproamento; (b) Azimute, força e potência nos propulsores; (c) posições da barcaça e forças médias nos propulsores 179

Figura 6.11 Lançamento S-lay, condição ambiental C2, embarcação em avanço de $24 \mathrm{~m}$ (a) Posição e aproamento; (b) Azimute, força e potência nos propulsores; (c) posições da barcaça e forças médias nos propulsores 180

Figura 6.12 Curva de $30^{\circ}$ simulada 181

Figura 6.13 Lançamento J-lay, condição ambiental C2, curva de $30^{\circ}$ (a) Posição e aproamento; (b) Azimute, força e potência nos propulsores; (c) erros de acompanhamento e aproamento (d) posições da barcaça, forças médias nos propulsores e trajetória do ponto de referência 182

Figura 6.14 Lançamento J-lay, condição ambiental C2 (velocidade de vento e correnteza e altura de onda reduzidas de $70 \%$ ), curva de $30^{\circ}$ 183

Figura 6.15 FPSO Norne 6608/10, com turret instalado próximo a maia nau e dotado de SPD assistido (adaptado de Offshore Technology, 2002) ..... 185

Figura 6.16 FPSO P-37, com turret instalado próximo à proa (extraído de Petrobrás, 2002) 186

Figura 6.17 FPSO com o navio aliviado conectado (direita) durante operação de descarga 187

Figura 6.18 Coeficientes estáticos de correnteza para VLCC 80\% carregado 188

Figura 6.19 Coeficientes de deriva do VLCC 80\% carregado para diversas direções de incidência de onda (a) surge; (b)sway; (c)yaw

Figura 6.20 Módulo dos RAO's dos movimentos horizontais da do VLCC 80\% carregado para diversas direções de incidência de onda (a) surge; (b)sway; (c)yaw 190

Figura 6.21 Suposta configuração dos propulsores para VLCC Vidal de Negreiros ... 191

Figura 6.22 Linhas de amarração e risers equivalentes utilizados no VLCC Vidal de Negreiros 191 
Figura 6.23 Curvas de restauração de: (a) linhas de amarração; (b) riser A ; (c) riser B ;

(d) riser $\mathrm{C}$

Figura 6.24 Condição ambiental utilizada na simulação do VLCC

Figura 6.25 Função $J(\psi)$ e ponto de aproamento ótimo.

196

Figura 6.26 Aproamento real e desejado para VLCC em manobra.

Figura 6.27 Posição X e Y do ponto de referência..... 198

Figura 6.28 Movimento vertical no ponto de turret e movimento de roll 198

Figura 6.29 Forças de propulsão para o VLCC 80\% carregado.....

Figura 6.30 Potência consumida pelos propulsores para o VLCC 80\% carregado ...... 200

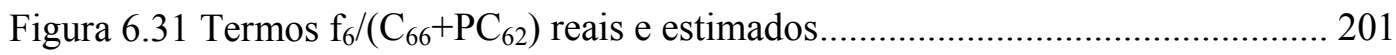

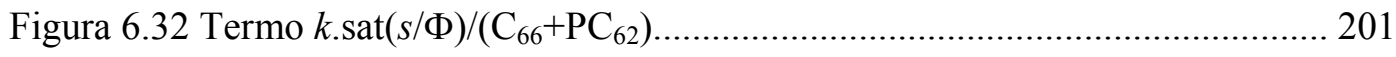

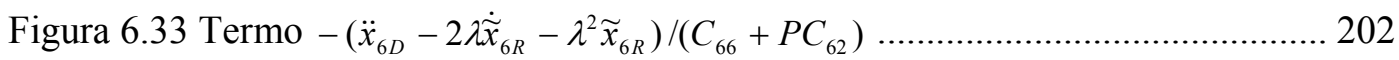

Figura 6.34 Posição X e Y do ponto de referência, com parâmetros $c_{1}=c_{2}=0$........... 202

Figura 6.35 Aproamento real e desejado para VLCC em manobra, com parâmetros

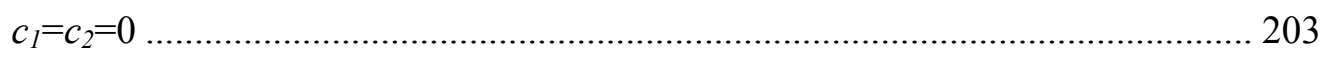

Figura A1.1 Configuração estática do riser ........................................................ 218

Figura A2.1 Princípio de funcionamento dos ADV's ........................................... 221

Figura A2.2 Modelo típico de um medidor de perfil de correnteza ........................... 222

Figura A2.3 Princípio de funcionamento dos ADCP's .......................................... 222

Figura A2.4 Tipos de anemômetros: (a) direção e velocidade independentes; (b) corpo

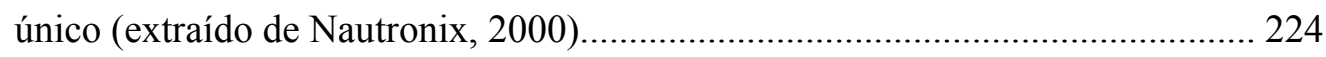

Figura A2.5 Problemas típicos que ocorrem com anemômetros instalados em embarcações dotadas de SPD (adaptados de Bray, 1998) .................................. 225

Figura A2.6 Girocompasso Modelo Robertson RGC10 ......................................... 227

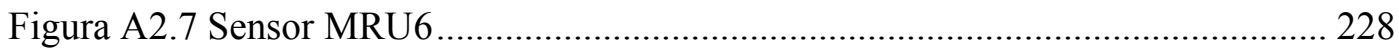

Figura A2.8 Principais sensores utilizados na medição da posição de embarcações (adaptado de Simrad, 2002). 228 
Figura A2.9 Sistema de posicionamento acústico LBL (adaptado de Sonardyne, 2002)

Figura A2.10 Sistema de posicionamento acústico SBL (adaptado de Sonardyne, 2002) 230

Figura A2.11 Sistema de posicionamento acústico USBL (adaptado de Sonardyne, 2002) 231

Figura A2.12 Radares Microondas - (a) Esquema de Funcionamento; (b) Antena com sistema de acompanhamento (adaptada de Bray, 1998) .................................... 234

Figura A2.13 Radar laser Fanbeam4 (MDL, 2002) .............................................. 235

Figura A2.14 Sistema de cabo tensionado (a) Esquema de funcionamento e limites operacionais; (b) Modelo produzido pela Simrad ............................................ 236

Figura A3.1 Diagrama de blocos geral do simulador da BGL1 ............................... 239

Figura A3.2 Diagrama interno do bloco Controlador/Propulsores............................ 239 


\section{LISTA DE TABELAS}

Tabela 4.1 Ganhos da malha de realimentação 96

Tabela 4.2 Pesos e limites considerados no cálculo de $\mathrm{J}(\psi)$ 123

Tabela 4.3 Aproamento ótimo - variação devido a erros na estimativa das condições ambientais..... 125

Tabela 5.1 Características do VLCC nas três condições de ensaio (dados em escala real)

Tabela 5.2 Condições de mar anuais, decenárias e centenárias na Bacia de Campos para

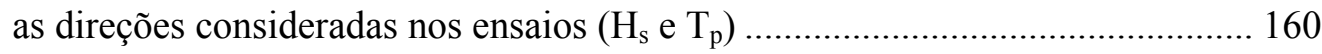

Tabela 5.3 Resultados da aplicação do método paramétrico aos ensaios - erros de estimação indicado entre parênteses................................................................ 162

Tabela 6.1 Características principais da barcaça BGL1 ......................................... 171

Tabela 6.2 Estimativas das condições ambientais e erros de modelagem máximos

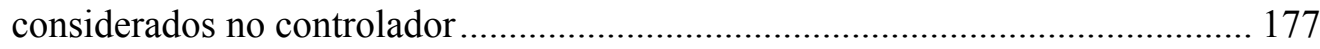

Tabela 6.3 Características principais da VLCC Vidal de Negreiros 80\% carregado ... 188

Tabela 6.4 Posições das âncoras das linhas de amarração .......................................... 192

Tabela 6.5 Posições das âncoras e propriedades dos risers equivalentes..................... 192

Tabela 6.6 Estimativas das condições ambientais e erros de modelagem máximos

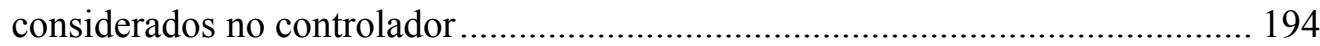

Tabela 6.7 Pesos e limites considerados no cálculo de $\mathrm{J}(\psi)$......................................... 195

Tabela 6.8 Valores dos critérios utilizados no cálculo do aproamento ótimo para o aproamento de equilíbrio, aproamento ótimo "real" e "estimado" ...................... 196

Tabela A1.1 Parâmetros do riser utilizados na formulação analítica empregada e valores numéricos utilizados nos exemplos do presente trabalho. 


\section{LISTA DE ABREVIATURAS}

\begin{tabular}{|c|c|}
\hline $\mathrm{ADCP}$ & Acoustic Doppler Current Profiler \\
\hline $\mathrm{ADV}$ & Acoustic Doppler Velocimeter \\
\hline DGPS & Differential Global Positioning System \\
\hline DICAS & Differential Compliance Anchoring System \\
\hline DITT/IPT & Divisão de Tecnologia de Transportes - Instituto de Pesquisas \\
\hline & Tecnológicas do Estado de São Paulo \\
\hline FPSO & Floating Production Storage and Offloading System \\
\hline GPS & Global Positioning System \\
\hline IMO & International Maritime Organisation \\
\hline IPT & Instituto de Pesquisas Tecnológicas do Estado de São Paulo \\
\hline ITTC & International Towing Tank Conference \\
\hline JONSWAP & Joint North Sea Wave Project \\
\hline LBL & Long base line \\
\hline LQ & Linear Quadrático \\
\hline MARIN & Maritime Research Institute Netherlands \\
\hline OCIMF & Oil Companies International Maritime Forum \\
\hline PID & Proporcional Integral Derivativo \\
\hline RAO & Response Amplitude Operator \\
\hline rms & Valor médio quadrático (Root mean square) \\
\hline SBL & Short Base Line \\
\hline SMS & Spread Mooring System \\
\hline SPM & Single-Point Mooring \\
\hline SPD & Sistema de Posicionamento Dinâmico \\
\hline
\end{tabular}


XX

SQP

TAL

TDP

TLP

USBL

USP

UPS

VLCC

VRU
Sequential Quadratic Programming

Thruster Allocation Logic

Touchdown point

Tension Leg Platform

Ultra-short Base Line

Universidade de São Paulo

Uninterruptible Power Supply

Very Large Crude Carrier

Vertical Reference Unit 


\section{LISTA DE SÍMBOLOS}

A notação (.) é utilizada para variáveis que não são relevantes para a definição da função. Em geral, utiliza-se negrito para representar parâmetros ou funções vetoriais ou matriciais. Utilizam-se também as letras $i$ e $j$ para representar índices.

\begin{tabular}{|c|c|}
\hline & Alfabeto Romano \\
\hline$a_{i}$ & Coeficientes de massa e massa adicionais $(i=1,2, \ldots, 5)$ \\
\hline$a_{A A}, b_{A A}, c_{A A}, d_{A A}$ & $\begin{array}{l}\text { Constantes utilizadas no cálculo das forças de } \\
\text { amortecimento e arrasto em linhas e risers }\end{array}$ \\
\hline$a_{X}, a_{Y}, a_{\psi}$ & $\begin{array}{l}\text { Acelerações no ponto de referência devidas às forças de } \\
\text { controle }\end{array}$ \\
\hline $\mathbf{A}$ & Matriz de alocação de empuxo relativa à seção mestra \\
\hline$A()$. & Amplitude de onda \\
\hline$A_{\text {frontal }}$ & Área projetada frontal da parte emersa \\
\hline$A_{\text {lateral }}$ & Área projetada lateral da parte emersa \\
\hline $\mathbf{A}_{\mathbf{R}}$ & $\begin{array}{l}\text { Matriz de alocação de empuxo relativa ao ponto de } \\
\text { referência }\end{array}$ \\
\hline $\mathbf{A}_{\mathbf{R}, \text { força }}, \mathbf{A}_{\mathbf{R}, \text { momento }}$ & Partições da matriz $\mathbf{A}_{\mathbf{R}}$ \\
\hline$b(),. b_{i j}()$. & $\begin{array}{l}\text { Funções que multiplicam a entrada } u\left(u_{j}\right) \text {, presentes na } \\
\text { dinâmica dos sistemas utilizados na explicação de Controle } \\
\text { por Modos Deslizantes do Capítulo } 4 \text {. }\end{array}$ \\
\hline$b_{w j}, b_{r j}$ & Coeficientes utilizados no cálculo da interação onda-corrente \\
\hline B & Matriz com os termos $b_{i j}$ \\
\hline$c_{1}, c_{2}$ & $\begin{array}{l}\text { Coeficientes de amortecimento adicionais aos movimentos } \\
\text { de surge e sway, introduzidos no controle de aproamento }\end{array}$ \\
\hline$C$ & Velocidade de onda \\
\hline $\mathbf{C}$ & Matriz definida em (4.37) \\
\hline$C_{0}$ & Coeficiente de resistência ao avanço \\
\hline
\end{tabular}


$C_{i j}$

$C_{1 \mathrm{C}}(),. C_{2 \mathrm{C}}(),. C_{6 \mathrm{C}}($.$) \quad Coeficientes estáticos de correnteza$

$C_{B}$

$C_{D}($.

$C_{D r}$

$C_{D, F A L T}(\cdot)$

$C_{V x}(),. C_{V y}(),. C_{V n}($.

$C_{Y}$

$d(),. d_{i}($.

$D(),. D_{i}($.

$D_{j}($.

$D_{j, U}(\cdot)$

$D_{r}$

$D_{P}$

$e_{i A A}$

$e_{i C}$

$e_{i D M}$

$e_{i V}$

$e_{i R e s}$ $j$ sobre o movimento $i$

Coeficiente de bloco

Coeficiente de arrasto seccional

Coeficiente de arrasto lateral

Distúrbio

Coeficiente de deriva $(j=1,2,6)$ $(j=1,2,6)$

Diâmetro da linha ou riser $(i=1,2,6)$ esforços de correnteza $(i=1,2,6)$ esforços de vento $(i=1,2,6)$
Coeficiente que representa a influência da força ou momento

Coeficiente de arrasto da linha ou riser

Coeficiente de arrasto seccional dado em Faltinsen (1990)

Coeficientes adimensionais de esforços de vento

Limitante superior do distúrbio $d$ e $d_{i}$

Coeficiente de deriva afetado pela interação onda-corrente

Diâmetro do propulsor

Erro percentual máximo não paramétrico na avaliação dos esforços de amortecimento e arrasto nas linhas e risers

Erro percentual máximo não paramétrico na avaliação dos

Erro percentual máximo não paramétrico na avaliação dos esforços de deriva média de ondas $(i=1,2,6)$

Erro percentual máximo não paramétrico na avaliação dos

Erro percentual máximo não paramétrico na avaliação dos esforços de restauração $(i=1,2,6)$ 
$E($.

$E_{i A A}($.

$E_{i \mathrm{C}(\bullet)}$

$E_{i D M}($.

$E_{i R e s}($.

$E_{i \nu}(\cdot)$

$f(),. f_{i}(),. \mathbf{f}($.

$f(\mathbf{T})$

$f_{i, d i n}($.

$f_{X, d i n}(),. f_{Y, d i n}(),. f_{\psi, d i n}($.

Função erro a ser minimizada no método de estimação de ondas

Erro máximo na avaliação dos esforços de amortecimento e arrasto nas linhas e risers $(i=1,2,6)$

Erro máximo na avaliação dos esforços de correnteza $(i=1$, $2,6)$

Erro máximo na avaliação dos esforços de deriva média de ondas $(i=1,2,6)$

Erro máximo na avaliação dos esforços de restauração $(i=1$, $2,6)$

Erro máximo na avaliação dos esforços de vento $(i=1,2,6)$

Função, ou vetor de funções, que define a dinâmica dos sistemas (parcela independente da entrada de controle)

Função que define o vínculo de igualdade utilizado no problema de alocação de empuxo

Funções com componentes de forças inerciais relativas ao movimento $i(\mathrm{i}=1,2,6)$

unções com componentes de forças inerciais relativas ao movimento nas direções $O X, O Y$ e à rotação em torno de $\mathrm{OZ}$

$F(),. F_{i}($. Limitante superior do erro de modelagem em $f($.$) e f_{i}($.

$F_{1}, F_{2}, F_{6}$ Forças de surge e sway e momento de yaw externos (sistema de forças aplicado no ponto $o$ )

$F_{1 A A}, F_{2 A A}, F_{6 A A}$

$F_{1 C}, F_{2 C}, F_{6 C}$

$F_{1 D L}, F_{2 D L}, F_{6 D L}$

$F_{I D M}, F_{2 D M}, F_{6 D M}$

$F_{I E}, F_{2 E}, F_{6 E}$

Forças e momento devidos ao amortecimento e arrasto em linhas e risers

Forças e momento devidos à correnteza

Forças e momento de deriva lenta

Forças e momento de deriva média

Forças e momento ambientais 

$F_{1 M}, F_{2 M}, F_{6 M} \quad$ Forças e momento devidos ao sistema de amarração
$F_{1 \text { Res }}, F_{2 \text { Res }}, F_{6 \text { Res }} \quad$ Forças e momento de restauração devidos ao sistema de amarração
$F_{1 R}, F_{2 R}, F_{6 R}$
$F_{1 R E}, F_{2 R E}, F_{6 R E}$
$F_{1 R M}, F_{2 R M}, F_{6 R M}$
$F_{1 R T}, F_{2 R T}, F_{6 R T}$
$\left(F_{1 R T}\right)_{\text {residual }},\left(F_{2 R T}\right)_{\text {residual }}$
Sistema de forças (surge e sway) e momento de yaw aplicado no ponto de referência
Forças e momento ambientais (aplicados no ponto de referência)
Forças e momento devidos ao sistema de amarração (aplicados no ponto de referência)
Forças e momento devidos aos propulsores (aplicados no ponto de referência)
Forças de controle residuais, resultantes dos empuxos nos propulsores responsáveis pelo momento de yaw requerido ( $\left.\mathbf{T}_{\text {momento }}\right)$

$\left(F_{2 R T}\right)_{a m o r t}$

$F_{1 T}, F_{2 T}, F_{6 T}$

$F_{1 V}, F_{2 V}, F_{6 V}$

$F_{g}$

$\mathbf{F}_{\mathbf{T}}$

$\bar{F}_{X}, \bar{F}_{Y}, \bar{N}_{Z}$

$F_{x}, F_{y}$

$g$

$g(z)$
Força de controle em sway responsável pelo aumento do amortecimento neste movimento

Forças e momento devidos aos propulsores

Forças e momento devidos ao vento

Função utilizada no cálculo do espectro de rajadas proposto em Occhi-Schin (1998)

Vetor com forças e momento de controle $\left(F_{1 T}, F_{2 T}, F_{6 T}\right)^{T}$

Forças e momento externos aplicados no centro de massa, projetados na direção $O X, O Y$ e $O Z$

Forças devidas ao amortecimento e arrasto em linha ou riser, projetadas na direção horizontal no plano da linha ou riser e na direção perpendicular a este plano respectivamente Aceleração da gravidade Função perfil de distribuição de velocidade de correnteza ao longo da profundidade 


\begin{tabular}{|c|c|}
\hline$g_{1}(x), g_{2}(x)$ & $\begin{array}{l}\text { Funções de ponderação dos coeficientes de arrasto } \\
\text { seccionais }\end{array}$ \\
\hline$h$ & Profundidade \\
\hline$H_{\text {onda }}(s)$ & Função de transferência do filtro de onda \\
\hline$H_{S}, H_{S, i}$ & $\begin{array}{l}\text { Altura significativa da onda; quando o índice estiver } \\
\text { presente, refere-se à altura significativa da } i \text {-ésima } \\
\text { componente do espectro bimodal }(i=1,2)\end{array}$ \\
\hline $\mathbf{i}, \mathbf{j}$ & Versores nas direções $o x_{1}$ e $o x_{2}$ respectivamente \\
\hline$I$ & Momento de inércia das estruturas girantes do propulsor \\
\hline $\mathbf{I}, \mathbf{J}$ & Versores nas direções $O X$ e $O Y$ respectivamente \\
\hline$I_{j}(v, r)$ & Integrais do coeficiente de arrasto seccional $(j=0,1,2,3)$ \\
\hline$I_{R}, I_{\tau}, I_{\Delta}, I_{W}$ & $\begin{array}{l}\text { Limites inferiores para os critérios utilizados no funcional } \\
J(\psi)\end{array}$ \\
\hline $\bar{I}_{Z}$ & Momento de inércia baricêntrico em relação ao eixo $O Z$ \\
\hline$J_{0}$ & Coeficiente adimensional de avanço em propulsores \\
\hline$J(\psi)$ & Função objetivo \\
\hline$k(),. k_{i}()$. & $\begin{array}{l}\text { Ganho do termo descontínuo do controlador por modos } \\
\text { deslizantes }(i=1,2, \ldots \text { ou } i=X, Y, \psi)\end{array}$ \\
\hline$K_{Q}$ & Coeficiente de torque no propulsor \\
\hline$K_{R}, K_{\tau}, K_{\Delta}, K_{W}$ & Pesos utilizados no funcional $J(\psi)$ \\
\hline$K_{T}$ & Coeficiente de empuxo no propulsor \\
\hline$K_{T N}$ & $\begin{array}{l}\text { Coeficiente de empuxo adicional no propulsor devido ao } \\
\text { bocal }\end{array}$ \\
\hline$l$ & Comprimento suspenso da linha ou riser \\
\hline$l^{\prime}$ & Comprimento do riser suportado pelo solo \\
\hline$l_{P}$ & $\begin{array}{l}\text { Distância longitudinal entre centro de pressão e secção } \\
\text { mestra }\end{array}$ \\
\hline
\end{tabular}


$L($.

$L_{\text {total }}$

$m$

$m_{a, r}$

$m_{r}$

M

$M_{11}, M_{22}, M_{66}, M_{26}$

$n$

$n_{\text {azim }}$

$n_{\text {fixo }}$

$n_{l}$

$n_{P}$

$n_{\text {prop }}$

$n_{r e f}$

$n_{T}$

$o$

$o x_{1} x_{2} x_{3}$

$O X Y Z$

$P$

$P_{i j}(\omega)$

$q_{r}$
Comprimento da embarcação

Funcional que representa o consumo total de energia pelos propulsores

Comprimento total do riser

Número de variáveis controladas e entradas de controle no exemplo da seção 4.1.1.2

Massa adicional do riser por unidade de comprimento

Massa do riser por unidade de comprimento

Massa da embarcação

Massas adicionais em baixa freqüência (relativas ao ponto $o$ )

Ordem do sistema dinâmico

Número de propulsores azimutais

Número de propulsores fixos

Número de linhas e risers equivalentes

Rotação do propulsor (rps)

Número total de propulsores

Referência de rotação do propulsor (rps)

Número de componentes do vetor $\mathbf{T}\left(n_{T}=2 n_{\text {azim }}+n_{\text {fixo }}\right)$

Ponto intersecção entre a linha de centro e a secção mestra

Referencial solidário ao navio

Referencial inercial fixo na Terra

Constante de proporcionalidade entre momento de controle $F_{6 R T}$ e força de sway residual $\left(F_{2 R T}\right)_{\text {residual }}$

Densidade espectral cruzada e de potência dos movimentos $i$ $\mathrm{e} j$

Peso submerso da linha ou riser por unidade de comprimento 
$Q_{e}$

$Q_{\text {Prop }}$

$R(\mathbf{T})$

Re

$R_{H}$

$S$

$s(),. s_{i}($.

$s_{i}$

S

$S($.

$S(\omega)$

$S_{j D L}(\omega)$

$S_{R}, S_{\tau}, S_{\Delta}, S_{W}$

$S_{V}(\omega)$

t

$t_{\text {alcance }}$

$T$

$T_{0}$

$T_{i}^{F}$

$T_{j}\left(\omega_{i}, \omega_{j}, \beta_{O}\right)$
Torque elétrico fornecido pelo motor do propulsor

Torque hidrodinâmico no propulsor

Função resíduo, utilizada no problema de alocação de empuxo

Número de Reynolds

Rigidez horizontal da linha ou riser

(Seção 3.3.2) Coordenada curvilínea ao longo da linha ou riser

(Capítulo 4) Variáveis que definem a superfície de escorregamento $S(t)(i=1,2, \ldots$ ou $i=X, Y, \psi)$

(Capítulo 5) Espalhamento direcional da i-ésima componente do espectro

Área molhada

Superfície de escorregamento (restrito à seção 4.1.1)

Densidade espectral de amplitude de onda

Densidade espectral das forças e momento de deriva lenta $(j=1,2,6)$

Limites superiores para os critérios utilizados no funcional $J(\psi)$

Densidade espectral da velocidade do vento (rajadas)

Tempo

Tempo para a trajetória atingir a superfície de escorregamento $S(t)$

Calado da embarcação

Tração estática no TDP

Empuxo fornecido pelo propulsor fixo $i$

Função de transferência quadrática 
$\mathbf{T}$

$T_{a d m}$

$T_{d}$

$T_{e}$

$T_{\max , i}$

$\mathbf{T}_{\text {momento }}$

$T_{N}$

$T_{P}$

$T_{\text {Prop }}$

$T_{r e f}$

$T_{S}$

$T_{x_{1} i}^{A}, T_{x_{2} i}^{A}$

$\mathbf{u}$

$u, u_{j}$

$u(),. v($.

$\hat{u}($.

$\mathbf{U}($.

$\mathbf{U}_{r}(\cdot)$

$V($.

$V_{C}$

$\overline{V_{C}}$
Vetor com empuxos em cada propulsor

Máxima compressão admissível pelo riser

Amplitude da tração dinâmica no riser

Tração elástica em risers

Máximo empuxo fornecido pelo propulsor $i$

Parcela do vetor de empuxos $\mathbf{T}$, responsável por fornecer o momento de yaw requerido

Empuxo fornecido pelo bocal do propulsor

Período de pico do espectro de onda

Empuxo fornecido pelo propulsor

Referência do empuxo a ser fornecido pelo propulsor

Tração total no ponto de conexão do riser no navio

Componentes em $o x_{1}$ e $o x_{2}$ do empuxo fornecido pelo propulsor azimutal $i$

Vetor com entradas de controle (Seções 4.1.1.1 e 4.1.1.2)

Entradas de controle (Seções 4.1.1.1 e 4.1.1.2)

Componentes da velocidade do ponto $o$ em relação ao meio fluido nos eixos $o x_{1}$ e $o x_{2}$

Termo de linearização por realimentação

Velocidade absoluta do ponto $o$ (em relação ao referencial fixo)

Velocidade do ponto $o$ em relação ao referencial ao meio fluido

Velocidade do vento

Velocidade da correnteza

Velocidade equivalente de correnteza considerando perfil de distribuição ao longo da profundidade 


\begin{tabular}{|c|c|}
\hline$V_{c r}$ & Velocidade da correnteza em relação ao casco \\
\hline$V_{c, x z}$ & Componente da velocidade da correnteza no plano da linha \\
\hline$V_{c, y z}$ & $\begin{array}{l}\text { Componente da velocidade da correnteza na direção } \\
\text { perpendicular ao plano da linha }\end{array}$ \\
\hline$V_{P}$ & Velocidade de avanço do propulsor \\
\hline$W_{\text {médio }}$ & Potência média total consumida pelos propulsores \\
\hline $\mathbf{x}()$. & Vetor de estados \\
\hline$\dot{x}_{1}(),. \dot{x}_{2}(),. \ddot{x}_{1}(),. \ddot{x}_{2}()$. & $\begin{array}{l}\text { Componentes da velocidade e aceleração do ponto } o \text { nos } \\
\text { eixos } o x_{1} \text { e } o x_{2}\end{array}$ \\
\hline$\dot{x}_{1 R}(),. \dot{x}_{2 R}(),. \ddot{x}_{1 R}(),. \ddot{x}_{2 R}()$. & $\begin{array}{l}\text { Componentes da velocidade e aceleração do ponto de } \\
\text { referência nos eixos } o x_{1} \text { e } o x_{2}\end{array}$ \\
\hline$x_{1, i P}, x_{2, i P}$ & Posição do propulsor $i$ em relação ao referencial $o x_{1} x_{2}$ \\
\hline$x_{6}()$. & Ângulo de aproamento \\
\hline$x_{j P O}()$. & Movimento de primeira ordem \\
\hline $\mathbf{x}_{\mathbf{d}}(),. x_{d}(\cdot), x_{d i}(\cdot)$ & $\begin{array}{l}\text { Valores desejados (set-points) para vetor de estados } \mathbf{x} \text {, } \\
\text { estado } x \text { e estado } x_{i} \text { respectivamente }\end{array}$ \\
\hline$x_{G}$ & Posição longitudinal do baricentro em relação ao ponto $o$ \\
\hline $\mathbf{x}_{\mathbf{r}}$ & Vetor com termos $x_{d i}-\lambda \widetilde{x}_{i}$ \\
\hline$x_{p}$ & $\begin{array}{l}\text { Posição longitudinal do ponto de turret em relação ao } \\
\text { sistema } o x_{1} x_{2}\end{array}$ \\
\hline$x_{R}$ & $\begin{array}{l}\text { Posição longitudinal do ponto de referência em relação ao } \\
\text { sistema } o x_{1} x_{2}\end{array}$ \\
\hline$x_{t}$ & Distância horizontal entre o ponto de conexão e o TDP \\
\hline$x_{v}$ & $\begin{array}{l}\text { Variável utilizada no cálculo do espectro de rajadas proposto } \\
\text { em Occhi-Schin (1998) }\end{array}$ \\
\hline$X(),. Y()$. & Posição do ponto $o$ em relação ao referencial $O X Y Z$ \\
\hline$X_{j}$ & Amplitude complexa do movimento $j$ da embarcação \\
\hline
\end{tabular}




\begin{tabular}{|c|c|}
\hline & Alfabeto Grego \\
\hline$\alpha$ & Direção de incidência da correnteza em relação à $o x_{1}$ \\
\hline$\alpha_{i P}$ & Orientação do propulsor $i$ \\
\hline$\alpha_{O}$ & Fator multiplicativo dos espectros de potência de onda \\
\hline$\alpha_{O X Y Z}$ & Direção de incidência da correnteza em relação à $O X$ \\
\hline$\alpha_{r}$ & $\begin{array}{l}\text { Direção de incidência (relativa ao casco) da correnteza em relação } \\
\text { ao eixo } o x_{1}\end{array}$ \\
\hline$\beta$ & $\begin{array}{l}\text { Parâmetro utilizado na definição da configuração estática do riser } \\
\text { (relação entre tração no TDP e peso suspenso por unidade de } \\
\text { comprimento) }\end{array}$ \\
\hline$\beta_{O}$ & Direção de incidência de onda em relação à $o x_{1}$ \\
\hline $\bar{\beta}_{O, i}$ & $\begin{array}{l}\text { Direção de incidência média da } i \text {-ésima componente do espectro } \\
\text { de ondas direcional }(i=1,2)\end{array}$ \\
\hline$\beta_{O, O X Y Z}$ & Direção de incidência de onda em relação à $O X$ \\
\hline$\beta_{V}$ & Direção de incidência do vento em relação à $o x_{1}$ \\
\hline$\beta_{V, O X Y Z}$ & Direção de incidência do vento em relação à $O X$ \\
\hline$\delta \dot{x}$ & $\begin{array}{l}\text { Velocidade do topo da linha projetada na direção horizontal } \\
\text { contida no plano da mesma }\end{array}$ \\
\hline$\delta \dot{y}$ & $\begin{array}{l}\text { Velocidade do topo da linha projetada na direção perpendicular ao } \\
\text { plano da mesma }\end{array}$ \\
\hline$\Delta F_{1 C}(),. \Delta F_{2 C}(\cdot)$ & Parcelas das forças e momento de correnteza devidas à rotação do \\
\hline$\Delta F_{6 C}()$. & casco \\
\hline$\Delta_{\text {médio }}$ & $\begin{array}{l}\text { Deslocamento médio do sistema de amarração em relação à } \\
\text { posição neutra }\end{array}$ \\
\hline
\end{tabular}


$\Delta_{r} \quad$ Deslocamento estático do ponto de conexão do riser no plano horizontal

$\Delta \omega \quad$ Diferença entre duas freqüências consecutivas na definição do espectro

$\varepsilon$

Erro de acompanhamento

$\Phi, \Phi_{i}$

Largura da camada limite $(i=1,2, \ldots$ ou $i=X, Y, \psi)$

$\gamma$

$\eta, \eta_{i}$

$\eta_{\text {arrasto,i }(.)}$

$\lambda$

$\lambda, \lambda_{i}$

$\Lambda$

$\mu$

$\mu_{r}$

$\theta_{h, j}$

$\theta_{S}$

$\theta(s)$

$\rho$

$\rho_{a}$
Fator de forma do espectro de JONSWAP

Parâmetro do controle por modos deslizantes $(i=1,2, \ldots$ ou $i=X$, $Y, \psi)$

Função de redução do empuxo do propulsor $i$ devido a efeitos de interferência com o casco

Vetor com multiplicadores de Lagrange utilizados na solução do problema de alocação de empuxo

Parâmetro do controle por modos deslizantes, relacionado à largura de banda em malha fechada $(i=1,2, \ldots$ ou $i=X, Y, \psi)$

Freqüência reduzida, utilizada no cálculo da tração dinâmica em risers

Diferença entre freqüências, utilizada no cálculo dos esforços de deriva lenta

Coeficiente de atrito do riser com o solo

Ângulo, no plano horizontal, entre linha ou riser e o eixo $O X$

Ângulo entre a tangente do riser e a reta horizontal, no ponto de conexão

Ângulo, no plano vertical, entre a linha ou riser com reta horizontal

Densidade da água

Densidade do ar 
$\tau_{\mathrm{RT}}$

$\omega$

$\omega_{0}, \omega_{0, q}$

$\omega_{1}, \omega_{2}, \omega_{3}$

$\omega_{c}$

$\omega_{e}$

$\omega_{i}, \omega_{f}$

$\omega_{n}$

$\Omega$

$\psi(t)$

$\zeta$

$\zeta_{0}$

$\mathrm{T}$
Fator do espectro de JONSWAP

Adimensional que quantifica o nível de tração dinâmica

Constante de tempo mecânica do sistema propulsor

Vetor com forças e momento requeridos pelo controlador em relação ao ponto de referência

Freqüência

Freqüência de pico do espectro de onda; quando o índice estiver presente, refere-se à freqüência de pico da i-ésima componente do espectro bimodal

Freqüências dos três picos de atenuação do filtro notch em cascata

Escala de freqüência da oscilação em modo de catenária, utilizada no cálculo da tração dinâmica em risers

Escala de freqüência da oscilação em modo elástico, utilizada no cálculo da tração dinâmica em risers

Freqüência mínima e máxima utilizada no cálculo do movimento de primeira ordem

Freqüência central de atenuação do filtro de onda notch

Coeficiente de freqüência, utilizada no cálculo da tração dinâmica em risers

Ângulo de aproamento

Parâmetro que regula a atenuação do filtro de onda notch ou notch em cascata

Coeficiente linearizado de amortecimento, utilizado no cálculo da tração dinâmica em risers

\section{Simbologia Especial}

(Sobrescrito) Transposição 


$\begin{array}{ll}+ & \text { (Sobrescrito) Pseudo Inversa } \\ & \text { (Sobre a variável) Valor estimado } \\ \sim & \text { (Sobre a variável) Erro - diferença entre valor real e valor desejado } \\ & \text { Valor linearizado } \\ - & \text { (Sobre a variável) Indica relação ao centro de massa } \\ \cdot & \text { (Sobre a variável) Derivada em relação ao tempo } \\ \cdot & \text { (Sobre a variável) Derivada de segunda ordem em relação ao } \\ & \text { tempo } \\ \text { max, min } & \text { (Subscritos) Valores máximos e mínimos }\end{array}$




\section{GLOSSÁRIO}

Movimento de surge Translação longitudinal (avanço); movimento indicado pelo índice 1

Movimento de sway Translação lateral (deriva) ; movimento indicado pelo índice 2

Movimento de heave Translação vertical (arfagem) ; movimento indicado pelo índice 3

Movimento de pitch Rotação (no plano vertical) em torno do eixo transversal (caturro); movimento indicado pelo índice 4

Movimento de roll Rotação (no plano vertical) em torno do eixo longitudinal (balanço ou jogo); movimento indicado pelo índice 5

Movimento de yaw Rotação no plano horizontal (guinada); movimento indicado pelo índice 6 


\section{Introdução}

O petróleo é a principal fonte energética da civilização atual, garantindo relevância política e econômica aos países que o possuem em grandes reservas. Parte delas encontra-se no mar, muitas vezes afastada da costa e em grandes profundidades. Vultosas somas de recursos, aliadas a grande desenvolvimento tecnológico, permitem a exploração em alto-mar, viabilizada pela importância e pelos altos preços do petróleo no âmbito mundial. No Brasil, por exemplo, 91\% das reservas de petróleo são marítimas (dados de 1999), sendo quase a totalidade concentrada na Bacia de Campos, Estado do Rio de Janeiro (ANP, 2002).

A exploração dos poços marítimos iniciou-se no final século XIX, sendo as primeiras instalações feitas na costa da Califórnia e no Mar Cáspio. Constituíamse de estruturas fixas conectadas à costa, sobre as quais suportavam-se os equipamentos para a perfuração e exploração dos poços (Figura 1.1). A profundidade alcançava, no máximo, $6 \mathrm{~m}$ (Fäy, 1990).

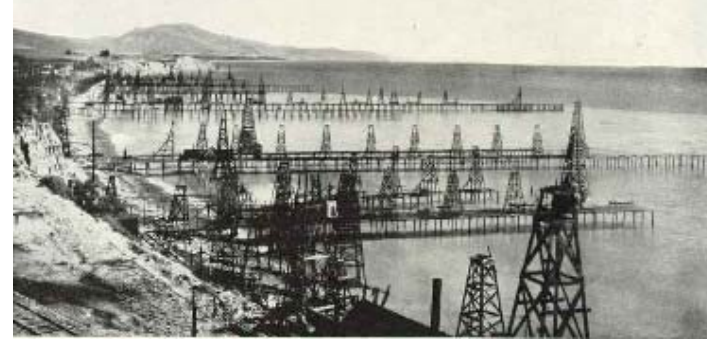

Figura 1.1 Exploração de petróleo no mar em Summerland, Califórnia, 1902 (extraído de The Hubbert Peak of Oil Production, 2002)

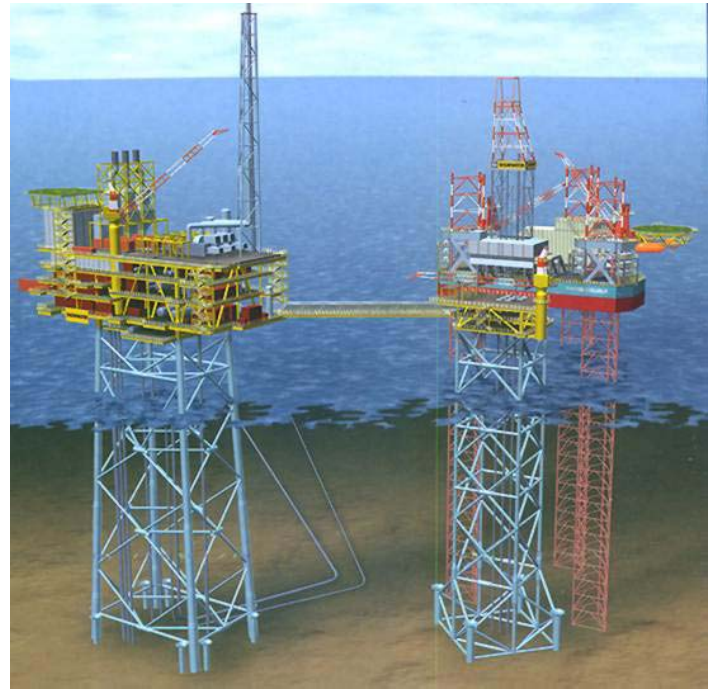

Figura 1.2 Plataforma do tipo jaqueta (extraído de Offshore Technology, 2002)
Maiores profundidades e distâncias em relação à costa foram alcançadas com a construção de plataformas do tipo jaqueta, utilizadas até hoje. São fixadas ao fundo do mar por treliças metálicas, ao longo das quais instalam-se as tubulações que levam o óleo à plataforma (Figura 1.2). No convés são instalados os equipamentos para a perfuração e manutenção do poço. 
A viabilidade técnica e econômica das jaquetas é garantida para profundidades inferiores a aproximadamente 500m, o que motivou o desenvolvimento de outras técnicas de exploração e operação em alto-mar, destacando-se, neste contexto, os sistemas de amarração. Estruturas flutuantes são amarradas por linhas ancoradas ao fundo do oceano, que compensam os esforços ambientais atuantes mantendo-as próximas à posição de equilíbrio inicial. Estes sistemas são empregados, por exemplo, em navios de perfuração, barcaças de lançamento de dutos e plataformas semisubmersíveis de produção.

A partir dos sistema de amarração foram concebidos, na década de 90, os FPSO's (Floating, Production, Storage and Offloading Systems), que se constituem de navios petroleiros amarrados atuando na exploração de poços e no armazenamento e processamento do petróleo, bastante difundidos hoje em dia (Figura 1.3).

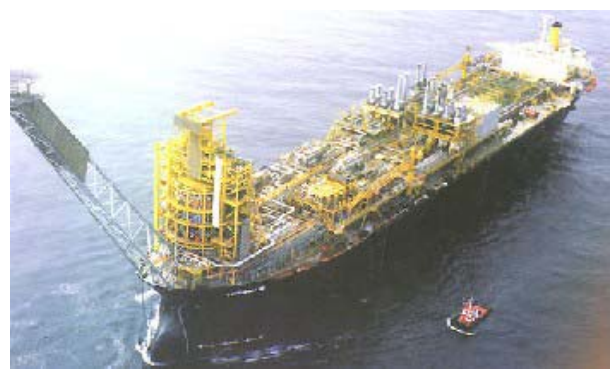

Figura 1.3 FPSO P-35 (José Bonifácio) (extraído de Petrobras, 2002)

Entretanto, os sistemas amarrados são compostos por grandes massas flutuantes suportadas por linhas elásticas e excitadas por forças ambientais, cenário propício para a ocorrência de grandes movimentos oscilatórios, que devem ser considerados nos projetos e muitas vezes dificultam operações como, por exemplo, produção e lançamento de dutos. A capacidade de movimentação dos sistemas amarrados também é muito baixa, sendo que excursões maiores requerem a utilização de rebocadores de âncoras para reposicioná-los. A análise de viabilidade econômica deve ser enfatizada quando a profundidade ultrapassa o valor de $1000 \mathrm{~m}$ aproximadamente, pois os custos das linhas e da operação de lançamento das mesmas podem se tornar muito altos.

Desde o início da década de 60 tornava-se necessário desenvolver um sistema que permitisse a prospecção de petróleo em profundidades superiores a 1000m. Em 1961, nos Estados Unidos, instalaram-se quatro propulsores azimutais controlados manualmente no navio de perfuração "Cuss 1", numa primeira tentativa de substituir o sistema de amarração composto por quatro linhas, até então utilizado neste navio. $\mathrm{O}$ controle da posição e aproamento era feito manualmente, utilizando-se as informações de posicionamento de um radar de superfície e de um sonar. Realizaram-se operações de prospecção em até $3500 \mathrm{~m}$ de profundidade, obtendo-se, devido ao controle manual, 
precisão de posicionamento de $180 \mathrm{~m}$. No mesmo ano desenvolveu-se o navio "Eureka", o primeiro realmente equipado com sistema de posicionamento dinâmico (SPD), possuindo um controlador analógico que recebia as informações de um sensor de posição do tipo fio tensionado (taut-wire) e comandava os propulsores (Bray, 1998).

Outros navios foram convertidos, ao longo da década de 60, para atuarem com SPDs, como o norte americano "Cardrill" e o francês "Térébel". Comparados aos modernos SPDs, eram extremamente simples, com controladores analógicos e sem redundância. Foram, porém, pioneiros nesta nova técnica. As aplicações dos navios posicionados dinamicamente começaram a se diversificar, incluindo, além de perfuração, suporte a mergulho e veículos submarinos, lançamento de dutos e cabos, pesquisa geofísica, etc...

Após a década de 70, o posicionamento dinâmico tornou-se uma técnica estabelecida, com aumento consistente em número (em 1980 eram 65; em 1997, alcançaram-se 400 embarcações equipadas) e em diversidade de operações. Além das atividades relacionadas ao petróleo, já se encontram aplicações em pesquisa oceanográfica geral, navios militares de suporte, navios de carga e cruzeiro e até mesmo em casos mais "exóticos", como plataformas de lançamento de foguetes em alto-mar (SeaLaunch, 2002), mostrada na Figura 1.4.

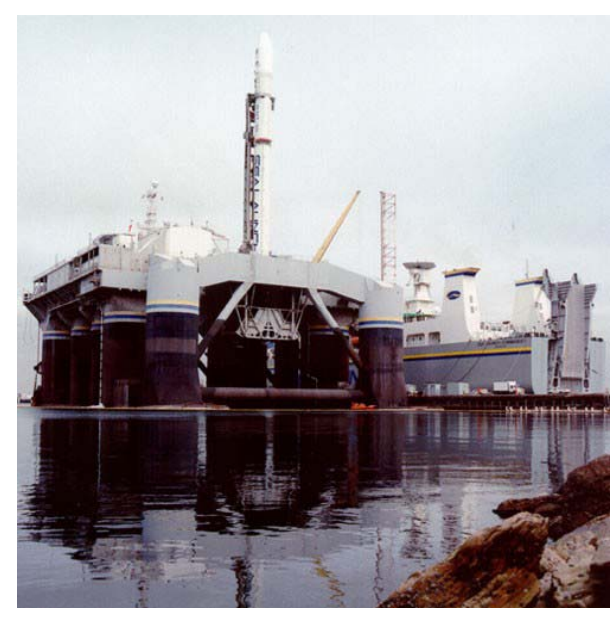

Figura 1.4 Plataforma de lançamento de foguetes em alto-mar (extraído de SeaLaunch, 2002)

Destaque especial deve ser dado ao fato de que, em 1986 desenvolveu-se, na Noruega, o primeiro sistema de posicionamento dinâmico combinado a sistema de

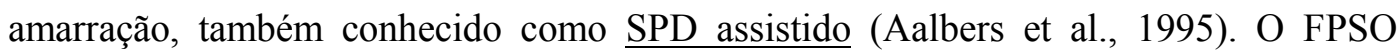
"Petrojarl" era dotado de um sistema de amarração tipo Turret, bastante empregado até os dias de hoje. Este sistema é constituído por um eixo vertical inserido no casco do navio, na base do qual são acopladas as linhas de amarração, risers $^{1}$ e umbilicais.

\footnotetext{
${ }^{1}$ Linhas que servem ao transporte de hidrocarbonetos do poço até o FPSO ou plataforma, e têm a função de controle das válvulas junto ao poço.
} 
Um sistema de rolamentos axiais possibilita que o casco gire em torno do Turret e, dessa forma, se alinhe com a resultante dos esforços ambientais (Figura 1.5). Para permitir a passagem do óleo para o navio, o aproamento deveria ser mantido próximo a um valor determinado, o que era conseguido por meio de um sistema de posicionamento dinâmico controlando o aproamento do FPSO.

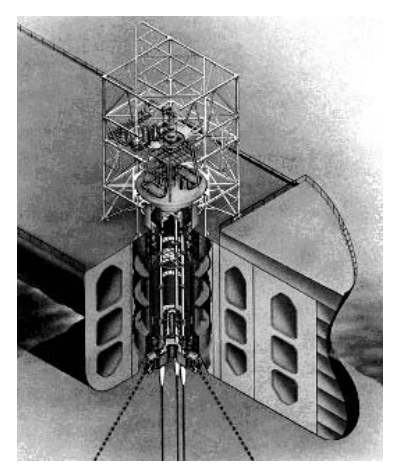

Figura 1.5 Sistema Turret

Tipo análogo de sistema assistido foi estudado simultaneamente no Brasil por Pesce (1987), com aplicações a operações de navios aliviadores.

Embora tenham sido desenvolvidos sistemas de transferência de óleo dos risers para o navio que independem do aproamento, chamados de tornéis (swivel), o conceito de SPD assistido continuou em uso, permitindo a minimização dos esforços nas linhas de amarração, a busca de aproamentos que melhorem o desempenho operacional, maior segurança de operação em condições ambientais extremas, maior regularidade de operação, amortecimento das oscilações de baixa freqüência, etc... (Christensson; Omberg, 1992). Embora já existam muitos FPSO's dotados de SPD assistido, diversos aspectos da integração entre posicionamento dinâmico e sistemas de amarração ainda são temas de pesquisa e desenvolvimento, como será discutido, em parte, ao longo do presente trabalho.

Analisado o panorama histórico do surgimento dos sistemas de posicionamento dinâmico e a rápida diversificação de suas aplicações, descrevem-se agora, em um maior nível de detalhamento, a composição e funcionalidades de tais sistemas, de forma a vislumbrar a contribuição do presente trabalho dentro deste assunto tão vasto.

Define-se posicionamento dinâmico como um sistema que controla automaticamente a posição e aproamento de uma embarcação por meio de propulsão ativa (Bray, 1998 e Fossen, 1994). A característica fundamental dos SPDs é a integração de um grande número de sub-sistemas operando conjuntamente. Na ocorrência de falha de qualquer um deles, o sistema todo é comprometido, o que implica a perda de posição e aproamento por parte da embarcação. As conseqüências desta ocorrência são, em geral, gravíssimas, devido à possibilidade de choques entre embarcações e rompimentos 
de linhas e dutos, o que pode levar a interrupções de operações de altíssimo custo, desastres ambientais e, até mesmo, perdas de vidas humanas.

A Figura 1.6 apresenta um diagrama com os sub-sistemas principais de um SPD, com a inter-relação entre eles. A seguir, serão descritos brevemente cada um dos subsistemas apresentados.

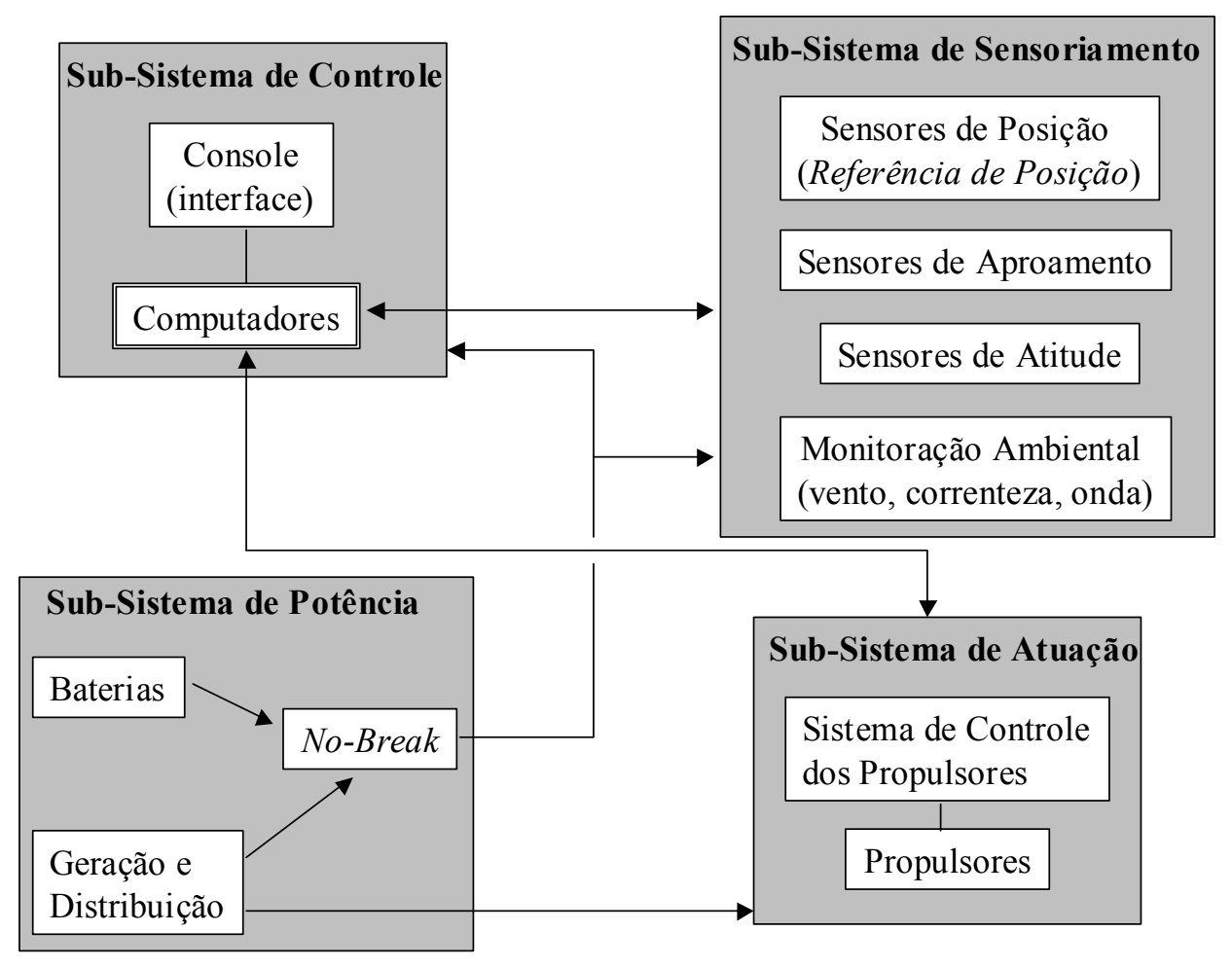

Figura 1.6 Elementos de um SPD

O sub-sistema de potência é responsável por fornecer energia aos propulsores, a alguns sensores e aos elementos de controle. O SPD consome uma grande parte da energia produzida na embarcação, com variações abruptas de carga devidas a súbitas mudanças das condições ambientais, como por exemplo a rajadas de vento. Assim, esses sistemas devem ser flexíveis para evitar consumo desnecessário de combustível e permitir resposta rápida a variações de carga. Diversas arquiteturas da planta de geração e distribuição são encontradas, destacando-se a opção diesel-elétrica, com todos os consumidores alimentados eletricamente e a potência gerada por alternadores diesel. Outra configuração consiste em uma parte diesel-elétrica e uma parte movida diretamente por motores diesel (propulsor principal em geral). Um no-break (conhecido como UPS - Uninterruptible Power Supply) associado a um banco de baterias é 
utilizado para estabilizar a energia fornecida aos componentes eletrônicos do SPD, eliminando flutuações e interrupções momentâneas e garantindo o funcionamento durante 30 minutos quando da ocorrência de interrupção prolongada (black-out).

O sub-sistema de atuação é responsável por fornecer as forças necessárias para o posicionamento da embarcação. É composto pelos diversos tipos de propulsores e pelos sistemas de controle associados a cada um deles. Os mais comuns são os propulsores principais, posicionados na popa da embarcação; os propulsores em túnel (Figura 1.7b), montados em túneis instalados transversalmente ao casco e os azimutais (Figura 1.7a), que podem direcionar o empuxo gerado, através de um grau de liberdade adicional de rotação. A variação do empuxo nos propulsores pode ser obtida pela variação do ângulo das pás (passo controlável) ou por variação da rotação (passo fixo). O número de propulsores utilizados depende da redundância necessária para cada aplicação, da potência requerida e de questões de arranjo. Tipicamente, são utilizados de 4 a 8 propulsores.

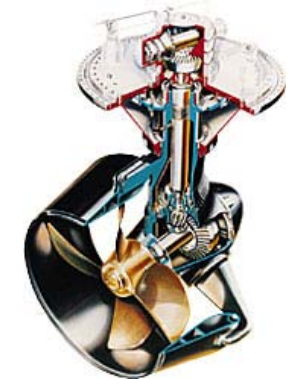

(a)

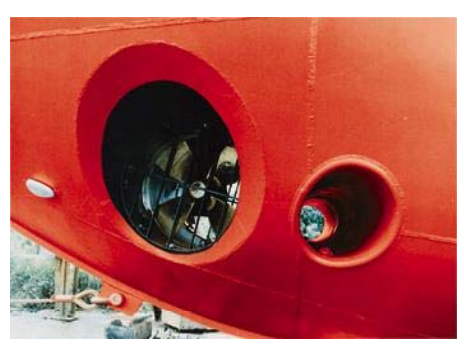

(b)

Figura 1.7 (a) Propulsor azimutal (b) Propulsor em túnel

O sub-sistema de sensoriamento é composto pelos equipamentos (sensores) responsáveis por fornecer as informações necessárias para que o controlador posicione a embarcação de forma desejada. Os sensores de posição, conhecidos como sistemas de referência de posição, medem a posição de um ponto da embarcação no plano horizontal. Existem diversas tecnologias empregadas para este fim, destacando-se os sistemas de localização por satélite (GPS), sistemas hidroacústicos, radares por microondas, dentre outros. Em geral, os SPDs possuem mais de um sensor de posição, valendo-se desta redundância para obter medidas mais precisas e com maior confiabilidade. O aproamento da embarcação é medido por girocompassos, também empregados de forma redundante. Utilizam-se também sensores que medem os 
movimentos verticais da embarcação (roll, heave e pitch). Estas medidas não são utilizadas pelo SPD diretamente pois, como será explicado adiante, estes movimentos não são controlados pelos SPDs devido a suas altas freqüências; entretanto, são utilizadas na correção das leituras feitas por alguns tipos de sistemas de referência de posição.

Existem também os sensores responsáveis pela medição das condições ambientais. A medição do vento (velocidade e direção) é feita pelos anemômetros, que são encontrados em todos os SPDs atuais pois o controlador utiliza suas informações para estimar as forças de baixa freqüência devidas ao vento e contrabalançá-las diretamente pelos propulsores (controle pré-alimentado ou feed-forward). Esta compensação direta dos esforços ambientais é feita, hoje em dia, apenas para o vento, pois a tecnologia para a medição da correnteza e ondas vem se desenvolvendo acentuadamente apenas nos últimos anos. Com isto, uma forte tendência nos trabalhos de pesquisa e desenvolvimento relacionados a SPDs é a inclusão das informações dos sensores (ou estimadores) das ondas e correnteza diretamente na malha de préalimentação, o que melhora o desempenho do sistema pois a compensação dos esforços é feita diretamente (de imediato), sem que seja necessário esperar que o navio saia da posição desejada. Compensadores de esforços ambientais vêm sendo estudados, no Brasil, desde Pesce (1987).

O sub-sistema de controle é composto pelos computadores e pelo console de interface, conhecido como man-machine interface (MMI). O computador é dotado de placas de entrada e saída (analógicas e digitais) e placas de comunicação, responsáveis pela leitura das informações dos diversos sensores e pelo comando sobre os sistemas de controle dos propulsores. Toda a "inteligência" dos SPDs está contida no programa computacional executado neste sub-sistema, que realiza a lógica de controle responsável pelo posicionamento da embarcação.

Um dos componentes deste programa é o algoritmo de controle (de nível inferior), responsável pelo cálculo das forças e momento necessários para que a embarcação mantenha-se próxima à posição e ao aproamento desejados (set-points). Ao longo do histórico de desenvolvimento dos SPDs, empregaram-se diversos algoritmos de controle, como o clássico PID, controladores ótimos (LQG) e, mais recentemente, controladores baseados em modelos, algumas vezes com mecanismos adaptativos. 
Metodologias de controle robustas e/ou não-linear também estão sendo desenvolvidas, porém ainda sem aplicação comercial.

O programa também é responsável pela distribuição das forças de comando pelos propulsores, de forma a minimizar o consumo de potência. Estes algoritmos são chamados de alocadores de empuxo (TAL - thruster allocation logic) e possuem papel fundamental no bom desempenho do SPD.

Os movimentos da embarcação possuem componentes de alta freqüência, excitadas por parcelas dos esforços de ondas, e por componentes de baixa freqüência, excitados pela correnteza e parcelas dos esforços de onda e vento. As componentes de alta freqüência devem ser eliminadas dos sinais medidos, pois o sistema propulsor não é projetado para compensar estes movimentos "rápidos". Esta ação exigiria uma enorme potência e poderia danificar os elementos mecânicos. Assim, o programa deve realizar também a "filtragem de ondas", que equivale a um filtro responsável pela atenuação destas componentes das medidas. Utilizam-se filtros convencionais (passa-baixas ou passa-banda) e, em alguns casos, filtros baseados em estimadores de Kalman.

Os programas também devem ser flexíveis, permitindo a execução de diversos modos de operação. No modo manual, o operador controla, por meio de um joystick, a posição e aproamento da embarcação. No modo automático, a posição e aproamento são mantidos próximos aos valores desejados, sem a interferência do operador. No modo de trajetória (Track-follow), a embarcação é mantida seguindo uma trajetória prédeterminada. No modo de alinhamento com o ambiente (Wheater Vaning) o aproamento da embarcação é mantido próximo do valor de menor solicitação do sistema de propulsores, que equivale ao aproamento alinhado com a "resultante" das forças ambientais. Diversos outros modos de controle são disponíveis nos SPDs atuais, cada um mais adequado à determinada operação. No presente trabalho, o modo de operação é denominado controlador de modo superior, pois é responsável por prover, ao controlador de nível inferior, os valores desejados (set-points) de posição e aproamento.

\subsection{Objetivos}

O presente trabalho visa a propor soluções para alguns problemas relacionados ao desempenho dos SPDs em diferentes condições ambientais, através da aplicação de uma metodologia de controle robusta não-linear ao projeto do controlador de nível inferior. 
No que se refere ao nível superior de controle, objetiva-se desenvolver um modo de controle de aproamento ótimo passível de ser aplicado em operações com liberdade direcional, que garanta a otimização simultânea de diversos critérios operacionais. Pretende-se mostrar que este modo de controle apresenta vantagens em relação aos modos já existentes em condições ambientais típicas da Bacia de Campos (correnteza, vento e ondas não-colineares).

Será abordado também o sub-sistema de sensoriamento, analisando-se a possibilidade de realizar estimação do espectro de ondas a partir da medição dos movimentos da embarcação.

Cada um dos objetivos será detalhado a seguir, devendo-se ressaltar que os desenvolvimentos propostos foram testados em um simulador computacional contendo o modelo dinâmico da embarcação no plano horizontal, modelo dos esforços ambientais e devidos às linhas de amarração e risers. Estes modelos são, em grande parte, frutos de trabalhos realizados pelo Departamento de Engenharia Naval e Oceânica e pelo Departamento de Engenharia Mecânica da Escola Politécnica da Universidade de São Paulo, com validações experimentais realizadas, em parceria, nos laboratórios do Instituto de Pesquisas Tecnológicas do Estado de São Paulo (IPT). O simulador contém, ainda, modelo dos propulsores, lógica de alocação de empuxo e filtros de ondas. Assim, uma contribuição adicional do presente trabalho refere-se à utilização destes modelos num ambiente de simulação integrado à análise de SPDs.

\subsubsection{Controlador de nível inferior}

O estudo sugere a aplicação de uma nova metodologia para o projeto do controlador de nível inferior, que executa a compensação direta dos esforços de vento, onda (deriva média) e correnteza, e integra também uma malha de realimentação para realizar correções de erros residuais. Esta metodologia é fundamentada na teoria de controle não-linear robusto por modos deslizantes.

Devido ao fato de ser não-linear, este controlador garantiria os requisitos de desempenho e estabilidade para qualquer aproamento da embarcação. Pelo fato de realizar a compensação direta dos esforços de vento, correnteza e onda (deriva média), asseguraria maior faixa de aplicabilidade em termos de condições ambientais, com desempenho satisfatório mesmo em condições críticas. Finalmente, por ser robusto, 
garantiria bom desempenho e estabilidade perante erros de modelagem e erros nas estimativas das condições ambientais além de facilidade no ajuste de parâmetros.

\subsubsection{Controlador de nível superior}

Será desenvolvido um novo modo de controle (controlador de nível superior), no qual o navio é aproado segundo uma direção que garante a otimização de um funcional relacionando diversos parâmetros operacionais relevantes, como o movimento de roll, a tração dinâmica em risers, a solicitação do sistema de amarração e o consumo de combustível. Este modo de controle seria bastante apropriado para locais como a Bacia de Campos, nos quais é comum a existência de desalinhamento entre os agentes ambientais. Como já descrito por Pinto et al. (1999), nestes casos, a utilização do tradicional modo weather vane pode levar à ocorrência de ondas de través, e todas as conseqüências negativas a ela relacionadas.

\subsubsection{Sensoriamento de ondas}

A metodologia de controle proposta utilizará estimativas de todas as condições ambientais (onda, vento e correnteza). A medição do espectro incidente de ondas ainda não está totalmente resolvida, envolvendo problemas técnicos-operacionais e econômicos. Assim, para garantir a aplicabilidade do controlador desenvolvido, a custos não proibitivos, pretende-se desenvolver um método para a estimação do espectro de ondas baseado na medição dos movimentos da embarcação. Será utilizadada uma abordagem paramétrica, na qual o espectro bimodal é parametrizado, e os 8 parâmetros descritivos são estimados por um algoritmo de otimização não-linear. O algoritmo será testado com resultados de ensaios em tanque de provas.

\subsection{Organização do texto}

O presente trabalho foi organizado de forma a expor as contribuições realizadas, sem perder de vista a complexidade dos SPDs e como cada tema abordado se insere, de forma integrada, dentro do sistema. No Capítulo 2, os problemas abordados são apresentados dentro do contexto atual do desenvolvimento de SPDs. Isto é feito através de uma revisão bibliográfica e discussão dos principais trabalhos desenvolvidos. Ao longo dos capítulos e seções seguintes, são feitas revisões e discussões bibliográficas 
específicas sobre cada assunto abordado, apresentadas, portanto, dentro de um contexto mais apropriado.

No Capítulo 3 são apresentados todos os modelos utilizados no simulador e no projeto do controlador. Apresentam-se, inicialmente, as equações de movimento dos 3 graus de liberdade horizontais de um corpo flutuante em um meio fluido. Em seguida, são descritos os modelos utilizados para representar os esforços devidos aos agentes ambientais (onda, vento e correnteza) atuantes sobre a embarcação. Como o controlador desenvolvido é aplicado ao caso de um FPSO amarrado, considera-se também o modelo dos esforços devidos às linhas de amarração e risers, com efeitos de restauração, amortecimento e arrasto. Finalmente, apresenta-se a modelagem matemática dos propulsores, realizando-se também uma breve discussão dos principais tipos de propulsores utilizados em SPDs e dos métodos mais comuns de controle de empuxo.

No Capítulo 4 são apresentados os desenvolvimentos realizados relativos ao subsistema de controle. Na seção 4.1 expõe-se o controlador de nível inferior, apresentando-se inicialmente a teoria de controle robusto não-linear por modos deslizantes. O modelo do sistema é, então, adaptado para a aplicação da técnica exposta, o que é feito em seguida para dois casos. Desenvolveu-se um controlador de aproamento, utilizado em SPDs assistidos, nos quais o posicionamento é garantido pelas linhas de amarração e um controlador combinado de posição e aproamento, utilizado em SPDs convencionais. O controlador é robusto a erros de modelagem e de medição das condições ambientais, sendo que as estimativas destes erros são calculadas em seguida.

$\mathrm{Na}$ seção 4.2 é detalhado o projeto do controlador de nível superior, que implementa um modo de controle de aproamento ótimo. Alguns critérios operacionais que podem ser otimizados simultaneamente no presente modo de controle são apresentados e discutidos em seguida, com a definição de uma função objetivo a ser minimizada. Discussões adicionais a respeito da sensibilidade do aproamento ótimo relativamente a erros de estimativas das condições ambientais são feitas utilizando-se um FPSO em turret sujeito a condições ambientais típicas da Bacia de Campos (RJ).

Em seguida, na seção 4.3, apresentam-se e discutem-se três algoritmos de alocação de empuxo comumente utilizados nos SPDs e suas principais limitações. É feita uma comparação entre os mesmos utilizando-se o exemplo de uma barcaça de lançamento de linhas equipada com 6 propulsores azimutais. Os filtros de ondas 
comumente empregados são, apresentados e discutidos na seção 4.4, com ênfase maior à abordagem adotada no simulador desenvolvido (filtro notch em cascata).

No Capítulo 5 é apresentado o algoritmo de estimação do espectro de ondas baseado nas medições dos movimentos da embarcação. Resultados de testes numéricos são então apresentados, utilizando-se o caso de um super-petroleiro (VLCC). Finalmente, experimentos conduzidos no tanque de provas do IPT foram utilizados para a aplicação e validação do algoritmo desenvolvido, que apresentou resultados bastante bons, compatíveis com a aplicação vislumbrada, e melhores do que os de métodos descritos na literatura já empregados no mesmo problema. Descrições de diversos tipos de sensores de correnteza, vento, posição, movimentos verticais e aproamento utilizados em SPDs, são apresentadas no Apêndice 2.

Dois casos de aplicação são estudados no Capítulo 6, para reforçar os conceitos expostos nos capítulos anteriores e realizar discussões adicionais sobre as vantagens dos controladores propostos. Inicialmente, aplica-se o controle de nível inferior (controle combinado de posição e aproamento) à barcaça de lançamento de tubulações BGL1. Em seguida, o controlador de nível superior (modo de aproamento ótimo) e o controlador de nível inferior (controle de aproamento) são aplicados ao caso de um VLCC atuando como um FPSO em turret sujeito a condições ambientais típicas da Bacia de Campos.

Por fim, o Capítulo 7 apresenta as conclusões e uma discussão sobre os principais resultados obtidos. Sugestões para trabalhos futuros são também delineadas. 


\section{Contextualização}

Neste capítulo, os principais tópicos abordados na presente tese serão inseridos no atual estado de desenvolvimento dos sistemas de controle aplicados em SPDs. Isto é feito através de uma revisão bibliográfica e discussões a respeito dos trabalhos já desenvolvidos, bem como de uma explanação do funcionamento (e dos problemas) dos SPDs comerciais existentes. Assim, obtêm-se justificativas das abordagens adotadas.

Ao longo do restante do texto, apresentam-se revisões bibliográficas específicas a respeito de alguns outros tópicos relevantes na análise e projeto de SPDs, que são, portanto, abordados oportunamente, conforme os mesmos são tratados.

\subsection{Controlador de nível inferior}

O controlador de nível inferior recebe as informações do posicionamento real da embarcação (vindas do sistema de sensoriamento) e envia os sinais de atuação para os propulsores de forma a levá-la à posição e aproamento desejados. Diversas características particulares de sistemas oceânicos fazem com que o projeto destes controladores seja bastante complexo e serão sumariamente descritas, a seguir, por meio de um breve histórico, justificando-se o desenvolvimento proposto no presente trabalho.

O primeiro tipo de controle empregado em SPDs foi o PID (proporcional-integralderivativo) que, devido à sua forma matemática simples, era passível de ser implementado pelos circuitos analógicos disponíveis até então. O controle dos movimentos de surge, sway e yaw era feito de maneira desacoplada, não considerando as interações dinâmicas e hidrodinâmicas entre os mesmos (Faÿ, 1990). Admitia-se, também, a linearidade do sistema, na medida em que o PID é um controlador linear e as técnicas para ajuste de seus ganhos são baseadas em modelos lineares do sistema a ser controlado. Os PIDs apresentavam problemas de desempenho e dificuldade no ajuste dos ganhos, principalmente devido ao acoplamento entre os movimentos, a variações no comportamento dinâmico do navio devido a mudanças das condições ambientais e a não-linearidades não consideradas no projeto. Na Figura 2.1 apresenta-se um diagrama de blocos completo do controle PID aplicado em SPDs. Deve-se destacar que, desde as primeiras aplicações, os esforços de vento de baixa freqüência eram compensados diretamente, utilizando-se as medidas provenientes dos anemômetros e estimando-se as 
forças e momento através dos coeficientes aerodinâmicos do casco e da superestrutura (controle feed-forward).

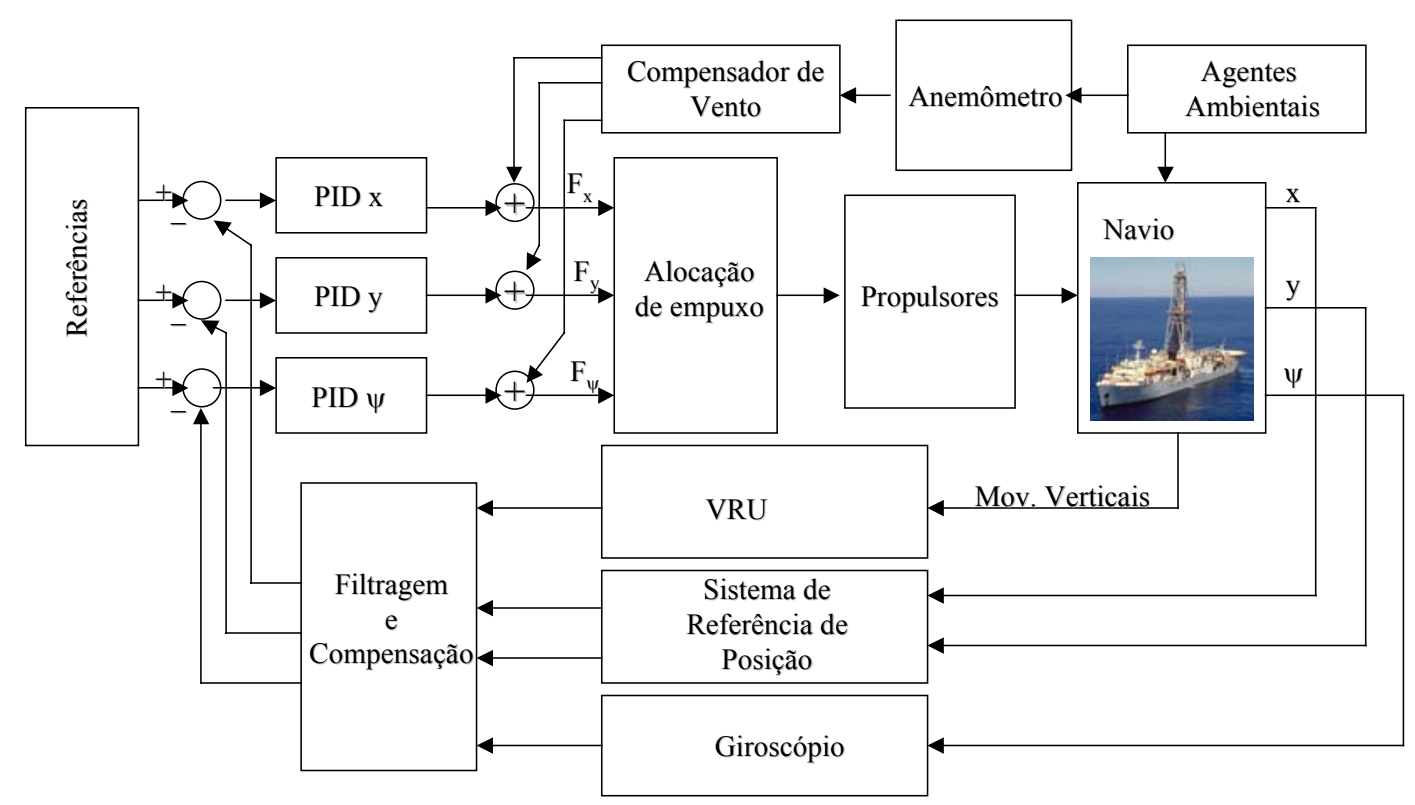

Figura 2.1 Diagrama de blocos do controle PID aplicado em SPDs

Num segundo estágio, com o advento da computação digital, aplicaram-se técnicas de controle linear mais avançadas, permitindo incorporar requisitos de otimização de desempenho. A utilização de filtros de Kalman para estimação e filtragem acoplados a controladores ótimos é, até hoje, muito empregada (ver por exemplo, Donha 2000, Donha, 1989; Di Masi; Finesso; Picci, 1986; Fung; Grimble, 1983 e Saelid; Jenssen; Balchen, 1983).

Como em todo sistema real, e mais acentuadamente neste, pois envolve fenômenos hidrodinâmicos bastante complexos, o controlador deve ser robusto a erros de modelagem, garantindo o desempenho e estabilidade para modelos próximos (mas não exatamente iguais) ao nominal utilizado no projeto. Questões de robustez a erros de modelagem passaram a ser abordadas dentro do contexto linear, através, por exemplo, da metodologia de controle $H_{\infty}$ (Katebi; Grimble; Zhang, 1997; Nakamura; Kajiwara, 1997, Tannuri; Donha, 2000 e Donha; Tannuri, 2001). Com este mesmo intuito, controladores adaptativos também foram aplicados ao problema de posicionamento dinâmico (ver, por exemplo, Barros, 1989). 
Entretanto, os modelos matemáticos que descrevem a dinâmica do sistema possuem um forte caráter não-linear. Assim, a utilização de técnicas clássicas de controle linear despreza toda a riqueza de detalhes contida em tais modelos. Grande quantidade de informação é desperdiçada quando o modelo é linearizado, a não ser que os estados permaneçam muito próximos do ponto de operação. Mas durante períodos de variação de condições ambientais, o navio controlado será reposicionado e neste caso, um modelo linearizado perderia sua validade. Uma solução que passou a ser empregada para esta questão é a utilização de diversos controladores lineares projetados nas vizinhanças dos vários pontos no espaço de estados que o navio percorre. Pouco se pode afirmar a priori a respeito da estabilidade (e desempenho) destes sistemas (Yoerger; Newman; Slotine, 1986), pois o "chaveamento" da lei de controle pode instabilizá-los. A análise de estabilidade é feita utilizando-se simulações exaustivas ou métodos numéricos como o apresentado em Pait; Kassab (2001).

Assim, controladores não-lineares passaram a ser estudados e implementados em SPDs como, por exemplo, controle de linearização por realimentação adaptativo (adaptive feedback linearization) e controle não-linear backstepping (Aarset; Strand; Fossen, 1998 e Fossen; Strand, 1998).

Outra questão importante refere-se à compensação dos esforços ambientais. Como mencionado, desde as primeiras aplicações de posicionamento dinâmico os esforços de vento de baixa freqüência eram compensados diretamente pelo controlador. O mesmo não era feito para os esforços de correnteza e ondas, devido à maior difículdade de medição destes agentes. Em algumas abordagens, consideram-se estas forças como perturbações quase estáticas na malha de controle, e o projeto é feito de forma a compensar tais efeitos através de uma ação integral incluída no controlador. A conseqüência direta desta abordagem é o fato do controle apresentar bom desempenho apenas nas condições ambientais para as quais os seus parâmetros foram ajustados. A “janela ambiental” para a qual o desempenho é satisfatório é bastante restrita. Como o ajuste de parâmetros é feito, normalmente, por testes no mar, é freqüente a necessidade de novos testes para corrigir problemas de desempenho detectados durante a operação.

Esta abordagem desperdiça grande quantidade de informação contida nos ricos modelos hidrodinâmicos já desenvolvidos destas forças (expostos na seção 3.2). Uma tendência atual é a de incorporar tais modelos no projeto do controlador. A utilização de controladores baseados em modelos, por exemplo, tenta solucionar esta questão, 
permitindo que as forças sejam estimadas ao longo do tempo e compensadas diretamente pelo controlador (Saelid; Jenssen; Balchen, 1983; Donha, 1989; Sørensen; Sagatun; Fossen, 1996). Donha (1989), por exemplo, propõe um controlador ótimo acoplado a um observador baseado em filtros de Kalman que realiza, simultaneamente, a filtragem de ondas e a estimação das forças ambientais de baixa freqüência, podendo compensá-las diretamente na saída do controlador. Donha (1989) realizou simulações numéricas e ensaios em tanque de provas do controlador proposto aplicado a plataforma semi-submersível, comprovando a eficácia do mesmo.

Em outra possível configuração, um modelo dinâmico do sistema é programado no controlador, considerando-se apenas o agente ambiental vento, cujas propriedades (velocidade e direção) são medidas (Bray, 1998). O controlador compara, a cada instante, as posições e velocidades estimadas pelo modelo e aquelas medidas pelo sistema de referência de posição e girocompasso. Estas diferenças são filtradas durante um período de 25 a 30 minutos e os valores persistentes são utilizados num modelo inverso, que calcula as forças que seriam responsáveis por esta diferença, então consideradas como devidas à "correnteza". Estas forças são então compensadas pelo controlador (controle feed-forwad), mantendo-se também a malha de realimentação do erro para correções "finas" (controle feedback). Esta solução é empregada em SPDs comerciais, e na Figura 2.2 apresenta-se um diagrama simplificado destes controladores.

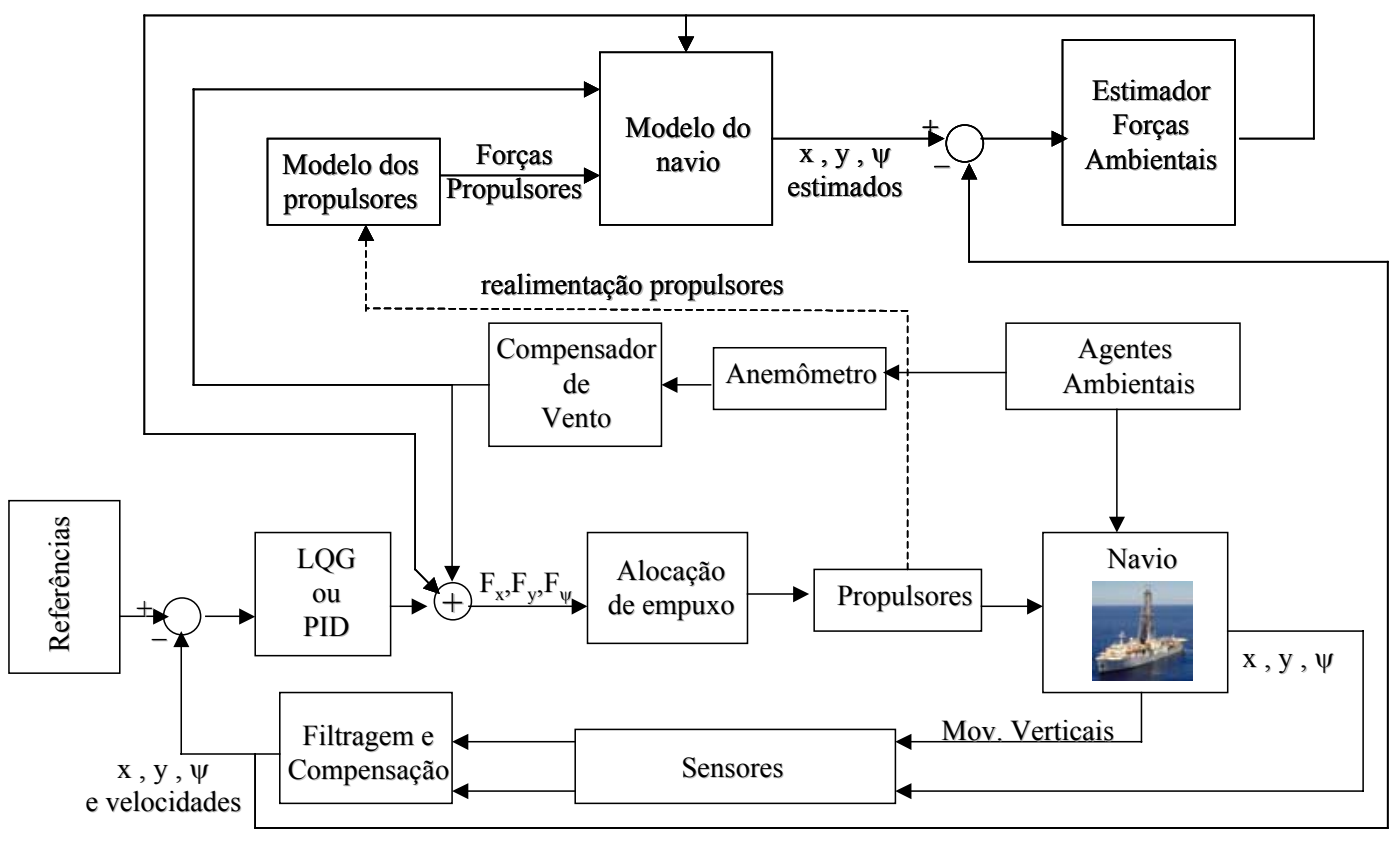

Figura 2.2 Diagrama de blocos de um tipo de controle baseado em modelo aplicado em SPDs 
Este processo encerra diversas fontes de erro, como por exemplo o fato das forças de deriva de ondas serem consideradas conjuntamente à correnteza, sendo ainda feitas grandes correções sobre a malha de realimentação. Porém, fortes vantagens são constatadas nesta abordagem. A compensação direta dos esforços (mesmo que grosseiramente estimados) garante um bom desempenho numa ampla faixa de condições ambientais, diferentemente da abordagem tradicional, na qual o controle é sintonizado para uma faixa restrita de condições ambientais (em geral, as de intensidade mediana, mais freqüentes), apresentando degradação de desempenho em condições severas. Adicionalmente, em caso de perda de referência de posição (falha nos sensores), o sistema é capaz de operar durante alguns minutos utilizando as estimativas da posição e aproamento provenientes do modelo, o que aumenta sobremaneira a confiabilidade do SPD.

Simultaneamente, passou-se a estudar a possibilidade de estimarem-se os esforços de ondas através de medidas do movimento relativo entre a superfície da água e o casco, por meio de sensores de nível instalados no costado (wave-probes). Pinkster (1978) e Aalbers; Nienhuis (1987) demonstraram a viabilidade teórica do método, que está sendo implementado em escala real num projeto internacional de cooperação entre indústrias e universidades (Aalbers, 2000).

Entretanto, a utilização dos modelos diretamente no controlador traz alguns problemas operacionais ainda não solucionados nas aplicações comerciais que já possuem esta tecnologia. O desempenho do controlador é fortemente dependente da qualidade dos coeficientes contidos nos modelos matemáticos, requerendo ajustes bastante refinados para garantir bom desempenho. Testes padronizados no mar são feitos para ajustar os coeficientes, antes do início da operação. Como em tais testes, não são varridas todas as condições ambientais e operacionais, não é rara a necessidade de se convocar novamente o fabricante para realizar novos ajustes e testes. Além disso, a malha de realimentação também encerra diversos coeficientes que são igualmente difíceis de serem calibrados.

Indo ao encontro desta tendência atual e tentando resolver os problemas supracitados, desenvolveu-se no presente trabalho uma metodologia de projeto de controle robusto não-linear integrado da malha de realimentação (feedback) e de compensação direta (feed-forward). A inclusão de termos que garantem a robustez elimina (ou minimiza) os problemas relacionados ao ajuste dos parâmetros do modelo 
contido no controlador. A abordagem não-linear elimina os problemas de linearização encontrados nos controles lineares, assim como torna bastante intuitivo e simples o processo de ajuste do parâmetros da malha de realimentação. A metodologia é fundamentada pela teoria de controle de modos deslizantes (Sliding Mode Control) proposta originalmente por Utkin (1978) e modificada e adaptada por Slotine (1984).

\subsection{Controlador de nível superior}

Sistemas de posicionamento dinâmico comerciais apresentam modos de controle apropriados para operações com liberdade de aproamento. Por exemplo, o sistema da empresa Nautronix (Nautronix, 2002) possui o modo de controle automático de aproamento, no qual mantém-se um aproamento fixo, determinado pelo operador. Para auxiliar a escolha do aproamento, apresenta-se um gráfico polar da porcentagem do empuxo total requerida para se manter qualquer aproamento (weather capability plot), baseando-se nas condições ambientais reais (medidas) ou hipotéticas, escolhidas pelo operador (Figura 2.3).

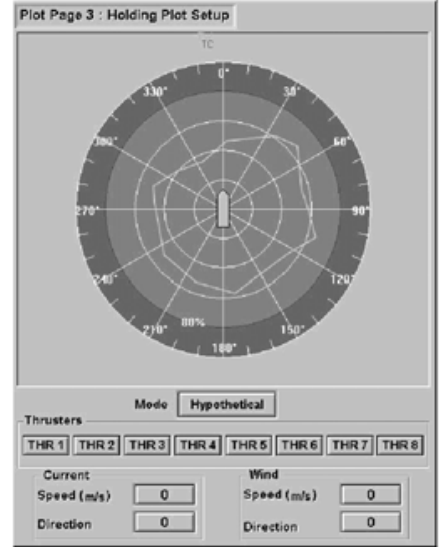

Figura 2.3 Gráfico de capacidade para manutenção de aproamento (extraído de Nautronix, 2000)

Existem também modos de seleção automática do aproamento, baseando-se na minimização do consumo de energia. O sistema busca o aproamento alinhado com a resultante das condições ambientais (weathervanig control), que é a condição de menor empuxo de controle necessário pois anulam-se a força de sway e o momento de yaw ambientais atuantes sobre a embarcação. A obtenção deste aproamento pode ser feita utilizando-se medições das condições ambientais e estimativas das forças. Neste caso, em geral, consideram-se apenas vento e correnteza devido a dificuldades práticas de monitoração das ondas. O sistema utiliza modelos de forças de correnteza e vento para realizar o cálculo do aproamento "ótimo", requerendo também o valor do calado da embarcação, o qual pode ser medido por sensores ou fornecido manualmente.

Alternativamente, Pinkster; Nienhuis (1986) verificaram que o controle desacoplado dos movimentos do ponto de referência em surge e sway, utilizando-se algoritmos PID, sem o controle direto do movimento de yaw, leva a embarcação a se alinhar naturalmente com a resultante das condições ambientais. Entretanto, este efeito apenas ocorre caso o ponto de referência esteja localizado a uma certa distância avante 
da meia nau, além de ser também necessário impor certas restrições na disposição dos propulsores. A vantagem do método de Pinkster e Nienhuis é que não requer estimativas das condições ambientais. Seguindo a mesma linha, Fossen; Strand (2001) desenvolveram um controlador adaptativo que realiza a busca automática do aproamento de menor consumo de energia, não impondo, neste caso, restrição alguma quanto ao ponto de referência ou quanto à configuração dos propulsores.

Entretanto, em determinadas condições ambientais, típicas da Bacia de Campos, a minimização da energia de controle não é o único critério a ser levado em conta. Por exemplo, consideram-se ondas swell vindas predominantemente de sul ou sudeste, na presença de correnteza vindo da direção norte ou nordeste. Neste caso, o ângulo típico entre correnteza e onda varia entre $90^{\circ}$ e $180^{\circ}$, dependendo da intensidade destes agentes, FPSO amarrados pelo sistema turret podem apresentar uma posição de equilíbrio (alinhada com a resultante dos agentes ambientais) sujeita a ondas de través com aproximadamente 4,0m de altura significativa. Esta situação pode ser inaceitável em termos operacionais, podendo levar a movimentos de roll com grande amplitude e mesmo à compressão dinâmica nos risers, sendo algumas vezes necessária a interrupção completa da planta de produção (Pinto et al., 1999). Para minimizar a oscilação de primeira ordem responsável pelos movimentos e pelo carregamento dinâmico nos risers, a embarcação deveria ser reposicionada de forma a se alinhar com a direção de incidência da onda. Entretanto, este também não é o único critério que deve ser considerado já que pela ação combinada da correnteza e do vento, ao se alinhar com as ondas o sistema de amarração pode ser muito solicitado, possivelmente levando à ruptura de linhas. Além disso, a potência total dos propulsores para que a embarcação seja mantida naquele aproamento pode ser excessiva e ultrapassar a capacidade instalada. Logo, para se garantir o aproamento ótimo da embarcação, é necessária a minimização de um critério multi-objetivo que leve em conta todos estes fatores (Tannuri; Pesce; Donha, 2001a).

Assim, o presente trabalho apresenta o desenvolvimento de um novo modo de controle (controle de nível superior), adaptado às condições ambientais da Bacia de Campos e passível de ser aplicado em embarcações com liberdade (total ou parcial) de aproamento. 


\subsection{Sensoriamento de ondas}

O controlador utiliza, na malha de compensação direta, estimativas ou medições da velocidade e direção do vento e da correnteza e do espectro de ondas. A medição do espectro incidente de ondas ainda não está totalmente resolvida, apresentando problemas técnicos, operacionais e econômicos. Assim, para garantir a aplicabilidade do controlador desenvolvido a custos não proibitivos, implementou-se e testou-se um algoritmo para estimar o espectro baseado nas medidas de movimento da embarcação, o qual apresentou bons resultados visando à aplicação para a qual fora desenvolvido.

Para se medir o espectro de ondas incidente sobre o navio tem-se utilizado, nos últimos 30 anos, bóias direcionais amarradas em alto-mar. Estas são equipadas com acelerômetros e inclinômetros que medem seus movimentos, a partir dos quais pode-se estimar a altura e inclinação da superfície do mar naquele ponto. Com um tratamento estatístico apropriado, consegue-se estimar o espectro das ondas. Estes sistemas são descritos em detalhes em Audunson; Barstow; Krogstad (1982) e Ewans; Van der Vlugt (1999).

Por possuírem massas diminutas, as bóias acompanham a elevação da superfície marítima, com dinâmica própria desprezível, o que torna os métodos bastante precisos. Entretanto, as bóias são sujeitas a freqüentes danos e necessitam de manutenção constante, além de apresentar desvantagens práticas e econômicas principalmente relacionadas à instalação do sistema de amarração em lâminas d'água profundas. Adicionalmente, em algumas aplicações de SPDs, é necessário que o sistema de monitoração ambiental seja instalado na própria embarcação, permitindo flexibilidade de operação.

Recentemente, utilizam-se radares por raio $X$ que se baseiam na análise da evolução temporal e espacial das ondas refletidas e espalhadas pela superfície do mar, como descrito em Muñoyerro; Borge (1997) e Reichert et al. (1999). Estes sistemas podem ser instalados na própria embarcação, porém requerem um complexo aparato computacional e possuem um alto custo inicial.

Uma idéia que vem se desenvolvendo há alguns anos é a utilização dos próprios navios como "bóias", ou seja, estimar o espectro baseando-se nas medidas dos movimentos das embarcações ocasionados pelas forças de ondas de primeira ordem. Este sistema requer apenas as informações provenientes dos sensores de movimentos 
verticais (VRU) e horizontais, o que torna o custo do mesmo bastante atraente. Além disso, é instalado a bordo da embarcação, sendo apropriado para aplicações em SPDs. Algumas implementações em navios em velocidade de cruzeiro já foram descritas, por exemplo, em Webster; Dillingham (1981), Hirayama (1987) e Iseki; Ohtsu (2000).

A aplicação destes métodos de estimação a navios de maior porte como, por exemplo, VLCCs operando como FPSOs, apresenta algumas particularidades e restrições. Devido à grande inércia do navio, ele não "responde" a ondas pequenas e de alta freqüência. Assim, estas componentes do espectro não podem ser estimadas. Entretanto, a baixa freqüência de corte do método não possui implicações severas, pelo próprio fato destas componentes não excitarem movimentos no navio. Além disso, em geral ondas de maior freqüência tendem a ser menos severas, já que a relação $H_{s} / T_{P}^{2}$ é aproximadamente constante para mares locais (Newman, 1977).

Tentando eliminar este problema alguns autores utilizam medidas dos movimentos relativos da superfície da água no casco, através de sensores de nível instalados no costado (Aalbers, 2000). Esta alternativa, segundo Pesce (1983), apresenta problemas durante mares agitados, pois efeitos de impacto hidrodinâmico, de características fortemente não-lineares, passam a ser significativos. Tais efeitos são complexos, e a inclusão de modelos dos mesmos no estimador induziria a erros muito elevados. Uma possível abordagem, não analisada no presente trabalho, seria a combinação dos dois métodos citados. O método baseado nos movimentos do navio é apropriado para mares mais agitados, que possuem menor freqüência porém induzem movimentos mais significativos no navio. O método baseado no movimento relativo da superfície da água no casco, por sua vez, é apropriado para mares mais calmos e intermediários, garantindo uma maior faixa de aplicabilidade do método composto.

Adicionalmente, a metodologia depende do conhecimento prévio da dinâmica de primeira ordem do navio em resposta a ondas incidentes, o que é modelado linearmente pelos RAO's (ver seção 3.2.2.4). Entretanto, para um FPSO, diversos fatores como por exemplo variações de carregamento, trim ou outros distúrbios aumentam a imprecisão dos RAO's calculados numericamente. Além disso, efeitos não-lineares são expressivos para oscilações maiores, principalmente para o movimento de roll. Assim, deve-se avaliar a sensibilidade do método a estes erros inerentes aos RAO's. 
Os métodos de estimação não paramétricos realizam uma discretização do espectro direcional no espaço de direções e freqüências, calculando então cada um dos pontos do espectro. Em princípio, são capazes de estimar qualquer forma de espectro, suportando até espectros bimodais compostos pela superposição de um mar local e de um swell. De fato, Benoit; Goasguen (1999) realizaram comparações entre diversos métodos de estimação aplicados a bóias direcionais e concluíram a superioridade do método não paramétrico Bayesiano. Este mesmo método foi aplicado por Iseki; Ohtsu (2000) a navios de médio porte, com bons resultados. Entretanto, Tannuri et al. (2001) mostraram a grande sensibilidade do método a incertezas a respeitos dos RAO's, o que, na prática, pode inviabilizar a aplicação do mesmo.

No presente trabalho, aplicou-se o método paramétrico e obtiveram-se bons resultados, validados por testes numéricos e experimentos em tanque de provas. Neste caso, o espectro é descrito segundo um conjunto de parâmetros e, por meio de algoritmos de minimização não-linear, estes parâmetros são estimados de forma a recuperar os movimentos medidos do navio. De acordo com a parametrização pode-se também estimar espectros bimodais. 


\section{Modelos}

Neste capítulo apresentam-se os modelos matemáticos que descrevem os movimentos de uma embarcação flutuante sujeita aos agentes ambientais de onda, vento e correnteza, amarrada ou não, incluindo-se a dinâmica dos propulsores. Estes modelos foram programados em simulador computacional, a partir do qual obtiveram-se todos os resultados numéricos da presente tese. Foram também utilizados no projeto dos controladores apresentados no Capítulo 4.

Na seção 3.1 apresentam-se, as equações de movimento segundo os 3 graus de liberdade horizontais de um corpo flutuante em um meio fluido.

$\mathrm{Na}$ seção 3.2 apresentam-se os modelos dos esforços ambientais. Em 3.2.1 consideram-se os esforços devido à correnteza, o que é feito através do Modelo Heurístico de Asa Curta, reelaborado na Universidade de São Paulo desde 1998. No trabalho de Leite et al.(1998) foram desenvolvidas expressões para as forças estáticas ${ }^{2}$ sobre o casco. As expressões foram validadas experimentalmente para dois tipos de petroleiros. A extensão do modelo para levar em conta termos dependentes da velocidade de rotação foi apresentada em Simos et al. (2001), com validação experimental em Tannuri et al.(2001). O desenvolvimento do modelo será brevemente exposto com alguns resultados experimentais ilustrativos de sua validação.

Em 3.2.2 serão expostos os modelos para os esforços devidos às ondas, que se dividem em forças de primeira e segunda ordem. Inicialmente, descrevem-se os espectros utilizados para representar a aleatoriedade do mar, priorizando-se as formulações mais utilizadas: de Pierson-Moskowitz e de JONSWAP. As forças de segunda ordem, que representam uma parcela significativa das forças de baixa freqüência atuantes sobre os sistemas flutuantes, são descritas em seguida. Elas são divididas em uma parcela constante (deriva média) e uma outra variável lentamente no tempo (deriva lenta). A parcela de força de deriva média é calculada por meio dos coeficientes de deriva, que são obtidos pela análise potencial do problema de interação do corpo flutuante com ondas, pelo método dos painéis, por exemplo. As forças de deriva lenta devem ser, rigorosamente, calculadas por meio das funções quadráticas de transferência, que requerem grande esforço computacional e grande capacidade de 
armazenamento de dados para processá-las. No entanto, a aproximação proposta em Aranha; Fernandes (1995) garante boa precisão na avaliação destes esforços sobre corpos flutuantes com grande massa e foi utilizada no presente trabalho. A interação entre onda e correnteza, conhecida como wave drift damping, é considerada através do modelo apresentado em Aranha (1994 e 1996).

As forças de primeira ordem possuem freqüências elevadas, na mesma faixa de freqüência do espectro de ondas. No presente trabalho utilizou-se o princípio da independência entre os movimentos de baixa freqüência (excitados pela correnteza, deriva e vento) e os de alta freqüência. Com isso, utilizam-se os Operadores de Amplitude de Resposta (RAO's) do navio para o cálculo dos movimentos devido às forças de primeira ordem, que são simplesmente somados aos movimentos de baixa freqüência. Este método pressupõe a linearidade entre a onda incidente e a resposta do navio. Verifica-se experimentalmente que esta hipótese é válida para todos os movimentos do navio exceto o de roll $^{3}$. Numa abordagem mais completa, o cálculo dos movimentos de primeira ordem deveria ser feito utilizando-se as forças de excitação obtidas na análise potencial de ondas, com inclusão de funções de memória que podem levar em conta efeitos viscosos não incluídos no cálculo potencial (Fucatu, 1998).

Apresenta-se em 3.2.3 o modelo para as forças e momento devido ao vento. $\mathrm{O}$ cálculo de tais esforços é baseado em curvas experimentais obtidas em ensaios em túnel de vento ou com o modelo emborcado em água, que quantificam a força e momento na parte emersa da embarcação sujeita a um fluxo de ar constante. Deve-se incluir também os efeitos de rajadas devidos a variações na velocidade do vento, o que é feito supondose uma distribuição espectral da velocidade do vento, que apresenta então uma parcela média e uma oscilatória. São apresentados os espectros de rajada utilizados no modelo de simulação desenvolvido, a saber: Ochi-Shin e Harris (Fossen, 1994).

Como o controlador desenvolvido é aplicado ao caso de um FPSO amarrado, considera-se, na seção 3.3, o modelo dos esforços devidos às linhas de amarração e risers, com efeitos de restauração, amortecimento e arrasto.

\footnotetext{
${ }^{2}$ Forças atuantes no caso de velocidade de rotação em yaw nula.

${ }^{3}$ Não linearidades no movimento de roll advém da preponderância do amortecimento viscoso neste movimento.
} 
As forças de restauração são calculadas através da composição vetorial das forças em cada linha, obtidas por meio das curvas de restauração. Estas curvas são calculadas supondo-se deslocamentos quase-estáticos sobre a linha, impondo-lhe a condição de equilíbrio no meio fluido, sem considerar efeitos de correnteza.

A avaliação das forças de amortecimento de linhas é baseada em Nishimoto et al. (1999). Neste trabalho os autores realizaram ensaios de decaimento em escala real que permitiram a validação da formulação proposta para o cálculo do amortecimento de linhas, além de demonstrar que este amortecimento é preponderante em condições ambientais amenas. A parcela de arrasto devido à correnteza é calculada supondo-se que a configuração da linha não se altera na presença da mesma (mantendo-se na forma geométrica de catenária) através de uma simples integração das forças elementares ao longo da linha. Finalmente, os termos cruzados, dependentes simultaneamente da velocidade do topo linha e da correnteza são calculados através de considerações de energia propostas em Aranha (1999).

Embora não incluído no simulador, apresenta-se em seguida um modelo analítico para avaliação da tração dinâmica em risers, utilizado no cálculo do aproamento ótimo (controlador de nível superior). Este modelo é detalhado no Apêndice 1, e é baseado na formulação analítica proposta em Aranha et al. (1993) e estendida em Pinto et al.(1999) e Pinto (2000).

$\mathrm{Na}$ seção 3.4 apresenta-se um diagrama de blocos dos modelos descritos, mostrando a inter-relação entre eles e como estão implementados no simulador.

Na seção 3.5 , apresenta-se a modelagem matemática dos propulsores, realizandose também uma breve discussão dos principais tipos de propulsores utilizados em SPDs e dos métodos mais comuns de controle de empuxo.

\subsection{Equações do movimento}

Nesta seção expõe-se a equação do movimento horizontal de baixa freqüência ${ }^{4}$ de uma embarcação no meio fluido. Utiliza-se a hipótese de que tal movimento é desacoplado dos movimentos verticais da embarcação, bem como dos movimentos horizontais de alta freqüência (faixa de freqüência das ondas incidentes).

\footnotetext{
${ }^{4}$ Movimentos que possuem componentes com freqüência menores que $0,05 \mathrm{rad} / \mathrm{s}$
} 
Serão utilizados dois sistemas de referência distintos, mostrados na Figura 3.1. O sistema inercial $O X Y Z$ é fixo na Terra e o sistema $o x_{1} x_{2} x_{3}$ é solidário ao navio, com origem na seção mestra da embarcação, em sua linha de centro. Os eixos $O Z$ e $o x_{3}$ são coincidentes, verticais e orientados para cima. O movimento ao longo do eixo $o x_{1}$ é o surge e ao longo de $o x_{2}$ é o sway.

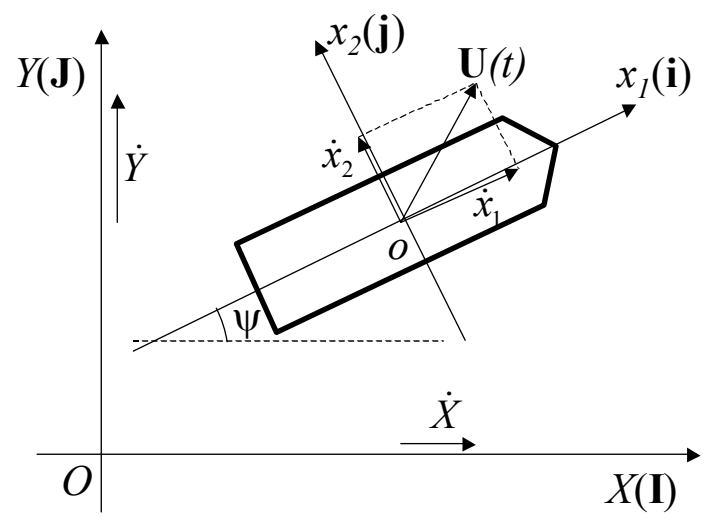

Figura 3.1 Sistemas de coordenadas utilizados

Admite-se simetria em relação ao plano $x_{1} x_{3}$, sendo que a projeção do centro de gravidade no plano horizontal localiza-se no ponto $\left(x_{G}, 0\right)$. A velocidade $\mathbf{U}(t)$ do ponto $o$ em relação ao referencial fixo $O X Y Z$ é:

$$
\mathbf{U}(t)=\dot{X}(t) \mathbf{I}+\dot{Y}(t) \mathbf{J}
$$

Como será visto adiante, a equação do movimento é escrita em termos das componentes da velocidade do ponto $o$ decompostas nos eixos $o x_{1}$ e $o x_{2}$, sendo a componente longitudinal (surge) denominada por $\dot{x}_{1}$ e a componente transversal (sway), denominada por $\dot{x}_{2}$, dadas por:

$$
\mathbf{U}(t)=\dot{x}_{1}(t) \mathbf{i}+\dot{x}_{2}(t) \mathbf{j}
$$

com 


$$
\begin{aligned}
& \dot{x}_{1}(t)=\dot{X} \cos (\psi)+\dot{Y} \operatorname{sen}(\psi) \\
& \dot{x}_{2}(t)=-\dot{X} \operatorname{sen}(\psi)+\dot{Y} \cos (\psi) \\
& \dot{x}_{6}(t)=\dot{\psi}
\end{aligned}
$$

A orientação angular do navio é dada, portanto, indistintamente pelo ângulo $\psi$ ou pela coordenada generalizada $x_{6}$, sendo a velocidade angular também referida por $\dot{\psi}$ ou $\dot{x}_{6}$.

Denotando-se por $(\bar{X}, \bar{Y})$ a posição do centro de massa $G$ do navio no referencial $\operatorname{OXYZ},\left(\bar{F}_{X}, \bar{F}_{Y}\right)$ as forças externas resultantes na direção $O X$ e $O Y$ aplicadas no centro de massa e $\bar{N}_{Z}$ o momento das forças externas em relação ao ponto $G$, na direção do eixo $O Z$, as leis da Mecânica Clássica fornecem:

$$
\begin{aligned}
M \ddot{\bar{X}} & =\bar{F}_{X} \\
M \ddot{\bar{Y}} & =\bar{F}_{Y} \\
\bar{I}_{Z} \ddot{\psi} & =\bar{N}_{Z}
\end{aligned}
$$

sendo $M$ a massa da embarcação e $\bar{I}_{Z}$ o momento de inércia baricêntrico em relação ao eixo $O Z$. Supõe-se, aqui, que o eixo paralelo a $O Z$ passando pelo centro de massa $G$ é um eixo principal de inércia. Aplicando-se a relação (3.3) ao centro de massa, derivando-a e substituindo em (3.4) obtêm-se as equações escritas em relação ao referencial $o x_{1} x_{2} x_{3}$ :

$$
\begin{aligned}
& M \ddot{\bar{x}}_{1}-M \dot{\bar{x}}_{6} \dot{\bar{x}}_{2}=\bar{F}_{1} \\
& M \ddot{\bar{x}}_{2}+M \dot{\bar{x}}_{6} \dot{\bar{x}}_{1}=\bar{F}_{2} \\
& \bar{I}_{Z} \ddot{\bar{x}}_{6}=\bar{F}_{6}
\end{aligned}
$$

sendo $\left(\bar{F}_{1}, \bar{F}_{2}, \bar{F}_{6}\right)$ as forças externas generalizadas correspondentes às coordenadas $x_{1}$, $x_{2}$ e $x_{6}$. Para obter as equações relativas ao ponto $o$, basta substituir as relações entre a velocidade, aceleração e forças aplicadas ao centro de massa às aplicadas ao ponto $o$ : 


$$
\begin{array}{lll}
\dot{\bar{x}}_{1}=\dot{x}_{1} & \ddot{\bar{x}}_{1}=\ddot{x}_{1} & \bar{F}_{1}=F_{1} \\
\dot{\bar{x}}_{2}=\dot{x}_{2}+\dot{x}_{6} \cdot x_{G} & \ddot{\bar{x}}_{2}=\ddot{x}_{2}+\ddot{x}_{6} \cdot x_{G} & \bar{F}_{2}=F_{2} \\
\dot{\bar{x}}_{6}=\dot{x}_{6} & \ddot{\bar{x}}_{6}=\ddot{x}_{6} & \bar{F}_{6}=F_{6}-F_{2} \cdot x_{G}
\end{array}
$$

Substituindo-se (3.6) em (3.5), obtêm-se:

$$
\begin{aligned}
& M \ddot{x}_{1}-M \dot{x}_{6} \dot{x}_{2}-M x_{G} \dot{x}_{6}^{2}=F_{1} \\
& M \ddot{x}_{2}+M x_{G} \ddot{x}_{6}+M \dot{x}_{6} \dot{x}_{1}=F_{2} \\
& I_{Z} \ddot{x}_{6}+M x_{G} \ddot{x}_{2}+M x_{G} \dot{x}_{1} \dot{x}_{6}=F_{6}
\end{aligned}
$$

O momento e as forças externas são compostos pelos esforços ambientais devidos à ação combinada de correnteza, ondas e vento, denotados por $F_{i E}(i=1,2$ ou 6$)$, pelos esforços devidos ao sistema de amarração, $F_{i M}$, pelos esforços dos propulsores, $F_{i T} \mathrm{e}$ pela reação inercial do fluido ao movimento do navio, calculada através da teoria potencial (Kat; Wichers, 1991). Portanto:

$$
\begin{aligned}
& F_{1}=F_{1 E}+F_{1 M}+F_{1 T}-M_{11} \ddot{x}_{1}+M_{22} \dot{x}_{6} \dot{x}_{2}+M_{26} \dot{x}_{6}^{2} \\
& F_{2}=F_{2 E}+F_{2 M}+F_{2 T}-M_{22} \ddot{x}_{2}-M_{26} \ddot{x}_{6}-M_{22} \dot{x}_{6} \dot{x}_{1} \\
& F_{6}=F_{6 E}+F_{6 M}+F_{6 T}-M_{66} \ddot{x}_{6}-M_{26} \ddot{x}_{2}-M_{26} \dot{x}_{6} \dot{x}_{1}
\end{aligned}
$$

sendo $M_{i j} \mathrm{o}$ tensor de massas adicionais em baixa freqüência relativo à meia nau. As forças e momento $F_{i E}$ e $F_{i M}$ são funções da posição, aproamento e velocidade da embarcação, sendo que esta dependência é omitida por questão de simplicidade de notação.

Assim, substituindo-se (3.8) em (3.7) obtêm-se as equações diferenciais que representam a dinâmica de baixa freqüência dos movimentos horizontais do corpo rígido, simétrico em relação ao eixo $o x_{l}$, no meio fluido:

$$
\begin{aligned}
& \left(M+M_{11}\right) \ddot{x}_{1}-\left(M+M_{22}\right) \dot{x}_{2} \dot{x}_{6}-\left(M x_{G}+M_{26}\right) \dot{x}_{6}^{2}=F_{1 E}+F_{1 M}+F_{1 T} ; \\
& \left(M+M_{22}\right) \ddot{x}_{2}+\left(M x_{G}+M_{26}\right) \ddot{x}_{6}+\left(M+M_{11}\right) \dot{x}_{1} \dot{x}_{6}=F_{2 E}+F_{2 M}+F_{2 T} ; \\
& \left(I_{Z}+M_{66}\right) \ddot{x}_{6}+\left(M x_{G}+M_{26}\right) \ddot{x}_{2}+\left(M x_{G}+M_{26}\right) \dot{x}_{1} \dot{x}_{6}=F_{6 E}+F_{6 M}+F_{6 T} .
\end{aligned}
$$


$\mathrm{Na}$ seção 3.2 e 3.3 serão apresentados os modelos para as forças e momento ambientais $\left(F_{i E}\right)$ e devidos ao sistema de amarração $\left(F_{i M}\right)$ respectivamente.

\subsection{Agentes Ambientais}

Nesta seção serão descritos os modelos das forças e momentos devidos aos agentes ambientais atuantes sobre a embarcação.

\subsubsection{Correnteza}

Os modelos convencionais de força de correnteza, que são comumente chamados de modelos de derivadas hidrodinâmicas, foram inicialmente propostos por Abkowitz (1964). Propõe-se a representação das forças e momento atuantes sobre o casco através de uma expansão em série de Taylor, tendo como variáveis as componentes de velocidade relativa casco-fluido. Nesta expansão, usualmente são retidos termos até terceira-ordem (termos cúbicos nas velocidades relativas). Os coeficientes estabelecidos na expansão em série de Taylor devem, então, ser determinados de forma experimental, com base em ensaios com modelos em escala reduzida ou através da aplicação de técnicas de identificação sobre resultados obtidos em testes de mar (escala real). Como o modelo de Abkowitz foi desenvolvido para o navio próximo à velocidade de cruzeiro,

algumas alterações ao modelo original foram propostas para análise de petroleiros amarrados, mantendo-se, porém, a essência do modelo original intacta. (Takashina, 1986; Wichers, 1987; Sphaier; Fernandes; Correa, 2000).

Estes modelos, entretanto, apresentam alguns problemas (Simos, 2001). Os efeitos de escala (relacionados ao número de Reynolds) são de difícil incorporação, o que é de fundamental importância para a extrapolação de resultados obtidos em ensaios com modelos reduzidos para o problema em escala real. Devido ao caráter eminentemente matemático do modelo, a dependência com o número de Reynolds fica imersa no meio dos diversos coeficientes, sendo difícil sua identificação. Além disso, o modelo de derivadas hidrodinâmicas requer a realização de diversos ensaios em escala de modelo reduzido e, devido à questão do efeito de escala, alguns ensaios em escala real, para a calibração dos coefícientes.

A abordagem utilizada no desenvolvimento do Modelo Heurístico de Asa Curta tenta solucionar os problemas supracitados. A origem física das forças atuantes sobre o 
casco é utilizada no desenvolvimento do modelo, o que permite que termos dependentes da escala sejam explicitados, podendo ser levados da escala de modelo para a escala real de forma direta. Outra vantagem desta abordagem é o modelo depender apenas das dimensões principais da embarcação e de 3 parâmetros experimentais, obtidos em simples ensaios com o casco cativo.

O Modelo Heurístico de Asa Curta incorpora as parcelas estáticas desenvolvidas em Leite et al. (1998) e as parcelas devido à rotação do casco, propostas em Simos et al. (2001). Uma descrição detalhada do modelo, com uma rica discussão a respeito de diversos modelos de forças de correnteza, pode ser encontrada em Simos (2001).

Para sistemas de posicionamento dinâmico, nos quais usualmente o navio mantém baixas rotações e velocidades, a parcela mais importante das forças de correnteza é a estática. Evidentemente, estas podem ser obtidas diretamente por ensaios cativos em tanques de prova, prescindindo da utilização do modelo estático. Como será visto no capítulo 4, o controlador proposto pode ser aplicado em ambos os casos, pois é formulado de forma genérica em relação ao modelo de esforço ambiental utilizado. Entretanto, para o caso de navios petroleiros, a aplicação do modelo estático fornece uma maneira rápida e bastante precisa para a avaliação destes esforços, como será mostrado a seguir.

\subsubsection{Modelo de Asa Curta Estático}

O modelo proposto por Leite et al. (1998) para determinação das forças estáticas de corrente sobre petroleiros baseia-se na analogia entre o navio e uma asa de pequena razão de aspecto, chamada de asa curta. Pressupõe baixas velocidades relativas e trata apenas da interação entre movimento longitudinal (surge) e transversal (sway), não incorporando efeitos devidos à rotação do casco (yaw). Dessa forma, o modelo se presta à análise de navios estacionários sob uma correnteza constante ou em movimentos de translação com velocidade constante.

Considera-se um corpo fluido sob ação de uma correnteza constante e de perfil uniforme ao longo da profundidade. Desprezam-se efeitos de superfície livre (geração de ondas) e de profundidade finita. O corpo possui movimento translacional com velocidade constante em relação à Terra. Seja a velocidade da correnteza denotada por $V_{c}$ (Figura 3.2), $\alpha$ a sua direção de incidência em relação ao referencial solidário ao casco e $\alpha_{O X Y Z}$ a direção em relação ao referencial fixo $\left(\alpha_{O X Y Z}=\alpha+\psi\right)$. 


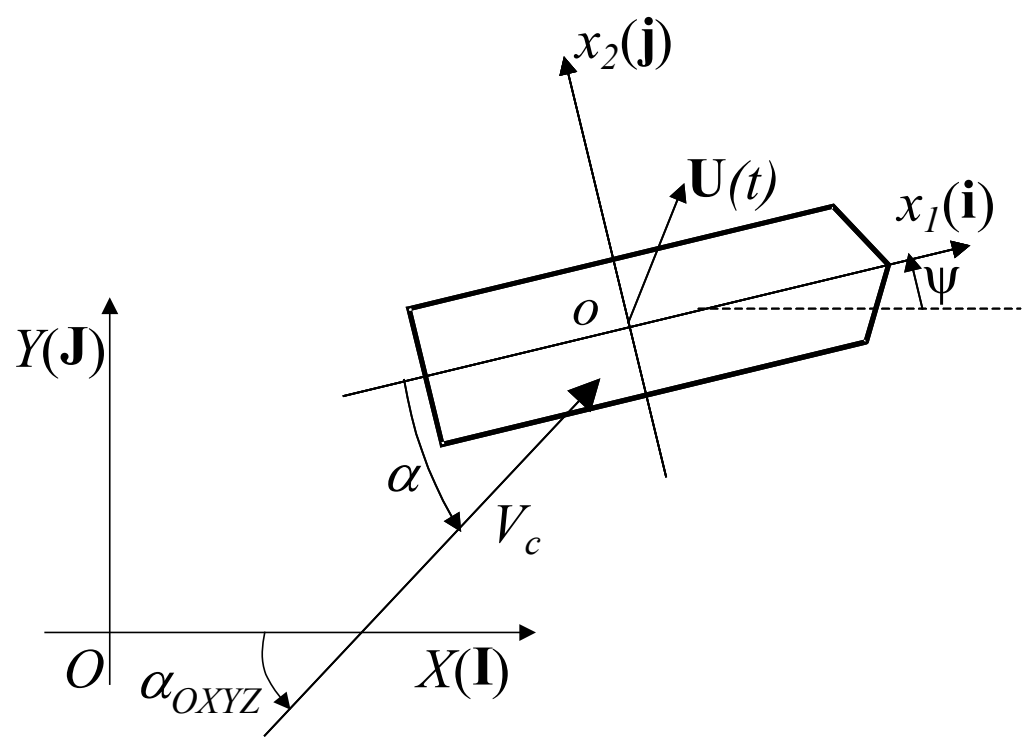

Figura 3.2 Definições para Modelo Estático de correnteza

As forças e momento devidos à correnteza dependem da velocidade do navio em relação ao meio fluido $\left(\mathbf{U}_{\mathrm{r}}(t)\right)$, que é dada por suas componentes no referencial solidário ao navio por:

$\mathbf{U}_{r}(t)=u(t) \mathbf{i}+v(t) \mathbf{j}$

com:

$$
\begin{aligned}
& u(t)=\dot{x}_{1}(t)-V_{C} \cos \alpha(t) \\
& v(t)=\dot{x}_{2}(t)-V_{C} \operatorname{sen} \alpha(t)
\end{aligned}
$$

Omitindo-se a variação temporal (que deve ser suposta lenta para a aplicação do presente modelo), a velocidade da correnteza em relação ao casco e a direção de incidência relativa são dadas, então, por:

$$
\begin{aligned}
& V_{c r}=\sqrt{u^{2}+v^{2}} \\
& \alpha_{r}=\pi+\arctan (v / u)
\end{aligned}
$$


As parcelas estáticas das forças de correnteza dependem de $u$ e $v$, sendo, aqui, a velocidade de rotação do casco $r=\dot{\psi}=0$. Estas são denotadas por $F_{i C}(u, v, 0)$ e são comumente escritas como:

$$
\begin{aligned}
& F_{1 C}(u ; v ; 0)=\frac{1}{2} \rho V_{c r}^{2} L T . C_{1 C}\left(\alpha_{r}\right) \\
& F_{2 C}(u ; v ; 0)=\frac{1}{2} \rho V_{c r}^{2} L T . C_{2 C}\left(\alpha_{r}\right) \\
& F_{6 C}(u ; v ; 0)=\frac{1}{2} \rho V_{c r}^{2} L^{2} T \cdot C_{6 C}\left(\alpha_{r}\right)
\end{aligned}
$$

nas quais $\rho$ é a densidade da água, $L$ é o comprimento do navio, $T$ o calado, $F_{1 C}$ e $F_{2 C}$ são as forças nas direções longitudinais e transversais respectivamente, $F_{6 C}$ é o momento de yaw e $C_{1 C}, C_{2 C}$ e $C_{6 C}$ são os coeficientes estáticos adimensionais de correnteza.

A expressão proposta para o coeficiente estático de força longitudinal $C_{l C}\left(\alpha_{r}\right)$ é:

$$
C_{1 C}\left(\alpha_{r}\right)=C_{0} \cos \alpha_{r}+\frac{1}{8} \frac{\pi T}{L}\left(\cos 3 \alpha_{r}-\cos \alpha_{r}\right)
$$

O segundo termo em (3.14) representa efeitos de asa de pequena razão de aspecto, generalizados, de maneira heurística, para toda a faixa de ângulos $\alpha_{r}$. O coeficiente $C_{0}$ compreende efeitos de resistência ao avanço do casco (viscosa e de forma), e pode ser medido em um simples ensaio de reboque realizado em tanque de provas. Alternativamente, Leite et al. (1998) propõem uma aproximação analítica para o coeficiente de resistência $C_{0}$ e obtêm, dessa forma, um coeficiente de força longitudinal explícito, ou seja, dependente apenas das dimensões principais do navio:

$$
C_{0} \cong \frac{0,094}{\left(\log _{10} \operatorname{Re}-2\right)^{2}} \frac{S}{T L}
$$


sendo $\mathrm{S}$ a área molhada e Re o número de Reynolds associado ao comprimento ( $\operatorname{Re}=\rho V_{C} L / \mu$, com $\mu$ o coeficiente de viscosidade da água). A expressão (3.15) permite extrapolar resultados obtidos em escala de tanque de provas para escala real, na medida em que a dependência com o número de Reynolds é explícita.

O coeficiente de força lateral $C_{2 C}\left(\alpha_{r}\right)$ é dado por:

$C_{2 C}\left(\alpha_{r}\right)=\left(C_{Y}-\frac{\pi T}{2 L}\right) \operatorname{sen} \alpha_{r}\left|\operatorname{sen} \alpha_{r}\right|+\frac{\pi T}{2 L} \operatorname{sen}^{3} \alpha_{r}+\frac{\pi T}{L}\left(1+0,4 \frac{C_{B} B}{T}\right) \operatorname{sen} \alpha_{r}\left|\cos \alpha_{r}\right|$

$\mathrm{Na}$ expressão acima, $C_{Y}$ representa o coeficiente de arrasto lateral do casco, que pode ser obtido por ensaio em tanque de provas ou aproximado pela curva proposta em Hoerner (1965). Assim, o primeiro termo em (3.16) representa o efeito do arrasto de forma devido à separação da camada-limite sobre o casco, segundo o princípio de crossflow. Os demais termos são provenientes dos efeitos de asa do casco, representando a projeção das forças de arrasto induzido e de sustentação na direção transversal.

Finalmente, o coeficiente estático de momento de yaw $C_{6 C}\left(\alpha_{r}\right)$ é escrito como:

$$
\begin{aligned}
C_{6 C}\left(\alpha_{r}\right)= & -\frac{l_{P}}{L} C_{Y} \operatorname{sen} \alpha_{r}\left|\operatorname{sen} \alpha_{r}\right|-\frac{\pi T}{L} \operatorname{sen} \alpha_{r} \cos \alpha_{r}- \\
& \left(\frac{1+\left|\cos \alpha_{r}\right|}{2}\right)^{2} \frac{\pi T}{L}\left(\frac{1}{2}-2,4 \frac{T}{L}\right) \operatorname{sen} \alpha_{r}\left|\cos \alpha_{r}\right|
\end{aligned}
$$

O primeiro termo representa o momento de cross-flow, admitindo-se que o centro de pressão do casco em incidência cruzada se situa a uma distância $l_{P}$ à ré da secção mestra. Esta distância pode ser obtida experimentalmente ou numericamente (teoria das faixas) ou, segundo Leite et al. (1998), pode ser aproximada, para cascos típicos de petroleiros, por $3,5 \%$ do comprimento $L$. O segundo termo corresponde a uma estimativa do momento de Munk (potencial) e o último termo engloba efeitos de asa curta e da presença do leme. 
Na Figura 3.3 são apresentados resultados extraídos de Leite et al. (1998) para o navio VLCC Vidal de Negreiros com seus tanques completamente carregados. As figuras contêm os três coeficientes estáticos calculados pelas expressões (3.15), (3.16) e (3.17) confrontados com resultados experimentais. Utilizou-se a expressão (3.15) para o cálculo do coeficiente $C_{0}$, sendo que apenas os coeficientes $C_{Y}$ e $l_{p}$ foram ajustados experimentalmente $\left(C_{Y}=0,60 ; l_{P} / L=3,0 \%\right)$.

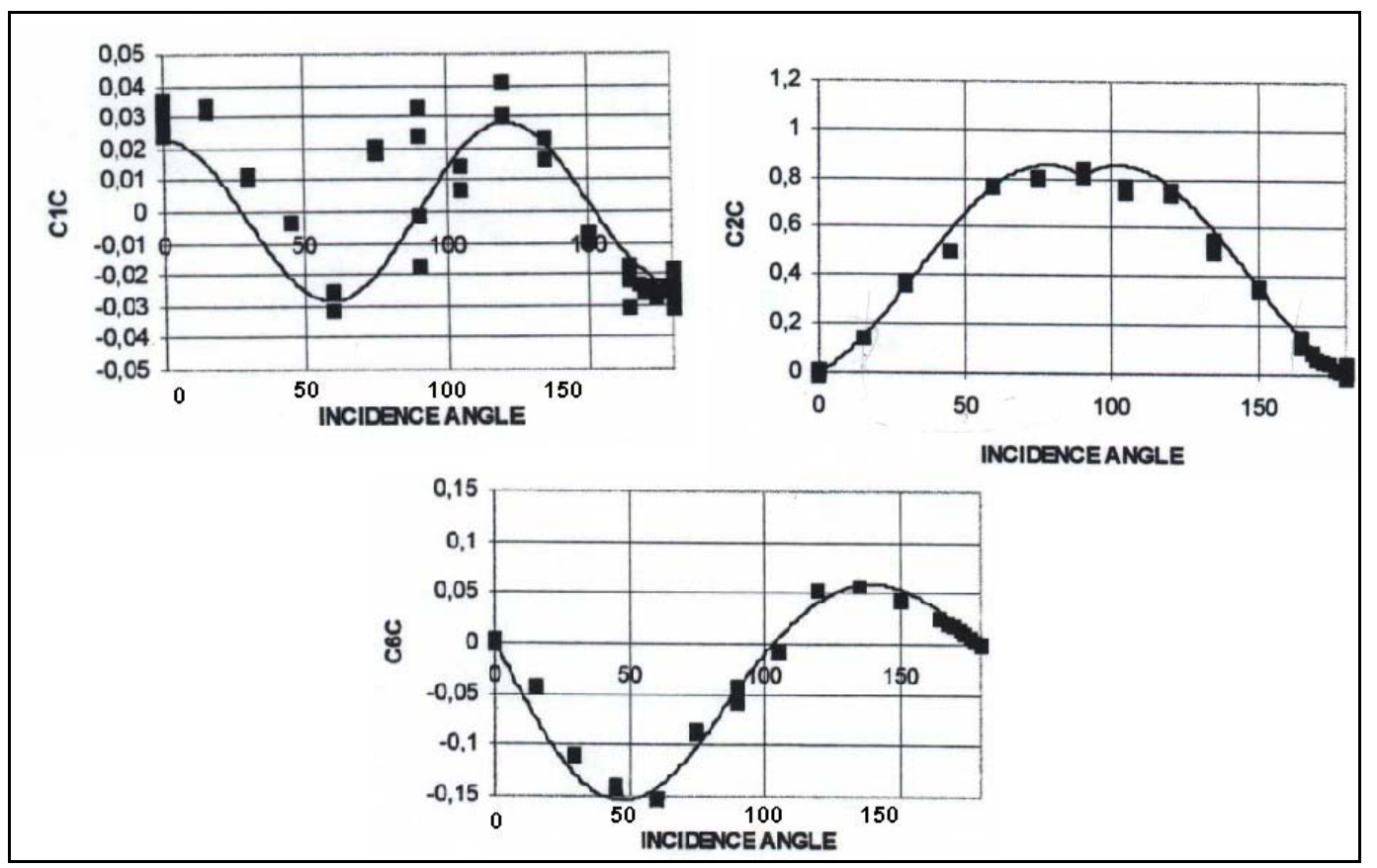

Figura 3.3 Coeficientes estáticos de forças e momento: comparação entre resultados teóricos e experimentais (resultados extraídos de Leite et al. (1998).

Nota-se uma boa aderência entre os valores teóricos e experimentais dos coeficientes $C_{2 C}$ e $C_{6 C}$. No caso do coeficiente $C_{1 C}$ existe uma grande dispersão nos pontos experimentais, provavelmente devido a dificuldades de instrumentação, pois estas forças são de pequena magnitude. Verifica-se, neste caso, que a curva teórica recupera a tendência média dos pontos experimentais. Deve-se ressaltar o fato de que o modelo é praticamente explícito, dependendo no máximo de 3 parâmetros experimentais que podem, numa primeira aproximação, ser obtidos por expressões ou curvas já mencionadas.

\subsubsection{Modelo de Asa Curta Estendido}

A extensão do Modelo de Asa Curta Estático foi proposta em Simos et al. (2001) e mantém o mesmo embasamento teórico utilizado no modelo estático para o cálculo 
dos termos de forças e momento dependentes da rotação do casco. Procura-se manter a característica explícita do modelo, ou seja, sua dependência apenas das dimensões principais da embarcação.

$\mathrm{Na}$ direção longitudinal (surge), o termo devido à rotação é também baseado na teoria de asa curta, dado por:

$$
\Delta F_{1 C}(u, v, r)=\left(M_{22}-\frac{1}{4} \rho \pi T^{2} L\right) \cdot v r-\frac{1}{16} \rho \pi T^{2} L^{2} \cos \alpha_{a} \cdot r^{2}
$$

sendo

$$
\alpha_{a}=\arctan (-v / u+r L / 2 u)
$$

Para o cálculo da força de sway e do momento de yaw, deve-se considerar também o cross-flow, que ocorre de maneira variável ao longo do casco devido a diferentes velocidades seccionais na presença de rotação. O coeficiente de arrasto seccional dado em Faltinsen (1990), sendo denotado por $C_{D, F A L T}(x)$, é normalizado para cada embarcação para recuperar os coeficientes globais de cross-flow $C_{Y}$ e $l_{P} C_{Y}$. Admite-se a seguinte forma para o coeficiente seccional de arrasto $C_{D}(x)$ :

$$
C_{D}(x)=C_{D, F A L T}(x) \cdot g_{1}(x) \cdot g_{2}(x)
$$

sendo as funções de ponderação $g_{j}(x)$ (ver Figura 3.4) determinadas a partir de:

$$
\begin{aligned}
& \frac{1}{L} \int_{-L / 2}^{L / 2} C_{D}(x) \cdot d x=C_{Y} \\
& \frac{1}{L^{2}} \int_{-L / 2}^{L / 2} C_{D}(x) \cdot x \cdot d x=l_{P} C_{Y}
\end{aligned}
$$

A Figura 3.4 apresenta as funções de ponderação $g_{j}(x), C_{D, F A L T}(x)$ e $C_{D}(x)$ para o VLCC Vidal de Negreiros $100 \%$ carregado. 


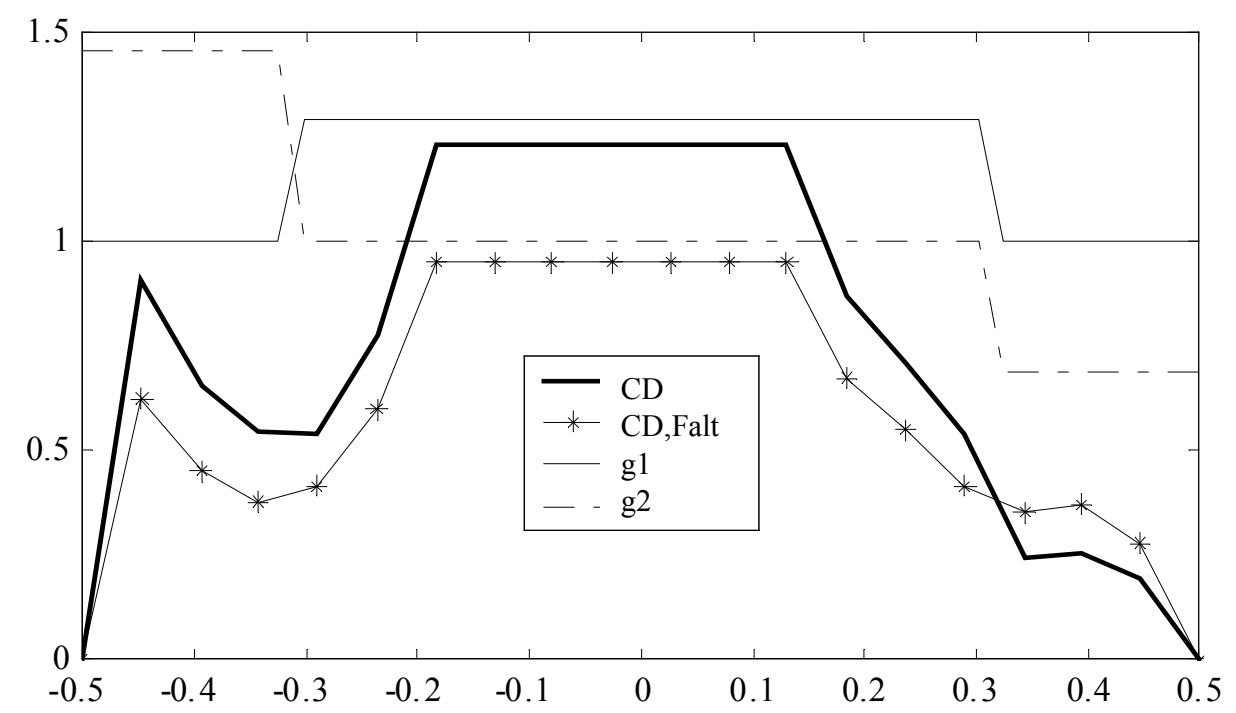

Figura 3.4 $C_{D, F A L T}(x)$ e funções de ponderação $g_{1}(x), g_{2}(x)$ e $C_{D}(x)$ calculados para o navio Vidal de Negreiros em situação carregada.

Introduzindo-se os coeficientes:

$$
I_{j}(v, r)=\frac{1}{L^{j+1}} \int_{-L / 2}^{L / 2} C_{D}(x) \cdot \operatorname{sinal}(v+r x) \cdot x^{j} d x ; \mathrm{j}=0,1,2,3
$$

a força lateral e o momento de yaw devido à rotação do casco, já incluindo a parcela de asa curta, são dadas por:

$$
\begin{aligned}
& \Delta F_{2 C}(u, v, r)=\frac{1}{4} \rho \pi T^{2} L\left(1-4.4 \frac{B}{L}+0.160 \frac{B}{T}\right) \cdot u r-\frac{1}{2} \rho T L\left[I_{0}(v, r) \cdot v^{2}-C_{Y} \cdot v|v|\right]- \\
& -\rho T L^{2} I_{1}(v, r) \cdot v r-\frac{1}{2} \rho T L^{3} I_{2}(v, r) r^{2} \\
& \Delta F_{6 C}(u, v, r)=-\frac{1}{8} \rho \pi T^{2} L^{2}\left(1+0.16 \frac{B}{T}-2 \cdot 2 \frac{B}{L}\right) \cdot u \mid r-\frac{1}{2} \rho T L^{2}\left[I_{1}(v, r)-I_{1}(v, 0)\right] \cdot v^{2}- \\
& -\rho T L^{3} I_{2}(v, r) \cdot v r-\frac{1}{2} \rho T L^{4} I_{3}(v, r) r^{2}
\end{aligned}
$$


O modelo foi comparado com ensaios de rotação sob avanço ${ }^{5}$ (yaw-rotating) para diversos navios, condições de carregamento e velocidades de avanço e rotação. A aderência aos resultados experimentais foi bastante boa, sendo apresentados dois exemplos na Figura 3.5.
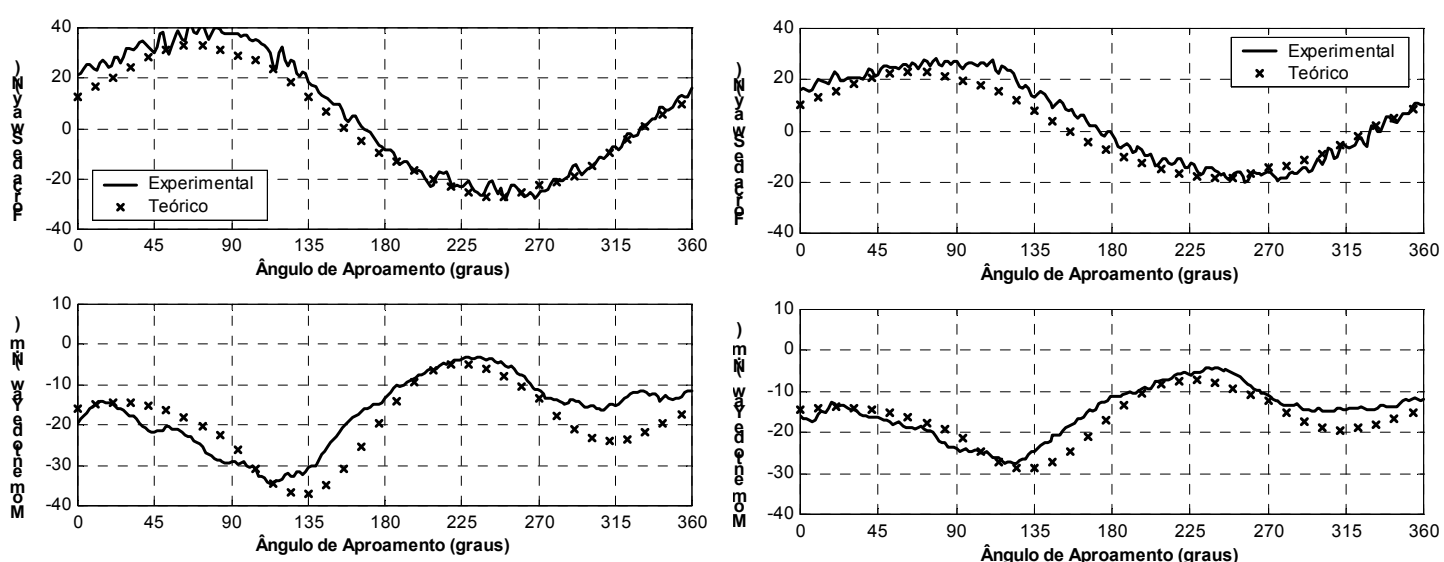

(a)

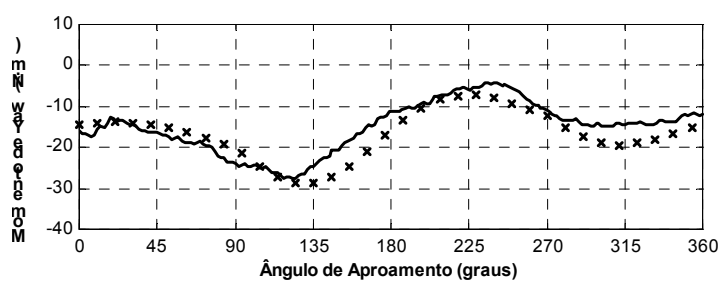

(b)

Figura 3.5 Navio Vidal de Negreiros, condição $100 \%$. Ensaios de yaw-rotating com rotação $\mathrm{r}=0.58 \%$ Velocidade de avanço $(a) U=2,37 \mathrm{~m} / \mathrm{s} ;(b) U=1,90 \mathrm{~m} / \mathrm{s}$ (extraídas de Simos, 2001).

\subsubsection{Ondas}

\subsubsection{Espectros de Onda}

As ondas do mar são geradas pela interação entre a superfície fluida e o vento ${ }^{6}$. Durante o início de uma tempestade, ventos intensos fornecem energia para as ondas curtas (de alta freqüência, pequeno comprimento de onda) que absorvem a maior parte da energia fornecida pelo vento. Por isso, no início da tempestade há uma concentração da energia em altas freqüências, e o mar é dito em desenvolvimento. Em seguida, estas ondas crescem em demasia e se quebram, dissipando a energia para ondas mais longas (menores freqüências). Neste instante, com o mar desenvolvido, a energia se distribui mais uniformemente pelas freqüências.

As ondas são dispersivas, o que significa que a velocidade de propagação depende da freqüência. As ondas de maior freqüência possuem menor velocidade e se dissipam ao final da tempestade após percorrerem um curto espaço . Contrariamente, as ondas de

\footnotetext{
${ }^{5} \mathrm{O}$ modelo é rebocado no tanque de provas com uma velocidade constante e, simultaneamente, um sistema acionador impõe sobre ele uma rotação também constante.

${ }^{6}$ A superfície do mar, sob a ação do vento, é na realidade uma folha de vórtices, que se instabiliza e entra em movimento sob a ação da gravidade.
} 
baixa freqüência (grandes comprimentos), percorrem longas distâncias a altas velocidades. Elas são observadas a distâncias bastante grandes da região de geração (tempestade) e são chamadas de swell. Neste tipo de mar a energia volta a se concentrar, porém numa região de menor freqüência.

Neste capítulo serão considerados apenas mares unidirecionais sem espalhamento. Assim, as ondas do mar são descritas por uma distribuição espectral da energia, que é proporcional ao quadrado da altura da onda em uma dada freqüência. Define-se o espectro $S(\omega)\left(\mathrm{m}^{2} / \mathrm{rad} / \mathrm{s}\right)$ em uma freqüência como (Price; Bishop, 1974) :

$$
S(\omega)=\lim _{\Delta \omega \rightarrow 0} \frac{A^{2}(\omega)}{2 \Delta \omega}
$$

sendo $A(\omega)$ a amplitude da onda para uma freqüência $\omega$ e $\Delta \omega$ a diferença entre duas freqüências sucessivas.

Mares desenvolvidos são, em geral, expressos pelo espectro de PiersonMoskowitz (Seixas, 1997).

$$
S(\omega)=\frac{\alpha_{O} g^{2}}{\omega^{5}} \cdot \exp \left(-\frac{5}{4}\left(\frac{\omega_{0}}{\omega}\right)^{4}\right)
$$

sendo o parâmetro $\alpha_{O}=0,0081$ o valor adotado para mares completamente desenvolvidos no Oceano Pacífico e $\omega_{0}$ a freqüência de pico do espectro. Uma alteração foi introduzida a posteriori para adaptar o espectro a casos mais gerais, em função também da altura significativa da onda ${ }^{7}\left(H_{S}\right)$, sugerindo-se:

$$
\alpha_{O}=\frac{5}{16 g^{2}} H_{S}^{2} \omega_{0}^{4}
$$

\footnotetext{
${ }^{7}$ Representa a altura média de $1 / 3$ das ondas mais altas.
} 
A formulação de espectro mais utilizada para mares em desenvolvimento é o JONSWAP (Joint North Sea Wave Project), introduzido na conferência 17th International Towing Tank Conference (ITTC, 1984). É uma generalização do espectro de Pierson-Moskowitz, pois introduz em sua formulação um parâmetro de forma $\gamma$ que permite "estreitar" o espectro em relação ao de Pierson-Moskowitz. Pode ser escrita como:

$$
S(\omega)=\frac{\alpha_{O} g^{2}}{\omega^{5}} \cdot \exp \left(-\frac{5}{4}\left(\frac{\omega_{0}}{\omega}\right)^{4}\right) \gamma^{\exp \left[-\left(\omega-\omega_{0}\right)^{2} /\left(2 \sigma^{2} \omega_{0}^{2}\right)\right]}
$$

com $\sigma$ dado por:

$$
\sigma= \begin{cases}0,07 & \omega \leq \omega_{0} \\ 0,09 & \omega>\omega_{0}\end{cases}
$$

e o parâmetro $\alpha$, para a Bacia de Campos, calculado por:

$$
\alpha_{O}=\frac{5}{16 . g^{2}} H_{s}^{2} \omega_{0}^{4}[1-0,287 \cdot \ln (\gamma)]
$$

Pode-se observar que se $\gamma=1$ o espectro de JONSWAP se iguala ao de PiersonMoskowitz quando $\alpha$ é dado por (3.27). Quanto maior este fator, mais estreito se torna o espectro de JONSWAP, tornando-se mais apropriado para representar mares swell.

Alternativamente, os espectros podem ser escritos como função do período de máxima densidade espectral $T_{P}$, relacionado à freqüência de pico por $T_{P}=2 \pi / \omega_{0}$. Apresenta-se na Figura 3.6 o espectro de onda calculado pelas duas formulações apresentadas para $T_{P}=11,4 \mathrm{~s}$ e $H_{S}=5,5 \mathrm{~m}$ e $\gamma=2,5$. Pode-se verificar que a energia, no espectro de JONSWAP com $\gamma>1$, é efetivamente mais concentrada numa faixa estreita de freqüência. $\mathrm{Na}$ Bacia de Campos, o período de pico das ondas durante tempestades encontra-se, em geral, no intervalo entre $8 \mathrm{~s}$ e $16 \mathrm{~s}$. 


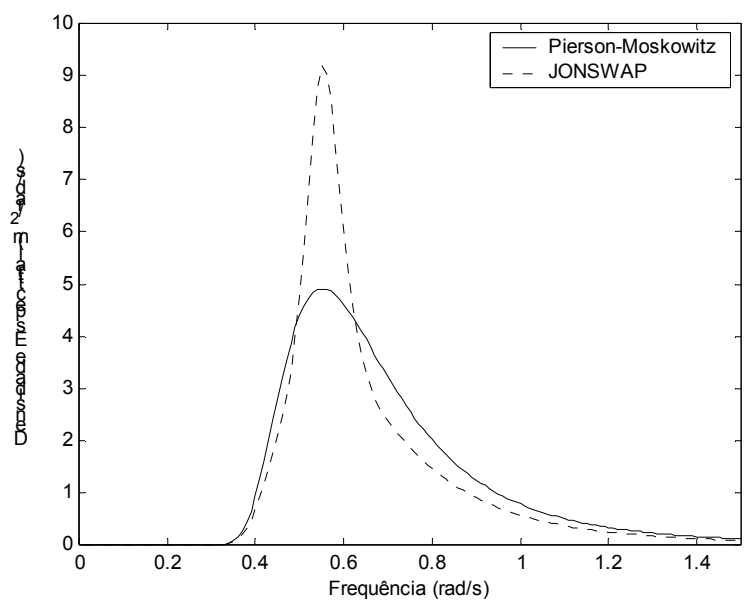

Figura 3.6 Espectros de onda para $T_{P}=11,4 \mathrm{~s}$ e $H_{S}=5,5 \mathrm{~m}$

\subsubsection{Forças de Segunda Ordem}

A incidência de ondas de gravidade sobre corpos próximos à superfície induz sobre eles um campo de pressão variável ao longo do tempo e do espaço. Da integração desta pressão sobre a superfície imersa do corpo pode-se calcular a força provocada pela incidência da onda. Verifica-se a existência de parcelas proporcionais à amplitude da onda, chamadas de forças de primeira ordem, que possuem a mesma freqüência da onda incidente. Existem também parcelas proporcionais à amplitude elevada ao quadrado, chamadas assim de forças de segunda ordem, que são, em amplitude, menores que as de primeira ordem.

As forças de segunda ordem, porém, exercem uma grande influência sobre os movimentos horizontais de sistemas de grande porte amarrados, pois apresentam componentes de baixa freqüência, excitando mais intensamente estes movimentos, que apresentam baixas freqüências naturais (em geral, menores que $0,06 \mathrm{rad} / \mathrm{s}$ ). Os esforços de segunda ordem médios (freqüência nula) são chamados de forças de deriva média, e as outras componentes (que são lentamente variáveis no tempo) são denominadas forças de deriva lenta (slow-drift forces).

Quando a onda incide sobre um corpo, parte da energia continua se propagando no mesmo sentido, passando pelo corpo (onda transmitida). Uma outra parte é refletida, passando a se propagar em sentido oposto. À grande variação da quantidade de movimento associada a esta parcela, que tem seu sentido de propagação invertido pela presença do corpo, associa-se a força de deriva média. Quando as dimensões do corpo 
são comparáveis ao comprimento da onda, a parcela refletida é bem pequena (o corpo “acompanha" a onda) e esta força é reduzida. Para ondas com comprimento pequeno em relação às dimensões características do corpo, esta parcela é considerável e a força de deriva média torna-se significativa (o corpo se comporta como "parede" para as ondas).

A dedução do cálculo das forças de deriva média pode ser encontrada em Mei (1989) e é baseado na definição dos coeficientes de deriva, que representam a força média atuante sobre o corpo para uma dada freqüência de onda, normalizada pelo quadrado da amplitude da onda. São calculados por integração do campo de pressão ao longo do casco, utilizando-se unicamente a teoria potencial de difração de ondas. No presente trabalho, utilizaram-se os coeficientes calculados pelo programa WAMIT, baseado no método numérico dos painéis.

Estes coeficientes são função da freqüência da onda incidente e da direção de incidência sobre o casco $\beta_{O}$ definido na Figura 3.7. A direção de incidência de onda em relação ao referencial fixo $O X Y Z$ é dada por $\beta_{O, O X Y Z}\left(\beta_{O, O X Y Z}=\beta_{O}+\psi\right)$.

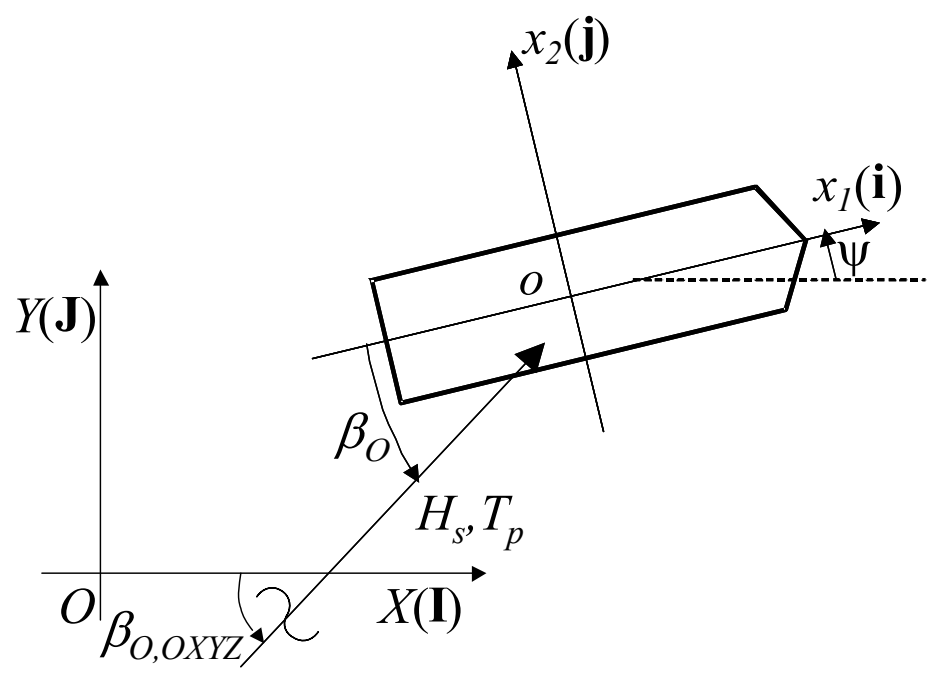

Figura 3.7 Definição dos ângulos de incidência de onda

Na Figura 3.8 apresenta-se o coeficiente de deriva da força lateral (sway), em incidência de través $\left(\beta_{O}=90^{\circ}\right)$ para o VLCC Vidal de Negreiros e para a barcaça BGL1. Como o VLCC apresenta dimensões maiores $(L=320 \mathrm{~m})$, verifica-se que a força de deriva passa a ser significativa para ondas com freqüência acima de $0,42 \mathrm{rad} / \mathrm{s}$. Para 
ondas de menor freqüência (e, portanto, de maior comprimento ${ }^{8}$ ) a reflexão é pequena, sendo a maior parte das ondas transmitidas pelo navio tornando a força de deriva média desprezível. Estas ondas ainda são consideradas de baixa freqüência para a BGL1 (que possui menores dimensões $\mathrm{L}=121,92 \mathrm{~m}$ ), que começa a apresentar reflexão significativa apenas para ondas com freqüência acima de $0,79 \mathrm{rad} / \mathrm{s}$. Os dados detalhados do VLCC e da barcaça aqui mencionados serão expostos no Capítulo 6.

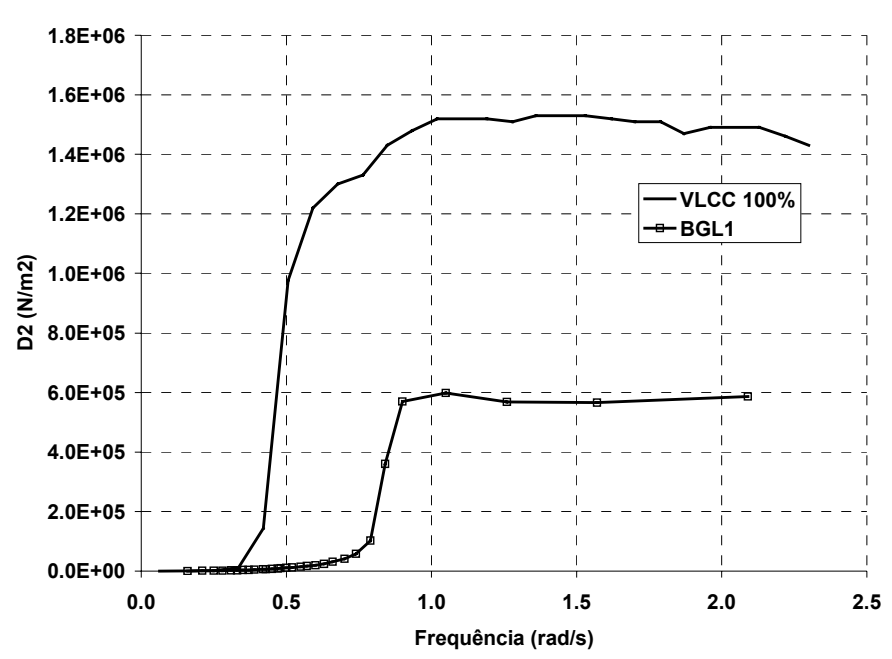

Figura 3.8 Coeficiente de deriva em sway incidência de través

Devido à incidência de uma onda de freqüência $\omega$, direção de incidência $\beta_{O} \mathrm{e}$ amplitude $A\left(\omega, \beta_{O}\right)$, a força média nas direções de surge, sway ( $j=1$ e 2 respectivamente) e o momento médio de yaw $(\mathrm{j}=6)$ são dados por:

$$
F_{j D M}\left(\omega, \beta_{O}\right)=A\left(\omega, \beta_{O}\right)^{2} D_{j}\left(\omega, \beta_{O}\right), j=1,2 \text { ou } 6
$$

sendo $D_{j}\left(\omega, \beta_{O}\right)$ o coeficiente de deriva na direção $j$. No caso real, de um mar aleatório unidirecional com espectro $S(\omega)$, utiliza-se a definição (3.25) e obtém-se:

\footnotetext{
${ }^{8}$ Ondas de gravidade em mares profundo respeitam a relação $\omega=\sqrt{2 \pi g / \lambda}$, sendo $\lambda$ o comprimento da onda. Assim, ondas de menor freqüência possuem maior comprimento.
} 


$$
F_{j D M}=2 \int_{0}^{\infty} S(\omega) D_{j}\left(\omega, \beta_{O}\right) d \omega \cong 2 \sum_{i=0}^{n} S\left(\omega_{i}\right) D_{j}\left(\omega_{i}, \beta_{O}\right) \Delta \omega, j=1,2 \text { ou } 6
$$

Apresentam-se ilustrativamente na Figura 3.9 as forças (e momento) de deriva média para o VLCC $100 \%$ carregado, sob incidência de uma onda com altura significativa de 5,5m e período de pico $11,4 \mathrm{~s}$, com espectro de Pierson-Moskowitz.
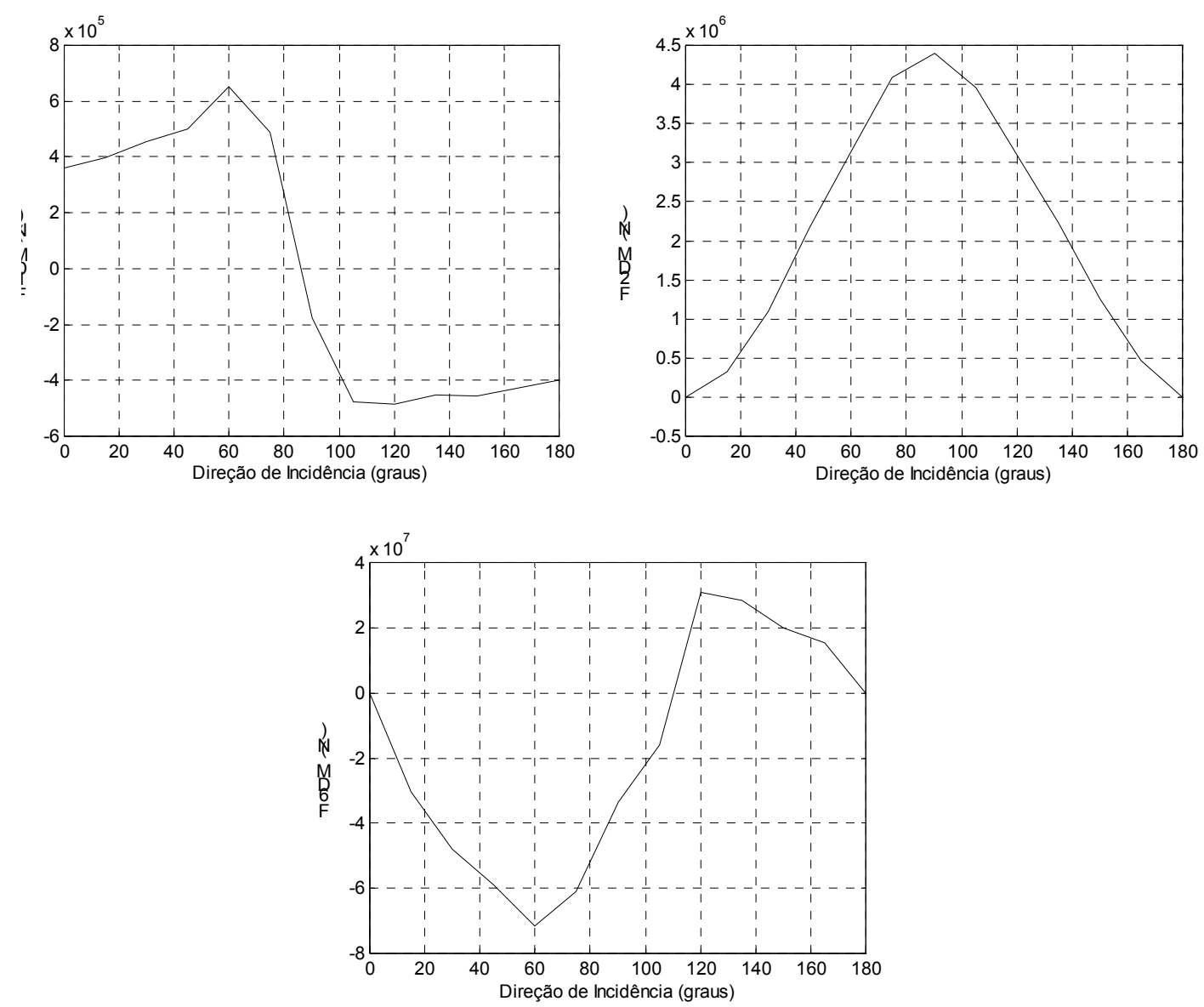

Figura 3.9 Forças de deriva média para VLCC $100 \%$ carregado $\left(T_{p}=11,4 \mathrm{~s}\right.$ e $\left.H_{s}=5,5 \mathrm{~m}\right)$

A interação não-linear entre ondas de diferentes freqüências em mar aleatório faz aparecer componentes no campo de pressão com a freqüência igual à soma e à diferença das freqüências das ondas originárias. $\mathrm{O}$ efeito das componentes com as freqüências soma tornam-se desprezíveis perante as forças de primeira ordem, na medida em que possuem amplitude bem menor e se situam em faixa de freqüência muito elevada. Entretanto, as componentes com as freqüências diferença (forças de deriva lenta) apresentam oscilações mais lentas, e, embora também possuam amplitude pequena 
comparada às forças de primeira ordem, podem excitar freqüências naturais dos sistemas oceânicos amarrados, induzindo elevados movimentos no plano horizontal.

A avaliação das forças de deriva lenta requer o cálculo das funções de transferência quadráticas (QFT's) do corpo, que expressam fisicamente a parcela da pressão, já integrada pela superfície imersa, que depende da interação entre ondas de freqüências $\omega_{i}$ e $\omega_{j}$. As QFT's são, portanto, funções de $\omega_{i}, \omega_{j}$ e da direção de incidência $\beta_{O}$ e, além de requererem um grande esforço numérico para serem calculadas, necessitam também de um sofisticado sistema para armazenamento e tratamento de dados durante a simulação.

Aranha; Fernandes (1995) desenvolveram uma aproximação bastante apropriada para sistemas oceânicos de grande porte, que possuem freqüências naturais bem abaixo das freqüências típicas das ondas. Os espectros das forças de deriva lenta $\left(S_{j D L}\right)$ em surge e sway e do momento de yaw podem ser escritos, então, como:

$$
S_{j D L}(\mu)=8 \int_{0}^{\infty} S(\omega) S(\omega+\mu)\left|T_{j}\left(\omega, \omega+\mu, \beta_{0}\right)\right|^{2} d \omega, \quad j=1,2 \text { ou } 6
$$

sendo $\mu$ a freqüência diferença e $T_{j}$ a QFT do movimento $j$. Para baixas freqüências, nas quais $\mu / \omega_{0}<<1$, sendo $\omega_{0}$ a freqüência de pico do espectro de onda, Aranha; Fernandes (1995) mostraram que:

$$
S_{j D L}(\mu)=8 \int_{0}^{\infty} S^{2}(\omega) D_{j}\left(\omega, \beta_{0}\right)^{2} d \omega+O\left[\left(\mu / \omega_{0}\right)^{2}\right], \quad j=1,2 \text { ou } 6
$$

ou seja, o espectro da força de deriva lenta pode ser considerado constante para baixas freqüências ${ }^{9}$, com erro proporcional a $\left(\mu / \omega_{0}\right)^{2}$, dependendo apenas dos coeficientes de deriva $D_{j}$. Como em geral a freqüência natural dos movimentos horizontais é aproximadamente 10 vezes menor que a freqüência de pico do espectro incidente, o erro

\footnotetext{
${ }^{9}$ A partir de agora a dependência na variável $\mu$ será, então, suprimida.
} 
implícito na aproximação (3.32) é da ordem de $1 \%$ na faixa de interesse do espectro. Análise semelhante foi apresentada também em Pesce (1984).

As forças de deriva lenta são calculadas, então, aplicando-se a transformada inversa de Fourier na forma discreta, dada por:

$$
F_{j D L}(t)=\sum_{i=1}^{n} \sqrt{2 S_{j D L} \Delta \mu} \cos \left(\mu_{i} t+\phi_{i}\right), \quad j=1,2 \text { ou } 6
$$

sendo $\phi_{i}$ uma fase aleatória dependente da freqüência. Para evitar o aparecimento de componentes com alta freqüência, deve-se limitar o valor de $\mu$ em (3.33) aproximadamente por $\mu<0,2 \omega_{0}$, já que para freqüências maiores a aproximação (3.32) deixa de ser válida.

Ilustram-se na Figura 3.10 séries temporais das forças de deriva lenta para os três movimentos horizontais para o VLCC Vidal de Negreiros 100\% carregado, sob incidência de uma onda com altura significativa de 5,5m e período de pico 11,4s, sob espectro de Pierson-Moskowitz.
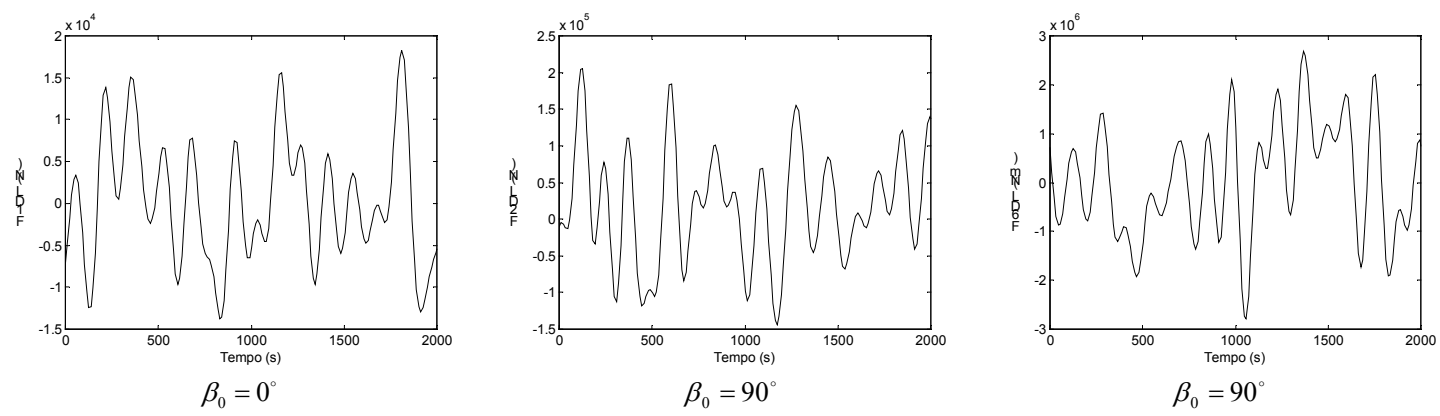

Figura 3.10 Realizações temporais das forças de deriva lenta para VLCC 100\% carregado $\left(T_{p}=11,4 \mathrm{~s}\right.$ e $\left.H_{s}=5,5 \mathrm{~m}\right)$

Considerando uma distribuição Gaussiana de amplitudes e um espectro de banda estreita, o valor máximo da força de deriva lenta é dado por (Price; Bishop, 1974): 


$$
\left[F_{j D L}\right]_{\max }=3,7 \sqrt{\int_{0}^{\mu_{\max }} S_{j D L} d \mu}, \quad j=1,2 \text { ou } 6
$$

\subsubsection{Interação Onda-Corrente}

As forças de segunda ordem são influenciadas pela presença de correnteza, devido ao efeito Doppler, ou seja, à variação da freqüência de encontro entre a onda e o corpo e à refração do trem de ondas incidente (fenômeno de aberração). Esta interação é chamada de wave damping (amortecimento de onda) pois, como será mostrado adiante, equivale a um termo proporcional à velocidade da correnteza adicionado (ou subtraído) das forças de deriva.

A formulação empregada no presente trabalho foi apresentada inicialmente por Aranha (1994) para o caso unidirecional (onda e correnteza alinhadas) e estendida em Aranha (1996) para o caso bidimensional. Não foi considerada a influência da correnteza nas forças de deriva lenta, o que ainda é um tema de pesquisa, sem resultados validados experimentalmente (Aranha; Martins, 2001).

Para uma onda harmônica incidente sobre o navio, com uma direção de incidência $\beta_{0}$, e sendo $V_{c r}$ e $\alpha_{r}$ a velocidade e direção da correnteza em relação ao casco (já incluindo a velocidade absoluta do navio) definidas em (3.12), mostra-se que os coeficientes de deriva do navio são alterados para:

$$
\begin{gathered}
D_{j, U}\left(\omega, \beta_{0}\right)=D_{j}\left(\omega, \beta_{0}\right)+\frac{V_{c r}}{c}\left[\cos \alpha_{r}\left(b_{w j} \cos \beta_{0}+b_{r j} \operatorname{sen} \beta_{0}\right)+, j=1,2 \text { ou } 6\right. \\
\left.\operatorname{sen} \alpha_{r}\left(b_{w j} \operatorname{sen} \beta_{0}+b_{r j} \cos \beta_{0}\right)\right]
\end{gathered}
$$

sendo $c$ a velocidade da onda no meio (para águas profundas, $c=g / \omega$ ) e :

$$
\begin{aligned}
& b_{w j}=4 D_{j}\left(\omega, \beta_{0}\right)+\omega \frac{\partial D_{j}\left(\omega, \beta_{0}\right)}{\partial \omega} \\
& b_{r j}=-2 \frac{\partial D_{j}\left(\omega, \beta_{0}\right)}{\partial \beta_{0}}
\end{aligned}
$$


Assim, o cálculo das forças de deriva média para mar irregular é feito utilizandose o novo coeficiente de deriva (3.35) em (3.30). Para ilustrar a grande importância deste efeito sobre a força de deriva média, considera-se o mesmo espectro de onda anterior (altura significativa de 5,5m, período de pico $11,4 \mathrm{~s}$, modelo de PiersonMoskowitz) incidindo simultaneamente a uma correnteza de $1,2 \mathrm{~m} / \mathrm{s}$ sobre o VLCC Vidal de Negreiros $100 \%$ carregado. Variou-se a direção de incidência da correnteza e calcularam-se as forças de deriva média em surge, sway e yaw. Para a força de surge, supôs-se a onda incidente na proa do navio e para a força de sway e o momento de yaw supôs-se a onda de través.
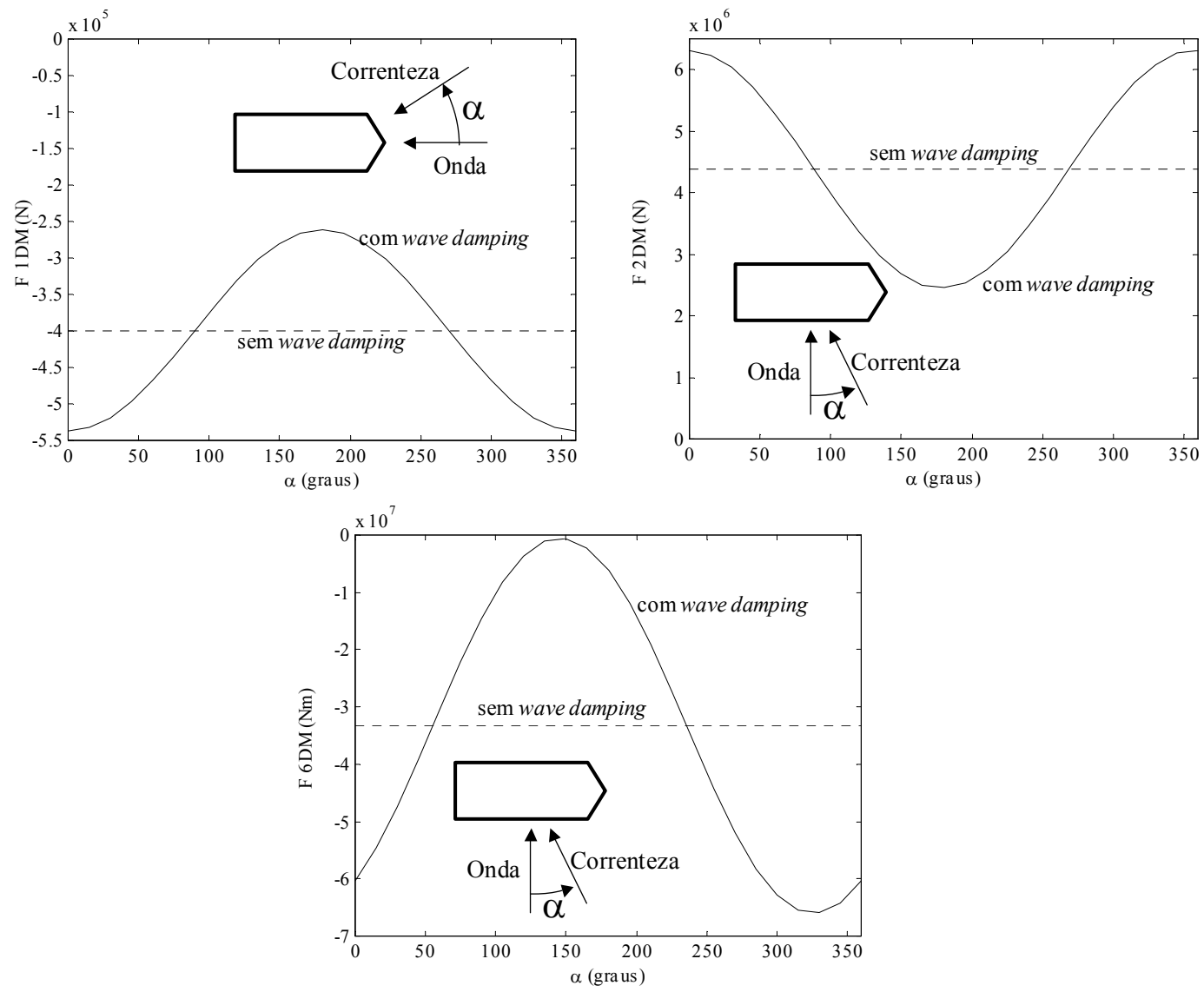

Figura 3.11 Efeito do wave damping sobre as forças de deriva média

Observa-se que, neste caso, o wave damping é responsável por variações de até $100 \%$ sobre os valores dos esforços de deriva média. Observa-se que quando onda e correnteza incidem no mesmo sentido as forças de deriva média aumentam em valor absoluto, o inverso ocorrendo em incidências contrárias. 


\subsubsection{Movimentos devido às Forças de Primeira Ordem}

As forças de primeira ordem são proporcionais à altura da onda incidente, possuindo assim uma elevada amplitude. Além disso, são esforços de alta freqüência, pois, diferentemente das forcas de deriva lenta, possuem a mesma freqüência da onda que os gera.

Como os graus de liberdade horizontais da embarcação amarrada (surge, sway e yaw) possuem freqüências naturais muito baixas, estas forças induzem nos mesmos oscilações de amplitudes relativamente pequenas quando comparadas às amplitudes dos movimentos de deriva lenta. Entretanto, possuem elevadas freqüências e, em sistemas de posicionamento dinâmico, devem ser filtradas das medições para evitar a geração de esforços de controle muito oscilatórios. Assim, a avaliação destes movimentos deve ser feita criteriosamente no projeto de SPD's, pois os filtros de onda interferem sobremaneira no desempenho dos controladores, podendo, quando não considerados em fase de projeto, levar à instabilidade devido ao atraso de fase que introduzem no sistema.

Os movimentos verticais (heave, roll e pitch) apresentam freqüências naturais bem maiores que os horizontais, sendo que as forças de primeira ordem são as suas principais excitações ambientais. As equações dos movimentos verticais não são, em geral, consideradas no projeto dos controladores dos SPDs, pois se admite que o movimento horizontal é desacoplado do vertical devido à discrepância entre as freqüências naturais. O controlador proposto no presente trabalho, entretanto, considera os movimentos verticais no cálculo do set-point da embarcação, pois estes movimentos são responsáveis por diversos problemas durante as operações offshore, por danos estruturais nos risers e linhas de amarração e por embarque de água no convés (greenwater).

Assim, são calculados todos os movimentos de primeira ordem da embarcação. Uma maneira de se realizar este cálculo é fazê-lo através da simulação dinâmica do sistema com os 6 graus de liberdade, impondo-se ao mesmo as forças de excitação oscilatórias de primeira ordem geradas pelas ondas incidentes. Estas forças são também obtidas por meio da integração do campo de pressão ao longo do casco, isolando-se convenientemente os termos de primeira e segunda ordem. Deve-se, adicionalmente, considerar efeitos viscosos que não estão incorporados no cálculo (potencial) das forças de excitação. 
Alternativamente, pode-se utilizar o cálculo direto dos movimentos de primeira ordem a partir dos RAO's, que representam as funções de transferência entre a altura da onda incidente e o movimento resultante, e que podem ser calculados a priori através das forças de excitação. Este método se baseia na linearidade dos movimentos em relação à altura de onda, o que é uma aproximação bastante razoável exceto para o movimento de roll, que é afetado por efeitos viscosos quadráticos. Comprova-se experimentalmente a linearidade citada em Soares; Fonseca; Pascoal (2001), por exemplo.

Esta solução foi adotada no presente trabalho devido ao menor tempo de processamento requerido, sendo utilizado um coeficiente de amortecimento subestimado para o movimento de roll de forma a se obter resultados a favor da segurança.

Os RAO's são funções complexas definidas como a relação entre a amplitude complexa do movimento induzido $X_{j}$ e a amplitude $A$ da onda numa freqüência $\omega$ (levando em conta a fase relativa entre este movimento e a onda incidente):

$$
R A O_{j}\left(\omega, \beta_{0}\right)=\left.\frac{X_{j}}{A}\right|_{\omega, \beta_{0}}, \quad j=1, \ldots, 6
$$

Apresentam-se na Figura 3.12 os RAO's dos movimento de sway (incidência de través) e pitch (incidência de proa) para o VLCC 100\% carregado e para a BGL1. Como esperado, os movimentos na BGL1 são mais intensos, devido a sua menor massa, sendo excitada por uma faixa de freqüências mais alta. Os RAO's são fornecidos por programas como o WAMIT, ou por ensaios em tanque de provas. 

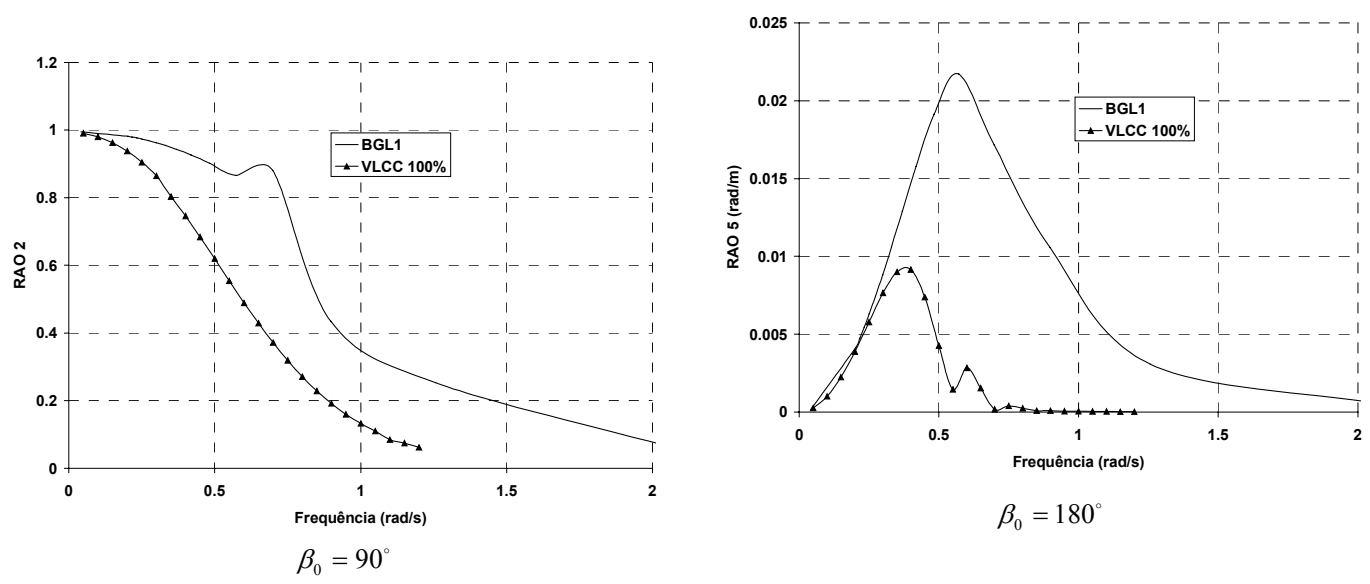

Figura 3.12 RAO's do movimento de sway (incidência de través) e do movimento de pitch (incidência de proa) - VLCC e BGL1.

Para mares irregulares descritos pelo espectro $S(\omega)$, aplica-se a definição (3.25) para se obter as funções de densidade espectral cruzada e densidade espectral de potência dos movimentos $\left(P_{i j}\right)$ :

$$
P_{i j}(\omega)=R A O_{i}\left(\omega, \beta_{0}\right) R A O_{j}^{*}\left(\omega, \beta_{0}\right) S(\omega), \quad i, j=1, \ldots, 6
$$

sendo (*) indicativo do complexo conjugado. Assim, pela transformação inversa de Fourier, podem-se obter realizações temporais dos movimentos de primeira ordem $x_{j P O}\left(t, \beta_{0}\right)$ :

$$
\begin{aligned}
& x_{j P O}\left(t, \beta_{0}\right)=\sum_{i=1}^{n} \sqrt{2 S\left(\omega_{i}\right) R A O_{j}\left(\omega_{i}, \beta_{0}\right)^{2} \Delta \omega} \cos \left(\omega_{i} t+\operatorname{fase}\left(R A O_{j}\left(\omega_{i}, \beta_{0}\right)\right)+\phi_{j}\right) \\
& j=1, \ldots, 6
\end{aligned}
$$

sendo $\phi_{i}$ uma fase aleatória dependente da freqüência. Na Figura 3.13 apresentam-se os movimentos de sway, yaw e roll do VLCC 100\% carregado sujeito a ondas com altura significativa de 5,5m e período de pico $11,4 \mathrm{~s}$, com espectro de Pierson-Moskowitz. O aproamento é controlado em $\beta_{0}=45^{\circ}$ e, para os modos horizontais (sway e yaw) distinguem-se as curvas dos movimentos de baixa frequência e de alta freqüência (obtidos pela equação (3.38)). 

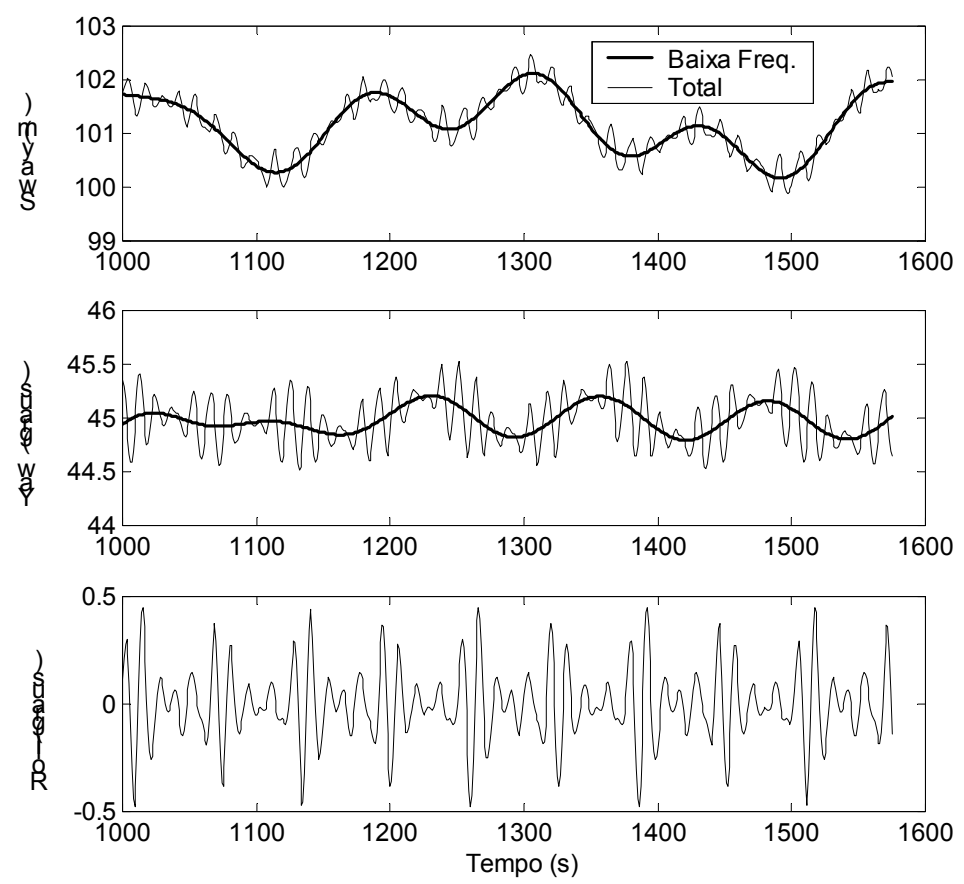

Figura 3.13 Movimentos de primeira e segunda ordem do VLCC $100 \%$ carregado sujeito a onda $\left(T_{p}=11,4 \mathrm{~s}\right.$ e $\left.H_{s}=5,5 \mathrm{~m}\right)$.

O valor máximo e o desvio padrão estimados para os movimentos de primeira ordem são calculados, supondo-se que o navio permaneça com aproamento aproximadamente constante, por (Price; Bishop, 1974):

$$
\begin{aligned}
& {\left[x_{j P O}\left(t, \beta_{0}\right)\right]_{r m s}=2 \sqrt{\int_{0}^{\infty} S(\omega) \cdot R A O_{j}^{2}\left(\omega, \beta_{0}\right) d \omega} \quad j=1, \ldots, 6} \\
& {\left[x_{j P O}\left(t, \beta_{0}\right)\right]_{\max }=1,866 \times\left[x_{j P O}\left(t, \beta_{0}\right)\right]_{r m s}}
\end{aligned}
$$

Como exemplo, a amplitude máxima dos movimentos de primeira ordem para o VLCC Vidal de Negreiros, com carregamento 100\%, nas condições da Figura 3.13, são: 0,52m (surge); 0,51m (sway); 1,28m (heave); 0,62 ${ }^{\circ}$ (roll); $1,77^{\circ}$ (pitch); 0,71 ${ }^{\circ}$ (yaw). 


\subsubsection{Ventos}

As forças na direção longitudinal (surge) e lateral (sway) e o momento de yaw devido à incidência do vento sobre a parte emersa da embarcação são modeladas através de coeficientes adimensionais. Admitindo que não haja variação espacial na velocidade e direção do vento incidente sobre a embarcação, são válidas as relações:

$$
\begin{aligned}
& F_{1 V}=\frac{1}{2} \rho_{a} C_{V x}\left(\beta_{V}\right) A_{\text {Frontal }} V^{2} \\
& F_{2 V}=\frac{1}{2} \rho_{a} C_{V y}\left(\beta_{V}\right) A_{\text {Lateral }} V^{2} \\
& F_{6 V}=\frac{1}{2} \rho_{a} C_{V n}\left(\beta_{V}\right) L A_{\text {Lateral }} V^{2}
\end{aligned}
$$

nas quais $\rho_{a}$ é a densidade do ar, $F_{1 V}$ e $F_{2 V}$ são as forças nas direções longitudinais e transversais respectivamente, $F_{6 V}$ é o momento de yaw, $C_{V x}, C_{V y}$ e $C_{V n}$ são os coeficientes adimensionais, $A_{\text {frontal }}$ e $A_{\text {Lateral }}$ são as áreas vélicas projetadas frontal e lateral (respectivamente) da parte emersa da embarcação e $V$ é a velocidade do vento. $\mathrm{O}$ ângulo de incidência em relação ao eixo fixo $O X$ é dado por $\beta_{V, O X Y Z}$ e o ângulo relativo à embarcação é dado por $\beta_{V}\left(\beta_{V, O X Y Z=} \beta_{V}+\psi\right)$, ambos definidos na Figura 3.14.

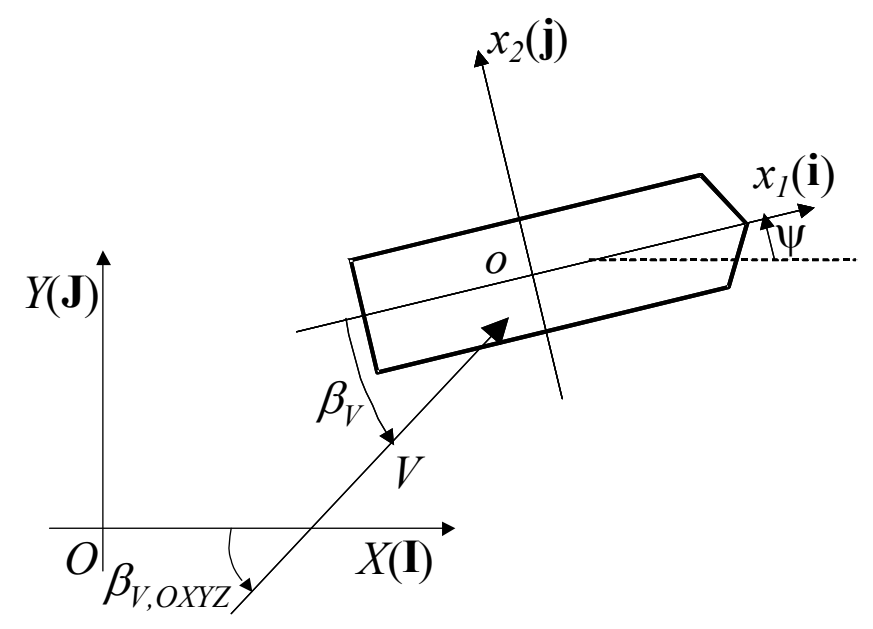

Figura 3.14 Ângulos de incidência de vento

A utilização direta da velocidade do vento e de sua direção na expressão (3.40), sem a realização de correções devido à velocidade do navio, pressupõe que esta última 
seja muito menor que a velocidade do vento. Esta hipótese é plenamente satisfeita em sistemas de posicionamento dinâmico, nos quais a velocidade do navio é em geral mantida muito baixa (da ordem de $0,1 \mathrm{~m} / \mathrm{s}$ ) comparada a velocidades típicas de vento (da ordem de $10 \mathrm{~m} / \mathrm{s}$ ). Em períodos de ventos suaves esta hipótese deixa de ser válida; entretanto, neste caso, os esforços devido ao vento são tão baixos que podem ser desprezados.

Os coeficientes adimensionais de vento são, em geral, obtidos por meio de ensaios em túnel de vento ou em tanques de prova com o modelo emborcado, sendo que existem algumas referências que podem ser consultadas para que uma primeira estimativa seja obtida. Por exemplo, Isherwood (1972) realizou a regressão de curvas de coeficientes de vento para diversos navios mercantes, derivando relações que dependem apenas das dimensões principais da embarcação. Da mesma forma, encontram-se em OCIMF (1977) curvas aproximadas para navios petroleiros VLCC's em diversas condições de carregamento. Na Figura 3.15 apresentam-se as curvas para o navio nas condições extremas de carregamento (100\% e 40\% do calado máximo) .
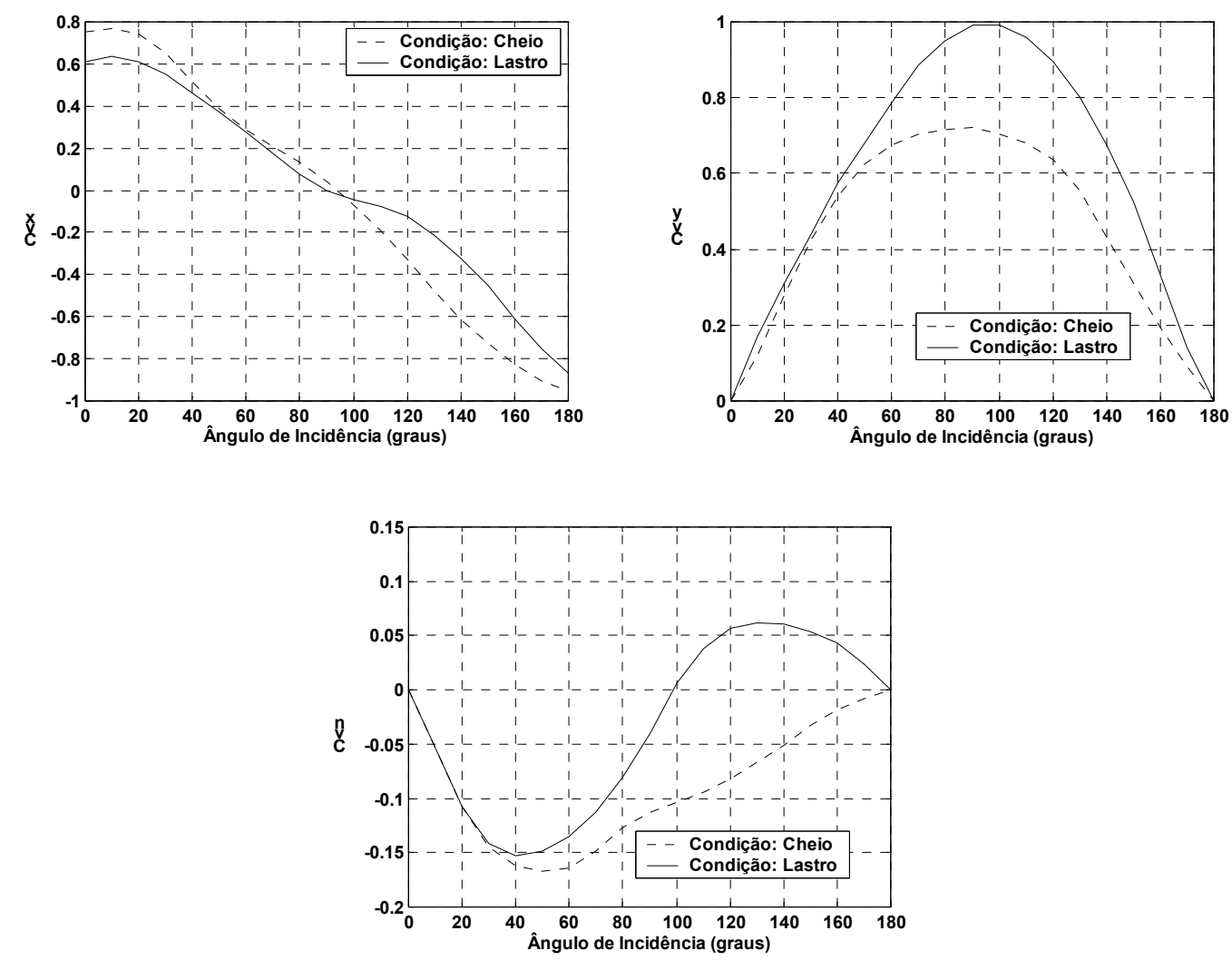

Figura 3.15 Coeficientes adimensionais de vento para um VLCC (OCIMF, 1977) 
A velocidade do vento, entretanto, não é constante ao longo do tempo. Pode-se considerar que possui uma parcela lentamente variável no tempo, responsável por esforços quase-estáticos sobre o sistema, e uma parcela oscilatória de alta freqüência. Esta parcela, conhecida como rajada, é descrita estatisticamente por meio de espectros de vento.

Uma das formulações espectrais mais utilizadas para rajadas de vento é o chamado espectro de Harris (Harris, 1971), dado por:

$$
S_{V}(\omega)=1146 . C \cdot V \cdot\left[2+\left(\frac{286 \omega}{V}\right)^{2}\right]^{-\frac{5}{6}}
$$

sendo $\omega$ a freqüência de oscilação da velocidade do vento, $S_{v}$ a densidade espectral $\left(\mathrm{m}^{2} / \mathrm{s}\right)$ e $C$ um coeficiente de arraste superficial, na faixa $0,0015-0,003$ para estados de mar moderados.

O espectro proposto em Occhi-Shin (1998) também é bastante utilizado, sendo expresso por:

$$
S_{V}(\omega)=\frac{(750+69 V) \cdot 10^{-6} V^{2} F_{g}}{\omega}
$$

na qual $\left(\operatorname{com} x_{v}=1,592 \omega / V\right)^{10}$ :

$$
F_{g}=\left\{\begin{array}{cc}
583 x_{v} & 0 \leq \frac{\omega}{V}<0,001885 \\
\frac{420 x_{v}{ }^{0,7}}{\left(1+x_{v}{ }^{0,35}\right)^{11,5}} & 0,001885 \leq \frac{\omega}{V}<0,0628 \\
\frac{838 x_{v}}{\left(1+x_{v}{ }^{0,35}\right)^{11,5}} & 0,0628 \leq \frac{\omega}{V}
\end{array}\right.
$$

\footnotetext{
${ }^{10} \mathrm{O}$ coeficiente dimensional $x_{v}$ possui dimensão $1 / \mathrm{m}$.
} 
Por exemplo, para uma velocidade média de vento de $20 \mathrm{~m} / \mathrm{s}$, os dois espectros são apresentados na Figura 3.16, na qual utilizou-se um coeficiente $C=0,002$ na formulação de Harris. O espectro de Occhi-Shin prevê uma oscilação maior da velocidade do vento, pois seu valor da densidade espectral é maior em todas as freqüências.

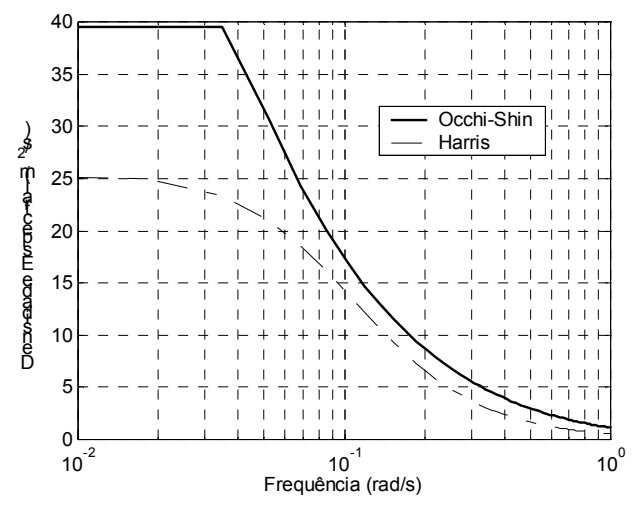

Figura 3.16 Espectros de rajada para velocidade média de vento de $20 \mathrm{~m} / \mathrm{s}$

A série temporal da velocidade do vento $V(t)$ pode ser obtida por transformação inversa de Fourier na sua forma discreta:

$$
V(t)=\sum_{i=1}^{n} \sqrt{2 S_{V}\left(\omega_{i}\right) \Delta \omega} \cos \left(\omega_{i} t+\phi_{i}\right)
$$

sendo $\left\{\omega_{1}, \ldots, \omega_{n}\right\}$ uma partição do intervalo de freqüências de interesse e $\phi_{i}$ uma fase aleatória dependente da freqüência.

Na Figura 3.17 são mostradas as séries temporais da velocidade do vento para os dois espectros, na qual se confirma a maior oscilação para o caso do espectro de OcchiSchin. Nas análises realizadas no presente trabalho serão utilizadas as duas formulações, indicadas oportunamente. 


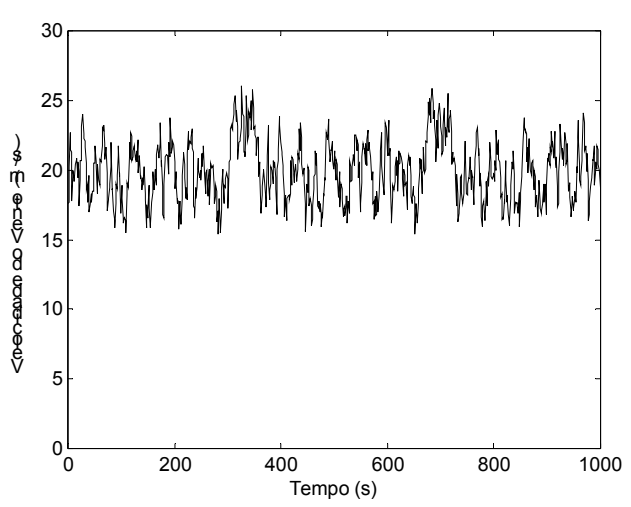

(a)

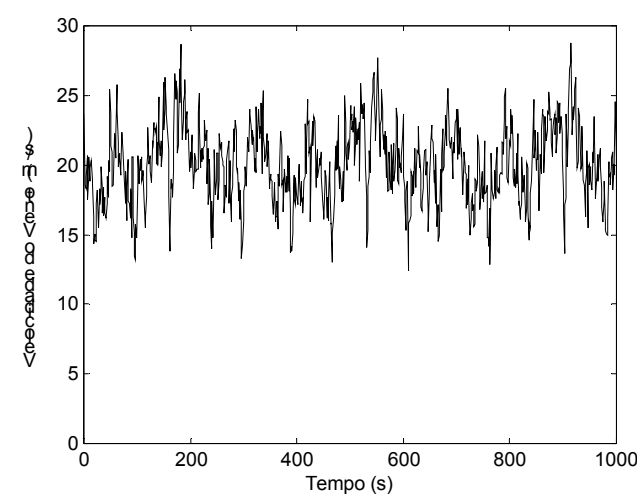

(b)

Figura 3.17 Velocidade do vento : (a) Espectro de Harris; (b) Espectro de Occhi-Shin

\subsection{Sistema de amarração e risers}

As linhas de amarração impõem ao sistema oceânico forças de restauração capazes de compensar as forças externas além de forças de amortecimento adicional devido ao movimento das mesmas relativo ao meio fluido. Os modelos matemáticos que representam tais forças serão expostos na presente seção.

Os risers adicionam efeito restaurador de pequena magnitude ao sistema, na medida em que são presos ao navio com um pequeno ângulo com a vertical, o que, como será mostrado adiante, resulta numa pequena rigidez horizontal. Entretanto, por serem muitos (num FPSO é comum a existência da ordem de 70 risers), este efeito, assim como o efeito de amortecimento, pode ser significativo. Ambos são considerados no modelo através de um número pequeno de risers equivalentes ${ }^{11}$.

\subsubsection{Forças de restauração}

As forças de restauração do sistema de amarração são calculadas através da composição vetorial das forças em cada linha de amarração e riser equivalentes, obtidas por meio das curvas de restauração. Estas curvas são calculadas supondo-se deslocamentos quase-estáticos sobre a linha, impondo-lhe a condição de equilíbrio no meio fluido, sem considerar efeitos de correnteza.

A obtenção destas curvas não será aqui abordada, o que pode ser encontrado, por exemplo, em Pesce (1997). Na Figura 3.18(a) apresenta-se um exemplo da curva de

\footnotetext{
${ }^{11} \mathrm{O}$ procedimento para o cálculo dos risers equivalentes não é abordado no presente trabalho.
} 
restauração de uma linha típica, instalada num sistema que opera numa região de profundidade de $1024 \mathrm{~m}$. A abscissa da curva é o deslocamento horizontal entre o ponto de conexão no navio e a âncora. Na Figura 3.18(b) calculou-se a rigidez da linha, ilustrando o fato de que para menores distâncias a linha fica mais "frouxa", com menor rigidez. Devido à sua respectiva função, as linhas de amarração operam no trecho final da curva de restauração (alta rigidez) e os risers operam na região de baixa solicitação.

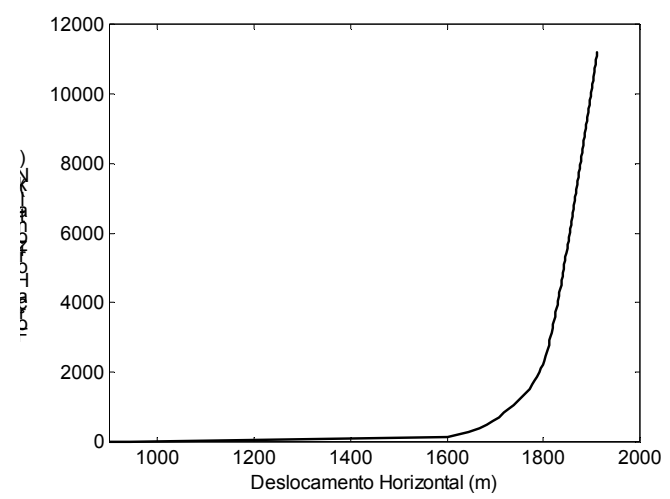

(a)

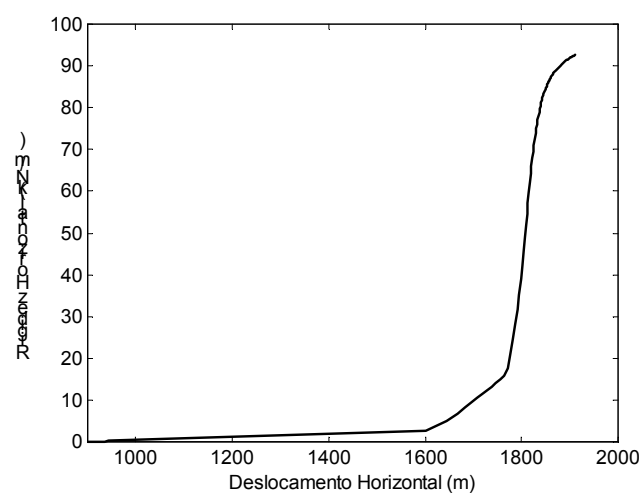

(b)

Figura 3.18 Linha de amarração típica composta por segmentos de poliéster e correntes de aço (a) Curva de restauração ; (b) Curva de rigidez

No presente trabalho considerou-se apenas o sistema de amarração em turret, constituído por uma torre vertical montada sobre rolamentos axiais, em cuja parte inferior fixam-se as linhas de amarração e os riser. Devido a esta liberdade rotacional, as forças horizontais das linhas atuantes na periferia da torre não causam momento em relação ao seu centro. Assim, o sistema foi modelado de forma simplificada, considerando-se todas as linhas e risers conectadas ao centro da torre.

Para cada linha e riser equivalente do sistema calcula-se (em cada instante de simulação) a distância horizontal entre a âncora e o turret. Com auxílio das curvas características calcula-se a força restauradora atuante $\left(F_{R e s}\right)$, que é projetada nas direções longitudinal $\left(F_{\text {lRes }}\right)$ e transversal $\left(F_{2 R e s}\right)$. A força transversal gera um momento em relação ao ponto $o$ (meia-nau) dado por $F_{6 R e s}=F_{2 R e s} x_{p}$, sendo $x_{p}$ a distância longitudinal entre a meia nau e o turret. O cálculo descrito é ilustrado na Figura 3.19. 


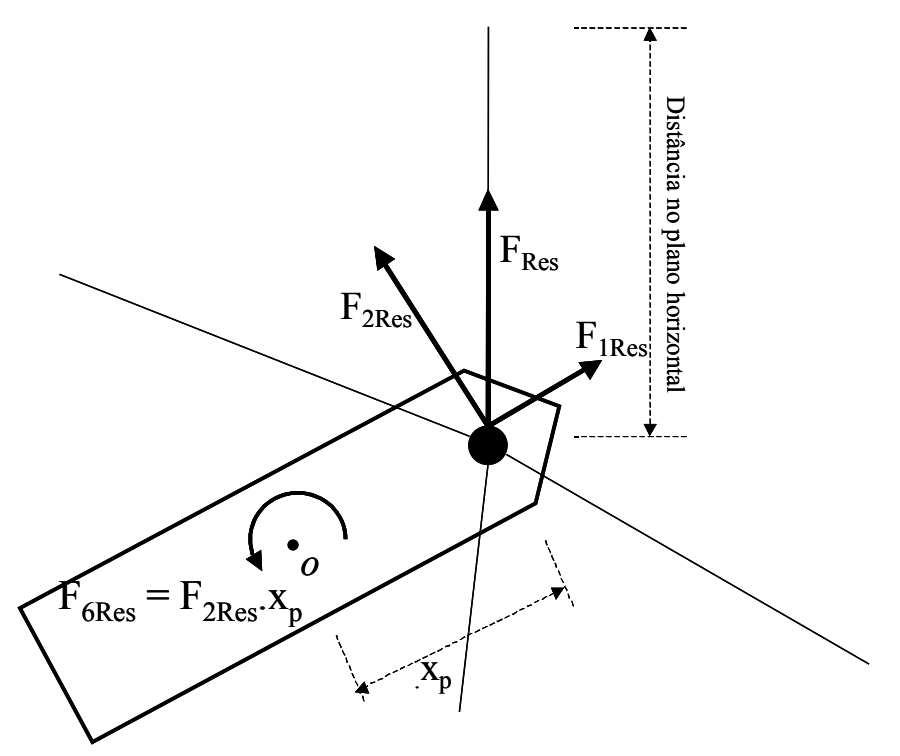

Figura 3.19 Cálculo das forças restauradoras no sistema turret

\subsubsection{Amortecimento e arrasto em linhas e risers}

Como mencionado, a avaliação das forças de amortecimento de linhas é baseada em Nishimoto et al. (1999) e Aranha (1999).

Considera-se uma linha de amarração, movendo-se com uma velocidade de topo (ponto A) genérica, possuindo uma parcela $\delta \ddot{x}$ no plano da mesma e uma parcela $\delta \ddot{y}$ na direção perpendicular ao plano da linha. A linha é exposta a uma corrente de velocidade $V_{C}$, também com componentes no plano da linha $\left(V_{c, x z}\right)$ e na direção perpendicular ao mesmo $\left(V_{c, y z}\right)$. A coordenada curvilínea ao longo da linha é dada por $s$ e o ângulo formada com a horizontal por $\theta(s)$. As forças no plano da linha $\left(F_{x}\right)$ e no plano perpendicular à mesma $\left(F_{y}\right)$ são composições de efeitos de amortecimento (devido ao movimento do topo) e de arrasto (devido à correnteza) e serão calculadas a seguir. As definições são esquematizadas na Figura 3.20.
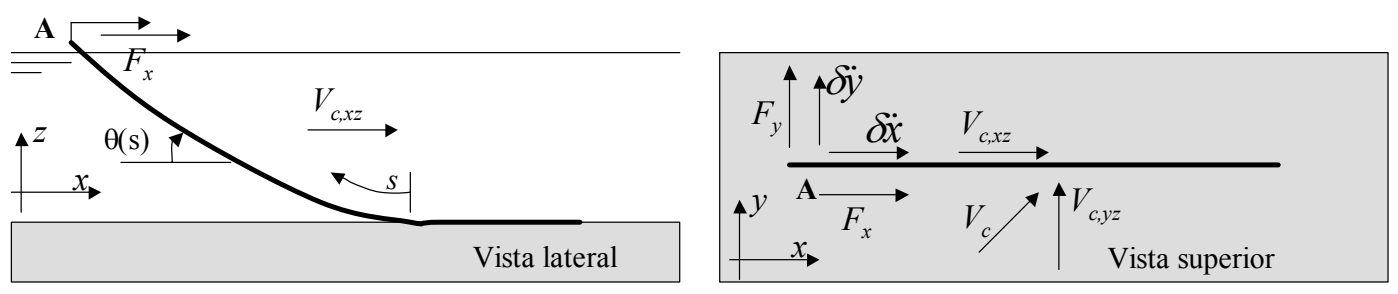

Figura 3.20 Movimentos dentro e fora do plano da linha 
A força $F_{x}$ é dada por

$$
F_{x}=-a_{A A} \delta \ddot{x}|\delta \ddot{x}|+b_{A A} V_{c, x z}|\delta \ddot{x}|+d_{\mathrm{AA}} V_{c, x z}\left|V_{c, x z}\right|
$$

que possui esta forma devido à natureza física do amortecimento e arrasto, que dependem do quadrado da velocidade relativa entre o corpo e o fluido.

Supondo-se uma linha homogênea (composta por um segmento apenas), e sendo $C_{D}$ o coeficiente de arrasto da linha, $D_{r}$ o seu diâmetro, $h$ a profundidade, $q$ o peso submerso por unidade de comprimento e $R_{H}$ a rigidez horizontal (derivada da curva característica), as constantes $a_{A A}, b_{A A}$ e $d_{A A}$ são calculadas por:

$$
\begin{aligned}
& a_{A A}=\frac{1}{2} \rho C_{D} D_{r} h \frac{\cos \theta_{A}}{1-\cos \theta_{A}}\left(\frac{R_{H}}{q}\right)^{3} \int_{0}^{\theta_{A}} \frac{|f(\theta)|^{3}}{\cos ^{2} \theta} d \theta \\
& b_{A A}=2 \rho C_{D} D_{r} h \frac{\cos \theta_{A}}{1-\cos \theta_{A}}\left(\frac{R_{H}}{q}\right)^{2} \int_{0}^{\theta_{A}} \frac{f(\theta)^{2} \operatorname{sen} \theta}{\cos ^{2} \theta} d \theta \\
& d_{A A}=\frac{1}{2} \rho C_{D} D_{r} h\left(\frac{\cos \theta_{A}}{1-\cos \theta_{A}}\right)^{2} \int_{0}^{\theta_{A}} \tan ^{2} \theta\left(\tan \theta \cdot(1-\cos \theta)+\cos \theta \operatorname{senh}^{-1}(\tan \theta)\right) d \theta
\end{aligned}
$$

$\operatorname{com} f(\theta)=\frac{1-\cos \theta_{A}}{\operatorname{sen} \theta_{A}} \operatorname{sen} \theta-\operatorname{sen} \theta \operatorname{senh}^{-1}(\tan \theta)+1-\cos \theta$. As constantes $a_{A A}, b_{A A} \mathrm{e}$ $d_{A A}$ são calculadas para a configuração inicial do sistema apenas, não sendo recalculadas a cada instante de simulação.

A força $F_{y}$, devida à velocidade fora do plano da linha, pode ser expressa por:

$$
F_{y}=-c_{A A}\left|\left(\delta \ddot{y}-V_{c, y z}\right)\right|\left(\delta \ddot{y}-V_{c, y z}\right)
$$

sendo $c_{A A}=\frac{1}{2} \rho C_{D} D_{r} h \frac{\operatorname{sen} \theta_{A}}{1-\cos \theta_{A}}$. 
Considerando-se a existência de $n_{l}$ linhas e risers equivalentes, cada um formando um ângulo $\theta_{h, j}\left(1<j<n_{l}\right)$ com o eixo $O X$, as forças de amortecimento e arrasto em cada linha, calculadas por (3.44) e (3.45), são denotadas então por $F_{x, j}$ e $F_{y, j}$. Assim, a força total de amortecimento e arrasto em surge e sway $\left(F_{1 A A}\right.$ e $\left.F_{2 A A}\right)$ e o momento de yaw $\left(F_{6 A A}\right)$ são dados por:

$$
\begin{aligned}
& F_{1 A A}=\sum_{j=1}^{n_{l}} F_{x, j} \cos \left(\theta_{h, j}-\psi\right)-F_{x, j} \operatorname{sen}\left(\theta_{h, j}-\psi\right) \\
& F_{2 A A}=\sum_{j=1}^{n_{l}} F_{x, j} \operatorname{sen}\left(\theta_{h, j}-\psi\right)+F_{x, j} \cos \left(\theta_{h, j}-\psi\right) \\
& F_{6 A A}=x_{p} F_{2 A A}
\end{aligned}
$$

Adicionalmente, introduz-se um fator de correção na velocidade da correnteza para levar em conta um perfil de distribuição ao longo da profundidade $g(z)$ dado por:

$$
V_{C}(z)=V_{C} \cdot g(z)
$$

Em Aranha (1999), mostra-se que o perfil equivale a considerar-se uma velocidade de corrente equivalente $\bar{V}_{C}$, dada por:

$$
\bar{V}_{C}=V_{C} \cdot \frac{\int_{0}^{l} \operatorname{sen}^{3} \theta(s) \cdot g^{2}(z(s)) d s}{\int_{0}^{l} \operatorname{sen}^{3} \theta(s) \cdot d s}
$$

sendo $l$ o comprimento suspenso da linha ou riser. Para um perfil linear da correnteza, por exemplo, e uma linha com ângulo de topo de $50^{\circ}$, este fator resulta 0,47 .

\subsubsection{Tração dinâmica}

A dinâmica própria de linhas e risers caracteriza-se, em geral, por apresentar freqüências naturais em faixas próximas àquela associada aos movimentos de primeira 
ordem do FPSO (ver, por exemplo, Pesce et al., 1999). No entanto, a elevada inércia do navio torna a influência das linhas sobre os citados movimentos pouco significativas. Obviamente, seu efeito acaba por ser atenuativo, posto que a energia transferida às linhas é dissipada no meio fluido. Assim, no modelo de simulação do sistema como um todo desconsidera-se a dinâmica própria das linhas.

Cabe observar no entanto que para o cálculo do aproamento ótimo, apresentado na seção 4.2, no qual um funcional que considera (entre outros aspectos) o carregamento dinâmico sobre os risers é minimizado, tais efeitos devem ser levados em consideração.

Por critérios de projeto e características de resistência, os risers são instalados com baixos valores de pré-tensão, resultando uma pequena carga axial estática de tração ao longo de seu comprimento. Além disso, por serem elementos tubulares esbeltos, possuem resistência à compressão muito pequena, sofrendo flambagem local quando a carga de compressão ultrapassa o valor limite.A flambagem é acompanhada de elevadas curvaturas e cargas flexionais, podendo causar danos momentâneos e acelerar o processo de fadiga (Pinto, 2000).

Neste contexto os esforços dinâmicos podem ser extremamente perigosos, pois são oscilatórios e podem, em parte do ciclo, levar a uma compressão momentânea maior do que a admissível, causando compressão dinâmica. Como a amplitude de tração dinâmica é quase constante ao longo de todo o comprimento do riser (por não haver excitação de modos axiais elásticos), este efeito ocorre mais intensamente no ponto de contato entre o riser e o solo, chamado de touchdown point (TDP) pois é o ponto de menor tração estática.

Utilizou-se a formulação analítica proposta em Aranha et al. (1993) e estendida em Pinto et al.(1999) e Pinto (2000), cujo resumo é apresentado no Apêndice 1. Dados a amplitude máxima e o valor médio quadrático (rms) do movimento vertical no topo do riser, calculado por (3.39), obtém-se o coeficiente adimensional $\tau$ definido abaixo, utilizado para quantificar a tração dinâmica:

$$
\tau=\frac{T_{d}}{T_{o}+T_{a d m}}
$$


sendo $T_{a d m}$ a máxima compressão admissível para riser (dada pelo fabricante), $T_{o}$ a tração estática no TDP e $T_{d}$ a amplitude da tração oscilatória dinâmica. Se $\tau>1$, em parte do ciclo a tração dinâmica ultrapassa a tração estática em um valor superior ao admissível, levando à compressão dinâmica.

A formulação apresenta bons resultados quando comparada à solução numérica não-linear utilizando o programa ORCAFLEX, conforme apresentado na Figura 3.21 para duas amplitudes do movimento vertical imposto ao topo do riser e período de 11,5s, em função do ângulo que a linha faz com a horizontal junto à conexão.

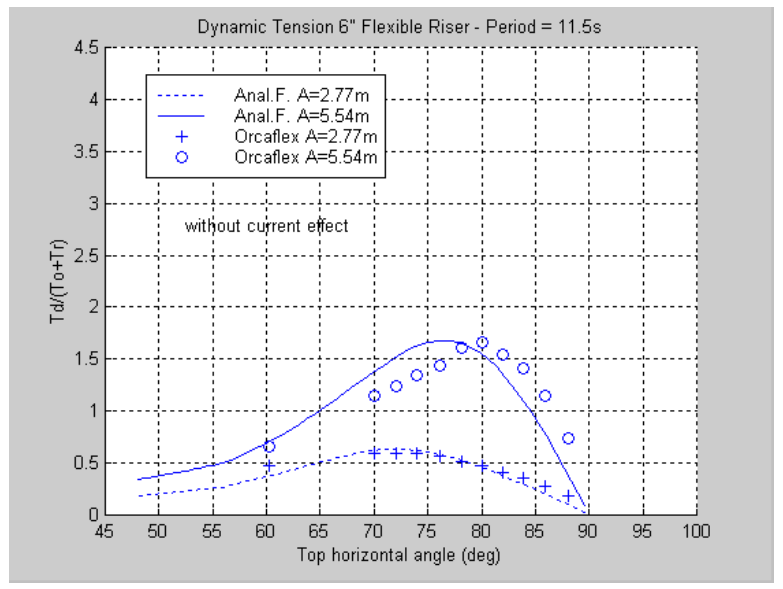

Figura 3.21 Comparação da formulação analítica (Aranha et al., 1993 e Pinto et al., 1999) para cálculo da tração dinâmica em risers com solução utilizando-se programa ORCAFLEX - extraída de Pinto et al., 1999

\subsection{Diagrama final}

Apresenta-se na Figura 3.22 o diagrama de blocos do modelo completo do movimento horizontal da embarcação, indicando-se o equacionamento utilizado. 


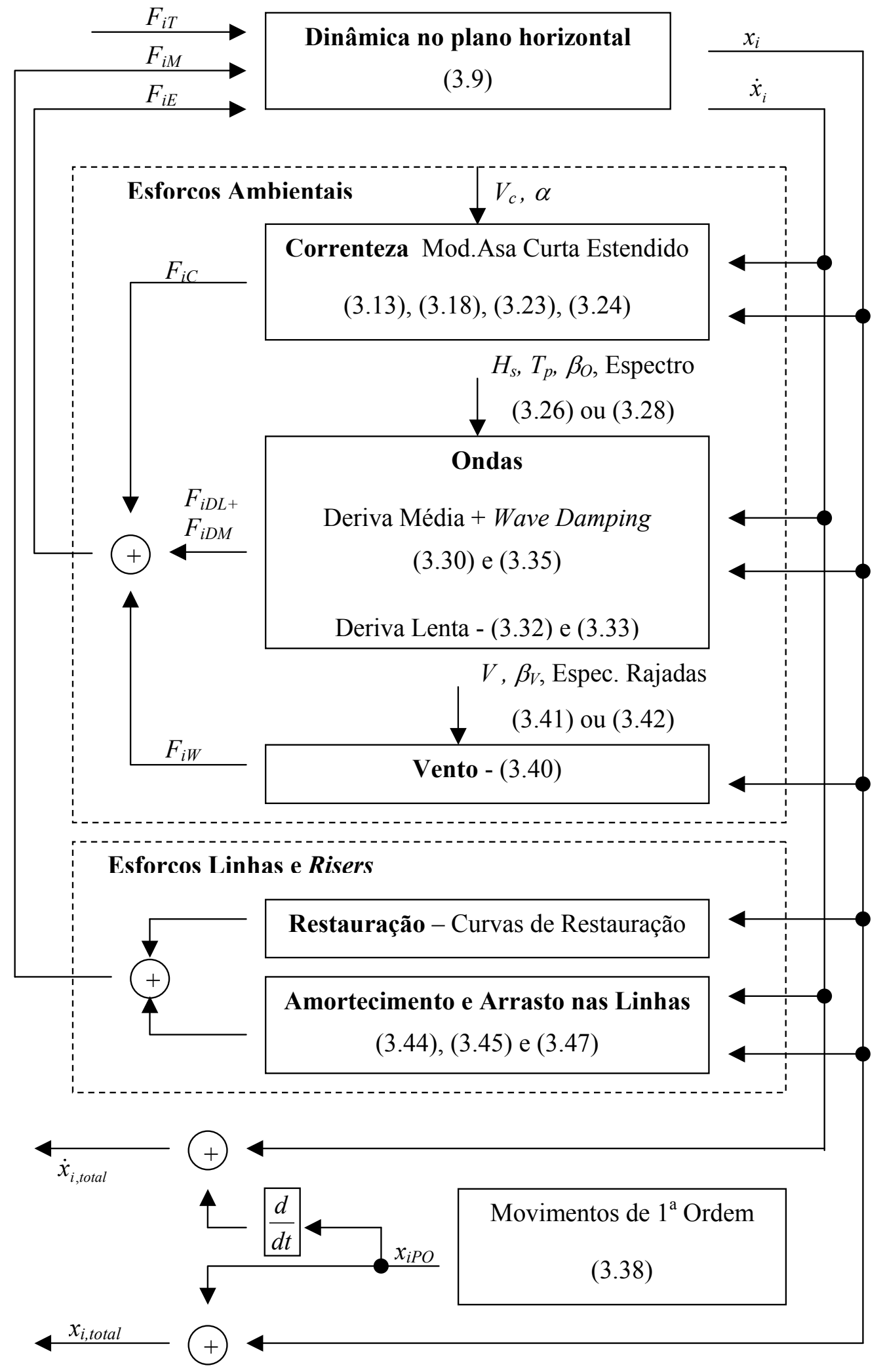

Figura 3.22 Diagrama de blocos do modelo completo do movimento horizontal da embarcação 


\subsection{Sistema de propulsão}

Nesta seção serão feitas algumas considerações a respeito dos principais tipos de sistemas de propulsão utilizados em SPDs. Em seguida, apresenta-se a modelagem matemática da dinâmica dos propulsores e de seus sistemas de controle.

\subsubsection{Considerações gerais}

Os sistemas de propulsão utilizados em posicionamento dinâmico devem possuir especificações especiais, que os diferem dos propulsores comumente utilizados em navegação.

Como as condições ambientais são variáveis, devido a efeitos de onda e vento oscilatórios, os propulsores devem apresentar resposta compatível às mudanças no empuxo requerido, reagindo rapidamente ao comando do sistema de controle. Atrasos na resposta podem comprometer o desempenho do sistema de controle, levando até, em casos extremos, à instabilidade.

Por este motivo, durante muito tempo os sistemas de posicionamento dinâmico baseavam-se em propulsores com passo controlável, nos quais a rotação é mantida constante e o controle do empuxo é feito ajustando-se o ângulo de passo das pás (Figura 3.23). Os propulsores eram em geral movidos por motores diesel e as pás acionadas por mecanismos hidráulicos, com resposta bastante rápida ao comando e apresentando boa precisão.

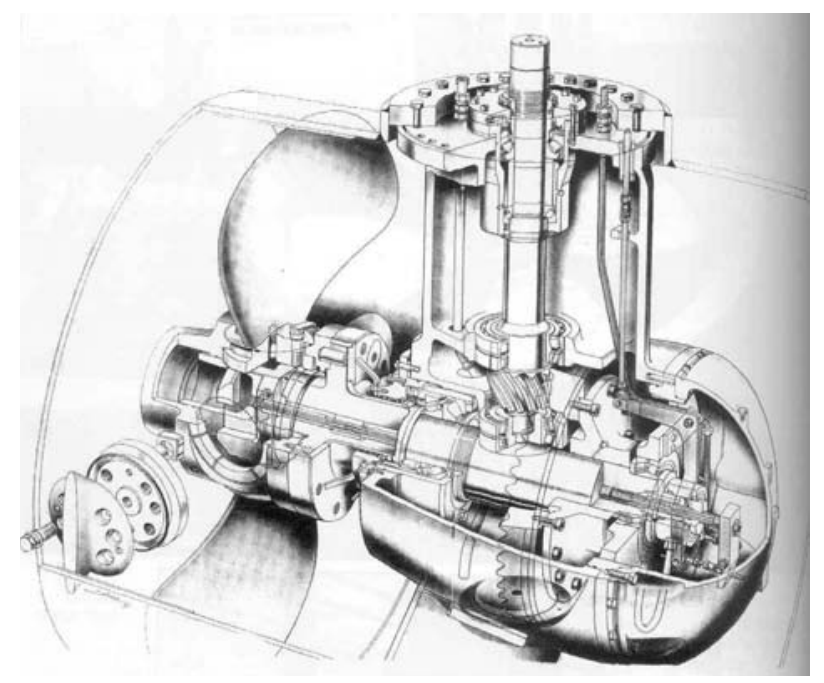

Figura 3.23 Propulsor de passo variável (adaptada de Bray, 1998) 
Estes propulsores, entretanto, são muito sujeito a falhas e necessitam de manutenção constante, pois possuem sofisticados mecanismos para variação do passo e ficam sujeitos a esforços elevados. Além disso, possuem eficiência de 2 a $4 \%$ inferior aos propulsores convencionais de passo fixo (Bray, 1998).

O desenvolvimento recente de sistemas de controle de rotação em motores elétricos (corrente contínua ou alternada) permitiu a utilização cada vez mais freqüente de propulsores com passo fixo, nos quais o controle do empuxo é dado pela variação da rotação (por exemplo, Hansen; Lauvdal; Ådnanes, 2000).

Os propulsores devem também ser projetados para suportar variações de rotação e carga, estando sujeitos a uma média de 750 alterações por hora em suas condições operacionais (Bond, 1980).

Além disso, como em geral as embarcações dotadas de posicionamento dinâmico possuem redundância para aumentar a confiabilidade do sistema, os propulsores devem apresentar tamanho reduzido e facilidade de montagem, de forma a que se possa acomodar muitos propulsores num mesmo casco. Neste sentido, os propulsores em túnel são bastante utilizados, pois permitem a geração de elevadas forças laterais e podem ser acomodados muito próximos um dos outros (Figura 3.24). Até navios de cruzeiro possuem, muitas vezes, este tipo de propulsor, para facilitar as operações de docagem nos portos.

Os sistemas de propulsão para posicionamento dinâmico devem permitir a geração de empuxo em qualquer direção. Desde os primeiros sistemas de posicionamento dinâmico, da década de 60 , os propulsores azimutais são bastante empregados, pois permitem o direcionamento do fluxo de água (e conseqüentemente do empuxo) para qualquer direção. O movimento azimutal é acionado por motores hidráulicos ou elétricos e o controle do empuxo pode ser feito pelo ângulo das pás (passo variável) ou rotação do hélice (passo fixo). Muitas vezes, o propulsor é montado no interior de um bocal para aumentar o empuxo fornecido (devido à força de sustentação adicional no bocal). Os dutos também provocam diminuição da cavitação, vibrações e ruídos. 


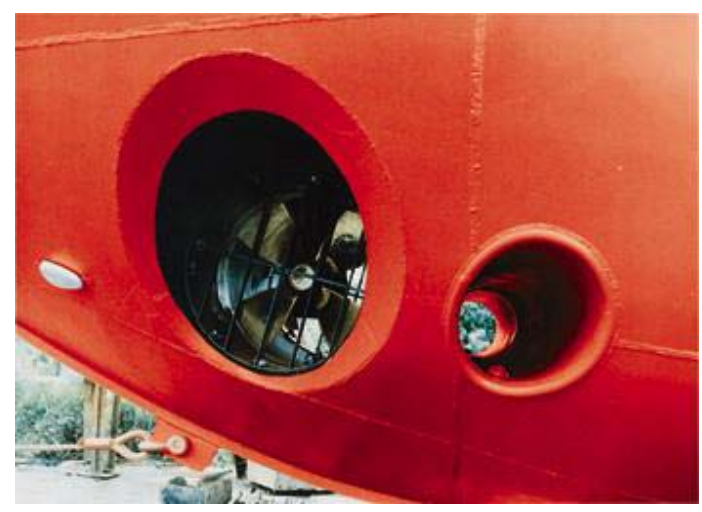

Figura 3.24 Propulsor em túnel (extraída de Schottel, 2002)

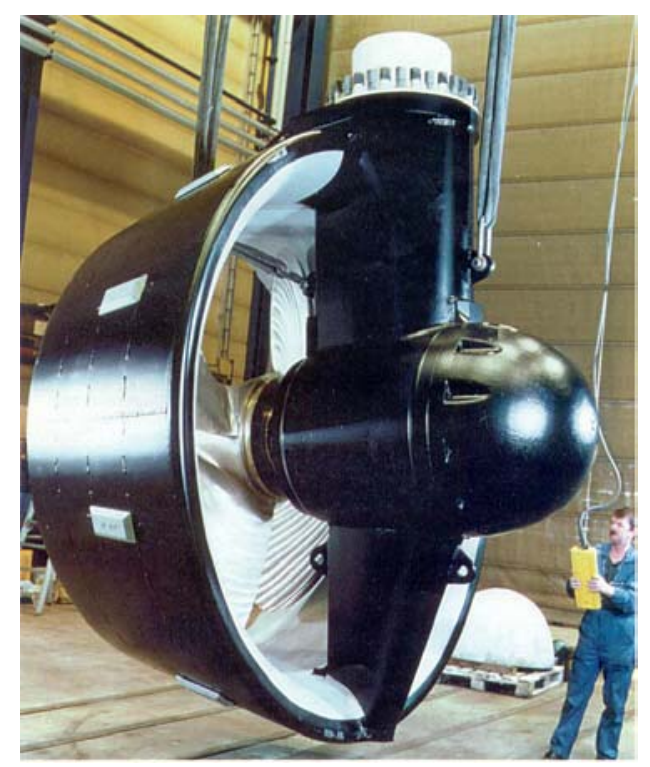

Figura 3.25 Propulsor azimutal montado em bocal (extraída de Marine Propulsion International, 1998)

Finalmente, a eficiência do sistema de propulsão (aqui expressa pelo empuxo gerado por unidade de potência - $\mathrm{kN} / \mathrm{kW}$ ) é um fator extremamente importante na sua seleção e projeto. Para ilustrar a importância deste fator, cita-se por exemplo o navio de perfuração Pélican operando no Mar do Norte, no qual a potência consumida pelo sistema de posicionamento dinâmico é da ordem de metade da potência elétrica total instalada (Fä̈, 1990).

Por isso, soluções como bocais, que aumentam o empuxo e a eficiência dos propulsores, são bastante difundidas. A utilização de acionamento direto também tem sido empregada, na medida em que elementos de transmissão mecânica em ângulo reto possuem perda por atrito de aproximadamente $2 \%$ e devem ser evitados. Em geral, a 
eficiência mecânica dos propulsores varia de $80 \%$ a 90\% (Fossen, 1994). Valores de eficiência característicos e comumente aplicados em projetos de SPDs são : 0,14$0,17 \mathrm{kN} / \mathrm{kW}$ para propulsores em bocais e $0,12-, 014 \mathrm{kN} / \mathrm{kW}$ para propulsores em túnel ou abertos.

Outra tendência é a utilização de motores diesel para o acionamento direto dos propulsores, o que apresenta dificuldades relacionadas ao controle de rotação.

Nesta seção será exposto um modelo simplificado da dinâmica do sistema de propulsão, a fim de se incluir no simulador sua resposta a comandos do sistema de controle. Objetiva-se, com isso, determinar se o atraso entre o comando e a resposta interfere no desempenho do sistema de posicionamento dinâmico. Adicionalmente, através desta modelagem, pode-se estimar a potência gasta pelo sistema, já que as curvas características dos propulsores também são consideradas.

A análise será restrita ao caso de propulsores com passo fixo acionado por motores elétricos.

\subsubsection{Modelo hidrodinâmico do propulsor}

A abordagem tradicional para o cálculo da força e do torque atuantes em um propulsor baseia-se em dados de ensaios em água aberta ${ }^{12}$ a partir dos quais obtêm-se as curvas características do propulsor. Estas curvas são definidas em termos do coeficiente adimensional de avanço $J_{0}$, dado por:

$$
J_{0}=\frac{V_{P}}{n_{P} D_{P}}
$$

sendo $V_{P}$ a velocidade de avanço do propulsor (ou a velocidade da correnteza projetada na entrada do propulsor), $n_{P}$ a rotação (em rps) e $D_{P}$ o seu diâmetro.

Num sistema de posicionamento dinâmico, a velocidade $V_{P}$ é, em geral, tomada como a velocidade à montante de cada propulsor projetada na direção de seu eixo. Como estas velocidades são, em geral, baixas, o coeficiente $J_{0}$ possui valores pequenos.

\footnotetext{
${ }^{12}$ Ensaios realizados com o sistema propulsor isolado do casco.
} 
Através dos ensaios em água aberta, obtêm-se os coeficientes de torque $K_{Q}$ e de empuxo $K_{T}$, funções do coeficiente de avanço $J_{0}$, definidos por:

$$
K_{T}=\frac{T_{\text {Prop }}}{\rho\left|n_{P}\right| n_{P} D_{P}^{4}} \quad K_{Q}=\frac{Q_{\text {Prop }}}{\rho\left|n_{P}\right| n_{P} D_{P}^{5}}
$$

sendo $\rho$ a densidade da água, $T_{\text {Prop }}$ o empuxo e $Q_{\text {Prop }}$ o torque hidrodinâmico no propulsor.

Propulsores em bocais possuem um empuxo adicional devido ao efeito do bocal, projetado para produzir um empuxo positivo na presença do escoamento induzido pelo propulsor. Este efeito é modelado pelo coeficiente $K_{T N}=T_{N} / \rho\left|n_{P}\right| n_{P} D_{P}{ }^{4}$ (Lewis, 1988), onde o índice $\mathrm{N}$ refere-se ao bocal (nozzle).

A determinação dos coeficientes $K_{T}, K_{Q}$ e $K_{T N}$ é feita através de ensaios experimentais em água aberta. Em Lewis (1988) as curvas características de diversas séries de propulsores são tabeladas por meio de aproximações polinomiais. Como exemplo, são apresentadas, na Figura 3.26, as curvas para um propulsor em bocal da série Ka utilizando um bocal No.19A, com $2 \mathrm{~m}$ de diâmetro e passo ${ }^{13} 1,6 \mathrm{~m}$.

O aumento do empuxo promovido pelo bocal é de aproximadamente $50 \%$ na região de baixa velocidade ( $J_{0}$ próximo de 0 ) confirmando assim a eficiência deste recurso. Verifica-se pelas curvas da Figura 3.26 que para baixas velocidades na entrada do propulsor $\left(V_{P}\right)$, um aumento da velocidade implica uma diminuição do empuxo, sendo o torque aproximadamente constante. Logo, a eficiência do propulsor diminui.

\footnotetext{
${ }^{13} \mathrm{O}$ passo é definido como a distância de avanço de uma helicóide suportada pela superfície da pá, na direção do eixo de rotação.
} 


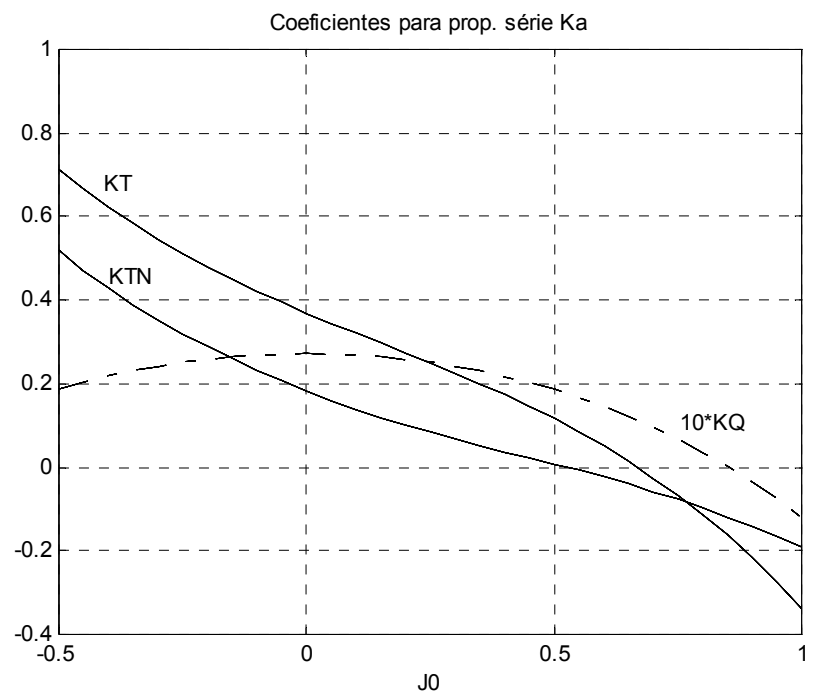

Figura 3.26 Curvas dos coeficientes de propulsor série Ka e bocal 19A. Passo 1,6m e diâmetro $2 \mathrm{~m}$.

Este efeito pode ser confirmado pelas curvas da Figura 3.27, que mostram a eficiência do propulsor exemplificado (em kN/kW) em função da potência. Supõe-se um rendimento eletromecânico de $80 \%$, ou seja, a potência elétrica consumida é calculada por $Q_{\text {Prop }} . n_{P} .(2 \pi) / 80 \%$. Pode-se verificar que para uma velocidade menor $(0,5 \mathrm{~m} / \mathrm{s})$ a eficiência é maior para toda a faixa de operação do propulsor se comparada a uma velocidade do fluxo de entrada de $1,2 \mathrm{~m} / \mathrm{s}$. Pode ser notado também que a eficiência decresce com o aumento da rotação dos propulsores, atingindo um valor mínimo de aproximadamente $0,175 \mathrm{kN} / \mathrm{kW}$ para velocidade de avanço de $1,2 \mathrm{~m} / \mathrm{s}$ e $0,2 \mathrm{kN} / \mathrm{kW}$ para velocidade de $0,5 \mathrm{~m} / \mathrm{s}$.

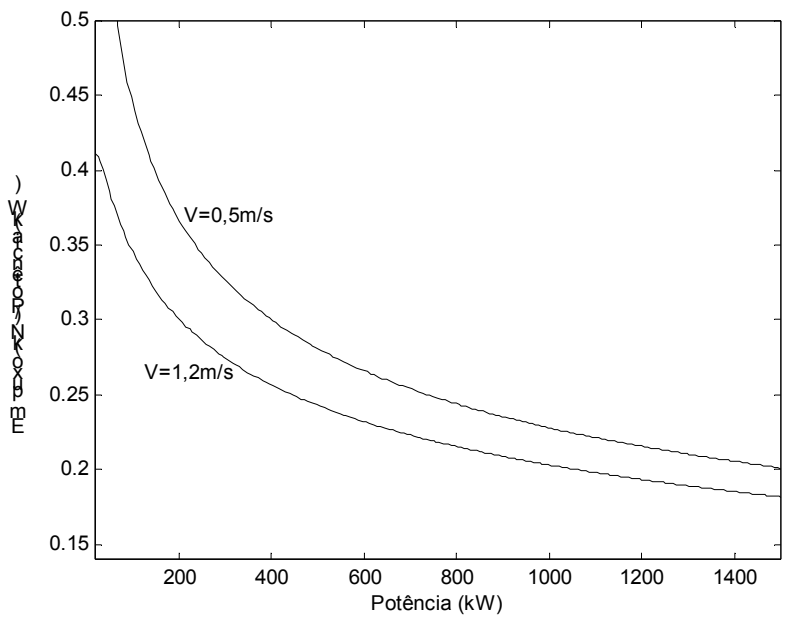

Figura 3.27 Eficiência do propulsor série Ka e bocal 19A (Passo 1,6m e diâmetro 2m) para duas velocidades $\mathbf{V}$ 


\subsubsection{Modelo do sistema de controle do propulsor}

O eixo do propulsor é sujeito ao torque elétrico fornecido pelo motor $\left(Q_{e}\right)$ e ao torque resistente hidrodinâmico $\left(Q_{\text {Prop }}\right)$. Sendo $I$ o momento de inércia das estruturas girantes, incluindo o propulsor, o eixo e a inércia hidrodinâmica adicional, pode-se escrever:

$$
\dot{n}_{P}=\frac{1}{2 \pi I}\left(Q_{e}-Q_{\text {Prop }}\right)
$$

lembrando-se que $n_{P}$ é a rotação (rps). Inserindo-se (3.50) em (3.51) obtém-se:

$$
\dot{n}_{P}=\frac{1}{2 \pi I}\left(Q_{e}-\rho D_{P}^{5} K_{Q} n_{P}\left|n_{P}\right|\right)
$$

que representa a dinâmica do eixo do propulsor.

Linearizando-se a equação (3.52) em torno de um ponto de operação (rotação $n_{P}{ }^{\prime}$, $\left.K_{Q}\left(n_{P}{ }^{\prime}\right)=K_{Q}{ }^{\prime}\right)$ pode-se obter uma estimativa de sua constante de tempo, denominada de constante de tempo mecânica. Utilizando o mesmo propulsor da Figura 3.26, supondo uma inércia total de $1300 \mathrm{~kg} . \mathrm{m}^{2}$ e operação em torno de $3 \mathrm{rps}$, a constante de tempo $\tau_{\text {mec }}=\pi I /\left(\rho D_{P}^{5} K_{Q}{ }^{\prime} n_{P}{ }^{\prime}\right)$ é, aproximadamente, $2 \mathrm{~s}$.

Um modelo acurado deveria levar em conta também a dinâmica do sistema elétrico que gera o torque de acionamento $Q_{e}$. Segundo Hansen; Lauvdal; Ådnanes (2000), a constante de tempo elétrica do sistema é menor que 50ms, bem menor, portanto, que a constante de tempo mecânica, a qual, como visto, é da ordem de segundos.

Os autores realizaram também comparações entre medições em escala real e resultados de simulações utilizando o modelo simplificado (desconsiderando a dinâmica do sistema elétrico) e o modelo completo. Concluíram que para se obter a rotação, empuxo e potência do propulsor o modelo simplificado é adequado, fornecendo resultados tão próximos das medidas quanto os do modelo completo. Além disso, o 
modelo simplificado possui menos parâmetros a ajustar e requer menor tempo de simulação.

Assim, a geração do torque elétrico pode ser considerada como instantânea, desprezando-se sua dinâmica, e a variável $Q_{e}$ pode ser considerada a variável de controle do sistema.

Para que o empuxo fornecido pelo propulsor acompanhe o empuxo comandado pelo algoritmo de alocação, deve existir uma realimentação (malha fechada). Tradicionalmente, a referência de empuxo $\left(T_{r e f}\right)$ é transformada em uma referência de rotação $\left(n_{r e f}\right)$ por meio da curva característica $K_{T}$. Devido a dificuldades de medição ou estimativa da velocidade a montante de cada propulsor, admite-se, em geral, operação em torno da velocidade de avanço nula, ou seja:

$$
n_{\text {ref }}=\operatorname{sinal}\left(T_{r e f}\right) \sqrt{\frac{\left|T_{r e f}\right|}{\rho D_{P}{ }^{4} K_{T 0}}} ; \quad K_{T 0}=\left.K_{T}\right|_{J=0}
$$

Assim, realiza-se um controle de rotação, conforme o diagrama de blocos da Figura 3.28.

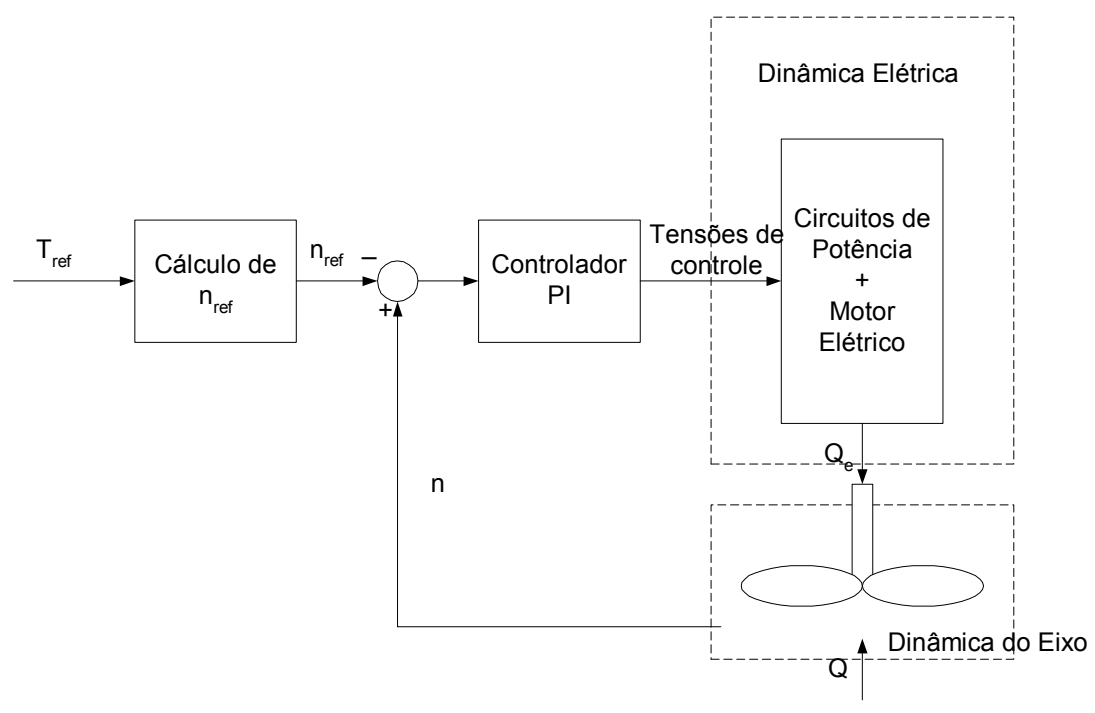

Figura 3.28 Diagrama de blocos do sistema de controle do propulsor - controle de rotação

A realimentação do próprio empuxo seria mais apropriada, na medida em que diversos efeitos já mencionados como interferência entre propulsores, interferência com 
casco e variação na velocidade do fluxo de entrada alteram a relação rotação-empuxo. Entretanto, a instalação de células de carga para este fim apresenta grandes dificuldades práticas, ligadas, por exemplo, à manutenção.

Assim, mesmo que a rotação do propulsor seja igual à comandada, o empuxo fornecido pode não ser igual ao requerido devido a estes efeitos não considerados em (3.53). Como ilustração, na Figura 3.29 apresenta-se a diferença porcentual entra o empuxo de comando e o empuxo fornecido utilizando-se o controle de rotação, considerando-se apenas efeitos de variação na velocidade de entrada do propulsor $\left(J_{0} \neq 0\right)$.

Uma faixa típica para o coeficiente $J_{0}$ na operação de sistemas de posicionamento dinâmico é de 0 a 0,1 , resultando portanto um erro máximo de $13 \%$ aproximadamente.

Uma possível solução para este problema seria a inclusão de estimativas destes efeitos durante o cálculo da rotação de referência, ou seja, utilizar uma estimativa mais acurada da velocidade de avanço no propulsor e também diagramas polares de interferência entre propulsores e de interferência com o casco.

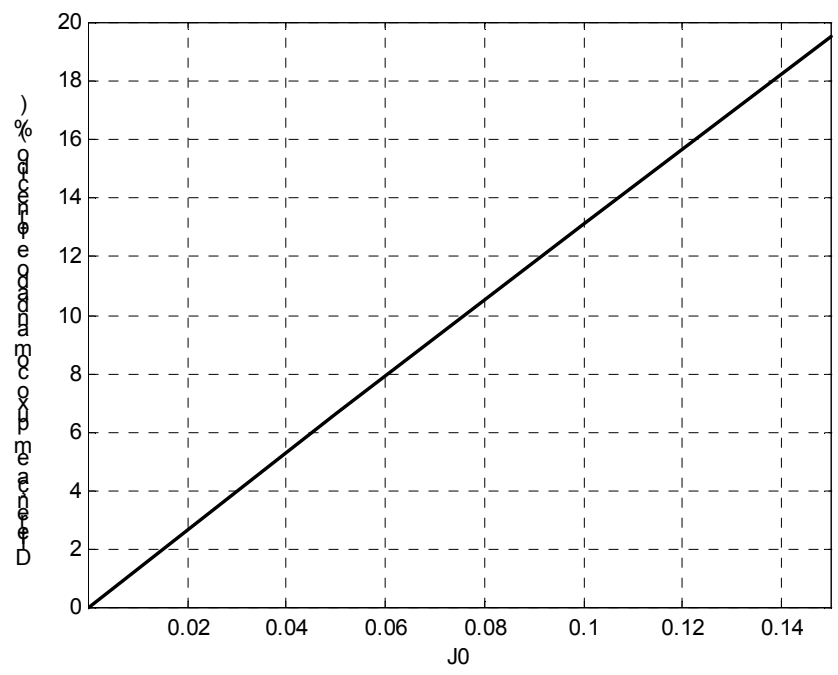

Figura 3.29 Diferença entre empuxo de comando $\left(T_{r e f}\right)$ e empuxo fornecido devido a variação da velocidade do fluxo na entrada do propulsor (série Ka e bocal 19A. Passo 1,6m e diâmetro 2m)

Sørensen et al. (1997) propuseram um método alternativo, no qual a referência de empuxo é transformada em referência de torque e potência, ao invés de rotação. $O$ controle é feito, portanto, através da realimentação do torque motriz ou da potência consumida. Estes autores avaliaram as funções sensibilidade dos três métodos de 
controle a reduções não modeladas no torque e empuxo e concluíram que os métodos propostos (controle de torque e potência) apresentam menor sensibilidade a tais efeitos não modelados.

Como o objetivo da presente análise é inserir no simulador o efeito do atraso entre o comando e a resposta dos propulsores, além de se incluir uma estimativa da potência gasta pelo sistema, os efeitos acima expostos não serão considerados no modelo. Admite-se que a rotação de referência tenha sido estimada através de um método mais acurado do que (3.53) no controle de rotação ou que se esteja utilizando o método de Sørensen et al. (1997).

Incluiu-se no simulador o controle de rotação conforme a Figura 3.28, e os ganhos do controlador PI são ajustados de forma que o tempo que o sistema leva para levar o propulsor da rotação nula para a máxima seja de $15 \mathrm{~s}$ (tempo de estabilização). Este tempo é típico em propulsores (ver por exemplo Faÿ, 1990 e Marintek, 1998). A Figura 3.30 apresenta a curva de resposta do propulsor utilizado anteriormente com controle de rotação.

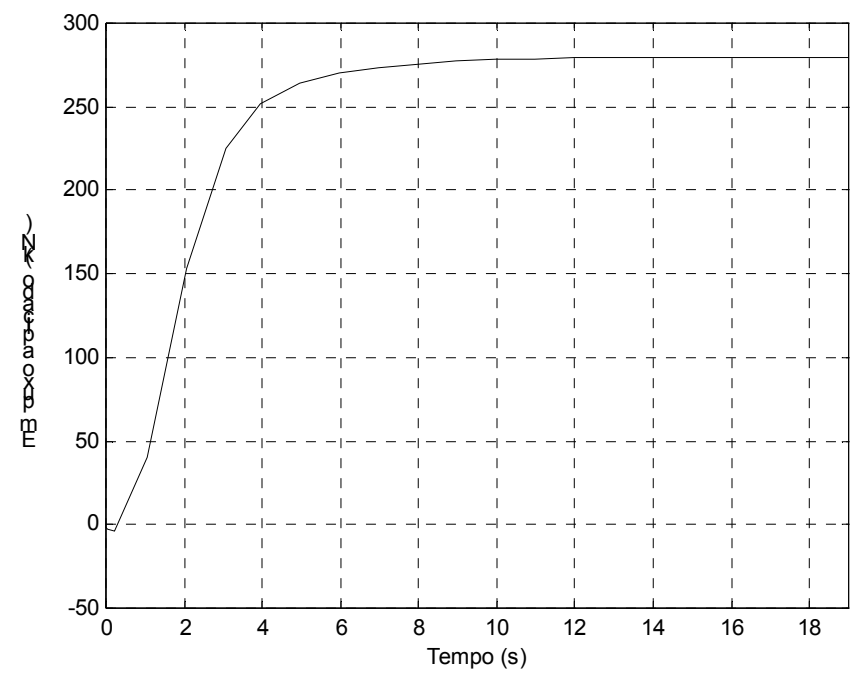

Figura 3.30 Empuxo aplicado pelo propulsor - referência igual ao empuxo máximo (280kN) 


\section{Controle}

Neste Capítulo são apresentados os desenvolvimentos relativos ao sub-sistema de controle realizados na presente tese.

$\mathrm{Na}$ seção 4.1 expõe-se o controlador de nível inferior, projetado através da metodologia de controle por modos deslizantes. Inicialmente (seção 4.1.1), expõem-se os fundamentos desta metodologia, aplicando-a a um caso simples de um sistema com uma única entrada. Por meio deste exemplo, os parâmetros do controlador são analisados e prova-se a estabilidade do sistema em malha fechada. O controlador é então estendido ao caso de múltiplas entradas.

Em seguida (seção 4.1.2) o modelo dos movimentos horizontais de baixa freqüência de uma embarcação, exposto na seção 3.1, é tratado para adequá-lo ao projeto do controlador por modos deslizantes. Baseado neste modelo, desenvolve-se, na seção 4.1.3, o modo de controle de aproamento com amortecimento dos movimentos de translação, que se baseia nas idéias do caso simples de um sistema com uma única entrada exposto anteriormente e cujo posicionamento é garantido pelas linhas de amarração. Na seção 4.1.4, desenvolve-se, também, um controlador combinado de posição e aproamento, utilizado em SPDs convencionais, utilizando-se a extensão do controlador para casos de múltiplas entradas. Ambos os controladores são robustos a erros de modelagem e de medição das condições ambientais, sendo que as estimativas destes erros são calculadas em seguida, na seção 4.1.5.

Na seção 4.2 expõe-se o projeto do controlador de nível superior, que implementa o modo de controle de aproamento ótimo. Alguns critérios operacionais que podem ser otimizados simultaneamente no presente modo de controle são apresentados e discutidos na seção 4.2.1, enfatizando-se o movimento de roll, tração dinâmica em risers, consumo de energia e deslocamento do sistema de amarração. Baseada nestes critérios, define-se na seção 4.2.2 uma função objetivo, cuja minimização fornece o aproamento ótimo do sistema. O modo de aproamento desenvolvido é aplicado, na seção 4.2.3, a um FPSO em turret sujeito a condições ambientais típicas da Bacia de Campos (RJ). Discussões adicionais a respeito da sensibilidade do aproamento ótimo relativamente a erros de estimativas das condições ambientais são feitas na seção 4.2.4, baseando-se no exemplo previamente analisado. 
Em seguida, na seção 4.3, apresentam-se e discutem-se três algoritmos de alocação de empuxo comumente utilizados nos SPDs e suas principais limitações. É feita uma comparação entre os mesmos utilizando-se o exemplo de uma barcaça de lançamento de linhas equipada com 6 propulsores azimutais.

Os filtros de ondas comumente empregados são, apresentados e discutidos na seção 4.4, com ênfase maior à abordagem adotada no simulador desenvolvido (filtro notch em cascata).

\subsection{Projeto do controlador de nível inferior}

Nesta seção será apresentado o projeto do controlador de nível inferior proposto, baseado na estratégia de modos deslizantes (Sliding Mode). O nível inferior do sistema recebe as informações do posicionamento real da embarcação (vindo do sistema de sensoriamento) e envia os sinais de atuação para os propulsores de forma a levá-la à posição calculada pelo nível superior.

Utiliza-se a metodologia de projeto de controle não-linear por modos deslizantes, desenvolvida em Utkin (1978), que se baseia no modelo não-linear completo do sistema e possui boas características de robustez, sendo adequada para casos de grandes incertezas e erros de modelagem. Através desta metodologia, mostra-se que é possível, ao menos em tese, alcançar um excelente desempenho em face de incertezas arbitrárias no modelo. Entretanto, este desempenho é obtido com esforços de controle elevados e muito oscilatórios. Uma modificação na metodologia original é então introduzida (Slotine, 1984) de forma a garantir esforços de controle razoáveis em detrimento de uma pequena degradação do desempenho global do sistema.

Uma grande vantagem deste controlador é a facilidade no ajuste dos parâmetros e sintonia do modelo utilizado no controle. Como será visto a seguir, a malha de realimentação requer no máximo três parâmetros por movimento, sendo que todos possuem interpretações físicas bastante claras, o que facilita o cálculo dos mesmos. Como o controlador é baseado no modelo completo não-linear do sistema, não requer um novo ajuste de parâmetros em caso de mudança de ponto de operação ou de variação das condições ambientais. No caso de controladores lineares convencionais aplicados a SPD, o ajuste dos ganhos de controle é uma tarefa bastante árdua. Um controlador LQ aplicado ao presente problema, por exemplo, requer duas matrizes de ganhos, que, 
supondo-as diagonais, requerem aproximadamente 12 parâmetros a serem ajustados. Estes não possuem interpretações físicas imediatas, utilizando-se muitas vezes regras práticas para seus ajustes, sendo necessário um esforço muito grande para refiná-los e assim obter a "melhor" solução. Além disso, sob variações do aproamento da embarcação em mais de $20^{\circ}$ aproximadamente, deve-se relinearizar o sistema, reprojetar o controle e reajustar os ganhos (Tannuri; Pesce, 2002).

No modelo do sistema, utilizado na malha de compensação direta (feed-forward), admitem-se faixas de erros, graças à robustez do controlador. Assim, não é necessária a realização exaustiva de testes no mar para a sintonia do modelo, como é feito nos controladores atuais baseados em modelo. O termo de robustez também garante o bom desempenho e estabilidade da malha de controle em face a erros nas estimativas das condições ambientais.

São desenvolvidas duas estratégias de controle, que serão aplicados aos diferentes casos analisados nas seções posteriores. Inicialmente, desenvolve-se o modo de controle de aproamento com amortecimento dos movimentos de translação. O controle do movimento de yaw é desacoplado dos movimentos de surge e sway, com uma função diferenciada em cada caso. Para os movimento de surge e sway, o controlador deve apenas atenuar as oscilações de baixa freqüência excitadas pelas forças de ondas de deriva lenta. As forças estáticas de correnteza, ondas (deriva média) e vento devem ser compensadas pelo sistema de amarração. Para estes movimentos, o controlador deverá atuar de forma a aumentar o amortecimento do sistema, diminuindo a amplitude do movimento do navio devida às forças de deriva lenta. A posição final de equilíbrio, entretanto, não será alterada pelo controlador, pois a mesma será dada pelo balanço entre as forças ambientais estáticas e as forças de restauração do sistema de amarração. Para o movimento de yaw, o controlador deve atuar de forma a manter um dado aproamento da embarcação, pois, como já citado, o controle de aproamento é fundamental para garantir a minimização dos esforços oscilatórios de primeira ordem em todo o sistema de amarração e risers. Esta estratégia de controle, como proposto em Strand; Sørensen; Fossen (1998), é típica de SPDs auxiliados por sistema de amarração (SPD assistido).

O controle de aproamento é feito por modos deslizantes, pois, para este movimento, a questão de robustez é fundamental já que o controlador deverá compensar os esforços ambientais, não perfeitamente conhecidos ou modelados. Para os 
movimentos de translação, as forças ambientais estáticas serão compensadas pelo sistema de amarração, e não pelo controlador, que possui o papel exclusivo de fornecer maior efeito de amortecimento ao sistema em malha fechada. Assim, utiliza-se um algoritmo de linearização por realimentação com termo extra proporcional à velocidade, que permite que o amortecimento do sistema em malha fechada alcance níveis desejados garantindo, assim, pequena resposta às forças de deriva lenta (Tannuri; Donha; Pesce, 2001 e Tannuri; Pesce; Donha, 2001b).

Em seguida, desenvolve-se o controlador combinado para movimentos de translação e rotação, que tem como objetivo acompanhar a posição e aproamento desejados (chamados de set-points), eliminando oscilações de baixa freqüência e offsets estáticos nos três movimentos horizontais. Para o caso de sistemas amarrados, a utilização deste tipo de controle não é adequada, pois com a escolha incorreta de uma referência de posição pode-se sobrecarregar o sistema de amarração (no caso dos propulsores atuando contra as forças de restauração) ou deixar de aproveitá-lo para contrabalançar esforços ambientais (no caso dos propulsores gerando esforços que poderiam ser gerados pelo efeito restaurador das linhas de amarração). Entretanto, em diversas aplicações de SPD este modo de controle é utilizado, como por exemplo em operações de perfuração, lançamento, FPSO sem amarração, etc. Mesmo em casos de sistemas amarrados, esta estratégia de controle pode ser aplicada para pequenas correções da posição do navio durante, por exemplos, operações de descarga (offloading). Esta estratégia de controle é implementada por meio de um controlador não-linear multivariável baseado em modos deslizantes.

Nos projetos dos controladores, pressupõe-se que os movimentos de baixa freqüência estejam disponíveis, incluindo a posição, aproamento, e suas respectivas velocidades. Na seção 4.4 discute-se em detalhes o filtro utilizado, responsável por eliminar os movimentos de alta freqüência das medidas, bem como possíveis técnicas de observação e estimação comumente aplicadas ao presente tipo de problema.

\subsubsection{Controle não-linear por modos deslizantes}

A metodologia de controle por modos deslizantes, conhecida como sliding mode control, foi desenvolvida na União Soviética na década de 70 (ver, por exemplo, Utkin, 1978), tendo sido empregada em diversos sistemas não-lineares. 
Considera-se um sistema descrito por equações de estado na qual uma das parcelas da entrada é descontínua através de uma hiper-superfície no espaço de estados. A metodologia se baseia no fato de que, se esta lei de controle for projetada de tal forma que todas as trajetórias do sistema convirjam para esta superfície, todas as trajetórias que se iniciam dentro da mesma permanecerão ali indefinidamente. Neste caso, as trajetórias permanecem "escorregando" pela superfície, que é então chamada de superfície de escorregamento (sliding surface). Evidentemente, a superfície de escorregamento deve ser definida convenientemente de forma que as trajetórias dentro da mesma se dirijam assintoticamente para os valores desejados (set-points). Nesta fase do movimento (dentro da superfície de escorregamento) diz-se que o sistema está em regime (modo) de escorregamento. A Figura 4.1 ilustra as trajetórias de um sistema com 3 estados.

A definição da superfície é feita apenas em função das variáveis de estado, sendo, portanto, insensível a perturbações na equação diferencial e a variações paramétricas. Assim, garantindo-se que, mesmo na presença destas perturbações e variações paramétricas, todas as trajetórias convirjam para a superfície de escorregamento, assegura-se que o sistema sempre convergirá para o estado desejado com erro (teoricamente) nulo. Como tal metodologia pode ser aplicada para sistemas não-lineares garantindo-se desempenho e estabilidade mesmo perante variações paramétricas e perturbações, ela é classificada como uma metodologia de controle robusto não-linear.

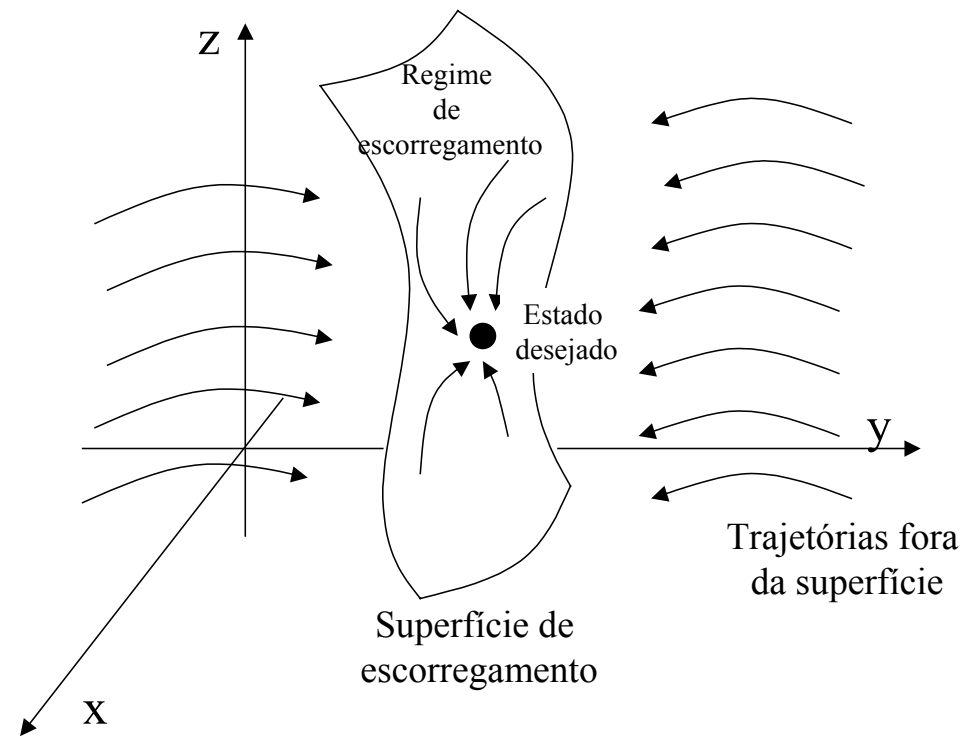

Figura 4.1 Trajetórias próximas a superfície de escorregamento 
Entretanto, da forma como fora proposta originalmente, esta metodologia possui alguns problemas que dificultam sua aplicação prática, relacionados aos elevados ganhos de controle e principalmente a existência de oscilações de alta freqüência (chaveamentos ${ }^{14}$ ) no esforço de controle. Este efeito é derivado do termo descontínuo da lei de controle, provocado pelo fato de que a ação de controle não é instantânea e por pequenas imprecisões numéricas. A Figura 4.2 ilustra uma trajetória sobre a superfície na ocorrência deste efeito, bem como o comportamento da ação de controle.

Slotine; Sastry (1983) desenvolveram adaptações na metodologia clássica para viabilizar sua implementação prática. Através da "suavização" do termo chaveado de controle, elimina-se o chattering, gerando, entretanto, um erro de acompanhamento que é tanto maior quanto maior for a incerteza a respeito do modelo utilizado.

Como será exposto a seguir, dados o modelo não-linear do sistema, limitantes superiores do erro de modelagem e a largura de banda para o sistema controlado, a metodologia resulta em um controle não-linear por realimentação com um dado erro máximo de acompanhamento. Este erro máximo, bem como a estabilidade do sistema, são garantidos caso o erro de modelagem não ultrapasse os limitantes impostos no projeto. O conceito de robustez fica bastante evidente, quantificado por grandezas simples e de fácil avaliação.

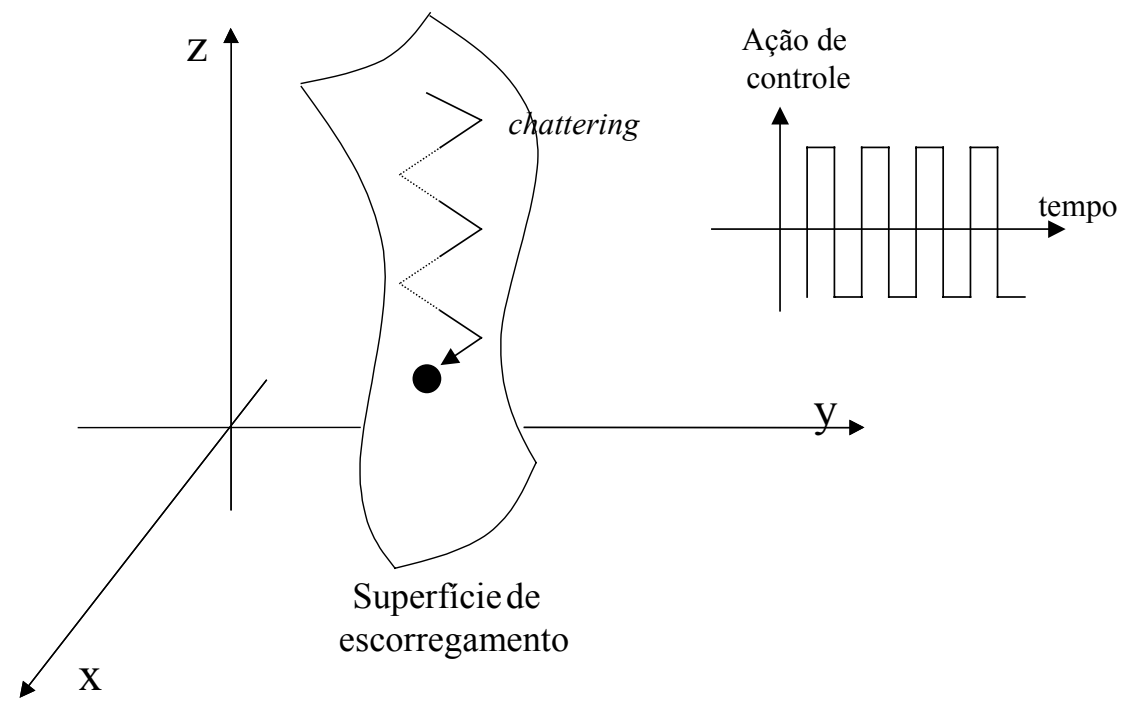

Figura 4.2 Efeito de chattering

${ }^{14} \mathrm{O}$ efeito de chaveamento (conhecido como chattering), é caracterizado por oscilações nas quais o
esforço de controle é levado do ponto superior ao ponto inferior de saturação a uma elevada freqüência. 
Esta metodologia foi aplicada com sucesso em diversos sistemas não-lineares, incluindo manipuladores robóticos (Slotine, 1985), sistemas de posicionamento de robôs submarinos (Yoerger; Newman; Slotine, 1986), controle de trajetórias de navios (Papoulias; Healey, 1992) e processos de polimerização (Fossen; Foss, 1991).

\subsubsection{Sistema com única entrada}

Uma ampla classe de problemas com uma única entrada, possuindo nãolinearidades associadas aos estados, porém lineares em relação à entrada, é descrita por:

$$
x^{(n)}=f(\mathbf{x}, t)+b(\mathbf{x}, t) u+d(t)
$$

no qual $\mathbf{x}$ é o vetor de estados do sistema, $\mathbf{x}=\left[\begin{array}{llll}x & \dot{x} & \ldots & x^{(n-1)}\end{array}\right]^{T}, x$ é a saída de interesse (por exemplo, a posição de um sistema mecânico), $u$ é a entrada de controle (por exemplo, um torque ou uma força), $d(t)$ é um distúrbio e as funções genéricas $f(\mathbf{x}, t)$ e $b(\mathbf{x}, t)$ são conhecidas com uma faixa limitada de incertezas.

Sendo $\mathbf{x}_{\mathbf{d}}(t)$ os valores desejados para os estados, o erro de acompanhamento é dado por $\widetilde{\mathbf{x}}=\mathbf{x}-\mathbf{x}_{\mathbf{d}}$. O problema de controle a ser tratado resume-se em fazer os estados $\mathbf{x}$ acompanharem $\mathbf{x}_{\mathbf{d}}(t)$ mesmo na presença de imprecisões nas funções $f(\mathbf{x}, t)$ e $b(\mathbf{x}, t)$ e do distúrbio $d(t)$.

Define-se a superfície de escorregamento $S(t)$ no espaço $\mathbf{R}^{\mathrm{n}}$ através da equação $s(\mathbf{x}, t)=0$, sendo $s$, por sua vez, definido pelo seguinte operador:

$$
s(\mathbf{x}, t)=\left(\frac{d}{d t}+\lambda\right)^{n-1} \widetilde{\mathbf{x}}
$$

no qual $\lambda$ é uma constante positiva. Por exemplo, para $n=2$, a equação (4.2) se reduz a $s=\dot{\widetilde{x}}+\lambda \widetilde{x}$, e a superfície de escorregamento é ilustrada na Figura 4.3. Por (4.2), conclui-se que o erro em malha fechada $\widetilde{\mathbf{x}}$ é a saída de um filtro passa baixa aplicado sobre a variável $s$, sendo $\lambda$ a freqüência de corte do filtro. 


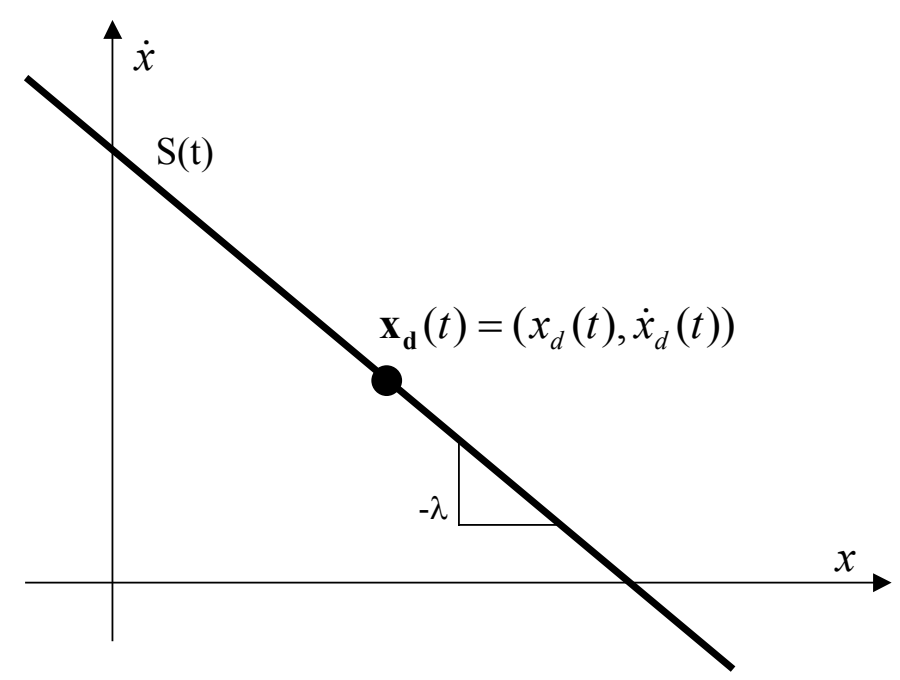

Figura 4.3 Superfície de escorregamento para o caso $n=2$ (adaptado de Slotine; Li, 1991)

O problema de acompanhamento $\left(\mathbf{x}=\mathbf{x}_{d}\right)$ é equivalente ao de se manter a trajetória do sistema em $S(t)$, já que $s=0$ é uma equação diferencial cuja solução decai exponencialmente para $\widetilde{\mathbf{x}}=0$. Ou seja, o problema de acompanhamento do vetor de estados de ordem $n$ é reduzido ao de manter a grandeza escalar $s$ nula.

Derivando-se (4.2) apenas uma vez aparece o termo $x^{(n)}$, no qual, substituindo-se (4.1) aparece a entrada $u$. Assim, o problema é de primeira ordem em $s$ possuindo a entrada de controle $u$. Por exemplo, para $\mathrm{n}=2$ :

$$
\dot{s}=\ddot{\widetilde{x}}+\lambda \dot{\widetilde{x}} \Rightarrow \dot{s}=f(x, \dot{x}, t)+b(x, \dot{x}, t) \cdot u+d(t)+\lambda \dot{\widetilde{x}}
$$

O módulo da variável $s$ representa uma medida da qualidade do acompanhamento, pois pode-se mostrar que existe uma relação entre $s$ e o erro de acompanhamento $\widetilde{\mathbf{x}}$ dada por (Slotine; Li , 1991):

$$
|s(t)|<\Phi \Rightarrow\left|\widetilde{x}^{(i)}(t)\right|<\frac{2^{i}}{\lambda^{n-i-1}} \Phi, \text { para qualquer } \Phi>0
$$

Por exemplo, o erro de posição $\tilde{x}$ é obtido substituindo-se $i=0$ em (4.3) resultando: 


$$
|s(t)|<\Phi \Rightarrow|\widetilde{x}(t)|<\frac{\Phi}{\lambda^{n-1}}
$$

Para que todas as trajetórias que se iniciam fora da superfície $S(t)$ convirjam para a mesma, deve-se escolher uma lei de controle que satisfaça a seguinte condição fora de $S(t)$, denominada "condição de escorregamento":

$$
\frac{1}{2} \frac{d}{d t} s^{2}<-\eta|s|
$$

na qual $\eta$ é uma constante positiva. Esta condição equivale a impor que a distância à superfície $S(t)$, medida por $s^{2}$, diminua para todas as trajetórias.

A convergência das trajetórias à superfície $S(t)$ é garantida pelo Lema de Barbalat para análise de estabilidade. Projetando um controle $u$ que satisfaça a condição (4.5), a função $V(s, t)=1 / 2 s^{2}$ (que é limitada inferiormente) terá derivada negativa semidefinida. Assim, aplicando-se o Lema de Barbalat, conclui-se que $\dot{V}(s, t) \rightarrow 0$, o que é equivalente, novamente utilizando-se (4.5), a $s \rightarrow 0$.

A velocidade de convergência está ligada ao parâmetro $\eta$. Mostra-se (Slotine; Li, 1991) que, iniciando-se de uma condição $\mathbf{x}(0)$ diferente de $\mathbf{x}_{d}(0)$ (o que equivale a $s(0) \neq 0$ ), o tempo para que o sistema controlado atinja a superfície $S(t)$ é dado por (fase de aproximação):

$$
t_{\text {alcance }} \leq \frac{|s(0)|}{\eta}
$$

Uma vez atingida a superfície, o erro de acompanhamento tende exponencialmente para 0 pois, a partir daí, o sistema passa a respeitar a dinâmica dada por (4.2). A representação gráfica das trajetórias, para o caso $n=2$, é ilustrada na Figura 4.4 . 


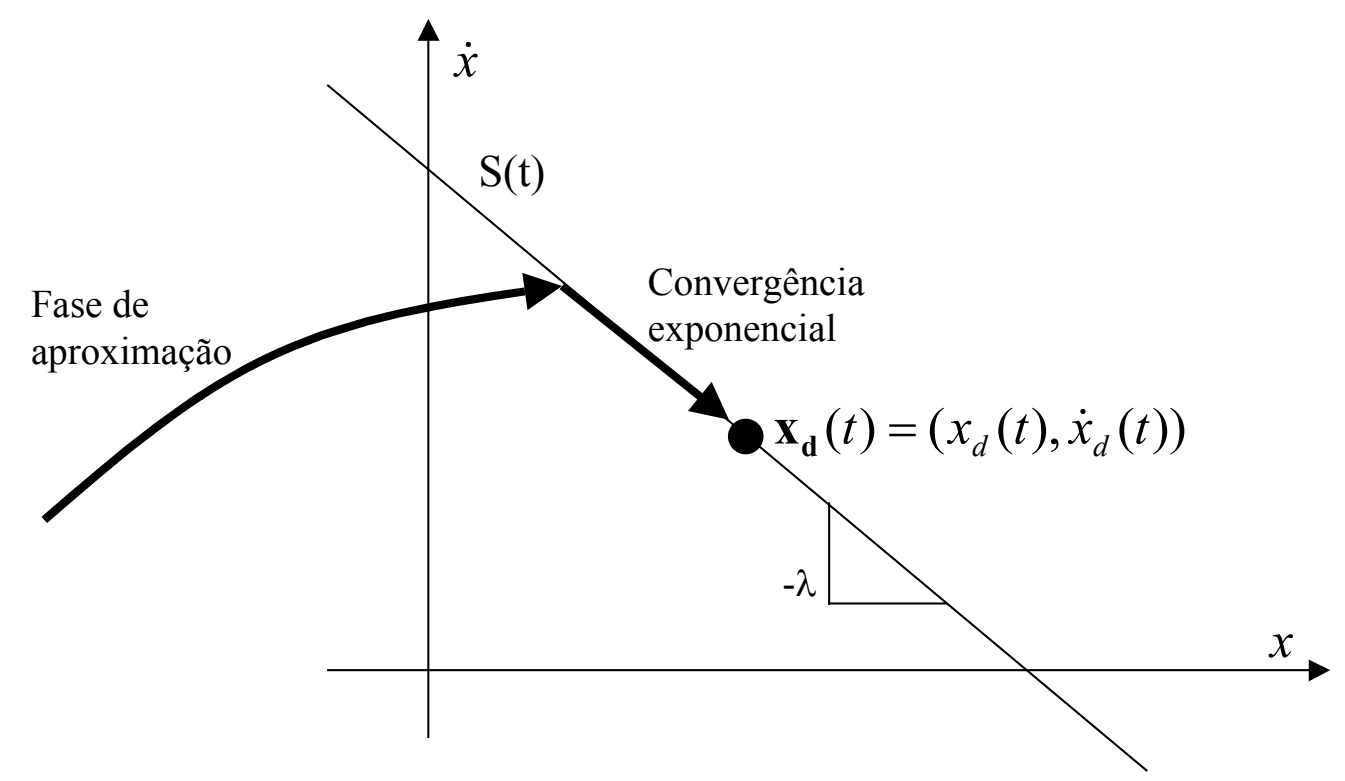

Figura 4.4 Trajetória típica de sistema controlado para caso $n=2$ (adaptado de Slotine; Li, 1991)

O cálculo da lei de controle $u$ que satisfaz (4.5) será ilustrado para o caso de um sistema de $2^{a}$ ordem com uma única entrada. A generalização dos resultados aqui apresentados é obtida de forma bastante simples (ver por exemplo Slotine, 1984), sendo que os principais conceitos e metodologias podem ser facilmente extrapoladas pelos resultados aqui apresentados. A extensão para o caso de múltiplas entradas será apresentada na próxima seção.

Considera-se, por ora, um sistema de $2^{\mathrm{a}}$ ordem dado por:

$$
\ddot{x}=f(x, \dot{x}, t)+u(t)+d(t)
$$

no qual $f(x, \dot{x}, t)$ é uma função não-linear genérica do estado e do tempo, não conhecida exatamente, com $\hat{f}(x, \dot{x}, t)$ seu valor estimado e $F(x, \dot{x}, t)$ o limitante superior do erro de modelagem:

$$
|\hat{f}(x, \dot{x}, t)-f(x, \dot{x}, t)|<F(x, \dot{x}, t)
$$


A partir deste ponto a dependência das funções $f, \hat{f}$ e $\mathrm{F}$ em relação às variáveis $(x, \dot{x})$ e ao tempo $t$ será suprimida por simplicidade de notação. $d(t)$ é uma perturbação variante no tempo com limitante superior $D(t)$ tal que:

$$
D(t) \geq|d(t)|
$$

sendo que a dependência das funções $d$ e $D$ em relação ao tempo $t$ será também suprimida a partir deste ponto.

Neste caso, a superfície $S(t)$ é definida por $s(t)=0$, sendo $s(t)$ dada em (4.2). Derivando-se (4.2) em relação ao tempo obtém-se:

$$
\dot{s}=\ddot{x}-\ddot{x}_{d}+\lambda \dot{\widetilde{x}}=f+u+d-\ddot{x}_{d}+\lambda \dot{\widetilde{x}}
$$

na qual foram omitidas as dependências funcionais, por simplicidade de notação. Assim, na ausência de erros de modelagem e de perturbações, o controle que forneceria um perfeito acompanhamento do estado desejado seria:

$$
\hat{u}=-\hat{f}+\ddot{x}_{d}-\lambda \dot{\tilde{x}}
$$

Este termo $\hat{u}$ equivale ao termo de linearização por realimentação. Para se considerar as incertezas do modelo, acrescenta-se um termo descontínuo através da superfície $S$ :

$$
u=\hat{u}-k(x, \dot{x}, t) \cdot \operatorname{sinal}(s)
$$

na qual $k$ representa o ganho do termo chaveado, a ser calculado através da condição de escorregamento (4.5). Sendo:

$$
\frac{1}{2} \frac{d}{d t} s^{2}=\dot{s} . s=[f-\hat{f}-k \cdot \operatorname{sinal}(s)] s=(f-\hat{f}+d) s-k|s|,
$$


a condição (4.5) será satisfeita para todos os valores admissíveis de $f$ e de $d$ se:

$$
k(x, \dot{x}, t)=F(x, \dot{x}, t)+D(t)+\eta
$$

Um resultado similar pode ser obtido em casos em que uma parcela de controle integral é necessária. A variável de interesse deve ser, então, $\int_{0}^{t} \widetilde{x}(r) d r$, e o sistema (4.7) torna-se agora de $3^{\text {a }}$ ordem relativamente a esta variável. A equação (4.2) fornece então:

$$
s=\left(\frac{d}{d t}+\lambda\right)^{2}\left(\int_{0}^{t} \tilde{x}(r) d r\right)=\dot{\widetilde{x}}+2 \lambda \tilde{x}+\lambda^{2} \int_{0}^{t} \tilde{x}(r) d r
$$

O novo termo de linearização por realimentação é dado por:

$$
\hat{u}=-\hat{f}+\ddot{x}_{d}-2 \lambda \dot{\widetilde{x}}-\lambda^{2} \tilde{x}
$$

Como esperado, a lei de controle (4.12) possui um termo descontínuo através da superfície $S(t)$, semelhante a um controle "liga-desliga" na variável $s$, e quanto maior o erro de modelagem e a perturbação, maior é este termo (ver equação (4.13)). Assim, pode ocorrer uma oscilação elevada de alta freqüência na ação de controle quando o sistema está próximo à superfície $S(t)$. Esta oscilação excita modos não modelados (modos de altas freqüências) além de causar danos nos atuadores, não sendo desejada na maioria dos casos. Para contornar este problema, "suaviza-se" a função sinal utilizada na lei de controle, definindo-se uma "camada limite" de largura $\Phi$ em torno da superfície $S(t)$ dentro da qual ocorre a transição de sinal (Figura 4.5). 


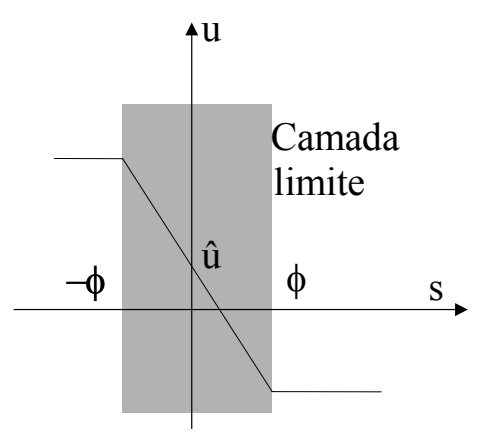

Figura 4.5 Suavização da lei de controle para evitar chattering (adaptado de Slotine; Li, 1991)

Utiliza-se portanto:

$u=\hat{u}-k \cdot \operatorname{sat}(s / \Phi)$

$\operatorname{sendo} \operatorname{sat}(y)=\left\{\begin{array}{cc}y & |y| \leq 1 \\ \operatorname{sinal}(y) & |y|>1\end{array}\right.$.

Para que seja avaliado o melhor valor para a largura da camada limite $\Phi$, deve-se reescrever a dinâmica da variável $s$, dada em (4.10), utilizando o novo controle (4.16), quando a mesma encontra-se dentro da camada limite, ou seja, quando $\operatorname{sat}(s / \Phi)=s / \Phi$ :

$$
\dot{s}=-k(x, \dot{x}, t) \frac{s}{\Phi}+(f(x, \dot{x}, t)-\hat{f}(x, \dot{x}, t)+d(t))
$$

Como, fora da camada limite, o controle u satisfaz a relação (4.5), as trajetórias são convergentes para a camada, o erro de acompanhamento fica limitado por $\varepsilon$ tal que:

$$
|\widetilde{x}(t)|<\frac{\Phi}{\lambda}=\varepsilon
$$


Definindo-se $\Delta f=f-\hat{f}$ e supondo-se que todas as funções sejam contínuas, a dinâmica da variável $s$ pode ser reescrita como:

$$
\dot{s}=-k\left(x_{d}, \dot{x}_{d}, t\right) \frac{s}{\Phi}+\left(\Delta f\left(x_{d}, \dot{x}_{d}, t\right)+d(t)+O(\varepsilon)\right)
$$

na qual está implícita a hipótese de que os estados do sistema controlado irão acompanhar os valores desejados $\left(x(t) \cong x_{d}(t)\right.$ e $\dot{x}(t) \cong \dot{x}_{d}(t)$ para todo $\left.t\right)$.

Assim, a variável $s$ é a saída de um filtro passa baixa de primeira ordem, cujas entradas dependem do erro de modelagem $(\Delta f)$ e dos distúrbios $(d(t))$. Com isso mostrase que o fenômeno de chattering é realmente eliminado através da camada limite.

Como já exposto, o erro em malha fechada $\widetilde{\mathbf{x}}$ é a saída de um filtro passa baixa com freqüência de corte $\lambda$ aplicado sobre a variável $s$. O cálculo da largura da camada limite $\Phi$ é feito de forma que o filtro (4.19) também possua freqüência de corte $\lambda$. Assim, utiliza-se a relação:

$$
\Phi=\frac{\max \left(k\left(x_{d}, \dot{x}_{d}, t\right)\right)}{\lambda}
$$

que pode ser calculada antes da aplicação da lei de controle. Este enfoque resulta uma espessura da camada constante ao longo do tempo, calculada baseando-se no maior valor do ganho $k$ ao longo da trajetória. Slotine; Li (1991) propuseram um método para o cálculo da espessura da camada limite variável no tempo. Com isso, nos instantes de menor incerteza a respeito do modelo (representada por menores valores no ganho $k$ ), a espessura pode ser reduzida, diminuindo-se o erro de acompanhamento dado em (4.18). Este método não foi implementado no presente trabalho, pois os resultado obtido com a espessura constante são bastante satisfatórios, conforme será visto no Capítulo 6 .

Substituindo-se (4.20) em (4.18) obtém-se:

$$
\varepsilon \lambda^{2}=\max \left(k\left(x_{d}, \dot{x}_{d}, t\right)\right)
$$


o qual afirma que quanto maior o erro de modelagem (implícito no cálculo de $k$ ), maior será o erro de acompanhamento esperado, a não ser que a largura de banda do sistema em malha fechada $(\lambda)$ possa ser aumentada.

Entretanto, a largura de banda do sistema em malha fechada não pode ser aumentada indefinidamente. Em Slotine; Li (1991), são fornecidas algumas regras práticas para o ajuste da mesma, como por exemplo:

1. a largura de banda deve ser menor que a freqüência do primeiro modo ressonante não modelado do sistema

2. a largura de banda deve ser menor que $1 / 3$ do inverso dos atrasos de transporte não incluídos no modelo

3. a largura de banda deve ser menor que $1 / 5$ da taxa de amostragem do sistema.

\subsubsection{Generalização para o caso com múltiplas entradas}

Considera-se agora um sistema não-linear com múltiplas entradas na forma:

$$
x_{i}^{\left(n_{i}\right)}=f_{i}(\mathbf{x}, t)+d_{i}(t)+\sum_{j=1}^{m} b_{i j}(\mathbf{x}, t) u_{j}
$$

sendo $u_{j}$ as entradas do sistema, $\mathbf{x}$ o vetor de estados composto pelas componentes controladas $x_{i}$ e suas primeiras $n_{i}-1$ derivadas com respeito ao tempo e $d_{i}$ os distúrbios. Será feita a restrição de que o sistema seja quadrado, ou seja, tenha o mesmo número de entradas e de variáveis controladas $(i=1, \ldots, \mathrm{m} ; j=1, \ldots, \mathrm{m})$. Para um sistema mecânico, por exemplo, cada componente controlada $x_{i}$ equivale à posição relativa a um grau de liberdade do sistema.

Os erros de modelagem e os distúrbios são limitados por:

$$
\begin{aligned}
& \left|\hat{f}_{i}-f_{i}\right| \leq F_{i} \\
& \left|d_{i}\right| \leq D_{i}
\end{aligned}
$$


Não serão considerados os erros nas funções $b_{i j}$, já que no problema tratado no presente trabalho estes erros são desprezíveis perante os erros nas funções $f_{i}$, como será mostrado na seção 4.1.2. Sendo $\tilde{x}_{i}=x_{i}-x_{d i}$, as variáveis $s_{i}$ que definem a superfície $S(t)$ serão dadas por:

$$
s_{i}=\left(\frac{d}{d t}+\lambda_{i}\right)^{\left(n_{1}-1\right)} \tilde{x}_{i}
$$

No caso de um sistema mecânico, $n_{i}=2$ para todo $i$, pois as equações dinâmicas são escritas nas segundas derivadas das variáveis de posição. A definição de $s_{i}$ fíca dada então por:

$$
s_{i}=\dot{\vec{x}}_{i}+\lambda_{i} \tilde{x}_{i}
$$

Sendo $\mathbf{u}=\left(\begin{array}{lll}u_{1} & \ldots & u_{m}\end{array}\right)^{T}, \mathbf{B}=\left\{b_{i j}\right\}, \hat{\mathbf{f}}=\left(\begin{array}{lll}\hat{f}_{1} & \ldots & \hat{f}_{m}\end{array}\right)^{T}, \mathbf{k} \operatorname{sgn}(\mathbf{s}) \quad$ o vetor com componentes $k_{i} \operatorname{sgn}\left(s_{i}\right)$ e $\quad \mathbf{x}_{\mathbf{r}}=\left(\begin{array}{llll}x_{d 1}-\lambda_{1} \widetilde{x}_{1} & \ldots & x_{d m}-\lambda_{m} \tilde{x}_{m}\end{array}\right)^{T}$, utiliza-se a lei de controle na forma:

$$
\mathbf{u}=\mathbf{B}^{-1}\left(-\hat{\mathbf{f}}+\dot{\mathbf{x}}_{\mathbf{r}}-\mathbf{k} \operatorname{sgn}(\mathbf{s})\right)
$$

Derivando-se (4.25) e substituindo-se em (4.22) e (4.26) vem:

$$
\dot{s}_{i}=f_{i}(\mathbf{x}, t)-\hat{f}_{i}(\mathbf{x}, t)-k_{i} \operatorname{sinal}\left(s_{i}\right),
$$

da qual se conclui que, se $k_{i} \geq \eta_{i}+F_{i}+D_{i}$, as condições de escorregamento $\frac{1}{2} \frac{d}{d t} s_{i}^{2}<-\eta_{i}\left|s_{i}\right|$ serão satisfeitas sempre. 


\subsubsection{Adaptações do modelo do sistema}

O modelo do movimento horizontal de baixa freqüência de uma embarcação no meio fluido (equação (3.9)) é tratado de forma a adequá-lo ao projeto do controlador de aproamento e do controlador combinado (translação e rotação), ambos realizados pela metodologia de modos deslizantes.

Como o controle é baseado no movimento de um ponto de referência genérico ao longo do eixo longitudinal do navio, cuja posição é dada pela coordenada $x_{R}$ (Figura 4.6), a equação (3.9) é reescrita em termos das acelerações e velocidades deste ponto, que são dadas por:

$$
\begin{aligned}
& \dot{x}_{1 R}=\dot{x}_{1} \\
& \dot{x}_{2 R}=\dot{x}_{2}+\dot{x}_{6} \cdot x_{R} \\
& \dot{x}_{6 R}=\dot{x}_{6}
\end{aligned}
$$

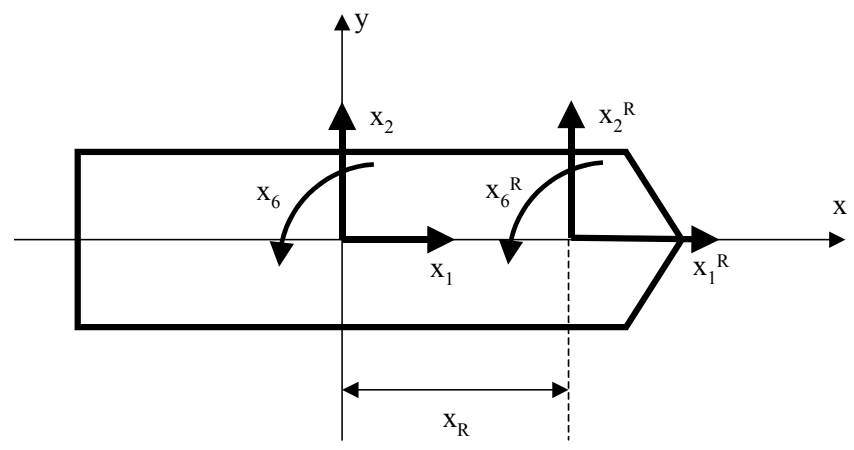

Figura 4.6 Ponto de referência genérico ao longo do eixo longitudinal

Da mesma forma, o sistema de forças $\left(F_{1}, F_{2}, F_{6}\right)$, com $F_{1}$ e $F_{2}$ aplicados na seção mestra é equivalente ao sistema $\left(F_{1 R}, F_{2 R}, F_{6 R}\right)$, com $F_{I R}$ e $F_{2 R}$ aplicados no ponto de referência se:

$$
\begin{aligned}
& F_{1 R}=F_{1} \\
& F_{2 R}=F_{2} \\
& F_{6 R}=F_{6}-F_{2} \cdot x_{R}
\end{aligned}
$$

Substituindo-se (3.6) em (3.9) obtém-se: 


$$
\begin{aligned}
& a_{1} \ddot{x}_{1 R}-a_{2} \dot{x}_{2 R} \dot{x}_{6 R}-a_{5} \dot{x}_{6 R}^{2}=F_{1 R E}+F_{1 R M}+F_{1 R T} ; \\
& a_{2} \ddot{x}_{2 R}+a_{5} \ddot{x}_{6 R}+a_{1} \dot{x}_{l R} \dot{x}_{6 R}=F_{2 R E}+F_{2 R M}+F_{2 R T} ; \\
& a_{3} \ddot{x}_{6 R}+a_{4} \ddot{x}_{2 R}+a_{4} \dot{x}_{1 R} \dot{x}_{6 R}=\left(F_{2 R E}+F_{2 R M}+F_{2 R T}\right) x_{R}+F_{6 R E}+F_{6 R M}+F_{6 R T} .
\end{aligned}
$$

com

$$
\begin{aligned}
& a_{1}=M+M_{11} \\
& a_{2}=M+M_{22} \\
& a_{3}=I_{Z}+M_{66}-\left(M_{26}+M x_{G}\right) x_{R} \\
& a_{4}=M x_{G}+M_{26} \\
& a_{5}=M x_{G}+M_{26}-\left(M+M_{22}\right) x_{R}
\end{aligned}
$$

Para o projeto do controlador no modo de controle de aproamento, é necessário que as acelerações sejam isoladas, o que é feito por meio de manipulações algébricas em (4.30), resultando:

$$
\begin{aligned}
& \ddot{x}_{1 R}=C_{11}\left(F_{1 R E}+F_{1 R M}+F_{1 R T}\right)+f_{1, \text { din }}\left(\dot{\mathbf{x}}_{\mathbf{R}}\right) \\
& \ddot{x}_{2 R}=C_{22}\left(F_{2 R E}+F_{2 R M}+F_{2 R T}\right)+C_{26}\left(F_{6 R E}+F_{6 R M}+F_{6 R T}\right)+f_{2, \text { din }}\left(\dot{\mathbf{x}}_{\mathbf{R}}\right) \\
& \ddot{x}_{6 R}=C_{62}\left(F_{2 R E}+F_{2 R M}+F_{2 R T}\right)+C_{66}\left(F_{6 R E}+F_{6 R M}+F_{6 R T}\right)+f_{6, \text { din }}\left(\dot{\mathbf{x}}_{\mathbf{R}}\right)
\end{aligned}
$$

com as constantes $C_{i j}$ representado a influência de cada força sobre os movimentos dadas por:

$$
\begin{array}{ll}
C_{11}=\frac{1}{a_{1}} & C_{22}=\frac{a_{3}-a_{5} x_{R}}{D} \\
C_{26}=-\frac{a_{5}}{D} & C_{62}=C_{26} \\
C_{66}=\frac{a_{2}}{D} & D=a_{2} a_{3}-a_{4} a_{5}
\end{array}
$$

e as funções $f_{i, d i n}$ contendo as seguintes componentes inerciais: 


$$
\begin{aligned}
& f_{1, \text { din }}\left(\dot{\mathbf{x}}_{\mathbf{R}}\right)=\frac{1}{a_{1}}\left(a_{2} \dot{x}_{2 R} \dot{x}_{6 R}+a_{5} \dot{x}_{6 R}^{2}\right) \quad f_{2, \text { din }}\left(\dot{\mathbf{x}}_{\mathbf{R}}\right)=\frac{-a_{3} a_{1}+a_{4} a_{5}}{D} \dot{x}_{1 R} \dot{x}_{6 R} \\
& f_{6, \text { din }}\left(\dot{\mathbf{x}}_{\mathbf{R}}\right)=\frac{a_{4}\left(a_{1}-a_{2}\right)}{D} \dot{x}_{1 R} \dot{x}_{6 R}
\end{aligned}
$$

Deve-se notar que os coeficientes $C_{i j}$ dependem apenas da massa, momento de inércia, massas adicionais e parâmetros geométricos.

Para o projeto do controlador no modo de controle combinado dos movimentos de translação e rotação, a equação do movimento deve estar escrita em função das coordenadas no sistema inercial $O X Y Z$. A posição do ponto de referência neste sistema de coordenadas é $\left(X_{R}, Y_{R}\right)$, sendo que a relação entre a velocidade e aceleração deste ponto no sistema de coordenadas $O x_{1} x_{2} x_{3}$ e no sistema $O X Y Z$ são dadas por:

$$
\begin{aligned}
& \dot{x}_{1 R}=\dot{X}_{R} \cos \psi+\dot{Y}_{R} \operatorname{sen} \psi \\
& \dot{x}_{2 R}=-\dot{X}_{R} \operatorname{sen} \psi+\dot{Y}_{R} \cos \psi \\
& \dot{x}_{6 R}=\dot{\psi} \\
& \ddot{x}_{1 R}=\ddot{X}_{R} \cos \psi+\ddot{Y}_{R} \operatorname{sen} \psi-\dot{X}_{R} \dot{\psi} \operatorname{sen} \psi+\dot{Y}_{R} \dot{\psi} \cos \psi \\
& \ddot{x}_{2 R}=-\ddot{X}_{R} \operatorname{sen} \psi+\ddot{Y}_{R} \cos \psi-\dot{X}_{R} \dot{\psi} \cos \psi-\dot{Y}_{R} \dot{\psi} \operatorname{sen} \psi \\
& \ddot{x}_{6 R}=\ddot{\psi}
\end{aligned}
$$

Substituindo-se (4.34) e (4.35) em (4.32) obtém-se o sistema de equações diferenciais procurado:

$$
\left(\begin{array}{c}
\ddot{X}_{R} \\
\ddot{Y}_{R} \\
\ddot{\psi}
\end{array}\right)=\left(\begin{array}{l}
f_{X, \text { din }}\left(\dot{\mathbf{X}}_{\mathbf{R}}\right) \\
f_{Y, \text { din }}\left(\dot{\mathbf{X}}_{\mathbf{R}}\right) \\
f_{\psi, \text { din }}\left(\dot{\mathbf{X}}_{\mathbf{R}}\right)
\end{array}\right)+\mathbf{C}\left(\begin{array}{c}
F_{1 R E}+F_{1 R M}+F_{1 R T} \\
F_{2 R E}+F_{2 R M}+F_{2 R T} \\
F_{6 R E}+F_{6 R M}+F_{6 R T}
\end{array}\right)
$$

no qual as funções devidas a efeitos inerciais são redefinidas como:

$$
\begin{aligned}
& f_{X, \operatorname{din}}\left(\dot{\mathbf{X}}_{\mathbf{R}}\right)=-\dot{Y}_{R} \dot{\psi}+f_{1, \text { din }}\left(\dot{\mathbf{X}}_{\mathbf{R}}\right) \cos \psi-f_{2, \text { din }}\left(\dot{\mathbf{X}}_{\mathbf{R}}\right) \operatorname{sen} \psi \\
& f_{Y, \text { din }}\left(\dot{\mathbf{X}}_{\mathbf{R}}\right)=\dot{X}_{R} \dot{\psi}+f_{1, \text { din }}\left(\dot{\mathbf{X}}_{\mathbf{R}}\right) \operatorname{sen} \psi+f_{2, \text { din }}\left(\dot{\mathbf{X}}_{\mathbf{R}}\right) \cos \psi \\
& f_{\psi, \text { din }}\left(\dot{\mathbf{X}}_{\mathbf{R}}\right)=f_{6, \text { din }}\left(\dot{\mathbf{X}}_{\mathbf{R}}\right)
\end{aligned}
$$


e a matriz $\mathbf{C}$ é dada por:

$$
\mathbf{C}=\left(\begin{array}{ccc}
C_{11} \cos \psi & -C_{22} \operatorname{sen} \psi & -C_{26} \operatorname{sen} \psi \\
C_{11} \operatorname{sen} \psi & C_{22} \cos \psi & C_{26} \cos \psi \\
0 & C_{62} & C_{66}
\end{array}\right)
$$

\subsubsection{Controle de aproamento}

O controle de aproamento tem como objetivo manter a embarcação com o aproamento próximo a um valor desejado (set-point). Os movimentos translacionais da embarcação são apenas amortecidos pelo controlador, não sendo estabelecida uma posição desejada para estes movimentos.

As forças de controle em surge e sway são implementadas por uma lei de controle de linearização por realimentação com um termo adicional proporcional à velocidade. Utilizando-se (4.32) conclui-se que:

$$
\begin{aligned}
& F_{1 R T}=\frac{1}{C_{11}}\left(-f_{1, \text { din }}\left(\dot{\mathbf{x}}_{\mathbf{R}}\right)-c_{1} \dot{x}_{1 R}\right) \\
& F_{2 R T}=\frac{1}{C_{22}}\left(-f_{2, \text { din }}\left(\dot{\mathbf{x}}_{\mathbf{R}}\right)-c_{2} \dot{x}_{2 R}\right)
\end{aligned}
$$

sendo os coeficientes $c_{1}, c_{2}$ ajustados para garantir amortecimento adequado aos movimentos. A dinâmica de translação em malha fechada será dada, então, por:

$$
\begin{aligned}
& \ddot{x}_{1 R}+c_{1} \dot{x}_{1 R}-C_{11} F_{1 R M}=C_{11} F_{1 R E} \\
& \ddot{x}_{2 R}+c_{2} \dot{x}_{2 R}+\left(-C_{22} F_{2 R M}-C_{26} F_{6 R M}\right)=C_{22} F_{2 R E}+C_{26}\left(F_{6 R E}+F_{6 R T}\right)
\end{aligned}
$$

que representam osciladores com rigidez não-linear dada pelas forças de restauração do sistema de amarração. Além disso, existem os termos de dissipação devidos ao sistema de amarração, que aumentam o amortecimento de tais movimentos, auxiliando, portanto, o controlador. As forças ambientais atuam como forças externas aos osciladores, sendo que o ponto de equilíbrio dos mesmos é dado pelo balanço entre a 
restauração do sistema de amarração e as forças ambientais. Os termos oscilatórios destas forças (deriva lenta) serão amortecidos pela ação do controlador. Devido ao acoplamento entre sway e yaw, o momento devido ao sistema de propulsão $X_{6 T}$ também interfere (como um termo de força externa) no movimento de sway.

O controlador do movimento de yaw deve compensar os esforços ambientais, garantindo que o aproamento acompanhe o valor desejado com grande precisão em face a erros e incertezas na modelagem de tais esforços. Como já explicado, utiliza-se a metodologia de modos deslizantes para o projeto deste controlador. Reescrevendo-se a terceira equação do sistema (4.32) no formato (3.40) obtém-se:

$$
\ddot{x}_{6 R}=f_{6}\left(\mathbf{X}_{\mathbf{R}}, \dot{\mathbf{x}}_{\mathbf{R}}\right)+C_{62} F_{2 R T}+C_{66} F_{6 R T}
$$

sendo

$$
f_{6}\left(\mathbf{X}_{\mathbf{R}}, \dot{\mathbf{x}}_{\mathbf{R}}\right)=f_{6, \text { din }}\left(\dot{\mathbf{x}}_{\mathbf{R}}\right)+C_{62}\left(F_{2 R E}+F_{2 R M}\right)+C_{66}\left(F_{6 R E}+F_{6 R M}\right)
$$

Utilizando o controlador por modos deslizantes dado em (4.13), (4.15) e (4.16) com um termo extra para eliminar a interferência da força de controle $F_{2 R T}$, obtém-se:

$$
F_{6 R T}=\frac{-C_{62}}{C_{66}} F_{2 R T}+\frac{1}{C_{66}}\left(-\hat{f}_{6}\left(\mathbf{X}_{\mathbf{R}}, \dot{\mathbf{x}}_{\mathbf{R}}\right)+\ddot{x}_{6 D}-2 \lambda \dot{\vec{x}}_{6 R}-\lambda^{2} \tilde{x}_{6 R}-k \cdot \operatorname{sat}(s / \Phi)\right)
$$

sendo $\hat{f}_{6}\left(\mathbf{X}_{\mathbf{R}}, \dot{\mathbf{x}}_{\mathbf{R}}\right)$ a estimativa para a função $f_{6}$ e $s=\dot{\tilde{x}}_{6 R}+2 \lambda \widetilde{x}_{6 R}+\lambda^{2} \int_{0}^{t} \widetilde{x}_{6 R} d \tau$, a variável que mede o erro de acompanhamento (com um termo integral). Os erros nas avaliações dos termos $C_{62}$ e $C_{66}$ são considerados pequenos em comparação aos erros na estimativa das funções $f_{6}\left(\mathbf{X}_{\mathbf{R}}, \dot{\mathbf{x}}_{\mathbf{R}}\right)$, pois os mesmos dependem apenas de grandezas bem conhecidas, como as massas adicionais em baixa freqüência e as propriedades de massa do navio. Em casos de navios petroleiros, nos quais a quantidade e a distribuição do óleo nos tanques altera as propriedades de massa do navio, deve-se prever um 
sistema de avaliação destes efeitos em tempo real, através de sistemas, acoplados ao SPD, de supervisão do nível de óleo em cada tanque.

Para que a condição (4.5) seja satisfeita, basta utilizar-se o ganho $k \geq \eta+\max \left|f_{6}-\hat{f}_{6}\right|$. Expandindo-se esta expressão e utilizando-se (4.41) obtém-se:

$$
\begin{gathered}
k \geq \eta+\left|C_{62}-C_{66} x_{R}\right|\left(\max \left|F_{2 E}-\hat{F}_{2 E}\right|+\max \left|F_{2 M}-\hat{F}_{2 M}\right|\right)+ \\
\left|C_{66}\right|\left(\max \left|F_{6 E}-\hat{F}_{6 E}\right|+\max \left|F_{6 M}-\hat{F}_{6 M}\right|\right)
\end{gathered}
$$

Assim, para a completa determinação da lei de controle, deve-se ter uma estimativa do erro de modelagem e imprecisões na força de sway e momento de yaw devido à ação ambiental e amarração. Estas estimativas são apresentadas na seção 4.1.5.

Uma análise detalhada da lei de controle (4.42) mostra que, excluindo-se o termo extra para eliminar a interferência de $F_{2 R T}$, é composta basicamente por duas ações básicas. A parcela $\hat{f}_{6}\left(\mathbf{X}_{\mathbf{R}}, \dot{\mathbf{x}}_{\mathbf{R}}\right)$ corresponde a malha de compensação direta dos esforços estimados devidos aos agentes ambientais e amarração.

As parcelas restantes implementam a malha de realimentação, responsável, principalmente, pelas correções de posicionamento não realizadas pela malha de compensação direta devido aos erros de modelagem. Enquanto a variável $s$, que representa uma medida do erro de posicionamento, apresentar valor absoluto menor que a espessura da camada limite $\Phi$, esta malha possui apenas ações proporcionais, derivativas e integrais, pois neste caso $\operatorname{sat}(s / \Phi)=s / \Phi$.

Utilizando-se a expressão (4.20), podem-se calcular os ganhos proporcional $(P)$, integral $(I)$ e derivativo $(D)$ do controlador, dados por:

$$
P=\lambda^{2}\left(1+2 \frac{k}{\max (k)}\right) ; I=\lambda^{3}\left(\frac{k}{\max (k)}\right) ; D=\lambda\left(2+\frac{k}{\max (k)}\right)
$$

Deve-se ressaltar que estes variam de acordo com a incerteza na modelagem, representada pelo ganho $k$, dado em(4.43). Assim, apresentam-se na Tabela 4.1 os 
ganhos para dois trechos distintos de uma suposta trajetória. No primeiro, o erro de modelagem é pequeno $(k \cong 0)$ e no segundo o erro é elevado $(k \cong \max (k))$.

Tabela 4.1 Ganhos da malha de realimentação

\begin{tabular}{|l|l|l|}
\hline Ganhos & $\begin{array}{l}\text { Pequeno erro } \\
\text { de modelagem }\end{array}$ & $\begin{array}{l}\text { Elevado erro de } \\
\text { modelagem }\end{array}$ \\
\hline $\mathrm{P}$ & $\lambda^{2}$ & $3 \lambda^{2}$ \\
\hline $\mathrm{I}$ & 0 & $\lambda^{3}$ \\
\hline $\mathrm{D}$ & $2 \lambda$ & $3 \lambda$ \\
\hline
\end{tabular}

Pode-se ver que no primeiro caso, a ação integral é nula, pois todos os esforços ambientais constantes ou lentamente variáveis são contrabalançados, idealmente, pelo termo de compensação direta $\hat{f}_{6}\left(\mathbf{X}_{\mathbf{R}}, \dot{\mathbf{x}}_{\mathbf{R}}\right)$. No segundo caso, a ação integral é significativa, pois deve compensar estes esforços que são estimados de forma imprecisa

pelo termo $\hat{f}_{6}\left(\mathbf{X}_{\mathbf{R}}, \dot{\mathbf{x}}_{\mathbf{R}}\right)$. Para evitar que este aumento do ganho integral cause grandes oscilações, o ganho derivativo é incrementado de 50\%, para prover adequado amortecimento ao sistema em malha fechada. O ganho proporcional, por sua vez, é triplicado em relação ao valor apresentado na ausência de erros de modelagem, pois possui a função de realizar as correções transitórias também efetuadas de forma imprecisa pela malha de compensação direta.

Quando a variável $s$ ultrapassa a espessura da camada limite, o controlador apresenta um termo chaveado, buscando levar a trajetória de volta às proximidades da superfície de escorregamento, o que é garantido pela relação (4.5).

\subsubsection{Alteração do controlador: sistema de amarração turret}

Utilizando-se o controlador definido por (4.38) e (4.42), as forças em cada propulsor são obtidas de forma a satisfazer o momento $F_{6 R T}$ em relação ao ponto de referência e, independentemente, as forças em surge e sway $\left(F_{1 R T}\right.$ e $\left.F_{2 R T}\right)$. Como será visto a seguir, o desacoplamento entre a geração do momento e das forças pode levar, em caso de um sistema amarrado, a um consumo desnecessário de energia. Nesta seção, será exposta uma correção no controlador para que este efeito seja levado em consideração.

O sistema de amarração do tipo turret é projetado de forma a não fornecer momento reativo a rotações do navio em torno do centro da torre (desconsiderando-se, 
evidentemente, efeitos de atrito). Assim, tomando-se o ponto de referência do controle como o centro da torre, a componente dos esforços de controle que não gera nenhuma reação no sistema de amarração é $F_{6 R T}$ e, como já feito em (4.42), a mesma deve ser utilizada para realizar o controle de aproamento.

Para um sistema de amarração do tipo SMS (spread mooring system), no qual as conexões das linhas são distribuídas pelo casco da embarcação, o mesmo conceito pode ser aplicado, colocando-se o ponto de referência próximo ao pólo em relação ao qual o momento das forças restauradoras é nulo. Embora não-linearidades da força de restauração nas linhas e variações do aproamento do navio façam com que este ponto apresente pequenas variações ao longo do tempo, pode-se utilizar uma localização "média" para o mesmo.

A geração do momento $F_{6 R T}$ pode ser feita de diversas maneiras pelo sistema de propulsores, devendo-se escolher a que minimiza o consumo de energia. Por exemplo, considera-se um FPSO com a torre próxima à proa com um propulsor no bulbo de proa e um na região de popa. Das duas configurações de esforços mostradas na Figura 4.7 resultam o mesmo momento $F_{6 R T}$ em relação ao ponto de referência coincidente com o centro do turret. A configuração (b) é mais eficiente em termos de consumo de energia, pois neste caso o propulsor no bulbo é bem menos solicitado, com praticamente a mesma força no propulsor de popa.

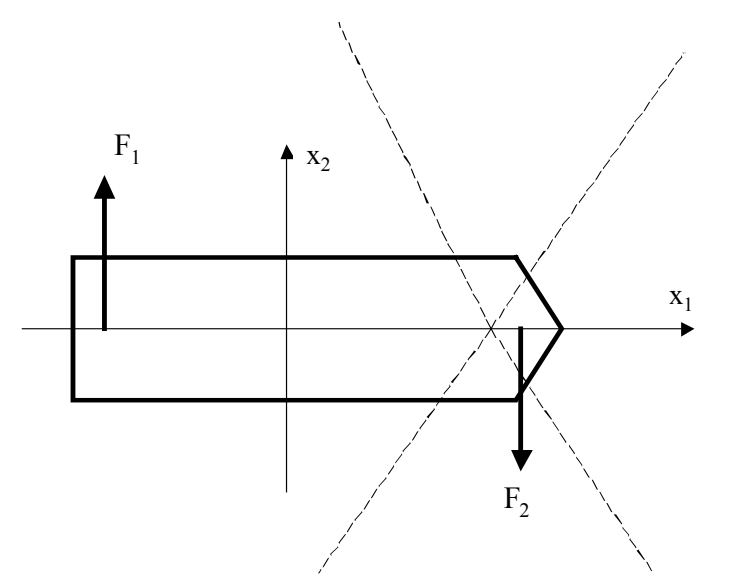

(a)

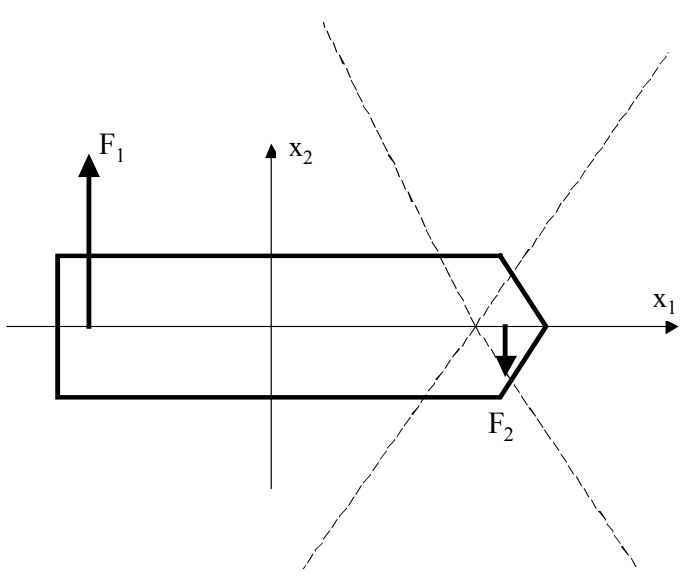

(b)

Figura 4.7 Esforços nos propulsores de um FPSO gerando o mesmo momento $F_{6 R T}$ 
As duas configurações acima diferem na força $F_{2 R T}$ resultante, sendo que a configuração (a) gera uma força em sway praticamente nula, diferente do caso (b). Assim, esta força deve ser calculada para ser levada em conta nas leis de controle (4.38) e (4.42).

A definição matemática da configuração de forças nos propulsores de menor consumo de energia para gerar um determinado momento $F_{6 R T}$ é feita utilizando-se os conceitos de alocação de empuxo expostos que serão expostos em detalhes na seção 4.3.

Sendo $\mathbf{T}$ o vetor com as $n_{T}$ componentes de esforços nos propulsores $\left(n_{T}=2 n_{\text {azim }}+n_{\text {fixo }}\right.$, com $n_{\text {fixo }}$ e $n_{\text {azim }}$ o número de propulsores fixos e azimutais respectivamente), $\mathbf{A}_{\mathbf{R}}$ uma matriz que depende da posição e orientação dos propulsores, definida em (4.85), e $\boldsymbol{\tau}_{\mathbf{R T}}=\left(F_{1 R T}, F_{2 R T}, F_{6 R T}\right)^{T}$ o vetor com as forças e momento resultante, vale a relação:

$$
\mathbf{A}_{\mathbf{R}\left(3 \times n_{T}\right)} \mathbf{T}_{\left(n_{T} \times 1\right)}=\boldsymbol{\tau}_{\mathbf{R T}(3 \times 1)}
$$

O sistema (4.45) fornece três equações, sendo a terceira relacionada ao esforço $F_{6 R T}$. Particionando-se a matriz $\mathbf{A}_{\mathbf{R}}$ em:

$$
\mathbf{A}_{\mathbf{R}}=\left(\begin{array}{c}
\left.\mathbf{A}_{\mathbf{R}, \text { força }}\right|_{2 \times n_{T}} \\
\left.\mathbf{A}_{\mathbf{R}, \text { momento }}\right|_{1 \times n_{T}}
\end{array}\right)
$$

As forças nos propulsores que minimizam o consumo de energia para gerar um determinado momento $F_{6 R T}$ são dadas por:

$$
\mathbf{T}_{\text {momento }\left(n_{T} \times 1\right)}=\left(\mathbf{A}_{\mathbf{R}, \text { momento }}\right)^{+} F_{6 R T}
$$

onde o símbolo $(+)$ refere-se à matriz pseudo-inversa. Entretanto, além destas forças gerarem um momento em torno do ponto de referência, geram também forças de surge e 
sway residuais (ver Figura 4.7 b). Estes esforços são obtidos substituindo-se (4.47) em (4.46) e (4.45):

$$
\left(\begin{array}{l}
F_{1 R T} \\
F_{2 R T}
\end{array}\right)_{\text {residual }}=\left(\mathbf{A}_{\mathbf{R}, \text { força }}\right)\left(\mathbf{A}_{\mathbf{R}, \text { momento }}\right)^{+} F_{6 R T}
$$

Para navios, que são corpos esbeltos, verifica-se que a componente residual em surge é pequena em comparação à (4.38). A componente em sway, entretanto, é significativa, e pode ser escrita como:

$$
\left(F_{2 R T}\right)_{\text {residual }}=P . F_{6 R T}
$$

sendo $P$ calculado a partir de (4.48). Este esforço residual deve ser considerado no controlador. Assim, a força de controle resultante na direção de sway deve ser composta pela parcela responsável pelo amortecimento deste movimento, dada em (4.38) e referida a partir deste ponto como $\left(F_{2 R T}\right)_{\text {amort }}$, adicionada ao termo residual (4.49). Assim:

$$
F_{2 R T}=\left(F_{2 R T}\right)_{\text {residual }}+\left(F_{2 R T}\right)_{\text {amort }}
$$

Substituindo-se (4.50) na equação de movimento de yaw (4.40) obtém-se:

$$
\ddot{x}_{6 R}=f_{6}\left(\mathbf{X}_{\mathbf{R}}, \dot{\mathbf{x}}_{\mathbf{R}}\right)+C_{62}\left(F_{2 R T}\right)_{\text {amort }}+\left(C_{66}+P C_{62}\right) F_{6 R T}
$$

e a nova lei de controle para o movimento de yaw é dada por:

$$
\begin{aligned}
& F_{6 R T}= \\
& \frac{1}{C_{66}+P C_{62}}\left[-C_{62}\left(F_{2 R T}\right)_{\text {amort }}+\left(-\hat{f}_{6}\left(\mathbf{X}_{\mathbf{R}}, \dot{\mathbf{x}}_{\mathbf{R}}\right)+\ddot{x}_{6 D}-2 \lambda \dot{\tilde{x}}_{6 R}-\lambda^{2} \tilde{x}_{6 R}-k \cdot \operatorname{sat}(s / \Phi)\right)\right]
\end{aligned}
$$


Será apresentado, a seguir, um exemplo que ilustra a efetividade das alterações propostas nesta seção sobre o desempenho do controlador desenvolvido em 4.1.3 para o caso de um navio amarrado pelo sistema turret.

Considera-se, neste exemplo, o VLCC Vidal de Negreiros, 100\% carregado, amarrado por uma torre instalada próxima à proa $\left(x_{p}=160 \mathrm{~m}\right)$, submetido a uma manobra indicada na figura a seguir, sendo a correnteza de $1,2 \mathrm{~m} / \mathrm{s}$ e ondas com altura significativa de $4,8 \mathrm{~m}$ e período de pico de espectro de 11,4s. Deve-se ressaltar que ambos os controladores foram projetados sob condições idênticas. O modelo completo de simulação utilizado e os dados do navio VLCC Vidal de Negreiros serão expostos em detalhes na seção 6.2.

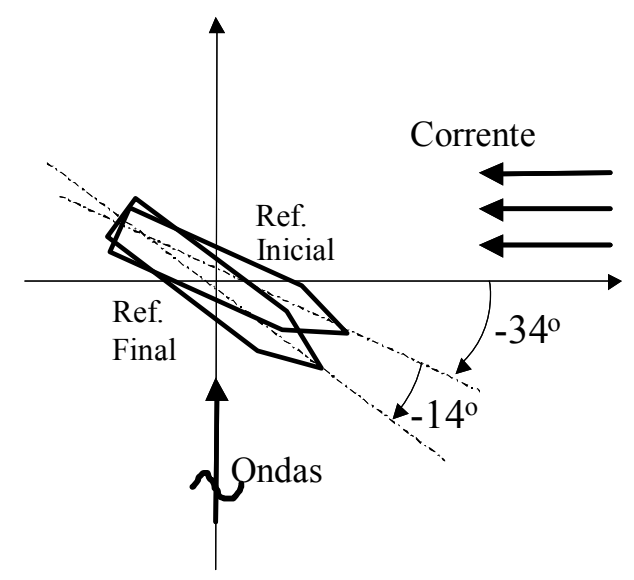

Figura 4.8 Manobra de alteração de aproamento - VLCC Vidal de Negreiros 100\% carregado

Supõe-se que o FPSO seja equipado com 3 propulsores em túnel de popa com as posições indicadas na Figura 4.9 e força máxima de $400 \mathrm{kN}$ cada, 1 propulsor principal responsável pelas forças longitudinais com empuxo máximo de $1000 \mathrm{kN}$ e um propulsor em túnel próximo à proa com empuxo máximo de $600 \mathrm{kN}$.

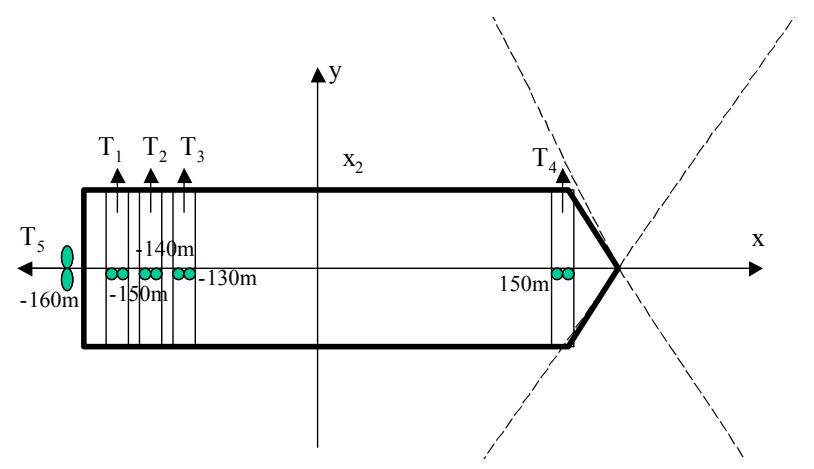

Figura 4.9 Suposta configuração dos propulsores para VLCC Vidal de Negreiros 
Apresenta-se na Figura 4.10 a simulação utilizando o controlador projetado em 4.1.3 sem as alterações da seção 4.1.3.1.

Observa-se que o sistema acompanha o aproamento desejado com erros menores que $1,0^{\circ}$ e garante uma amplitude no movimento de translação menor que $12 \mathrm{~m}$. Na Figura 4.11 apresentam-se as forças nos propulsores, na qual se evidencia a grande solicitação do propulsor 4 que atua, inutilmente, em substituição ao sistema de amarração, chegando a ocorrer saturação (atinge o valor máximo de empuxo de $600 \mathrm{kN}$ ) entre os instantes 2200 s e 2600 s aproximadamente.

A Figura 4.12 apresenta a simulação para o caso do controlador com as alterações propostas em 4.1.3.1. Pode-se verificar que o desempenho do sistema é semelhante ao obtido anteriormente, com erro de aproamento inferior a $1,0^{\circ}$ e amplitude no movimento de translação menor que $10 \mathrm{~m}$. Na Figura 4.13 a vantagem deste controlador fica clara, notando-se que o propulsor de proa 4 é bem menos solicitado, já que, com o novo procedimento, evita-se que o mesmo atue contra o sistema de amarração.

Considerando-se que a potência consumida pelo sistema propulsor seja proporcional à soma dos empuxos elevados à potência $3 / 2$, pode-se verificar que a alteração proposta em 4.1.3.1 leva a uma economia de $30 \%$, comparativamente ao caso analisado anteriormente. 

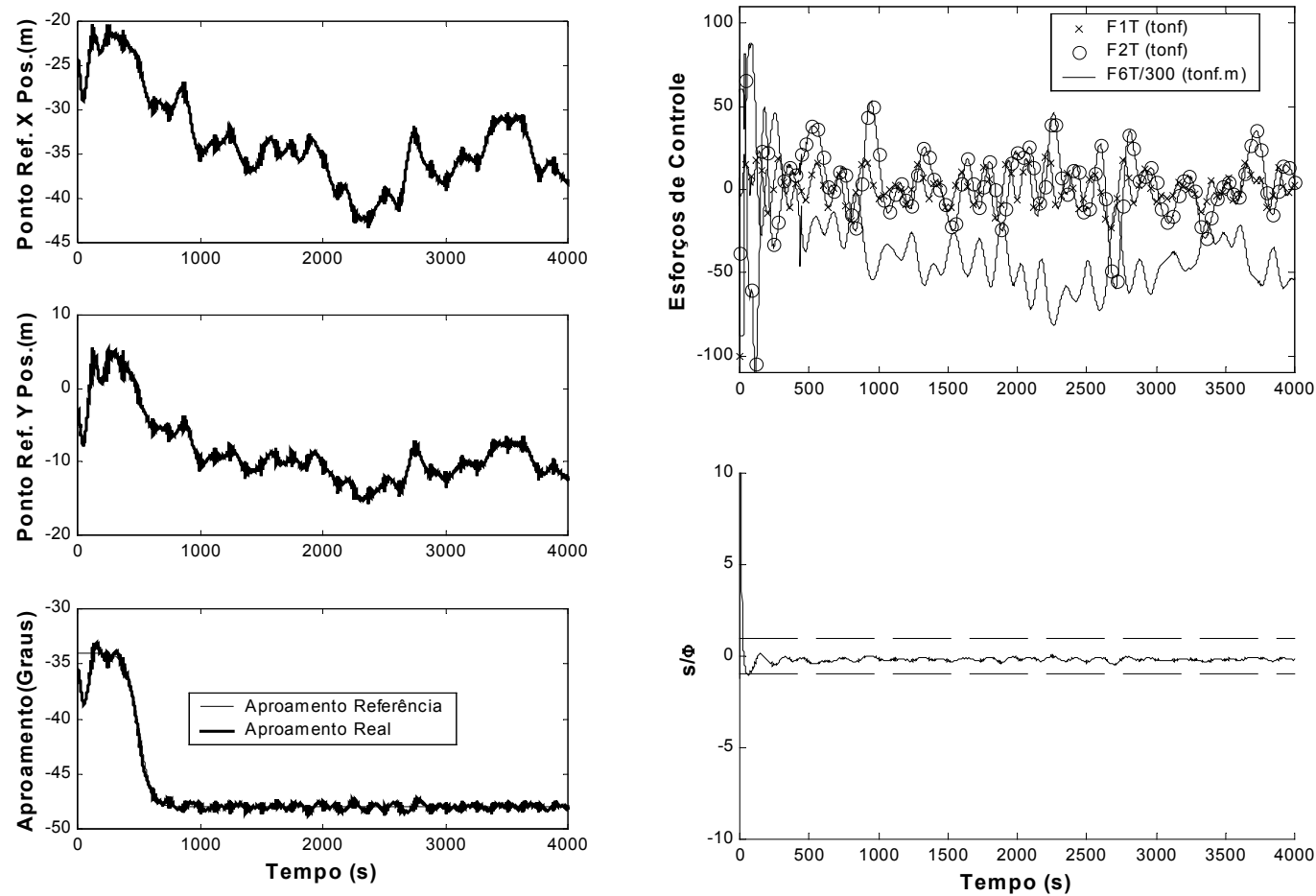

Figura 4.10 Simulação com controlador sem as alterações da seção 4.1.3.1. Esquerda: Posição do ponto de referência e aproamento; direita: esforços de controle e variável $s(t)$

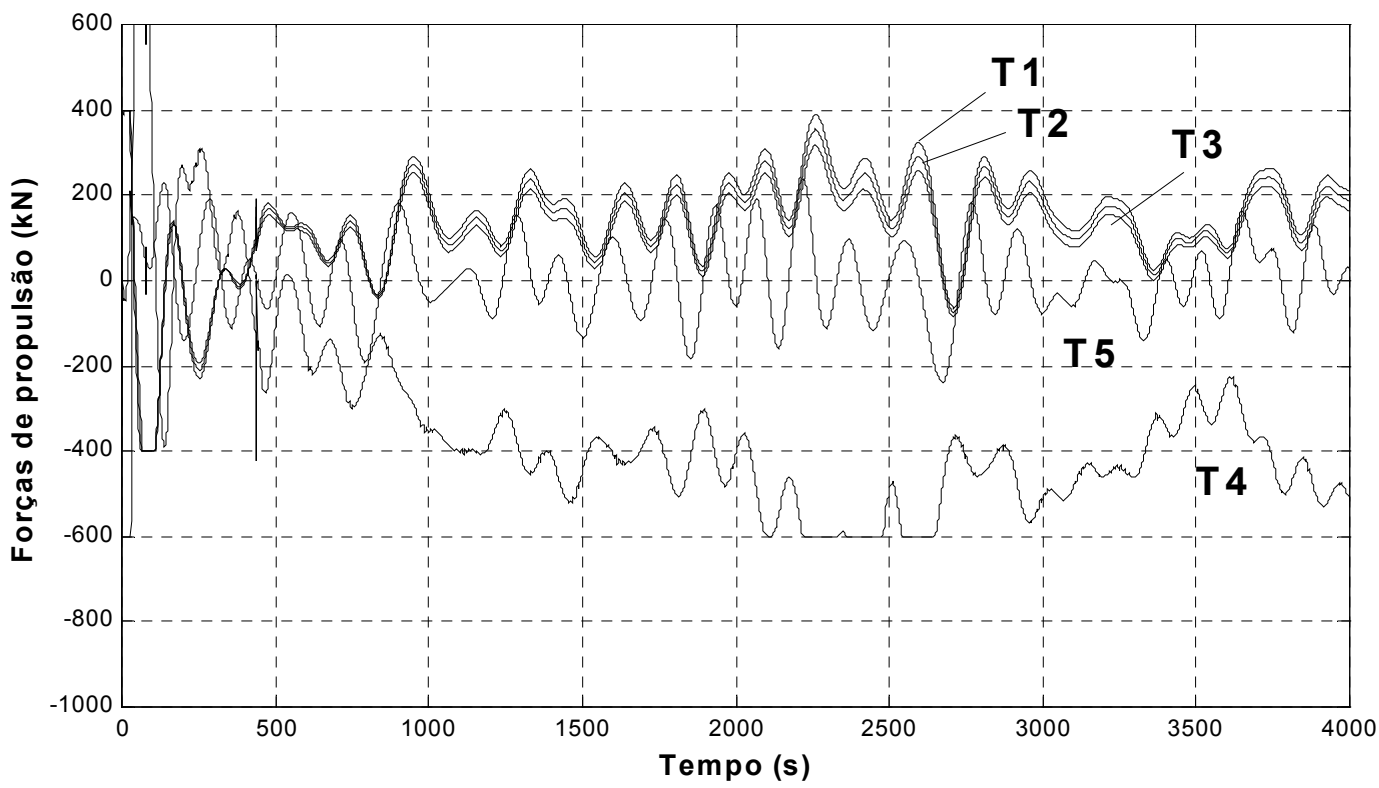

Figura 4.11 Simulação com controlador sem as alterações da seção 4.1.3.1. Forças nos propulsores 

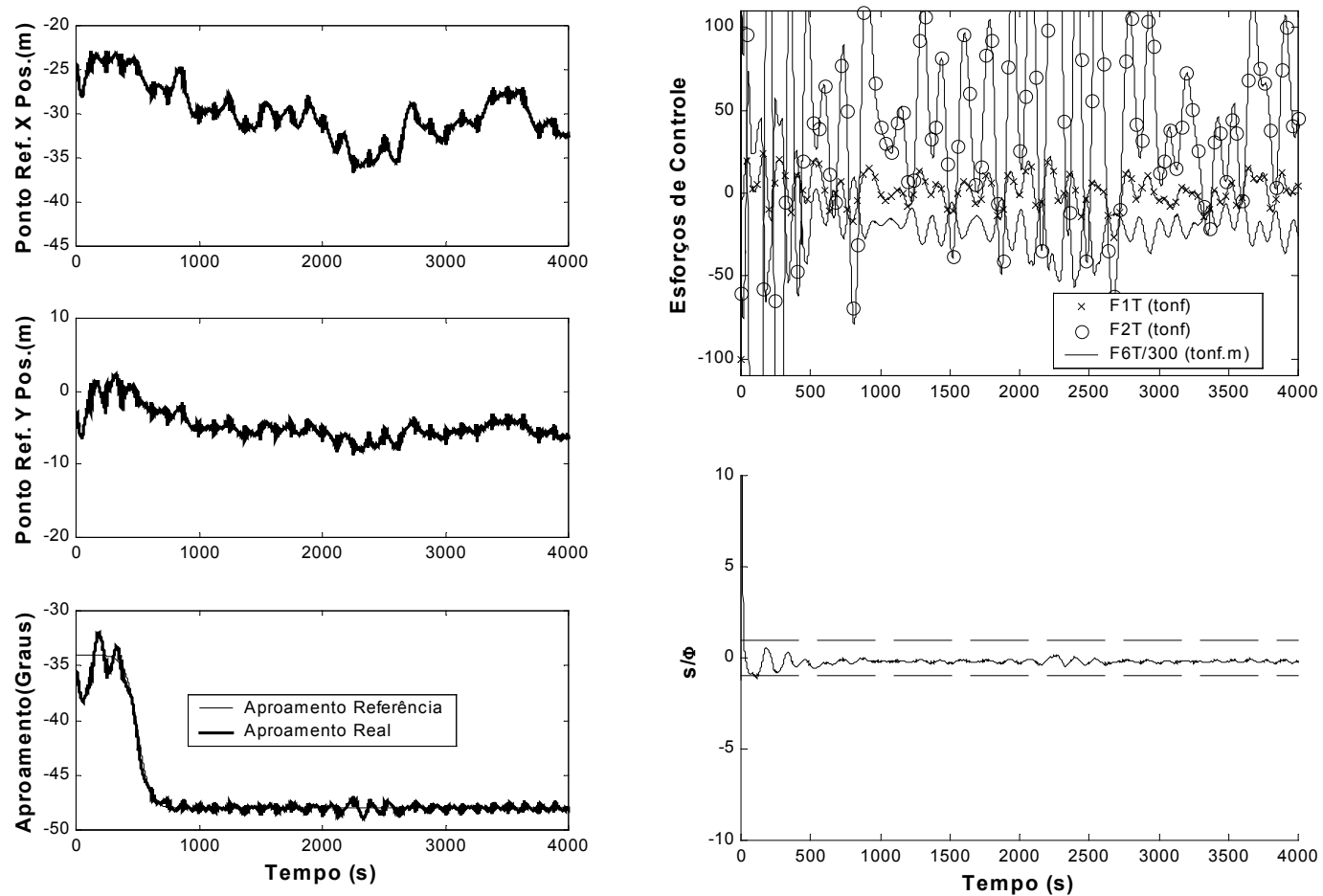

Figura 4.12 Simulação com controlador com as alterações da seção 4.1.3.1

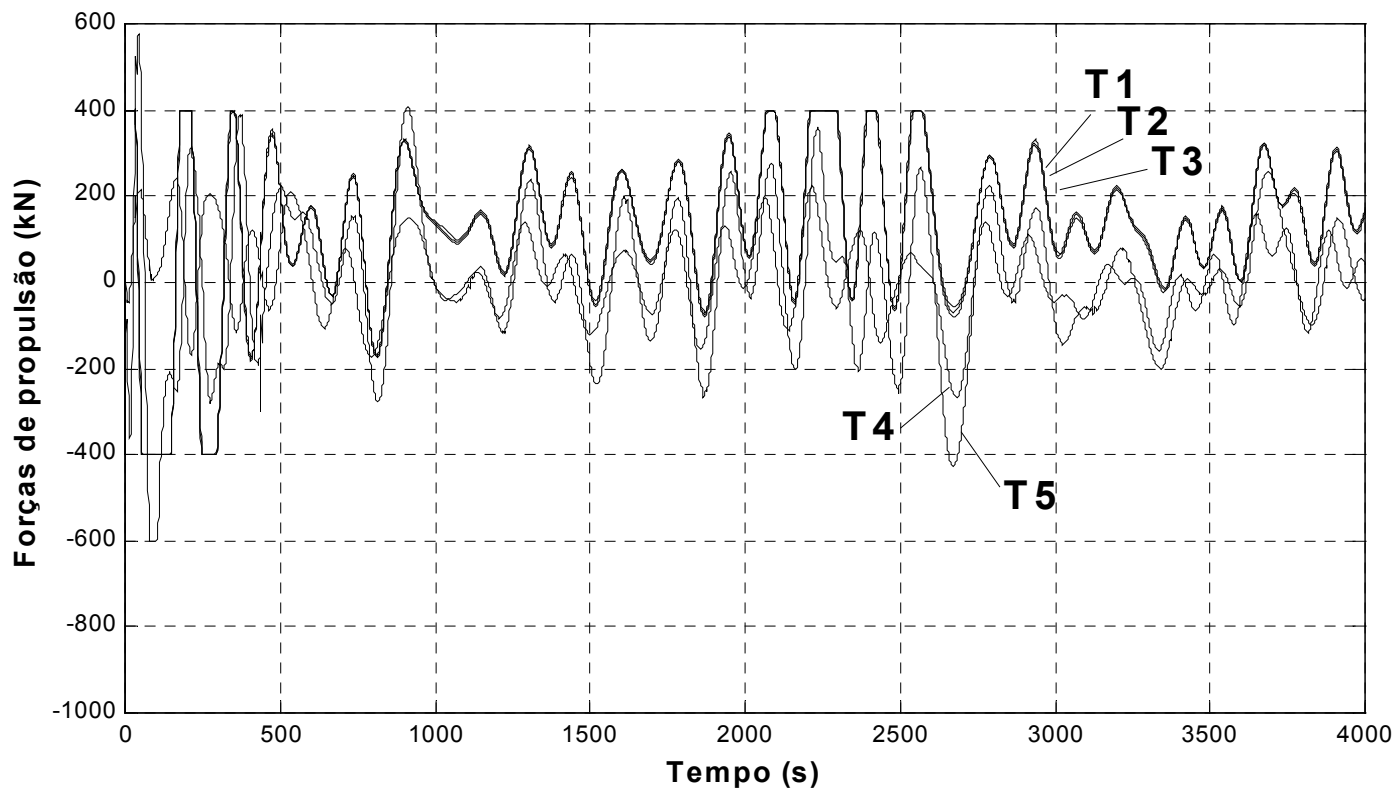

Figura 4.13 Simulação com controlador com as alterações da seção 4.1.3.1. Forças nos propulsores 


\subsubsection{Controle combinado dos movimentos de translação e rotação}

O controle combinado dos movimentos de translação e rotação tem como objetivo manter a embarcação próxima da posição e aproamento desejados (set-points). Estes são dados como coordenadas no sistema global $O X Y Z$ do ponto de referência da embarcação, além do ângulo de aproamento, sendo expressas por $\left(X_{D}, Y_{D}, \psi_{D}\right)$.

Portanto, o projeto do controlador é feito utilizando-se as equações (4.36) escritas em função das variáveis $\left(X_{R}, Y_{R}, \psi\right)$. Seguindo a metodologia de projeto de controle por modos deslizantes, exposta na seção 4.1.1, devem-se isolar as forças devidas ao sistema propulsor. Assim, reescrevendo-se (4.36) obtém:se:

$$
\left(\begin{array}{c}
\ddot{X}_{R} \\
\ddot{Y}_{R} \\
\ddot{\psi}
\end{array}\right)=\left(\begin{array}{l}
f_{X, d i n}\left(\dot{\mathbf{X}}_{\mathbf{R}}\right) \\
f_{Y, d i n}\left(\dot{\mathbf{X}}_{\mathbf{R}}\right) \\
f_{\psi, d i n}\left(\dot{\mathbf{X}}_{\mathbf{R}}\right)
\end{array}\right)+\mathbf{C}\left(\begin{array}{c}
F_{1 R E}+F_{1 R M} \\
F_{2 R E}+F_{2 R M} \\
F_{6 R E}+F_{6 R M}
\end{array}\right)+\left(\begin{array}{c}
a_{X} \\
a_{Y} \\
a_{\psi}
\end{array}\right)
$$

sendo que o vetor $\left(\begin{array}{lll}a_{X} & a_{Y} & a_{\psi}\end{array}\right)^{T}$ representa as acelerações devidas às forças de controle, sendo dadas por:

$$
\left(\begin{array}{l}
a_{X} \\
a_{Y} \\
a_{\psi}
\end{array}\right)=\mathbf{C}\left(\begin{array}{l}
F_{1 R T} \\
F_{2 R T} \\
F_{6 R T}
\end{array}\right)
$$

Como será mostrado adiante, a metodologia de projeto do controlador irá resultar no cálculo do vetor $\left(\begin{array}{lll}a_{X} & a_{Y} & a_{\psi}\end{array}\right)^{T}$. O cálculo das forças e momento devidos ao sistema propulsor $\left(\begin{array}{lll}F_{1 R T} & F_{2 R T} & F_{6 R T}\end{array}\right)$ é feito multiplicando-se o vetor $\left(\begin{array}{lll}a_{X} & a_{Y} & a_{\psi}\end{array}\right)^{T}$ pela inversa da matriz C, definida em (4.37), o que é sempre possível, pois esta é não singular para qualquer ângulo $\psi$. Assim: 


$$
\begin{gathered}
\left(\begin{array}{c}
F_{1 R T} \\
F_{2 R T} \\
F_{6 R T}
\end{array}\right)=\mathbf{C}^{-1}\left(\begin{array}{l}
F_{X} \\
F_{Y} \\
F_{\psi}
\end{array}\right) \\
\operatorname{com} C^{-1}=\left(\begin{array}{ccc}
a_{1} \cos \psi & a_{1} \operatorname{sen} \psi & 0 \\
-a_{2} \operatorname{sen} \psi & a_{2} \cos \psi & a_{5} \\
-a_{5} \operatorname{sen} \psi & a_{5} \cos \psi & a_{3}-a_{5} x_{R}
\end{array}\right) \text { e as constantes } a_{i} \text { definidas em (4.31). }
\end{gathered}
$$

Definem-se as variáveis $s$ como:

$$
\begin{aligned}
& s_{X}=\dot{\widetilde{X}}_{R}+2 \lambda_{X} \widetilde{X}_{R}+\lambda_{X}^{2} \int_{0}^{t} \widetilde{X}_{R} d t, \quad \tilde{X}_{R}=X_{R}-X_{D} \\
& s_{Y}=\dot{\widetilde{Y}}_{R}+2 \lambda_{Y} \widetilde{Y}_{R}+\lambda_{Y}^{2} \int_{0}^{t} \widetilde{Y}_{R} d t, \quad \widetilde{Y}_{R}=Y_{R}-Y_{D} \\
& s_{\psi}=\dot{\widetilde{\psi}}+2 \lambda_{\psi} \widetilde{\psi}+\lambda_{\psi}^{2} \int_{0}^{t} \widetilde{\psi} d t, \quad \widetilde{\psi}_{R}=\psi_{R}-\psi_{D}
\end{aligned}
$$

sendo o símbolo til $(\sim)$ indicativo dos erros de acompanhamento. Adicionaram-se parcelas integrais para eliminar possíveis diferenças em regime estacionário (offsets) entre o valor real e o desejado.

O controlador será robusto a imprecisões na avaliação dos esforços devido ao sistema de amarração e aos agentes ambientais. Como já explicado, estas imprecisões devem-se a erros de modelagem e, no caso dos agentes ambientais, a dificuldades na monitoração dos mesmos (onda, vento e correnteza). Não serão considerados erros na matriz $\mathbf{C}$ e nas funções $f_{\text {din }}$, pois dependem apenas das massas adicionais do casco e das posições e velocidades da embarcação. Assim, obtêm-se:

$$
\left(\begin{array}{l}
a_{X} \\
a_{Y} \\
a_{\psi}
\end{array}\right)=-\left(\begin{array}{c}
f_{X, \operatorname{din}}\left(\dot{\mathbf{X}}_{\mathbf{R}}\right) \\
f_{Y, \operatorname{din}}\left(\dot{\mathbf{X}}_{\mathbf{R}}\right) \\
f_{\psi, \operatorname{din}}\left(\dot{\mathbf{X}}_{\mathbf{R}}\right)
\end{array}\right)-\mathbf{C}\left(\begin{array}{c}
\hat{F}_{1 R E}+\hat{F}_{1 R M} \\
\hat{F}_{2 R E}+\hat{F}_{2 R M} \\
\hat{F}_{6 R E}+\hat{F}_{6 R M}
\end{array}\right)+\left(\begin{array}{c}
\ddot{X}_{D}-2 \lambda_{X} \dot{\tilde{X}}-\lambda_{X}^{2} \tilde{X}-k_{X} \operatorname{sat}\left(s_{X} / \Phi_{X}\right) \\
\ddot{Y}_{D}-2 \lambda_{Y} \dot{\tilde{Y}}-\lambda_{Y}^{2} \tilde{Y}-k_{Y} \operatorname{sat}\left(s_{Y} / \Phi_{Y}\right) \\
\ddot{\psi}_{D}-2 \lambda_{\psi} \dot{\tilde{\psi}}-\lambda_{\psi}^{2} \widetilde{\psi}-k_{\psi} \operatorname{sat}\left(s_{\psi} / \Phi_{\psi}\right)
\end{array}\right)
$$


sendo as constantes positivas $\left(\lambda_{X}, \lambda_{Y}, \lambda_{\psi}\right)$ relacionadas à largura de banda de cada movimento em malha fechada e os parâmetros $\left(\Phi_{\mathrm{X}}, \Phi_{\mathrm{Y}}, \Phi_{\psi}\right)$ sintonizados de forma a evitar o efeito de chattering, explicado na seção 4.1.1.

Os ganhos $\left(k_{X}, k_{Y}, k_{\psi}\right)$ são calculados de acordo com estimativas do erro de modelagem e imprecisões nas forças e momentos devido a agentes ambientais e à amarração. Expandindo-se a expressão (4.58), utilizando a relação (4.29) e aplicando-se os conceitos expostos em 4.1.1 conclui-se que tais ganhos devem respeitar:

$$
\begin{gathered}
k_{X} \geq \eta_{X}+\left|c_{\psi}\right| C_{11}\left(\max \left|F_{1 E}-\hat{F}_{1 E}\right|+\max \left|F_{1 M}-\hat{F}_{1 M}\right|\right)+ \\
\left|s_{\psi}\right|\left|C_{22}-C_{26} x_{R}\right|\left(\max \left|F_{2 E}-\hat{F}_{2 E}\right|+\max \left|F_{2 M}-\hat{F}_{2 M}\right|\right)+ \\
\left|s_{\psi}\right|\left|C_{26}\right|\left(\max \left|F_{6 E}-\hat{F}_{6 E}\right|+\max \left|F_{6 M}-\hat{F}_{6 M}\right|\right) \\
k_{Y} \geq \eta_{Y}+\left|s_{\psi}\right| C_{11}\left(\max \left|F_{1 E}-\hat{F}_{1 E}\right|+\max \left|F_{1 M}-\hat{F}_{1 M}\right|\right)+ \\
\left|c_{\psi}\right|\left|C_{22}-C_{26} x_{R}\right|\left(\max \left|F_{2 E}-\hat{F}_{2 E}\right|+\max \left|F_{2 M}-\hat{F}_{2 M}\right|\right)+ \\
\left|c_{\psi}\right|\left|C_{26}\right|\left(\max \left|F_{6 E}-\hat{F}_{6 E}\right|+\max \left|F_{6 M}-\hat{F}_{6 M}\right|\right) \\
k_{\psi} \geq \eta_{\psi}+\left|C_{62}-C_{66} x_{r}\right|\left(\max \left|F_{2 E}-\hat{F}_{2 E}\right|+\max \left|F_{2 M}-\hat{F}_{2 M}\right|\right)+ \\
C_{66}\left(\max \left|F_{6 E}-\hat{F}_{6 E}\right|+\max \left|F_{6 M}-\hat{F}_{6 M}\right|\right)
\end{gathered}
$$

Como já explicado, as constantes positivas $\left(\eta_{X}, \eta_{Y}, \eta_{\psi}\right)$ relacionam-se ao tempo para que as trajetórias atinjam a superfície $S(t)$. O cálculo dos máximos erros na estimativa das forças ambientais e das forças de amarração é exposto na seção seguinte.

\subsubsection{Cálculo do valor estimado e do máximo erro para esforços atuantes}

O controlador proposto requer estimativas dos esforços atuantes sobre o sistema $\left(\hat{F}_{i E}\right.$ e $\left.\hat{F}_{i M}\right)$, bem como dos máximos erros admissíveis em tais estimativas.

Admite-se que as condições ambientais são monitoradas e obtêm-se valores aproximados para os parâmetros representativos (velocidades e direções), com erros máximos conhecidos. Admitem-se, adicionalmente, erros de modelagem não paramétricos, tornando a metodologia proposta a seguir bastante abrangente. 


\subsubsection{Correnteza}

O valor estimado para a velocidade média de correnteza é dado por $\hat{V}_{C}$ e para a direção de incidência em relação ao sistema fixo $O X Y Z$, por $\hat{\alpha}_{O X Y Z}$. A imprecisão no monitoramento deste agente ambiental (Figura 4.14) é limitada por:

$$
\begin{aligned}
& V_{C, \text { min }} \leq V_{C} \leq V_{C, \max } \\
& \alpha_{O X Y Z \min } \leq \alpha_{O X Y Z} \leq \alpha_{O X Y Z \max }
\end{aligned}
$$

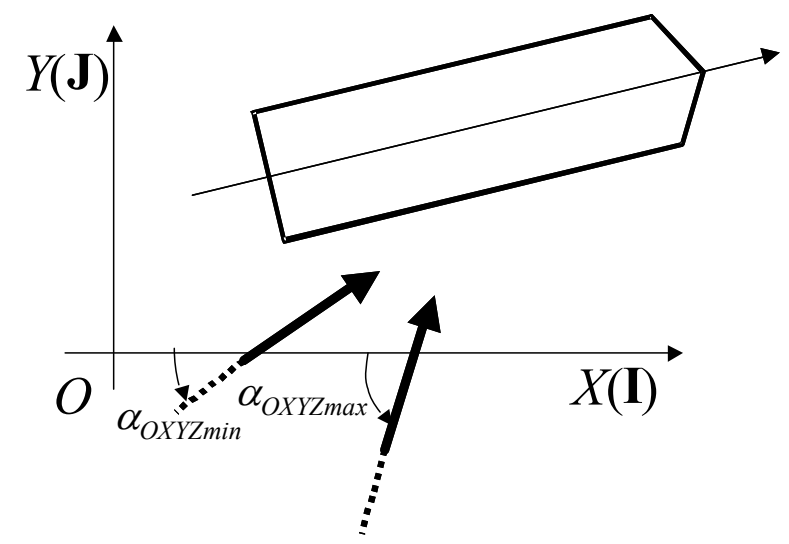

Figura 4.14 Incertezas na intensidade e direção de correnteza

Como $\alpha=\alpha_{O X Y Z}-\psi$ (ver Figura 3.2), a incerteza na direção $\alpha_{O X Y Z}$ pode ser considerada como uma incerteza no ângulo $\alpha$ pois supõe-se que o aproamento do navio $(\psi)$ é conhecido com grande precisão. Assim, pode-se obter para cada instante o ângulo estimado $\hat{\alpha}$, utilizado no modelo de força de correnteza. Logo, os esforços estimados devido à correnteza $\left(\hat{F}_{i C}\right)$ são obtidos substituindo-se $\hat{V}_{C}$ e $\hat{\alpha}$ no modelo apresentado na seção 3.2.1. O cálculo dos erros máximos na avaliação destes esforços é feito supondose uma aproximação em série de Taylor para a função erro, dada por:

$E_{i C}\left(V_{C}, \alpha\right)=\left(\frac{\partial E_{i C}}{\partial V_{C}}\right)_{\hat{V}_{C}, \hat{\alpha}}\left(V_{C}-\hat{V}_{C}\right)+\left(\frac{\partial E_{i C}}{\partial \alpha}\right)_{\hat{V}_{C}, \hat{\alpha}}(\alpha-\hat{\alpha})+O[2]$

${ }^{15} \mathrm{O}[2]$ refere-se a erros da ordem $\left(V_{C}-\hat{V}_{C}\right)^{2},(\alpha-\hat{\alpha})^{2}$ ou $\left(V_{C}-\hat{V}_{C}\right)(\alpha-\hat{\alpha})$. 
na qual $E_{i C}\left(V_{C}, \alpha\right)=F_{i C}-\hat{F}_{i C}$, com $E_{i C}\left(\hat{V}_{C}, \hat{\alpha}\right)=0$. Admite-se, adicionalmente, um erro máximo não paramétrico na modelagem da força de correnteza, quantificado por uma parcela $\left(e_{i C}\right)$ das forças estimadas . Assim, o máximo erro é então aproximado por:

$$
\max \left[E_{i C}\left(V_{C}, \alpha\right)\right] \leq\left|\left(\frac{\partial E_{i C}}{\partial V_{C}}\right)_{\hat{V}_{C}, \hat{\alpha}}\right| \max \left|V_{C}-\hat{V}_{C}\right|+\left|\left(\frac{\partial E_{i C}}{\partial \alpha}\right)_{\hat{V}_{C}, \hat{\alpha}}\right| \max |\alpha-\hat{\alpha}|+e_{i C}\left|\hat{F}_{i C}\right|
$$

sendo que as máximas incertezas em $V_{C}$ e $\alpha$ são obtidas por (4.62). A seguir serão calculadas aproximações para as derivadas de (4.64) para os esforços de correnteza em surge, sway e yaw. A força de surge é dada em (3.13) e (3.18), levando à seguinte função erro $E_{1 C}$ :

$$
\begin{aligned}
E_{1 C}\left(V_{C}, \alpha\right)= & \frac{1}{2} \rho L T \cdot\left(C_{1 C}\left(\alpha_{r}\right) V_{c r}{ }^{2}-C_{1 C}\left(\hat{\alpha}_{r}\right) \hat{V}_{c r}{ }^{2}\right)+X_{v r} \cdot r(v-\hat{v}) \\
& +X_{r r} r^{2}\left(\cos \alpha_{a}-\cos \hat{\alpha}_{a}\right)
\end{aligned}
$$

sendo $X_{v r}=M_{22}-1 / 4 \rho \pi T^{2} L$ e $X_{r r}=-\frac{1}{16} \rho \pi T^{2} L^{2}$. Fazendo-se a suposição de que nos SPDs, em condições ambientais significativas, as velocidades da embarcação são pequenas em comparação com a velocidade de correnteza atuante $\left(\dot{x}_{1}, \dot{x}_{2}, \dot{x}_{6} L / 2<<V_{C}\right)$ as expressões (3.11), (3.12) e (3.19) são simplificadas para:

$$
\begin{array}{lll}
u \cong-V_{C} \cos \alpha & V_{c r} \cong V_{C} & \alpha_{a} \cong \alpha \\
v \cong-V_{C} \operatorname{sen} \alpha & \alpha_{r} \cong \alpha &
\end{array}
$$

Assim, pode-se concluir que:

$$
\left(\frac{\partial E_{1 C}}{\partial V_{C}}\right)_{\hat{V}_{C}, \hat{\alpha}}=\rho L T C_{1 C}(\hat{\alpha}) \hat{V}_{C}-X_{v r} r \operatorname{sen} \hat{\alpha}
$$




$$
\left(\frac{\partial E_{1 C}}{\partial \alpha}\right)_{\hat{V}_{C}, \hat{\alpha}}=\frac{1}{2} \rho L T\left(\frac{d C_{1 C}}{d \alpha}\right)_{\hat{\alpha}} \hat{V}_{C}^{2}-X_{v r} r \hat{V}_{C} \cos \hat{\alpha}-X_{r r} r^{2} \operatorname{sen} \hat{\alpha}
$$

A força de sway é calculada por (3.13) e (3.23), e depende das integrais definidas em (3.22). A única dependência destas integrais em $V_{C}$ e $\alpha$ ocorre na função $\operatorname{sinal}(v+r x)$ que, utilizando-se das mesmas hipóteses (4.66) e supondo-se que as variações admissíveis em $V_{C}$ e $\alpha$ não alterem o sinal de $v$, apresenta valor constante para todo $x$, dado por $\operatorname{sinal}\left(-\hat{V}_{C} \operatorname{sen} \hat{\alpha}\right)$. Assim, será admitido que :

$$
I_{j}(v, r)=I_{j}\left(-\hat{V}_{C} \operatorname{sen} \hat{\alpha}, 0\right)
$$

Com a expressão (4.68) e as hipóteses (4.66), o termo $\left[I_{0}(v, r) \cdot v^{2}-C_{Y} \cdot v|v|\right] \mathrm{da}$ força de sway será nulo e a função erro será dada então por:

$$
E_{2 C}\left(V_{C}, \alpha\right)=\frac{1}{2} \rho L T .\left(C_{2 C}\left(\alpha_{r}\right) V_{c r}{ }^{2}-C_{2 C}\left(\hat{\alpha}_{r}\right) \hat{V}_{c r}{ }^{2}\right)+Y_{u r} \cdot r(u-\hat{u})+Y_{v r} \cdot r(v-\hat{v})
$$

sendo $Y_{u r}=\frac{1}{4} \rho \pi T^{2} L\left(1-4,4 \frac{B}{L}+0,160 \frac{B}{T}\right)$ e $\quad Y_{v r}=-\rho T L^{2} I_{1}(v, r)$. As derivadas da função erro são, portanto:

$$
\begin{aligned}
& \left(\frac{\partial E_{2 C}}{\partial V_{C}}\right)_{\hat{V}_{C}, \hat{\alpha}}=\rho L T C_{2 C}(\hat{\alpha}) \hat{V}_{C}-Y_{u r} r \cos \hat{\alpha}-Y_{v r} r \operatorname{sen} \hat{\alpha} \\
& \left(\frac{\partial E_{2 C}}{\partial \alpha}\right)_{\hat{V}_{C}, \hat{\alpha}}=\frac{1}{2} \rho L T\left(\frac{d C_{2 C}}{d \alpha}\right)_{\hat{\alpha}} \hat{V}_{C}{ }^{2}+Y_{u r} r \hat{V}_{C} \operatorname{sen} \hat{\alpha}-Y_{v r} r \hat{V}_{C} \cos \hat{\alpha}
\end{aligned}
$$

O momento de yaw é calculado por (3.13) e (3.24). Admitindo ainda as hipóteses (4.66) e (4.68), o erro pode ser escrito como: 


$$
E_{6 C}\left(V_{C}, \alpha\right)=\frac{1}{2} \rho L^{2} T .\left(C_{6 C}\left(\alpha_{r}\right) V_{c r}{ }^{2}-C_{2 C}\left(\hat{\alpha}_{r}\right) \hat{V}_{c r}{ }^{2}\right)+N_{u r} \cdot r(|u|-|\hat{u}|)+N_{v r} \cdot r(v-\hat{v})
$$

$\operatorname{com} N_{u r}=-\frac{1}{8} \rho \pi T^{2} L^{2}\left(1+0.16 \frac{B}{T}-2.2 \frac{B}{L}\right)$ e $N_{v r}=-\rho T L^{3} I_{2}(v, r)$. As derivadas parciais do erro são dadas por:

$$
\begin{aligned}
& \left(\frac{\partial E_{6 C}}{\partial V_{C}}\right)_{\hat{V}_{C}, \hat{\alpha}}=\rho L^{2} T C_{6 C}(\hat{\alpha}) \hat{V}_{C}-N_{u r} r|\cos \hat{\alpha}|-N_{v r} r \operatorname{sen} \hat{\alpha} \\
& \left(\frac{\partial E_{6 C}}{\partial \alpha}\right)_{\hat{V}_{C}, \hat{\alpha}}=\frac{1}{2} \rho L^{2} T\left(\frac{d C_{6 C}}{d \alpha}\right)_{\hat{\alpha}} \hat{V}_{C}^{2}+N_{u r} r \hat{V}_{C} \operatorname{sen} \hat{\alpha} \cdot \operatorname{sinal}(-\cos \hat{\alpha})-N_{v r} r \hat{V}_{C} \cos \hat{\alpha}
\end{aligned}
$$

\subsubsection{Ondas}

No caso de ondas, a altura significativa estimada é dada por $\hat{H}_{S}$, o período de pico do espectro por $\hat{T}_{p}$ e a direção de incidência em relação ao referencial fixo por $\hat{\beta}_{O, O X Y Z}$. Admitem-se erros em tais estimativas (Figura 4.15) limitados por:

$$
\begin{aligned}
& H_{S, \text { min }} \leq H_{S} \leq H_{S, \text { max }} \\
& \beta_{O, O X Y Z \min } \leq \beta_{O, O X Y Z} \leq \beta_{O, O X Y Z \max } \\
& T_{P, \text { min }} \leq T_{P} \leq T_{P, \max }
\end{aligned}
$$

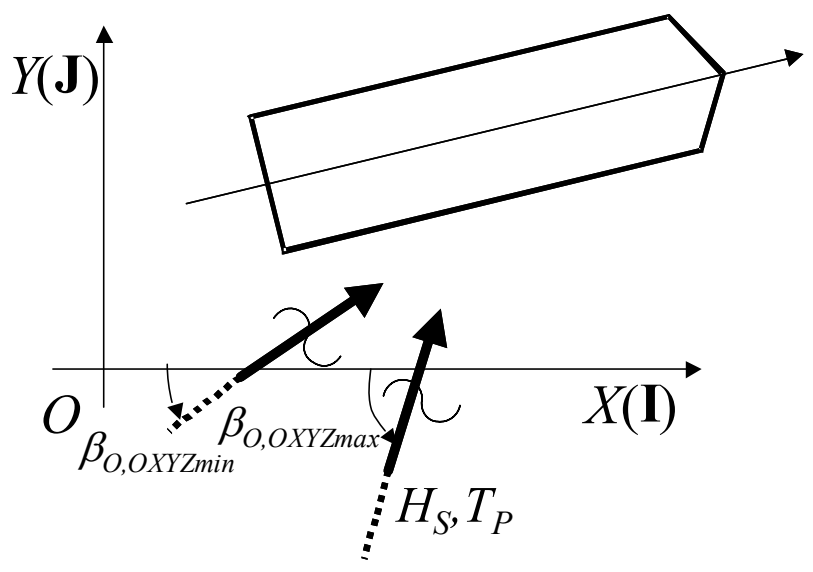

Figura 4.15 Incertezas na altura, período e direção de onda 
Da mesma forma que para a correnteza, $\beta_{O}=\beta_{O, O X Y Z}-\psi$ (ver Figura 3.7), a incerteza na direção $\beta_{O, O X Y Z}$ pode ser considerada como uma incerteza no ângulo $\beta_{O}$ pois supõe-se que o aproamento do navio $(\psi)$ é conhecido com grande precisão. As forças de deriva média devidas às ondas podem ser estimadas baseadas em $\hat{H}_{S}, \hat{T}_{P}$ e $\hat{\beta}_{O}$ desde que se conheça o espectro de ondas incidente, utilizando-se a expressão (3.30). Entretanto, como do procedimento de monitoração de ondas proposto no Capítulo 5 resultam apenas os parâmetros significativos do espectro, restando indeterminado o seu formato, será admitida nos cálculos da força estimada e do máximo erro de estimação a forma de Pierson-Moskowitz (3.26). Esta hipótese não acarreta grandes erros na estimação, pois as forças de deriva média são pouco sensíveis ao formato do espectro, sendo mais dependentes da energia contida no espectro do que nos detalhes de forma do mesmo. Este fato é ilustrado na Figura 4.16. Considerou-se altura significativa de 5,5m e período de pico de $11,4 \mathrm{~s}$ incidindo sobre o VLCC $100 \%$ carregado, e foram calculadas as forças e momento de deriva média em surge, sway e yaw. Para cada um dos movimentos, escolheu-se a pior incidência (maior força ou momento) e calculou-se a relação entre a força para um espectro de JONSWAP com parâmetro de forma $\gamma$ (definido em (3.28)) variando de 1 a 2,4 (faixa típica para Bacia de Campos) e para um espectro de Pierson Moskowitz. Pode-se ver que a variação máxima ocorre para o momento de yaw, valendo aproximadamente 14\%. Esta possível fonte de erro pode ser incluída como erro não paramétrico, conforme será mostrado adiante. 


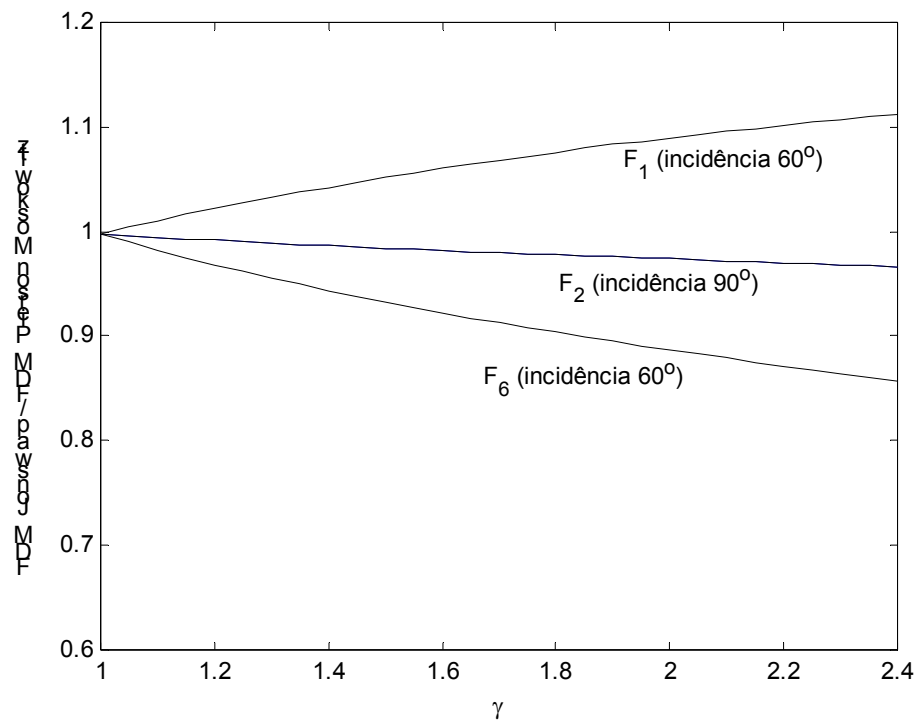

Figura 4.16 Relação entre forças e momento de deriva média para diferentes espectros de incidência (VLCC100\%, $\left.H_{s}=5,5 \mathrm{~m}, \mathrm{~T}_{\mathrm{p}}=11,4 \mathrm{~s}\right)$

O efeito de interação onda-corrente também pode ser avaliado por (3.35) utilizando-se a velocidade de correnteza estimada $\hat{V}_{C}$ e sua direção $\hat{\alpha}$.

Assim, a força de deriva média estimada $\left(\hat{F}_{i D M}, i=1,2,6\right)$ dependerá dos parâmetros de onda e correnteza, sendo que o máximo erro em tal estimativa $E_{i D M}=F_{i D M}-\hat{F}_{i D M}$ é aproximado por:

$$
\begin{aligned}
& E_{i D M}\left(H_{S}, T_{P}, \beta_{O}, V_{C}, \alpha\right)=\left(\frac{\partial E_{i D M}}{\partial H_{S}}\right)_{\substack{\hat{H}_{S}, \hat{T}_{P}, \hat{\beta}_{0}, \hat{V}_{C}, \hat{\alpha}}}\left(H_{S}-\hat{H}_{S}\right)+\left(\frac{\partial E_{i D M}}{\partial T_{P}}\right)_{\substack{\hat{H}_{S}, \hat{T}_{P}, \hat{\beta}_{0}, \hat{V}_{C}, \hat{\alpha}}}\left(T_{P}-\hat{T}_{P}\right)+ \\
& \left(\frac{\partial E_{i D M}}{\partial \beta_{O}}\right)_{\substack{\hat{H}_{s}, \hat{T}_{p}, \hat{\beta}_{o}, \hat{V}_{C}, \hat{\alpha}}}\left(\beta_{O}-\hat{\beta}_{O}\right)+\left(\frac{\partial E_{i D M}}{\partial V_{C}}\right)_{\substack{\hat{H}_{s}, \hat{T}_{p}, \hat{\beta}_{O}, \hat{V}_{C}, \hat{\alpha}}}\left(V_{C}-\hat{V}_{C}\right)+\left(\frac{\partial E_{i D M}}{\partial \alpha}\right)_{\substack{\hat{H}_{S}, \hat{T}_{P}, \hat{\beta}_{o}, \hat{V}_{C}, \hat{\alpha}}}(\alpha-\hat{\alpha})+O[2]
\end{aligned}
$$

Admite-se, adicionalmente, um erro máximo não paramétrico na modelagem da força de deriva média devido à onda, quantificado por uma parcela $\left(e_{i D M}\right)$ das forças estimadas .

Além disso, deve-se incluir também uma estimativa das máximas forças de deriva lenta que são consideradas como distúrbios no sistema de controle (análogos aos 
termos $d_{i}(t)$ em (4.22)), o que é feito utilizando-se a equação (3.34) com as estimativas $\hat{H}_{S}, \hat{T}_{P}$ e $\hat{\beta}_{O}$. O máximo erro é então aproximado por:

$$
\begin{aligned}
& \max \left[E_{i D M}\right]=\left|\left(\frac{\partial E_{i D M}}{\partial H_{S}}\right)_{\substack{\hat{H}_{S}, \hat{P}_{P}, \hat{\beta}_{0}, \hat{V}_{C}, \hat{\alpha}}}\right| \max \left|H_{S}-\hat{H}_{S}\right|+\left|\left(\frac{\partial E_{i D M}}{\partial T_{P}}\right)_{\substack{\hat{H}_{S}, \hat{T}_{P}, \hat{\beta}_{o}, \hat{V}_{C}, \hat{\alpha}}}\right| \max \left|T_{P}-\hat{T}_{P}\right|+
\end{aligned}
$$

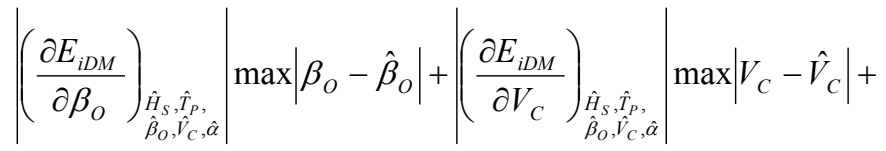

$$
\begin{aligned}
& \left|\left(\frac{\partial E_{i D M}}{\partial \alpha}\right)_{\substack{\hat{H}_{s}, \hat{T}_{p}, \hat{\beta}_{o}, \hat{V}_{c}, \hat{\alpha}}}\right| \max |\alpha-\hat{\alpha}|+\max \left|\hat{F}_{i D L}\right|+e_{i D M}\left|\hat{F}_{i D M}\right|
\end{aligned}
$$

Devido à complexidade algébrica de (3.26), (3.30) e (3.35), as derivadas de (4.75) são calculadas numericamente por diferenças finitas.

\subsubsection{Ventos}

Como já é tradicional em SPDs, esforços devidos ao vento são diretamente compensados pelo controlador, ou seja, são calculados utilizando-se da velocidade de vento medida e inseridos na saída de controle (controle feedforward). Deve-se prever também um filtro para evitar que componentes de rajadas de alta freqüência afetem o controle.

Avaliam-se, portanto, os esforços devidos ao vento $\left(\hat{F}_{i V}\right)$ substituindo-se a velocidade de vento filtrada e a direção de incidência medida em (3.40), utilizando-se as curvas de coeficientes do navio em questão. Utilizou-se no presente trabalho um filtro passa baixa de primeira ordem para eliminar as componentes de rajadas de alta freqüência.

A predição dos esforços $\hat{F}_{i V}$ esconde erros devidos, por exemplo, a imprecisões nas curvas de coeficientes, variações locais da velocidade do vento, bem como erros na monitoração deste agente. Os dois primeiros fatores citados enquadram-se como erros não paramétricos e o último como paramétrico na velocidade $V$ e direção $\beta_{V}$ do vento.

Assim, da mesma forma que para correnteza e ondas, a velocidade medida do vento é dada por $\hat{V}$ e a direção de incidência em relação ao sistema fixo $O X Y Z$ por 
$\hat{\beta}_{V, O X Y Z}$. A imprecisão no monitoramento deste agente ambiental é limitada, a cada instante, por:

$$
\begin{aligned}
& V_{\min } \leq V \leq V_{\max } \\
& \beta_{V, O X Y Z \min } \leq \beta_{V, O X Y Z} \leq \beta_{V, O X Y Z \max }
\end{aligned}
$$

Como já anteriormente citado, $\beta_{V}=\beta_{V, O X Y Z}-\psi$ (ver Figura 3.14) e a incerteza na direção $\beta_{V, O X Y Z}$ pode ser considerada como uma incerteza no ângulo $\beta_{V}$. Assim, sendo $E_{i V}\left(V, \beta_{V}\right)=F_{i V}-\hat{F}_{i V}$ e o máximo erro não paramétrico na estimativa das forças de vento quantificado por uma parcela $\left(e_{i V}\right)$ das forças avaliadas, obtém-se:

$\max \left[E_{i V}\left(V, \beta_{V}\right)\right] \leq\left|\left(\frac{\partial E_{i V}}{\partial V}\right)_{\hat{V}, \hat{\beta}_{V}}\right| \max |V-\hat{V}|+\left|\left(\frac{\partial E_{i V}}{\partial \beta_{V}}\right)_{\hat{V}, \hat{\beta}_{V}}\right| \max \left|\beta_{V}-\hat{\beta}_{V}\right|+e_{i V}\left|\hat{F}_{i V}\right|$

sendo as derivadas obtidas diretamente por (3.40).

\subsubsection{Sistema de amarração e risers}

O controlador proposto requer uma estimativa dos esforços devidos ao sistema de amarração e risers $\left(\hat{F}_{i M}\right)$ bem como do máximo erro de modelagem implícito nesta estimativa.

As estimativas das forças de restauração $\left(\hat{F}_{i R e s}\right)$ são obtidas através das curvas características de cada uma das linhas e risers do sistema. Conhecendo-se em cada instante a posição do ponto de conexão, calculam-se as forças em cada linha e realiza-se a soma vetorial das mesmas.

O modelo adotado para as forças de restauração (baseado nas curvas características) independe das condições ambientais. Portanto, possíveis fontes de erros nas estimativas previamente descritas são, por exemplo, efeitos não modelados de correnteza sobre estas curvas. Assim, admite-se um erro máximo não paramétrico $e_{i R}$, de forma que o erro de modelagem das forças de restauração, $E_{i R}$, são dados por: 


$$
\max \left[E_{\text {iRes }}\right]=e_{i R e s}\left|\hat{F}_{i R e s}\right|
$$

As forças de amortecimento e arrasto devidos a linhas e risers são estimadas $\left(\hat{F}_{i A A}\right)$ utilizando-se o modelo (3.44), (3.45) e (3.46), supondo-se um perfil linear da correnteza em função da profundidade em (3.47). Para o cálculo do máximo erro esperado, devem-se considerar também variações devido a imprecisões na estimativa de velocidade e direção de correnteza. Admitindo-se que a velocidade da embarcação seja bem menor que a velocidade de correnteza $\left(\delta \ddot{x}, \delta \dot{y}<<V_{C}\right)$ as forças (3.44) e (3.45) se reduzem a:

$$
\begin{aligned}
& F_{x, j}=d_{A A j} \bar{V}_{C}^{2} \cos \left(\theta_{h, j}-\alpha\right)\left|\cos \left(\theta_{h, j}-\alpha\right)\right| \\
& F_{y, j}=-c_{A A j} \bar{V}_{C}^{2} \operatorname{sen}\left(\theta_{h, j}-\alpha\right)\left|\operatorname{sen}\left(\theta_{h, j}-\alpha\right)\right|
\end{aligned}
$$

Caso os valores de $\bar{V}_{C}$ e $\alpha$ fossem conhecidos, substituindo-se (4.79) em (3.46) obter-se-iam as forças $F_{i A A}$. Assim, definindo-se o erro na estimativa $E_{i A A}\left(\bar{V}_{C}, \alpha\right)=F_{i A A}-\hat{F}_{i A A}$ e incluindo-se, adicionalmente, um erro máximo não paramétrico na modelagem, quantificado por uma parcela $\left(e_{i A A}\right)$ das forças estimadas, obtêm-se:

$$
\max \left[E_{i A A}\right]=\left|\left(\frac{\partial E_{i A A}}{\partial \bar{V}_{C}}\right)_{\hat{\bar{V}}_{C}, \hat{\alpha}}\right| \max \left|\bar{V}_{C}-\hat{\bar{V}}_{C}\right|+\left|\left(\frac{\partial E_{i A A}}{\partial \alpha}\right)_{\hat{\bar{V}}_{C}, \hat{\alpha}}\right| \max |\alpha-\hat{\alpha}|+e_{i A A}\left|\hat{F}_{i A A}\right|
$$

sendo que as derivadas podem ser facilmente calculadas por (4.79) e (3.46).

\subsection{Projeto de controlador de nível superior}

Algumas operações offshore podem ser realizadas com o veículo oceânico apresentado diversos aproamentos. Existe assim uma liberdade para que o mesmo seja escolhido de forma a satisfazer critérios operacionais definidos. Em alguns casos, esta liberdade é total, ou seja, o aproamento pode ser escolhido entre $0^{\circ}$ e $360^{\circ}$, como por 
exemplo em determinadas operações de lançamento de dutos, perfuração ou FPSO's em turret. Existem também casos de liberdade parcial, nos quais o aproamento pode variar dentro de um arco pré-definido, por restrições construtivas e operacionais. Exemplos são os casos de navios aliviadores e de alguns casos de amarração em turret.

De posse de estimativas de todos os agentes ambientais, desenvolveu-se um novo modo de controle (controle de nível superior), que realiza a otimização simultânea de diversos critérios operacionais, não apenas do consumo de energia como é feito pelos modos de controle comumente encontrados nos SPDs comerciais.

\subsubsection{Critérios operacionais utilizados no cálculo do aproamento ótimo}

Nesta seção serão apresentados e discutidos alguns fatores relevantes que devem ser considerados durante o cálculo do aproamento de um navio petroleiro amarrado em configuração turret. Os conceitos desenvolvidos e os critérios considerados podem ser utilizados para outros tipos de navios e operações, com algumas adaptações dependentes das particularidades e restrições de cada situação.

\subsubsection{Amplitude de oscilação em roll}

Em geral, os equipamentos que compõem a planta de produção instalada em um FPSO possuem limite operacional, relativo ao máximo movimento de roll, de $7^{\circ}$. Quando o movimento da embarcação atinge um valor superior, deve-se interromper a produção (shut-down), o que envolve, conseqüentemente, elevados custos diretos e indiretos.

O cálculo da máxima amplitude de roll $\left(\left[x_{4 P O}\right]_{\max }\right)$ é feito por meio da expressão (3.39) e dos RAO's, os quais, como já citado, representam a resposta do navio para a incidência de uma onda com altura unitária. Pressupõe-se a linearidade entre a onda e a resposta, o que não é válido para o movimento de roll, pois este apresenta um amortecimento fortemente influenciado por termos viscosos não-lineares. Entretanto, como é usual nas análises dinâmicas de sistemas offshore, utiliza-se esta expressão considerando um valor de amortecimento calibrado por ensaios de forma a recuperar ao menos a amplitude extrema do movimento para ondas típicas. 
O RAO de roll é máximo para incidência de ondas na direção perpendicular ao casco (ondas de través). Como já citado, ocorrem com freqüência na Bacia de Campos condições ambientais que levam a embarcação a situações deste tipo, principalmente na presença de ondas swell. O fato de que estas ondas possuem períodos de pico entre $11 \mathrm{~s}$ e $12 \mathrm{~s}$ agrava a situação, pois a freqüência natural do movimento de roll para VLCC's se encontra próxima a esta faixa, variando entre 13 e $16 \mathrm{~s}$.

Um estudo apresentado por Albuquerque et al. (2000) mostrou que para um VLCC típico, a amplitude de oscilação do movimento de roll pode atingir $14^{\circ}$ para uma altura significativa de 4,5m e incidência de través. Além disso, mostra-se que a situação mais grave ocorre para condições de carregamentos leves e intermediárias, pois o período natural tende a se aproximar do período de pico das ondas. De fato, na Figura 4.17 mostra-se a amplitude do movimento de roll para três condições de carregamento em função do período de pico do espectro incidente, indicando-se o intervalo típico do período das ondas. Além disso, foram calculados os movimentos para diferentes distribuições do óleo nos tanques (o que altera a altura metacêntrica, e conseqüentemente o RAO). As linhas cheias correspondem a uma distribuição com o maior número de tanques possível estando completamente cheio ou vazio. As linhas pontilhadas correspondem ao caso de distribuição de carga uniforme nos tanques.
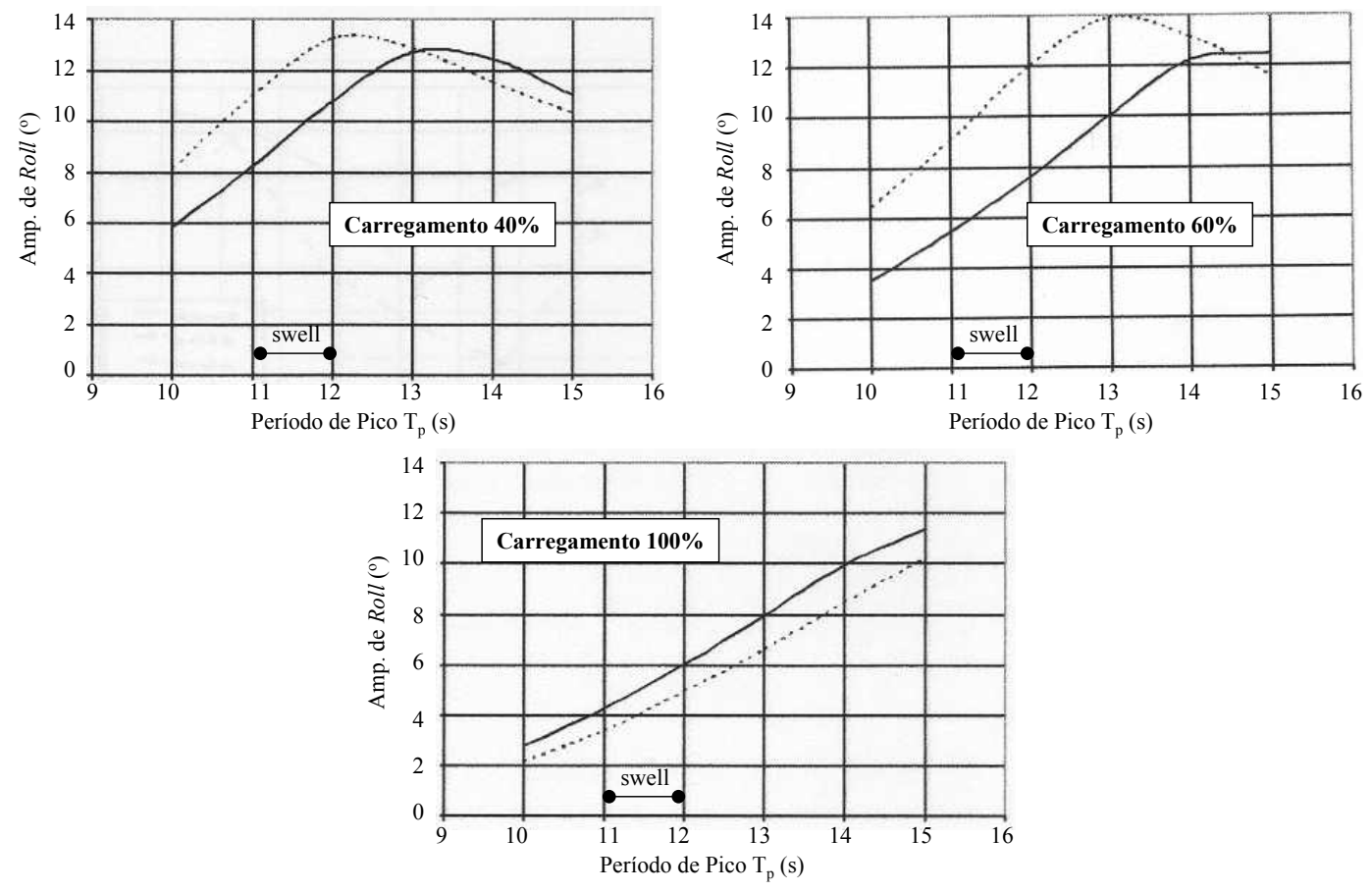

Figura 4.17 Amplitudes do movimento de roll para VLCC em três condições de carregamento $(40 \%, 60 \%$ e $100 \%)$ - adaptado de Albuquerque et al. (2000) 


\subsubsection{Tração dinâmica nos risers}

Como mencionado na seção 3.3.3, a tração oscilatória nos risers resultante do movimento da embarcação devido à ação das ondas é crítica em projetos de sistemas amarrados. Esta tração pode levar à ocorrência de compressão localizada em alguns trechos do riser que, por serem elementos esbeltos, ocasiona flambagem e elevadas cargas flexionais.

Pinto et al. (1999) mostraram que devem ser impostas severas restrições no ângulo de incidência de onda para se evitar a ocorrência de compressão dinâmica em condições extremas da Bacia de Campos. Este fenômeno é ainda mais crítico no caso do turret instalado próximo à proa, como é o caso de alguns sistemas instalados na Bacia de Campos, pois os movimentos verticais na região de proa são mais intensos (devido ao movimento de pitch).

A tração dinâmica é calculada pela formulação analítica citada na seção 3.3.3, sendo que o adimensional $\tau$ definido em (3.48) indica a ocorrência de compressão dinâmica acima do valor admissível.

\subsubsection{Deslocamento médio do sistema de amarração}

Os sistemas de amarração são projetados para suportar deslocamentos médios da ordem de $10 \%$ da profundidade de lâmina d'água. Alguns aproamentos podem levar a forças ambientais que induzem deslocamentos superiores a este valor. Deve-se, portanto, realizar uma verificação deste critério no cálculo do aproamento ótimo.

Dadas as estimativas das condições ambientais, utilizam-se os modelos apresentados no capítulo 3 e estimam-se as forças e momentos médios associados. De posse das curvas características das linhas de amarração pode-se, então, obter a estimativa do deslocamento médio do sistema de amarração $\Delta_{\text {médio }}$ através da solução de um sistema de equações não-lineares.

\subsubsection{Consumo médio de potência de controle}

Considerando-se um FPSO amarrado por sistema turret sob controle de aproamento (descrito em 4.1.3), o momento de controle $\left(F_{6 R T}\right)$ em relação ao ponto de referência apresenta um valor médio não nulo, pois compensa os momentos ambientais médios de forma a manter a embarcação próxima ao aproamento desejado. Além disso,

a este momento associa-se uma parcela da força de controle de sway $\left(F_{2 R T}\right)_{\text {residual }}$ que é 
proporcional ao momento (ver equação (4.49)) e portanto apresenta média não nula. As forças adicionais de surge $\left(F_{1 R T}\right)$ e de sway $\left(F_{2 R T}\right)$ possuem a função de aumentar o amortecimento das oscilações lentas dos movimentos de translação da embarcação, possuindo portanto média nula ao longo do tempo.

Conclui-se, assim, que as forças nos propulsores terão média proporcional ao valor médio do momento $F_{6 R T}$. Como a potência consumida em cada propulsor é proporcional ao empuxo elevado à potência 3/2 (ver seção 3.5.2), pode-se concluir que a potência média total consumida pelo sistema $\left(W_{\text {médio }}\right)$ é proporcional ao valor médio de $F_{6 R T}$ elevado a esta mesma potência.

De posse de estimativas das condições ambientais, pode-se calcular o valor médio de $F_{6 R T}$ considerando-se apenas os esforços estáticos de correnteza (3.13) e vento (3.40) e deriva média devida a ondas (3.30), incluindo a interação onda-corrente (3.35).

\subsubsection{Definição da função objetivo}

A amplitude de oscilação em roll e a tração dinâmica nos risers são diretamente relacionadas ao ângulo de incidência de ondas, e são minimizadas quando a embarcação fica aproada com relação às ondas. Entretanto, verifica-se que a potência de controle média é minimizada quando a embarcação se alinha com a resultante dos esforços ambientais (equilíbrio) e o deslocamento do sistema de amarração é mínimo num aproamento próximo ao de equilíbrio. Portanto, deve-se definir o funcional (4.81) que pondera a importância de cada um dos fatores e que deve ser minimizado de forma a satisfazê-los da maneira mais adequada.

$$
J(\psi)=\left(K_{R}\left[x_{4 P O}\right]_{\max }\right)^{2}+\left(K_{\tau} \tau\right)^{2}+\left(K_{\Delta} \Delta_{\text {médio }}\right)^{2}+\left(K_{W} W_{\text {médio }}\right)^{2}
$$

no qual as constantes $K_{R}, K_{\tau}, K_{\Delta}$ e $K_{W}$ são pesos para cada critério. Além disso, podemse inserir as restrições (4.82) na minimização do funcional de forma a garantir que os critérios não ultrapassem limites inferiores $\left(I_{R}, I_{\tau}, I_{\Delta}\right.$ e $\left.I_{W}\right)$ e superiores $\left(S_{R}, S_{\tau}, S_{\Delta}\right.$ e $\left.\mathrm{S}_{W}\right)$. 


$$
\begin{array}{cc}
I_{R} \leq\left[x_{4 P O}\right]_{\max } \leq S_{R} & I_{\Delta} \leq \Delta_{\text {médio }} \leq S_{\Delta} \\
I_{\tau} \leq \tau \leq S_{\tau} & I_{W} \leq W_{\text {médio }} \leq S_{W}
\end{array}
$$

A escolha correta dos pesos depende das características da condição ambiental atuante. Por exemplo, em mares calmos a minimização da potência de controle (relacionada ao consumo de combustível) deve ser priorizada perante os outros fatores, já que normalmente este é um estado de mar que persiste por um longo tempo. Ao contrário, durante tempestades, ou na presença de fortes mares swell, os outros parâmetros tornam-se críticos, e o consumo de combustível deve ser menos valorizado. Podem-se desenvolver algoritmos automáticos de ajuste dos pesos em função de descrições qualitativas do estado de mar, baseados em lógica fuzzy por exemplo, o que não é, entretanto, abordado no presente trabalho.

No caso de liberdade parcial de aproamento, podem-se adicionar à minimização restrições na variável $\psi$, de forma que $\psi_{\min } \leq \psi \leq \psi_{\max }$.

\subsubsection{Aplicação a uma condição ambiental típica}

Nesta seção, o procedimento de cálculo do aproamento ótimo será aplicado para o VLCC Vidal de Negreiros em condição de carregamento 80\% com o turret instalado próximo à proa $\left(x_{p}=160 \mathrm{~m}\right)$. Por meio do exemplo, na próxima seção será analisada a sensibilidade do método a erros nas estimativas das condições ambientais.

Considera-se uma correnteza anual de $1,47 \mathrm{~m} / \mathrm{s}$ vindo da direção norte incidindo simultaneamente a onda (também anual) com altura significativa de 4,5m e período de pico de 10,29s vinda da direção sudeste. O espectro de onda é descrito pela formulação de JONSWAP com fatores $\alpha=0,0081$ e $\gamma=1,54$. No presente exemplo não se inclui a ação do vento.

As duas configurações de equilíbrio do sistema são mostradas na Figura 4.18. 


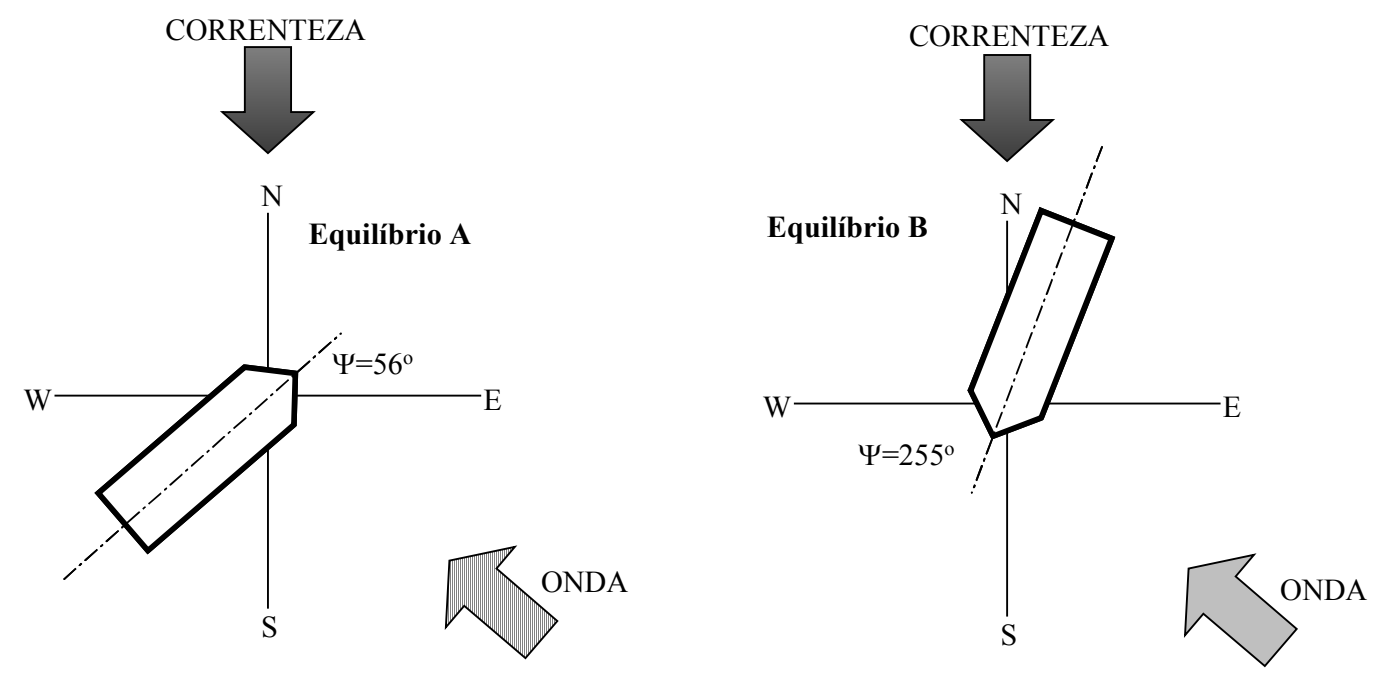

Figura 4.18 Configurações de equilíbrio para VLCC $80 \%$ carregado sujeito a onda e correnteza anuais.

De fato, na Figura 4.19 apresenta-se o momento médio de controle em relação ao ponto de instalação do turret, que apresenta valor nulo nas duas posições de equilíbrio do sistema. Um método sistemático para a obtenção das configurações de equilíbrio em sistemas oceânicos é apresentado em Souza Júnior; Morishita (2002). O momento é um dos critérios utilizados no cálculo do aproamento ótimo pois, como explicado em 4.2.1.4, representa uma medida da potência de controle.

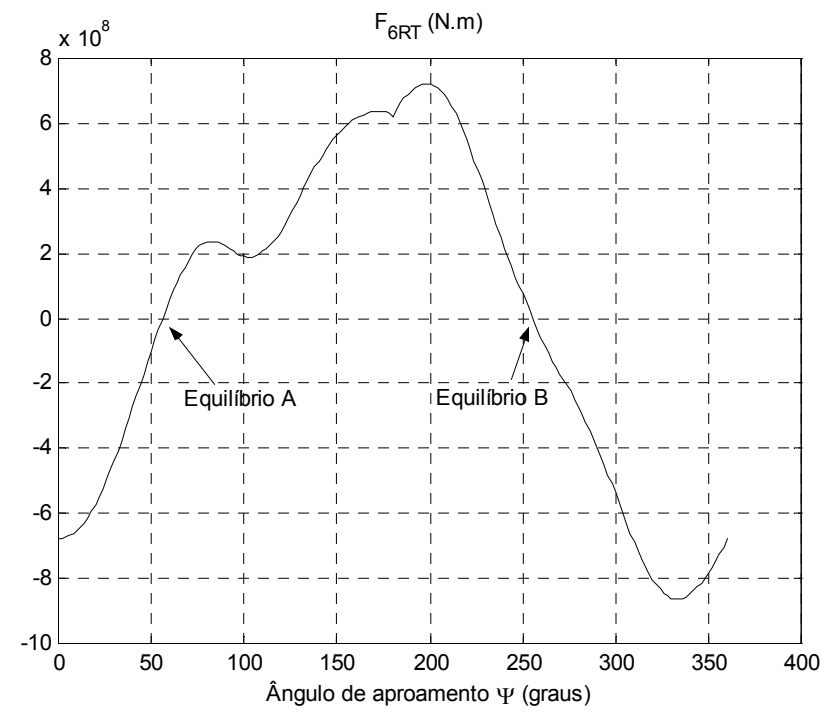

Figura 4.19 Momento médio de controle em relação ao turret 
O deslocamento médio do sistema de amarração é apresentado na Figura 4.20. Indicam-se, na figura, os dois aproamentos correspondentes ao mínimo deslocamento e, como já mencionado, são próximos às configurações de equilíbrio do navio.

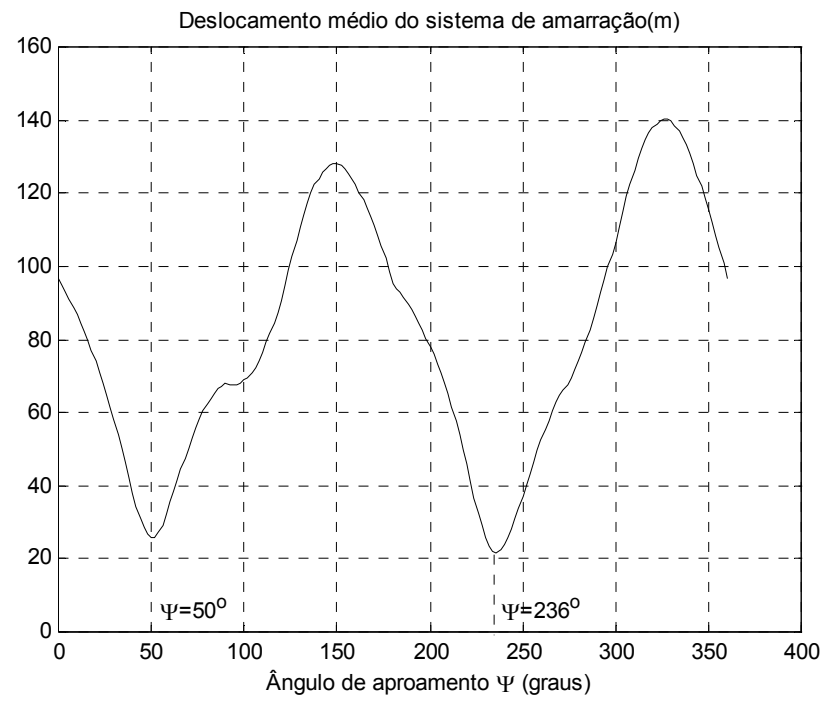

Figura 4.20 Deslocamento médio do sistema de amarração

A Figura 4.21 apresenta a amplitude máxima de roll da embarcação e o coeficiente adimensional de tração dinâmica de um dos risers do sistema. Como exemplo, considerou-se um riser de $8,5^{\prime}(216 \mathrm{~mm})$ de diâmetro, $85 \mathrm{kN}$ de compressão máxima admissível e ângulo de topo de $80^{\circ}$.
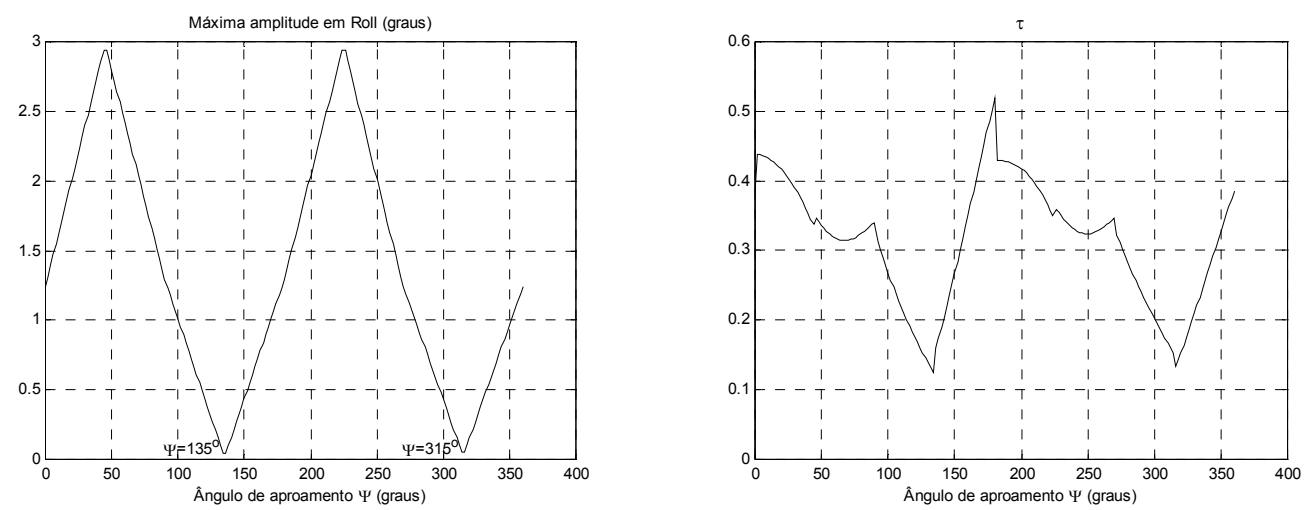

Figura 4.21 Máxima amplitude de roll e tração dinâmica em um riser do sistema

Os dois critérios são minimizados para as configurações nas quais a onda incide sobre o navio pela popa ou pela proa, que correspondem às situações de menor 
movimento vertical de primeira ordem induzido. Estas configurações são mostradas na Figura 4.22.

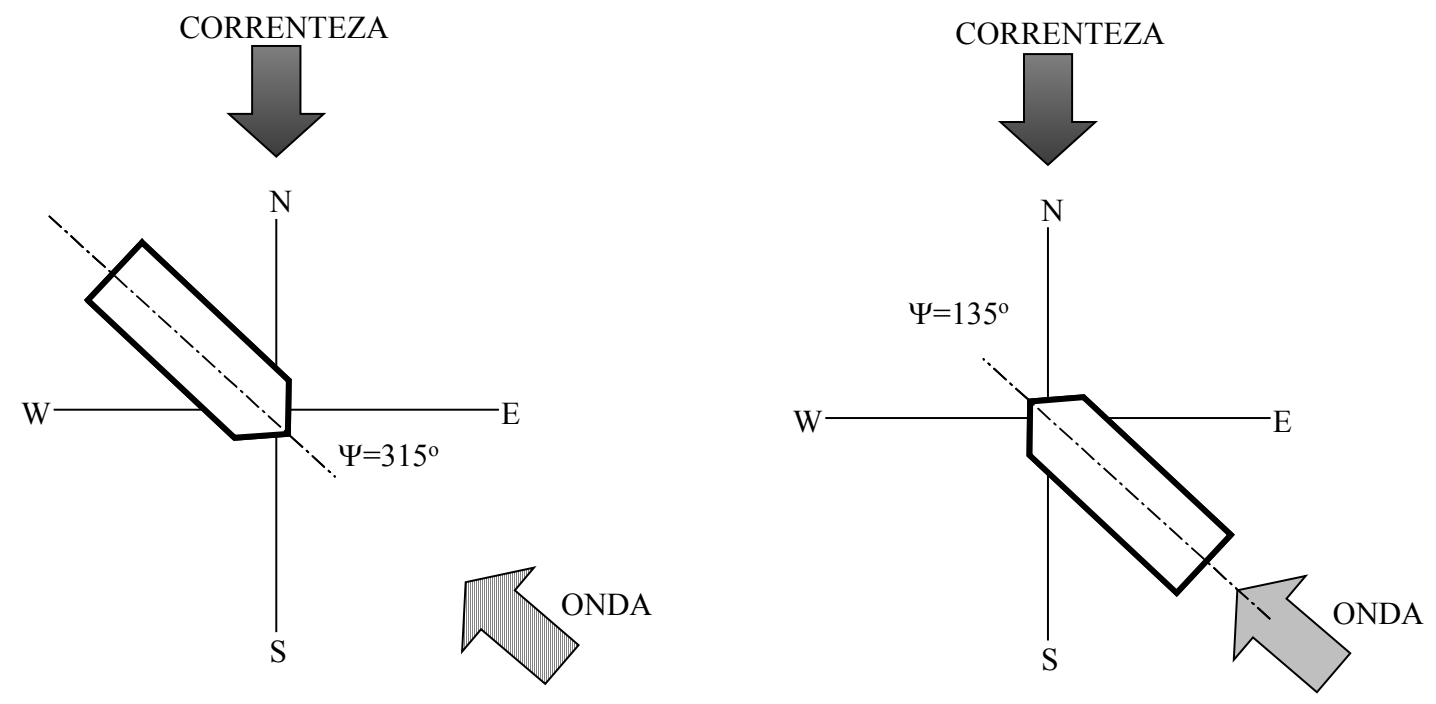

Figura 4.22 Configurações de mínimo movimento de primeira ordem induzido

Calculou-se então a função $J(\psi)$ para todos os aproamentos, considerando-se os pesos e valores limites indicados na Tabela 4.2. O ajuste dos pesos foi feito utilizandose um critério de normalização, semelhante ao comumente utilizado em ajustes de matrizes de ponderação de controladores ótimos LQG. Procurou-se, contudo, dar maior importância relativa ao movimento de roll e tração dinâmica, pois se trata de uma condição ambiental extrema.

Tabela 4.2 Pesos e limites considerados no cálculo de $\mathbf{J}(\psi)$

\begin{tabular}{|c|l|l|l|}
\hline \multicolumn{1}{|c|}{ Critério } & \multicolumn{1}{c|}{ Peso } & \multicolumn{1}{c|}{ Limite Inferior } & \multicolumn{1}{c|}{ Limite Superior } \\
\hline Potência de controle & $K_{W}=\left(4.10^{8} \mathrm{Nm}\right)^{-3 / 2}$ & $I_{W}=(0 \mathrm{Nm})^{3 / 2}$ & $S_{W}=\left(4.10^{8} \mathrm{Nm}\right)^{3 / 2}$ \\
\hline Desloc.sist. amarr. & $K_{\Delta}=(100 \mathrm{~m})^{-1}$ & $I_{\Delta}=0 \mathrm{~m}$ & $S_{\Delta}=100 \mathrm{~m}$ \\
\hline Max. amp. de roll & $K_{R}=\left(5^{0}\right)^{-1}$ & $I_{R}=-7^{0}$ & $S_{R}=7^{0}$ \\
\hline Tração dinâmica & $K_{\tau}=(0.3)^{-1}$ & $I_{\tau}=0$ & $S_{\tau}=1$ \\
\hline
\end{tabular}

Apresenta-se, na Figura 4.23, a função $J(\psi)$ sendo que os pontos marcados correspondem a aproamentos nos quais nenhum limitante é violado. O aproamento ótimo é dado, portanto, pelo ponto ao qual corresponde o menor valor de $J(\psi)$ e nenhum limitante seja violado. Neste caso, isto ocorre para $\psi=111^{\circ}$. 


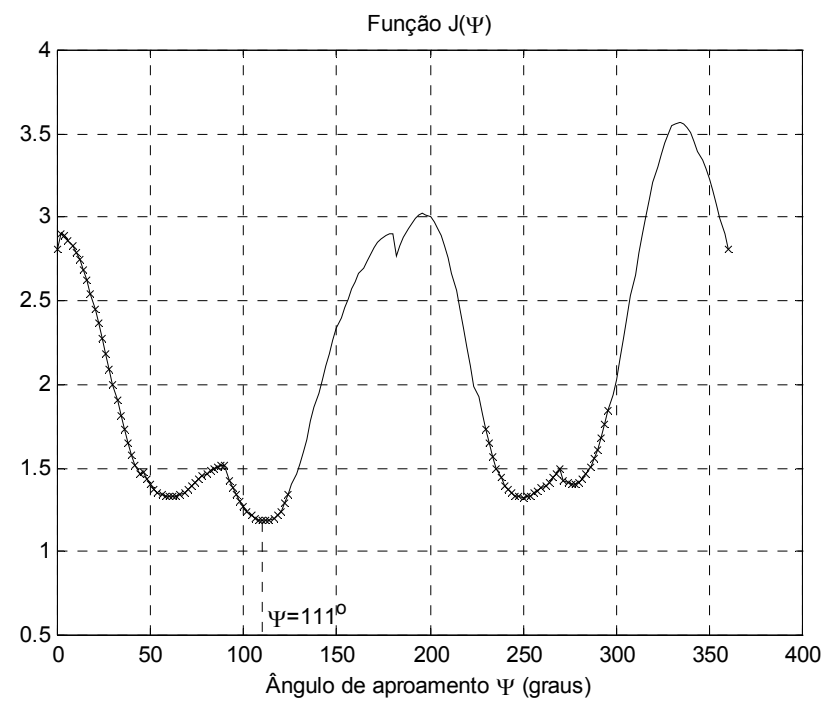

Figura 4.23 Função $\mathbf{J}(\psi)$; os pontos marcados com (x) correspondem a aproamentos nos quais os limites superiores e inferiores dos critérios não são violados

O aproamento ótimo para esta situação é ilustrado na Figura 4.24. Deve-se observar que como foi dada maior importância para a minimização dos critérios relacionados aos movimentos de primeira ordem, esta situação é próxima a uma das posições de mínimo movimento apresentadas na Figura 4.22.

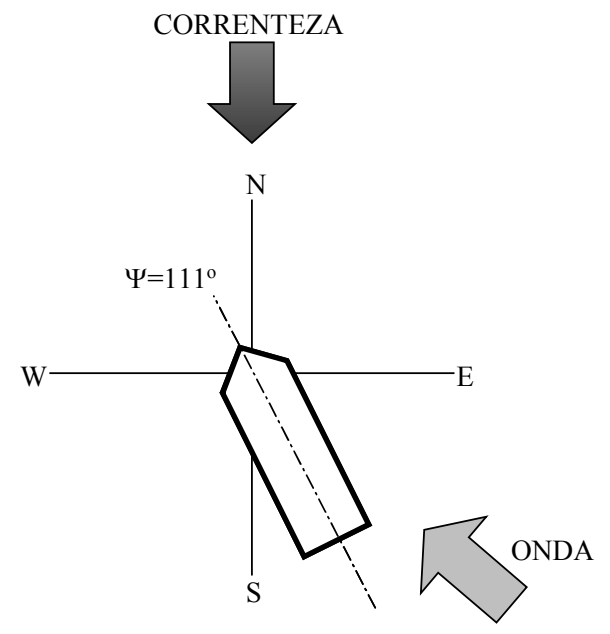

Figura 4.24 Aproamento ótimo

\subsubsection{Sensibilidade a erros nas condições ambientais}

O procedimento exposto é aplicado utilizando-se as condições ambientais medidas ou estimadas. Devido a diferenças entre estes valores e os reais, o aproamento ótimo 
calculado difere do aproamento ótimo efetivo para as condições ambientais reais. Este fato indica a necessidade de se realizar uma análise de sensibilidade do procedimento a estes erros, verificando-se a variação do aproamento ótimo em face de erros nas condições ambientais, bem como a influência desta variação no comportamento do sistema.

Esta análise foi feita para o exemplo analisado na seção anterior. Foram alterados, independentemente, cada um dos parâmetros ambientais e recalculado o aproamento ótimo, verificando-se a diferença com relação ao valor $\psi=111^{\circ}$ obtido com as condições ambientais reais. A Tabela 4.3 apresenta o valor do aproamento ótimo para variações de $\pm 5 \%$ nos parâmetros (ou $\pm 5^{\circ}$ quando se trata de uma direção). Na última linha apresenta-se também o aproamento ótimo calculado utilizando-se espectro de Pierson-Moskowitz ao invés do espectro de JONSWAP.

Tabela 4.3 Aproamento ótimo - variação devido a erros na estimativa das condições ambientais

\begin{tabular}{|l|c|c|}
\hline \multicolumn{1}{|c|}{ Grandeza Alterada } & $+5 \%$ & $-5 \%$ \\
& $\left(+5^{\circ}\right.$ para $\alpha_{W, O X Y Z}$ e $\left.\alpha_{O X Y Z}\right)$ & $\left(-5^{\circ}\right.$ para $\alpha_{W, O X Y Z}$ e $\left.\alpha_{O X Y Z}\right)$ \\
\hline Velocidade de Correnteza $\left(V_{C}\right)$ & $106^{\circ}$ & $111^{\circ}$ \\
\hline Direção de Correnteza $\left(\alpha_{O X Y Z}\right)$ & $113^{\circ}$ & $106^{\circ}$ \\
\hline Altura significativa $\left(H_{S}\right)$ & $114^{\circ}$ & $108^{\circ}$ \\
\hline Período de Pico $\left(T_{P}\right)$ & $116^{\circ}$ & $106^{\circ}$ \\
\hline Direção de Onda $\left(\alpha_{W, O X Y Z}\right)$ & $110^{\circ}$ & $107^{\circ}$ \\
\hline Espectro Pierson-Moskowitz & \multicolumn{2}{|c|}{$112^{\circ}$} \\
\hline
\end{tabular}

Pode-se verificar portanto que ocorrem variações de $\pm 5^{\circ}$ em relação ao valor obtido com as condições ambientais reais. Evidentemente, erros simultâneos na estimação das condições ambientais resultam valores mais elevados de erros no cálculo do aproamento ótimo.

Entretanto, isto não acarreta uma alteração significativa no valor final da função $J(\psi)$. De fato, na Figura 4.25 apresenta-se esta função nas proximidades do ponto de aproamento ótimo $\psi=111^{\circ}$ e pode-se verificar que variações de até $\pm 10^{\circ}$ no aproamento provocam incrementos menores que 0,064 no valor de $J(\psi)$, que corresponde a uma variação porcentual de apenas $6 \%$. 


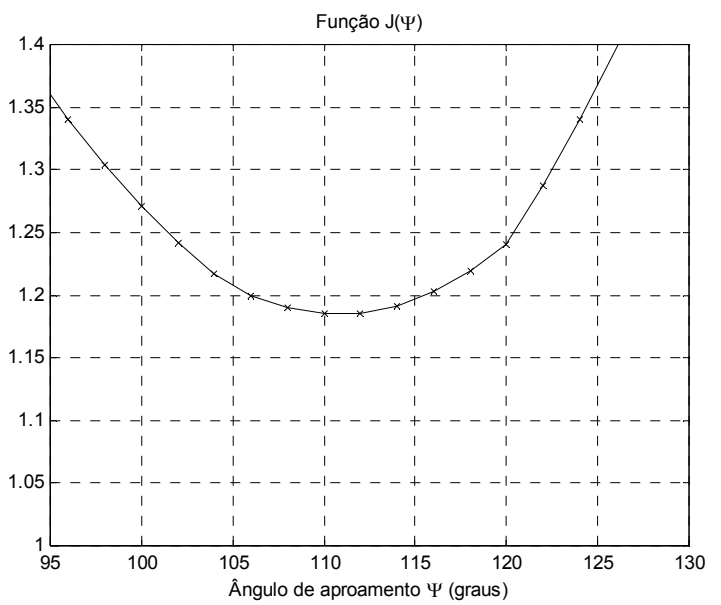

Figura 4.25 Função J( $\psi$ ) próxima ao ponto de aproamento ótimo

Em um grande número de casos, o ponto de mínimo global da função $J(\psi)$ satisfaz as restrições (4.82), correspondendo, portanto, ao aproamento ótimo procurado. Nestes casos, como as variações ocorrem em torno de um ponto de mínimo global, pode-se escrever:

$$
\left.\Delta J \cong \frac{1}{2} \frac{d^{2} J}{d \psi^{2}}\right|_{\psi_{\text {otimo }}}(\Delta \psi)^{2}
$$

o que mostra que a segunda derivada $\left(d^{2} J / d \psi^{2}\right)_{\psi_{\text {otimo }}}$ quantifica a sensibilidade do procedimento acima a erros de estimação das condições ambientais. Nos casos em que as restrições (4.82) não são satisfeitas no ponto de mínimo global, o aproamento ótimo corresponde a um ponto de mínimo local, em torno do qual pode não ser válida a relação (4.83). A estes casos, a análise feita a seguir não poderia, portanto, ser aplicada.

Para o caso analisado na Figura 4.25, a segunda derivada obtida numericamente vale 4,2 que, substituída em (4.83) leva à variação $\Delta J=0,064$ para a variação angular de $\pm 10^{\circ}$, como já citado anteriormente.

Mantendo-se as mesmas intensidades dos agentes ambientais considerados anteriormente, variou-se o ângulo entre a onda e a correnteza e foi avaliado o valor da segunda derivada $\left(d^{2} J / d \psi^{2}\right)_{\psi_{\text {otimo }}}$. Isto foi feito mantendo-se a correnteza fixa e 
variando-se a direção da onda $\alpha_{W, O X Y Z}$, apresentado-se o resultado na Figura 4.26a. Pode-se ver que para as direções nas quais os agentes ambientais se alinham $\left(\alpha_{W, O X Y Z}=\right.$ $90^{\circ}$ ou $270^{\circ}$ ) a segunda derivada apresenta maior valor, indicando que erros na avaliação dos agentes ambientais podem levar a maiores variações nos critérios incluídos na função $J(\psi)$.
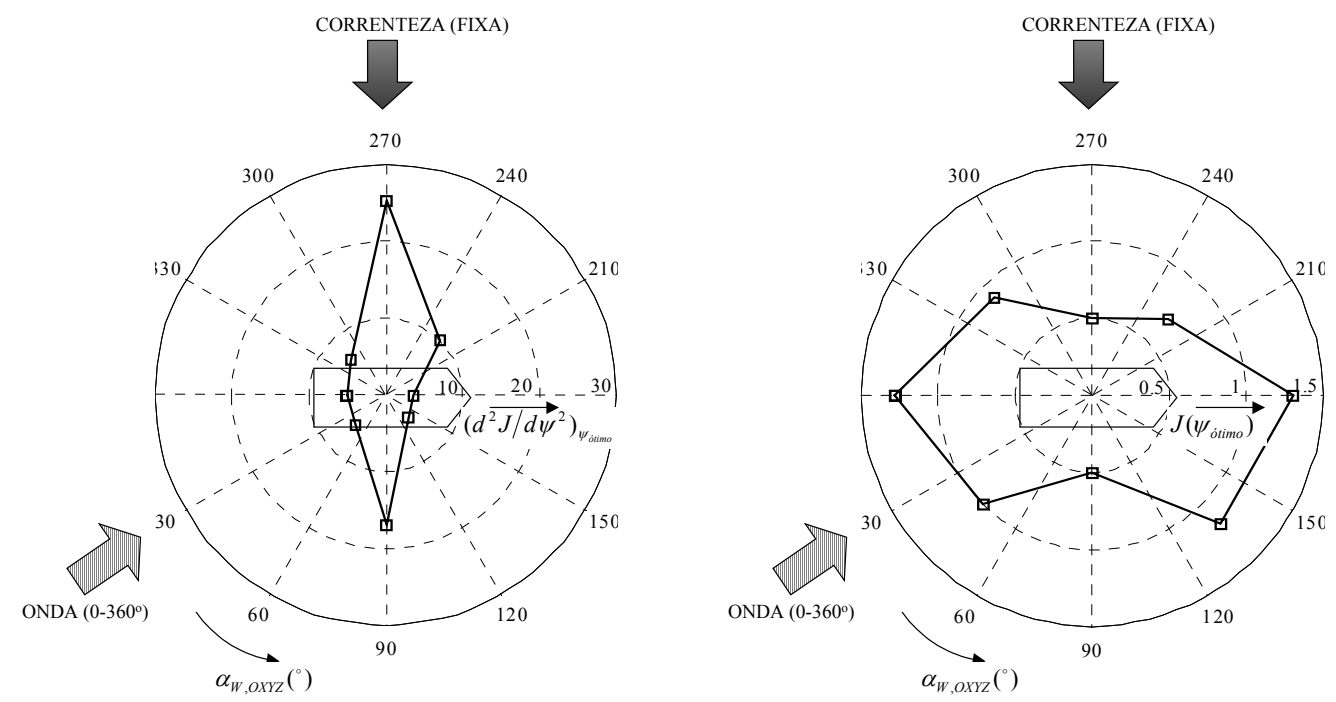

Figura 4.26 (a) Segunda derivada de $J(\psi)$ no ponto de mínimo; (b) Valor $J(\psi)$ no ponto de mínimo

Na Figura 4.26b apresenta-se o valor mínimo da função $J(\psi)$, na qual pode-se ver que, de forma contrária, quando os agentes ambientais se alinham, a função apresenta valores menores no aproamento ótimo. Assim, nestes casos nos quais a sensibilidade a erros na avaliação dos agentes ambientais é maior, as conseqüências destes erros serão menos intensas, já que se consegue alcançar valores menores de $J(\psi)$.

Por exemplo, no caso $\alpha_{W, O X Y Z}=270^{\circ}$, a segunda derivada vale 25,3 que, substituída em (4.83), resulta a variação $\Delta J=0,38$ para a variação angular de $\pm 10^{\circ}$. Como o valor ótimo de $J(\psi)$ é 0,5 neste caso, poder-se-ia alcançar um valor de $J(\psi)=0,88$, que é ainda baixo quando comparado a outras direções de onda.

Este exemplo permite inferir que, para as condições mais "fracas", o aproamento ótimo é mais sensível a erros nas estimativas ambientais. Ao contrário, condições críticas, que efetivamente podem levar a valores não admissíveis para os critérios operacionais, são mais "robustas". Ou seja, o aproamento ótimo calculado com 
condições ambientais ligeiramente diferentes das reais leva a um desempenho próximo ao obtido caso as condições ambientais reais fossem conhecidas com exatidão.

Deve-se ressaltar o fato de que estas inferências foram baseadas no exemplo analisado, não representando conclusões gerais a respeito da sensibilidade do presente método. Um algoritmo em malha fechada para o ajuste do aproamento ótimo poderia ser implementado para diminuir a sensibilidade do método, que possui tipicamente características de um sistema em malha aberta. Este tópico não será abordado no presente trabalho.

\subsection{Alocação de empuxo}

\subsubsection{Formulação do problema geral}

O problema considerado consiste no cálculo da força e ângulo azimutal (azimute) em cada um dos propulsores de forma que a força e momento resultantes sejam iguais aos comandados pelo controlador.

Seja $\mathbf{F}_{\mathbf{T}}=\left(F_{1 T}, F_{2 T}, F_{6 T}\right)^{T}$ o vetor com as forças de surge e sway e o momento de yaw comandados. Define-se o vetor $\mathbf{T}$ com as componentes em surge e sway da força de cada um dos $n_{\text {azim }}$ propulsores azimutais e a força dos $n_{\text {fixo }}$ propulsores fixos $\left(n_{\text {azim }}+n_{\text {fixo }}=n_{\text {prop }}\right)$ :

$$
\mathbf{T}=\left(\begin{array}{lllllllll}
T_{x_{1} 1}^{A} & \ldots & T_{x_{1} n_{\text {azim }}}^{A} & T_{x_{2} 1}^{A} & \ldots & T_{x_{2} n_{\text {azim }}}^{A} & T_{1+n_{\text {azim }}}^{F} & \ldots & T_{n_{\text {prop }}}^{F}
\end{array}\right)^{T}
$$

$\mathrm{Na}$ expressão, o sobrescrito A refere-se a azimutal e $\mathrm{F}$ a fixo. A relação entre os vetores $\mathbf{F}_{\mathbf{T}}$ e $\mathbf{T}$ é linear, dependente da posição dos propulsores $\left(x_{1, i P} ; x_{2, i P}\right), i=1 . . n$, em coordenadas locais do navio e da orientação $\alpha_{j P}\left(j=1+n_{\text {azim }} . . n_{\text {prop }}\right)$ dos propulsores fixos, e dada por:

$$
\mathbf{A T}=\mathbf{F}_{\mathbf{T}}
$$

com 


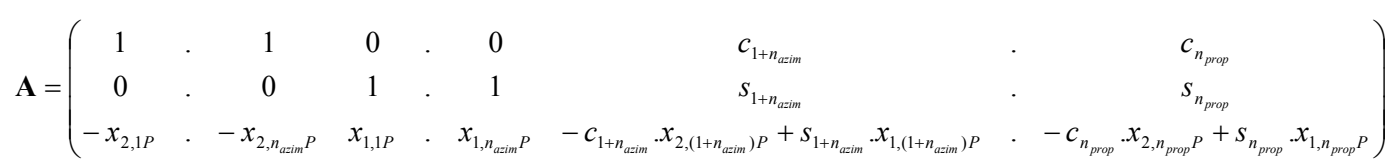

sendo $c_{i}=\cos \left(\alpha_{i P}\right)$ e $s_{i}=\operatorname{sen}\left(\alpha_{i P}\right)$.

A figura a seguir apresenta uma força gerada por um propulsor azimutal e por um propulsor fixo. No caso do propulsor azimutal, a força é tratada pelas suas componentes nas direções ox $_{1}$ e ox $_{2}$, já que pela liberdade de azimute $\left(\alpha_{i P}\right.$ variável) estas componentes podem variar independentemente, diferente dos propulsores fixos $\left(\alpha_{i P}\right.$ fixo).

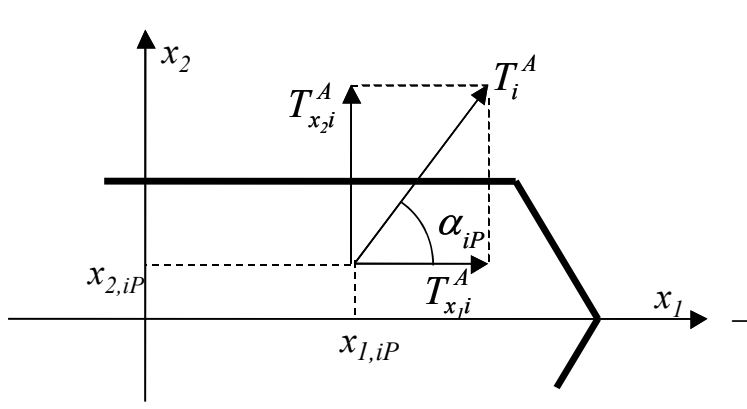

(a)

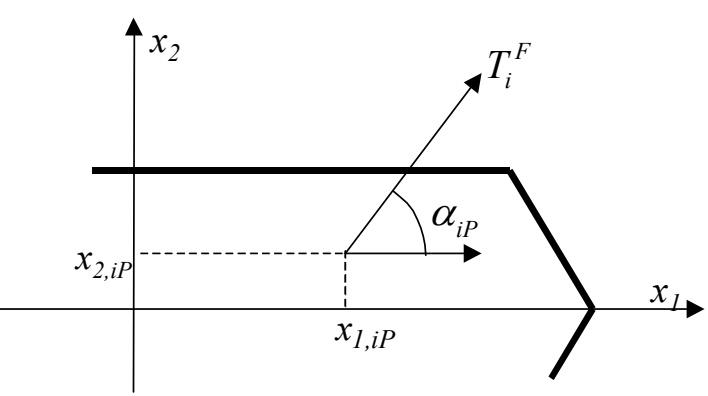

(b)

Figura 4.27 Definições para (a) propulsores azimutais - $i=1 . . n_{\text {azim }}$ e (b) propulsores fixos -

$$
i=1+n_{\text {azim }} \ldots n_{\text {prop }}
$$

Dado o vetor comandado $\mathbf{F}_{\mathbf{T}}$, a solução do vetor $\mathbf{T}$ pela equação (4.85) é, no geral, indeterminada, pois o número de igualdades, 3 , é menor que o número de incógnitas ${ }^{16}$ $\left(2 n_{\text {azim }}+n_{\text {Fixo }}\right)$. Esta indeterminação permite que se utilize um funcional que define a “melhor" solução, que no geral é definida como a que resulte num menor consumo de energia.

O problema de minimização pode, portanto, ser escrito como:

\footnotetext{
${ }^{16}$ Neste caso, o sistema é chamado de sobre-atuado. Em caso de número de variáveis de controle (incógnitas do problema de minimização) maior que 3, o sistema é dito sub-atuado.
} 
O funcional $L(\mathbf{T})$ representa uma medida do consumo de energia. No geral, fazse a aproximação de que a energia consumida seja proporcional à soma dos quadrados das forças de propulsão pois assim recai-se num problema de minimização com solução analítica, quando problemas de saturação forem desconsiderados, como será mostrado adiante. Numa análise mais acurada, entretanto, deve-se considerar a dependência correta entre força de propulsão e energia. ${ }^{17}$

Para se considerar a saturação dos propulsores durante a alocação das forças impõe-se $n_{\text {prop }}$ vínculos de desigualdade ao problema:

$$
\left\{\begin{array}{cc}
\sqrt{\left(T_{x_{1} i}^{A}\right)^{2}+\left(T_{x_{2} i}^{A}\right)^{2}} \leq T_{\max i} & i=1 . . . n_{\text {azim }} \\
T_{i}^{F} \leq T_{\max i} & i=1+n_{\text {azim }} . . n_{\text {prop }}
\end{array}\right.
$$

Para propulsores fixos sem reversão deve-se levar em conta também o vínculo de desigualdade $T_{i}^{F} \geq 0$.

\subsubsection{Considerações adicionais ao problema de alocação de empuxo}

A perda de eficiência dos propulsores quando direcionados para determinadas estruturas do casco pode ser incorporada no problema de alocação de empuxo. Este efeito é representado na Figura 4.28 para uma plataforma, na qual a força de arrasto que surge no flutuador oposto diminui a força total de propulsão.

\footnotetext{
${ }^{17}$ Em alguns trabalhos como o de Sinding e Andersen (1998), admite-se que a energia e a força de propulsão são proporcionais à rotação elevada a potência 3 e 2 respectivamente, resultando uma minimização da soma das forças elevadas a potência 3/2. Esta aproximação é mais próxima da realidade.
} 


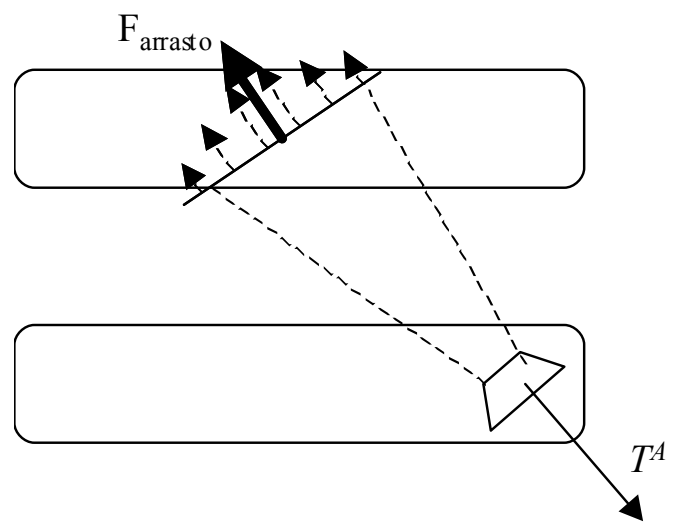

Figura 4.28 Interação casco-propulsor em uma plataforma

A Figura 4.29 contém o empuxo de um propulsor instalado em um casco tipo catamarã de uma plataforma semi-submersível. Há uma redução significativa do empuxo para direções nas quais o fluxo é propelido ao longo do flutuador $(20 \%$ de redução para $345^{\circ}$ até $15^{\circ}$ aproximadamente) ou em direção ao outro flutuador (redução de $30 \%$ para $270^{\circ}-285^{\circ}$ aproximadamente).

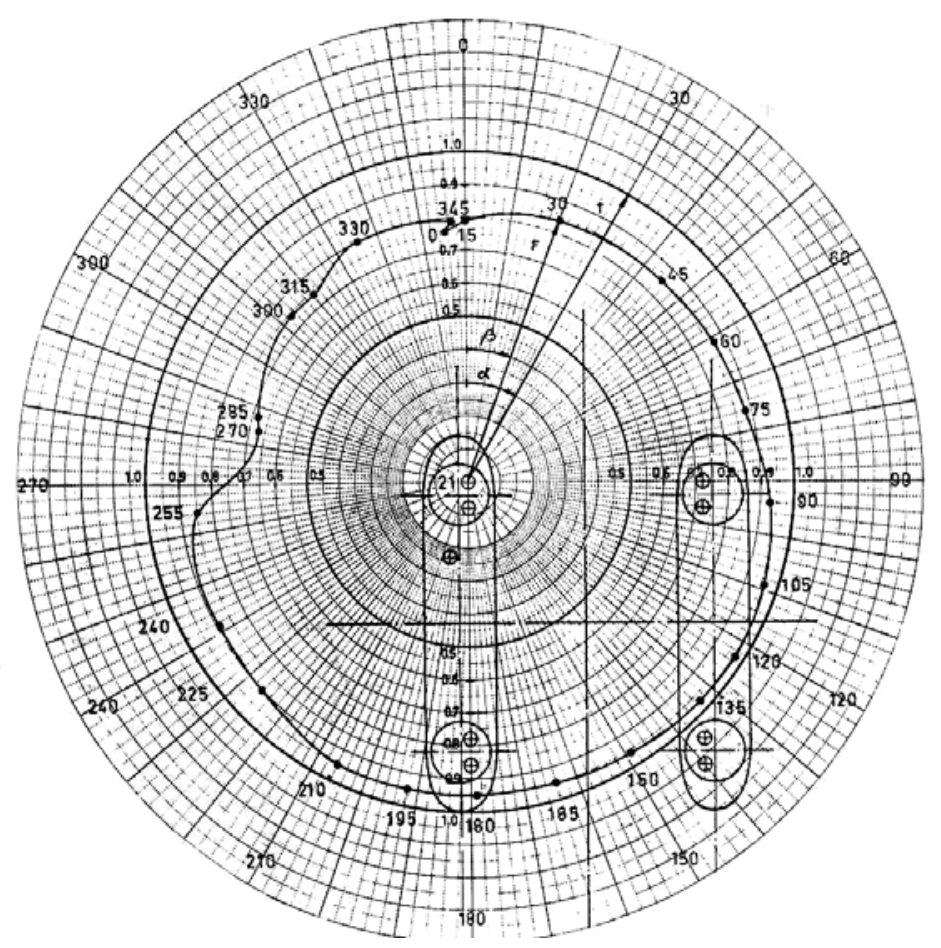

Figura 4.29 Interação entre propulsor e casco em um casco tipo catamarã de uma plataforma semisubmersível (extraído de Moberg; Hellstrõm, 1993) 
Uma abordagem possível para considerar este efeito na alocação de empuxo é a definição de "zonas proibidas" para o azimute, que são expressas matematicamente por vínculos de desigualdade. Alternativamente, este efeito pode ser levado em conta através de um coeficiente de perda de eficiência dependente do azimute $\eta_{\text {arrasto }, i}\left(\alpha_{i P}\right)$ incorporado à matriz $\mathbf{A}$, fazendo com que o vínculo (4.85) deixe de ser linear. Neste caso, é mais adequado utilizar um novo vetor de variáveis a minimizar e, conseqüentemente, um novo vínculo de igualdade:

$$
\begin{aligned}
& \mathbf{T}=\left(\begin{array}{lllllllll}
T_{1}^{A} & \ldots & T_{n_{\text {azim }}}^{A} & \alpha_{1 P}^{A} & \ldots & \alpha_{n_{\text {azim }} P}^{A} & T_{1+n_{\text {azim }}}^{F} & \ldots & T_{n_{\text {prop }}}^{F}
\end{array}\right)^{T} \\
& \sum_{i=1}^{n_{\text {azim }}} \eta_{\text {arrasto }, i}\left(\alpha_{i}\right) T_{i}^{A} c_{i}+\sum_{i=1+n_{\text {azim }}}^{n_{\text {prop }}} T_{i}^{F} c_{i}=F_{1 T} \\
& \sum_{i=1}^{n_{\text {azim }}} \eta_{\text {arrasto }, i}\left(\alpha_{i P}\right) T_{i}^{A} s_{i}+\sum_{i=1+n_{\text {azim }}}^{n_{\text {prop }}} T_{i}^{F} S_{i}=F_{2 T} \\
& \sum_{i=1}^{n_{\text {azim }}} \eta_{\text {arrasto }, i}\left(\alpha_{i P}\right) \cdot T_{i}^{A} \cdot\left(-x_{2, i P} c_{i}+x_{1, i P} s_{i}\right)+\sum_{i=1+n_{\text {azim }}}^{n_{\text {prop }}} T_{i}^{F} \cdot\left(-x_{2, i P} \cdot c_{i}+x_{1, i P} s_{i}\right)=F_{6 T}
\end{aligned}
$$

lembrando-se que $c_{i}=\cos \left(\alpha_{i P}\right)$ e $s_{i}=\operatorname{sen}\left(\alpha_{i P}\right)$. A interferência entre propulsores, que ocorre quando dois propulsores operam aproximadamente alinhados, também pode ser considerada no procedimento de alocação. Alguns modelos semi-empíricos vêm sendo desenvolvidos para se quantificar tais efeitos (Brandner; Renilson, 1998), mas ainda o procedimento convencional é baseado em ensaios exaustivos. Moberg; Hellstrõm (1983) realizaram medições da interferência entre propulsores e concluíram que seu efeito é relevante em caso de distância entre propulsores menor do que 20 diâmetros. A Figura 4.30 contém a relação entre o coeficiente adimensional de empuxo $K_{T}$, definido em (3.50) para o propulsor a jusante do fluxo gerado por um outro propulsor, e coeficiente $K_{T 0}$, referente ao caso sem a presença do propulsor a montante. 


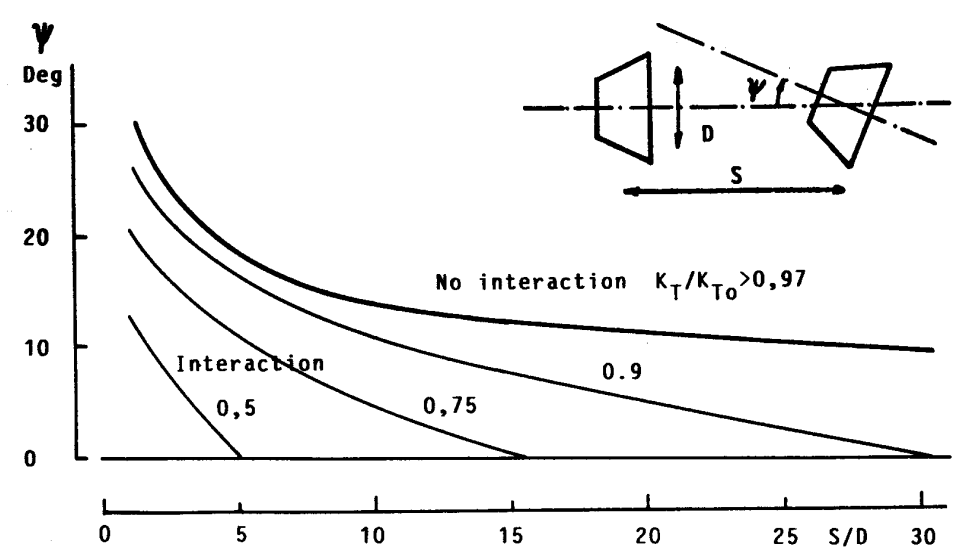

Figura 4.30 Interação entre propulsores (extraída de Moberg e Hellstrõm , 1983)

Devido à redundância utilizada em projetos de sistemas de posicionamento dinâmico, no geral os propulsores são posicionados relativamente próximos um dos outros e estes efeitos devem ser considerados. A abordagem utilizada no tratamento da interferência com o casco também pode ser utilizada na interferência entre propulsores.

Mais detalhes a respeito destes efeitos adicionais pode ser encontrado em Sinding; Andersen (1998).

Para se evitar desgaste no sistema de rotação azimutal dos propulsores, muitas vezes inclui-se no algoritmo de alocação um limitador de velocidade de rotação azimutal. Algumas abordagens para este problema serão expostas a seguir.

Sørdalen (1997) divide o problema de alocação em dois, sendo a primeira parte responsável pelo cálculo dos azimutes, cujas variações são atenuadas por meio de filtros passa-baixa. Além disso, rotações de $180^{\circ}$ são evitadas ao máximo aproveitando a capacidade de alguns propulsores de reversão da rotação das pás. Em seguida, estes azimutes são utilizados no cálculo das forças de propulsão. Posições singulares do sistema de propulsão são tratadas por meio da análise dos valores singulares da matriz $\mathbf{A}(\alpha)$.

Sinding; Andersen (1998), por sua vez, estimam a velocidade de rotação azimutal do propulsor por meio de diferenças finitas e impõem vínculos de desigualdade adicionais aos ângulos azimutais de forma que estas estimativas não ultrapassem um valor máximo estabelecido. 


\subsubsection{Solução do problema de alocação de empuxo}

\subsubsection{Solução sem considerar saturação}

Desconsiderando-se a saturação e qualquer outro vínculo de desigualdade, podese obter a solução analítica do problema de minimização (4.86), pois se trata de um caso de minimização de um funcional quadrático sujeito a um vínculo de igualdade linear.

O funcional $L(\mathbf{T})$ e o vínculo de igualdade $f(\mathbf{T})=0$ podem ser escritos como:

$$
\begin{aligned}
L(\mathbf{T}) & =\mathbf{T}^{T} \mathbf{T} \\
f(\mathbf{T}) & =\mathbf{A} \mathbf{T}-\mathbf{F}_{\mathbf{T}}
\end{aligned}
$$

Seguindo o procedimento convencional, exposto por exemplo em Lewis (1986), define-se um vetor de multiplicadores de Lagrange $\lambda$ com 3 elementos (um para cada vínculo de igualdade) e a função $F(\mathbf{T}, \lambda)=L(\mathbf{T})+\lambda f(\mathbf{T})$. A condição necessária satisfeita pela solução do problema de minimização é dada pelas $\left(2 . n_{\text {azim }}+n_{\text {prop }}+3\right)$ equações:

$$
\left\{\begin{array}{l}
\frac{\partial F}{\partial \mathbf{T}}=0 \quad \Rightarrow 2 \mathbf{T}+\mathbf{A}^{\mathbf{T}} \boldsymbol{\lambda}=0 \\
\frac{\partial F}{\partial \boldsymbol{\lambda}}=0 \quad \Rightarrow \mathbf{A T}-\boldsymbol{\tau}=0
\end{array}\right.
$$

sendo $\partial F / \partial \mathbf{T}$ e $\partial F / \partial \lambda$ vetores compostos pelas derivadas da função $F(\mathbf{T}, \boldsymbol{\lambda})$ em relação aos componentes dos vetores $\mathbf{T}$ e $\lambda$.

De (4.90)-a obtém-se $\mathbf{T}=1 / 2 \mathbf{A}^{T} \cdot \boldsymbol{\lambda}$ que substituído em (4.90)-b fornece os multiplicadores de Lagrange $\lambda=-2\left(\mathbf{A A}^{T}\right)^{-1} \mathbf{F}_{\mathbf{T}}$. Finalmente, voltando a (4.90)-a obtémse:

$$
\mathbf{T}=\mathbf{A}^{T}\left(\mathbf{A A}^{T}\right)^{-1} \mathbf{F}_{\mathbf{T}}
$$


A condição necessária (4.90) garante que a solução encontrada seja um ponto estacionário do funcional $L(\mathbf{T})$ sobre o vínculo definido por $f(\mathbf{T})=0$. Para que tal solução seja um ponto de mínimo, deve-se garantir também que a matriz $\partial^{2} F / \partial \mathbf{T}^{2}$, composta pelas segundas derivadas de $F(\mathbf{T}, \lambda)$ em relação aos elementos do vetor $\mathbf{T}$ seja positiva-definida. De fato:

$$
\frac{\partial^{2} F}{\partial \mathbf{T}^{2}}=2 . \mathbf{I}
$$

com I a matriz identidade com $\left(2 . n_{\text {azim }}+n_{\text {prop }}\right)$ linhas e colunas.

A matriz $\mathbf{A}^{T}\left(\mathbf{A A}^{T}\right)^{-1}$ é chamada de pseudo-inversa, denotada por $\mathbf{A}^{+}$. Logo, a solução deste problema é a simples multiplicação do vetor de força de comando $\tau$ por uma matriz constante previamente calculada.

A dedução acima é válida apenas quando o número de variáveis é maior do que o número de equações (4.85), ou seja, quando posto $(\mathbf{A}) \geq 3$ e o vínculo de igualdade $f(\mathbf{T})=0$ pode ser respeitado. Em caso contrário $^{18}$, o novo objetivo passa a ser a minimização do resíduo entre as forças e momento efetivamente aplicados pelos propulsores AT e os comandados $\mathbf{F}_{\mathbf{T}}$, que pode ser escrito como $\left\|\mathbf{A T}-\mathbf{F}_{\mathbf{T}}\right\|$. O novo problema pode ser escrito como:

$$
\min _{\mathbf{T}} R(\mathbf{T}), \operatorname{com} R(\mathbf{T})=\left\|\mathbf{A} \mathbf{T}-\mathbf{F}_{\mathbf{T}}\right\|
$$

A condição necessária satisfeita pela solução do problema acima é dada por:

$$
\frac{\partial R}{\partial \mathbf{T}}=0
$$

\footnotetext{
${ }^{18}$ Este caso ocorre em sistemas sub-atuados ou, como será visto adiante, sistemas sobre-atuados com diversos propulsores saturados.
} 
o que após algumas manipulações algébricas leva a $\mathbf{T}=\left(\mathbf{A}^{T} \mathbf{A}\right)^{-1} \mathbf{A}^{T} \mathbf{F}_{\mathbf{T}}$. Como $\partial^{2} R / \partial \mathbf{T}^{2}=\mathbf{A}^{T} \mathbf{A}$ é semipositiva definida, a solução encontrada fornece um mínimo para o resíduo $R(\mathbf{T})$. Quando posto $(\mathbf{A})<3$, a matriz $\left(\mathbf{A}^{T} \mathbf{A}\right)^{-1} \mathbf{A}^{T}$ é justamente a pseudoinversa de $\mathbf{A}$.

Assim, $\mathbf{T}=\mathbf{A}^{+} \mathbf{F}_{\mathbf{T}}$ minimiza $\left\|\mathbf{A T}-\mathbf{F}_{\mathbf{T}}\right\|$ quando posto $(\mathbf{A})<3$ e como o valor numérico do momento de yaw é, em geral, duas ordens de grandeza superior às forças de surge e sway, esta minimização significa priorizar fortemente o momento perante as forças $^{19}$. Para muitos casos de posicionamento dinâmico, nos quais o controle de aproamento é mais importante do que a translação, este efeito é interessante.

A utilização do conceito de pseudoinversas em problemas de alocação de propulsores pode ser encontrada por exemplo em Sørdalen (1997). Definições matemáticas e deduções mais detalhadas a respeito de matrizes pseudoinversas são apresentadas em Demmel (1997) e Ogata (1990).

Quando um ou mais propulsores atinge o valor máximo de sua força, o método acima perde a validade, na medida em que o vínculo de igualdade passa a ser desrespeitado. Para abordar estes problemas, deve-se formular o problema completo com os vínculos de desigualdade (saturação) indicados em (4.87).

\subsubsection{Solução considerando saturação}

A solução do problema completo levando em conta o vínculo (4.87) é mais complexa do que o caso anterior, por se tratar de um vínculo de desigualdade não-linear. Existem diversos métodos numéricos para abordar este tipo de problema, como por exemplo a Programação Quadrática Seqüencial (SQP), na qual o problema geral com vínculos é dividido em subproblemas de Programação Quadrática com vínculos lineares obtidos por linearização (Bazaara; Sherali; Shetty, 1993). Em geral, o tempo computacional despendido por tais métodos é bastante alto. Uma abordagem alternativa para este problema, que leva a uma solução num tempo computacional bem inferior, será descrita a seguir.

\footnotetext{
${ }^{19}$ Deve-se notar que quando o problema é adimensionalizado, o valor numérico do momento de yaw se torna da mesma ordem dos valores das forças. Neste caso, a minimização de $\|\mathbf{A T}-\boldsymbol{\tau}\|$ não prioriza mais a componente do momento.
} 
Inicialmente, resolve-se o problema sem vínculo de desigualdade utilizando o procedimento descrito em (4.3.3.1). Caso a força de propulsão não tenha ultrapassado o valor de saturação em nenhum propulsor, o problema está resolvido. Em caso contrário, procede-se uma nova minimização sem desigualdade, desconsiderando agora os propulsores saturados e redefinindo-se a força comandada, de forma a desconsiderar da mesma a parcela já fornecida pelos propulsores saturados. O processo iterativo é interrompido quando nenhum dos propulsores restante satura. Ou, caso isto não ocorra, até que todos os propulsores estejam saturados.

Em casos extremos, a saturação de diversos propulsores leva a uma minimização na qual o número de variáveis é menor que 3, e a equação (4.85) deixa de ser respeitada. Isto acontece quando, por exemplo, restam apenas 2 propulsores fixos ou 1 propulsor azimutal não saturados. Nestes casos, a solução $\mathbf{T}=\mathbf{A}^{+} \mathbf{F}_{\mathbf{T}}$ minimiza o resíduo $\left\|\mathbf{A T}-\mathbf{F}_{\mathbf{T}}\right\|$ e, como já mencionado, apenas o momento de yaw comandado é respeitado.

Deve-se ressaltar que não se realizou uma prova formal de que este método leva à solução ótima. Porém, para o caso analisado na seção seguinte, efetivamente permitiu a obtenção da solução ótima num tempo computacional bem inferior ao algoritmo SQP.

\subsubsection{Comparação entre os métodos}

A fim de se ilustrar o desempenho de cada um dos métodos propostos, será utilizada a configuração de propulsores da BGL1, uma barcaça de lançamento de linhas que será equipada com um sistema de posicionamento dinâmico atuado por 6 propulsores azimutais, posicionados conforme a Figura 4.31. Cada propulsor possui potência de $1650 \mathrm{~kW}$, com um empuxo máximo de aproximadamente $300 \mathrm{kN}$.

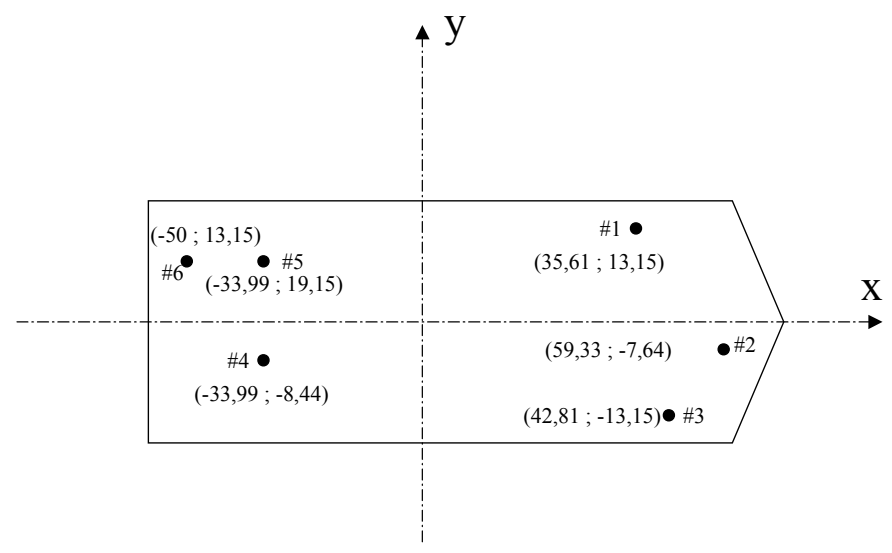

Figura 4.31 Posição dos 6 propulsores azimutais da BGL1 
Para ilustrar de maneira clara a diferença fundamental entre os métodos, considera-se o caso de que o sistema de controle requeira: força em surge nula e força de sway e momento de yaw seguindo as séries temporais mostradas na Figura 4.32.

No caso da minimização sem levar em conta a saturação, o propulsor 2 satura-se em 330s (ver Figura 4.33) e a partir deste instante as forças e momento efetivamente aplicadas pelo sistema de propulsão deixam de acompanhar as comandadas, como mostrado na Figura 4.34.

Já com a minimização considerando a saturação dos propulsores utilizando o algoritmo proposto em (4.3.3.2), a saturação do propulsor 2 em 330s não afeta a força aplicada pelo sistema de propulsão, na medida em que é compensada pelos propulsores 1 e 3 (Figura 4.35 e Figura 4.36). Quando a saturação é atingida em todos os propulsores de proa (em 380s), os propulsores de popa (4, 5 e 6) conseguem compensálos até $422 \mathrm{~s}$, quando resta apenas o propulsor 4 ainda não saturado. A partir deste instante, apenas o momento comandado consegue ser respeitado, na medida em que o número de variáveis (forças $T_{x_{1} 4}^{A}$ e $T_{x_{2} 4}^{A}$ ) se torna menor que o número de equações a serem satisfeitas (3 equações) e o método passa a minimizar o resíduo $\left\|\mathbf{A T}-\mathbf{F}_{\mathbf{T}}\right\|$. Em 440s todos os propulsores atingem a saturação e não se respeita tampouco o momento comandado.

O algoritmo de minimização SQP também foi testado, e os resultados são apresentados na Figura 4.37 e Figura 4.38. Pode-se ver que apresenta resultados semelhantes ao do método exposto anteriormente até 422s, quando ocorre a saturação de todos os propulsores exceto o de número 4. A partir daí, o algoritmo não mais consegue manter o vínculo de igualdade (4.85) e deixa de ser aplicável, mantendo nem mesmo o momento aplicado próximo ao comandado. O tempo computacional gasto pelo método SQP é da ordem de 80 vezes superior ao gasto pelo algoritmo proposto em 4.3.3.2. 

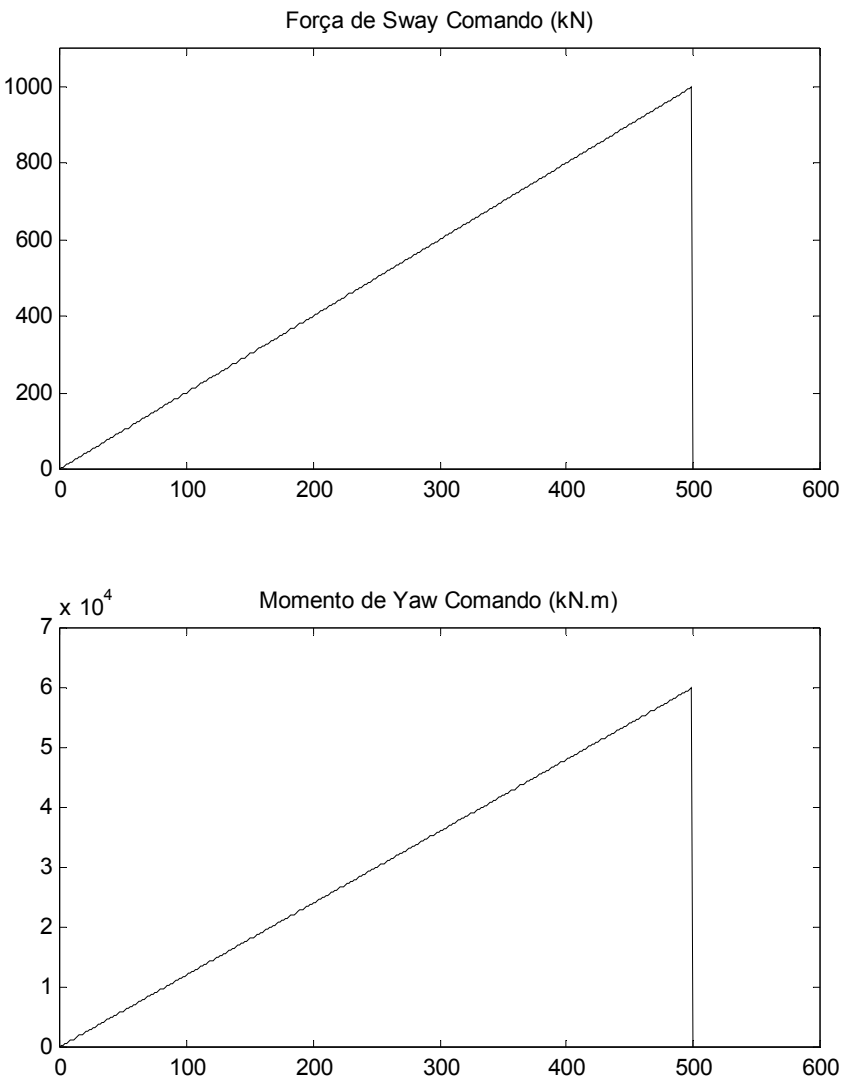

Figura 4.32 Força de sway e momento de yaw comandados 
140
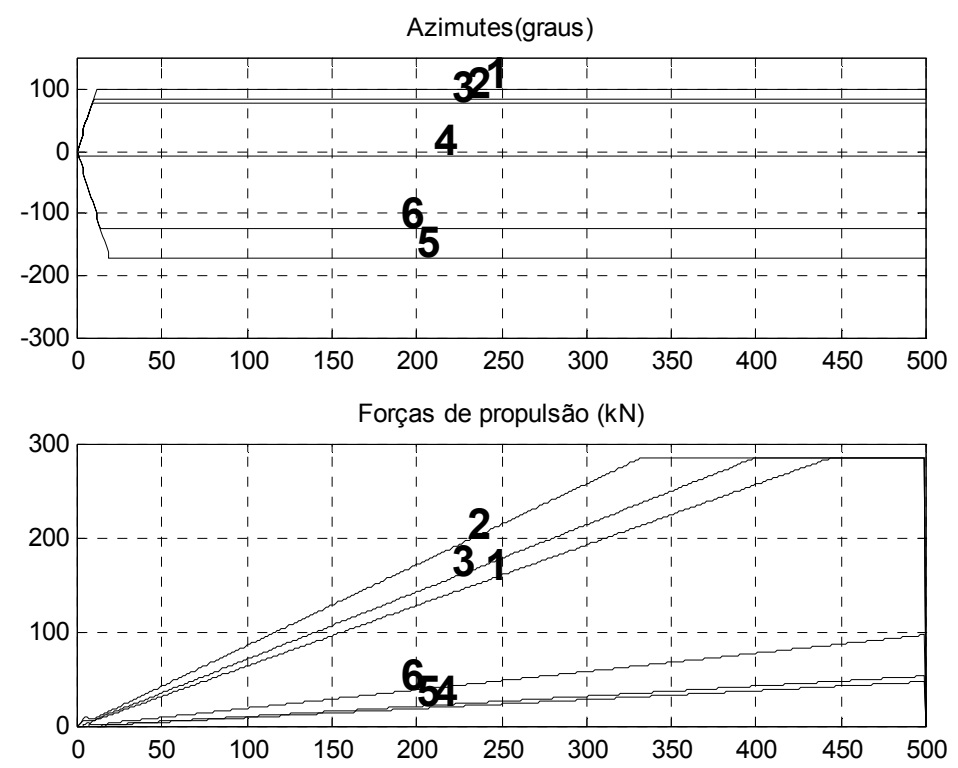

Figura 4.33 Azimutes e Forças de propulsão em cada propulsor - minimização sem considerar saturação
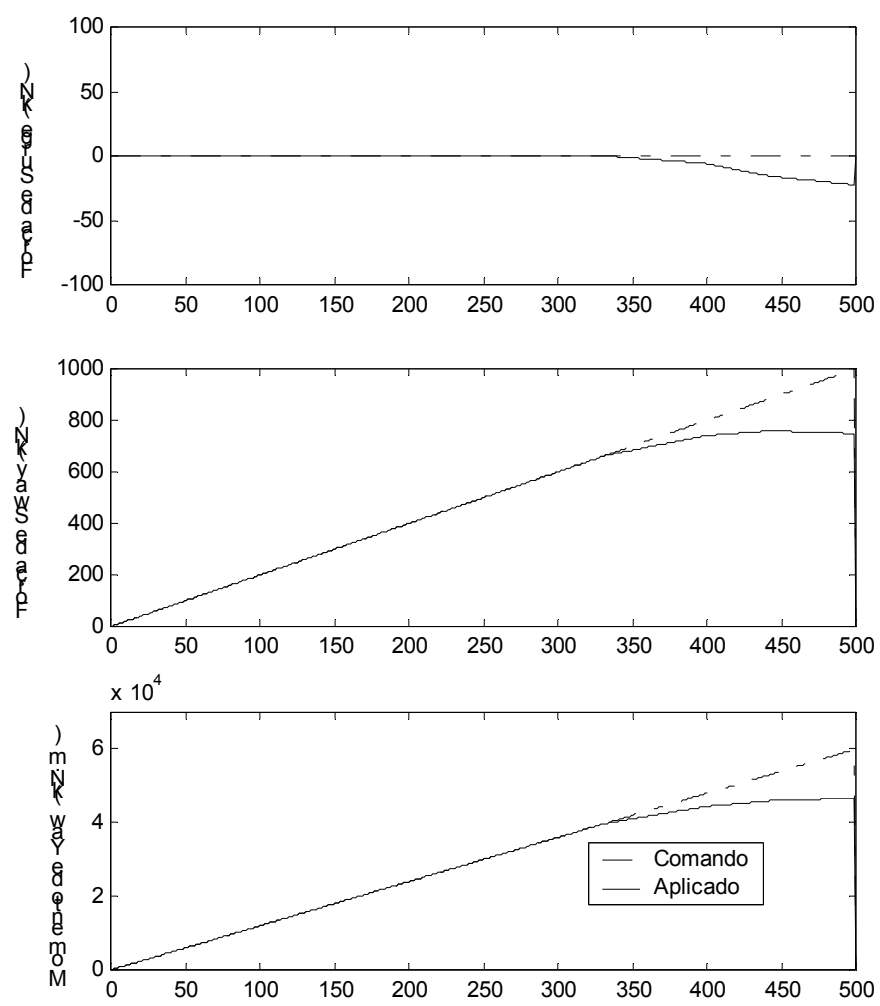

Figura 4.34 Forças comandadas e forças efetivamente aplicadas - minimização sem considerar saturação 

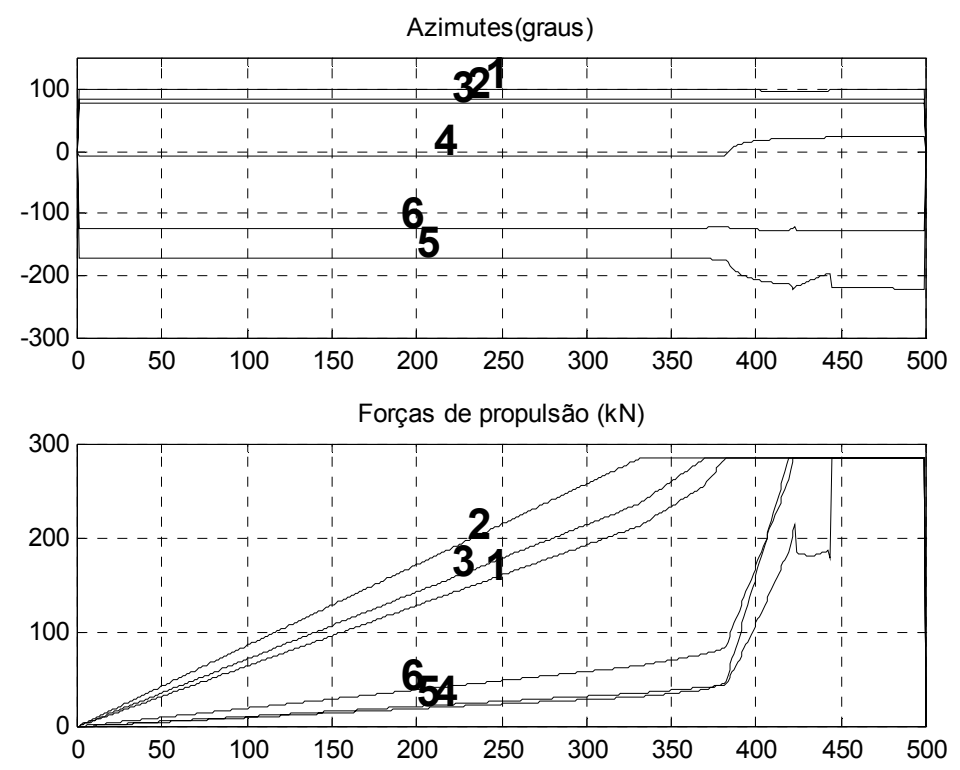

Figura 4.35 Azimutes e Forças de propulsão em cada propulsor - minimização considerando saturação
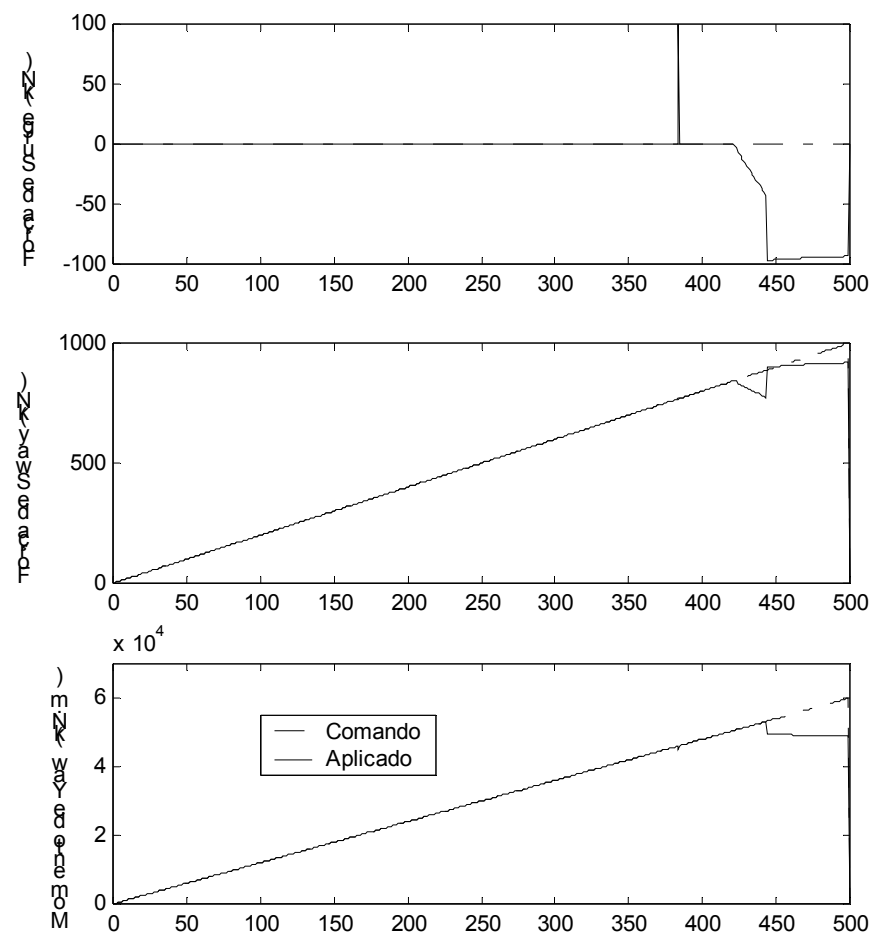

Figura 4.36 Forças comandadas e forças efetivamente aplicadas - minimização considerando saturação 

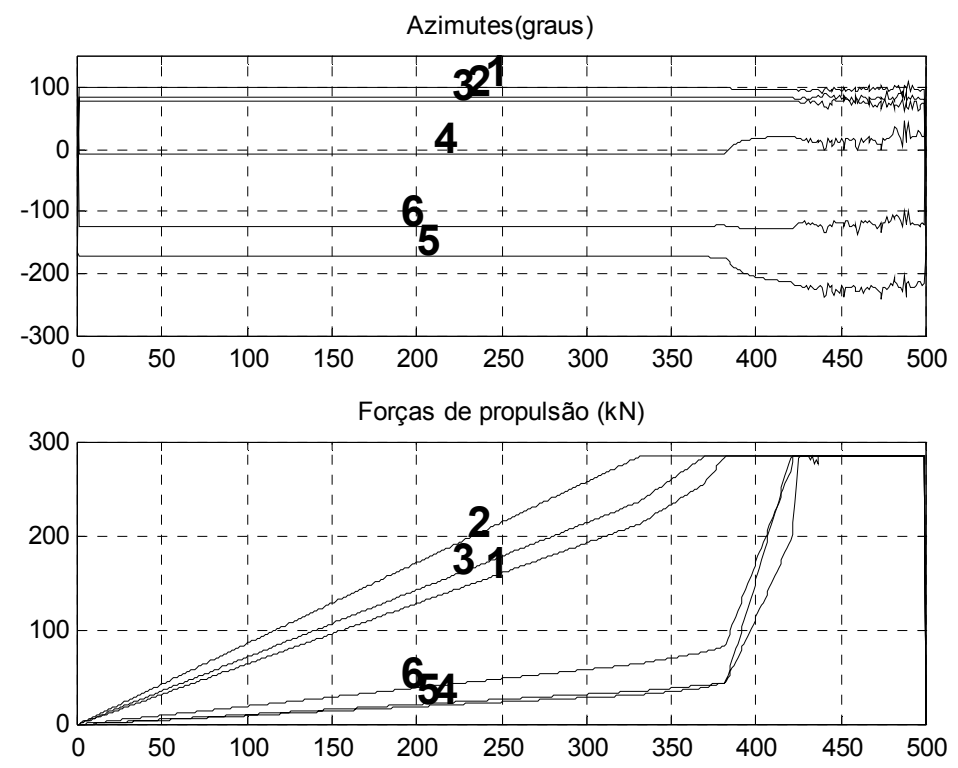

Figura 4.37 Azimutes e Forças de propulsão em cada propulsor - algoritmo SQP
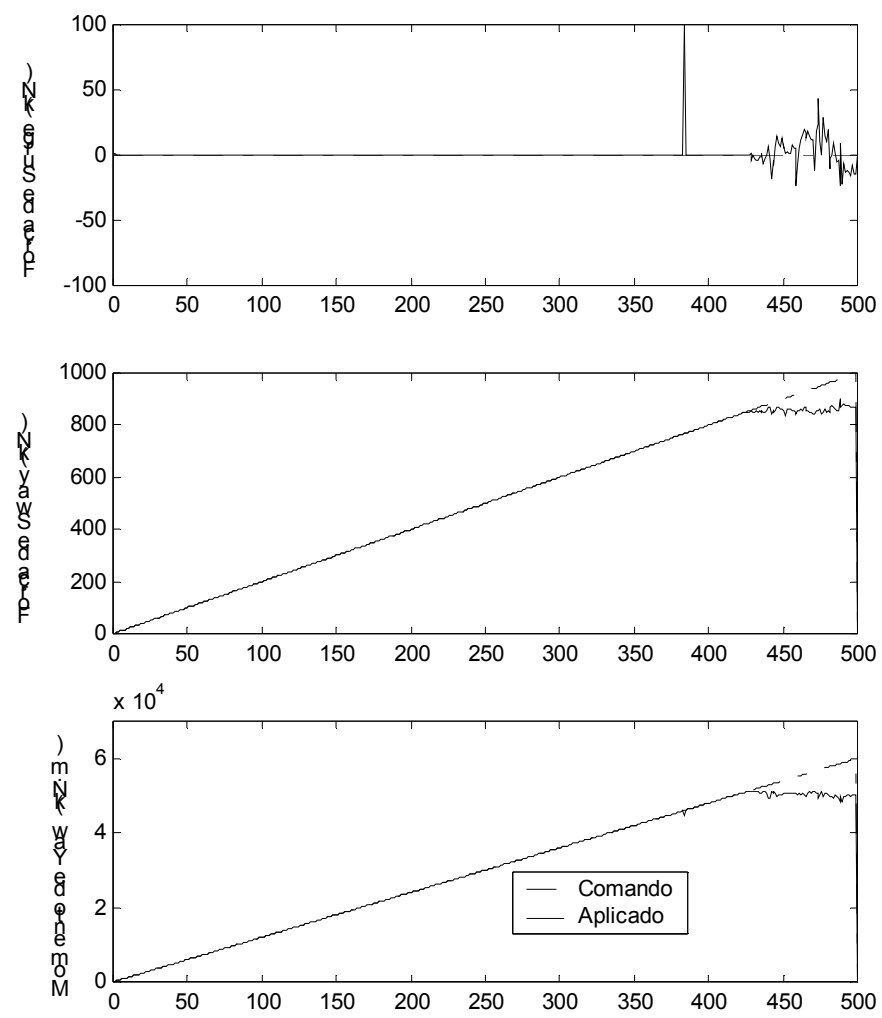

Figura 4.38 Forças comandadas e forças efetivamente aplicadas - algoritmo SQP 
Os métodos de alocação propostos foram implementados no simulador do sistema de posicionamento dinâmico da BGL1. Com o intuito de compará-los, utilizou-se uma estratégia de controle "ideal", baseada na inversão do modelo simulado da dinâmica e dos agentes ambientais (linearização por realimentação - feedback linearization). Para condições ambientais não extremas, os propulsores não atingem a saturação e os dois métodos comportam-se de maneira totalmente equivalente. Ao contrário, em condições extremas alguns propulsores atingem a saturação, e o método descrito em 4.3.3.2 apresenta um desempenho bem superior, como é evidenciado na análise a seguir. Nesta comparação o algoritmo SQP não foi analisado, por requerer um tempo computacional exageradamente alto $^{20}$.

Considerando uma operação de lançamento S-lay ${ }^{21}$ com o propulsor 4 inativo, correnteza de $1 \mathrm{~m} / \mathrm{s}$, ondas de altura significativa $2 \mathrm{~m}$, período de pico de $8,4 \mathrm{~s}$ e ventos com rajadas de $12 \mathrm{~m} / \mathrm{s}$, todos incidentes a $90^{\circ}$ em relação à embarcação, verifica-se a saturação quase permanente dos propulsores 5 e 6 . Utilizando o algoritmo de alocação que não leva em conta a saturação, obtém-se um passeio médio no ponto de lançamento de $13,9 \mathrm{~m}$ e passeio máximo de 22,6m, o que já inviabiliza a operação, além de um erro médio de $6,3^{\circ}$ no aproamento com valor máximo de $9,8^{\circ}$. Na Figura 4.39 apresenta-se o resultado desta simulação, incluindo o traço das posições da barcaça, o passeio do ponto de referência e as séries temporais dos azimutes e das forças de propulsão. A potência total média gasta pelo sistema de propulsão é de $6522 \mathrm{~kW}$.

Já no caso do algoritmo que considera a saturação (Figura 4.40), os propulsores 2 e 3 atuam de forma a compensar os propulsores 5 e 6 . Neste caso, o passeio do ponto de referência se reduz a 2,0m em média, com valor máximo de $11 \mathrm{~m}$ e o aproamento é mantido em $0^{\circ}$ com valor máximo de $3,5^{\circ}$, viabilizando a operação. Observa-se também uma variação mais intensa dos azimutes, que entretanto não ultrapassam o valor máximo admissível de $9 \%$ s. A potência total média gasta pelo sistema de 5 propulsores é de $6600 \mathrm{~kW}$, superior ao caso anterior, o que é esperado na medida em que os propulsores 2 e 3 passam a ser mais solicitados.

\footnotetext{
${ }^{20}$ Em casos de processamento em tempo real, em virtude da lenta resposta do sistema, a implementação de um algoritmo deste tipo é viável.

21 No lançamento S-lay, o duto lançado impõe uma força longitudinal média de 90ton sobre a embarcação. Esta força é aplicada na popa, na extremidade do stinger, a 90,7m da secção mestra e afastado $12,9 \mathrm{~m}$ à boreste da linha de centro.
} 

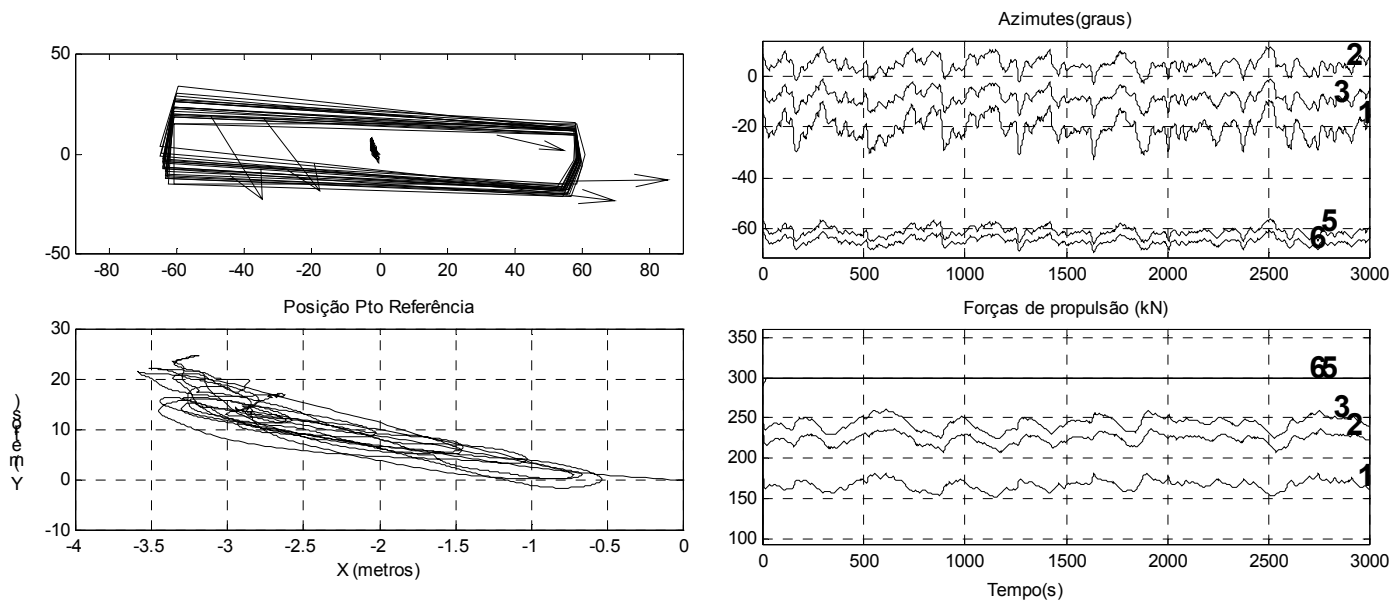

Figura 4.39 Sistema de posicionamento dinâmico aplicado a BGL1 - algoritmo de alocação sem considerar saturação
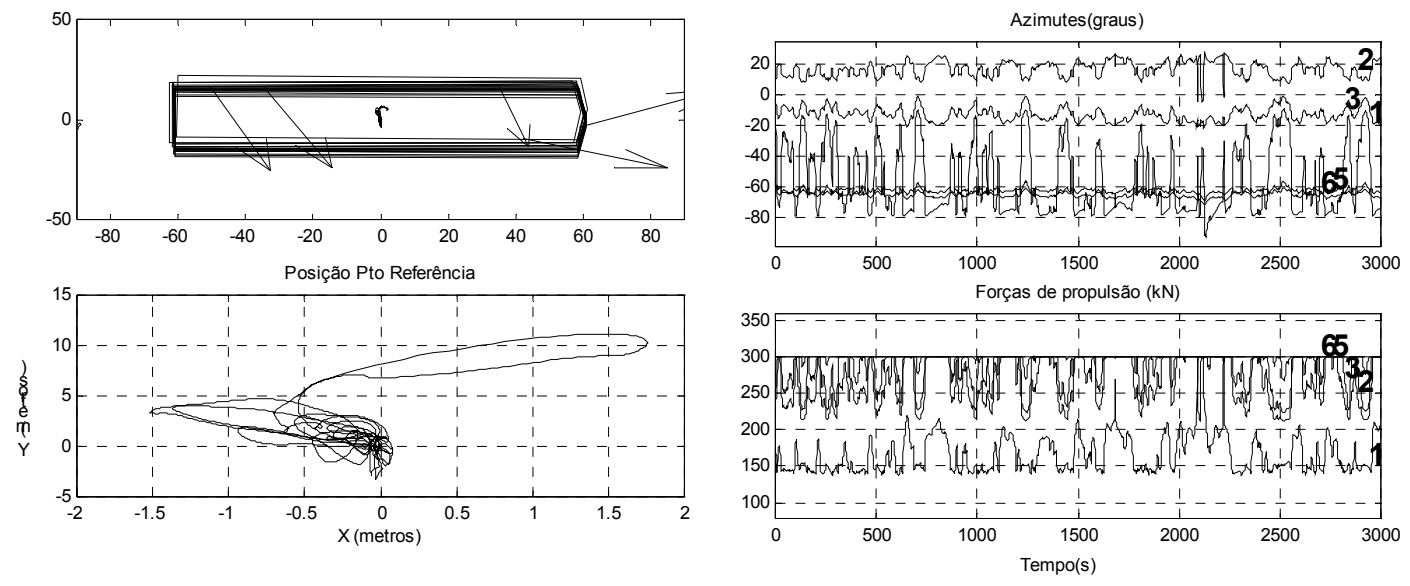

Figura 4.40 Sistema de posicionamento dinâmico aplicado a BGL1 - algoritmo de alocação considerando saturação

\subsection{Filtros de onda}

Nesta seção descrevem-se os filtros de onda comumente utilizados, responsáveis pela atenuação das componentes de alta freqüência das medidas (componentes excitadas pelas forças de primeira ordem devidas a ondas). Embora no presente trabalho tenha-se utilizado unicamente o filtro notch em cascata, descrito em Fossen (1994), serão expostos outros tipos de filtros e serão feitas comparações entre eles.

Os movimentos de primeira ordem devem ser eliminados das medidas dos movimentos horizontais do navio, pois os mesmos não podem ser atenuados pelo 
controlador já que possuem elevada freqüência e exigiriam potência impraticável do sistema de controle. Além disso, as forças comandadas pelo controlador, na presença destes movimentos "corrompendo" as medidas, tornam-se extremamente oscilatórias e podem danificar o sistema de atuação (propulsores e comandos) além de representar gastos de energia desnecessários.

As ondas do mar apresentam componentes significativas na faixa de $0,3 \mathrm{rad} / \mathrm{s}$ a $1,25 \mathrm{rad} / \mathrm{s}$, bastante distinta da faixa de interesse para os movimentos horizontais de baixa freqüência que devem efetivamente ser controlados $(\omega<0.1 \mathrm{rad} / \mathrm{s})$ em navios de grande e médio porte.

No início do desenvolvimento de SPDs utilizaram-se filtros convencionais do tipo passa baixa de Butterworth e filtros notch (Fossen, 1994). Os filtros passa baixa, entretanto, introduzem um atraso de fase muito significativo sobre o sinal, diminuindo o desempenho do sistema em malha fechada e podendo levar até mesmo à instabilidade. Apresenta-se na Figura 4.41 por exemplo um filtro Butterworth de ordem 3 com freqüência de corte de 0,3rad/s. Supondo-se uma freqüência de pico de espectro de $0,5 \mathrm{rad} / \mathrm{s}$ (equivalente a um período de pico de 12,5s), a atenuação nesta freqüência é de $-23 \mathrm{~dB}$ e o atraso de fase alcança o elevado valor de $220^{\circ}$.

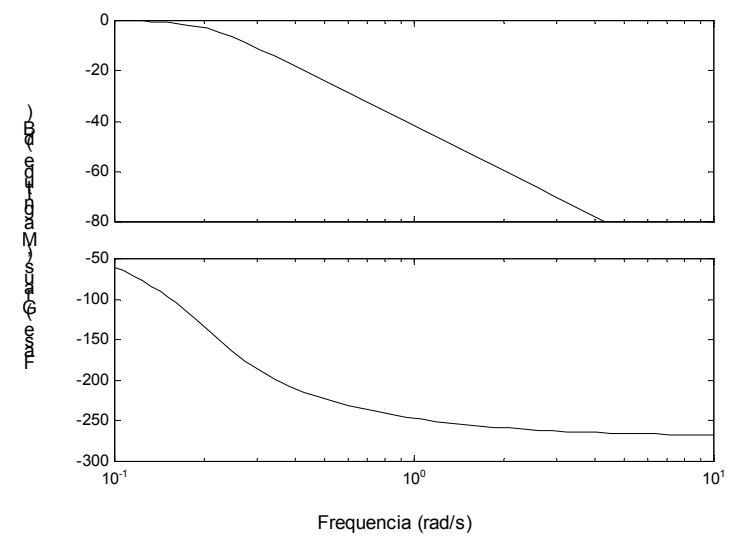

Figura 4.41 Gráfico de Bode do filtro Butterworth de ordem 3 e freqüência de corte $0,2 \mathrm{rad} / \mathrm{s}$

Para contornar este problema, os filtros notch passaram a ser empregados, pois garantem uma atenuação maior na faixa de freqüências de ondas às custas de um menor atraso de fase. A formulação deste filtro é dada por: 


$$
H_{\text {onda }}(s)=\frac{s^{2}+2 \zeta \omega_{n} s+\omega_{n}^{2}}{\left(s+\omega_{n}\right)^{2}}
$$

sendo $\omega_{n}$ a freqüência central de atenuação que deve ser ajustada o mais próximo possível da freqüência de pico do espectro de ondas e $\zeta$ um parâmetro que regula a atenuação e o atraso de fase. Ajustando-se $\omega_{n}=0.5 \mathrm{rad} / \mathrm{s}$ e $\zeta=0.1$ obtém-se o gráfico de Bode mostrado na Figura 4.42. De fato, pode-se ver que para uma atenuação em $0,5 \mathrm{rad} / \mathrm{s}$ de $-20 \mathrm{~dB}$ (próxima à alcançada com o filtro Butterworth), obtém-se um atraso de fase inferior a $55^{\circ}$, para todas as freqüências de interesse.

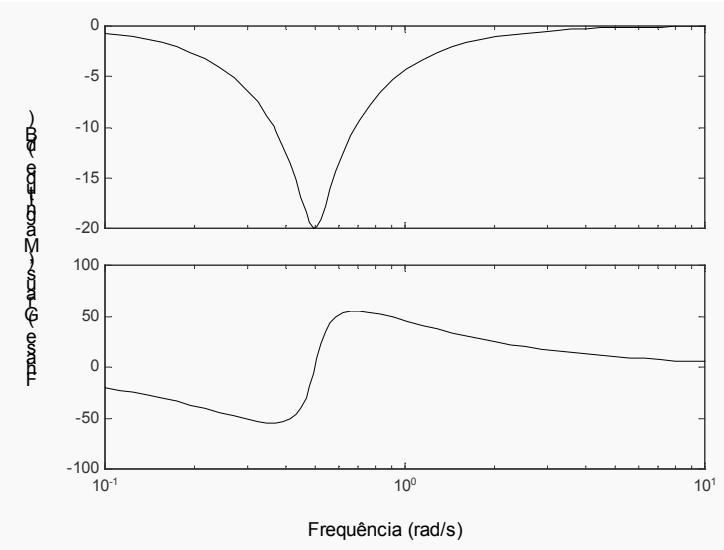

Figura 4.42 Gráfico de Bode do filtro notch (4.95) com $\omega_{\mathrm{n}}=0.5 \mathrm{rad} / \mathrm{s}$ e $\zeta=0.1$

Entretanto, estes filtros requerem uma estimativa muito acurada da freqüência de pico de espectro. Caso o projeto seja feito com uma freqüência diferente da real, o desempenho da filtragem diminui significativamente, já que a faixa de atenuação é muito estreita. Para resolver este problema, em geral associam-se a estes filtros estimadores de freqüência de pico de espectro, como citado em Sørhein; Galtun (1977).

Como a evolução da computação digital, diferentes abordagens também passaram a ser desenvolvidas, através da utilização de observadores de estados. As matrizes de ganho dos observadores podem ser calculadas por métodos de alocação de pólos, abordagem LQG/LTR ou filtros de Kalman. A grande vantagem deste último filtro é o uso do modelo do sistema na separação entre as componentes de alta e baixa freqüência, levando, teoricamente, a um desempenho superior. 
Schei (1996) realizou uma comparação entre filtros notch convencionais e filtros de Kalman, concluindo que aproximadamente o mesmo desempenho é alcançado em ambos os casos. Entretanto, o autor ressalva que os filtros de Kalman possuem a vantagem adicional de permitirem a estimação em tempo real da freqüência de pico do espectro, atualizando os ganhos do filtro conforme ocorre uma mudança lenta nesta freqüência. Com isso, consegue-se uma filtragem mais efetiva para todos os estados de mar. Schei não analisou, entretanto, mecanismos de estimação de freqüência aplicados aos filtros notch.

Este problema já havia sido observado por Sørhein; Galtun (1977), que realizaram comparações entre filtros de Kalman e filtros notch. Devido a estimação da freqüência de pico de espectro realizada pelo filtro de Kalman, seu desempenho mostrou-se bom para todos os estados de mar. No caso dos filtros notch, entretanto, diferentes estados de mar levam a diferentes desempenhos, já que a freqüência de pico do espectro não é estimada. Novamente, o autor não analisou mecanismos de estimação de freqüência aplicados aos filtros notch.

Uma alteração nos filtros notch foi apresentada em Grimble; Johnson (1989), que associaram três filtros, dando origem ao filtro notch em cascata. Neste caso, conseguese grande atenuação para uma faixa de freqüência mais larga, podendo ser aplicado para diversos estados de mar. Diminui-se assim o problema dos filtros notch convencionais, sem introduzir com isso atrasos de fase muito elevados.

No simulador em desenvolvimento, implementou-se o filtro notch em cascata dado por:

$$
H_{\text {onda }}(s)=\prod_{i=1}^{3} \frac{s^{2}+2 \zeta \omega_{i} s+\omega_{i}^{2}}{\left(s+\omega_{i}\right)^{2}}
$$

com $\omega_{1}=0,4 \mathrm{rad} / \mathrm{s} ; \omega_{2}=0,63 \mathrm{rad} / \mathrm{s} ; \omega_{3}=1,0 \mathrm{rad} / \mathrm{s}$ e $\zeta=0,1$. O gráfico de bode do filtro é apresentado na Figura 4.43. 


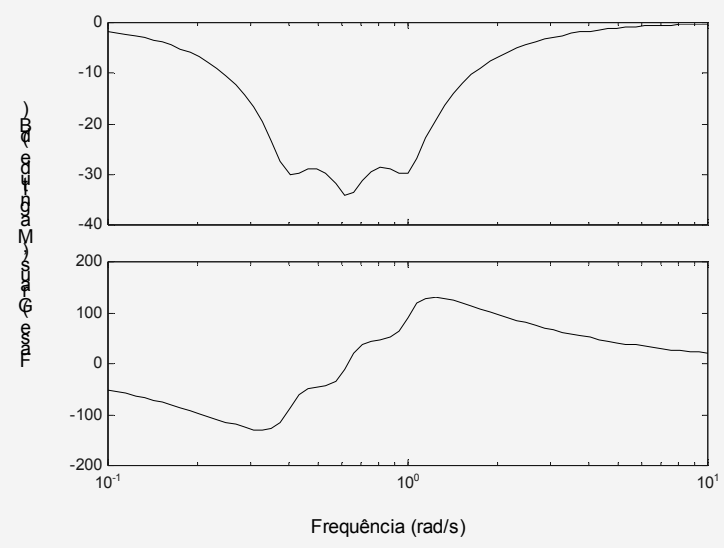

Figura 4.43 Gráfico de Bode do filtro notch em cascata implementado no simulador

Como exemplo, considera-se o VLCC Vidal de Negreiros 100\% carregado sujeito às condições ambientais indicadas na Figura 4.44a, com aproamento controlado em $48^{\circ}$ em relação à correnteza e $42^{\circ}$ em relação às ondas. A velocidade de correnteza é de $1,2 \mathrm{~m} / \mathrm{s}$ e a onda apresenta altura significativa de $4,8 \mathrm{~m}$ e período de pico de espectro de 12s. Apresentam-se na Figura 4.44b os movimentos totais e os movimentos filtrados por meio do filtro notch em cascata. Pode-se verificar a boa eficiência do filtro, atenuando as componentes de alta freqüência e introduzindo um atraso não significativo às medições.

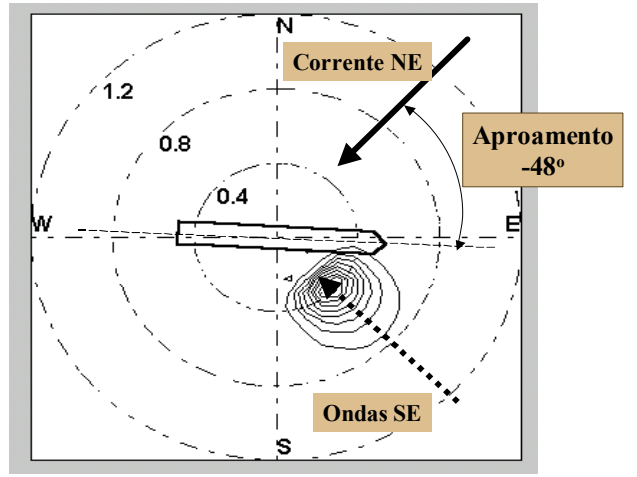

(a)
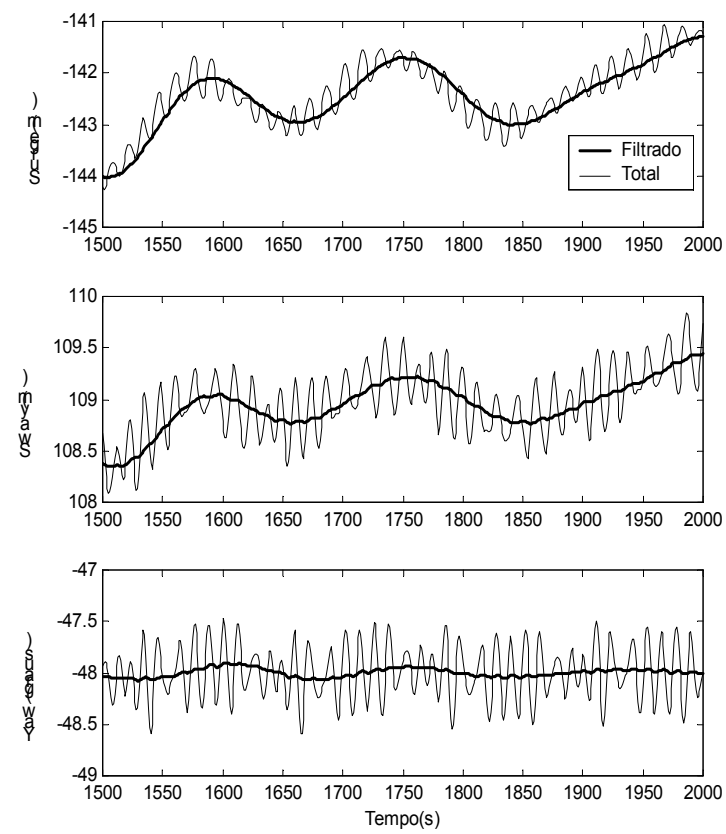

(b)

Figura 4.44 (a) Condições ambientais; (b) Movimento total medido e movimento filtrado utilizando-se o filtro notch em cascata 


\section{Sensoriamento de ondas}

No projeto do controlador de nível inferior (seção 4.1) e de nível superior (seção 4.2), verificou-se a necessidade de se obter estimativas das condições ambientais (ondas, vento e correnteza). Uma atenção especial é dada ao caso das ondas, já que os sensores já existentes são, em geral, complexos e apresentam problemas operacionais descritos em 2.3.

Assim, desenvolveu-se um método de estimação do espectro de ondas incidentes baseado no sensoriamento das acelerações da embarcação. O método é apresentado na seção 5.1, baseando-se em uma abordagem paramétrica na qual o espectro direcional é escrito em função de 8 parâmetros a determinar. Através de algoritmo de otimização não-linear, a diferença (erro) entre os movimentos medidos e os preditos pela aplicação do espectro parametrizado sobre o navio é minimizada, fornecendo os valores estimados para os parâmetros. Consideram-se espectros unimodais e bimodais.

O método pressupõe a linearidade entre o movimento da embarcação e a onda incidente. Assim, o movimento de roll não pode ser utilizado, pois efeitos viscosos nãolineares são muito importantes neste movimento. Além disso, uma sensibilidade muito grande dos movimentos em relação a pequenas variações das condições de carregamento do navio pode comprometer a acurácia da estimação. Portanto, uma análise detalhada a respeito de quais movimentos devem ser utilizados na aplicação do método é apresentada na seção 5.2 .

$\mathrm{Na}$ seção 5.3 apresentam-se simulações numéricas realizadas para se analisar o método paramétrico proposto e para calcular o intervalo de freqüências de ondas que o mesmo é capaz de estimar. Em todas as análises considerou-se o navio VLCC Vidal de Negreiros.

Finalmente, apresenta-se na seção 5.4 a validação experimental do método, o que foi feito através de ensaios com o VLCC em três condições de carregamento sob diversas direções de incidência de ondas.

No Apêndice 2 serão descritos os principais tipos de sensores utilizados na monitoração de ventos e correnteza. Descrevem-se também os diversos tipos de sensores de posição e movimento, que são utilizados na malha de controle, enfocandose a faixa de aplicação de cada um, vantagens e desvantagens. 


\subsection{Método Paramétrico de Estimação de Espectro de Ondas}

A expressão (3.37) fornece as funções de densidade espectral cruzada e de potência dos movimentos $\left(P_{i j}\right)$, admitindo-se onda incidente unidirecional. Expandindose a mesma para espectros direcionais $S\left(\omega, \beta_{O}\right)$ obtém-se a seguinte integral:

$$
P_{i j}(\omega)=\int_{-\pi}^{\pi} R A O_{i}\left(\omega, \beta_{0}\right) R A O_{j}^{*}\left(\omega, \beta_{0}\right) S\left(\omega, \beta_{o}\right) d \beta_{o}, \quad i, j=1, \ldots, 6
$$

O espectro de potência da onda pode ser calculado a partir de seu espectro direcional por:

$$
S(\omega)=\int_{-\pi}^{\pi} S\left(\omega, \beta_{o}\right) d \beta_{o}
$$

Dividindo-se o intervalo de freqüência de interesse $\left[\omega_{i}, \omega_{f}\right]$ em P pontos $\left\{\omega_{p}\right\}_{p=0}^{P-1}$, a aproximação na forma discreta da expressão (5.1) pode ser obtida supondo-se o integrando constante em cada intervalo $\Delta \beta_{O}$ :

$$
P_{i j}\left(\omega_{p}\right)=\Delta \beta_{O} \sum_{k=1}^{K} R A O_{i k}\left(\omega_{p}\right) R A O_{j k}^{*}\left(\omega_{p}\right) S_{k}\left(\omega_{p}\right)
$$

sendo $\Delta \beta_{O}=2 \pi / K, K$ o número de pontos da partição, $S_{k}\left(\omega_{p}\right)=S\left(\omega_{p}, \beta_{O, k}\right)$ e $R A O_{j k}\left(\omega_{p}\right)=R A O_{j}\left(\omega_{p}, \beta_{O, k}\right)$.

O Método Paramétrico utilizado considera a seguinte representação simplificada em 8 parâmetros de um espectro bimodal (Hogben; Cobb, 1986): 


$$
S\left(\omega, \beta_{O}\right)=\sum_{q=1}^{2} \frac{5}{16} \frac{\omega_{0, q}^{4} H_{S, q}^{2}}{\omega^{5}} \exp \left[-\frac{5}{4}\left(\frac{\omega_{0, q}}{\omega}\right)^{4}\right] A\left(s_{q}\right) \cos ^{2 s_{q}}\left(\frac{\beta_{O}-\bar{\beta}_{O, q}}{2}\right)
$$

$\operatorname{com} A\left(s_{q}\right)=\frac{2^{2 s-1} \Gamma^{2}\left(s_{q}+1\right)}{\pi \Gamma\left(2 s_{q}+1\right)}$, onde $\Gamma$ é a função especial Gama.

$\mathrm{Na}$ expressão (5.4) identificam-se as duas componentes do espectro bimodal $(q=1,2)$, sendo cada uma delas representada por um espectro de Pierson Moskowitz (ver expressão (3.26) com freqüência de pico de espectro $\omega_{0, q}$ e altura significativa $H_{S, q}$. Além disso, cada componente possui um espalhamento direcional dependente do parâmetro $s_{q}$, com direção de incidência média $\bar{\beta}_{O, q}$. Uma onda bastante espalhada direcionalmente apresenta um baixo valor do parâmetro $s_{q}$. Ao contrário, uma onda com uma direção principal bem definida apresenta um valor elevado para este parâmetro. Pode-se verificar que o caso de espectro unidirecional coincide com o limite $s_{q} \rightarrow \infty$.

Por exemplo, apresenta-se na Figura 5.1 as curvas de nível de um espectro bimodal, sendo que as circunferências indicam linhas de iso-frequência. A primeira componente do espectro apresenta $\omega_{0, I}=1,02 \mathrm{rad} / \mathrm{s}$ e $H_{S, I}=1,5 \mathrm{~m}$, com direção média de $45^{\circ}$ e espalhamento $s_{1}=30$. A segunda componente apresenta $\omega_{0,2}=0,54 \mathrm{rad} / \mathrm{s}$ e $H_{S, 2}=1,5 \mathrm{~m}$, com direção média de $264^{\circ}$ e menor espalhamento direcional $\left(s_{2}=50\right)$.

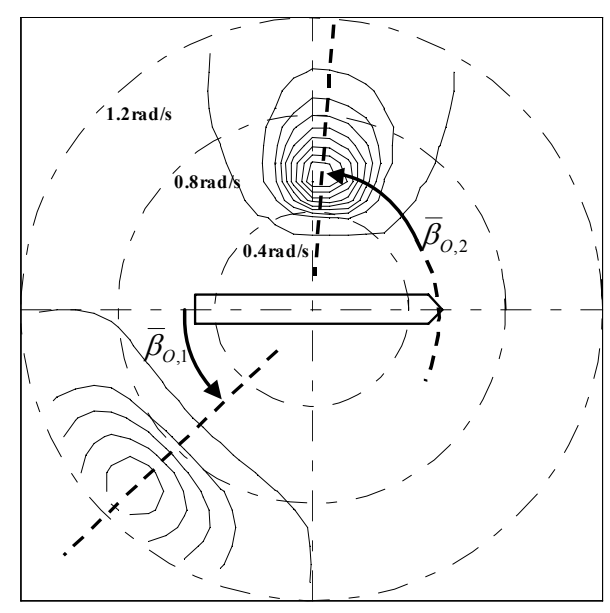

Figura 5.1 Espectro bimodal 
O método paramétrico é baseado na minimização do erro quadrático entre os movimentos esperados pela aplicação de (5.1) ao espectro estimado e os movimentos efetivamente medidos. Denotando-se as densidade espectrais obtidas pela expressão (5.1) por $\hat{P}_{i j}\left(\omega_{p}\right)$, a função erro a ser minimizada é dada por:

$$
E(\mathbf{x})=\left[\sum_{i, j} \sum_{p=0}^{P-1}\left[P_{i j}\left(\omega_{p}\right)-\hat{P}_{i j}\left(\omega_{p}\right)\right]^{2}\right]^{1 / 2}
$$

sendo $P$ o número de freqüências consideradas dentro do intervalo de interesse e $\mathbf{x}$ o

vetor de parâmetros a estimar $\mathbf{x}=\left[\omega_{0,1} H_{S, 1} s_{1} \bar{\beta}_{o, 1} \omega_{0,2} H_{S, 2} s_{2} \bar{\beta}_{o, 2}\right]^{T}$. Os movimentos $(i, j)$ utilizados na estimação serão discutidos na próxima seção.

O método é capaz de estimar estados de mar bimodais, sendo que para mares unimodais espera-se que o método estime uma das alturas significativas $\left(H_{S, 1}\right.$ ou $\left.H_{S, 2}\right)$ próxima de zero.

Para contornar problemas numéricos de convergência do método de otimização, adotou-se a solução de separar a estimação em duas partes. Inicialmente resolve-se o problema de otimização de forma a estimar apenas uma das componentes do espectro, ou seja, resolve-se um problema de 4 parâmetros. Em seguida, os parâmetros obtidos na primeira parte do processo são utilizados na estimação da segunda componente, mantendo-os, entretanto, fixos. A segunda interação também é, portanto, um problema de otimização com apenas 4 parâmetros livres. Verificou-se que este procedimento possui uma convergência mais rápida do que o cálculo dos 8 parâmetros simultâneos, levando, ao final, à mesma solução.

\subsection{Movimentos utilizados na estimação}

Supondo-se um corpo simétrico em relação ao eixo longitudinal $\left(o x_{1}\right)$ e transversal $\left(o x_{2}\right)$, são necessários no mínimo 3 movimentos para a determinação, sem ambigüidade, da direção de uma onda unidirecional incidente. A escolha mais natural seria a utilização dos movimentos verticais de primeira ordem (heave, roll e pitch), pois são, em geral, mais intensos que os horizontais e apresentam médias nulas, prescindindo de filtragens adicionais para o cálculo de suas densidades espectrais. 
Entretanto, o movimento de roll apresenta forte comportamento não-linear, pois envolve efeitos viscosos não levados em conta no modelo de RAO's. Adicionalmente, é um movimento pouco amortecido com um pico ressonante muito pronunciado. Este fato faz com que pequenas variações nas propriedades de massa do navio alterem sua freqüência de ressonância, alterando bastante seu comportamento. A Figura 5.2 apresenta o módulo do RAO do VLCC Vidal de Negreiros para um onda incidindo a $135^{\circ}$, considerando-se três condições de carregamento (100\%, 90\% e $80 \%$ carregado). Pode-se ver que o pico ressonante sofre um deslocamento e, pelo fato de o movimento ser pouco amortecido, altera significativamente o valor do RAO para todas as freqüências.

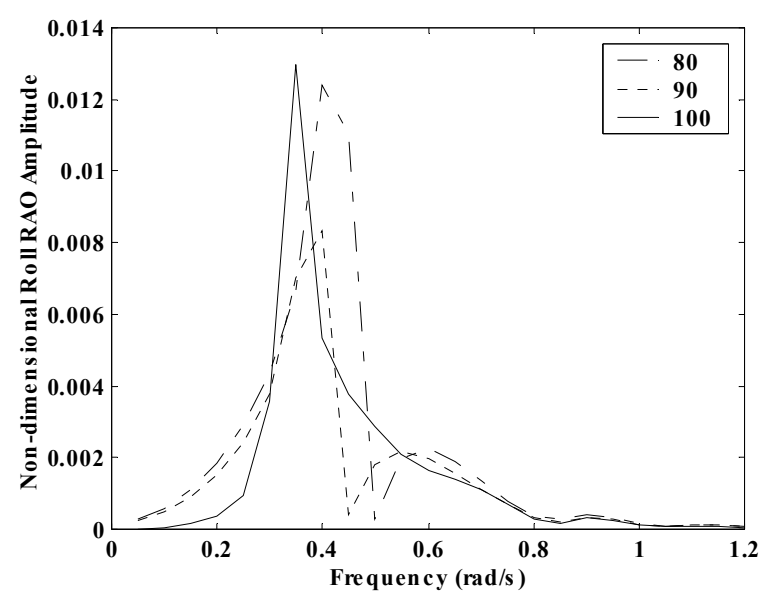

Figura 5.2 RAO's do movimento de roll para onda incidente a $135^{\circ}$ (extraído de Tannuri et al., 2001)

Assim, a utilização do movimento de roll no método de estimação faria com que o mesmo se tornasse muito sensível a pequenas imprecisões na avaliação das condições reais de carregamento do navio. Mesmo que, idealmente, estas imprecisões fossem nulas, os efeitos não-lineares do roll provocariam elevados erros nas estimativas resultantes.

Como mencionado por Webster; Dillingham (1981), o movimento de sway apresenta as mesmas informações a respeito da direção da onda incidente contidas no movimento de roll, pois as fases de ambos os movimentos são funções ímpares da direção em relação ao eixo longitudinal e pares em relação ao eixo transversal da embarcação. Portanto, utilizaram-se no Método Paramétrico os movimentos de sway, heave e pitch. Estes movimentos apresentam efeitos não-lineares bem inferiores dos de 
roll, já que as forças e momentos de primeira ordem nestas direções são basicamente de origem potencial. Além disso, apresentam menor sensibilidade a variações de carregamento, conforme pode ser verificado na Figura 5.3, que apresenta o valor absoluto dos RAO's do VLCC Vidal de Negreiros para incidência de $135^{\circ}$ e as 3 condições de carregamento previamente consideradas.

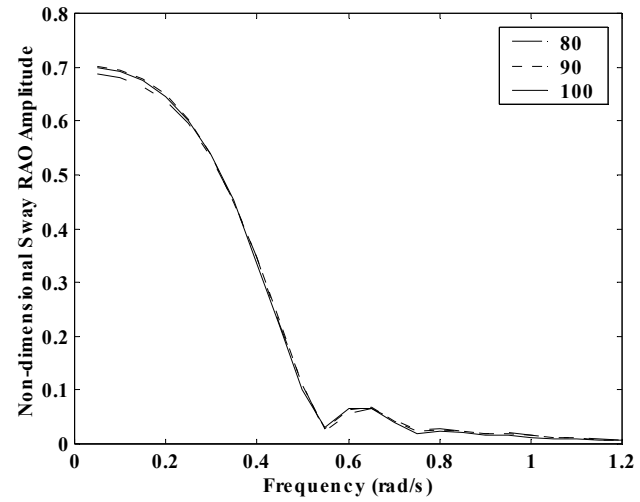

Sway

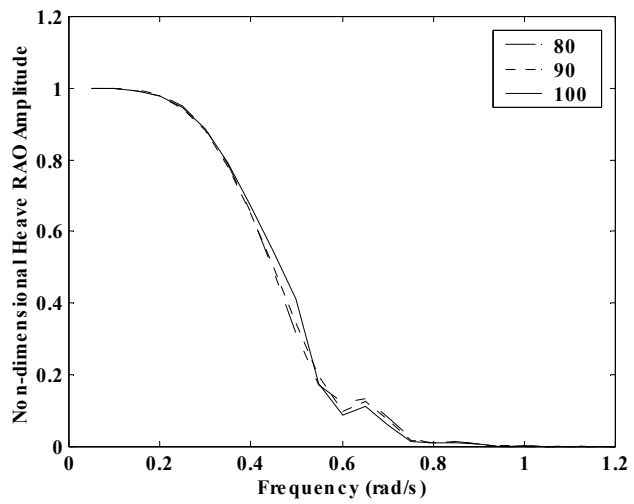

Heave

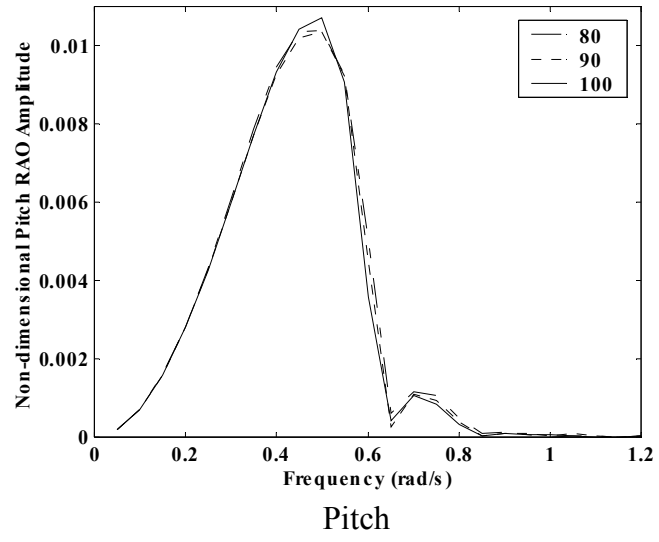

Figura 5.3 RAO's dos movimentos de sway, heave, pitch para onda incidente a $135^{\circ}$ (extraído de Tannuri et al., 2001)

\subsection{Análise numérica de mares unimodais}

Simulações numéricas foram realizadas para se analisar o método paramétrico proposto e para calcular o intervalo de freqüências de ondas que o mesmo é capaz de estimar. Em todas as análises considerou-se o navio VLCC Vidal de Negreiros.

Estes testes foram feitos através da geração numérica dos espectros dos movimentos do navio sujeito a um determinado espectro de ondas e a posterior aplicação do método paramétrico para estimar os parâmetros do espectro incidente. $\mathrm{Na}$ aplicação real, a resposta do navio (modelada pelos RAO's) não é conhecida 
perfeitamente devido a diversos erros como diferenças não consideradas na distribuição de massas, efeitos de superfície livre do óleo nos tanques, efeitos viscosos não-lineares etc...

Assim, para emular numericamente estes erros, os movimentos do navio foram gerados utilizando-se os RAO's do navio com calado $10 \%$ diferente do calado utilizado para se estimar as ondas. $\mathrm{Na}$ análise do navio $100 \%$ carregado, por exemplo, consideraram-se os RAO's do navio com calado de $90 \%{ }^{22}$ para a geração dos movimentos e utilizaram-se os RAO's do navio com calado máximo para a aplicação do algoritmo. $\mathrm{Na}$ análise do navio em condição de lastro, utilizaram-se os RAO's do navio com calado $30 \%$ na geração dos movimentos e os RAO's do navio com calado $40 \%$ na aplicação do algoritmo.

Analisaram-se os casos de incidência de um mar unimodal com altura significativa de $1 \mathrm{~m}$ e período de pico entre 7 e 20 s. Consideraram-se as direções de incidência de $90^{\circ}, 135^{\circ}$ e $180^{\circ}$, ilustradas na Figura 5.4.

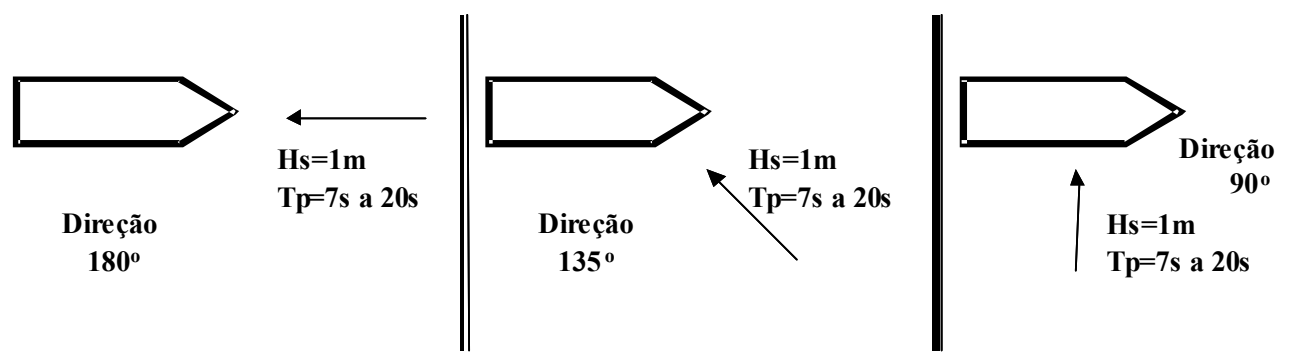

Figura 5.4 Direções de incidência consideradas na análise numérica do método paramétrico

Na Figura 5.5 apresentam-se os resultados para a condição de navio carregado. Os máximos erros obtidos para as três direções de incidência consideradas são apresentados em função do período de pico da onda. Pode-se ver que para períodos maiores que aproximadamente 11s os erros na estimação da altura, período e direção são menores que $7,5 \%, 2,5 \%$ e $1,5^{\circ}$ respectivamente.

A perda de acurácia do método para períodos de onda menores pode ser explicada pelo fato de o navio não "responder" a estas ondas, como já mencionado. Por exemplo,

\footnotetext{
${ }^{22}$ Refere-se aqui à porcentagem em relação ao valor de calado máximo, correspondente ao calado do navio com os tanques $100 \%$ carregados de óleo.
} 
considerando-se uma onda de $2 \mathrm{~m}$ de altura significativa incidindo a $90^{\circ}$ e período de pico de 8,5s, o movimento de heave induzido possui amplitude da ordem de apenas $50 \mathrm{~cm}$. Para uma onda de mesma altura e direção, com período de pico de $16 \mathrm{~s}$, a amplitude de heave alcança o elevado valor de $1,7 \mathrm{~m}$.

Esta análise numérica permite, portanto, se avaliar um período de pico mínimo que o método é capaz de estimar. Como conseqüência, considerando-se o VLCC carregado, espectros com períodos de pico estimados abaixo de $11 \mathrm{~s}$ devem ser descartados, pois escondem erros muito elevados.

\section{VLCC Calado 100\% - Erros de Estimação}

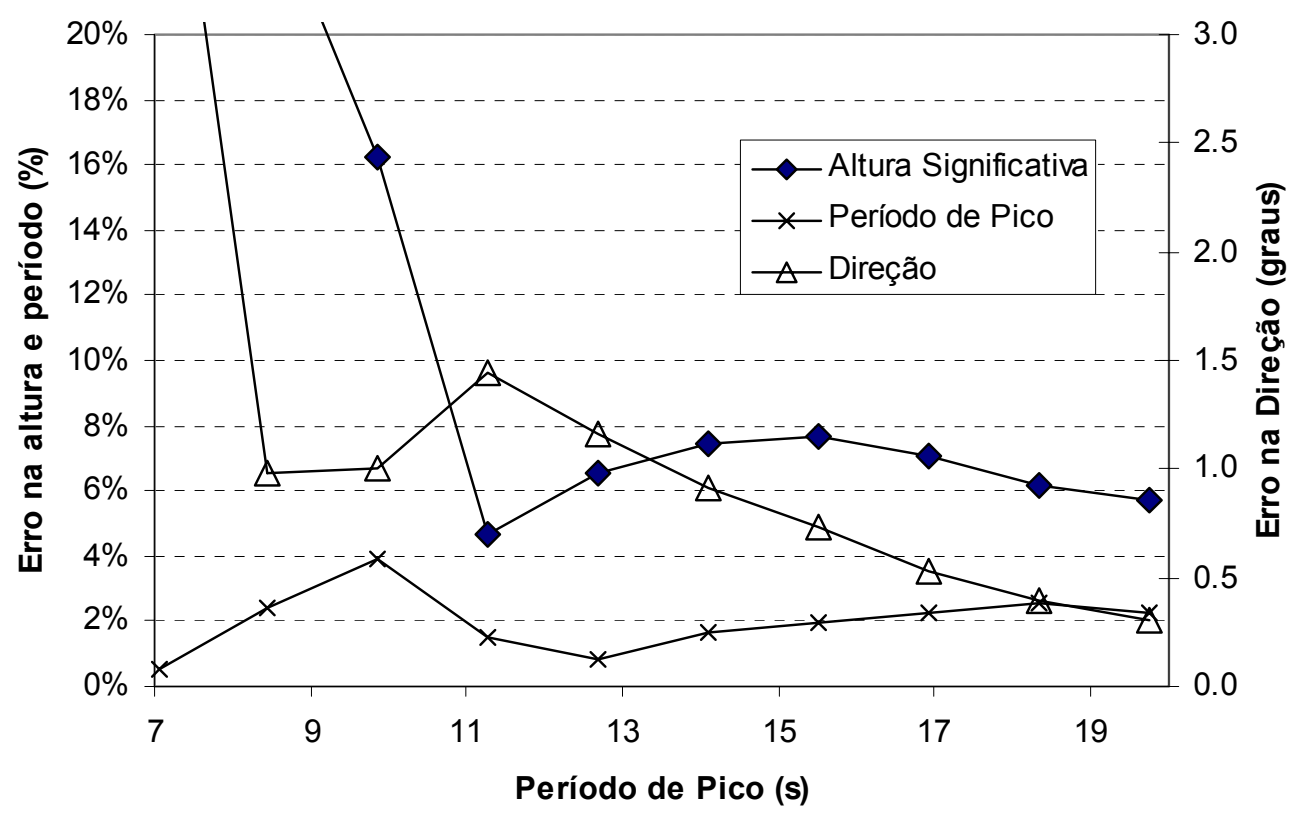

Figura 5.5 Máximos erros de estimação para mares unimodais - análise numérica - Condição carregada

Os resultados para condição de lastro (calado 40\%) são apresentados na Figura 5.6. Neste caso, para períodos de pico maiores que 10s os erros máximos de estimação da altura, período e direção são de $9 \%, 3,5 \%$ e 1,3 $3^{\circ}$. Nesta condição, portanto, o método é capaz de estimar ondas com períodos de pico superiores a $10 \mathrm{~s}$. Como a inércia do navio descarregado é menor, ele possui movimentos de primeira ordem mais intensos, sendo capaz de estimar ondas com períodos ligeiramente menores quando comparados aos do caso cheio. 


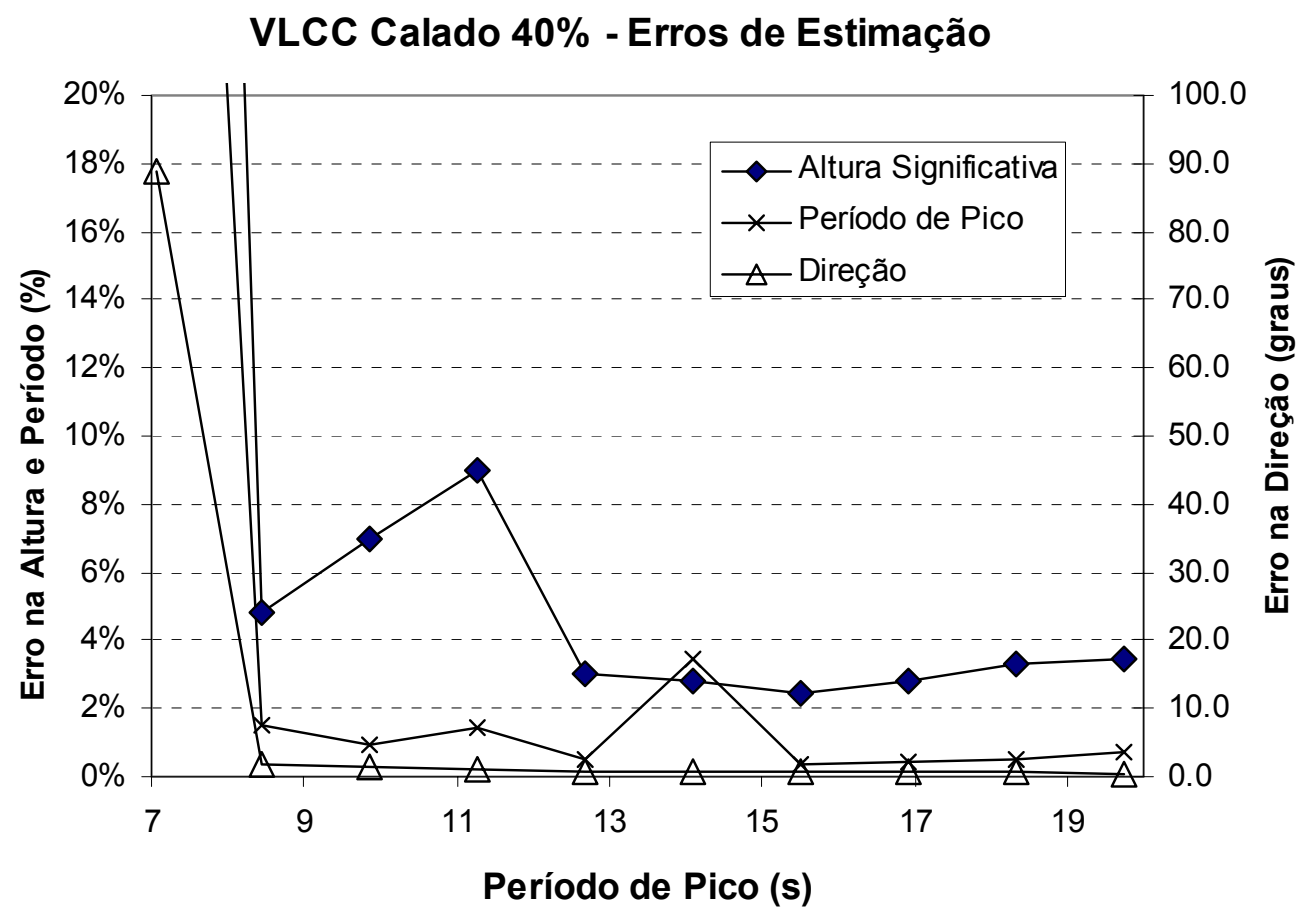

Figura 5.6 Máximos erros de estimação para mares unimodais - análise numérica - Condição de lastro

\subsection{Resultados Experimentais}

Para a validação experimental do método paramétrico, utilizaram-se ensaios realizados pela Divisão de Tecnologia de Transportes do Instituto de Pesquisas Tecnológicas do Estado de São Paulo (DITT-IPT), encomendados pela Petrobrás e posteriormente disponibilizados para fins de validação do método ora apresentado. Os ensaios foram realizados com o modelo do VLCC Vidal de Negreiros, em escala 1:90. Foram consideradas três condições de carregamento, cujas características principais são dadas na Tabela 5.1.

Tabela 5.1 Características do VLCC nas três condições de ensaio (dados em escala real)

\begin{tabular}{|l|l|l|l|}
\hline & Cheio & Intermediário & Lastro \\
\hline Massa & 302028 ton & 198944 ton & 115838 ton \\
\hline Calado & $21,0 \mathrm{~m}$ & $14,7 \mathrm{~m}$ & $9,0 \mathrm{~m}$ \\
\hline Raio de giração roll & $16,83 \mathrm{~m}$ & $16,92 \mathrm{~m}$ & $23,22 \mathrm{~m}$ \\
\hline Raio de giração pitch & $86,31 \mathrm{~m}$ & $82,43 \mathrm{~m}$ & $90,54 \mathrm{~m}$ \\
\hline Raio de giração yaw & $80,00 \mathrm{~m}$ & $80,00 \mathrm{~m}$ & $80,00 \mathrm{~m}$ \\
\hline
\end{tabular}


Considerou-se o navio amarrado por um sistema DICAS com aproamento aproximadamente constante em relação ao Norte de $202,5^{\circ}$. Para cada uma das condições de carregamento, realizaram-se ensaios com as quatro direções de incidência mostradas na Figura 5.7, sendo o ângulo indicado entre parênteses medido em relação ao eixo longitudinal do navio. No ensaio, o aproamento foi mantido por um conjunto de 8 molas que simularam o efeito das linhas de amarração.

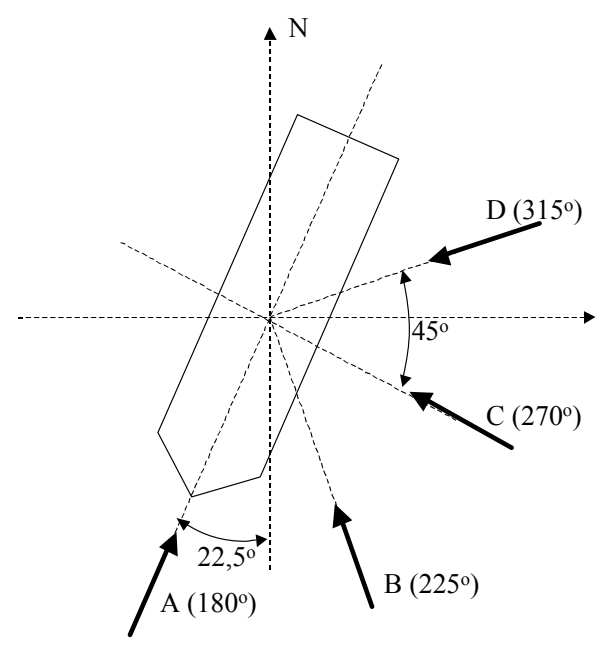

Figura 5.7 Direções de incidência consideradas nos ensaios

Mediram-se todos os movimentos do navio com auxílio de um sistema de medição ótico. A altura da onda incidente foi monitorada por meio de um medidor capacitivo de nível (wave-probe) instalado próximo ao navio. O aparato experimental é apresentado na Figura 5.8.

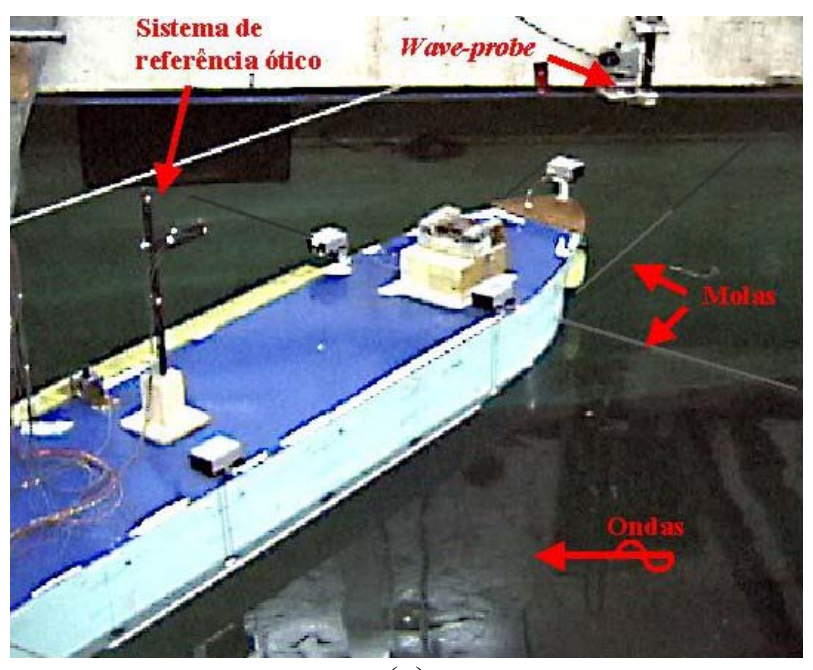

(a)

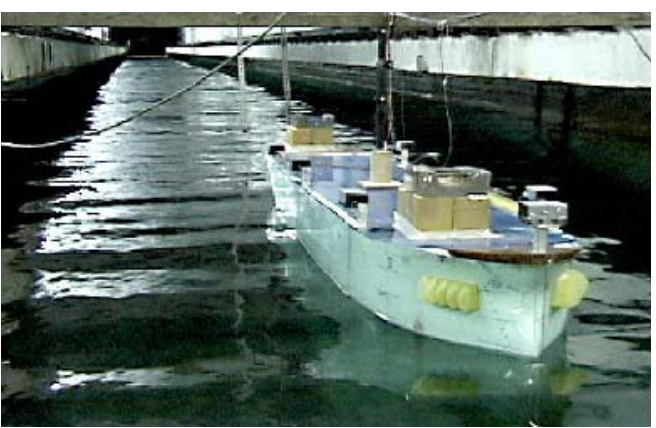

(b)

Figura 5.8 (a)Aparato experimental durante ensaio de incidência B (b)Ensaio de incidência A (fotografia gentilmente cedida pela Petrobrás) 
Os ensaios tiveram duração de 7,5min em escala real (47s em escala de modelo) e os dados foram amostrados a uma freqüência de $51 \mathrm{~Hz}$, o que corresponde a $5,4 \mathrm{~Hz} \mathrm{em}$ escala real. Os cálculos das densidades espectrais cruzadas e de potência foram feitos utilizando-se o método ponderado proposto em Welch (1967), com 4096 pontos utilizados nas transformações rápidas de Fourier, janela do tipo Hanning com 256 pontos, com sobreposição de 128 pontos entre duas janelas consecutivas.

O espectro de ondas efetivamente incidente sobre o navio foi obtido pelo cálculo da densidade espectral de potência do sinal da altura da onda monitorado pelo waveprobe. Por exemplo, apresenta-se na Figura 5.9a a série temporal da altura de onda em um dos ensaios da incidência B. Na Figura 5.9b, apresenta-se o espectro de potência da onda medida.

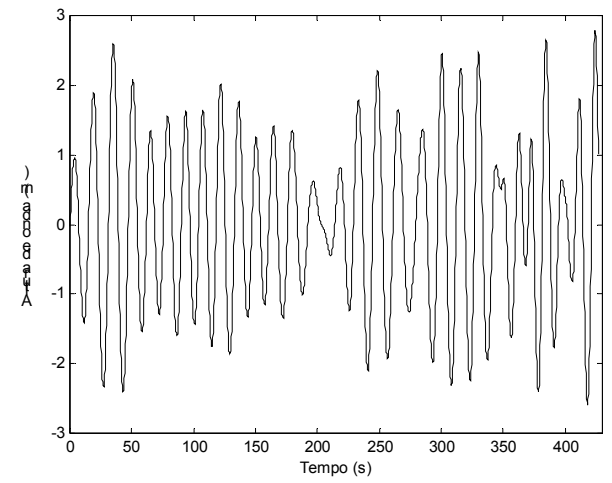

(a)

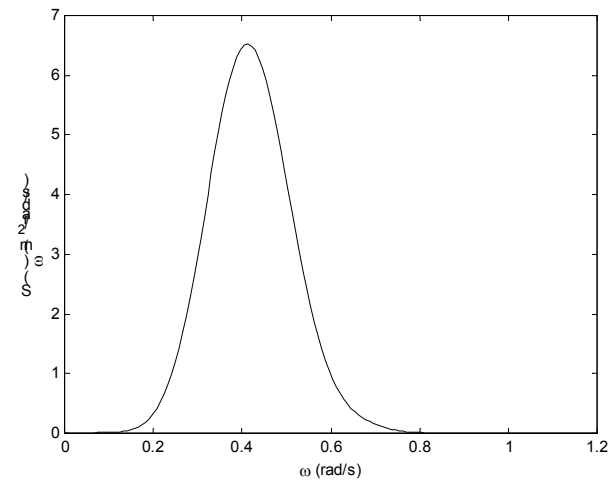

(b)

Figura 5.9 (a) Altura de onda medida ; (b) Espectro de potência calculado (ambos em escala real)

Para mar unimodal, a altura significativa pode ser obtida a partir do espectro, por:

$$
H_{S}=4 \sqrt{\int_{0}^{\infty} S(\omega) d \omega}
$$

e o período de pico é simplesmente dado pelo inverso da freqüência (em $\mathrm{Hz}$ ) na qual o espectro atinge seu valor máximo. Assim, para cada um dos ensaios calcularam-se os valores da altura significativa e do período de pico, que foram considerados como os parâmetros reais com os quais as estimativas serão comparadas. A altura significativa e 
o período de pico das ondas geradas variaram entre condições extremas anuais e centenárias para cada direção de incidência, dadas na Tabela 5.2.

Tabela 5.2 Condições de mar anuais, decenárias e centenárias na Bacia de Campos para as direções consideradas nos ensaios $\left(H_{s}\right.$ e $\left.T_{p}\right)$

\begin{tabular}{|c|c|c|c|c|c|c|}
\hline \multirow{2}{*}{ Incidência } & \multicolumn{2}{|c|}{ Anual } & \multicolumn{2}{c|}{ Decenário } & \multicolumn{2}{c|}{ Centenário } \\
\cline { 2 - 7 } & $H_{S}$ & $T_{p}$ & $H_{S}$ & $T_{p}$ & $H_{S}$ & $T_{p}$ \\
\hline $\mathbf{A}$ & $5,7 \mathrm{~m}$ & $13,7 \mathrm{~s}$ & $6,9 \mathrm{~m}$ & $14,6 \mathrm{~s}$ & $7,8 \mathrm{~m}$ & $15,3 \mathrm{~s}$ \\
\hline $\mathbf{B}$ & $5,1 \mathrm{~m}$ & $13,2 \mathrm{~s}$ & $6,1 \mathrm{~m}$ & $14,0 \mathrm{~s}$ & $7,0 \mathrm{~m}$ & $14,7 \mathrm{~s}$ \\
\hline $\mathbf{C}$ & $4,5 \mathrm{~m}$ & $10,3 \mathrm{~s}$ & $5,5 \mathrm{~m}$ & $10,8 \mathrm{~s}$ & $6,7 \mathrm{~m}$ & $11,3 \mathrm{~s}$ \\
\hline $\mathbf{D}$ & $3,9 \mathrm{~m}$ & $8,5 \mathrm{~s}$ & $4,7 \mathrm{~m}$ & $9,0 \mathrm{~s}$ & $5,4 \mathrm{~m}$ & $9,4 \mathrm{~s}$ \\
\hline
\end{tabular}

Os resultados do método de estimação do espectro são apresentados na Tabela 5.3. Na tabela, destacaram-se os resultados cujos períodos de pico estimados são inferiores a 11s (no caso cheio) e 10s (nos casos lastro e intermediário). Estes resultados devem ser desprezados, na medida em que a análise numérica realizada em 5.3 indicou que estes estados de mar não podem ser estimados pelo presente método ${ }^{23}$. De fato, o erro na estimação da altura e direção é muito elevado nestes ensaios, alcançando $80 \%$ e $70^{\circ}$ respectivamente. O período de pico, entretanto, é estimado com boa acurácia, com erro inferior a 7\%, o que permite o "julgamento" das estimativas pela comparação do período estimado com o período mínimo obtido na análise numérica. Para o navio cheio, em incidência $\mathrm{C}$, o período de pico real do mar é muito próximo do limite de $11 \mathrm{~s}$, sendo que as estimativas encontram-se na faixa 11,0-11,5s, acima do limite. Neste caso, os resultados não são desprezados, porém verifica-se que, pela proximidade com o período de pico mínimo, as estimativas da altura significativa possuem erros elevados de até $25 \%$. Assim, poder-se-ia estabelecer uma margem de segurança no valor do período de pico mínimo, de forma a evitar estes valores muito próximos do limite.

Em todos os ensaios, uma das alturas significativas estimadas $\left(H_{S, 1}\right.$ ou $\left.H_{S, 2}\right)$ resultou próxima de zero, indicando a capacidade do método em identificar mares unimodais. O coeficiente de espalhamento direcional s é, teoricamente, infinito para mares unidirecionais, como o ensaiado no tanque de provas. Para a incidência $\mathrm{C}$, estimou-se o valor $\mathrm{s}=85$, bastante elevado e podendo ser considerado praticamente unidirecional. Para incidências A e B, entretanto, o valor do espalhamento s variou

\footnotetext{
${ }^{23}$ A análise numérica não foi realizada para a condição intermediária, utilizando-se, para esta condição, o mesmo período mínimo obtido para a condição de lastro (10s).
} 
entre 12 e 30, indicando um maior espalhamento da energia. A Figura 5.10 apresenta as curvas de nível para um ensaio em cada uma das incidências A, B e C, ilustrando o maior espalhamento nas incidências A e B. 
Tabela 5.3 Resultados da aplicação do método paramétrico aos ensaios - erros de estimação indicado entre parênteses

\begin{tabular}{|c|c|c|c|c|c|c|c|}
\hline \begin{tabular}{|l|} 
Cond. \\
\end{tabular} & Incidência & Repet. & $\mathrm{H}_{\mathrm{S}}$ real $(\mathrm{m})$ & $T_{p}$ real $(s)$ & H $_{\mathrm{S}}$ est (m) & \begin{tabular}{|l|} 
Tp est (s) \\
\end{tabular} & Dir. est \\
\hline \multirow{16}{*}{ } & \multirow{4}{*}{$\underset{\&}{\stackrel{0}{\infty}}$} & 1 & 6,4 & 14,6 & $7,3(15 \%)$ & $13,0(-10 \%)$ & $180,2^{\circ}\left(0^{\circ}\right)$ \\
\hline & & 2 & 7,0 & 14,8 & $7,2(3 \%)$ & \begin{tabular}{|l|}
$13,9(-6 \%)$ \\
\end{tabular} & $180,2^{\circ}\left(0^{\circ}\right)$ \\
\hline & & 3 & 7,8 & 13,3 & $8,5(9 \%)$ & $12,6(-5 \%)$ & $180,2^{\circ}\left(0^{\circ}\right)$ \\
\hline & & 4 & 9,0 & 14,5 & $9,8(8 \%)$ & $13,9(-4 \%)$ & $180,2^{\circ}\left(0^{\circ}\right)$ \\
\hline & \multirow{4}{*}{ 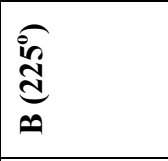 } & 1 & 4,9 & 15,2 & $6,0(22 \%)$ & \begin{tabular}{|l|}
$14,8(-2 \%)$ \\
\end{tabular} & $217,4^{\circ}\left(-8^{\circ}\right)$ \\
\hline & & 2 & 6,1 & 12,9 & $7,7(26 \%)$ & \begin{tabular}{|l|}
$13,2(3 \%)$ \\
\end{tabular} & $225,4^{\circ}\left(0^{\circ}\right)$ \\
\hline & & 3 & 9,1 & 12,7 & $9,0(-1 \%)$ & $13,6(7 \%)$ & $214,4^{\circ}\left(-11^{\circ}\right)$ \\
\hline & & 4 & 7,3 & 14,3 & $8,8(21 \%)$ & $14,1(-1 \%)$ & $214,7^{\circ}\left(-10^{\circ}\right)$ \\
\hline & \multirow{4}{*}{$\underset{v}{\stackrel{\sigma}{d}}$} & 1 & 5,3 & 10,8 & $4,3(-18 \%)$ & \begin{tabular}{|l|l}
$11,0(1 \%)$ \\
\end{tabular} & $269,1^{\circ}\left(1^{\circ}\right)$ \\
\hline & & 2 & 5.3 & 10,9 & $4,2(-19 \%)$ & $11,3(4,8 \%)$ & $269,1^{\circ}\left(1^{\circ}\right)$ \\
\hline & & 3 & 6,8 & 10,9 & $5,2(-24 \%)$ & $11,5(5 \%)$ & $269,3^{\circ}\left(1^{\circ}\right)$ \\
\hline & & 4 & 7,8 & 11,0 & $5,8(-25 \%)$ & $11,5(5 \%)$ & $269,6^{\circ}\left(0^{\circ}\right)$ \\
\hline & \multirow{4}{*}{$\frac{\text { in }}{0}$} & 1 & 4,3 & 10,0 & $5,4(26 \%)$ & $9,8(-2 \%)$ & $337,0^{\circ}\left(22^{\circ}\right)$ \\
\hline & & 2 & 4,9 & 9,5 & $6,7(-5 \%)$ & $9,7(2 \%)$ & $339,0^{\circ}\left(24^{\circ}\right)$ \\
\hline & & 3 & 5,7 & 10,1 & $7,5(31 \%)$ & $9,4(-7 \%)$ & $358,1^{\circ}\left(43^{\circ}\right)$ \\
\hline & & 4 & 6,0 & 10,2 & $5,0(-18 \%)$ & \begin{tabular}{|l|}
$10,2(0 \%)$ \\
\end{tabular} & $351,2^{\circ}\left(36^{\circ}\right)$ \\
\hline \multirow{16}{*}{ 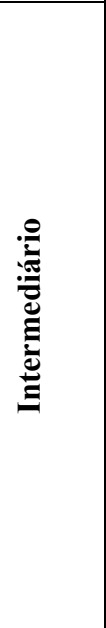 } & \multirow{4}{*}{$\underset{\&}{\stackrel{\mathscr{E}}{\rightleftarrows}}$} & 1 & 6.6 & 14.9 & $6.4(-4 \%)$ & $13.4(-10 \%)$ & $180.0^{\circ}\left(0^{\circ}\right)$ \\
\hline & & 2 & 6.8 & 15.2 & $6.8(0 \%)$ & $13.7(-10 \%)$ & $180.0^{\circ}\left(0^{\circ}\right)$ \\
\hline & & 3 & 8.2 & 13.6 & $9.0(10 \%)$ & $12.7(-6 \%)$ & $180.0^{\circ}\left(0^{\circ}\right)$ \\
\hline & & 4 & 9.4 & 14.6 & $9.6(2 \%)$ & $13.5(-7 \%)$ & $180.0^{\circ}\left(0^{\circ}\right)$ \\
\hline & \multirow{4}{*}{ 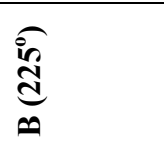 } & 1 & 5.0 & 15.2 & $5.8(15 \%)$ & $14.6(-3 \%)$ & $221.7^{\circ}\left(-3^{\circ}\right)$ \\
\hline & & 2 & 6.3 & 13.3 & $6.6(4 \%)$ & $13.2(-1 \%)$ & $217.8^{\circ}\left(-7^{\circ}\right)$ \\
\hline & & 3 & 8.6 & 13.1 & $8.4(-2 \%)$ & $13.5(3 \%)$ & $222.5^{\circ}\left(-3^{\circ}\right)$ \\
\hline & & 4 & 7.7 & 14.0 & $8.3(8 \%)$ & $14.0(0 \%)$ & $222.4^{\circ}\left(-3^{\circ}\right)$ \\
\hline & \multirow{4}{*}{$\underset{0}{\stackrel{6}{\stackrel{\overbrace{}}{d}}}$} & 1 & 4.8 & 10.8 & $5.2(8 \%)$ & \begin{tabular}{|l|}
$11.3(4 \%)$ \\
\end{tabular} & $268.8^{\circ}\left(-1^{\circ}\right)$ \\
\hline & & 2 & 6.2 & 10.9 & $6.0(-4 \%)$ & $12.6(16 \%)$ & $269.4^{\circ}\left(-1^{\circ}\right)$ \\
\hline & & 3 & 7.8 & 10.3 & $6.5(-16 \%)$ & $11.8(15 \%)$ & $269.3^{\circ}\left(-1^{\circ}\right)$ \\
\hline & & 4 & 6.6 & 10.7 & $6.5(-1 \%)$ & \begin{tabular}{|l|}
$11.3(6 \%)$ \\
\end{tabular} & $269.1^{\circ}\left(-1^{\circ}\right)$ \\
\hline & \multirow{4}{*}{$\frac{\text { in }}{a}$} & 1 & 4.3 & 9.8 & $5.9(36 \%)$ & $9.8(0 \%)$ & $353,8^{\circ}\left(39^{\circ}\right)$ \\
\hline & & 2 & 5.3 & 9.6 & $6.2(18 \%)$ & $9.4(-2 \%)$ & $344.5^{\circ}\left(30^{\circ}\right)$ \\
\hline & & 3 & 5.1 & 10.1 & $8.7(70 \%)$ & $9.6(-5 \%)$ & $354.7^{\circ}\left(40^{\circ}\right)$ \\
\hline & & 4 & 5.9 & 10.2 & $6.7(14 \%)$ & \begin{tabular}{|l|}
$9,9(-3 \%)$ \\
\end{tabular} & $354.9^{\circ}\left(40^{\circ}\right)$ \\
\hline \multirow{16}{*}{ 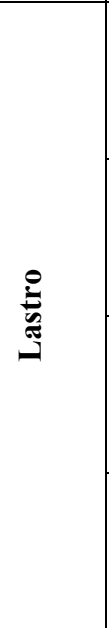 } & \multirow{4}{*}{$\underbrace{\stackrel{\mathscr{\infty}}{\sigma}}_{4}$} & 1 & 6.7 & 14.6 & $6.7(0 \%)$ & $13.5(-8 \%)$ & $180.0^{\circ}\left(0^{\circ}\right)$ \\
\hline & & 2 & 7.1 & 14.3 & $6.9(-4 \%)$ & $14.1(-2 \%)$ & $180.0^{\circ}\left(0^{\circ}\right)$ \\
\hline & & 3 & 8.4 & 14.1 & $8.4(0 \%)$ & $13.2(-6 \%)$ & $180.0^{\circ}\left(0^{\circ}\right)$ \\
\hline & & 4 & 9.3 & 14.9 & $10.2(9 \%)$ & \begin{tabular}{|l|l}
$13.4(-10 \%)$ \\
\end{tabular} & $180.0^{\circ}\left(0^{\circ}\right)$ \\
\hline & \multirow{4}{*}{$\underset{\sim}{\stackrel{\tilde{J}}{\mathfrak{d}}}$} & 1 & 4.9 & 15.2 & $5.9(20 \%)$ & $14.3(-6 \%)$ & $224.6^{\circ}\left(0^{\circ}\right)$ \\
\hline & & 2 & 6.1 & 13.3 & $7.0(15 \%)$ & $12.9(-3 \%)$ & $220.0^{\circ}\left(-5^{\circ}\right)$ \\
\hline & & 3 & 8.4 & 13.6 & $8.7(4 \%)$ & $13.3(-2 \%)$ & $224.0^{\circ}\left(-1^{\circ}\right)$ \\
\hline & & 4 & 7.5 & 14.3 & $8.3(11 \%)$ & $13.9(-3 \%)$ & $225.7^{\circ}\left(1^{\circ}\right)$ \\
\hline & \multirow{4}{*}{$\underset{\cup}{\stackrel{\mathscr{Q}}{\mathfrak{d}}}$} & 1 & 4.1 & 10.8 & $5.1(24 \%)$ & \begin{tabular}{|l|}
$11.4(5 \%)$ \\
\end{tabular} & $269.5^{\circ}\left(-1^{\circ}\right)$ \\
\hline & & 2 & 6.2 & 11.2 & $6.2(0 \%)$ & $12.5(12 \%)$ & $269.7^{\circ}\left(0^{\circ}\right)$ \\
\hline & & 3 & 6.2 & 10.3 & $7.5(20 \%)$ & $11.3(11 \%)$ & $269.7^{\circ}\left(0^{\circ}\right)$ \\
\hline & & 4 & 6.1 & 10.7 & $7.0(15 \%)$ & \begin{tabular}{|l|}
$11.4(7 \%)$ \\
\end{tabular} & $269.6^{\circ}\left(0^{\circ}\right)$ \\
\hline & \multirow{4}{*}{$\frac{6}{\frac{i n}{0}}$} & 1 & 4.4 & 10.1 & $7.7(74 \%)$ & $9.5(-6 \%)$ & $351.0^{\circ}\left(36^{\circ}\right)$ \\
\hline & & 2 & 4.8 & 9.7 & $8.7(80 \%)$ & $9.2(-5 \%)$ & $337.7^{\circ}\left(23^{\circ}\right)$ \\
\hline & & 3 & 5.3 & 10.0 & $10.1(0 \%)$ & $9.5(-5 \%)$ & $358.2^{\circ}\left(43^{\circ}\right)$ \\
\hline & & 4 & 5.8 & 10.1 & $8.3(42 \%)$ & $9.5(-6 \%)$ & $350.8^{\circ}\left(36^{\circ}\right)$ \\
\hline
\end{tabular}




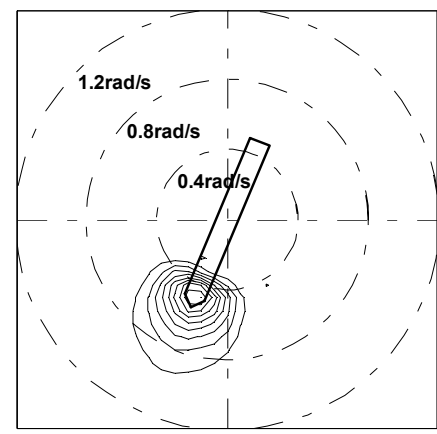

Lastro, Incidência A, Repet.1 $\mathrm{s}=26$

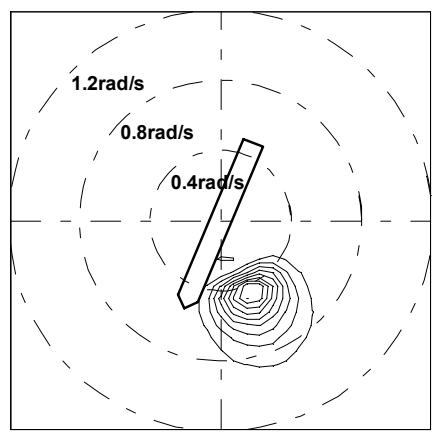

Lastro, Incidência B, Repet.1 $\mathrm{s}=23$

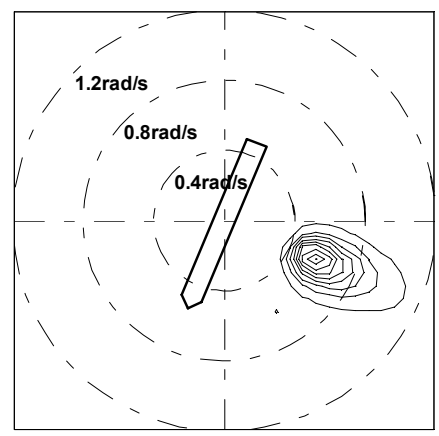

Lastro, Incidência C, Repet.1 $\mathrm{s}=85$

Figura 5.10 Exemplos de espectros estimados para três incidências

Algumas hipóteses podem ser levantadas para explicar este fato, sobretudo relacionadas à reflexão das ondas pela parede do tanque, alterando o espectro incidente. No caso da incidência $\mathrm{C}$, as ondas difratadas e refletidas pelo modelo propagam-se preferencialmente na mesma direção do tanque, paralelamente às paredes. Nos casos $\mathrm{A}$ e $\mathrm{B}$, entretanto, uma parcela destas ondas propaga-se em direção às paredes, sendo refletidas nas mesmas e voltando a incidir sobre o modelo. Nestes casos, espera-se efetivamente um maior espalhamento direcional das ondas.

Uma análise geral dos ensaios realizados mostra que o método apresenta erros de até $25 \%$ na estimativa da altura significativa, $15 \%$ no período de pico e $10^{\circ}$ na direção. Estes erros não afetam o desempenho do controlador proposto, como será exemplificado no Capítulo 6. As curvas da Figura 5.11 (a) e (b) ilustram os erros encontrados, ficando claro que a dispersão na estimativa da altura significativa é maior que aquela correspondente ao período de pico.

Na Figura 5.11 (c) ilustram-se as direções estimadas para todos os ensaios válidos, na qual pode-se notar a maior dispersão no caso da incidência $\mathrm{B}$, com erro máximo de $11^{\circ}$. 


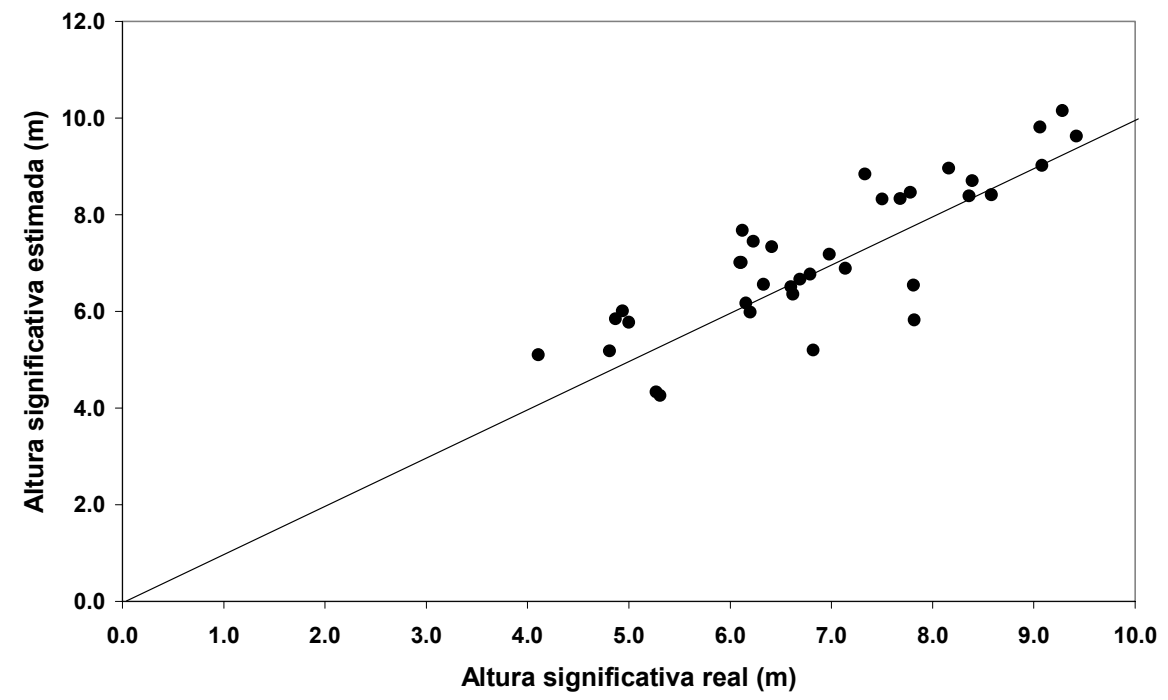

(a)

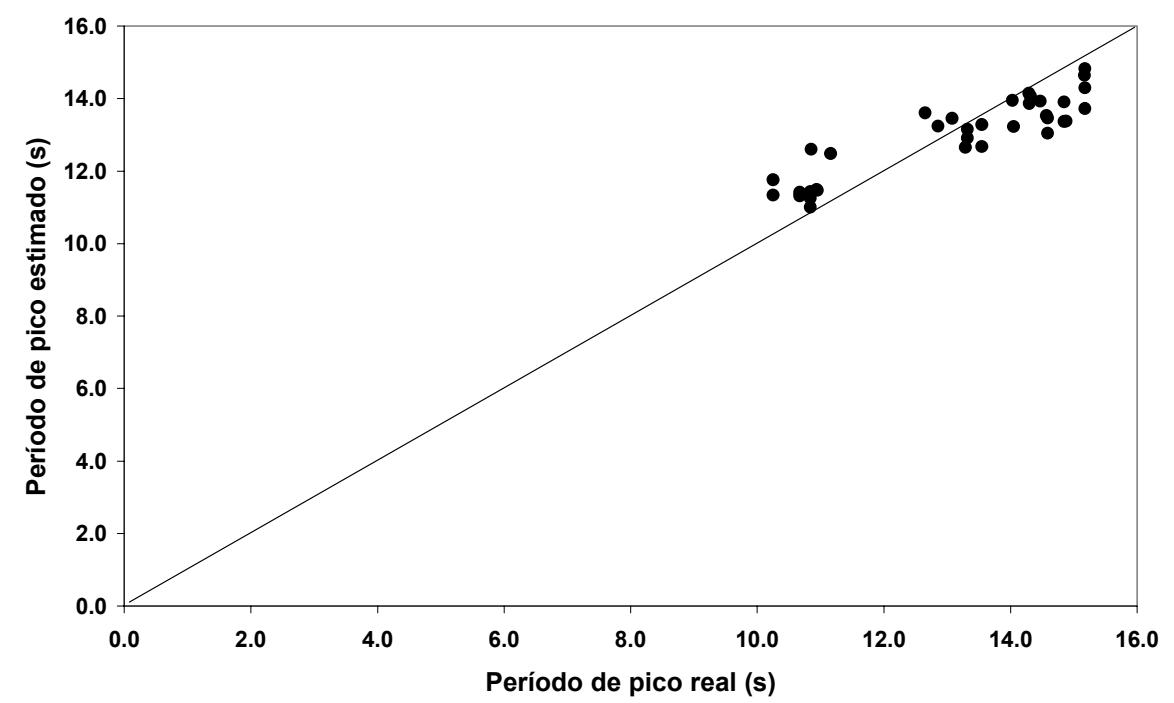

(b)

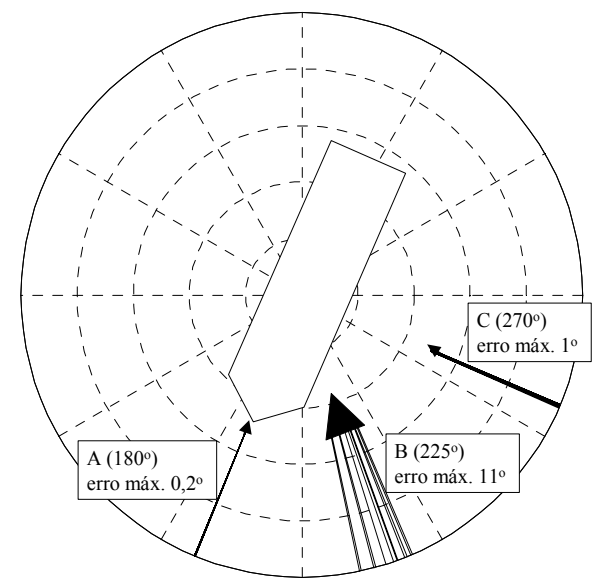

(c)

Figura 5.11 Resultados do método paramétrico (a) altura significativa; (b) período de pico; (c) direção 
Uma característica importante do método é que apresenta bons resultados mesmo quando o espectro de potência da onda incidente não possui o formato do modelo de Pierson-Moskowitz, que corresponde à parametrização considerada. De fato, a Figura 5.12 ilustra o caso do navio Cheio, incidência A, repetição 3. Pode-se ver que o espectro real apresenta formato mais "estreito" que a parametrização de Pierson-Moskowitz, assemelhando-se mais a um espectro de JONSWAP com fator $\gamma>1$ (ver equação (3.28)). Entretanto, a despeito desta diferença, o método consegue recuperar os parâmetros descritivos do espectro (altura significativa e período de pico) de forma acurada, com erro de $9 \%$ para a altura e $-5 \%$ para o período.

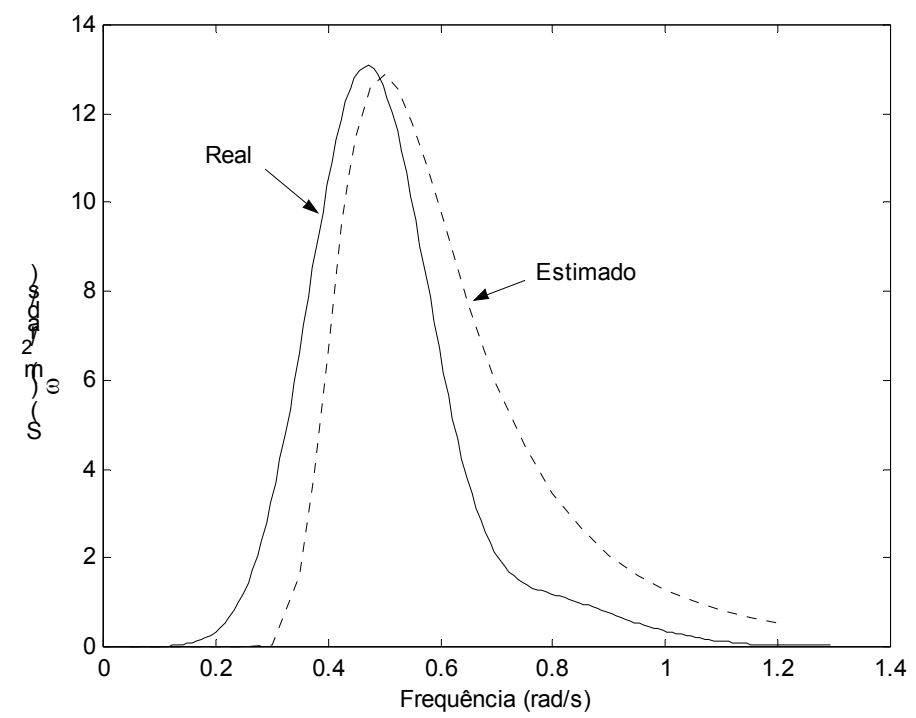

Figura 5.12 Espectro de potência real e estimado. Caso Cheio, incidência A, repetição 3.

Para realizar uma comparação, aplicou-se o método não paramétrico Bayesiano aos dados experimentais, já mencionado no início desta seção. Os erros de estimação foram maiores do que os obtidos com o método paramétrico, alcançando $35 \%$ para a altura significativa, $31 \%$ para o período de pico e $30^{\circ}$ para a direção. Na Figura 5.13 apresentam-se os resultados do método Bayesiano, ficando clara a superioridade do método paramétrico analisado anteriormente. 


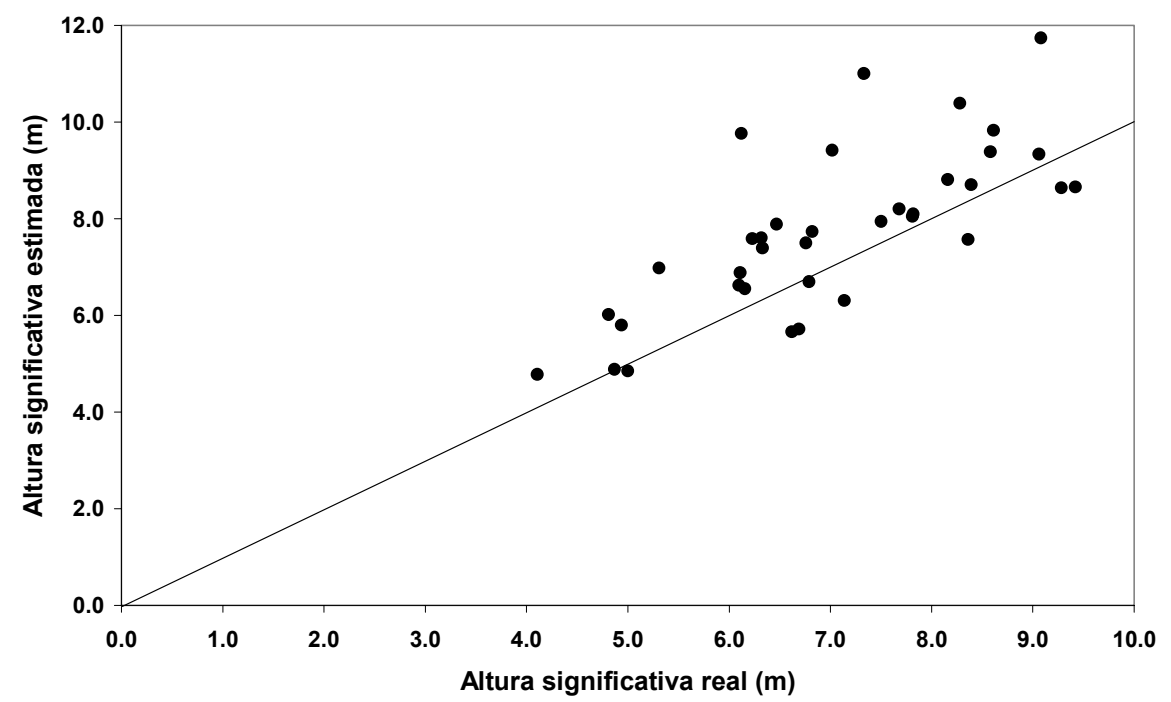

(a)

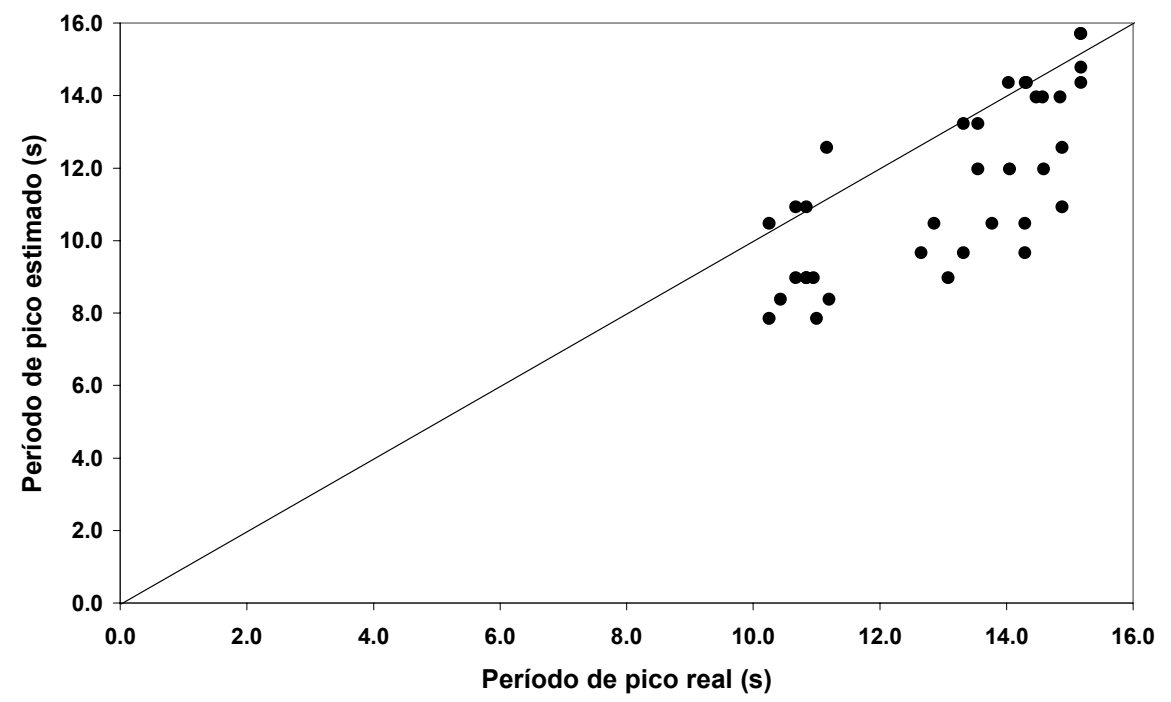

(b)

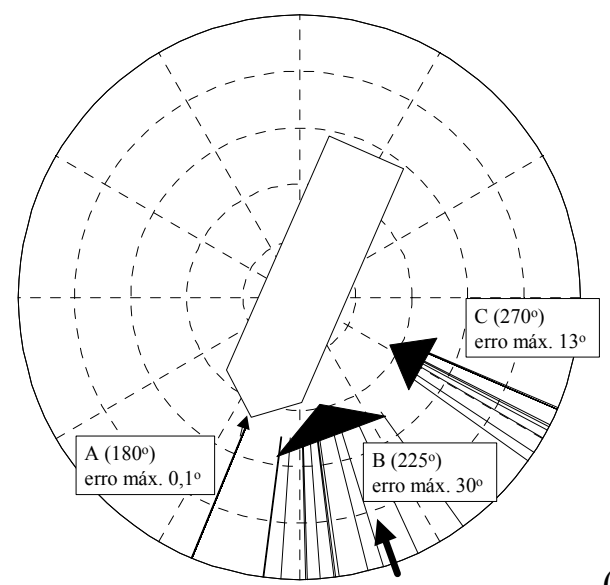

(c)

Figura 5.13 Resultados do método não paramétrico Bayesiano (a) altura significativa; (b) período de pico; (c) direção 


\section{Estudo de Casos}

Nesta seção, o controlador desenvolvido no Capítulo 4 será aplicado a dois sistemas oceânicos e serão realizados diversos testes numéricos através de simuladores desenvolvidos com o programa Matlab/Simulink versão 5.3 aplicados a cada um dos sistemas.

No primeiro caso, considera-se a operação de lançamento de dutos realizada pela barcaça BGL1 da Petrobras. Durante esta operação, a barcaça deve seguir uma trajetória determinada pelo rota projetada para a instalação do duto. Atualmente, opera-se sem auxílio de um SPD, realizando o posicionamento ao longo do percurso por meio de linhas de amarração, máquinas de reboque e navios de manuseio de âncora. Iniciativas atuais da Petrobras indicaram o interesse em converter a barcaça, dotando-a de um SPD e possibilitando a realização das operações de forma muito mais econômica e ágil. Além disso, com um SPD viabiliza-se o lançamento em águas profundas, não realizado atualmente devido ao procedimento que envolveria o reposicionamento das linhas de amarração. Assim, novamente supôs-se que a barcaça seja dotada do SPD proposto, e aplicou-se o controlador desenvolvido na seção 4.1.4, que controla os três graus de liberdade da embarcação.

No segundo estudo de caso, considera-se um navio petroleiro VLCC amarrado em alto-mar pelo sistema turret, operando como FPSO. Este sistema (navio Vidal de Negreiros) opera na Bacia de Campos de forma passiva, auxiliado, em períodos de tempestade ou durante operações de descarga, por rebocadores. Neste estudo de caso, supõe-se que o mesmo seja equipado com um sistema de posicionamento dinâmico assistido, atuando de forma conjunta às linhas de amarração, controlando o aproamento em torno do valor ótimo. Aplicam-se, portanto, o controlador de nível superior (seção 4.2) para cálculo deste aproamento ótimo e o controlador de aproamento de nível inferior (seção 4.1.3) para o posicionamento.

Para "emular" condições reais durante os testes numéricos realizados, os modelos dos agentes ambientais e das linhas de amarração utilizados durante a simulação foram alterados em relação aos utilizados na fase de projeto do controlador. A introdução destes erros permite avaliar a robustez do controlador proposto, característica desejável fundamental em SPDs. Utilizaram-se valores de erros relativos entre $10 \%$ e $20 \%$, 
indicados em cada caso e que condizem com erros de modelagem implícitos dos modelos apresentados no Capítulo 3. Além disso, pelo fato de o controlador proposto utilizar as intensidades e direções dos agentes ambientais, as condições ambientais utilizadas no projeto do controlador são alteradas em relação às utilizadas na simulação, com erros condizentes com a precisão dos sensores apresentados no Apêndice 2 e do método de estimação do espectro de ondas apresentado no Capítulo 5.

\subsection{Operação de Lançamento}

Nesta seção será apresentada a aplicação do controlador proposto à operação de lançamento de dutos realizada pela barcaça BGL1, supostamente equipada por um SPD.

Inicialmente, serão expostos os tipos de operação realizados, que envolvem o lançamento em águas rasas por meio da configuração S-lay e em águas profundas por meio da configuração J-lay. Os dados da barcaça utilizados no modelo são então apresentados, compreendendo os coeficientes de forças de correnteza e vento (obtidos em ensaios em tanque de provas), as forças de deriva de ondas e RAO's (obtidos pelo método numérico dos painéis). Em seguida, apresenta-se a configuração do sistema de controle, expondo-se a posição e o número de propulsores, a potência de cada um e suas características dinâmicas mais importantes.

O controlador desenvolvido em 4.1.4 é então aplicado, apresentando-se o cálculo dos parâmetros de controle seguindo as recomendações expostas naquela seção. Diversas simulações são apresentadas, afirmando as boas características de estabilidade e desempenho do controlador.

\subsubsection{Tipos de operação de lançamento}

A barcaça de lançamento BGL1 (Figura 6.1) opera em águas brasileiras há mais de 20 anos. Projetada originalmente para operação em profundidades pequenas e intermediárias (até $500 \mathrm{~m}$ ), é equipada com um sistema de amarração convencional composto por 10 linhas, e a sua movimentação é feita por meio de máquinas de reboque que impulsionam a BGL1 "puxando" as linhas de amarração de proa e liberando as de popa. Diversos navios de manuseio de âncoras auxiliam a operação, reposicionando as âncoras continuamente. Com isso, a embarcação se move avante conforme o duto é lançado, permitindo que o mesmo seja posicionado convenientemente. 


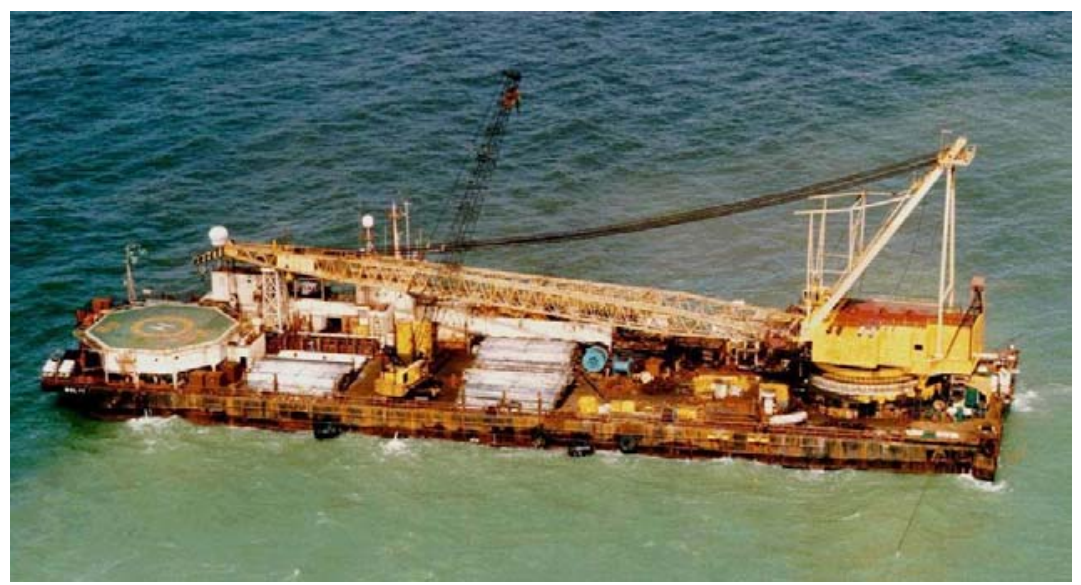

Figura 6.1 Barcaça BGL1

Nestas profundidades, a operação de lançamento é realizada em configuração $S$ lay, utilizando uma rampa de lançamento instalada da barcaça, com ou sem a estrutura de prolongamento chamada de stinger (Figura 6.2). O duto é soldado durante a operação e a tração no mesmo é controlada por uma máquina de tração.

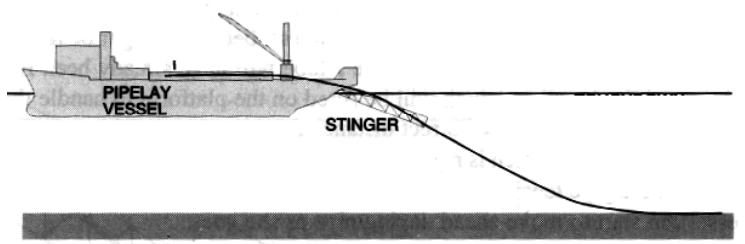

Figura 6.2 Operação de lançamento $S$-lay (adaptado de Bray, 1998)

Para profundidades elevadas, a operação em configuração J-lay é mais recomendada (Figura 6.3), sendo o duto lançado com pequeno ângulo com relação à vertical. A estrutura de lançamento pode ser instalada lateralmente ou num orifício no centro da embarcação (moon-pool). A complexidade da operação com o sistema de posicionamento convencional (baseado nas linhas de amarração) inviabiliza o lançamento em águas profundas, devendo-se utilizar para tanto um SPD. ${ }^{24}$

\footnotetext{
${ }^{24}$ A BGL1 ainda não possui a estrutura para lançamento J-lay, admitindo-se a instalação da mesma num moon-pool.
} 


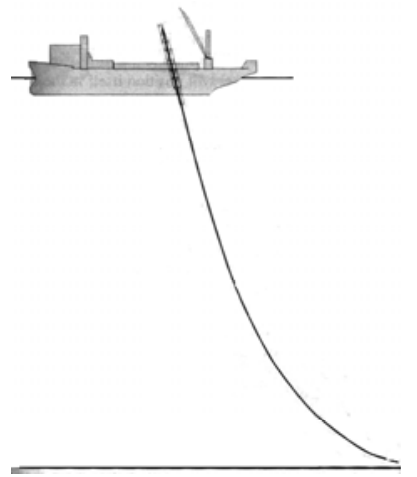

Figura 6.3 Operação de lançamento J-lay (adaptado de Bray, 1998)

A utilização de um SPD permite que as operações sejam realizadas em menos tempo e a menores custos. Além disso, a ausência do sistema de amarração permite lançamentos em locais com grande concentração de estruturas e cabos subaquáticos e próximos a plataformas ou FPSO’s amarrados. Por este fato, adicionado aos altos custos envolvidos na operação, os SPDs aplicados a barcaças de lançamento devem atender a severos requisitos de confiabilidade - IMO classe 3 - que equivale à necessidade de manutenção de posicionamento mesmo na falha de um componente ativo ou passivo do sistema.

A força exercida pelo duto lançado sobre a barcaça é controlada pela máquina de tração. Células de carga instaladas na máquina informam ao SPD o valor da tensão controlada, permitindo ao mesmo a compensação direta desta força, que representa uma grande parte da força total exercida pelos propulsores em condições ambientais de operação.

No lançamento S-lay, o duto possui pequeno ângulo de saída com relação à horizontal e a projeção da força atuante no mesmo no plano horizontal alcança valores elevados, chegando a $900 \mathrm{kN}$, aplicada ao final do stinger ou ao final da rampa de lançamento $^{25}$. No lançamento J-lay, esta projeção é menor, pois o duto possui ângulo de aproximadamente $70^{\circ}$ com a horizontal. Assim admite-se um valor máximo de $200 \mathrm{kN}$, aplicado no moon-pool. A direção desta força, no caso do J-lay, pode ser ajustada antes da operação, requerendo a rotação da estrutura de lançamento. A Figura 6.4 contém a posição do ponto de aplicação destas forças na BGL1.

\footnotetext{
${ }^{25}$ Como a linha de ação desta força é paralela à direção da rampa de lançamento e do stinger, pode-se considerar indistintamente o ponto de aplicação como o ponto extremo do stinger ou da rampa.
} 


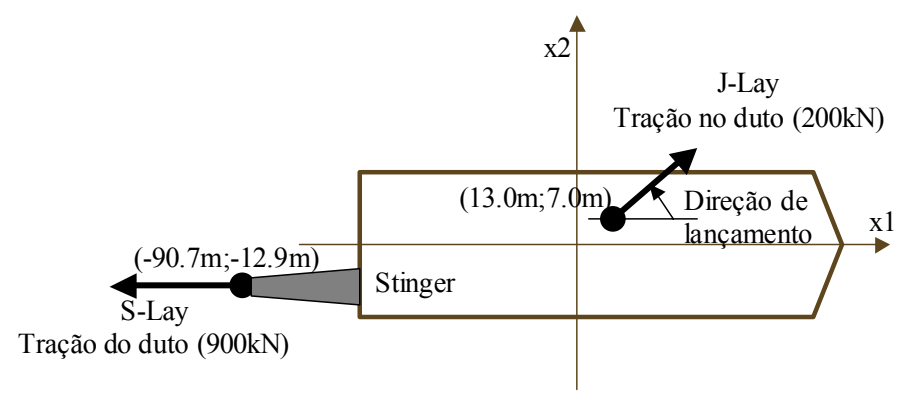

Figura 6.4 Forças do duto durante lançamento e pontos de aplicação; casos J-lay e S-lay

\subsubsection{Características da barcaça e comentários sobre o modelo utilizado}

As dimensões e características principais da BGL1 são apresentadas na Tabela 6.1 .

Tabela 6.1 Características principais da barcaça BGL1

\begin{tabular}{|l|l|}
\hline Comprimento $(\mathrm{L})$ & $121.9 \mathrm{~m}$ \\
\hline Boca $(\mathrm{B})$ & $30.48 \mathrm{~m}$ \\
\hline Calado $(\mathrm{T})$ & $5.18 \mathrm{~m}$ \\
\hline Posição do CG $\left(\mathrm{x}_{\mathrm{G}}\right)$ & $-4.18 \mathrm{~m}$ \\
\hline Massa $(\mathrm{M})$ & $17177.10^{3} \mathrm{~kg}$ \\
\hline Momento de Inércia $\left(\mathrm{I}_{\mathrm{Z}}\right)$ & $1.79 .10^{10} \mathrm{~kg} \cdot \mathrm{m}^{2}$ \\
\hline Massa Adicional Surge $\left(\mathrm{M}_{11}\right)^{*}$ & $1717.10^{3} \mathrm{~kg}$ \\
\hline Massa Adicional Sway $\left(\mathrm{M}_{22}\right)^{*}$ & $8588.10^{3} \mathrm{~kg}$ \\
\hline Massa Adicional Yaw $\left(\mathrm{M}_{66}\right)^{*}$ & $1.28 .10^{10} \mathrm{~kg} \cdot \mathrm{m}^{2}$ \\
\hline Área Lateral $\left(A_{L}\right)$ & $1500 \mathrm{~m}^{2}$ \\
\hline Área Frontal $\left(A_{F}\right)$ & $420 \mathrm{~m}^{2}$ \\
\hline \multicolumn{2}{|c|}{ * em baixa freqüência } \\
\hline
\end{tabular}

As forças de correnteza estáticas foram calculadas por (3.13). Os coeficientes estáticos foram medidos em ensaios cativos conduzidos no DITT-IPT, sob encomenda da Petrobras. Os experimentos foram realizados supondo-se uma operação $J$-lay, ou seja sem o stinger montado. Analisou-se também a condição S-lay, com o stinger, com e sem trim de popa operacional de $1 \%$, algumas vezes presente nesta condição. Verificouse que as diferenças entre os coeficientes de correnteza são muito pequenas, afetando muito pouco o desempenho e projeto do SPD (Pesce; Tannuri, 2001). Apresentam-se na Figura 6.5 os coeficientes para o caso S-lay, sem banda. As forças de correnteza associadas à rotação do casco foram calculadas pelo Modelo de Asa Curta Estendido discutido em 3.2.1.2. 


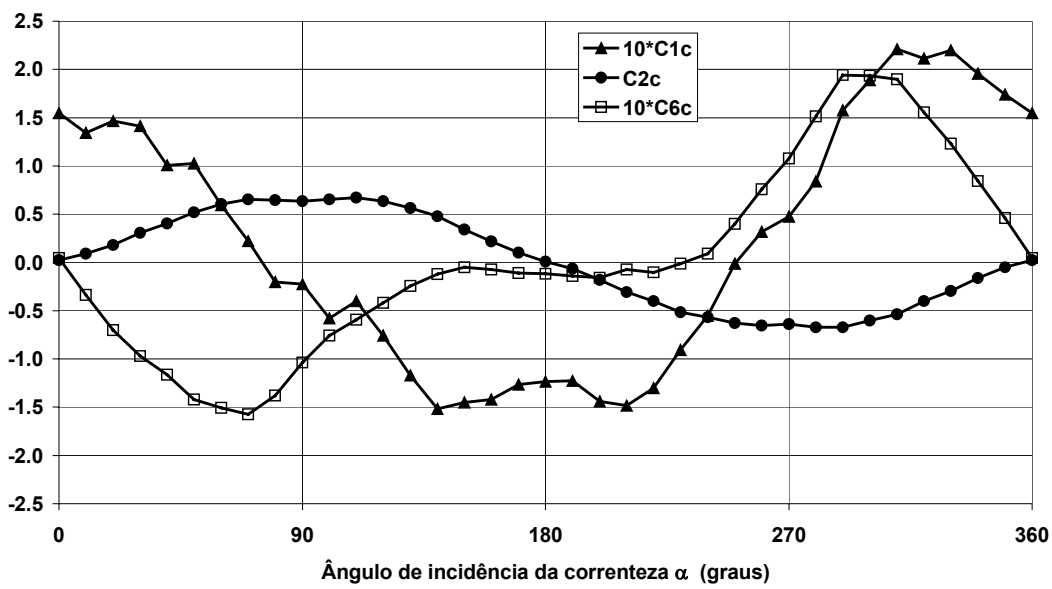

Figura 6.5 Coeficientes de corrente para BGL1, com stinger e sem banda

As forças e momento de vento foram modeladas por (3.40) e os coeficientes foram obtidos por ensaios cativos realizados com o modelo emborcado no tanque de provas (Figura 6.6). Utilizou-se o espectro de Harris (3.41) para representar as rajadas de vento, com coeficiente $C=0,003$.

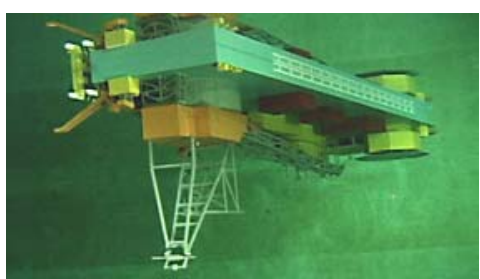

(a)

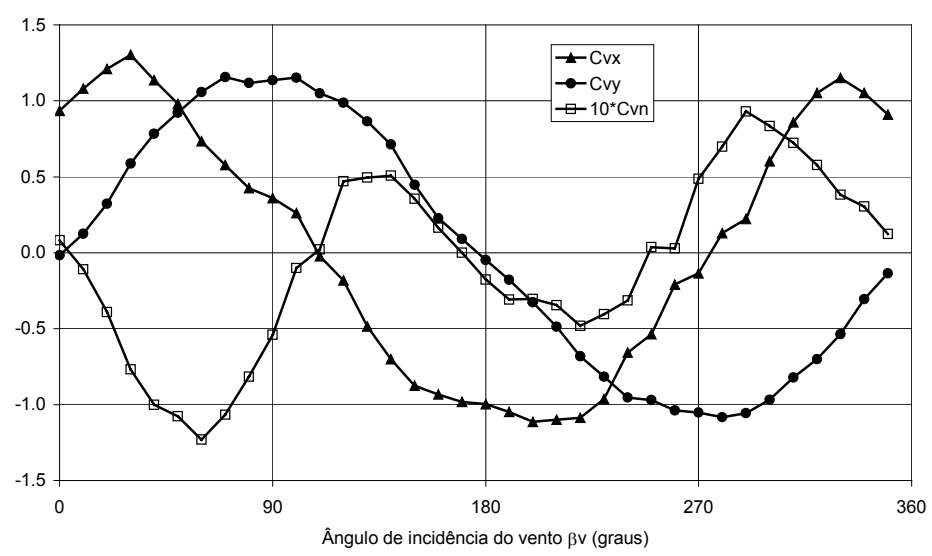

(b)

Figura 6.6 (a)Ensaio cativo de vento com o modelo emborcado; (b)Coeficientes de vento

As forças de segunda ordem de ondas foram calculadas segundo a formulação apresentada em 3.2.2.2, utilizando-se os coeficientes de deriva provenientes do programa WAMIT, que considera, através do métodos dos painéis, apenas os efeitos potenciais do escoamento. Apresentam-se na Figura 6.7 os coeficientes de deriva para diversos ângulos de incidência. A interação onda corrente foi calculada por 3.2.2.3. 


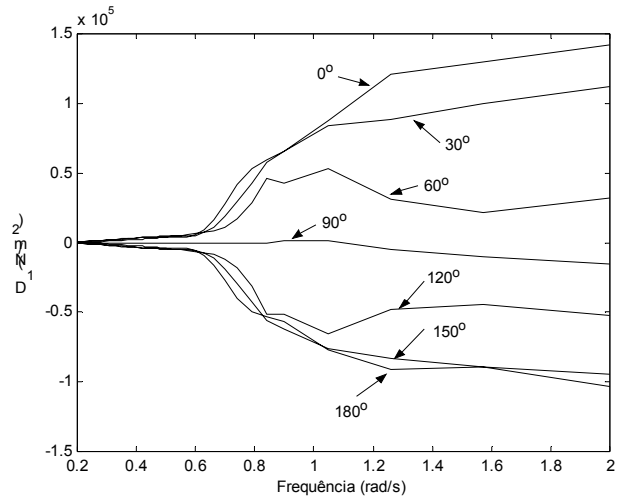

(a)

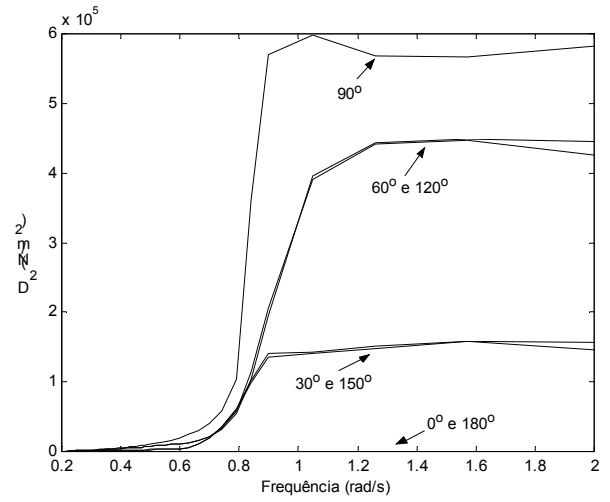

(b)

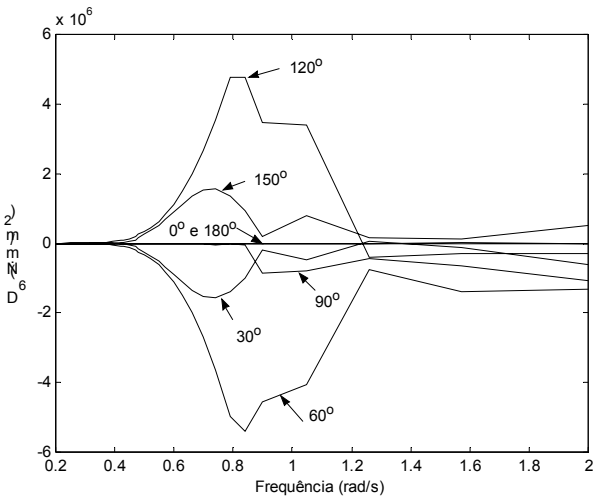

(c)

Figura 6.7 Coeficientes de deriva da BGL1 para diversas direções de incidência de onda (a) surge; (b)sway; (c)yaw

Os movimentos de primeira ordem são calculados por meio dos RAO's também provenientes do programa WAMIT, cujos módulos são apresentados na Figura 6.8. O espectro de mar considerado nas simulações foi o de JONSWAP, com parâmetro $\gamma=1,4$. 


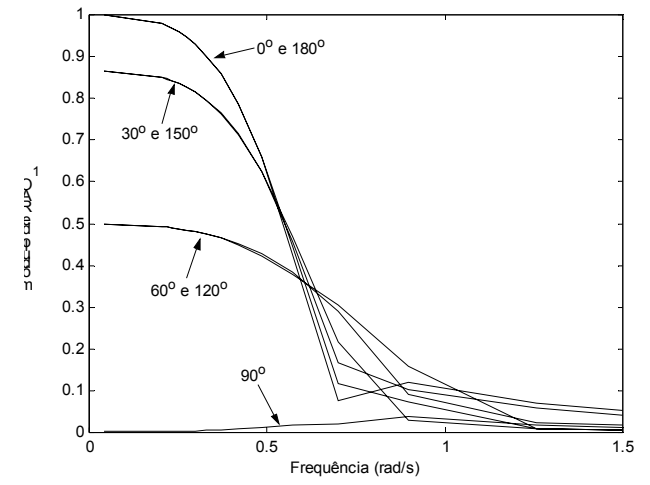

(a)

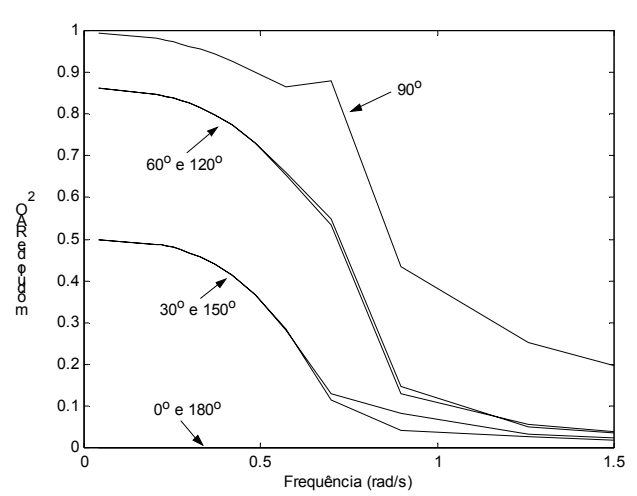

(b)

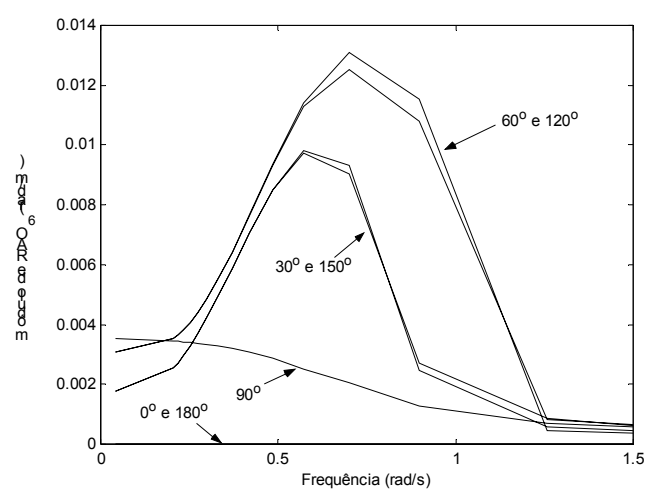

(c)

Figura 6.8 Módulo dos RAO's dos movimentos horizontais da BGL1 para diversas direções de incidência de onda (a) surge; (b)sway; (c)yaw

\subsubsection{Configuração do sistema de propulsão}

A barcaça será equipada por 6 propulsores azimutais, cujas posições satisfazem critérios de arranjo e foram mostradas na Figura 4.31. Para a realização de simulações, utilizaram-se propulsores em bocal da série Ka com um bocal No.19A, 2m de diâmetro e passo1,6m. As curvas dos coeficientes $K_{T}, K_{Q}$ e $K_{T N}$ são dadas em Lewis (1988) e foram apresentadas na Figura 3.26.

Admitiu-se um rendimento mecânico de $80 \%$, do qual resultam curvas de eficiência global, definida como o empuxo fornecido por unidade de potência consumida $(\mathrm{kN} / \mathrm{kW})$, já apresentadas na Figura 3.27. Adotou-se também uma potência máxima de $1650 \mathrm{~kW}$ para cada propulsor.

O sistema de controle dos propulsores incluído no simulador foi apresentado em 3.5.3, e os ganhos foram ajustados para que o empuxo seja levado de zero ao valor máximo em $15 \mathrm{~s}$, com a curva de resposta apresentada na Figura 1.30. Utilizou-se o 
algoritmo de alocação de empuxo exposto em 4.3.3.2, que considera a saturação, redistribuindo o empuxo em caso de saturação de um ou mais propulsores.

\subsubsection{Projeto do controlador e ajuste de parâmetros}

O principal objetivo do SPD instalado na barcaça é manter o ponto de referência (ponto de lançamento do duto) próximo a trajetória requerida, determinada pelo futuro traçado do duto. Para tanto, utiliza-se o controlador combinado dos movimentos e translação e rotação desenvolvido em 4.1.4, com um set-point móvel, segundo a trajetória requerida. Os parâmetros do controlador foram ajustados seguindo os procedimentos indicados no Capítulo 4, e serão expostos novamente a seguir.

Os parâmetros $\lambda_{X}, \lambda_{Y}$ e $\lambda_{\psi}$ foram ajustados em 0,042rad/s. Como visto em 4.1.4, representam a largura de banda do sistema em malha fechada, ou seja, a largura de banda quando se opera sobre a superfície de escorregamento, e devem ser ajustados respeitando-se as regras práticas expostas em 4.1.1.1.

A primeira delas recomenda que estes parâmetros sejam menores que o primeiro modo ressonante não modelado, o que no presente caso se relaciona aos movimentos verticais $^{26}$ não incluídos no modelo de controle, atingindo valores aproximados de $0,5 \mathrm{rad} / \mathrm{s}$.

A segunda recomendação relaciona-se aos atrasos de transporte não incluídos no modelo, que são decorrentes do filtro de onda (4.96) que introduz um atraso de aproximadamente $8 \mathrm{~s}$ entre o movimento real de baixa freqüência e o sinal realimentado. Este valor foi obtido por análise detalhada das séries temporais provenientes de simulações. Assim, é recomendável que os parâmetros $\lambda_{X}, \lambda_{Y}$ e $\lambda_{\psi}$ tenham valores inferiores a $0,042 \mathrm{rad} / \mathrm{s}$.

Finalmente, adotando-se uma freqüência de amostragem de aproximadamente 1s, a terceira recomendação sugere valores inferiores a $0,2 \mathrm{rad} / \mathrm{s}$. A aplicação simultânea das recomendações resulta, portanto, que o valor de $0,042 \mathrm{rad} / \mathrm{s}$ para os três parâmetros em questão.

\footnotetext{
${ }^{26}$ Embora o acoplamento entre os movimentos verticais e horizontais seja pequeno (e foi desconsiderado no modelo (3.9)), as forças de controle horizontais podem excitar os movimentos verticais caso possuam componentes na freqüência de ressonância dos mesmos.
} 
As espessuras das camadas limites $\left(\Phi_{X}, \Phi_{Y}\right.$ e $\left.\Phi_{\psi}\right)$ foram ajustadas utilizando-se a relação (4.20). Assim, dadas as estimativas das condições ambientais e suas variações máximas, as relações obtidas na seção 4.1 .5 são aplicadas para que sejam calculados os valores máximos dos ganhos $k_{X}, k_{Y}$ e $k_{\psi}$, definidos em (4.59), (4.60) e (4.61) respectivamente e, a partir deles, obterem-se as espessuras.

Finalmente, os parâmetros $\eta_{X}, \eta_{Y}$ e $\eta_{\psi}$ foram calculados utilizando-se a relação (4.6), requerendo-se um tempo de 200 s para que o sistema atinja a superfície de escorregamento caso apresente um erro de $5 \mathrm{~m}$ nas direções $\mathrm{X}$ e $\mathrm{Y}$ e $5^{\circ}$ em yaw. Por exemplo, o cálculo de $\eta_{X}$ é feito por:

$$
\eta_{X}=\frac{2 \lambda_{X} \tilde{X}}{t_{\text {alcance }}}=\frac{2 \times 0,04 \times 5}{200}=0,002
$$

Nas simulações a seguir serão consideradas duas condições ambientais esquematizadas na Figura 6.9. Em ambas as condições, considera-se o espectro de onda de JONSWAP com $\gamma=1,4$ e espectro de rajadas de vento de Harris com $\mathrm{C}=0,003$.

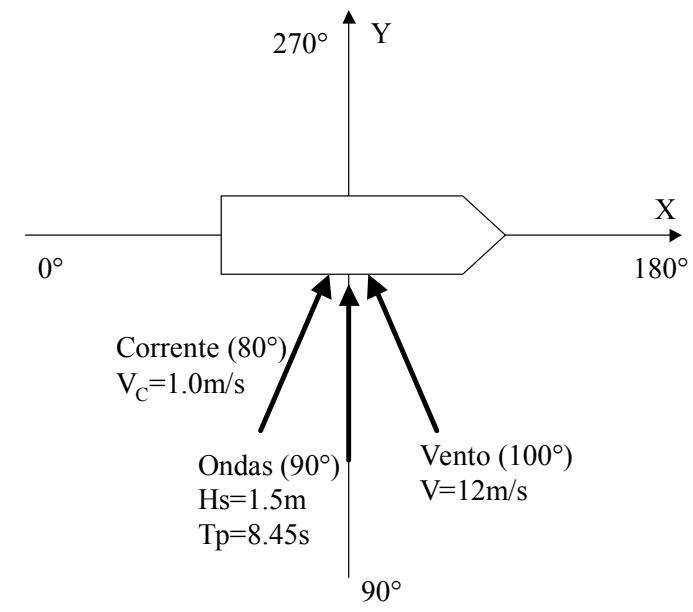

(C1)

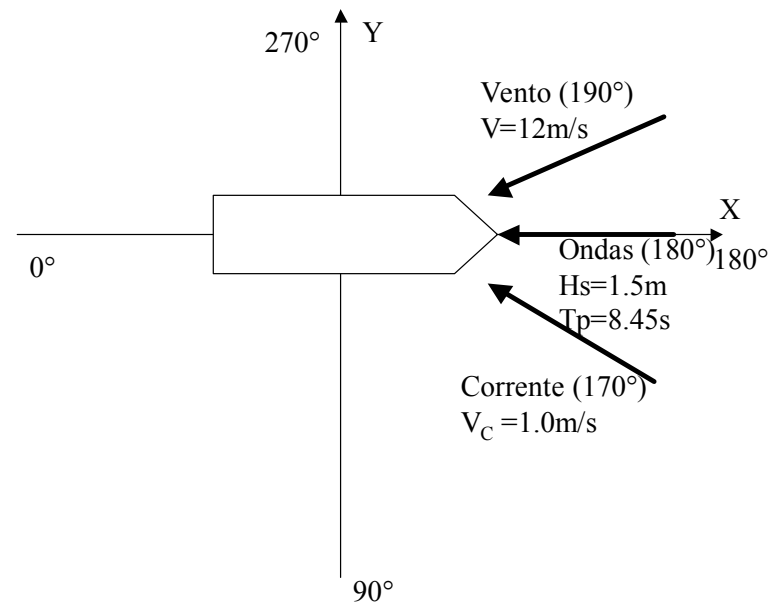

(C2)

Figura 6.9 Condições ambientais consideradas nas simulações (C1) incidência de través ; (C2) incidência de proa

Apresentam-se na segunda coluna da Tabela 6.2 os valores das intensidades e direções dos agentes ambientais consideradas no simulador e os erros de modelagem introduzidos na avaliação de suas forças e momentos. Como já mencionado, foram 
utilizados erros de modelagem de $\pm 20 \%$, apropriados aos modelos considerados. $\mathrm{Na}$ terceira coluna são apresentados os valores "estimados" das intensidades e direções, que são utilizados no controlador. Finalmente, na quarta coluna apresentam-se os limites considerados no projeto do controlador, utilizados nos cálculos dos ganhos $K$ apresentados em 4.1 .5 e que garantem a robustez do controlador.

Tabela 6.2 Estimativas das condições ambientais e erros de modelagem máximos considerados no controlador

\begin{tabular}{|c|c|c|c|c|c|}
\hline \multirow{2}{*}{\multicolumn{2}{|c|}{\begin{tabular}{|l|} 
Parâmetro \\
Vel. De correnteza \\
\end{tabular}}} & \multirow{3}{*}{$\begin{array}{l}\begin{array}{l}\text { Valor utilizado } \\
\text { na simulação }\end{array} \\
V_{C}=1,0 \mathrm{~m} / \mathrm{s} \\
\alpha_{O X Y Z}=80^{\circ}\end{array}$} & \multirow{3}{*}{$\begin{array}{l}\text { Valor estimado } \\
\text { utilizado no controlador } \\
\hat{V}_{C}=1,1 \mathrm{~m} / \mathrm{s} \\
\hat{\alpha} O X Y Z=90^{\circ}\end{array}$} & \multicolumn{2}{|c|}{$\begin{array}{lll}\text { Limites considerados } & \text { no } \\
\text { projeto do controlador } & \end{array}$} \\
\hline & & & & \multirow{2}{*}{$\begin{array}{l}V_{C, \min }=1,0 \mathrm{~m} / \mathrm{s} \\
\alpha_{O X Y Z, \min }=80^{\circ}\end{array}$} & \multirow{2}{*}{$\begin{array}{l}V_{C, \max }=1,2 \mathrm{~m} / \mathrm{s} \\
\alpha_{O X Y Z, \operatorname{maz}}=100^{\circ}\end{array}$} \\
\hline de & (C1) & & & & \\
\hline correnteza & $(\mathbf{C 2})$ & $\alpha_{O X Y Z}=170^{\circ}$ & $\hat{\alpha} O X Y Z=180^{\circ}$ & $\alpha_{O X Y Z, \min }=170^{\circ}$ & $\alpha_{O X Y Z, \operatorname{maz}}=190^{\circ}$ \\
\hline \multicolumn{2}{|c|}{$\begin{array}{l}\text { Erro de modelagem } \\
\text { da correnteza }\end{array}$} & $+20 \%$ & & \multicolumn{2}{|c|}{$e_{1 C}=e_{2 C}=e_{6 C}=20 \%$} \\
\hline \multicolumn{2}{|l|}{ Altura Sig. } & $H_{S}=1,5 \mathrm{~m}$ & $\hat{H}_{S}=2,0 \mathrm{~m}$ & $H_{S, \text { min }}=1,0 \mathrm{~m}$ & $H_{S, \max }=2,0 \mathrm{~m}$ \\
\hline \multirow[t]{2}{*}{ Dir. de onda } & (C1) & $\beta_{O, O X Y Z}=90^{\circ}$ & $\hat{\beta}_{O, O X Y Z}=70^{\circ}$ & $\beta_{O, O X Y Z \min }=50^{\circ}$ & $\beta_{O, O X Y Z \max }=90^{\circ}$ \\
\hline & (C2) & $\beta_{O, O X Y Z}=180^{\circ}$ & $\hat{\beta} O, O X Y Z=160^{\circ}$ & $\beta_{O, O X Y Z \min }=140^{\circ}$ & $\beta_{O, O X Y Z \max }=180^{\circ}$ \\
\hline \multicolumn{2}{|l|}{ Per. Pico } & $T_{P}=8,45 \mathrm{~s}$ & $\hat{T}_{P}=7,1 \mathrm{~s}$ & $T_{P, \min }=5,6 \mathrm{~s}$ & $T_{P, \operatorname{Max}}=8,5 \mathrm{~s}$ \\
\hline \multicolumn{2}{|c|}{$\begin{array}{l}\text { Erro de modelagem } \\
\text { de deriva média }\end{array}$} & $+20 \%$ & & \multicolumn{2}{|c|}{$e_{1 D M}=e_{2 D M}=e_{6 D M}=20 \%$} \\
\hline \multicolumn{2}{|l|}{ Vel. de vento } & $V=12 \mathrm{~m} / \mathrm{s}(*)$ & $\hat{V}=V-10 \% . V$ & \multicolumn{2}{|c|}{$V_{\min / \max }=V \pm 10 \% . \mathrm{V}$} \\
\hline \multirow[t]{2}{*}{ Dir. de vento } & (C1) & $\beta_{V, O X Y Z}=100^{\circ}$ & $\hat{\beta}_{O, O X Y Z}=90^{\circ}$ & $\beta_{V, \text { OXYZmin }}=80^{\circ}$ & $\beta_{V, \text { OXYZmax }}=100^{\circ}$ \\
\hline & (C2) & $\beta_{V, O X Y Z}=190^{\circ}$ & $\hat{\beta} O, O X Y Z=180^{\circ}$ & $\beta_{V, \text { OXYZmin }}=170^{\circ}$ & $\beta_{V, \text { OXYZmax }}=190^{\circ}$ \\
\hline \multicolumn{2}{|c|}{$\begin{array}{l}\text { Erro de modelagem } \\
\text { de vento }\end{array}$} & $-20 \%$ & & \multicolumn{2}{|c|}{$e_{1 V}=e_{2 V}=e_{6 V}=20 \%$} \\
\hline
\end{tabular}

(*) além da velocidade variável devido às rajadas

Pode-se verificar que os erros de estimação são sobre-estimados perante a precisão dos sistemas de sensoriamento ambiental expostos no Apêndice 2, garantindo uma "margem de segurança" nas análises. No caso da correnteza, por exemplo, consideram-se erros de $10 \%$ na medição de velocidade e de $10^{\circ}$ na direção, bastante superiores aos valores especificados pelos fabricantes de sensores baseados em efeito Doppler (ver A2.1). Para as ondas, consideraram-se erros de 33\% na estimativa da altura significativa, $-20^{\circ}$ na direção e $-16 \%$ no período de pico, superiores (em valor absoluto) aos erros máximos obtidos nos experimentos com o método paramétrico de estimação de ondas. Finalmente, no caso dos ventos consideraram-se erros de $-10 \%$ na medição da velocidade instantânea e $-10^{\circ}$ na direção, também sobre-estimados considerando-se os sensores disponíveis para tal medição. 


\subsubsection{Simulações utilizando controlador por modos deslizantes}

O simulador, desenvolvido em ambiente Matlab/Simulink (v. 5.3), inclui todos os modelos discutidos no Capítulo 3 adicionalmente ao controlador apresentado em 4.1.4. No Apêndice 3, é feita uma breve apresentação do simulador.

O dimensionamento do sistema propulsor é realizado considerando-se as possíveis combinações dos agentes ambientais incidindo sobre a embarcação controlada de forma a manter a posição do ponto de referência com um passeio máximo inferior a determinado valor. Tannuri et al. (2002) realizaram este procedimento aplicado à BGL1, a partir do qual verificou-se que a potência instalada é suficiente para atender os requisitos operacionais nos lançamentos J-lay e S-lay para todas as condições ambientais e de falhas requeridas. Inicialmente, apresenta-se a apenas um dos exemplos de simulação realizado naquele trabalho, focando-se aqui a discussão das características do controlador implementado. Em seguida aplica-se o controlador para uma manobra de avanço, realizada durante o lançamento de um trecho do duto. Finalmente, simula-se a realização de uma curva de $30^{\circ}$, manobra utilizada nas alterações da direção de lançamento.

O primeiro caso analisado foi extraído de Tannuri et al. (2002) e corresponde a um set-point estacionário, durante a realização da operação S-lay com a condição ambiental C1. Apresenta-se na Figura 6.10(a) a posição do ponto de referência nos eixo $O X$ e $O Y$ e aproamento da embarcação durante 1000s. Na Figura 6.10(b) são apresentados os azimutes, forças e potências em cada propulsor. Na Figura 6.10(c) apresentam-se as posições da barcaça durante a simulação e as direções e intensidades relativas das forças nos propulsores. A simulação foi realizada utilizando-se o método de integração de Dormand-Prince com passo simples de 0,25s.

Observa-se que a posição do ponto de referência é mantida próxima da desejada, a menos das componentes de alta freqüência não controladas, originadas das forças de onda de primeira ordem e de oscilações rápidas da velocidade do vento. Estas componentes são mais pronunciadas na direção $O Y$, pois a incidência ambiental é de través. As oscilações de baixa freqüência excitadas pelas forças de deriva lenta e pelas variações lentas da velocidade do vento são compensadas pelo controlador com bastante eficiência. $\mathrm{O}$ aproamento apresenta comportamento semelhante, com grande atenuação 
dos movimentos de baixa freqüência. O erro médio em regime é nulo para todos os movimentos devido à ação integral adicionada ao controlador.
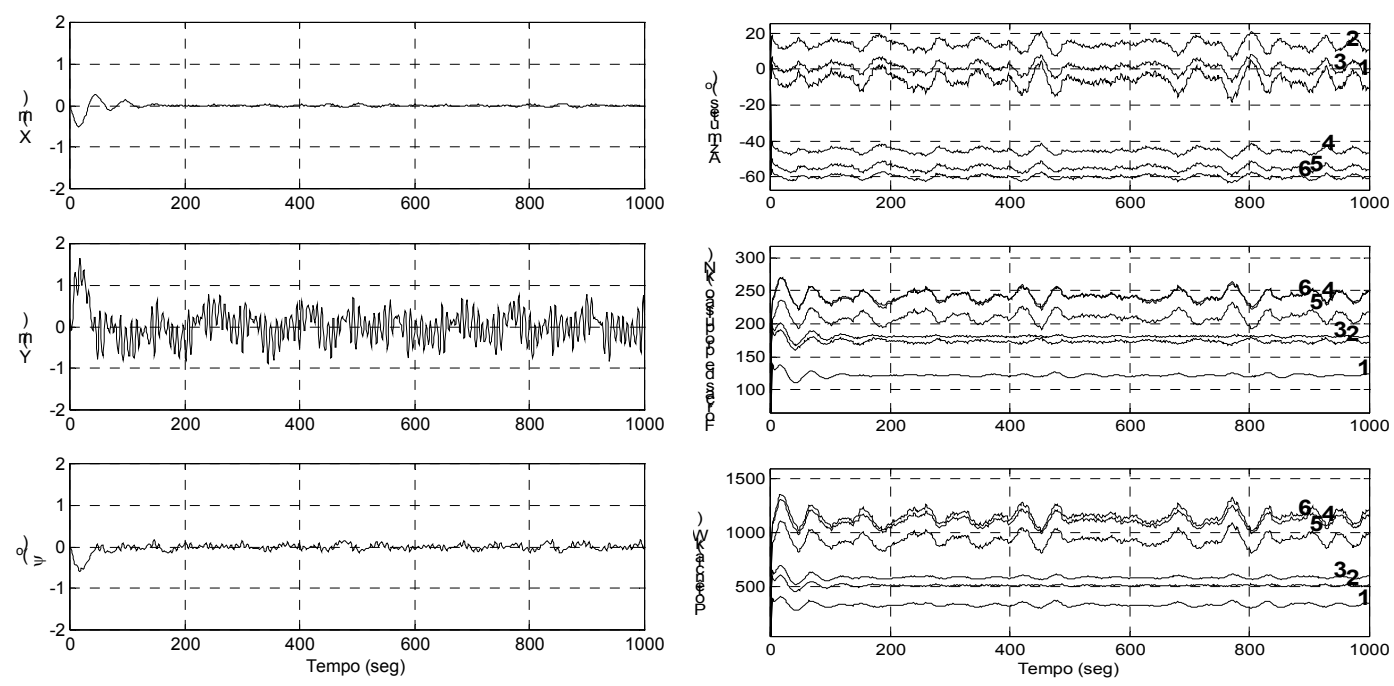

(a)

(b)

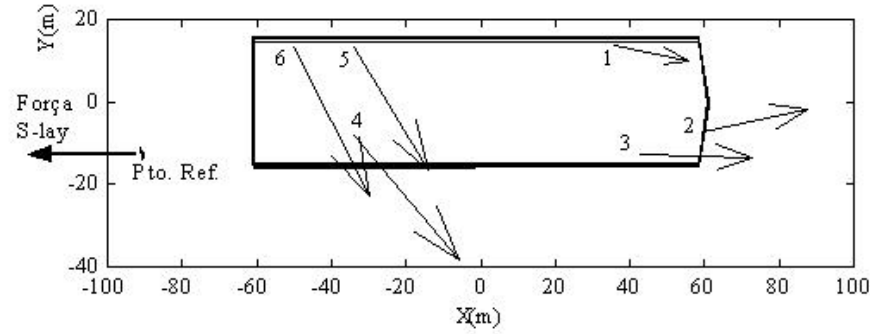

(c)

Figura 6.10 Lançamento $S$-lay, condição ambiental C1, embarcação estacionária (a) Posição e aproamento; (b) Azimute, força e potência nos propulsores; (c) posições da barcaça e forças médias nos propulsores

Pode-se verificar, também, que as forças nos propulsores não apresentam oscilações de alta freqüência (modulação), o que indica que a definição da camada limite realmente elimina a ocorrência deste fenômeno. Além disso, estas forças também não apresentam componentes significativas em freqüências próximas às das ondas, indicando o bom funcionamento do filtro de ondas utilizado. Pela Figura 6.10(c) podese ver que os propulsores de popa $(4,5$ e 6$)$ são responsáveis pela compensação dos esforços ambientais incidindo a $90^{\circ}$ na embarcação e, conjuntamente com os de proa (1, 2 e 3), responsabilizam-se por compensar a força de $900 \mathrm{kN}$ exercida pelo duto lançado. Como o lançamento é feito na rampa lateral da barcaça, esta força gera um momento elevado em relação à meia nau, o que resulta na distribuição bastante assimétrica dos empuxos, solicitando mais intensamente os propulsores de popa. 
Uma segunda análise requerida para este tipo de SPD refere-se à movimentação controlada da barcaça, o que é feito em passos de aproximadamente $24 \mathrm{~m}$, equivalente ao comprimento do trecho do duto lançado e soldado no convés. Durante o avanço não pode ocorrer sobre-sinal, o que provocaria esforços muito elevados no duto. Devido à dificuldade deste tipo de controle, a prática comum dos operadores de barcaças de lançamento dotadas de SPD é a inserção de um set-point inferior a $24 \mathrm{~m}$ com o posterior desligamento do sistema após o avanço de aproximadamente $21 \mathrm{~m}$, sendo o restante percorrido livremente. Ao alcançar a posição desejada, acionam o modo de controle de posição fixa.
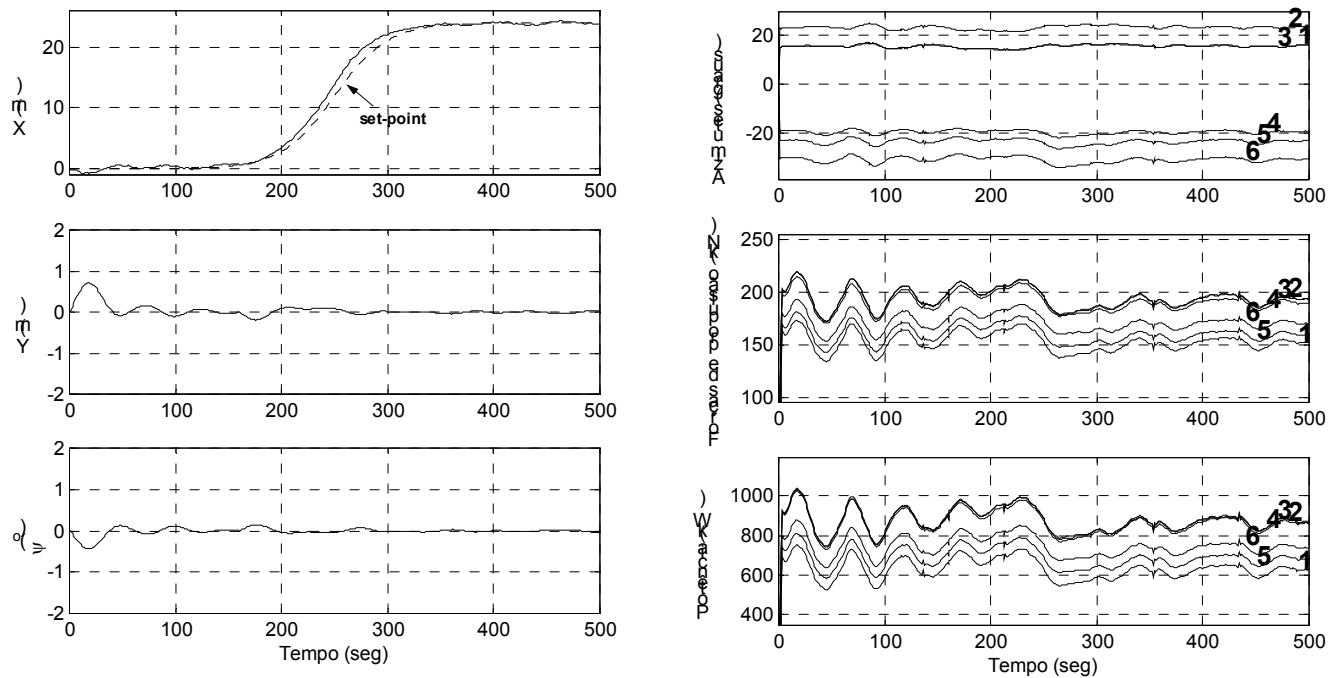

(a)

(b)

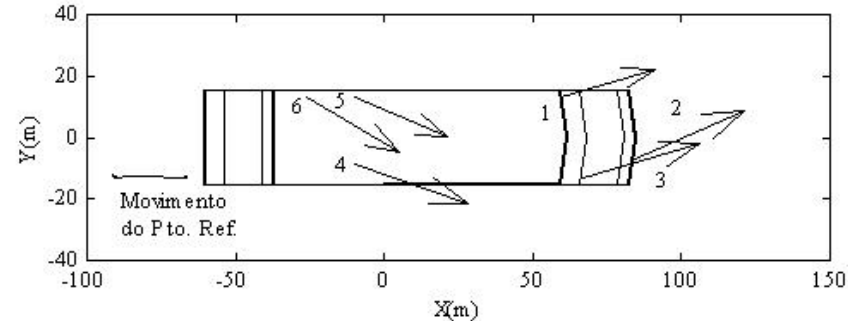

(c)

Figura 6.11 Lançamento $S$-lay, condição ambiental C2, embarcação em avanço de $24 \mathrm{~m}$ (a) Posição e aproamento; (b) Azimute, força e potência nos propulsores; (c) posições da barcaça e forças médias nos propulsores

Utilizando-se o controlador proposto, verifica-se que o avanço pode ser efetuado sem a utilização do recurso "prático" acima descrito. De fato, a Figura 6.11 apresenta o resultado da simulação da manobra de avanço de $24 \mathrm{~m}$ sob a condição $\mathrm{C} 2$, bastante adversa neste caso pois a incidência ambiental ocorre na proa da embarcação, em 
oposição ao movimento. O set-point é indicado na Figura 6.11(a), utilizando-se uma função tangente hiperbólica para representar a variação suave de 0 a $24 \mathrm{~m}$ durante aproximadamente 180s. Verifica-se que a barcaça acompanha a trajetória desejada com erro menor que $1,5 \mathrm{~m}$ na direção $O X$, com sobre-sinal nulo. A posição no eixo $O Y$ do ponto de referência apresenta, após transitório inicial, desvios menores que $0,2 \mathrm{~m}$ e o aproamento possui desvios menores que $1^{\mathrm{o}}$. Os esforços de controle e azimutes, mostrados na Figura 6.11(b), não apresentam novamente modulação e componentes na freqüência da onda.

A realização de curvas durante a operação também deve ser analisada, pois em determinados casos os dutos devem ser lançados em trajetórias curvas para, por exemplo, desviar de obstáculos subaquáticos. Considerou-se uma curva de $30^{\circ}$ conforme esquematizado na Figura 6.12, sendo todo o trajeto realizado a $0,1 \mathrm{~m} / \mathrm{s}$, realizando-se operação J-lay com direção de lançamento de $90^{\circ}$.

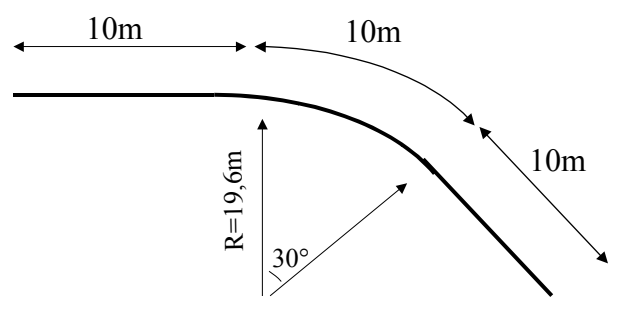

Figura 6.12 Curva de $30^{\circ}$ simulada

O resultado da simulação é apresentado na Figura 6.13, de onde se pode que o erro de acompanhamento é inferior a $1 \mathrm{~m}$ e o erro de aproamento menor que $5^{\circ}$ (em valor absoluto), apresentando um bom desempenho na realização da manobra requerida. Deve-se ressaltar que os azimutes são definidos entre $-180^{\circ} \mathrm{e}+180^{\circ}$, o que justifica as aparentes variações abruptas nos valores destes ângulos na Figura 6.13(b). 

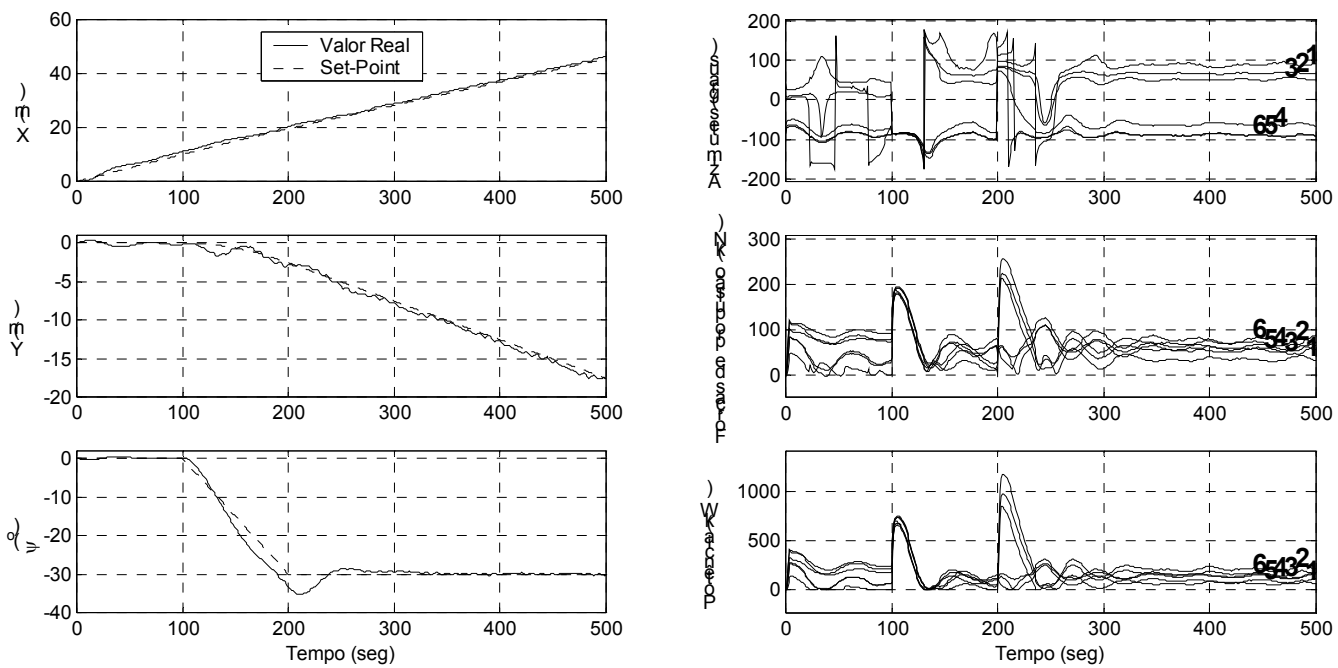

(a)

(b)

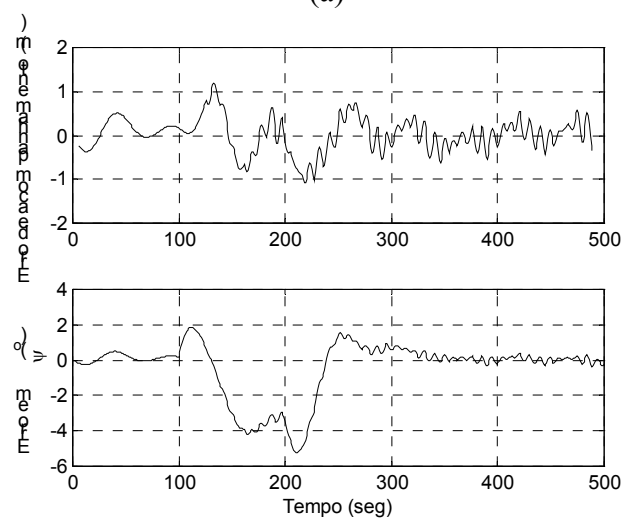

(c)
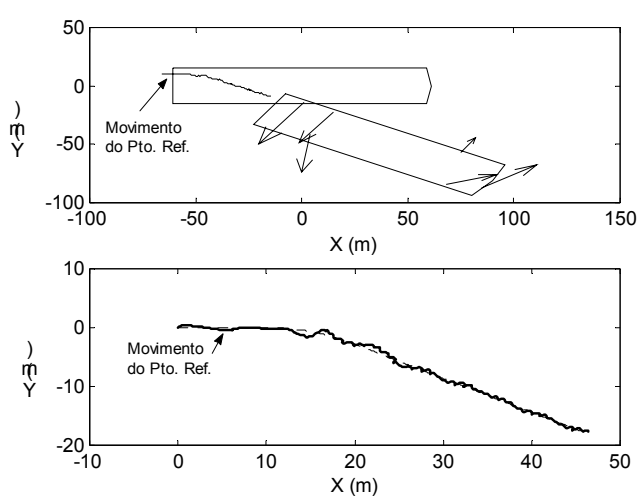

(d)

Figura 6.13 Lançamento J-lay, condição ambiental C2, curva de $30^{\circ}$ (a) Posição e aproamento; (b) Azimute, força e potência nos propulsores; (c) erros de acompanhamento e aproamento (d) posições da barcaça, forças médias nos propulsores e trajetória do ponto de referência

O controlador projetado apresenta uma larga “janela” ambiental, ou seja, garante bom desempenho em em face de grandes variações nas condições ambientais. $\mathrm{O}$ controlador se "adapta" às mudanças pelo fato de "conhecer" como o sistema se comporta, já que possui em sua estrutura o modelo dinâmico do sistema, além de conhecer estimativas das condições ambientais presentes. De fato, simulou-se a realização da curva de $30^{\circ}$ sob a condição ambiental C2 atenuada, com uma redução de $70 \%$ nas velocidades de correnteza e vento e na altura significativa. Pode-se ver (Figura 6.14) que o desempenho do sistema é praticamente igual ao caso das condições mais severas (Figura 6.13). 

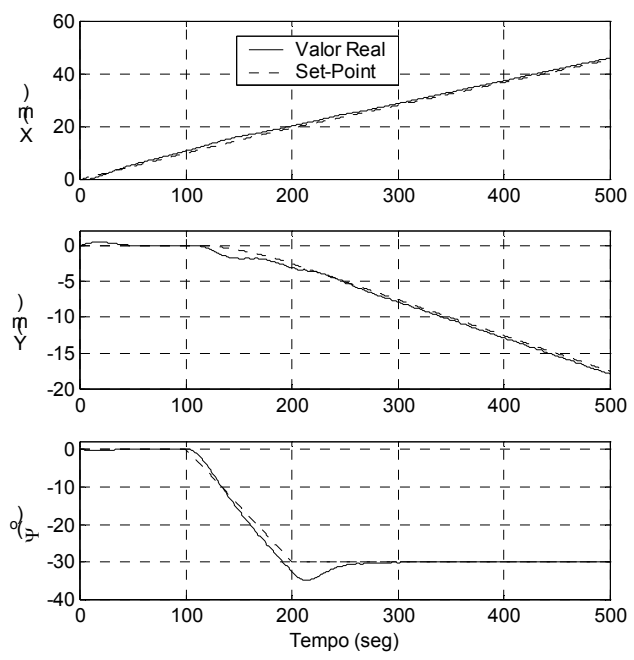

(a)

Figura 6.14 Lançamento J-lay, condição ambiental C2 (velocidade de vento e correnteza e altura de onda reduzidas de $70 \%$ ), curva de $30^{\circ}$

\subsection{FPSO amarrado em sistema turret}

Nesta seção será apresentada a aplicação do controle de aproamento desenvolvido em 4.1.3, conjuntamente ao controlador de nível superior desenvolvido em 4.2, ao VLCC Vidal de Negreiros operando como FPSO, supostamente equipado por um SPD. Uma análise semelhante foi feita em Tannuri et al. (2001a), sendo aqui realizada uma discussão mais detalhada.

Inicialmente, apresenta-se uma breve descrição dos FPSOs, destacando-se suas vantagens e características principais que os tornaram um sistema bastante utilizado pela indústria de exploração de petróleo. Em seguida, os dados do VLCC com 80\% de carregamento são apresentados, incluindo-se a descrição do sistema de amarração e risers empregados e a configuração dos propulsores que supostamente equipam o navio. Apresentam-se, então, os parâmetros utilizados no controlador e os erros de modelagem e estimação das condições ambientais utilizados na simulação e projeto de controle. Ao final, os resultados são apresentados e analisados.

\subsubsection{Sistemas FPSOs}

Diversas características dos petroleiros, como a grande área de convés e capacidade de armazenamento, além da oferta de mercado, os tornaram uma boa opção 
para uso na produção e exploração de petróleo em alto-mar. Assim, foram criados os sistemas FPSOs, que se constituem de navios petroleiros amarrados em alto-mar, realizando o armazenamento do óleo em seus tanques e o pré-processamento do mesmo, através de uma planta de processamento instalada no convés.

Até 1985, os FPSOs eram construídos a partir de petroleiros convertidos, sendo que atualmente, além das conversões, existem unidades que são especialmente projetadas e construídas para este fim. Segundo Henery; Inglis (1995), o primeiro FPSO foi instalado em 1977, sendo que em 1995 já havia 27 em operação e 11 em construção.

Entre os diversos tipos de sistemas de amarração disponíveis, o sistema turret destaca-se devido à liberdade de aproamento que confere ao FPSO, conforme foi ilustrado na Figura 1.5. Em alguns casos, a torre é instalada próxima à meia nau da embarcação, o que diminui os movimentos verticais na mesma, minimizando problemas de trações dinâmicas elevadas nos risers que se conectam ao FPSO na periferia da torre. Entretanto, neste caso o sistema perde a capacidade de alinhamento em relação à resultante ambiental (weather vane), conforme é apresentado em Pesce; Tannuri (1997). Este fato pode levar o FPSO a um aproamento de equilíbrio tal que a incidência ambiental provoque esforços muito elevados no sistema de amarração, requerendo-se, não raro, a interferência de navios aliviadores para reposicionar o FPSO em um aproamento mais adequado.

A aplicação de sistemas de posicionamento dinâmico assistido em FPSOs deste tipo permitiu maior independência das unidades, que passaram a possuir a capacidade de correção do aproamento independente de navios rebocadores, conforme descrito em Aalbers et al. (1995) e ilustrado na Figura 6.15, referente ao FPSO norueguês Norne $6608 / 10$. 


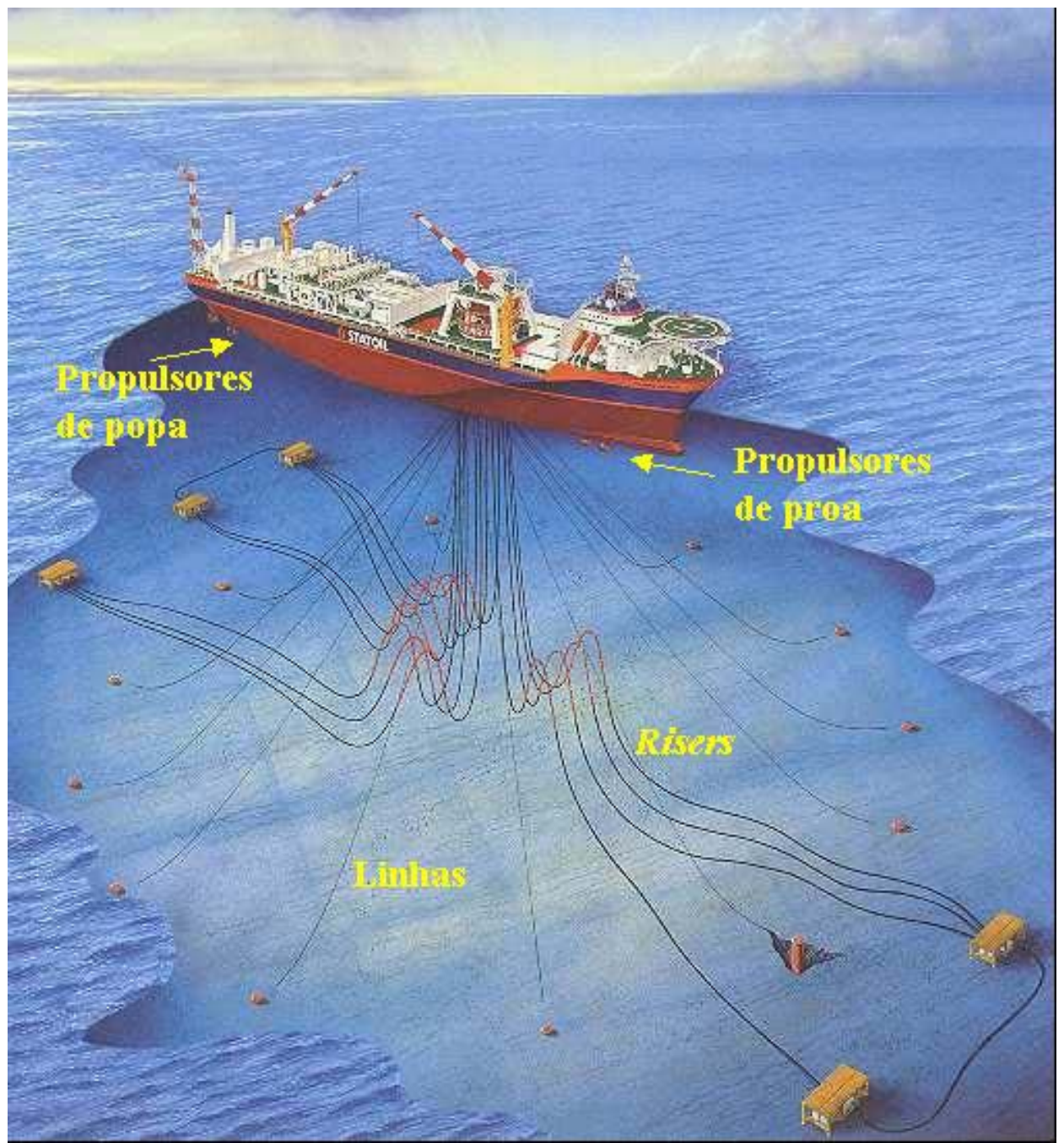

Figura 6.15 FPSO Norne 6608/10, com turret instalado próximo a maia nau e dotado de SPD assistido (adaptado de Offshore Technology, 2002)

No Brasil, a Petrobras tem optado, por enquanto, pela instalação de sistemas com a torre posicionada próxima à proa da embarcação, pois o sistema passa a possuir a capacidade natural de se alinhar com a resultante das condições ambientais. Exemplos deste sistema são apresentados na Figura 1.3 (FPSO P-31) e Figura 6.16 (FPSO P-37), nas quais pode-se verificar a estrutura do turret instalada próxima à proa do navio. Neste caso, o alinhamento com a incidência ambiental representa um ponto de equilíbrio estável. Assim, os FPSOs prescindiriam, a princípio, de um SPD assistido para realizar correções em seu aproamento (Leite et al., 1999). 


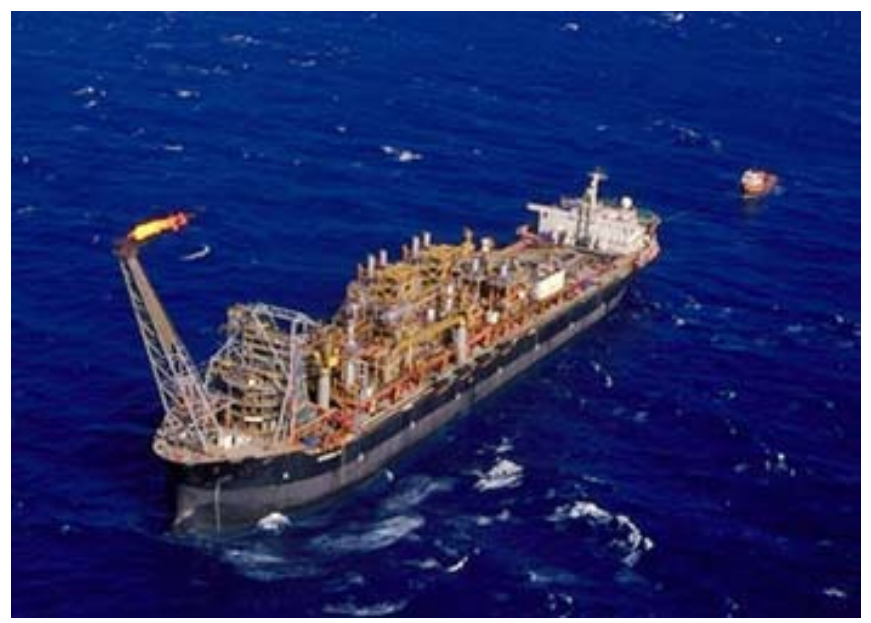

Figura 6.16 FPSO P-37, com turret instalado próximo à proa (extraído de Petrobras, 2002)

Entretanto, conforme mostrado em Pinto et al. (1999) e Leite et al. (1999), podem ocorrer situações nas quais o alinhamento com a resultante ambiental provoca a incidência de grandes ondas quase perpendicularmente ao casco, com todas as conseqüências associadas (elevadas amplitudes no movimento de roll, compressão dinâmica nos risers, embraque de água no convés, etc...). Estas situações são recorrentes na Bacia de Campos, onde é comum a ocorrência de correnteza e ondas em diferentes direções.

Devido a este fato, torna-se necessária a utilização de navios rebocadores em situações extremas, alterando o aproamento do FPSO em condições ambientais que recaiam no problema descrito anteriormente. Conforme discutido em detalhes na seção 2.2, os modos de controle existentes nos SPDs comerciais não são capazes de realizar esta "busca" de um aproamento ótimo, não levando em conta os movimentos de primeira ordem induzidos pela incidência de ondas de través. Assim, desenvolveu-se no presente trabalho o controlador de nível superior que implementa o modo de controle de aproamento ótimo. Alguns resultados já foram apresentados na seção 4.2.3, sendo que no presente estudo de caso este modo de controle será analisado, por meio de um exemplo, em conjunto ao controlador de nível inferior desenvolvido na seção 4.1.3. Serão ilustrados os problemas associados às condições ambientais não alinhadas e a eficácia do controlador proposto.

Um outro tópico de pesquisa e desenvolvimento na área de SPDs assistidos referese à operação de descarga em FPSOs. O óleo é levado à costa através de navios alivadores, em geral petroleiros de menor porte, que periodicamente se aproximam do 
FPSO e, durante uma operação delicada, se conectam ao mesmo através de um mangote e retiram parte do óleo de seus tanques (Figura 6.17). Durante esta operação, navios rebocadores garantem uma distância de segurança entre os dois petroleiros, evitando também que se afastem em demasia, o que poderia desconectar o mangote.

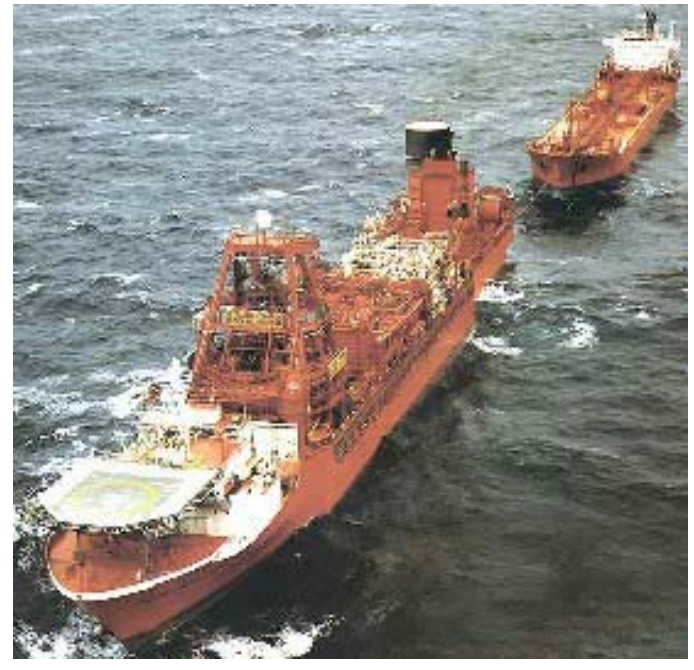

Figura 6.17 FPSO com o navio aliviado conectado (direita) durante operação de descarga

Recentemente, alguns navios aliviadores são dotados de SPDs, realizando a aproximação e manutenção da posição de forma automática, com menor interferência humana e menor risco de colisão. Efeitos hidrodinâmicos complexos e a rica dinâmica dos dois navios próximos ainda são temas recentes de pesquisa e desenvolvimento, conforme é visto, por exemplo, em Souza Júnior; Morishita (2002), Morishita; Souza Júnior; Cornet (2001), Morishita; Souza Júnior; Fernandes (2000) e Cornet; Fucatu; Morishita (1999). Esta aplicação de SPDs não será abordada no presente estudo de caso.

\subsubsection{Características do VLCC e comentários sobre o modelo utilizado}

Nesta seção, considera-se o FPSO P-31 Vidal de Negreiros, um super-petroleiro (VLCC) cujas dimensões e características principais, quando 80\% carregado, são apresentadas na Tabela 6.3. Apresentam-se também alguns parâmetros adicionais utilizados no cálculo das forças e momento devidos a correnteza, utilizando-se o modelo apresentado em 3.2.1. 
Tabela 6.3 Características principais da VLCC Vidal de Negreiros $80 \%$ carregado

\begin{tabular}{|l|l|}
\hline Comprimento $(\mathrm{L})$ & $320 \mathrm{~m}$ \\
\hline Boca $(\mathrm{B})$ & $54,5 \mathrm{~m}$ \\
\hline Calado $(\mathrm{T})$ & $17 \mathrm{~m}$ \\
\hline Posição do CG $\left(\mathrm{x}_{\mathrm{G}}\right)$ & $8 \mathrm{~m}$ \\
\hline Massa $(\mathrm{M})$ & $257500.10^{3} \mathrm{~kg}$ \\
\hline Momento de Inércia $\left(\mathrm{I}_{\mathrm{Z}}\right)$ & $1,65.10^{12} \mathrm{~kg} \cdot \mathrm{m}^{2}$ \\
\hline Massa Adicional Surge $\left(\mathrm{M}_{11}\right)^{*}$ & $12790.10^{3} \mathrm{~kg}$ \\
\hline Massa Adicional Sway $\left(\mathrm{M}_{22}\right)^{*}$ & $183700.10^{3} \mathrm{~kg}$ \\
\hline Massa Adicional Yaw $\left(\mathrm{M}_{66}\right)^{*}$ & $1,08.10^{12} \mathrm{~kg} . \mathrm{m}^{2}$ \\
\hline Área Lateral $\left(A_{L}\right)$ & $7975 \mathrm{~m}^{2}$ \\
\hline Área Frontal $\left(A_{F}\right)$ & $2025 \mathrm{~m}^{2}$ \\
\hline Área Molhada $(\mathrm{S})$ & $24198 \mathrm{~m}^{2}$ \\
\hline Coeficiente de arrasto lateral $\left(\mathrm{C}_{\mathrm{Y}}\right)$ & 0,78 \\
\hline Coeficiente de bloco $\left(\mathrm{C}_{\mathrm{B}}\right)$ & 0,76 \\
\hline$l_{P}($ distância secção mestra - centro de pressão) & $5 \% \mathrm{~L}$ \\
\hline
\end{tabular}

* em baixa freqüência

Os coeficientes estáticos de forças de correnteza, calculados por (3.14), (3.16) e (3.17) são mostrados na Figura 6.18.
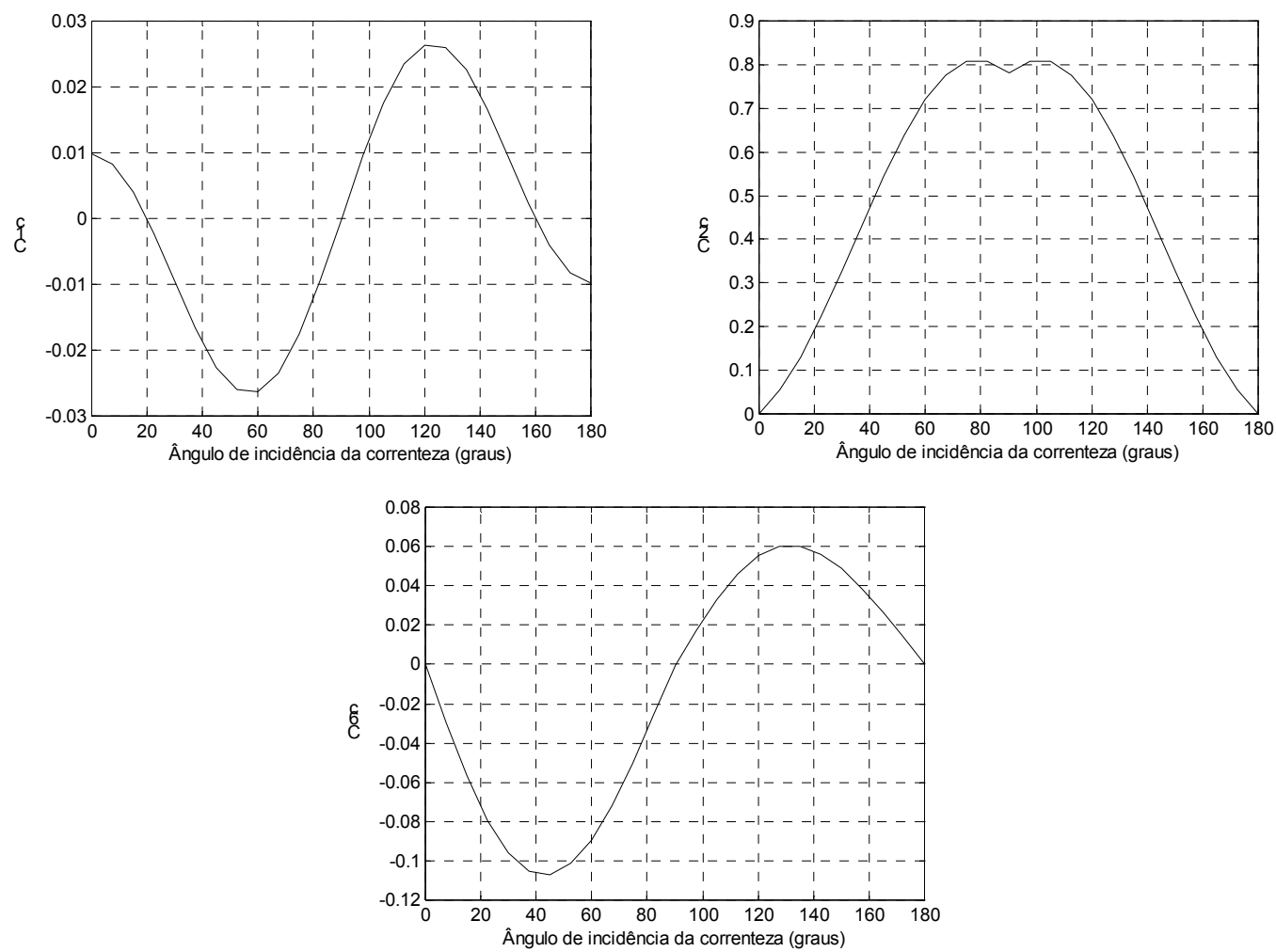

Figura 6.18 Coeficientes estáticos de correnteza para VLCC 80\% carregado

As forças de segunda ordem de ondas foram calculadas segundo a formulação apresentada em 3.2.2.2, utilizando-se os coeficientes de deriva provenientes do 
programa WAMIT, que considera, através do métodos dos painéis, apenas os efeitos potenciais do escoamento. Apresentam-se na Figura 6.19 os coeficientes de deriva para diversos ângulos de incidência. A interação onda corrente foi calculada como descrito em 3.2.2.3.

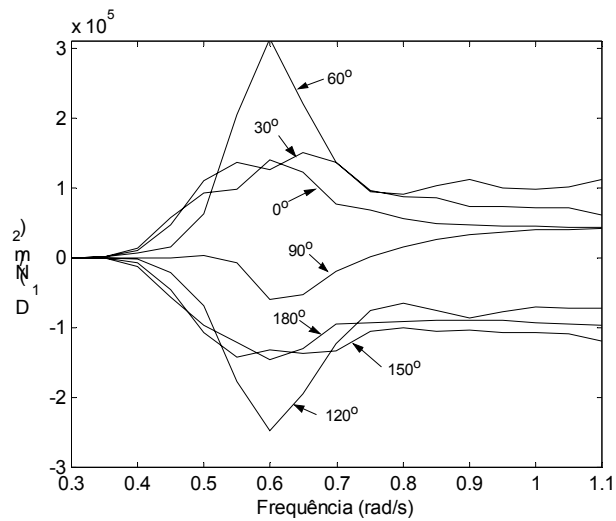

(a)

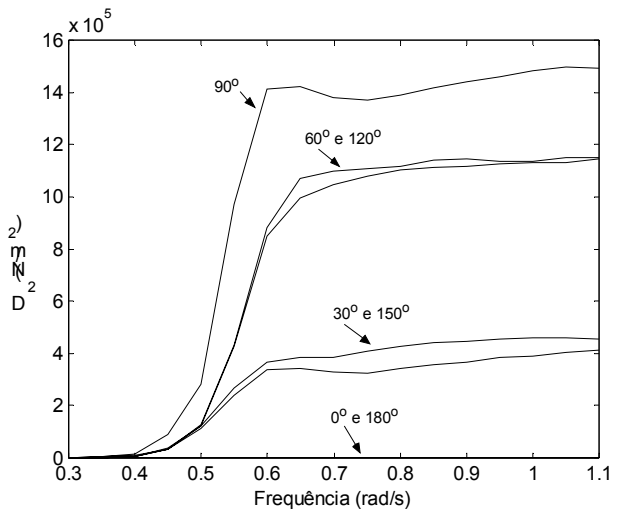

(b)

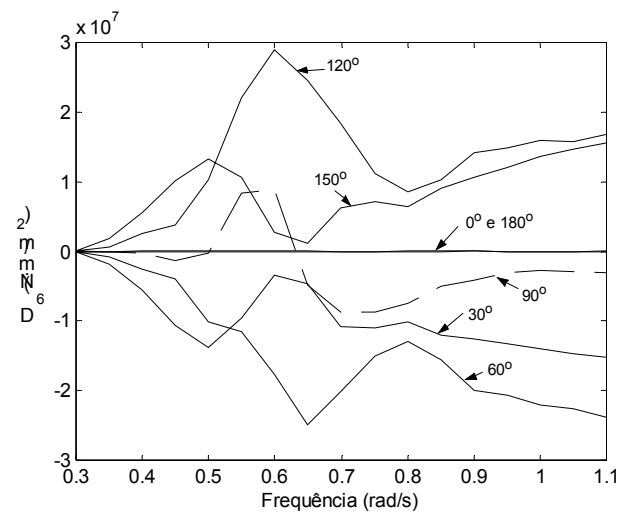

(c)

Figura 6.19 Coeficientes de deriva do VLCC 80\% carregado para diversas direções de incidência de onda (a) surge; (b)sway; (c)yaw

Os movimentos de primeira ordem são calculados por meio dos RAO's também provenientes do programa WAMIT, cujos módulos são apresentados na Figura 6.8. O espectro de mar considerado nas simulações foi o de JONSWAP, com parâmetro $\gamma=1,4$. 


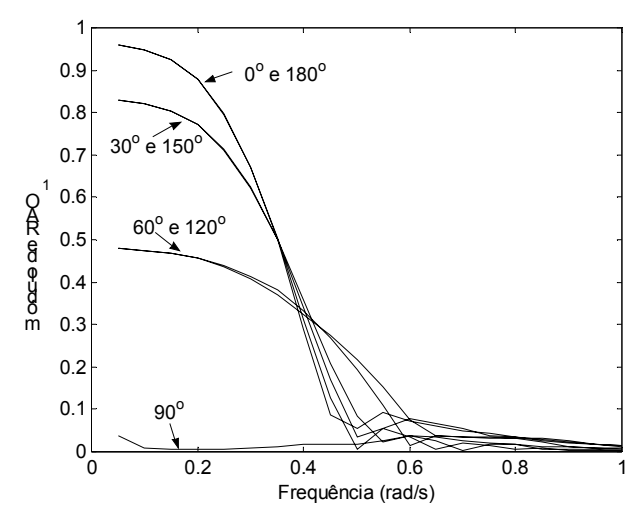

(a)

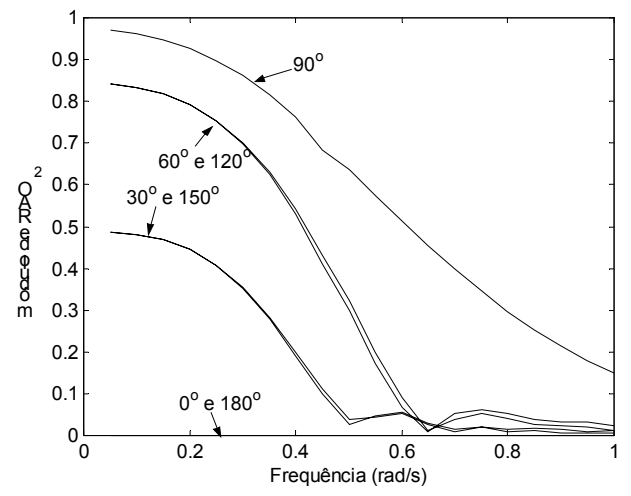

(b)

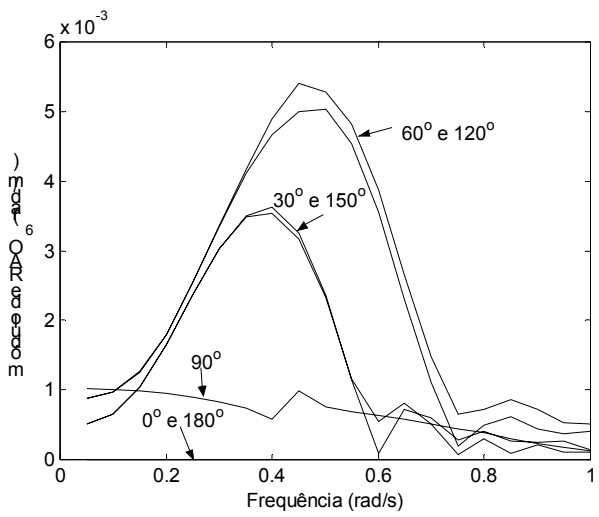

(c)

Figura 6.20 Módulo dos RAO's dos movimentos horizontais da do VLCC 80\% carregado para diversas direções de incidência de onda (a) surge; (b)sway; (c)yaw

As forças e momento de vento foram modeladas por (3.40), utilizando-se os coeficientes da OCIMF (Figura 3.15).

Seguindo o mesmo exemplo utilizado na seção 4.1.3.1, supõe-se que o FPSO seja equipado com 3 propulsores em túnel de popa com as posições indicadas na Figura 6.21 e potência máxima de $1200 \mathrm{~kW}$ cada, um propulsor principal responsável pelas forças longitudinais com potência máxima de $2200 \mathrm{~kW}$ e um propulsor em túnel próximo à proa com potência máxima de $4800 \mathrm{~kW}$.

Para todos, utilizaram-se propulsores da série $\mathrm{Ka}$, com $2 \mathrm{~m}$ de diâmetro, cujas curvas dos coeficientes $K_{T}$ e $K_{Q}$ foram apresentadas em Figura 3.26. Supondo-se um rendimento mecânico de $80 \%$, pode-se verificar que os propulsores 1,2 e 3 fornecem um empuxo máximo de $400 \mathrm{kN}$, o propulsor 4 de $600 \mathrm{kN}$ e o propulsor 5 de $1000 \mathrm{kN}$. 


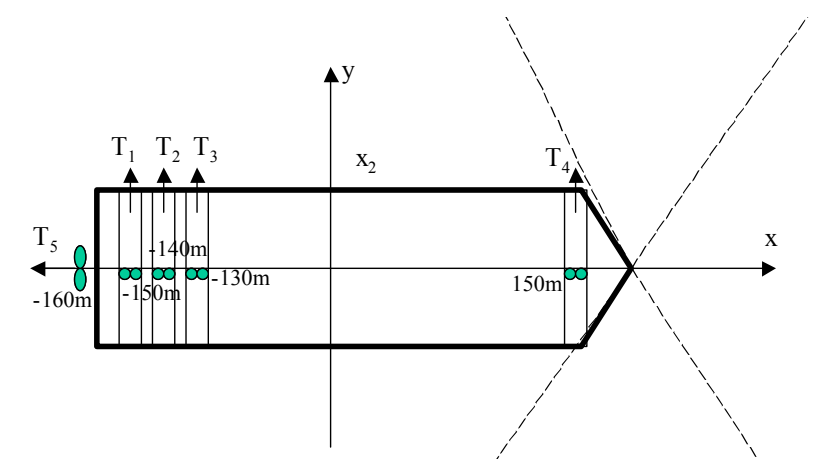

Figura 6.21 Suposta configuração dos propulsores para VLCC Vidal de Negreiros

\subsubsection{Sistema de amarração e risers}

O FPSO é amarrado por meio de uma torre (turret) instalada próxima à proa do navio, adotando-se, idealmente, a posição da torre em $x_{p}=0,5 . L$. A profundidade local é de $855 \mathrm{~m}$. O sistema de amarração é composto por 9 linhas, dispostas segundo a configuração mostrada na Figura 6.22. O sistema de risers é representado por 3 risers equivalentes, indicados pelas linhas tracejadas na Figura 6.22.

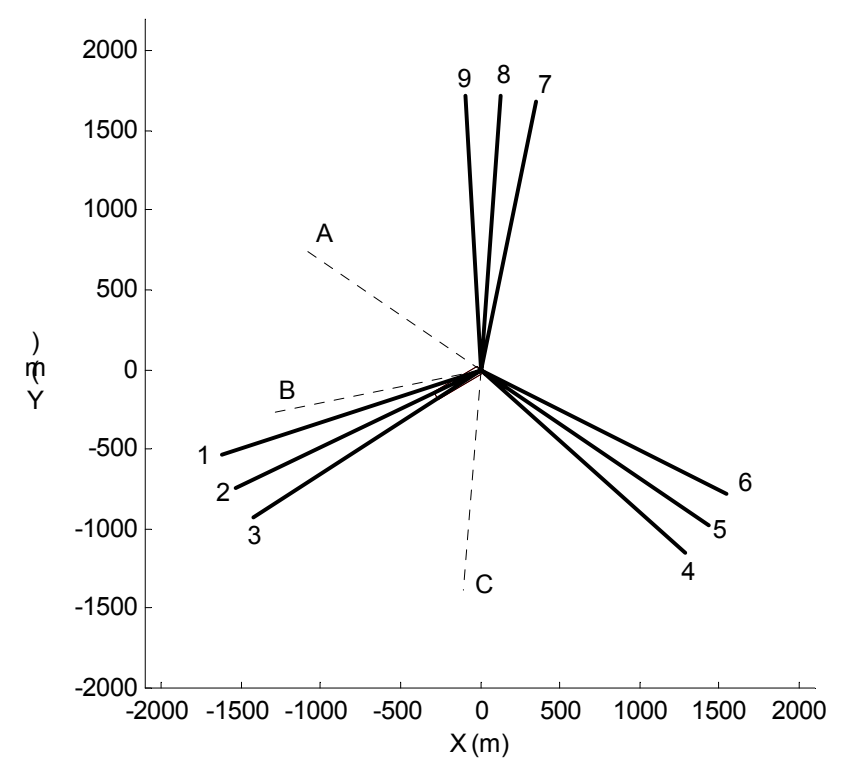

Figura 6.22 Linhas de amarração e risers equivalentes utilizados no VLCC Vidal de Negreiros

As linhas de amarração possuem coeficiente de arrasto $\left(C_{D r}\right)$ de 2,8, diâmetro $\left(D_{r}\right)$ de $164 \mathrm{~mm}$ e peso submerso $\left(q_{r}\right)$ de $1139 \mathrm{~N} / \mathrm{m}$. As posições das âncoras, em relação ao sistema OXY, são apresentadas na Tabela 6.4. A posição das âncoras dos risers equivalentes e suas propriedades principais são apresentadas na Tabela 6.5. 
Tabela 6.4 Posições das âncoras das linhas de amarração

\begin{tabular}{|l|l|l|}
\hline Linha & Posição X da âncora & Posição Y da âncora \\
\hline 1 & $-1620 \mathrm{~m}$ & $-531 \mathrm{~m}$ \\
\hline 2 & $-1537 \mathrm{~m}$ & $-739 \mathrm{~m}$ \\
\hline 3 & $-1429 \mathrm{~m}$ & $-934 \mathrm{~m}$ \\
\hline 4 & $1291 \mathrm{~m}$ & $-1156 \mathrm{~m}$ \\
\hline 5 & $1432 \mathrm{~m}$ & $-978 \mathrm{~m}$ \\
\hline 6 & $1548 \mathrm{~m}$ & $-784 \mathrm{~m}$ \\
\hline 7 & $353 \mathrm{~m}$ & $1686 \mathrm{~m}$ \\
\hline 8 & $130 \mathrm{~m}$ & $1715 \mathrm{~m}$ \\
\hline 9 & $-95 \mathrm{~m}$ & $1716 \mathrm{~m}$ \\
\hline
\end{tabular}

Tabela 6.5 Posições das âncoras e propriedades dos risers equivalentes

\begin{tabular}{|l|l|l|l|l|l|}
\hline Riser & $\boldsymbol{C}_{\boldsymbol{D} \boldsymbol{r}}$ & $\boldsymbol{q}_{\boldsymbol{r}}$ & $\boldsymbol{D}_{\boldsymbol{r}}$ & Pos. X da âncora & Pos. Y da âncora \\
\hline A & 4,1 & $11270 \mathrm{~N} / \mathrm{m}$ & $1057 \mathrm{~mm}$ & $-1085 \mathrm{~m}$ & $741 \mathrm{~m}$ \\
\hline B & 3,7 & $2747 \mathrm{~N} / \mathrm{m}$ & $505 \mathrm{~mm}$ & $-1325 \mathrm{~m}$ & $-273 \mathrm{~m}$ \\
\hline C & 1,2 & $1953 \mathrm{~N} / \mathrm{m}$ & $324 \mathrm{~mm}$ & $-105 \mathrm{~m}$ & $-1387 \mathrm{~m}$ \\
\hline
\end{tabular}

As curvas de restauração das linhas e dos risers equivalentes são apresentada na Figura 6.23.

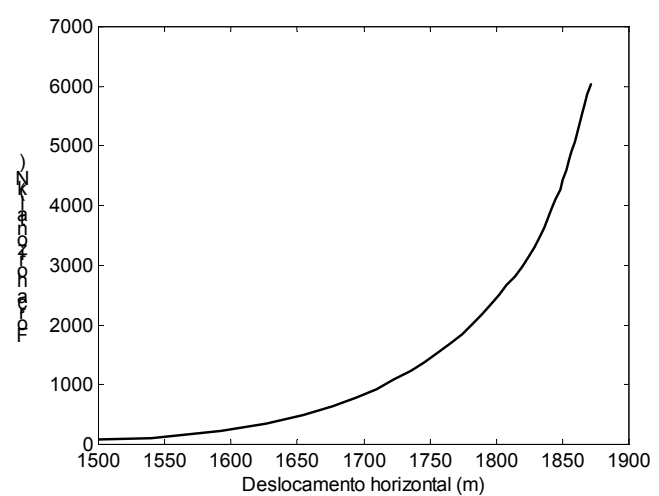

(a)

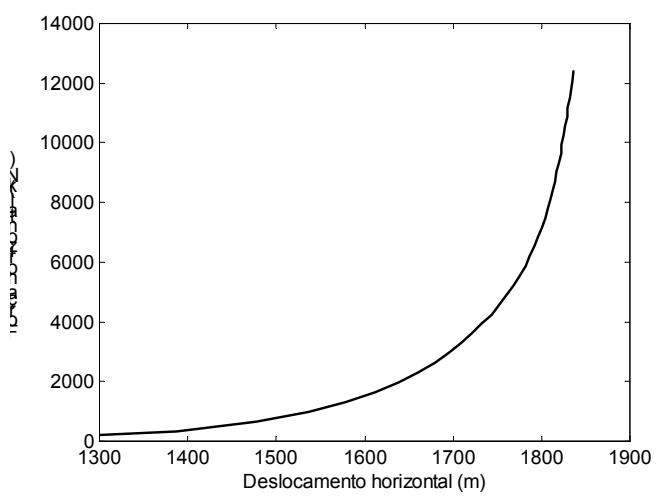

(c)

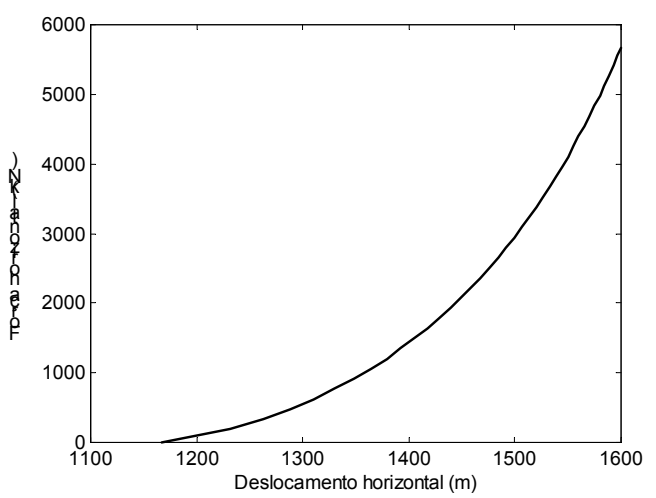

(b)

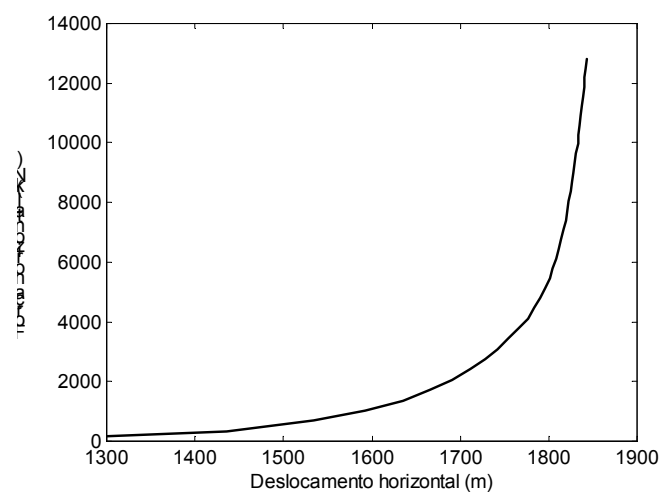

(d)

Figura 6.23 Curvas de restauração de: (a) linhas de amarração; (b) riser A ; (c) riser B ; (d) riser C 


\subsubsection{Projeto do controlador e ajuste de parâmetros}

O SPD instalado no VLCC é composto pelo controlador de nível superior, responsável pelo cálculo do aproamento ótimo utilizado como referência pelo controlador de nível inferior. Este, por sua vez, é composto pelo algoritmo de controle de aproamento descrito em 4.1.3.

O parâmetro $\lambda$ foi ajustado em $0,042 \mathrm{rad} / \mathrm{s}$, seguindo o mesmo procedimento já explicado para o caso da barcaça BGL1, na seção 6.1.4. A espessura da camada limite (Ф) foi calculada utilizando-se a relação (4.20), da mesma forma explicada na seção 6.1.4. Finalmente, o parâmetro $\eta$ foi calculado utilizando-se a relação (4.6), requerendose um tempo de 200s para que o sistema atinja a superfície de escorregamento caso apresente um erro inicial de $5^{\circ}$ no aproamento.

Os movimentos de surge e sway são amortecidos pelo controlador, através dos termos $-c_{1} \dot{x}_{1 R} \mathrm{e}-c_{2} \dot{x}_{2 R}$ presentes na lei de controle (4.38). Utilizaram-se os valores $c_{1}=\mathrm{c}_{2}=0,04$, ambos ajustados por meio de simulações de forma a garantir adequado amortecimento ao sistema. A dinâmica de translação em malha fechada (4.39), conjuntamente a valores linearizados da rigidez e amortecimento devidos às linhas e risers, poderia ser utilizada para o cálculo preciso dos valores de $c_{1}$ e $c_{2}$ que garantiriam o fator de amortecimento desejado em cada movimento. Este procedimento, entretanto, não foi empregado no presente trabalho.

Considerou-se a condição ambiental ilustrada na Figura 6.24, com a correnteza proveniente da direção $\mathrm{NE}$ com velocidade de $1,0 \mathrm{~m} / \mathrm{s}$ e ondas vindas de $\mathrm{SE}$, com altura significativa de 4,0m e período de pico de $14 \mathrm{~s}$. Admitiu-se, também, uma distribuição espectral de JONSWAP, com fator $\gamma=1,35$. 


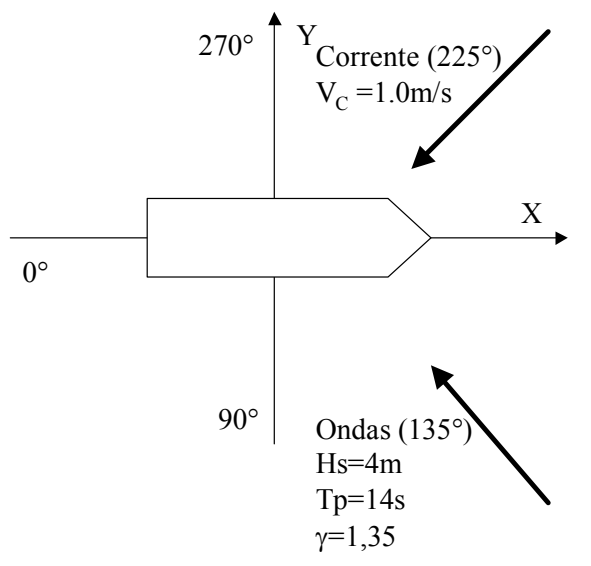

Figura 6.24 Condição ambiental utilizada na simulação do VLCC

Apresentam-se na segunda coluna da Tabela 6.6 os valores das intensidades e direções dos agentes ambientais consideradas no simulador e os erros de modelagem introduzidos na avaliação de suas forças e momentos. Como já mencionado, foram utilizados erros de modelagem de $\pm 20 \%$, apropriados aos modelos considerados. $\mathrm{Na}$ terceira coluna são apresentados os valores "estimados" das intensidades e direções, que são utilizados no controlador. Finalmente, na quarta coluna apresentam-se os limites considerados no projeto do controlador.

Tabela 6.6 Estimativas das condições ambientais e erros de modelagem máximos considerados no controlador

\begin{tabular}{|c|c|c|c|c|}
\hline Parâmetro & $\begin{array}{l}\text { Valor utilizado } \\
\text { na simulação }\end{array}$ & $\begin{array}{l}\text { Valor estimado } \\
\text { utilizado no controlador }\end{array}$ & \multicolumn{2}{|c|}{$\begin{array}{l}\text { Limites considerados } \\
\text { projeto do controlador }\end{array}$} \\
\hline Vel. De correnteza & $V_{C}=1,0 \mathrm{~m} / \mathrm{s}$ & $\hat{V}_{C}=1,1 \mathrm{~m} / \mathrm{s}$ & $V_{C, \min }=1,0 \mathrm{~m} / \mathrm{s}$ & $V_{C, \max }=1,2 \mathrm{~m} / \mathrm{s}$ \\
\hline \begin{tabular}{|l|l|}
$\begin{array}{l}\text { Dir. de } \\
\text { correnteza }\end{array}$ & $(\mathrm{C} 1)$ \\
\end{tabular} & $\alpha_{O X Y Z}=225^{\circ}$ & $\hat{\alpha} O X Y Z=220^{\circ}$ & $\alpha_{O X Y Z, \min }=220^{\circ}$ & $\alpha_{O X Y Z, m a z}=230^{\circ}$ \\
\hline $\begin{array}{l}\text { Erro de modelagem } \\
\text { da correnteza }\end{array}$ & $-20 \%$ & & \multicolumn{2}{|c|}{$e_{1 C}=e_{2 C}=e_{6 C}=20 \%$} \\
\hline Altura Sig. & $H_{S}=4,0 \mathrm{~m}$ & $\hat{H}_{S}=4,8 \mathrm{~m}$ & $H_{S, \min }=3,8 \mathrm{~m}$ & $H_{S, \max }=5,8 \mathrm{~m}$ \\
\hline Dir. de onda & $\beta_{O, O X Y Z}=135^{\circ}$ & $\hat{\beta} O, O X Y Z=130^{\circ}$ & $\beta_{O, O X Y Z \min }=120^{\circ}$ & $\beta_{O, O X Y Z \max }=140^{\circ}$ \\
\hline Per. Pico & $T_{P}=14 \mathrm{~s}$ & $\hat{T}_{P}=13 \mathrm{~s}$ & $T_{P, \min }=12 \mathrm{~s}$ & $T_{P, \operatorname{Max}}=14 \mathrm{~s}$ \\
\hline $\begin{array}{l}\text { Erro de modelagem } \\
\text { de deriva média }\end{array}$ & $-20 \%$ & & \multicolumn{2}{|c|}{$e_{1 D M}=e_{2 D M}=e_{6 D M}=20 \%$} \\
\hline $\begin{array}{llr}\text { Erro de modelagem } \\
\text { das forças de } \\
\text { amarração }\end{array}$ & $-20 \%$ & & \multicolumn{2}{|c|}{$\begin{array}{l}e_{1 \text { Res }}=e_{2 \text { Res }}=e_{6 \text { Res }}=20 \% \\
e_{1 A A}=e_{2 A A}=e_{6 A A}=20 \%\end{array}$} \\
\hline
\end{tabular}

Da mesma forma como foi feito na análise da barcaça BGL1, pode-se verificar que os erros de estimação são sobre-estimados perante a precisão dos sistemas de sensoriamento ambiental expostos no Apêndice 2, garantindo uma "margem de 
segurança" nas análises. Verifica-se, por exemplo, que a simulação foi realizada com altura significativa de onda de $4,0 \mathrm{~m}$, sendo que o controlador considera o valor estimado de 4,8m, correspondendo a uma diferença de 20\%. Adicionalmente, o

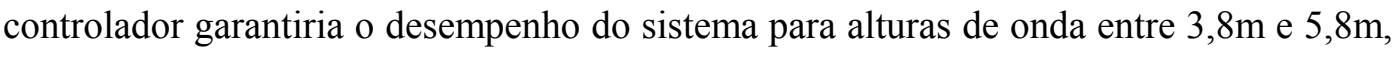
o que confere a aplicabilidade prática do presente controle em casos de estimativas pouco acuradas dos parâmetros ambientais.

Como os fenômenos físicos envolvidos no sistema são bastante complexos, consideraram-se elevados erros de modelagem na simulação $(-20 \%)$, sendo que o controlador é projetado para garantir o desempenho perante erros dentro do intervalo $[-20 \%,+20 \%]$.

\subsubsection{Aplicação do controlador de nível superior e inferior}

Os resultados desta seção foram obtidos por meio de um simulador, desenvolvido em ambiente Matlab/Simulink (v. 5.3), que inclui todos os modelos discutidos no Capítulo 3 adicionalmente ao controlador apresentado em 4.1 .3 e 4.2.

Aplicando-se o controlador de nível superior com as condições ambientais estimadas e erros de modelagem expressos na Tabela 6.6, obtém-se o ângulo de aproamento ótimo para o navio. Os pesos e valores limites utilizados para o cálculo da função a minimizar $J(\psi)$ são dados na Tabela 6.7. Utiliza-se, como já mencionado, um procedimento de normalização.

Tabela 6.7 Pesos e limites considerados no cálculo de $\mathbf{J}(\psi)$

\begin{tabular}{|c|l|l|l|}
\hline \multicolumn{1}{|c|}{ Critério } & \multicolumn{1}{c|}{ Peso } & \multicolumn{1}{c|}{ Limite Inferior } & \multicolumn{1}{c|}{ Limite Superior } \\
\hline Potência de controle & $K_{W}=\left(4.10^{8} \mathrm{Nm}\right)^{-3 / 2}$ & $I_{W}=(0 \mathrm{Nm})^{3 / 2}$ & $S_{W}=\left(4.10^{8} \mathrm{Nm}\right)^{3 / 2}$ \\
\hline Desloc.sist. amarr. & $K_{\Delta}=(100 \mathrm{~m})^{-1}$ & $I_{\Delta}=0 \mathrm{~m}$ & $S_{\Delta}=100 \mathrm{~m}$ \\
\hline Max. amp. de roll & $K_{R}=\left(5^{0}\right)^{-1}$ & $I_{R}=-7^{0}$ & $S_{R}=7^{0}$ \\
\hline Tração dinâmica & $K_{\tau}=(0.8)^{-1}$ & $I_{\tau}=0$ & $S_{\tau}=1$ \\
\hline
\end{tabular}

Obtém-se o ângulo de aproamento ótimo de $350^{\circ}$, conforme é mostrado no gráfico da função $J(\psi)$ na Figura 6.25. Como este aproamento é calculado com as condições e modelo estimados, é referido como aproamento ótimo "estimado". Quando o cálculo é feito de forma ideal, ou seja, utilizando-se as condições ambientais reais e na ausência de erros de modelagem, o ângulo de aproamento ótimo "real" obtido seria de $353^{\circ}$, apresentando uma diferença pouco significativa em relação ao "estimado". 


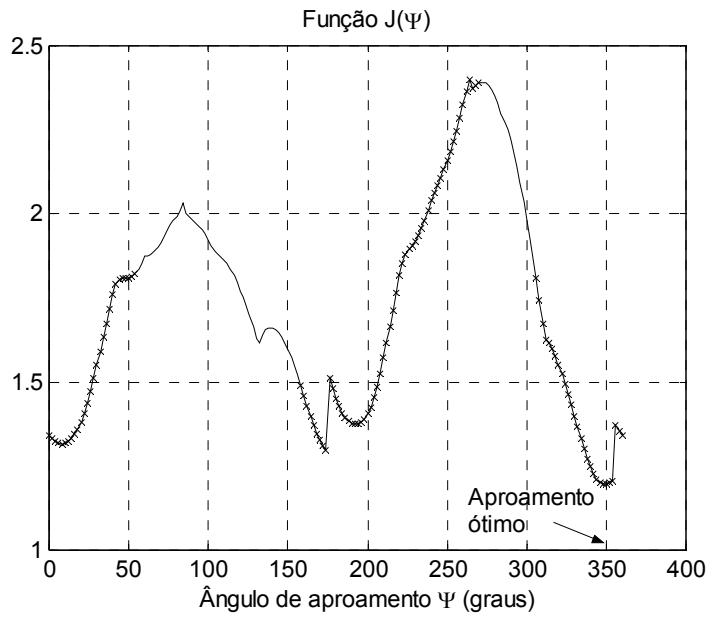

Figura 6.25 Função $J(\psi)$ e ponto de aproamento ótimo

Uma análise de interesse é feita na Tabela 6.8, na qual apresentam-se os valores dos critérios calculados para três aproamentos distintos. Na primeira coluna apresentamse os valores para o aproamento de equilíbrio $\left(\psi=18^{\circ}\right)$, que corresponderiam ao caso do navio com modo de controle do tipo weather vane ou na ausência de controle. $\mathrm{Na}$ segunda coluna apresenta-se o aproamento ótimo "real" $\left(\psi=353^{\circ}\right)$ e finalmente na terceira coluna o aproamento ótimo "estimado" $\left(\psi=350^{\circ}\right)$.

Tabela 6.8 Valores dos critérios utilizados no cálculo do aproamento ótimo para o aproamento de equilíbrio, aproamento ótimo "real" e "estimado"

\begin{tabular}{|l|l|l|l|}
\hline Critério & $\begin{array}{l}\text { Aproamento de } \\
\text { equilíbrio }\left(18^{\circ}\right)\end{array}$ & $\begin{array}{l}\text { Aproamento ótimo } \\
\text { real }\left(353^{\circ}\right)\end{array}$ & $\begin{array}{l}\text { Aproamento ótimo } \\
\text { "estimado" }\left(350^{\circ}\right)\end{array}$ \\
\hline Momento de controle & $0 \mathrm{~N} . \mathrm{m}$ & $-2,0.10^{8} \mathrm{~N} \cdot \mathrm{m}$ & $-2,2.10^{8} \mathrm{~N} \cdot \mathrm{m}$ \\
\hline Desloc.sist. amarr. & $18,4 \mathrm{~m}$ & $42,0 \mathrm{~m}$ & $46,5 \mathrm{~m}$ \\
\hline Max. amp. de roll & $4,5^{\circ}$ & $2,6^{\circ}$ & $2,4^{\circ}$ \\
\hline Tração dinâmica & 0,75 & 0,66 & 0,62 \\
\hline
\end{tabular}

Pode-se verificar que no modo weather vane os critérios de deslocamento estático do sistema de amarração e momento médio de controle em relação ao ponto de turret são minimizados. Entretanto, devido à incidência não alinhada da correnteza e onda, neste aproamento o navio recebe ondas com incidência de $63^{\circ}$ em relação ao casco, o que provoca grandes amplitudes de movimentos de primeira ordem, expressos pelos elevados valores dos critérios de roll e tração dinâmica. 
Verifica-se também que as diferenças relativas entre os critérios calculados no aproamento ótimo "real" e "estimado" são pequenas, inferiores a 10\%, o que mais uma vez indica a baixa sensibilidade do método em condições ambientais severas, como já mencionado na seção 4.2.4.

Aplica-se então o controlador de nível inferior por modos deslizantes ao presente caso, supondo-se uma manobra que leva o navio do aproamento de equilíbrio $\left(18^{\circ}\right)$ para o aproamento ótimo estimado $\left(350^{\circ}\right.$ ou $\left.-10^{\circ}\right)$, durante 500 s aproximadamente. A Figura 6.26 apresenta o aproamento real e desejado, demonstrando o bom desempenho do controlador. O set-point atinge o valor final de $-10^{\circ}$ no instante $1350 \mathrm{~s}$, sendo que após aproximadamente $250 \mathrm{~s}$ o aproamento real atinge este valor desejado, com erro inferior a $1^{\mathrm{o}}$, devido em grande parte ao movimento de primeira ordem não controlado.

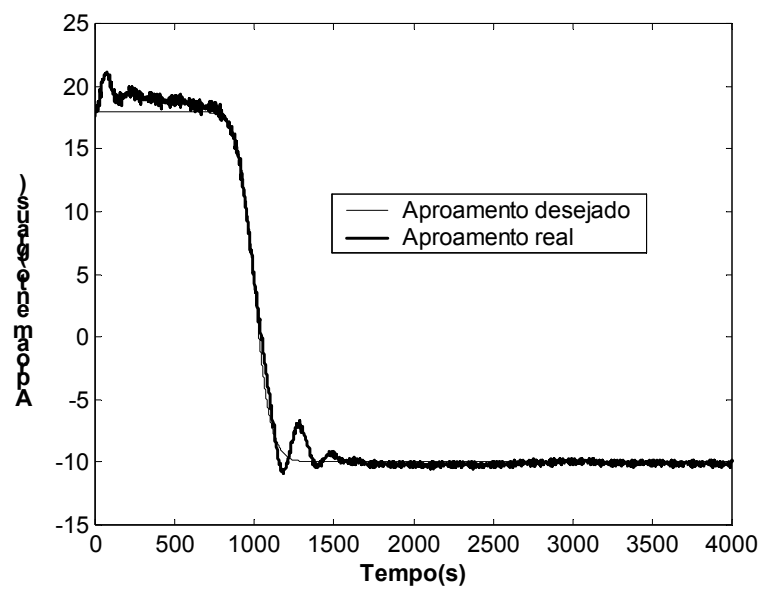

Figura 6.26 Aproamento real e desejado para VLCC em manobra

A posição nos eixos $O X$ e $O Y$ do ponto de referência, adotado como o centro do turret, é apresentada na Figura 6.27. Pode-se verificar que os movimentos oscilatórios de baixa freqüência de translação são bem amortecidos, apresentando amplitude máxima de $4 \mathrm{~m}$ na direção $O X$ e $4 \mathrm{~m}$ em $O Y$, valores obtidos por inspeção dos gráficos da Figura 6.27 ampliados. 

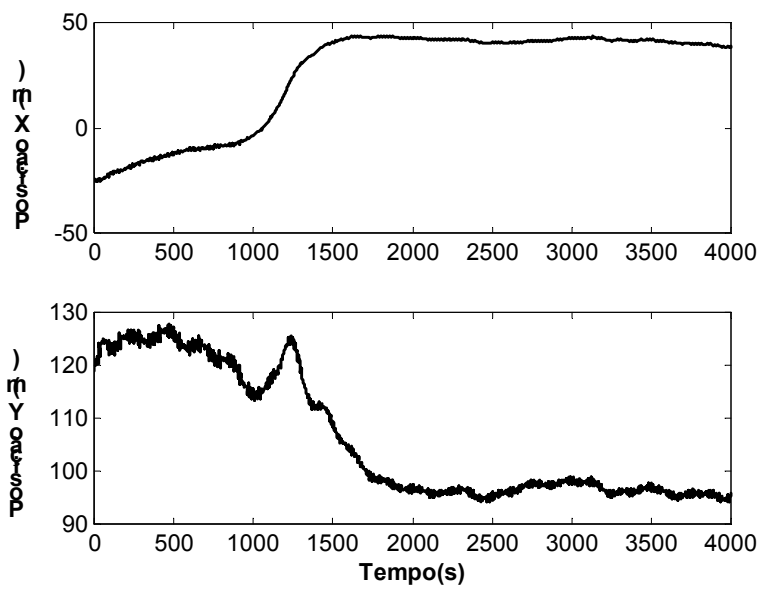

Figura 6.27 Posição X e Y do ponto de referência

O controle "indireto" dos movimentos de primeira ordem, através do aproamento, é bem ilustrado pela Figura 6.28, que contém as séries temporais do movimento vertical no ponto central do turret e do movimento de roll da embarcação. Pode-se ver que para o roll, por exemplo, a alteração do aproamento provoca uma diminuição da amplitude máxima de $3^{\circ}$ para $1^{\circ}$ aproximadamente, coerente com a alteração prevista pelo controlador de nível superior para o valor máximo $\left(4,5^{\circ}\right.$ para $\left.2,6^{\circ}\right)$. Esta diferença de deve ao fato das séries temporais serem realizações finitas dos espectros, utilizando a relação (3.38).
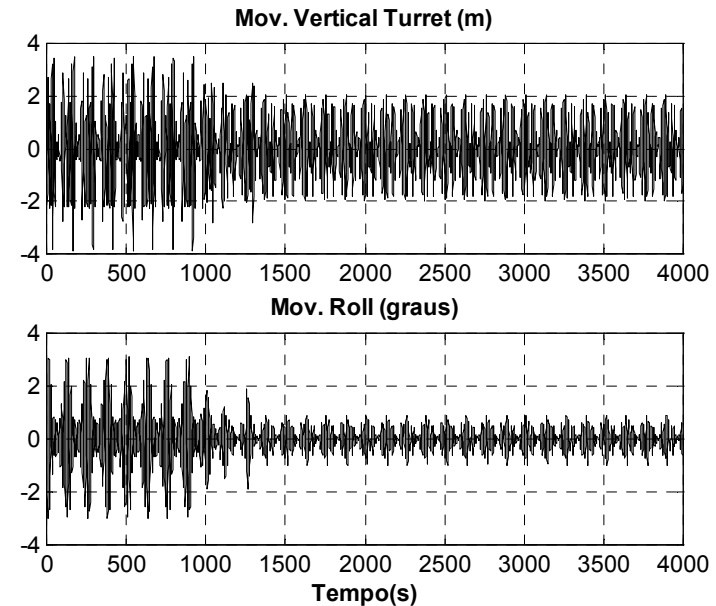

Figura 6.28 Movimento vertical no ponto de turret e movimento de roll

As forças de propulsão são apresentadas na Figura 6.29. Verifica-se que os propulsores 1, 2 e 3 apresentam empuxos bastante semelhantes, pois localizam-se muito 
próximos entre si. O empuxo médio nos mesmos, após 1500 s, é de aproximadamente $180 \mathrm{kN}$, responsável pelo momento médio em relação ao ponto de turret, que mantém o navio no aproamento ótimo de $-10^{\circ}$. Além disso, verifica-se que os empuxos nos propulsores 4 e 5 , após $1500 \mathrm{~s}$, apresentam média $22 \mathrm{kN}$ e $-3 \mathrm{kN}$ respectivamente, valores bastante baixos pois estes são responsáveis principalmente pelo amortecimento dos movimentos de translação, opondo-se às forças oscilatórias (e de média nula) de deriva lenta de ondas. Como o controlador implementado contém as alterações descritas em 4.1.3.1, os propulsores 4 e 5 não atuam em substituição ao sistema de amarração, cabendo a este último a responsabilidade de compensar as forças ambientais médias nas direções de surge e sway.

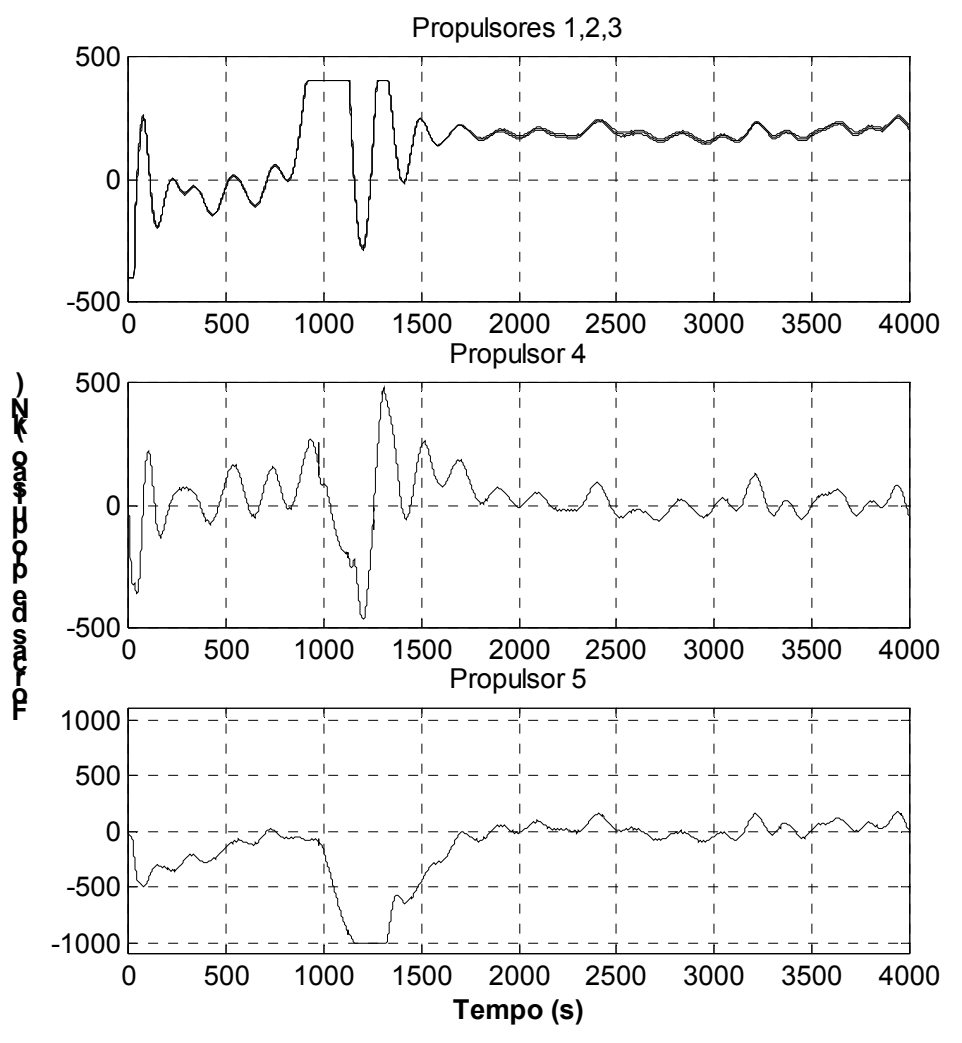

Figura 6.29 Forças de propulsão para o VLCC $80 \%$ carregado

A potência nos propulsores é apresentada na Figura 6.30. Verifica-se uma potência média consumida a partir de $1500 \mathrm{~s}$ de aproximadamente $400 \mathrm{~kW}$ para os propulsores 1,2 e 3 , de $61 \mathrm{~kW}$ para o propulsor 4 e de $111 \mathrm{~kW}$ para o propulsor 5 . O consumo total médio, após 1500 s, é de $1365 \mathrm{~kW}$. 

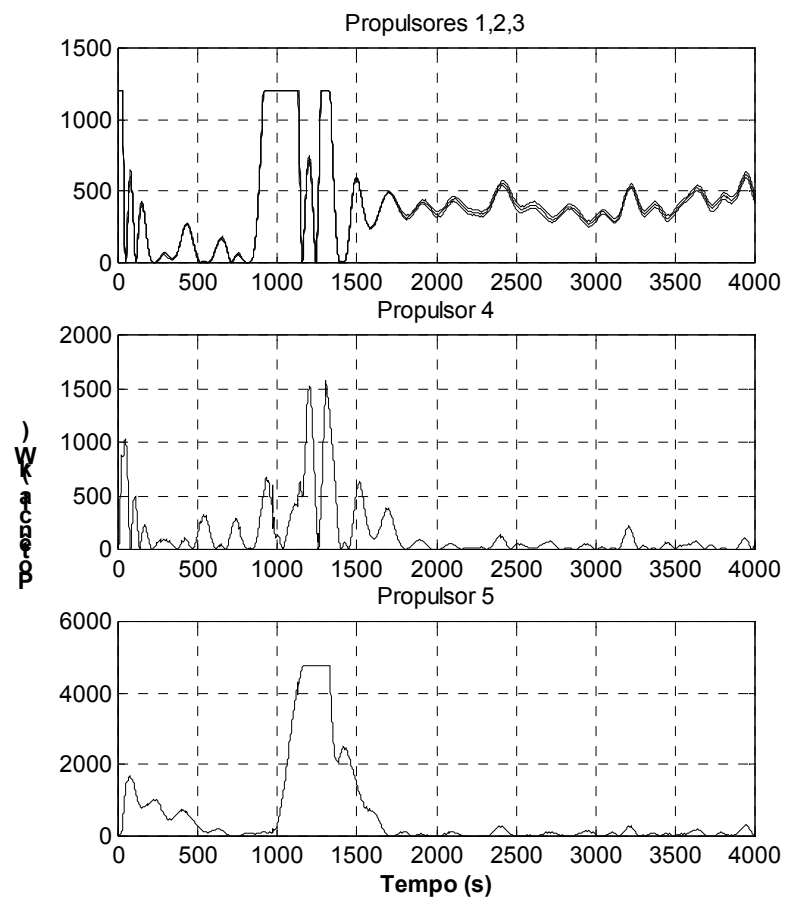

Figura 6.30 Potência consumida pelos propulsores para o VLCC 80\% carregado

A partir deste exemplo, pode-se fazer uma análise da lei de controle por modos deslizantes (4.52), verificando-se a importância relativa de seus termos. Inicialmente, verifica-se na Figura 6.31 o termo $-\hat{f}_{6} /\left(C_{66}+P C_{62}\right)$, responsável pela compensação direta dos esforços ambientais, comparado ao termo real $-f_{6} /\left(C_{66}+P C_{62}\right)$, não conhecido pelo controlador, e que pode ser calculado por (4.41). A estimativa apresenta um erro médio, após o fim da manobra em $1500 \mathrm{~s}$, de $0,5.10^{5} \mathrm{kN}$, o que representa aproximadamente $30 \%$ do momento real. Assim, o termo de compensação direta é responsável por $70 \%$ do momento de controle médio após a manobra. Pode-se ver também que grande parte da parcela oscilatória dos esforços ambientais são compensados pelo termo $-\hat{f}_{6} /\left(C_{66}+P C_{62}\right)$. 


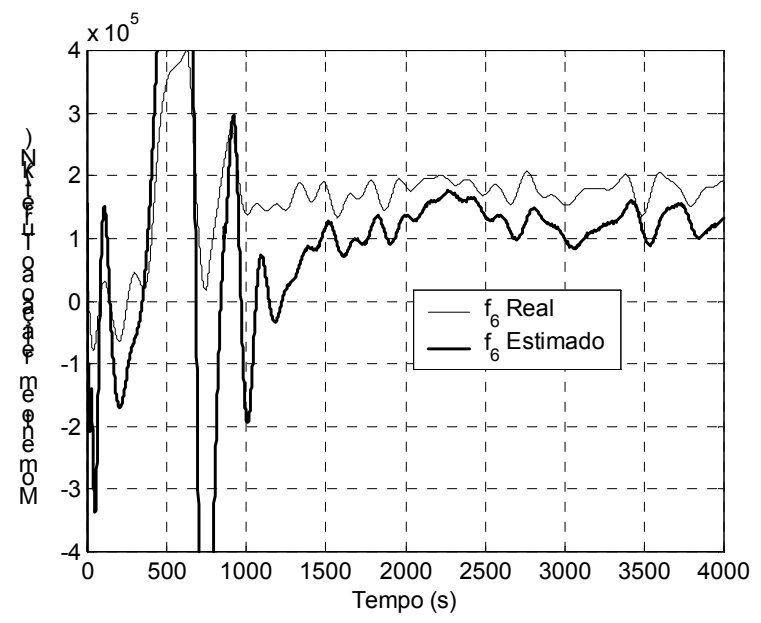

Figura 6.31 Termos $\mathrm{f}_{6} /\left(\mathrm{C}_{66}+\mathrm{PC}_{62}\right)$ reais e estimados

A diferença entre estes termos é devida aos erros de modelagem e de estimativa das condições ambientais. O termo $k \cdot \operatorname{sat}(s / \Phi) /\left(C_{66}+P C_{62}\right)$ compensa este erro, conforme pode ser visto na Figura 6.32. De fato, o valor médio deste termo após sua estabilização ao final da manobra, em $2500 \mathrm{~s}$, é aproximadamente $0,47.10^{5} \mathrm{kN}$, próximo à diferença entre $f_{6}$ e $\hat{f}_{6}$ verificada anteriormente. Este termo é responsável, portanto, por 30\% do momento de controle médio após a manobra, possuindo importância menor na compensação das forças oscilatórias.

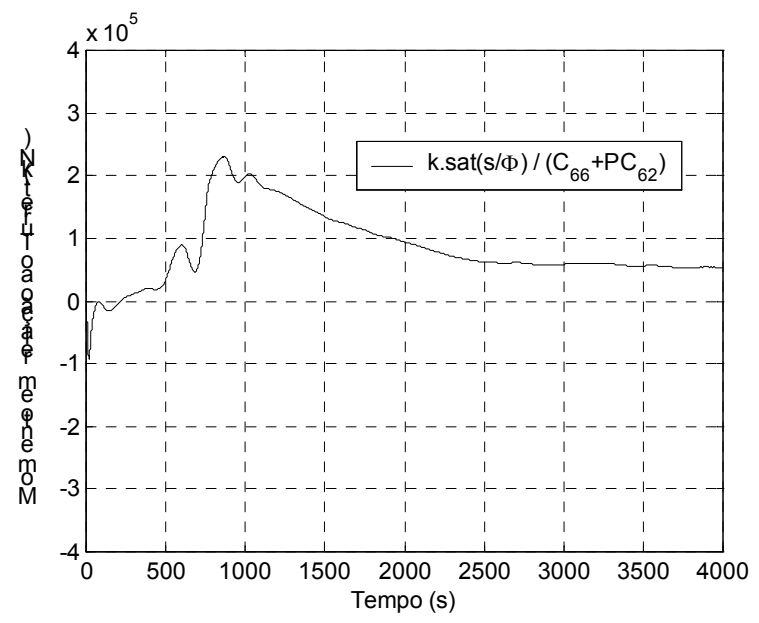

Figura 6.32 Termo $k . s a t(s / \Phi) /\left(\mathrm{C}_{66}+\mathrm{PC}_{62}\right)$ 
Finalmente, o termo $-\left(\ddot{x}_{6 D}-2 \lambda \dot{\widetilde{x}}_{6 R}-\lambda^{2} \widetilde{x}_{6 R}\right) /\left(C_{66}+P C_{62}\right)$ é apresentado na Figura 6.32, na qual verifica-se que possui valor médio e termos oscilatórios, após a manobra, de pequena importância, sendo apenas significativo durante a mesma.

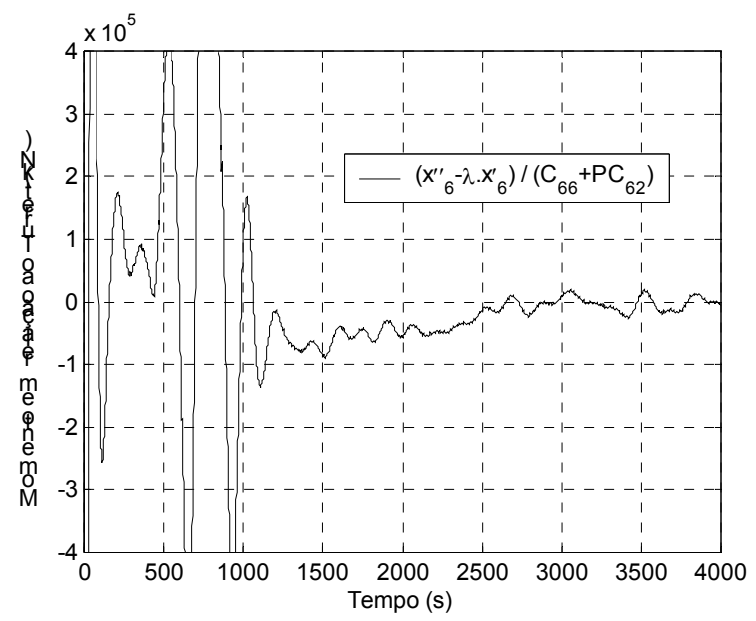

Figura 6.33 Termo $-\left(\ddot{x}_{6 D}-2 \lambda \dot{\tilde{x}}_{6 R}-\lambda^{2} \tilde{x}_{6 R}\right) /\left(C_{66}+P C_{62}\right)$

A importância dos termos dos termos $-c_{1} \dot{x}_{1 R} \mathrm{e}-c_{2} \dot{x}_{2 R}$ incluídos na lei de controle (4.38), responsáveis pelo amortecimento adicional nos movimentos de translação, é evidenciada pela análise a seguir, na qual anularam-se os parâmetros $c_{1} \mathrm{e}$ $c_{2}$. Na Figura 6.34 apresentam-se as posições do ponto de referência nos eixos $O X$ e $O Y$, na qual verifica-se que existem oscilações em baixa freqüência com amplitude de $8 \mathrm{~m}$ em $O X$ e $7 \mathrm{~m}$ em $O Y$, aproximadamente o dobro dos valores apresentado na Figura 6.27.
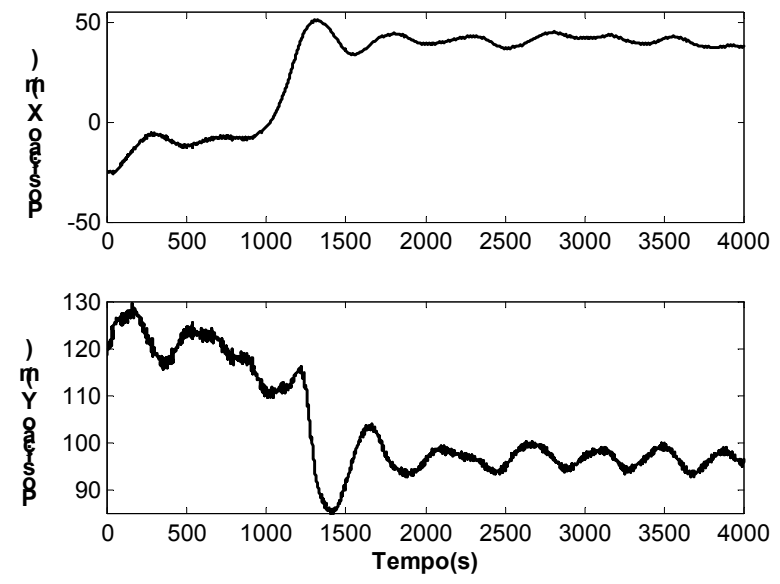

Figura 6.34 Posição X e Y do ponto de referência, com parâmetros $c_{1}=c_{2}=0$ 
Estas oscilações provocam uma pequena degradação do movimento de yaw, conforme é apresentado na Figura 6.35. Durante a manobra, podem-se verificar erros superiores aos encontrados na Figura 6.26, devido ao acoplamento entre os movimentos de yaw e sway, o qual, neste caso, apresenta oscilações com amplitude elevada. Após 2000 s, entretanto, o erro no ângulo de yaw também é considerado pequeno, mantendose inferior a $1^{\circ}$ aproximadamente.

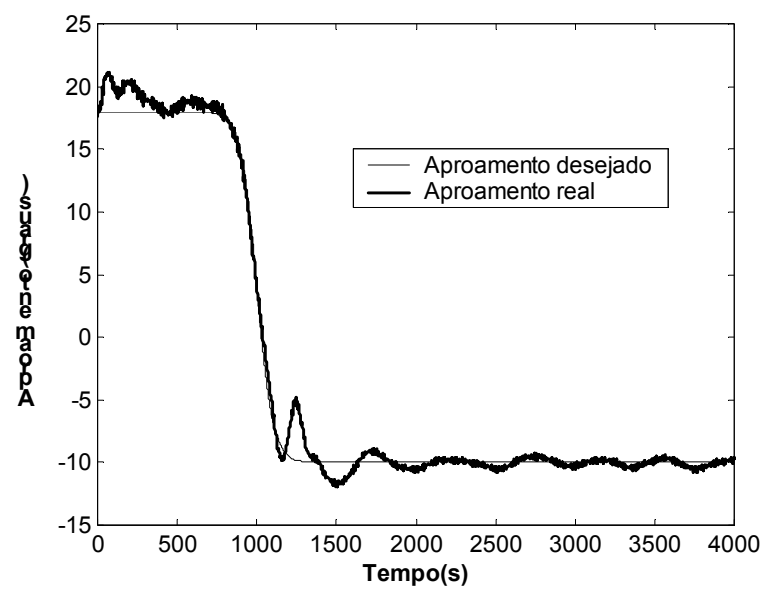

Figura 6.35 Aproamento real e desejado para VLCC em manobra, com parâmetros $c_{1}=c_{2}=0$

A potência total média consumida após $1500 \mathrm{~s}$ é, no caso de $c_{1}=c_{2}=0,1190 \mathrm{~kW}$, inferior à obtida na simulação com amortecimento dos movimentos de translação. Esta diferença se deve ao fato de que, com $c_{1}=c_{2}=0$, os propulsores 4 e 5 tornam-se praticamente inativos, pois estes são responsáveis principalmente pelo amortecimento dos movimentos de translação, o que não existe neste caso. 


\section{Conclusões e Comentários Finais}

O presente trabalho realizou contribuições para diversos tópicos de pesquisa e desenvolvimento em Sistemas de Posicionamento Dinâmicos, focando-se o sub-sistema de controle.

Desenvolveu-se uma nova metodologia para o projeto do controlador de nível inferior, executando a compensação direta dos esforços de vento, onda (deriva média) e correnteza, integrando também uma malha de realimentação para realizar correções de erros residuais. É fundamentado na teoria de controle não-linear robusto por modos deslizantes e, da forma com que foi aplicado no problema de posicionamento dinâmico, apresentou várias vantagens em relação aos controladores comumente utilizados.

Devido ao fato de possuir uma estrutura não-linear, e utilizar o modelo não-linear do sistema a ser controlado, este controlador garante os mesmos requisitos de desempenho e estabilidade qualquer que seja o aproamento da embarcação. Contrariamente às inúmeras "soluções" encontradas para se utilizar controladores lineares em sistemas com fortes termos não-lineares, o controlador não requer alterações nos ganhos (gain-scheduling) ou no modelo de projeto (múltiplos modelos) quando ocorrem mudanças de aproamento.

Pelo fato de realizar a compensação direta dos esforços de vento, correnteza e onda (deriva média), garante-se maior faixa de aplicabilidade em termos de condições ambientais. Os controladores convencionais apresentam forte degradação de desempenho durante condições extremas, pois são sintonizados em condições diferentes, e não possuem capacidade de se adaptar a tais variações.

Finalmente, por possuir um termo que lhe confere robustez, elimina-se o problema comum dos controladores baseados em modelos que requerem exaustivos testes em mar para a calibração fina dos diversos parâmetros do modelo neles contido. O controlador desenvolvido garante o desempenho e estabilidade do sistema perante erros de modelagem, ou seja, não é necessário um ajuste refinado dos modelos através de testes no mar. Adicionalmente, a característica de robustez também confere ao controlador capacidade de "lidar" com erros nas estimativas das condições ambientais, utilizadas na compensação direta dos esforços. 
O controlador foi adaptado para o modo de controle de aproamento exclusivo, utilizado em SPDs assistidos por sistemas de amarração, e testado num simulador computacional do VLCC Vidal de Negreiros amarrado pelo sistema turret, sob condições ambientais típicas da Bacia de Campos. Foi também adaptado para o modo de controle combinado de posição e aproamento, utilizado nos SPDs convencionais, testado num simulador computacional de uma barcaça de lançamento de dutos operada por posicionamento dinâmico.

Os simuladores desenvolvidos utilizam modelos dos esforços ambientais amplamente validados ao longo de diversos anos de pesquisa e desenvolvimento nos departamentos da Escola Politécnica da USP. Uma contribuição adicional do presente trabalho refere-se à utilização destes modelos num ambiente de simulação integrado à análise de SPDs.

As simulações numéricas foram realizadas de forma a emular erros de modelagem e de estimação das condições ambientais, a fim de se testar as propriedades de robustez do controlador. Os resultados confirmaram o bom desempenho do controlador perante tais erros e em diversas condições ambientais, com extrema facilidade no ajuste dos parâmetros. Para se alcançar uma validação ainda mais veemente, propõe-se como trabalho futuro a realização de ensaios mais abrangentes em tanque de provas.

Abordou-se também um novo modo de controle (controlador de nível superior), no qual o navio é aproado segundo uma direção que garante a otimização de um funcional relacionando diversos parâmetros operacionais relevantes, como o movimento de roll, a tração dinâmica em risers, a solicitação do sistema de amarração e o consumo de combustível. Mostrou-se que este modo de controle é bastante apropriado para locais como a Bacia de Campos, nos quais é comum a existência de desalinhamento entre os agentes ambientais.

Análises numéricas indicaram que a sensibilidade do valor "ótimo" do funcional a erros nas estimativas das condições ambientais não é significativa para situações extremas, para as quais o aproamento ótimo mostra-se bastante robusto. No caso de condições amenas a sensibilidade é maior, porém as conseqüências de pequenos erros no aproamento são menos importantes. Adicionalmente, todo o processo de otimização depende dos pesos relativos que são dados a cada critério que se objetiva minimizar. A escolha coerente dos pesos garante um compromisso adequado entre todos os critérios. 
Entretanto, dependendo da condição ambiental e operacional deve-se realizar uma nova ponderação, aumentando a importância de determinado critério em detrimento de outro.

Neste sentido propõem-se, como futuros trabalhos dentro desta linha de desenvolvimento, a implementação de uma estratégia de realimentação para diminuir a sensibilidade do método de obtenção do aproamento ótimo, através da estimativa em tempo real do valor do funcional e comparação com o valor ótimo teoricamente determinado. Além disso, deve-se também implementar um algoritmo de ajuste automático dos pesos relativos, que, dadas descrições qualitativas do estado de mar e da condição operacional, seja capaz de ponderar coerentemente os critérios. Isto aumentaria a confiabilidade na utilização deste modo de controle, pois não dependeria de conhecimentos aprofundados do operador sobre os critérios que estão sendo otimizados. Como uma primeira abordagem poder-se-ia aplicar os conceitos de lógica fuzzy para a solução deste problema.

Desenvolveu-se também um método para a estimação do espectro de ondas baseado nos movimentos da embarcação. Foi utilizada uma abordagem paramétrica, na qual o espectro bimodal é parametrizado, e os 8 parâmetros descritivos são estimados por um algoritmo de otimização não-linear. Esta otimização utiliza as funções de resposta do navio a ondas (RAO's) e calcula os parâmetros de forma a aproximar os movimentos preditos teoricamente com os medidos. A sensibilidade do método a erros no cálculo dos RAO's foi analisada por testes numéricos, o que permitiu definir uma freqüência de corte para o mesmo. Ondas com freqüência de pico maiores do que as de corte não são estimadas com acurácia, pois a resposta do navio à incidência das mesmas passa a ser muito pequena e os erros nos RAO's passam a ser muito significativos. Foram realizados testes em tanque de provas, com o VLCC Vidal de Negreiros, que validaram a análise numérica. O método foi comparado com a abordagem não paramétrica Bayesiana, muito utilizada em trabalhos correlatos descritos na literatura, apresentando resultados mais acurados.

Os erros de estimativa alcançaram, nos ensaios, $25 \%$ no caso da altura significativa. Este valor é, conforme se analisou nas simulações, plenamente satisfatório para o controlador, devido às boas características de robustez do mesmo. Assim, o método paramétrico constitui-se em um boa opção para a compensação direta dos esforços de onda, quando da utilização de um controlador robusto. Como estudos futuros, propõe-se a realização de testes em tanque oceânico com mares bimodais, além 
da verificação se a integração de medidas da altura relativa da onda no casco melhora o desempenho do método. 


\section{Referências Bibliográficas}

AALBERS, A.B.; NIENHUIS, U. Wave Direction Feed-Forward on Basis of Relative Motion Measurements to Improve Synamic Positioning Performance, In: Proceedings of Offshore Technology Conference (OTC1987), Houston, Estados, Unidos, OTC 5445, pp.225-232, 1987.

AALBERS, A.B. et al. DP assisted and Passive Mooring for FPSO's, In: Proceedings of Offshore Technology Conference (OTC1995), Houston, Estados, Unidos, OTC 7722, pp.281-288, 1995.

AALBERS, A.B. DP-JIP Proposal. Holanda: Maritime Research Institute Netherlands (Marin), 2000. (Proposal Rev. 3.0, Marin Ref. 15425).

AARSET, M.F.; STRAND, J.P.; FOSSEN, T.I. Nonlinear Vectorial Observer Backstepping With Integral Action and Wave Filtering for Ships. In: Proceedings of the IFAC Conference on Control Applications in Marine Systems (CAMS'98), Fukuoka, Japão, pp.83-89, 1998.

ABKOWITZ, M. Lectures on ship hydrodynamics, steering and manoeuvrability, Hydro-Og Aerodynamisk Laboratorium, Report Hy-5, Lyngby, Dinamarca, pp113, 1964.

ALBUQUERQUE, C.F.A. et al. Comportamento de FPSOs em mar de través, In: Anais do Congresso da Sociedade Brasileira de Engenharia Naval (SOBENA 2000), Rio de Janeiro, CD-ROM.

ANP, Agência Nacional de Petróleo, Brasil, Disponível em <www.anp.gov.br>. Acesso em: 12 de abril de 2002.

ARANHA, J.A.P. et al. Mechanics of Submerged Cables, Asymptotic Solution and Dynamic Tension, In: Proceedings of International Offshore and Polar Engineering Conference (ISOPE'93), Singapura, 1993.

ARANHA, J.A.P. A formula for 'wave damping' in the drift of a floating body, Journal of Fluid Mechanics, Vol.275, pp.147-155, 1994.

ARANHA, J.A.P.; FERNANDES, A.C. On the second-order slow drift force spectrum, Applied Ocean Research, Vol.17, pp.311-313, 1995.

ARANHA, J.A.P. Second order horizontal steady forces and moment on a floating body with small forward speed, Journal of Fluid Mechanics, Vol.313, 1996.

ARANHA, J.A.P. Adaptações ao modelo de amortecimento de linhas, Comunicação Pessoal, 1999.

ARANHA, J.A.P., MARTINS, M.R. Low frequency wave force spectrum influenced by wave-current interaction, Applied Ocean Research, Vol.23, pp.147-157, 2001.

AUDUNSON, T.; BARSTOW, S.F.; KROGSTAD, H.E. Analysis of wave 
directionality from a heave, pitch and roll buoy operated offshore Norway, Ocean Science Engineering, 7(8), pp.291-319, 1982.

BARROS, E.A. Aplicação de um Controlador Auto-Ajustável ao Sistema de Posicioamento Dinâmico de uma Plataforma Semi-Submersível, São Paulo, 1989. 1v. Dissertação (mestrado) - Escola Politécnica, Universidade de São Paulo.

BAZAARA, M.S.; SHERALI, H.D.; SHETTY, C.M. Nonlinear Programming, Theory and Algorithms, 2a Edição, John Wiley \& Sons, pp.438-448, 1993.

BENOIT, M.; GOASGUEN, G. Comparative evaluation of directional wave analysis techniques applied to field measurements, In: Proceeding of the Ninth International Offshore and Polar Engineering Conference (ISOPE'99), pp.87-95, 1999.

BOND, R. Dynamic Positioning Systems for Ships, GEC Journal of Science \& Technology, Vol. 46, No. 1, 1980.

BRANDNER, P.; RENILSON, M. Interaction Between Two Closely Spaced Azimuthing Thrusters, Journal of Ship Research, Vol.42, No.1, Março, 1998.

BRAY, D. Dynamic Positioning, The Oilfield Seamanship Series, Volume 9, Oilfield Publications Ltd. (OPL), 1998.

CHRISTENSSON, C.G.; OMBERG, D.O. Floating Production and Offshore Loading Using Dynamic Positioning, In: Proceedings of Offshore Technology Conference (OTC1992), Houston, Estados, Unidos, OTC 6960, pp.139-147, 1992.

CORNET, B.J.J.; FUCATU, C.H.; MORISHITA, H.M. A Study of the Dynamics and Control of Floating Multibody Systems, In: Anais do $\mathbf{1 5}^{\circ}$ Congresso Brasileiro de Engenharia Mecânica, (COBEM'99), Águas de Lindóia, Brasil, 1999.

DEMMEL, J.W. Applied Numerical Linear Algebra, SIAM, 1997.

DI MASI, G.B.; FINESSO, L.; PICCI, G. Design of a LQG Controller for Single Point Moored Large Tankers, Automática, Vol.22, No. 2, pp.155-169, 1986.

DONHA, D.C. Estudo do Posicionamento Dinâmico para Plataforma SemiSubmersível, São Paulo, 1983. 1v. Dissertação (mestrado) - Escola Politécnica, Universidade de São Paulo.

DONHA, D.C. Estudo, Implementação, Teste e Avaliação de um Sistema de Posicionamento Dinâmico, São Paulo, 1989. 1v. Dissertação (doutorado) - Escola Politécnica, Universidade de São Paulo.

DONHA, D.C. Sistemas de controle marítimos, São Paulo, 2000. 1v. Dissertação (livre-docência) - Escola Politécnica, Universidade de São Paulo.

DONHA, D.C.; TANNURI, E.A. Non-linear semi-submersible positioning system using an H-infinity controller, In: Proceedings of Control Applications in Marine Systems Conference (IFAC-CAMS 2001), CD-ROM Glasgow, Escócia, 2001. 
EL-HAWARY, F. The Ocean Engineering Handbook, CRC Press, 2000.

EWANS, C.; VAN DER VLUGT, T. Estimating Bimodal Frequency-Direction Spectra from Surface Buoy Data Recorded during Tropical Cyclones, Journal of Offshore Mechanics and Arctic Engineering, vol. 121, pp.172-180, August, 1999.

FALTINSEN, O.M. Sea Loads on ships and offshore structures, Cambridge University Press, 1990.

FAŸ, H. Dynamic Positioning Systems, Principles, Design and Applications, Editions Technip, 1990.

FOSSEN, T.I.; FOSS, B.A. Sliding Control of MIMO Nonlinear Systems, In: Proceedings of the European Control Conference, pp1855-1860, França, 1991.

FOSSEN, T.I. Guidance and Control of Ocean Vehicles, John Wiley and Sons, Ltd., 1994.

FOSSEN, T.I.; STRAND, J.P. Nonlinear Ship Control, In: Proceedings of Control Applications in Marine Systems Conference (IFAC-CAMS'98 - Seção Tutorial), Fukuoka, Japão, pp. 1-75, 1998.

FOSSEN, T.I.; STRAND, J.P. Nonlinear Passive Weather Optimal Positioning Control (WOPC) System for Ships and Rigs: Experimental Results, Automatica, Vol.37, No. 5, pp701-715, 2001.

FUCATU, C.H. Desenvolvimento de um simulador dinâmico para análise de navios amarrados, São Paulo, 1998. 1v. Dissertação (mestrado) - Escola Politécnica, Universidade de São Paulo.

FUNG, P.T.K.; GRIMBLE, M.J. Dynamic Ship Positioning Using a Self-Tuning Kalman Filter, IEEE Transactions on Automatic Control, Vol.AC-28, No.3, pp339$350,1983$.

FURUNO, Estados Unidos, Furuno USA Inc. Disponível em: $<$ http://www.furuno.com> Acesso em: 06 de jun de 2002.

GRIMBLE, M.J.; JOHNSON, M.A. Optimal Control and Stochastic Estimation. Theory and Applications, John Wiley \& Sons Ltd, 1989.

HANSEN, J.F.; LAUVDAL, T., ÅDNANES, A.K. Modelling and Simulation of Variable Speed Thrusters Drives with Full-Scale Verification, In: Proceedings of the 5th IFAC Conference on Maneuvering and Control of Marine Crafts (MCMC), Dinamarca, 2000.

HARRIS, R.I. The Nature of the Wind, the Modern Design of Wind-Sensitive Structures, Construction Industry Research and Information Association, Londres, pp.29-55, 1971.

HENERY, D.; INGLIS, R.B. Prospects and Challenges for the FPSO, In: Proceedings of $27^{\text {th }}$ Offshore Technology Conference (OTC), 1995. 
HERBICH , J.B. Handbook of Coastal and Ocean Engineering: Offshore Structures, Marine Foundations, Sediment Processes, and Modeling, Gulf Professional Publishing Company, 1991.

HIRAYAMA, T. Real-time estimation of sea spectra based on motions of a running ship (2nd report), Journal of Kansai Society of Naval Architects, 204, pp.21-27, 1987.

HOERNER, S.F. Fluid dynamic drag, Author's Publication, New Jersey, EUA, 1965.

HOGBEN, N.; COBB, F.C. Parametric modelling of directional wave spectra, In: Proceedings of $\mathbf{1 8}^{\text {th }}$ Offshore Technology Conference (OTC), 1986.

ISEKI, T.; OHTSU, K. Bayesian estimation of directional wave spectra based on ship motions, Control Engineering Practice, 8, pp.215-219, 2000.

ITTC Report of the Seakeeping Committee, In: Proceedings of the $15^{\text {th }}$ International Towing Tank Conference, pp.531-534, 1984.

KAT, J.O., WICHERS, J.E.W. Behavior of a Moored Ship in Unsteady Current, Wind and Waves, Marine Technology, Setembro, pp.251-264, 1991.

KATEBI, M.R.; GRIMBLE, M.J., ZHANG, Y. H r $_{\infty}$ robust control design for dynamic ship positioning, IEE Proc. Control Theory Appl, Vol.144, No.2, pp. 110-120, 1997.

LEITE, A.J.P. et al. Current forces in tankers and bifurcation of equilibrium of turret systems: hydrodynamic model and experiments, Applied Ocean Research, No.20, pp.145-56, 1998.

LEITE, A.J.P. et al. FPSO-Turret system stability and wave heading, In: Proceedings of International Offshore and Polar Engineering Conference (ISOPE'99), Brest, França, 1999.

LEWIS, E.V. Principles of Naval Architecture, The Society of Naval, Jersey City, 1998.

LEWIS, F. Optimal Control, John Wiley \& Sons, 1986.

MARINE PROPULSION INTERNATIONAL, Estados Unidos, Junho, 1998.

MARINTEK REPORT, Dynamic Positioning Analysis for the BGL-1 Pipe-Laying Barge (with the modified positioning system), report no. 60156400.01, 1998.

MEI, C.C. Applied Dynamics of Ocean Surface Waves, World Scientific Pub. Co., $2^{\mathrm{a}}$ Edição, 1989.

MOBERG, S.; HELlSTRÕM, S.A. Dynamic Positioning of a four-collumn semisubmersible. Model tests of interaction forces and a philosophy about optimum strategy when operating thrusters, In: Proceedings of Second International Symposium on Ocean Engineering and Ship Handling, Swedish Maritime Research Centre SSPA, pp,443-480, 1983. 
MORISHITA, H.M.; SOUZA JÚNIOR, J.R.; FERNANDES, C.G. Nonlinear dynamics of a FPSO and shuttle vessel in tandem configuration, In: Proc. Eleventh International Offshore and Polar Engineering Conference (ISOPE'00), pp. 336-342, Stavanger, Noruega, 2000.

MORISHITA, H.M.; SOUZA JÚNIOR, J.R.; CORNET, B.J.J. Systematic investigation of the dynamics of a turret FPSO unit in single and tandem configuration, In: Proceedings of the 20th International Conference on Offshore Mechanics and Arctic Engineering (OMAE'01), Rio de Janeiro, Brasil, 2001.

MUÑOYERRO, M.A.A.; BORGE, J.C.N. Directional wave navigation radar measurements compared with pitch-roll buoy data, Journal of Offshore Mechanics and Arctic Engineering, vol. 119, pp25-29, February, 1997.

NAKAMURA, M.; KAJIWARA, H. Control system design and model experiments on thruster assisted mooring system, In: Proc. Seventh International Offshore and Polar Engineering Conference (ISOPE), pp. 641-648, EUA, 1997.

NAUTRONIX GROUP, Estados Unidos, Dynamic Positioning and Integrated Control Systems. Disponível em: $<$ http://www.nautronix.com.au/ask5000.htm>. Acesso em: 27 de jan de 2002.

NEWMAN, J. Second-order slowly varying forces on vessels in irregular waves, In: Proc. Int. Symp. On Dynamics of Marine Vessels, Londres, 1974.

NISHIMOTO, K. et al. Full Scale Decay Test of a Moored Tanker: Field Data and Theoretical Analysis, Ocean Engineering, Vol.26, pp.125-145, 1999.

NORTEK AS, Estados Unidos. Disponível em $<$ http://www.nortek-as.com/>. Acesso em: 07 de fev de 2002.

OFFSHORE TECHNOLOGY, Estados Unidos. Disponível em $<$ http://www.offshoretechnology.com>. Acesso em 01 de jun de 2002.

OCCHI, M.K.; SHIN, Y.S. Wind Turbulent Spectra for Design Considerations of Offshore Structures, In: Proceedings of $\mathbf{2 0}^{\text {th }}$ Annual OTC, Houston, EUA, pp.461-476, 1988.

OCIMF, Prediction of Wind and Current Loads on VLCCs, Oil Companies International Marine Forum, Londres, pp.1-77, 1977.

OGATA, K. Engenharia de Controle Moderno, Prentice Hall do Brasil, 1990.

PAIT, F.M.; KASSAB, F.J. On a class of switched, robustly stable, adaptive systems, International Journal of Adaptive Control and Signal Processing, Vol.15(3), pp. 213-238, Maio 2001.

PAPOULIAS, F.A.; HEALEY, A.J. Path control of surface ships using sliding modes, Journal of Ship Research, Vol.36, No.2, pp141-153, 1992.

PESCE, C.P. Monitoração do transporte da jaqueta PCR-1 sobre a balsa BS-3, Relatório 
Final, Relatório IPT 18.303, Instituto de Pesquisas Tecnológicas, IPT, 1983.

PESCE, C.P. Cálculo de força de deriva sobre corpos cilíndricos flutuantes sujeitos a ação de ondas aleatórias: os efeitos potenciais de primeira e segunda ordens em lâmina d'água de profundidade finita, São Paulo, 1984. 1v. Dissertação (mestrado) Escola Politécnica, Universidade de São Paulo.

PESCE, C.P. Considerações sobre um projeto de um posicionador dinâmico auxiliar para uma embarcação fundeada, Publicação Técnica IPT $\mathbf{n}^{\mathbf{0}} \mathbf{8 5}$, Instituto de Pesquisas Tecnológicas, IPT, 1987.

PESCE, C.P.; TANNURI, E.A. Stability and Dynamics of Offshore Single Point Mooring Systems, In: Revista Brasileira de Ciências Mecânicas, vol. XIX (4), pp.531-552, 1997.

PESCE, C.P. Mecânica de Cabos e Tubos Submersos lançados em "Catenária": uma Abordagem Analítica e Experimental, Tese de Livre Docência, Escola Politécnica, Universidade de São Paulo, 1997.

PESCE, C.P. et al. Analytical and closed form solutions for deep water riser-like eigenvalue problem, In: Proceedings of International Offshore and Polar Engineering Conference (ISOPE'99), Brest, França, 1999.

PESCE, C.P.; TANNURI, E.A. BGL1-Estudo teórico-experimental do desempenho de sistema de posicionamento dinâmico. Relatório Técnico EPUSP/Petrobras, 2001.

PETROBRAS Petróleo Brasileiro S.A., Brasil. Disponível em $<\mathrm{http}$ ://www.petrobras. com.br>. Acesso em 01 de jul de 2002.

PINKSTER, J.A. Wave Feed-Forward as a Means to Improve Dynamic Positioning, In: Proceedings of Offshore Technology Conference (OTC1978), Houston, Estados, Unidos, OTC 3057, pp.105-112, 1978.

PINKSTER, J.A.; NIENHUIS,U. Dynamic positioning of large tankers at sea, In: Proceedings of the Offshore Technology Conference (OTC'86), Houston, EUA, pp459-476, 1986.

PINTO, M.M.O. et al. Turret positioning, DICAS heading and loading on catenary risers, In: Proceedings of the 18th International Conference on Offshore Mechanics and Arctic Engineering (OMAE'99), St. Johns, Newfoundland, Canada, 1999.

PINTO, M.M.O. Estatística de máximos de tração dinâmica em linhas oceânicas suspensas em catenária :uma aproximação analítica e comparações numéricas, São Paulo, 2000. 1v. Dissertação (doutorado) - Escola Politécnica, Universidade de São Paulo.

PRICE, W.G.; BISHOP, R.E.D., Probabilistic Theory of Ship Dynamics, Chapman and Hall Ltd, 1974.

REICHERT K. et al. WaMoS II: A radar based wave and current monitoring system, In: Proceedings of the Ninth International Offshore and Polar Engineering 
Conference (ISOPE'99), pp139-143, 1999.

SAELID, S.; JENSSEN, N.A.; BALCHEN, J.G. Design and Analysis of a Dynamic Positioning System Based on Kalman Filtering and Optimal Control, IEEE Transactions on Automatic Control, Vol.AC-28, No.3, pp331-339, 1983

SCHEI, T.S. Wave disturbance filtering in dynamic positioning systems, Modeling, Identification and Control, Vol. 17, No.2, pp87-96, 1996.

SCHOOL OF OCEAN SCIENCES, University of Wales, Reino Unido. Disponível em $<$ http://www.sos.bangor.ac.uk/ oss110/>. Acesso em: 07 de fev de 2002.

SCHOTTEL GMBH \& CO Alemanha. Disponível em <http://www.schottel.de/>. Acesso em: 09 de fev de 2002.

SEA-LAUNCH, Estados Unidos, Disponível em $<$ http://www.sea-launch.com>. Acesso em: 12 de abril de 2002.

SEATEX KONGSBERG, Noruega. Disponível em <http://www.seatex.no>. Acesso em: 10 de fev. de 2002.

SEIXAS, N.A.B. Clima de Ondas da Bacia de Campos: Análise dos Dados e Proposta de Parametrização, Dissertação (doutorado), Observatório Nacional, Rio de Janeiro, 1997.

SIMOS, A.N. Modelo hidrodinâmico heurístico para análise de navios petroleiros amarrados sujeitos à ação de correnteza, São Paulo, 2001. 1v. Dissertação (doutorado) - Escola Politécnica, Universidade de São Paulo.

SIMOS, A.N. et al. A quasi-explicit hydrodynamic model for the dynamic analysis of a moored FPSO under current action, Journal of Ship Research, Vol.45, No.4, pp289$301,2001$.

SIMRAD KONGSBERG, Estados Unidos. Disponível em $<$ http://www.simradusa.com>. Acesso em: 10 de fev de 2002.

SINDING, P., ANDERSEN, S.V. A Force Allocation Strategy for Dynamic Positioning, In: Proceedings of the Eighth International Offshore and Polar Engineering Conference (ISOPE'98), Canada, p.346-353, 1998.

SLOTINE, J.J.E.; SASTRY, S.S. Tracking control of non-linear systems using sliding surfaces, with application to robot manipulators, Int. J. Control, Vol. 38, No.2, pp465492, 1983.

SLOTINE, J.J.E., Sliding controller design for non-linear systems, Int. J. Control, Vol.40, No.2, pp421-434, 1984.

SLOTINE, J.J.E. The robust control of robot manipulators, Int. J. Robotics Research, Vol. 4, No. 2, pp49-64, 1985.

SLOTINE, J.J.E.; LI, W. Applied Nonlinear Control, Prentice Hall, New Jersey, 1991. 
SOARES, C.G.; FONSECA, N.; PASCOAL, R. Experimental and Numerical Study of the Motions of a Turret Moored FPSO in Waves, In: Proceedings of the 20th International Conference on Offshore Mechanics and Arctic Engineering (OMAE'01), Rio de Janeiro, Brasil, 2001.

SONARDYNE, Reino Unido. $\quad$ Disponível em $<$ http://www.sonardyne.co.uk/theory.htm>. Acesso em:10 de fev de 2002.

SØRDALEN, O.J. Optimal Thrust Allocation for Marine Vessels, Control Engineering Practice, Vol.5, No.9, pp1223-1231, 1997.

SØRENSEN, A.J.; SAGATUN, S.I.; FOSSEN, T.I. Design of a Dynamic Positioning System Using Model Based Control, Journal of Control Engineering Practice, Vol.4(3), pp.359-368, 1996.

SØRENSEN, A.J., et. al. A New Method of Thruster Control in Positioning of Ships Based on Power Control, In: Proceedings of the 4th IFAC Conference on Maneuvering and Control of Marine Crafts (MCMC), Croácia, 1997.

SØRHEIN, H.R.; GALTUNG, F.L. Wave Filter Performance Evaluation, In: Proceedings of Offshore Technology Conference (OTC1977), OTC2869, pp489-498, 1977.

SOUZA JÚNIOR, J.R.; MORISHITA, H.M. Dynamic Behavior of a Turret FPSO in Single and Tandem Configurations in Realistic Sea Environments, In: Proceedings of the 21th International Conference on Offshore Mechanics and Arctic Engineering (OMAE'02), Oslo, Noruega, 2002.

SPHAIER, S.H.; FERNANDES, A.C.; CORREA, S.H.S. Maneuvering coefficients from model testing for FPSO's station keeping behavior, In: Proceedings of the 19th International Conference on Offshore Mechanics and Arctic Engineering (OMAE'00), 8p. 2000.

STRAND, J.P.; SØRENSEN, A.J.; FOSSEN, T.I. Design of automatic assisted position mooring systems for ships, Modeling, Identification and Control, Vol. 19, No. 2, pp. 61-75, 1998.

TAKASHINA, J. Ship manouvering motion due to tugboats and its mathematical model, Journal of the Society of Naval Architects of Japan, Vol.160, pp.93-104, 1986.

TANNURI, E.A.; DONHA, D.C., $H_{\infty}$ Controller Design for Dynamic Positioning of a Turret Moored FPSO, In: Proceedings of $5^{\text {th }}$ IFAC Conference on Manoeuvring and Control of Marine Crafts (MCMC2000), pp.269-274, Dinamarca, 2000.

TANNURI, E.A. et al. Experimental Validation of a Quasi-Explicit Hydrodynamic Model: Fishtailing Instability of a Single Point Moored Tanker in Rigid Hawser Configuration, Journal of Ship Research, Vol.45, No.4, Dezembro, pp302-314, 2001.

TANNURI, E.A., et al. Directional Wave Spectrum Estimation Based on moored FPSO Motions, In: Proceedings of OMAE2001 Conference, Junho 3-8, Rio de Janeiro, RJ, 
Brasil, 2001.

TANNURI, E.A.; DONHA, D.C.; PESCE, C.P. Dynamic Positioning of a Turret Moored FPSO Using Sliding Mode Control, Int $\mathbf{J}$ of Robust and Nonlinear Control, Vol.11, pp.1239-1256, Maio, 2001.

TANNURI, E.A.; PESCE, C.P.; DONHA, D.C. Assisted Dynamic Positioning System for a FPSO based on Minimization of a Cost Function, In: Proceedings of Control Applications in Marine Systems Conference (IFAC-CAMS 2001), CD-ROM Glasgow, Escócia, 2001a.

TANNURI, E.A.; PESCE, C.P.; DONHA, D.C. Dynamic Positioning of a Turred Moored FPSO Using Sliding Mode Control, In: Proceedings of the 20th International Conference on Offshore Mechanics and Arctic Engineering (OMAE'01), Rio de Janeiro, Brasil, 2001b.

TANNURI, E.A., PESCE, C.P. Comparing two different control algorithms applied to dynamic positioning of a pipeline launching barge, 10th Mediterranean Conference On Control And Automation, 2002.

TANNURI, E.A. et al. Dynamic Positioning of a Pipeline Launching Barge, In: Proceeding of the $12^{\text {th }}$ International Offshore and Polar Engineering Conference (ISOPE'02), Kyushu, Japão, 2002.

THE HUBBERT PEAK OF OIL PRODUCTION, Estados Unidos, Disponível em $<$ http://www.hubbertpeak.com/>. Acesso em: 10 de abril de 2002.

UTKIN, V.I. Sliding Modes and their application to variable structure systems, MIR Publishers, Moscow, 1978

WEBSTER, W.C.; DILLINGHAM, J.T. Determination of directional seas from ship motions, In: Proceedings of Directional Wave Spectra Applications'81, Berkeley, pp.1-20, 1981.

WELCH, P.D The Use of Fast Fourier Transform for the Estimation of Power Spectra: A Method Based on Time Averaging Over Short, Modified Periodograms, IEEE Trans. Audio Electroacoustics, Vol. AU-15, Junho, pp. 70-73, 1967.

WICHERS, J.E.W. The prediction of the behaviour of single point moored tankers, Developments in Marine Technology, Vol.4, Floating Structures and Offshore Operations, Novembro, pp.124-42, 1987.

YOERGER, D.R.; NEWMAN, J.B.; SLOTINE, J.J.E. Supervisory Control System for the JASON ROV, IEEE Journal on Oceanic Engineering, Vol. OE-11, No. 3, pp392400, 1986. 


\section{Apêndice 1 - Modelo analítico para tração dinâmica}

\section{em risers}

O cálculo da tração dinâmica atuante nos risers é feito utilizando-se o modelo analítico proposto em Aranha et al. (1993) e estendido em Pinto et al. (1999). Uma simplificação do modelo analítico desconsidera o efeito da correnteza, e será brevemente apresentada a seguir.

Na Tabela A1.1 apresentam-se os parâmetros do riser necessários para a aplicação do modelo, e, na terceira coluna, os valores utilizados nos exemplos desenvolvidos em 4.2 e 6.2 .

Tabela A1.1 Parâmetros do riser utilizados na formulação analítica empregada e valores numéricos utilizados nos exemplos do presente trabalho

\begin{tabular}{|l|l|l|}
\hline Parâmetro & Símbolo & Valor numérico utilizado \\
\hline Diâmetro externo & $D_{r}$ & $216 \mathrm{~mm}\left(8,5{ }^{\prime}\right)$ \\
\hline Massa por unidade de comprimento & $m_{r}$ & $67 \mathrm{~kg} / \mathrm{m}$ \\
\hline Massa adicional por unidade de comprimento & $m_{a, r}$ & $37,5 \mathrm{~kg} / \mathrm{m}$ \\
\hline Rigidez axial & $E A$ & $192000 \mathrm{kN}$ \\
\hline Rigidez flexional & $E J$ & $9,84 \mathrm{kN} . \mathrm{m}^{2}$ \\
\hline Coeficiente de arrasto seccional & $C_{D r}$ & 1,1 \\
\hline Coeficiente de atrito com o solo & $\mu_{r}$ & 0,4 \\
\hline Comprimento total & $L_{\text {total }}$ & $1895 \mathrm{~m}$ \\
\hline Profundidade & $h$ & $855 \mathrm{~m}$ \\
\hline Máxima compressão admissível & $T_{a d m}$ & $85 \mathrm{kN}$ \\
\hline
\end{tabular}

O peso submerso por unidade de comprimento $\left(q_{r}\right)$ pode ser calculado por :

$$
q_{r}=\left(m_{r}-\rho \pi D_{r}^{2} / 4\right) \cdot g
$$

A configuração estática do riser depende do deslocamento estático $\left(\Delta_{\mathrm{r}}\right)$ do ponto de conexão no navio, sendo esquematizada na Figura A1.1. A tração estática no ponto de contato com o solo (TDP - touchdown point) é indicada por $T_{0}$, a tração total no ponto de conexão por $T_{S}$, o ângulo entre a tangente ao cabo na extremidade suspensa e a horizontal por $\theta_{S}$, a distância horizontal entre o ponto de conexão e o TDP por $x_{t}$ e o comprimento suspenso por $l$. 


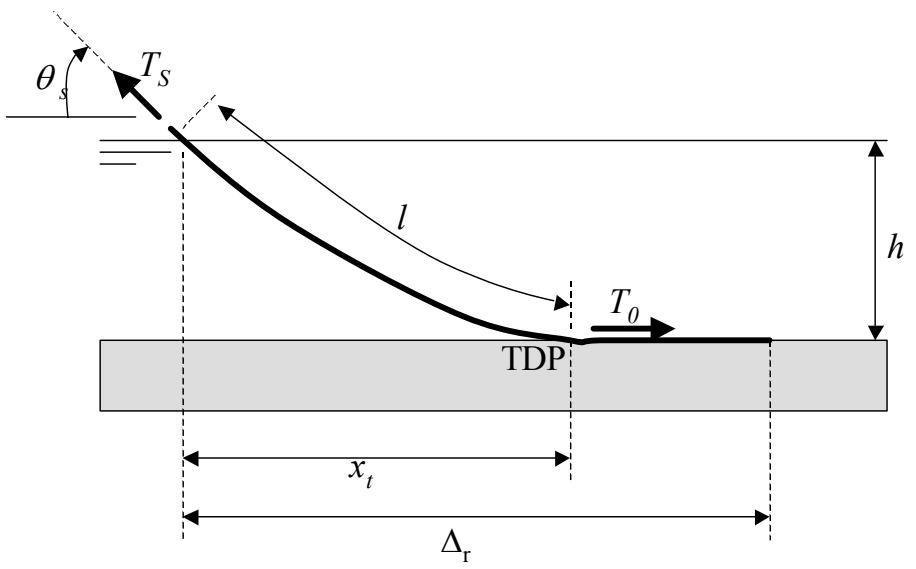

Figura A1.1 Configuração estática do riser

Assim, dado o deslocamento estático, $\Delta_{\mathrm{r}}$, podem-se obter os parâmetros que determinam a configuração estática do $\operatorname{riser}\left(\theta_{\mathrm{S}}, \beta=T_{0} / q_{r}, x_{t}, l, T_{s}\right)$ utilizando-se:

$$
\begin{array}{ll}
\beta=\frac{T_{0}}{q_{r}}=\frac{h}{\sec \theta_{S}-1}, & x_{t}=\beta \operatorname{acosh}\left(\frac{\mathrm{h}}{\beta}+1\right) \\
l=\beta \sqrt{\left(1+\frac{h}{\beta}\right)^{2}-1}, & L_{\text {total }}=l+\Delta-x_{t} \\
T_{S}=\sqrt{\left(q_{r} l\right)^{2}+T_{0}^{2}} &
\end{array}
$$

Utilizam-se também os coeficientes integrais de forma dados por:

$$
\begin{aligned}
I_{2} & =\frac{1}{\operatorname{sen} 2 \theta_{S}}\left(\theta_{S}+\frac{\operatorname{sen} 2 \theta_{S}}{2}\right) \\
I_{3} & =\frac{1}{4 \cos \theta_{S} \operatorname{sen} 2 \theta_{S}}\left(3 \theta_{S}+2 \operatorname{sen} 2 \theta_{S}+\frac{\operatorname{sen} 4 \theta_{S}}{4}\right)
\end{aligned}
$$

e o comprimento l', equivalente à parte do riser suportada pelo solo, cujo atrito seco se contrapõe à força $T_{0}$, dada por:

$$
l^{\prime}=\min \left(L_{\text {total }}-l, T_{0} / \mu_{r} q_{r}\right)
$$


Após a definição da configuração estático, podem-se obter os parâmetros que determinam o comportamento dinâmico do riser, excitado por um movimento harmônico com amplitude máxima $\left[x_{P O}\right]_{\max }$ e valor rms $\left[x_{P O}\right]_{r m s}$ na direção tangente ao cabo na extremidade suspensa e freqüência $\omega$. No caso de um movimento não harmônico, utiliza-se a freqüência de pico do espectro do movimento.

A freqüência reduzida $(\Lambda)$, a escala de freqüência de catenária $\left(\omega_{c}\right)$, a escala de freqüência elástica $\left(\omega_{e}\right)$ e o coeficiente de freqüência $(\Omega)$ são dados por:

$$
\begin{array}{ll}
\Lambda=\frac{q_{r} l}{T_{S}} \sqrt{I_{2}\left(\frac{E A}{T_{S}}\right)\left(\frac{l}{l+l^{\prime}}\right)}, & \omega_{e}=\frac{\pi}{l} \sqrt{\frac{E A}{m_{r}}} \\
\omega_{c}=\frac{\pi}{l} \sqrt{\frac{T_{S}}{m_{r}+m_{a, r}}} & , \quad \Omega=\frac{\pi}{\Lambda}\left(\frac{\omega}{\omega_{c}}\right)
\end{array}
$$

A escala de tração elástica é dada por

$$
T_{e}=E A \frac{\left[x_{P O}\right]_{r m s}}{l+l^{\prime}}
$$

O coeficiente linearizado de amortecimento é dado por:

$$
\zeta_{0}=\frac{16 C_{D r}}{3 \pi^{2}} \frac{m_{a, r}}{m_{a, r}+m_{r}} \frac{I_{3}}{I_{2}^{2}} \frac{\left[x_{P O}\right]_{\max }}{D_{r}} \frac{1}{\operatorname{sen} \theta_{S}}
$$

Com o qual finalmente obtém-se a amplitude da tração dinâmica no TDP $\left(T_{d}\right)$ :

$$
\begin{aligned}
& T_{d}=T_{e} \times\left[\frac{\left(\sqrt{b^{2}+4 \zeta_{0}^{2} / \Omega^{4}}-b\right)^{2}+2\left(\sqrt{b^{2}+4 \zeta_{0}^{2} / \Omega^{4}}-b\right)}{\left(4 \zeta_{0}^{2} / \Omega^{4}\right)}\right]^{1 / 2}, \text { com } \\
& b=\left(\frac{1-\omega^{2}}{\omega^{2}}\right)^{2}
\end{aligned}
$$




\section{Apêndice 2 - Principais sensores utilizados em SPDs}

Neste Apêndice serão expostos os principais tipos de sensores utilizados na monitoração ambiental de ventos e correnteza, medição de posição, aproamento e movimento. Enfocam-se a faixa de aplicação, vantagens e desvantagens de cada um.

Deve-se mencionar que Donha (1983) apresenta uma rica discussão a respeito de alguns sensores mencionados a seguir, destacando-se os sensores hidroacústicos, sistemas de cabo tensionados e girocompassos.

\section{A2.1 Correnteza}

A correnteza superficial em alto-mar é, em geral, medida por estações instaladas em bóias amarradas. Como as bóias são corpos pequenos, o fluxo de água em suas proximidades não é afetado significativamente, o que permite uma estimativa acurada da correnteza. Em algumas aplicações de posicionamento dinâmico, entretanto, os sensores devem ser instalados onboard, permitindo flexibilidade de operação.

Dois problemas dificultaram bastante o desenvolvimento de sensores de correnteza adequados para SPDs. As linhas de corrente são bastante afetadas pela presença do navio e sobretudo pelo funcionamento dos propulsores, fazendo com que os sensores instalados no próprio navio fornecessem, a princípio, uma leitura bastante diferente da correnteza real. Além disso, o movimento da embarcação afeta as medidas de correnteza, e devem-se inserir procedimentos de correção da leitura para uma melhor estimativa da correnteza real. Estes problemas vêm sendo solucionados com auxílio de tecnologias adequadas, como será descrito a seguir.

Os sensores de correnteza baseados em efeito Doppler são os mais utilizados hoje em dia. Encontram-se disponíveis sensores capazes de medir a velocidade em um ponto nas três direções, chamados de ADV (Acoustic Doppler Velocimeters). Outra opção são os sensores que medem o perfil de velocidades ao longo da profundidade, chamados de ADCP (Acoustic Dopler Current Profiler). Em ambos os casos, os sensores baseiam-se na emissão de pulsos acústicos e na determinação da diferença de freqüência entre o pulso emitido e o sinal refletido por partículas suspensas, zôoplancton ou bolhas. Pelo efeito Doppler, esta diferença de freqüência é proporcional à velocidade do ponto onde ocorre a reflexão. 
Os ADV's possuem, em geral, um emissor central que envia o pulso a cada período de amostragem. Após um intervalo de tempo determinado, três emissores recebem sinais refletidos por partículas existentes no ponto monitorado, que fica a uma distância, em geral, menor do que $0,5 \mathrm{~m}$ do sensor. Circuitos eletrônicos calculam a diferença entre a freqüência do sinal enviado e dos sinais recebidos nos três receptores. Pela disposição dos mesmos, simples composições geométricas permitem que se calcule as velocidades de correnteza nas três direções (Figura A2.1).

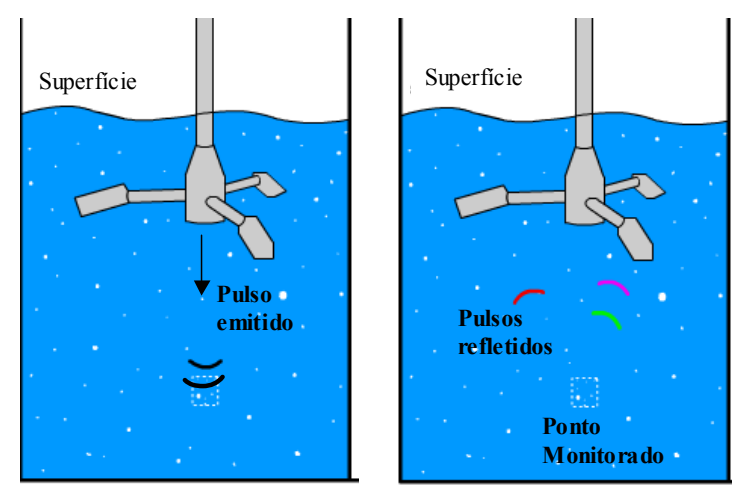

Figura A2.1 Princípio de funcionamento dos ADV's

Estes equipamentos possibilitam que os pulsos sejam enviados e tratados a uma alta taxa de amostragem, alcançando da ordem de 60 amostragens por segundo. Tratamentos estatísticos permitem que componentes de alta freqüência devidas a ondas sejam eliminadas das medições.

Os ADCP's, por sua vez, são compostos por três ou quatro emissores distribuídos simetricamente em relação ao eixo vertical formando um ângulo de $30^{\circ}$ com relação ao mesmo (Figura A2.2). A cada período de amostragem, os emissores emitem pulsos acústicos que passam a percorrer cada um dos eixos. A velocidade da correnteza em diferentes profundidades é estimada pela detecção dos sinais refletidos em instantes de tempo determinados após a emissão do pulso (Figura A2.3). Pela disposição geométrica dos eixos, as diferenças de fase dos sinais refletidos permitem a inferência da velocidade nas três direções para cada profundidade. A resolução em termos de profundidades é função da freqüência do pulso emitido, pois depende do comprimento da onda associada. Altas freqüências permitem maior resolução, entretanto a atenuação do sinal é mais rápida não se podendo traçar um perfil até elevadas profundidades. Freqüências de 300 a $600 \mathrm{kHz}$ garantem resolução de 1 a $4 \mathrm{~m}$ e máxima profundidade de 60 a 200m (School Of Ocean Sciences, 2002). 


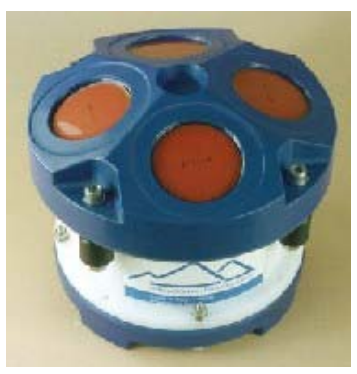

Figura A2.2 Modelo típico de um medidor de perfil de correnteza
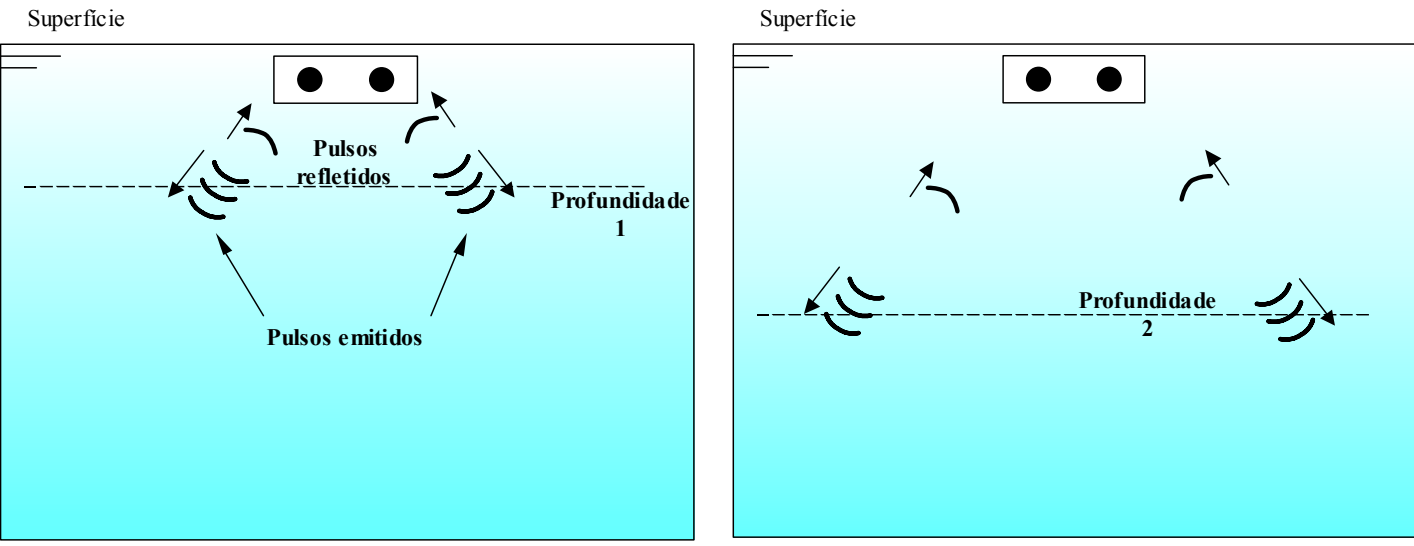

Figura A2.3 Princípio de funcionamento dos ADCP's

Para ambos os tipos de sensores, quando a montagem é feita em um navio, devese retirar da medida a velocidade do mesmo. Para águas rasas, utilizam-se os pulso acústicos refletidos pelo fundo do mar, que fornecem a velocidade do navio em relação a este referencial fixo, podendo-se então descontá-la das medidas realizadas.

Em águas profundas o pulso não alcança o fundo do mar, e isto é feito utilizandose as medidas obtidas pelos sistemas descritos em A2.3, como DGPS, giroscópios e acelerômetros. Deve-se garantir uma boa precisão no monitoramento das velocidades lineares e angulares do navio e uma alta taxa de amostragem (maior que 50 medidas por segundo). Isto é em geral obtido por sistemas que combinam acelerômetros, giroscópios e DGPS, como o modelo Seapath já citado (Seatex, 2002). Alguns modelos de ADCP's já permitem este tipo de compensação, possuindo recursos de comunicação com os sensores de velocidade do navio. Para o modelo da empresa Nortek, por exemplo, garante-se uma acurácia nas componentes da velocidade de correnteza de $\pm 0,5 \mathrm{~cm} / \mathrm{s}$ (Nortek, 2002). 
Como já citado, a presença de grandes corpos flutuantes e o funcionamento dos propulsores modificam as linhas de fluxo nas proximidades e a medição de correnteza deve ser feita com o sensor instalado convenientemente de forma a minimizar a influência destes efeitos. Os ADCP's possuem a vantagem de medir a velocidade em um ponto distante, o que permite que sua montagem seja feita próxima ao casco, apontando para baixo. No caso de águas profundas, a diferença entre a correnteza superficial e a medida a uma profundidade de aproximadamente $50 \mathrm{~m}$ é pequena, o que não introduz erros significativos nesta técnica de medição. A utilização de ADV's, entretanto, requer uma estrutura que o posicione numa profundidade adequada de forma a medir pontos com velocidade menos influenciadas pela presença do navio e propulsores.

Os sensores de correnteza baseados em rotores e propulsores, conhecidos como sensores mecânicos, são bastante utilizados em estações de medição instaladas em altas profundidades, porém apresentam problemas na medição de correnteza superficial devido à presença de ondas, não possuindo, portanto, aplicabilidade em SPDs (ElHawary, 2000).

Técnicas de estimação da velocidade superficial de correnteza baseando-se nos movimentos lentos do navio vêm sendo estudadas, constituindo-se em uma opção bastante vantajosa em termos econômicos. Neste caso, medem-se ou estimam-se a intensidade e direção dos ventos e ondas. A partir daí, consegue-se eliminar os efeitos destes agentes das medidas de posição e velocidade do navio, sendo que os movimentos restantes são, em teoria, decorrentes da ação da correnteza. Utilizam-se, então, estimadores baseados em filtros de Kalman para realizar a estimação da velocidade e direção da correnteza. Este assunto está sendo abordado em um projeto internacional de cooperação entre indústrias e universidades (Aalbers, 2000), sendo ainda tema de pesquisa sem resultados validados.

\section{A2.2 Vento}

A direção e velocidade do vento são medidas por meio de anemômetros instalados sobre a embarcação. Como visto em 4.1, estes dados são utilizados pelo controlador que realiza a compensação direta das forças de vento (feed-forward). Anemômetros convencionais utilizados na indústria marítima atendem, em geral, as necessidades de SPDs (Herbich, 1991). 
Um dos modelos de anemômetros caracterizam-se por realizar a medição de velocidade e direção de forma independente. Neste caso, cascas semi-esféricas rotativas medem a velocidade (Figura A2.4a) e, separadamente, uma aleta com liberdade azimutal rotativa se alinha com o vento, medindo, portanto, a direção de incidência.

Existem também anemômetros de corpo único, no qual a velocidade é medida por meio de hélices e a direção é obtida pelo alinhamento do próprio corpo com o vento (Figura A2.4b).

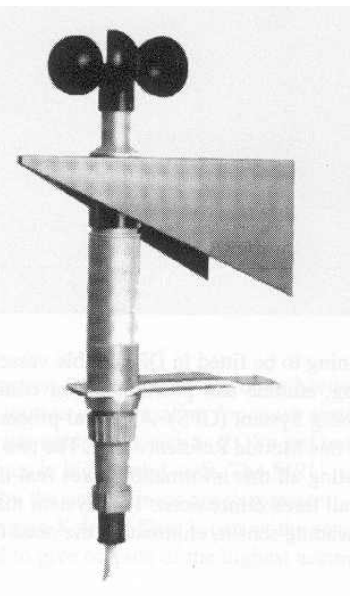

(a)

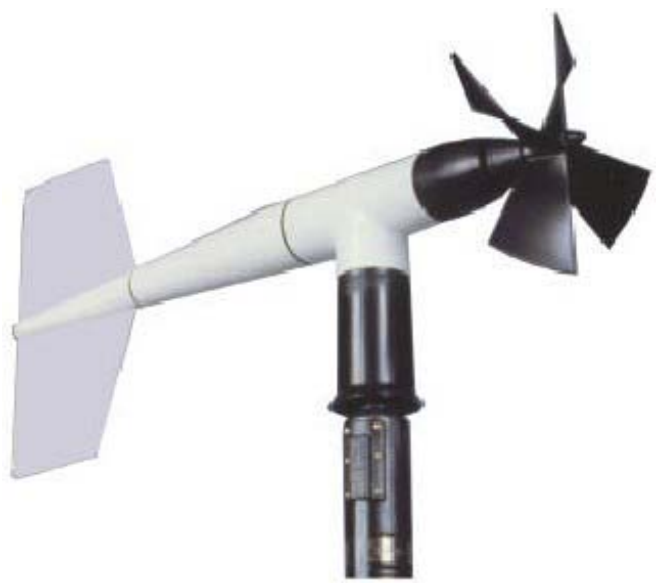

(b)

Figura A2.4 Tipos de anemômetros: (a) direção e velocidade independentes; (b) corpo único (extraído de Nautronix, 2000)

Falhas nos anemômetros causam grandes desvios de posição, pois o sistema de controle tenta compensar as forças de vento estimadas erroneamente. Assim, em geral utilizam-se dois ou mais anemômetros e um critério de seleção ou combinação automática das leituras de cada um.

Além de possíveis falhas mecânicas e elétricas, as medidas de um determinado anemômetro devem ser desconsideradas pelo sistema de controle quando o escoamento aerodinâmico é afetado na região do sensor, por exemplo, pela proximidade com uma outra embarcação ou plataforma ou pelo fluxo induzido durante o pouso de um helicóptero. Algumas vezes, as medidas de todos os anemômetros devem ser desconsideradas, sendo que nestes casos a compensação direta das forças de vento deve ser feita baseada na velocidade e direção médias atuantes em instantes anteriores. $\mathrm{O}$ sistema perde a capacidade de compensar as forças de rajadas nestes instantes. 
Dois exemplos descritos em Bray (1998) ilustram estes problemas. No caso da Figura A2.5a o anemômetro instalado no mastro recebe um escoamento bastante atenuado pela presença da plataforma à montante da embarcação. Entretanto, o casco e a superestrutura estão sujeitos ao vento quase diretamente, já que o mesmo passa pela estrutura inferior da plataforma. Neste caso, as rajadas não são "sentidas" pelo anemômetro, e o sistema não é capaz de compensá-las.

Já na Figura A2.5b ilustra-se o caso oposto, no qual uma estrutura à montante atenua o vento que atua sobre o casco e superestrutura. $\mathrm{O}$ escoamento próximo ao sensor, entretanto, não é sujeito a esta atenuação, e a cada rajada o controlador comanda uma força de compensação no sistema propulsor que efetivamente não existe. $\mathrm{O}$ navio então sofre um deslocamento indesejado nestes instantes, compensados em seguida pelos mecanismos de realimentação presentes no controlador. Este efeito representa um consumo desnecessário de energia de controle.

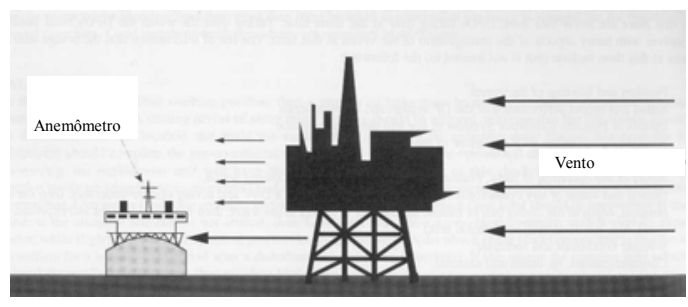

(a)

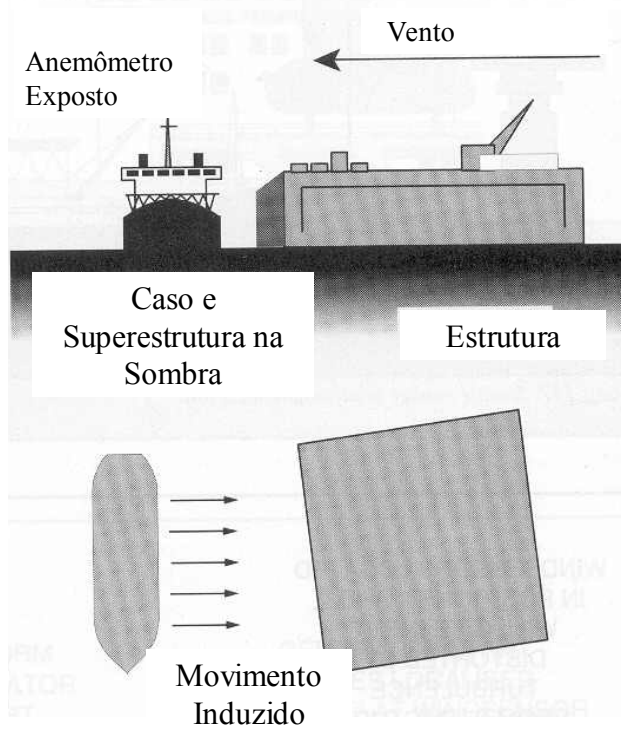

(b)

Figura A2.5 Problemas típicos que ocorrem com anemômetros instalados em embarcações dotadas de SPD (adaptados de Bray, 1998)

Outro ponto crucial no sensoriamento de ventos relaciona-se à posição de instalação dos anemômetros. Deve-se evitar a proximidade com qualquer estrutura que possa afetar o escoamento nas proximidades do sensor. Uma solução é a instalação em pontos elevados, como no mastro principal. Nestes casos, pode ser necessária a introdução de um fator de correção na medida de velocidade através da modelagem da 
camada limite aerodinâmica, pois o vento tende a soprar mais intensamente conforme se aumenta a altitude.

\section{A2.3 Posição e Velocidade}

Os sistemas de medição de posição e velocidade ${ }^{27}$, aplicados em posicionamento dinâmico, devem possuir requisitos especiais de acurácia, confiabilidade e taxa de amostragem. Os sistemas de navegação comerciais apresentam, em geral, erros maiores do que $15 \mathrm{~m}$, sendo insuficientes para SPDs que requerem erros máximos de aproximadamente $5 \mathrm{~m}$. Além disso, a taxa de atualização dos dados é irregular e muito lenta, podendo alcançar horas, sendo que para SPDs esta taxa deve ser menor do que 1s. Finalmente, como a medida de posição determina o comportamento do sistema, questões de confiabilidade e redundância devem ser consideradas na especificação do sistema de sensoriamento.

Diversas tecnologias podem ser aplicadas ao sensoriamento de posição e velocidade. Em geral utilizam-se, simultaneamente, mais de um tipo de sensor para a mesma medição, aplicando-se algoritmos estatísticos para combinar a leitura de cada uma, diminuindo o erro e permitindo a eliminação de leituras provenientes de sensores danificados. Em Bray (1998) estes algoritmos são descritos, baseados, por exemplo, em médias ponderadas com pesos dependentes da variância de cada sinal, filtros de Kalman ou comparação média-mediana.

Em seguida, serão descritos os sensores mais utilizados para medição de aproamento, movimentos verticais e posição no plano horizontal.

\section{A2.3.1 Aproamento}

A medição de aproamento é feita por girocompassos, instrumentos que utilizam um rotor a alta rotação, e que se alinha ao Norte verdadeiro, desenvolvidos desde o início do século XX. O aproamento é utilizado pelo algoritmo de controle e por alguns sensores de posição para a transformação do sistema de coordenadas, sendo necessário, portanto, alta precisão (alguns equipamentos alcançam erros menores que $0,1^{\circ}$ ).

\footnotetext{
${ }^{27}$ Referem-se aqui, genericamente, aos 6 graus de liberdade de movimento da embarcação.
} 
Para se aumentar a confiabilidade, utilizam-se dois ou três girocompassos operando simultaneamente e, como já exposto, algoritmos de detecção da ocorrência de falhas em alguma unidade. Um modelo típico fabricado pela empresa Kongsberg/Simrad (Simrad, 2002) é apresentado na Figura A2.6.

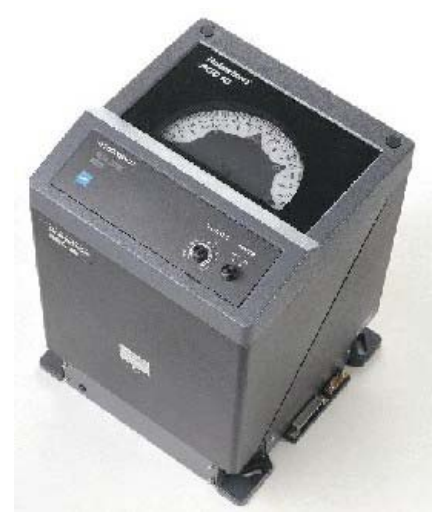

Figura A2.6 Girocompasso Modelo Robertson RGC10

\section{A2.3.2 Movimentos verticais}

Os movimentos de roll, pitch e heave não são controlados diretamente pelo SPD, entretanto são utilizados para corrigir a leitura de diversos tipos de sensores de posição. Além disso, a monitoração destes movimentos é importante em FPSO's pois eles são os responsáveis por trações dinâmicas nos risers e linhas de amarração, por problemas na produção e desconforto da tripulação.

Em geral, os ângulos de roll e pitch são medidos por inclinômetros, que se constituem de pêndulos amortecidos operando dentro de uma câmera contendo fluido viscoso, sendo a inclinação medida por espiras eletromagnéticas. O movimento de heave é medido por acelerômetros verticais auxiliados por algoritmos de integração, filtragem e correção devido à inclinação do sensor. As unidades responsáveis pela monitoração destes ângulos são chamadas de VRU (Unidade de Referência Vertical Vertical Reference Unit).

Hoje em dia existem também VRU's baseadas em acelerômetros e giros piezoelétricos integrados, com diversas faixas de erros e custos. Por exemplo, o modelo MRU6 (Seatex, 2002), ilustrado na Figura A2.7, apresenta erros menores que $0,03^{\circ}$ para roll e pitch e $5 \mathrm{~cm}$ para heave, com boa resposta dinâmica e alta taxa de amostragem (100 leituras por segundo). 


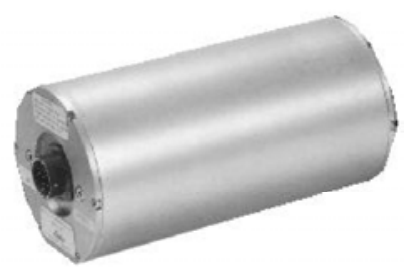

Figura A2.7 Sensor MRU6

\section{A2.3.3 Posição no plano horizontal ${ }^{28}$}

Existem diversas tecnologias para a medição da posição horizontal de embarcações, sendo as principais mostradas na Figura A2.8 e descritas ao longo da presente seção.

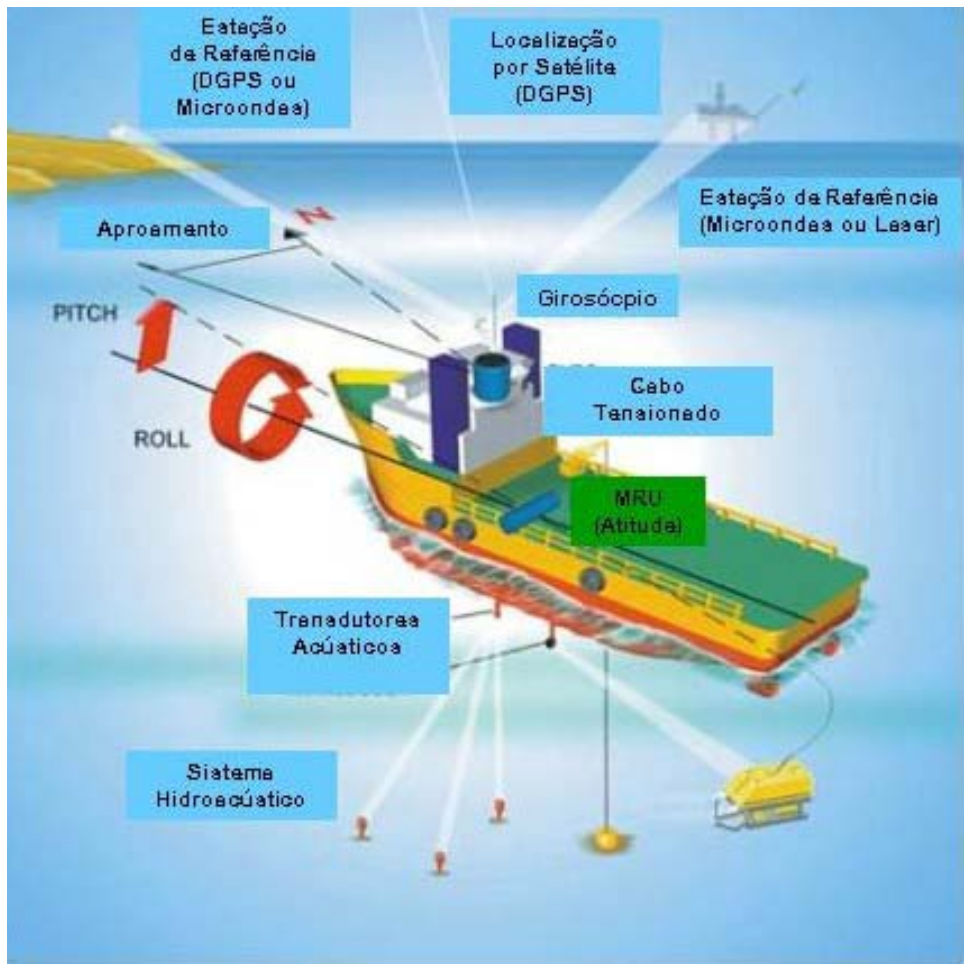

Figura A2.8 Principais sensores utilizados na medição da posição de embarcações (adaptado de Simrad, 2002)

\section{A2.3.3.1 Sistemas Hidroacústicos ${ }^{29}$}

Utilizam ondas acústicas que se propagam a partir de trandutores instalados no navio até retransmissores fixos no fundo do mar (chamados de transponders), sendo a

\footnotetext{
${ }^{28}$ Também conhecidos como Sistemas de Referência de Posição
} 
posição obtida pela diferença de tempo entre os diversos sinais recebidos. De acordo com o número de emissores e transponders, os sistemas acústicos obtêm a posição do navio de diversas formas.

O sistema de linhas de base longas (LBL) é composto por quatro ou mais transponders instalados no fundo do mar comunicando-se com um transdutor instalado na parte de baixo do casco do navio (Figura A2.9). A cada intervalo de amostragem, o emissor emite um pulso sonoro que é retransmitido pelos transponders. Os instantes de tempo em que as ondas acústicas alcançam o transdutor são registrados e a distância entre o mesmo e cada transponder é calculada, permitindo-se obter a posição do navio em relação aos transponders por meio de um simples sistema de equações algébricas. Embora o procedimento de calibração da posição dos transponders seja trabalhoso, os sistemas LBL possuem boa acurácia de posicionamento, já que as distâncias entre os transponders (linhas de base) são grandes. Para os modelos da empresa Sonardyne (2002), por exemplo, os erros são inferiores a 0,1\%, com a máxima distância entre o transdutor e os transponders podendo valer até $10 \mathrm{~km}$ aproximadamente.

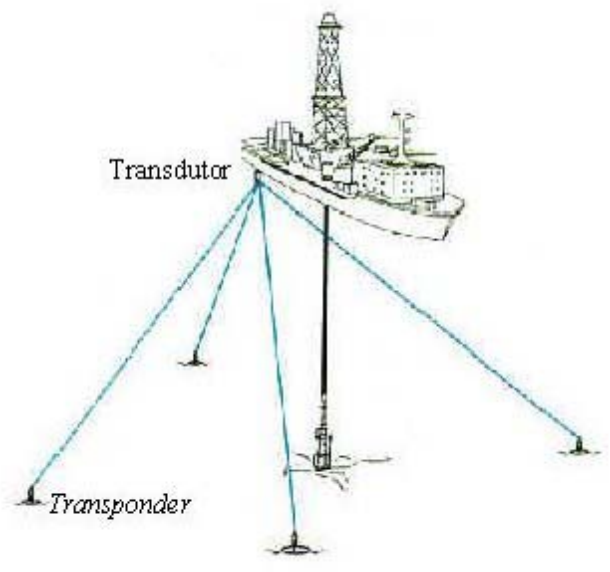

Figura A2.9 Sistema de posicionamento acústico LBL (adaptado de Sonardyne, 2002)

Como o sistema requer a transmissão e a posterior retransmissão do sinal, o tempo para a realização de cada ciclo de posicionamento permite uma taxa de atualização de uma leitura por segundo apenas para profundidades inferiores a $500 \mathrm{~m}$; profundidades

\footnotetext{
${ }^{29}$ Uma discussão mais detalhada a respeito de sensores hidroacústicos é encontrada em Donha (1983).
} 
maiores levam a um aumento de até 4 vezes neste valor, podendo ser restritivo em alguns casos de SPDs.

Sistemas de linhas de base curtas (SBL) são compostos por um emissor instalado no fundo do mar emitindo pulsos acústicos em intervalos de tempo regulares. Os pulsos são recebidos por 3 ou 4 transdutores instalados no casco dispostos adequadamente de forma a permitir o cálculo da posição baseado nos instantes de tempo em que cada transdutor recebe o pulso (Figura A2.10). Correções devidas aos movimentos de roll e pitch devem ser introduzidas no cálculo, utilizando as medidas provenientes dos sensores de movimentos verticais. Este fato, aliado ao menor comprimento das linhas de base (distância entre os transdutores) faz com que os erros deste sistema sejam superiores aos do LBL, podendo chegar até $0,5 \%$ da distância entre o transdutor e o emissor. A taxa de atualização dos sistemas SBL é alta (aproximadamente 1 amostra por segundo para todas as profundidades) pois o som é emitido do fundo do mar, não sendo necessária a retransmissão como no caso dos LBL's.

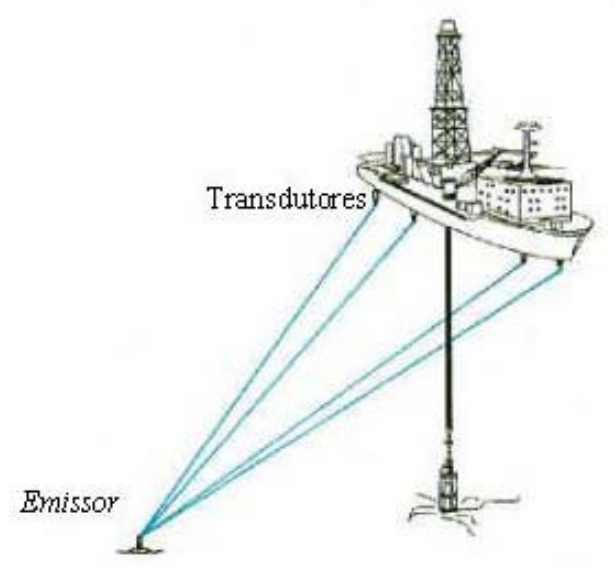

Figura A2.10 Sistema de posicionamento acústico SBL (adaptado de Sonardyne, 2002)

Finalmente, desenvolveu-se o sistema de linhas de base "super curtas" (USBL), que se baseia num princípio muito similar a SBL, excetuando-se o fato de que os transdutores são todos construídos em um único corpo. As distâncias são medidas como nos sistemas SBL, entretanto as diferenças de tempo são muito menores pois os transdutores encontram-se muito próximos. Estas diferenças são medidas de maneira mais acurada pelo atraso de fase entre os sinais acústicos senoidais. Os erros de posicionamento são, em teoria, maiores que para os outros sistemas devido ao pequeno 
comprimento das linhas de base e influência dos movimentos de roll e pitch, alcançando $1 \%$ em modelos convencionais. Alguns modelos atuais que possuem transdutores mais sensíveis e utilizam filtros de Kalman conseguem reduzir os erros para 0,1\% (Simrad, 2002).

Existem também sistemas integrados, que combinam os métodos acima permitindo aumentar a confiabilidade e a acurácia das medidas, porém não serão expostos no presente trabalho pois possuem muitas variações, de acordo com o fabricante.

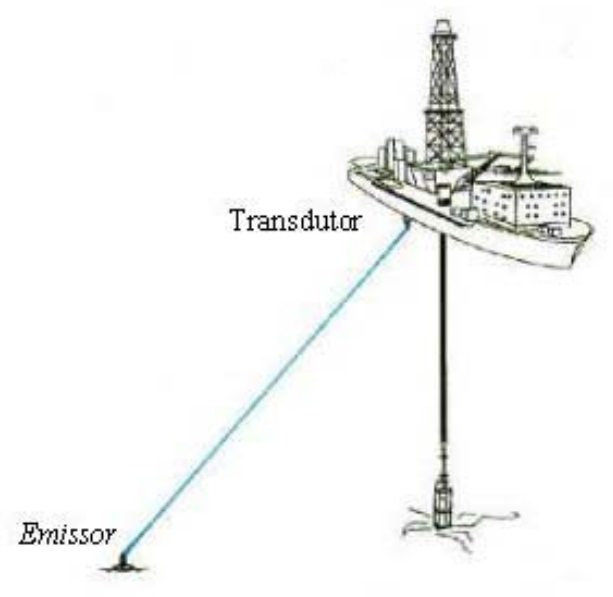

Figura A2.11 Sistema de posicionamento acústico USBL (adaptado de Sonardyne, 2002)

\section{A2.3.3.2 Localização por satélite}

$\mathrm{Na}$ última década, sistemas de localização por satélite apresentaram desenvolvimentos significativos, tornando-se o método mais difundido para medição de posição em SPDs.

O sistema GPS (Sistema de Posicionamento Global), implementado a partir de 1980, utiliza 24 satélites em 6 órbitas diferentes transmitindo suas posições por meio de sinais precisamente sincronizados em duas linhas de freqüência. Cinco estações de controle em terra acompanham as trajetórias de cada satélite e enviam sinais de correção de suas posições a cada 6 horas.

A cada instante, em qualquer ponto do planeta, sempre existem entre 5 e 9 satélites à vista, e os receptores GPS captam os sinais transmitidos podendo obter a posição do ponto onde está instalado. Como os sinais (contendo a posição do satélite e o 
tempo) são enviados no mesmo instante, a simples solução de um sistema de equações algébricas permite obter a posição $(\mathrm{x}, \mathrm{y}, \mathrm{z})$ do receptor. Entretanto, o relógio interno do receptor não possui a mesma qualidade dos relógios atômicos instalados nos satélites, devendo-se acrescentar uma variável extra no sistema de equações, referente ao erro de sincronismo entre os satélites e o receptor. Assim, utilizando-se os sinais de 4 satélites, pode-se obter a posição desejada, sendo que alguns receptores captam sinais de até 9 satélites, aumentando a acurácia do valor obtido.

O sistema GPS garante erros entre 5 e 30m. Até o ano de 2000, o Governo Norte Americano manteve a Avaliabilidade Seletiva (SA), que permitia aos usuários civis o acesso a apenas uma das linhas de freqüência, à qual adicionavam-se ruídos para aumentar a faixa de erro para aproximadamente $100 \mathrm{~m}$. Apenas usuários militares norte americanos e aliados possuíam acesso aos sinais puros do sistema.

Assim, a aplicação dos receptores GPS em SPDs não foi possível até o desenvolvimento, na década de 1990, de técnicas de localização diferenciais que originaram o sistema DGPS. Utilizam-se receptores de referência fixos, localizados em pontos cujas posições são conhecidas com precisão. $O$ erro entre a posição real deste receptor e sua posição, obtida pelo GPS, é transmitido, via telemetria, para o receptor GPS móvel instalado no navio. Este erro é introduzido como correção na medida do GPS, obtendo-se a posição com erros inferiores a $5 \mathrm{~m}$.

De acordo com a tecnologia de transmissão utilizada no sistema de telemetria, a estação referência pode estar até $700 \mathrm{~km}$ distante do navio monitorado. Existem atualmente receptores DGPS capazes de receber sinais de múltiplas estaçõesreferências, o que permite diminuir os erros envolvidos. Por exemplo, o receptor DPS100 (Kongsberg, 2002) fornece a posição e velocidade com erros inferiores a 1m e $0,1 \mathrm{~m} / \mathrm{s}$ respectivamente, utilizando-se a tecnologia de múltiplas referências. Os sinais do sistema GPS são enviados a uma freqüência de $1 \mathrm{~Hz}$, garantindo uma taxa de amostragem compatível com SPDs.

A confiabilidade dos sistemas DGPS é grande para navios em mar aberto. A proximidade com estruturas possibilita a ocorrência de reflexão no sinal proveniente da estação-referência ou perda de comunicação com a mesma, gerando perda momentânea da medida de posição. Além disso, interferência decorrente de telefones celulares, radares ou outros equipamentos eletrônicos também podem causar problemas nos 
receptores. Alguns sistemas já são equipados com sensores inerciais (acelerômetros e giroscópios) capazes de fornecer a posição do navio durante os intervalos em que o DGPS está inoperante. Por exemplo, o modelo Seapath, produzido pela empresa Kongsberg (Kongsberg, 2002), possui este recurso.

Com o fim da Avaliabilidade Seletiva, em maio de 2000, os erros máximo associados aos receptores GPS reduziram-se para 30m. Estes erros ocorrem devido a distorções das ondas emitidas pelos satélites na ionosfera, que afeta o tempo de recepção dos sinais. Além disso, problemas de transmissão de dados fazem com que o sistema GPS não seja capaz de fornecer a posição do receptor ininterruptamente, com grande confiabilidade. Assim, para aplicações em SPDs ainda utiliza-se o sistema diferencial (DGPS), que elimina os problemas mencionados através da correção diferencial. Adicionalmente, com o fim da SA o erro associado a receptores DGPS reduziu-se para apenas $2 \mathrm{~m}$ (Furuno, 2002).

\section{A2.3.3.3 Radares microondas}

Os radares microondas obtêm a distância e direção de um ponto do navio, onde se encontra a antena direcional móvel, em relação a um ponto fixo no qual é instalada a antena direcional fixa. Estabelece-se entre as antenas uma comunicação contínua por microondas de baixa potência, e a distância entre as mesmas é obtida pelo atraso entre o sinal emitido e a sua recepção pela antena móvel.

As antenas possuem um sistema de acompanhamento através do sistema de controle azimutal que mantém o alinhamento entre as mesmas durante a movimentação da embarcação. O ângulo formado pela antena fixa fornece a direção da embarcação, sendo transmitido ao sistema embarcado pelo próprio sinal de comunicação entre as antenas. As alterações da posição da antena móvel decorrentes dos movimentos de roll e pitch são corrigidas utilizando-se as leituras das VRU's. Apresentam-se, na Figura A2.12, um esquema de funcionamento dos radares e uma típica antena com sistema de acompanhamento. 


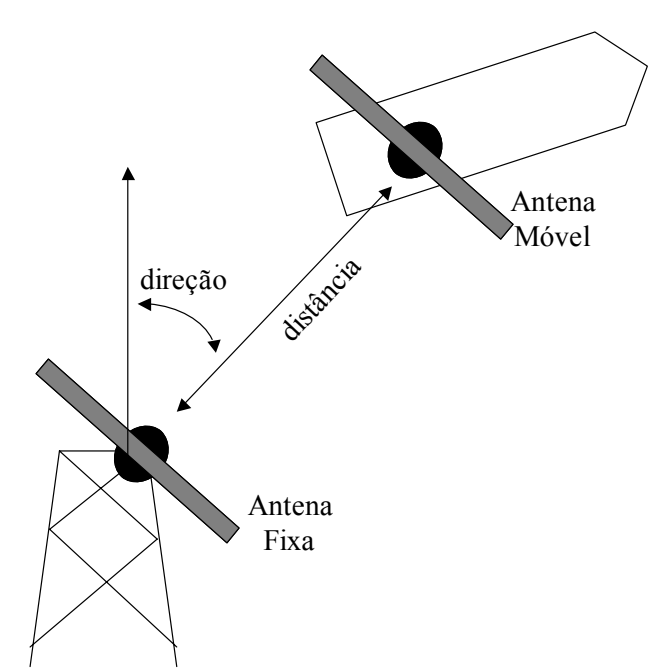

(a)

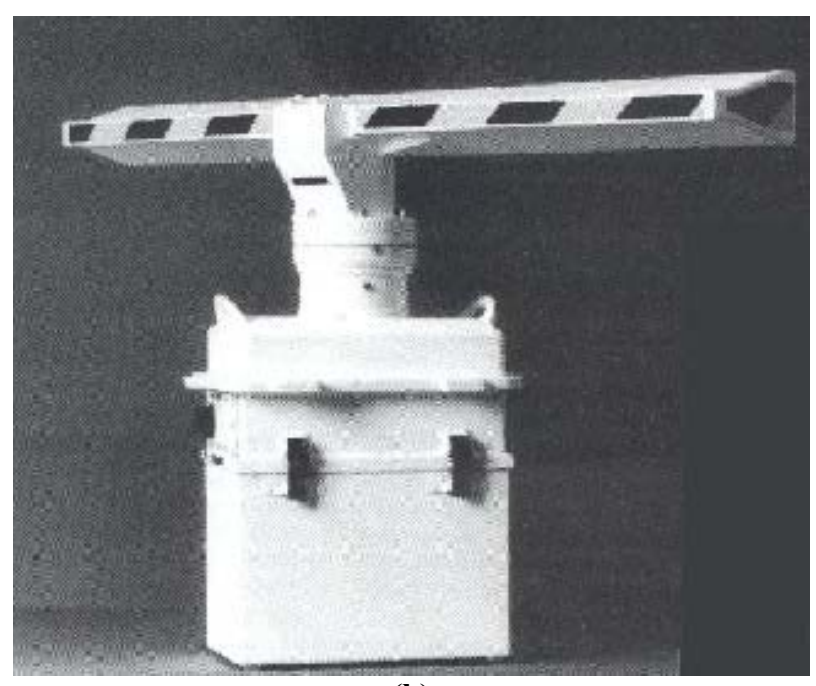

(b)

Figura A2.12 Radares Microondas - (a) Esquema de Funcionamento; (b) Antena com sistema de acompanhamento (adaptada de Bray, 1998)

Os intervalos de medição e erros máximos dependem de cada modelo, sendo que de forma ilustrativa apresentam-se os dados relativos ao modelo Artemis MkIV (Bray, 1998). Este produto permite que a distância entre a base fixa e o navio varie entre $10 \mathrm{~m}$ e $30 \mathrm{~km}$, com erro entre $0,1 \mathrm{~m}$ e $1 \mathrm{~m}$, dependente da distância e das condições ambientais. A direção do navio é medida com erro menor que $0,02^{\circ}$. Além das vantagens de possuírem ampla faixa de funcionamento e grande acurácia, estes sistemas independem da profundidade de lâmina d'água, podendo operar em águas profundas.

Como desvantagens, pode-se citar a necessidade de instalação e manutenção da estação fixa, problemas na comunicação devidos a existência de estruturas entre as antenas além de interferência por outros radares e por reflexão do sinal pela água.

\section{A2.3.3.4 Radares Óticos}

Os radares óticos são compostos por um emissor laser apontado para um refletor instalado em uma estação fixa. O feixe refletido é direcionado a um conjunto de diodos fotossensíveis que produzem um sinal elétrico. A distância entre o refletor e o navio é então calculada pelo tempo decorrido entre a emissão e a recepção do sinal.

O feixe possui uma abertura vertical de $20^{\circ}$ e horizontal de $0,001 \mathrm{rad}$. Assim, o radar possui um mecanismo de controle horizontal que permite que o sinal refletido seja sempre direcionado aos diodos fotossensíveis. O controle não é necessário na direção vertical devido à grande abertura do feixe nesta direção. A direção do navio é dada pelo 
ângulo formado pelo radar, medido por meio de um encoder óptico. $\mathrm{O}$ alvo é composto por uma simples superfície refletora, o que garante fácil instalação facilita a manutenção. As alterações da posição do radar decorrentes dos movimentos de roll e pitch são corrigidas utilizando-se as leituras das VRU's.

O modelo Fanbeam4 da empresa MDL (MDL, 2002) permite máxima distância entre o alvo e o navio de aproximadamente $2000 \mathrm{~m}$, com erro menor que $20 \mathrm{~cm}$ para a distância e $0,02^{\circ}$ para a direção (Figura A2.13). Observa-se que o emissor é instalado no mesmo corpo que os diodos fotossensíveis.

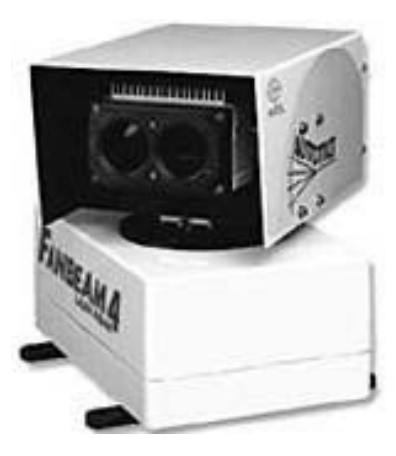

Figura A2.13 Radar laser Fanbeam4 (MDL, 2002)

Os radares ópticos são bastante utilizados em SPDs porém possuem alguns problemas típicos como a reflexão do feixe por alvos falsos, obstrução do feixe por perda da linha de visão ou, mesmo, sujeira nas lentes.

\section{A2.3.3.5 Sistemas de cabo tensionado (taut-wire)}

Cabos tensionados constituem-se de um dos primeiros sistemas para medição de posição, sendo bastante utilizado até hoje como sensor secundário ou reserva em operações realizadas em profundidades menores que aproximadamente $500 \mathrm{~m}$.

Existem diversas configurações possíveis, sendo a mais comum composta por um pequeno guincho instalado na lateral do convés do navio, do qual é lançado um cabo de aço com uma âncora na extremidade (Figura A2.14). Após a âncora tocar o fundo do mar, o cabo é mantido sob tensão constante por um sistema de controle de tração e os ângulos que o cabo forma com a vertical são medidos por sensores instalados no guindaste. 
O comprimento do cabo e os ângulos medidos definem o deslocamento do ponto onde o guindaste é instalado nas direções de surge e sway do navio. Correções devem ser feitas correções devidas aos movimentos de roll e pitch, utilizando-se as medidas das VRU's.

Para profundidades de até $300 \mathrm{~m}$, pode-se garantir um bom controle de tensão e um pequeno efeito da correnteza sobre o cabo. Entretanto, admitem-se ângulos máximos de $30^{\circ}$ aproximadamente, pois a partir deste valor existe o risco de movimentar-se a âncora e perder-se a referência. Em alguns casos, este ângulo sofre uma limitação mais severa devida à proximidade com o casco ou alguma estrutura, como a quilha (Figura A2.14a). Este efeito limita o deslocamento máximo medido pelo sistema.

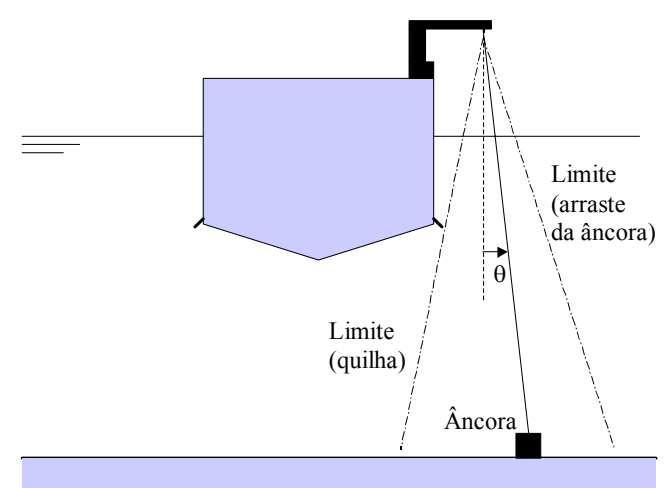

(a)

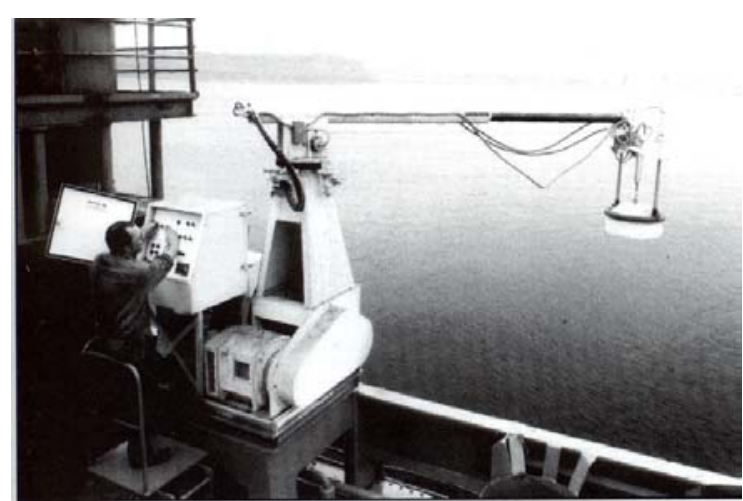

(b)

Figura A2.14 Sistema de cabo tensionado (a) Esquema de funcionamento e limites operacionais; (b) Modelo produzido pela Simrad

A operação sob correnteza pode levar a uma degradação na acurácia do sistema. Como a medição depende da retilinidade do cabo, o mesmo deve ser mantido tensionado. Quanto maior a profundidade, menor será a rigidez do cabo tornando a medida mais suscetível a deformações devidas a correnteza. Em águas profundas, o perfil não uniforme da correnteza induz um perfil complexo no cabo, dificultando até mesmo predições teóricas e algoritmos de correção. Assim, em geral admite-se operação até $300 \mathrm{~m}$, desprezando-se a deformação do cabo devida a correntezas. Alguns sistemas possuem algoritmos de correção que, associados a medidores de perfil da correnteza, permitem a operação até $500 \mathrm{~m}$ de profundidade. 
A acurácia de sistemas de cabos tensionados é pequena, fortemente dependente da profundidade e das condições de correnteza. Por exemplo, para o modelo Bandak MkVII (Bray, 1998) admitem-se erros de 1,2m e 7,5m em profundidades de $100 \mathrm{~m}$ e $300 \mathrm{~m}$ respectivamente. Na presença de correnteza, os erros aumentam para 2,4m e $28 \mathrm{~m}$ respectivamente. Assim, em geral são utilizados como sistemas secundários ou reserva. 


\section{Apêndice 3 - Simulador dinâmico da barcaça BGL1 dotada de SPD}

O simulador desenvolvido em diagrama de blocos será brevemente descrito a seguir. Na Figura A3.1 apresenta-se o diagrama geral, no qual podem-se destacar os seguintes blocos:

- Set-Points: fornece os valores desejados de posição e velocidade (translação e rotação).

- Controlador/Propulsores: contém o filtro de ondas, o controlador por modos deslizantes desenvolvido em 4.1.4, o algoritmo de alocação de empuxo e os modelos dinâmicos dos propulsores, possuindo como entradas as posições e velocidades reais e as desejadas e como saída as forças de surge e sway e o momento de yaw resultantes dos propulsores (ver detalhes na Figura A3.2).

- Dinâmica: contém o modelo dinâmico da barcaça, representado pelo sistema de equações diferenciais (3.9).

- Forças Ambientais: contém o cálculo das forças e momento de correnteza, vento e ondas.

- $\quad$ Forças de operação: fornece as forças e momento devido ao duto lançado.

- Primeira ordem: contém o cálculo dos movimentos (posições e velocidades) de primeira ordem devidos às ondas que, somados aos movimentos de baixa freqüência, resultam o movimento final da embarcação.

Desenvolveu-se também o simulador para o VLCC Vidal de Negreiros amarrado pelo sistema turret assistido por um SPD. A configuração geral dos blocos deste simulador é semelhante ao da BGL1 apresentado nas figuras seguintes. As particularidades, referentes à existência do sistema de amarração, não ficam evidentes por meio dos blocos, e sim nos equacionamentos internos aos mesmos. Assim, para evitar duplicidade, os diagramas de blocos do simulador do VLCC não são apresentados. 


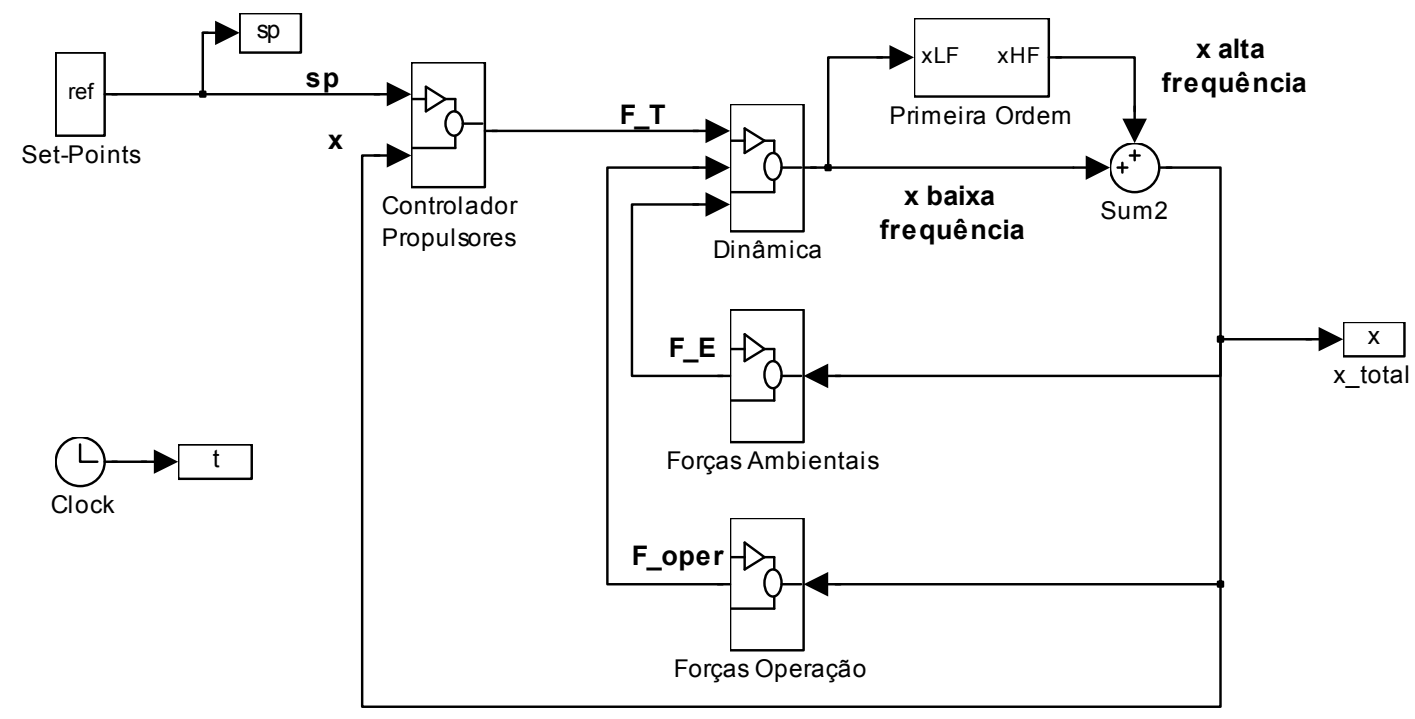

Figura A3.1 Diagrama de blocos geral do simulador da BGL1

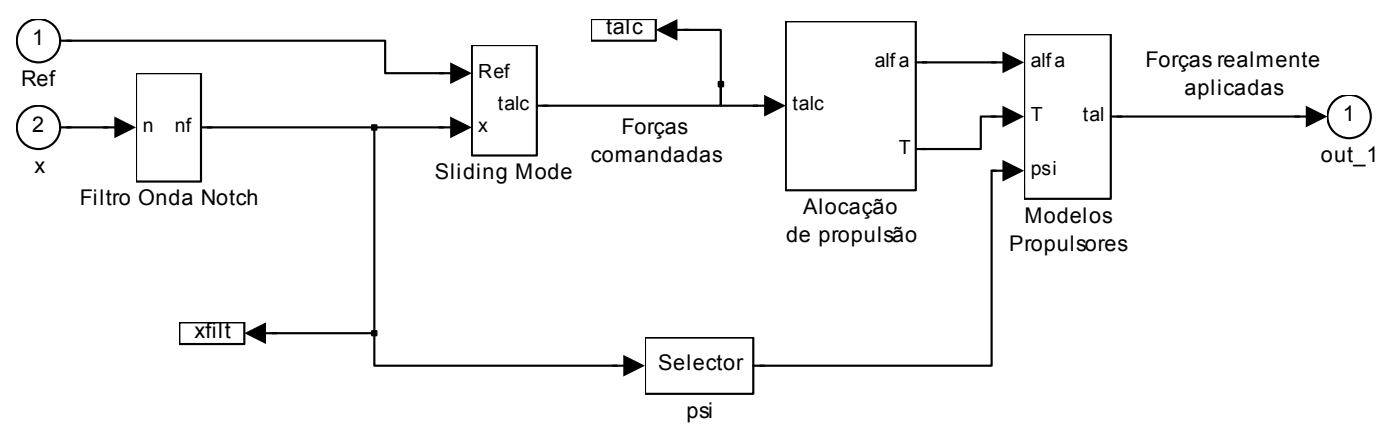

Figura A3.2 Diagrama interno do bloco Controlador/Propulsores 